\title{
Fiscal Year 1994 1/25-Scale Sludge Mobilization Testing
}
M.R. Powell
C.M. Gates
C.R, Hýmás
M.A. Sprecher
N.J. Morter

July 1995

Prepared for the U:S. Department of Energy under Contràct DE-AC06-76RLO 1830

Pacific Northwest Laboratory Operated for the U.S. Department of Energy by Battelle Memorial Institute 


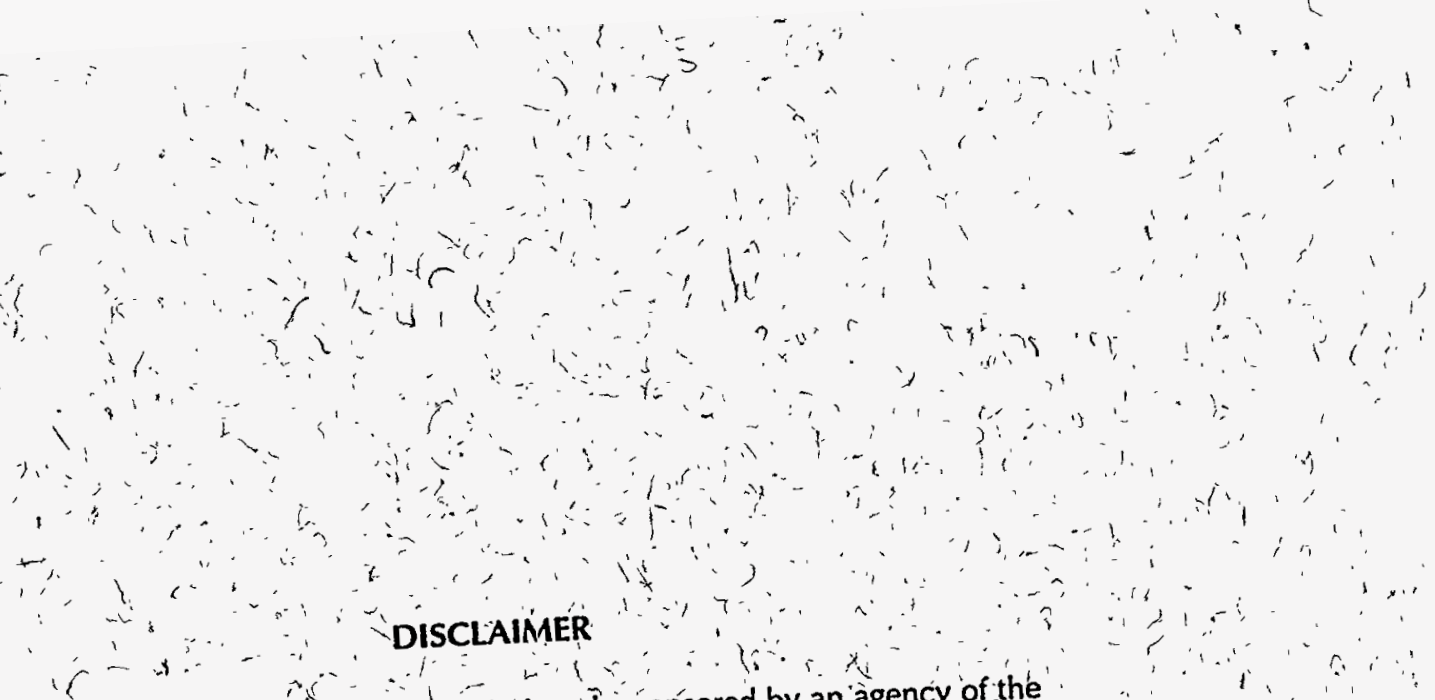

This report was prepared as an account of work sponsored by an agency of the Neitherthe United States Government nor any agency United States Covernment: Neitherthe nor any of their employees, makes any thereof, nor Battelle Memorial Institute, hor any legal liability or responsibility for warranty; expressed or implied, or assumes any legal ration, appáatus, product, the accuracy, completeness, or usefulness ow would not iniringeprivately owned or process disclosed, or represents that ts rights. Reference herein to any specific comber does not necessarily constitute trade name, trademark, manufacturer, ordation, or favoring by the United States or imply its endorsement, recommendation, or favoral institute. The views,and Government or any agency thereof, or Battelle Msarily state or reflect those of the

opinions of authors expressed here

\section{PACIFIC NORTHWEST LABORATORY}

BATTELLEMEMORIAL INSTITUTE

?.

(C) for the UNITED STATES DEPARTMENT OF ENERGY

\section{$\lambda_{2} \quad$ Printed in the United States of America \\ Available to $D O E$ and DOE contractors from the}

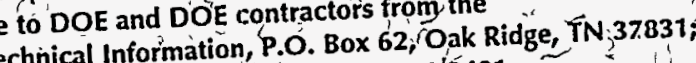
prices available from (615) 576-8401. FTS 626-8401.

Available to the public from the National Technical Information Service,

U.S. Department of

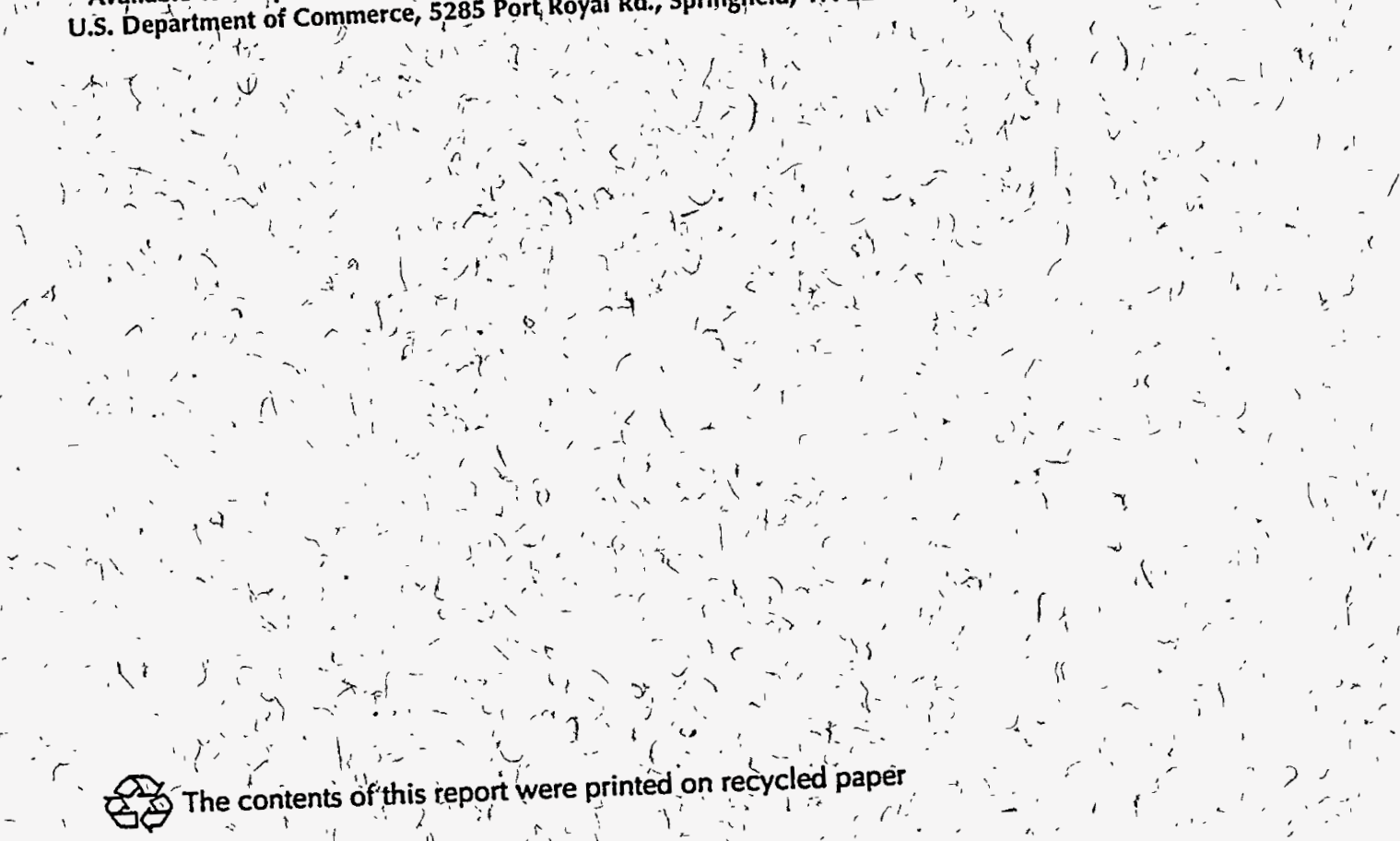




\section{DISCLAIMER}

Portions of this document may be illegible in electronic image products. Images are produced from the best available original document. 


\section{Fiscal Year 1994 1/25-Scale Sludge Mobilization Testing}

M. R. Powell

C. M. Gates

C. R. Hymas

M. A. Sprecher

N. J. Morter ${ }^{(a)}$

July 1995

Prepared for the U.S. Department of Energy under Contract DE-AC06-76RLO 1830

Pacific Northwest Laboratory

Richland, Washington 99352

(a) Associated Western Universities, Inc. - Northwest Division

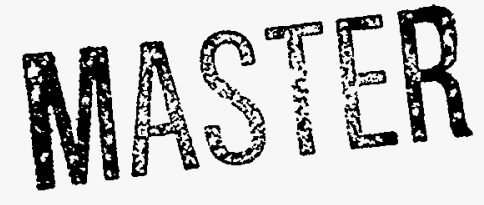

$$
\text { DISTRIBUTION OF THIS DOCUMENT IS UNLIMTED WW }
$$


,

- 


\section{Summary}

There are 28 one-million-gallon double-shell radioactive waste tanks on the Hanford Reservation in southeastern Washington State. The waste in these tanks was generated during processing of nuclear materials. Solids-laden slurries were placed into many of the tanks. Over time, the waste solids have settled to form a layer of sludge in the bottom of these tanks. The sludge layer thickness varies from tank to tank with some having only a few centimeters or no sludge up to some tanks which have about $4.5 \mathrm{~m}(15 \mathrm{ft})$ of sludge.

It is planned that the waste will be removed from these tanks as part of the overall Hanford Site cleanup efforts. Jet mixer pumps are to be placed into the tanks to stir up (mobilize) the sludge and form a uniform slurry suitable for pumping to downstream processing facilities. These mixer pumps use powerful jets of tank fluid directed horizontally out of two, diametrically opposed nozzles near the tank bottom. These fluid jets impinge upon the sludge and stir it up. The amount of sludge mobilized by the mixer pump jets depends not only on the jet properties, but also on the ability of the sludge to resist the jets. It is the goal of the work described in this document to develop the ability to predict how much sludge will be mobilized by the mixer pumps based on the size and velocity of the mixer pump jets and the physical and chemical properties of the tank sludge.

It is necessary to correlate the mobilization resistance of double-shell tank sludge with measurable sludge properties so that sludge retrieval systems can be successfully designed. With the ability to accurately predict mixer pump performance, the number of mixer pumps required to recover any desired fraction of the sludge can be determined. This directly benefits the Hanford Site cleanup efforts by both eliminating the extra cost of unnecessary mixer pumps and by reducing the risk that the number of mixer pumps placed in a given tank will not mobilize an acceptable fraction of the waste. The life-cycle cost of a single mixer pump is at least several million dollars, and project delays resulting from lower-than-expected pump performance can result in costs of similar magnitude.

To be of benefit to the tank retrieval system designers, any correlation of mixer pump performance with sludge properties must be sufficiently accurate to assist in making key decisions. These decisions include how many mixer pumps of what design should be installed into a tank containing sludge of known thickness and physical properties. Considering the typical riser locations in the Hanford double-shell tanks and the plans for re-use of these tanks for storage of other wastes, it is estimated that the mixer pump performance predictions must be accurate to within about $\pm 10 \%$ to be of greatest value. $^{(a)}$ Currently the ability to predict pump performance this accurately does not exist.

Previous sludge mobilization testing has been conducted in a 1/25-scale tank, a 1/12-scale tank, and in 100-gal plastic drums (bench-scale). These tests demonstrated that the mobilization resistance of selected sludge simulants correlates with sludge shear strength. However, it was clear from these tests that physical property measurements in addition to shear strength are needed to predict sludge mobilization. There were some indications that the sludge cohesiveness, as measured by tensile strength, may provide a reasonably direct measurement of sludge mobilization resistance. To

(a) Uncertainty in mixer pump performance predictions can be addressed by overdesigning the mixer pumps by the amount of uncertainty. Thus, the ability to predict pump performance is of some value regardless of the uncertainty in the prediction. In practical applications, however, it is desirable to minimize overdesign to reduce costs. 
investigate this possibility, additional tests were conducted. Tests designed to simulate the mobilization of tank sludge by mixer pumps were conducted in a $1 / 25$-scale model of a tank with a centrally located mixer pump. These tests were undertaken in an effort to identify the physical properties of tank sludge that have the greatest role in determining the degree of sludge mobilization obtained by the mixer pumps. These tests are described in this document.

The testing described in this report determined that the resistance of sludge simulants to the mobilizing action of the mixer pump correlates with the cohesiveness of the simulants. Cohesiveness is a measure of the ability of the sludge to hold itself together, which is most directly quantified by its tensile strength. Measuring tensile strength of sludge-like materials has proven to be difficult, however. The testing indicates that shear strength may provide an adequate characterization of the mobilization resistance provided that the sludge shear strength is due primarily to cohesive rather than frictional forces. Specific tests are being developed that allow the determination of whether tank sludge meets this criterion.

The testing results are highly significant as they provide confidence that the correlation of mobilization resistance with sludge shear strength is possible. Correlating mixer pump performance to sludge shear strength is preferred to correlations that include sludge tensile strength because shear strength measurement techniques are well developed. In addition, the testing indicates that sludge not classified as cohesive will be easier to mobilize than cohesive sludge of the same shear strength. Thus, the correlation of mixer pump performance with shear strength for cohesive sludge will provide a conservative estimate of the pump performance expected when the tank contains non-cohesive sludge.

It is planned that mobilization testing will be conducted at larger scale (e.g., 1/12-scale) for the purpose of developing the correlation between pump performance and shear strength because the relative uncertainty in the pump performance measurements decreases as the scale of the test is increased. The result of this larger-scale testing will be a correlation that allows the number of mixer pumps required to mobilize the double-shell tank waste to be predicted based on sludge properties. The 1/25-scale data are not suitable for the development of this correlation due to the larger measurement uncertainties and the fact that the scaleup of the mobilization data has yet to be adequately addressed.

The $1 / 25$-scale testing described herein also was used to determine the effects of various mixer pump operation procedures (e.g., pump column rotation vs. indexing), slurry rheology, nozzle design, and salt concentration effects. No significant difference in mobilization could be demonstrated between continuous pump column rotation (oscillation) and dis-continuous (indexed) column rotation. Slurry rheology was found to affect the apparent mobilization resistance of the sludge simulants. An increase in the slurry yield stress resulted in a higher apparent mobilization resistance. Nozzle design was found to impact pump mobilization performance. Osmotic permeation forces that result when the eroding fluid has a lower salt concentration than that within the sludge were not found to significantly affect the mobilization of the sludge simulant tested. 


\section{Acknowledgments}

One of us (N. J. Morter) gratefully acknowledges support from the U.S. Department of Energy, Division of University and Industry Programs, Office of Energy Research, as a Science and Engineering Research Semester program participant at PNL. 


\section{Contents}

Summary $\ldots \ldots \ldots \ldots \ldots \ldots \ldots \ldots \ldots \ldots \ldots \ldots \ldots \ldots \ldots \ldots \ldots \ldots \ldots$

Acknowledgments . . . . . . . . . . . . . . . .

Nomenclature $\ldots \ldots \ldots \ldots \ldots \ldots \ldots \ldots \ldots \ldots \ldots \ldots \ldots \ldots \ldots \ldots \ldots$

1.0 Introduction $\ldots \ldots \ldots \ldots \ldots \ldots \ldots \ldots \ldots \ldots \ldots \ldots \ldots \ldots \ldots \ldots \ldots \ldots \ldots \ldots$

2.0 Conclusions and Recommendations $\ldots \ldots \ldots \ldots \ldots \ldots \ldots \ldots \ldots \ldots \ldots \ldots$

3.0 Experimental Method $\ldots \ldots \ldots \ldots \ldots \ldots \ldots \ldots \ldots \ldots \ldots \ldots \ldots \ldots \ldots$

$3.11 / 25$-Scale Test Facility Description $\ldots \ldots \ldots \ldots \ldots \ldots \ldots \ldots \ldots .1$

3.2 Experimental Procedure for $1 / 25$-Scale Tests $\ldots \ldots \ldots \ldots \ldots \ldots \ldots .10$

3.3 Measurement and Test Equipment $\ldots \ldots \ldots \ldots \ldots \ldots \ldots \ldots \ldots \ldots \ldots \ldots$

3.4 Simulants used for $1 / 25$-Scale Testing $\ldots \ldots \ldots \ldots \ldots \ldots \ldots \ldots \ldots \ldots \ldots$

3.5 Mixer Pump Operation Data . . . . . . . . . . . . . . 3.25

4.0 Results and Analyses $\ldots \ldots \ldots \ldots \ldots \ldots \ldots \ldots \ldots \ldots \ldots \ldots \ldots \ldots$

4.1 ECR Correlation Development $\ldots \ldots \ldots \ldots \ldots \ldots \ldots \ldots \ldots \ldots \ldots$

4.1.1 ECR vs. Shear Strength $\ldots \ldots \ldots \ldots \ldots \ldots \ldots \ldots \ldots \ldots .2$

4.1.2 ECR vs. Tensile Strength $\ldots \ldots \ldots \ldots \ldots \ldots \ldots \ldots \ldots \ldots \ldots$

4.1.3 Salt Gradient Effects on Mobilization $\ldots \ldots \ldots \ldots \ldots \ldots \ldots .47$

4.2 Nozzle Design Effects $\ldots \ldots \ldots \ldots \ldots \ldots \ldots \ldots \ldots \ldots . \ldots \ldots$

4.2.1 Nozzle Length-to-Diameter Ratio $\ldots \ldots \ldots \ldots \ldots \ldots \ldots \ldots \ldots .50$

4.2 .2 Nozzle Diameter Effects . . . . . . . . . . . . . . 4.57

4.2.3 Nozzle Inclination Angle Effects $\ldots \ldots \ldots \ldots \ldots \ldots \ldots \ldots \ldots .60$ 
4.3 Slurry Effects on Mobilization $\ldots \ldots \ldots \ldots \ldots \ldots \ldots \ldots . \ldots \ldots$

4.3.1 Slurry Rheology Effects $\ldots \ldots \ldots \ldots \ldots \ldots \ldots \ldots \ldots . \ldots \ldots$

4.3.2 Slurry-Density Effects on Mobilization $\ldots \ldots \ldots \ldots \ldots \ldots .64$

4.3.3 Mobilization Enhancement by Dispersants $\ldots \ldots \ldots \ldots \ldots .66$

4.4 Mixer-Pump Operation Effects on Mobilization . . . . . . . . . . 4.67

4.4.1 Indexed vs. Oscillating Nozzle Movement $\ldots \ldots \ldots \ldots \ldots \ldots .67$

4.4.2 Mobilization Near the Tank Wall $\ldots \ldots \ldots \ldots \ldots \ldots \ldots \ldots .68$

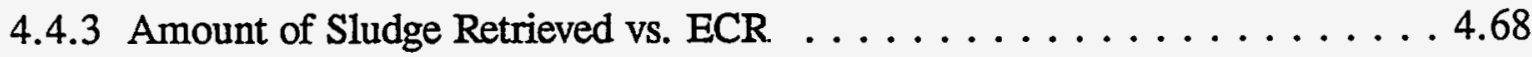

4.5 Recommended Future Mobilization Testing $\ldots \ldots \ldots \ldots \ldots .7 . \ldots \ldots$

5.0 References $\ldots \ldots \ldots \ldots \ldots \ldots \ldots \ldots \ldots \ldots \ldots \ldots \ldots \ldots \ldots \ldots \ldots \ldots \ldots \ldots \ldots .1$

Appendix A $-1 / 25$-Scale Test Data $\ldots \ldots \ldots \ldots \ldots \ldots \ldots \ldots \ldots \ldots$ A.1

Appendix B - ECR Profile Sketches $\ldots \ldots \ldots \ldots \ldots \ldots \ldots \ldots \ldots$ B.1

Appendix C - Nozzle Diameter Effects Testing Results . . . . . . . . . . C.1

Appendix D - Nozzle Diameter Effects Test Plan $\ldots \ldots \ldots \ldots \ldots$ D. 1 


\section{Figures}

$3.1 \quad 1 / 25$-Scale Tank with Mixer Pump Assembly in place $\ldots \ldots \ldots \ldots \ldots \ldots \ldots$

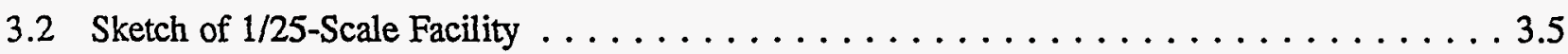

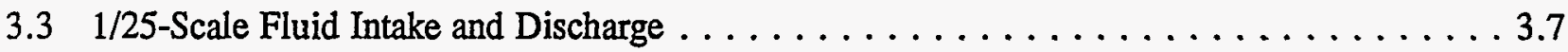

$3.4^{`} 1 / 25-$ Scale Nozzle Design (Nominal Nozzle) $\ldots \ldots \ldots \ldots \ldots \ldots \ldots$

$3.51 / 25$-Scale Tank Loaded with 50 liters of Sludge Simulant (Test 1-K) $\ldots \ldots \ldots$. . . . . 3.11

$3.61 / 25$-Scale Tank Loaded with Sludge and Supernate Simulants $\ldots \ldots \ldots \ldots . \ldots . \ldots$

3.7 Sludge Remaining in Tank after Test $1-\mathrm{K} \ldots \ldots \ldots \ldots \ldots \ldots \ldots \ldots$

3.8 Vertical Split-Cell Tensile Strength Measurement Device . . . . . . . . . . . . . 3.20

3.9 Sketch of Horizontal and Vertical Extrusion Tensiometer Apparatus . . . . . . . . . 3.21

3.10 Sketch of Horizontal Split-Cell Tensiometer $\ldots \ldots \ldots \ldots \ldots . \ldots \ldots \ldots$

$4.11 / 25-$ Scale Simulant ECR vs. Shear Strength Data $\ldots \ldots \ldots \ldots \ldots \ldots \ldots \ldots$

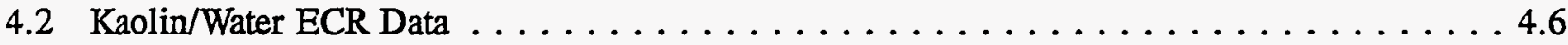

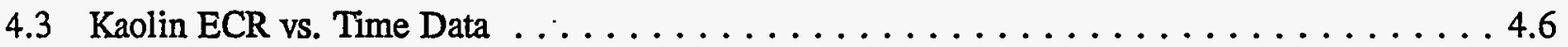

4.4 Kaolin Shear Strength vs. wt\% Kaolin $\ldots \ldots \ldots \ldots \ldots \ldots \ldots \ldots \ldots$

4.5 Bentonite Shear Strength vs. wt\% Bentonite $\ldots \ldots \ldots \ldots \ldots \ldots$

4.6 Bentonite ECR Data . . . . . . . . . . . . . . . . . 4.13

4.7 Bentonite/water ECR vs. Time $\ldots \ldots \ldots \ldots \ldots \ldots \ldots \ldots \ldots \ldots \ldots \ldots \ldots \ldots$

4.8 Bentonite/Kaolin ECR Data $\ldots \ldots \ldots \ldots \ldots \ldots \ldots \ldots \ldots \ldots \ldots \ldots$

4.9 Bentonite/Kaolin ECR vs. Time $\ldots \ldots \ldots \ldots \ldots \ldots \ldots \ldots \ldots \ldots \ldots$

$4.10 \mathrm{Kaolin} /$ Bentonite ECR Data . . . . . . . . . . . . . . . . . . . . . 4.19

$4.11 \mathrm{Kaolin} /$ Bentonite ECR vs. Time Data . . . . . . . . . . . . . . . . . 4.19

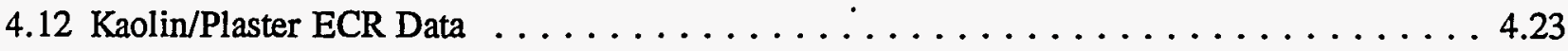

$4.13 \mathrm{Kaolin} / \mathrm{Plaster}$ ECR vs. Time Data $\ldots \ldots \ldots \ldots \ldots \ldots \ldots \ldots \ldots \ldots . \ldots \ldots$ 
$4.14 \mathrm{Kaolin} / \mathrm{Ludox}^{\circledR}$ ECR Data $\ldots \ldots \ldots \ldots \ldots \ldots \ldots \ldots \ldots \ldots \ldots \ldots$

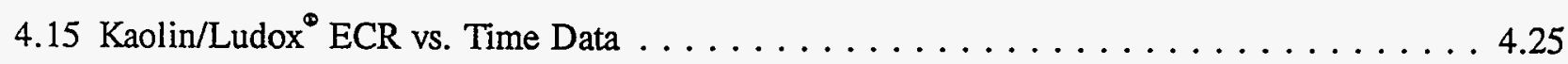

$4.16 \mathrm{KaOlin} / \mathrm{NaCl}_{(\mathrm{aq})}$ ECR Data $\ldots \ldots \ldots \ldots \ldots \ldots \ldots \ldots \ldots \ldots \ldots \ldots$

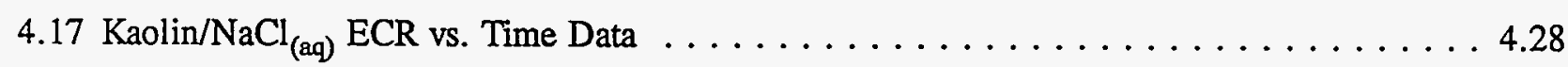

4.18 Split-Cell Tensile Strength vs. Shear Strength $\ldots \ldots \ldots \ldots \ldots \ldots \ldots$

4.19 Vertical Extrusion Tensile Strength vs. Shear Strength . . . . . . . . . . . 4.36

4.20 Horizontal Split-Cell Tensile Strength vs. Shear Strength $\ldots \ldots \ldots \ldots \ldots$. . . . . . 4.37

4.21 Shear Strength vs. Vane Rotation Speed for Kaolin/Water . . . . . . . . . . . . . . 4.39

4.22. Shear Strength vs. Vane Rotation Speed for Bentonite/Water . . . . . . . . . . . . 4.39

4.23 Simulant Slumping During Horizontal Extrusion Test $\ldots \ldots \ldots \ldots \ldots$. . . . . . . 4.41

4.24 ECR Data vs. Split-Cell Tensile Strength $\ldots \ldots \ldots \ldots \ldots \ldots \ldots$

4.25 ECR Data vs. Vertical Extrusion Tensile Strength $\ldots \ldots \ldots \ldots \ldots \ldots \ldots . \ldots \ldots$

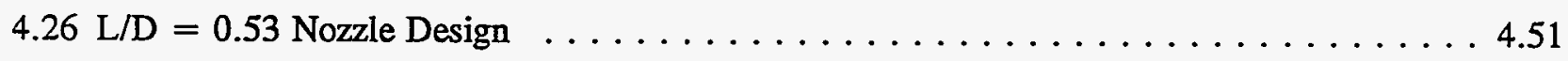

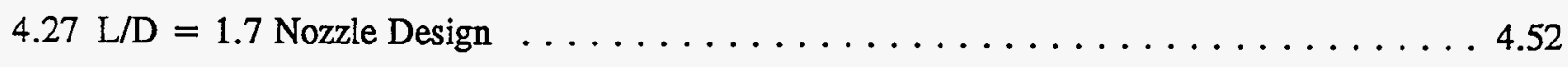

$4.28 \mathrm{~L} / \mathrm{D}=5$ Nozzle Design $\ldots \ldots \ldots \ldots \ldots \ldots \ldots \ldots \ldots \ldots \ldots \ldots \ldots$

4.29 Effect of Nozzle L/D Ratio $\ldots \ldots \ldots \ldots \ldots \ldots \ldots \ldots \ldots$

4.30 Nozzle Entrance Effects $\ldots \ldots \ldots \ldots \ldots \ldots \ldots \ldots \ldots$

4.31 Large Diameter Nozzle Design $\ldots \ldots \ldots \ldots \ldots \ldots \ldots$

4.32 Rheogram for Test $21-\mathrm{K}$ Slurries and $0.075 \%$ Carbopol $\ldots \ldots \ldots \ldots . \ldots$

4.33 Fraction of Sludge Actually Retrieved vs. Fraction Predicted by ECR . . . . . . . . 4.69 


\section{Tables}

$3.1 \quad 1 / 25$-Scale Simulant Compositions and Physical Properties $\ldots \ldots \ldots \ldots \ldots .23$

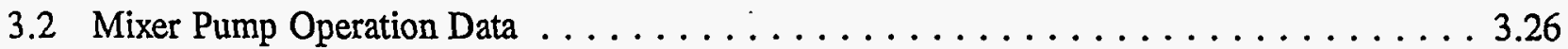

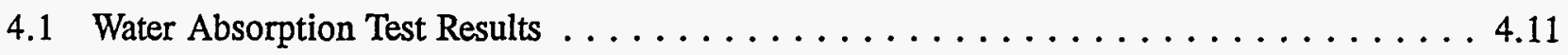




\section{Nomenclature}

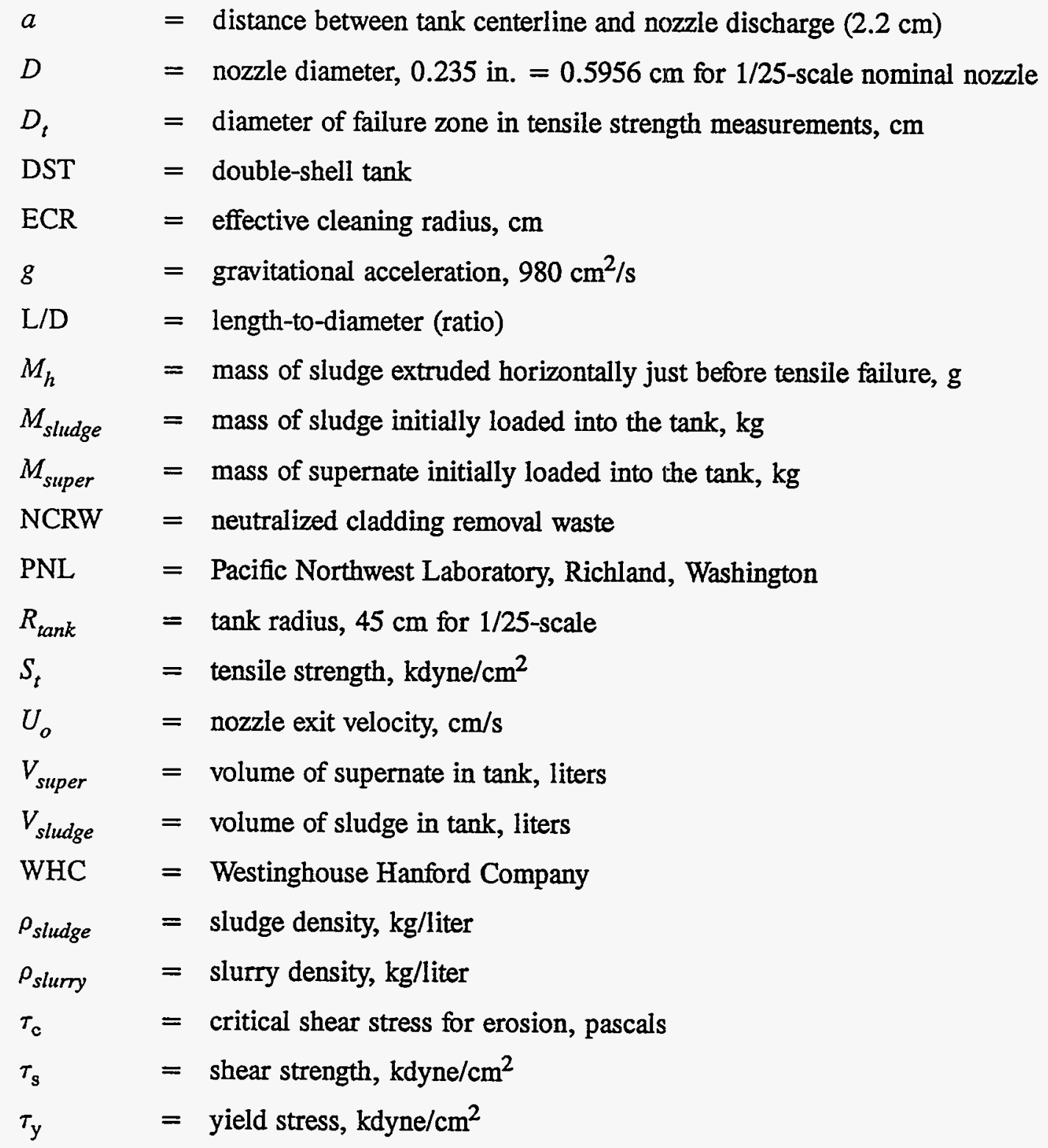

Sludge Simulant Identifiers:

B Bentonite clay

BK Mixture of 67 wt\% kaolin and 33 wt\% bentonite (dry basis)

K Kaolin clay

KB Mixture of 98 wt\% kaolin and 2 wt\% bentonite (dry basis)

KL Kaolin/Ludox ${ }^{\circ}$

$\mathrm{KN}$ Kaolin clay and sodium chloride mixture

KP Kaolin clay and plaster of paris mixture 


\subsection{Introduction}

There are 28 one-million-gallon double-shell radioactive waste tanks on the Hanford Reservation in southeastern Washington State. The waste in these tanks was generated during processing of nuclear materials. Solids-laden slurries were placed into many of the tanks. Over time, the solids have settled to form a layer of sludge in the bottom of many tanks. The sludge layer thickness varies from tank to tank with some having only a few centimeters or no sludge up to some tanks which have about $4.5 \mathrm{~m}$ (15 ft) of sludge.

It is planned that the waste will be removed from these tanks as part of the overall Hanford Site cleanup efforts. Jet mixer pumps are to be placed into the tanks to stir up (mobilize) the sludge and form a uniform slurry suitable for pumping to downstream processing facilities. These mixer pumps utilize powerful jets of tank fluid directed horizontally out of two, diametrically opposed nozzles near the tank bottom. These fluid jets impinge upon the sludge bank and stir up the sludge. The amount of sludge mobilized by the mixer pump jets depends not only on the power of the jets, but also on the ability of the sludge to resist the jets. It is the goal of the work described in this document to eventually develop the ability to predict how much sludge will.be mobilized by the mixer pumps based on the strength of the mixer pump jets and the physical and chemical properties of the tank sludge.

This report documents fiscal year 1994 technical progress on the sludge mobilization task of the Tank Waste Retrieval System Retrieval Technology Development Project, which is being conducted by Westinghouse Hanford Company (WHC) and Pacific Northwest Laboratory (PNL). ${ }^{\text {(a) }}$ The testing described in this report was performed by PNL. During fiscal year 1994, a series of $1 / 25$-scale sludge mobilization tests were performed primarily to identify the sludge simulant physical properties that can be used to predict the mobilization of tank sludge when exposed to submerged fluid jets. These critical simulant physical properties were used to improve upon the correlation between the effective cleaning radius (ECR) of the mixer pump and waste simulant properties. Also of interest for the fiscal year 1994 testing program were the effects of slurry density, slurry rheology, and nozzle design on mixer pump performance.

It is necessary to correlate the mobilization resistance of double-shell tank (DST) sludge with measurable sludge properties so that successful DST sludge retrieval systems cari be designed. It is planned that mixer pumps will be used in the Hanford DSTs to resuspend the layers of sludge that cover the bottoms of many of the tanks. The number of mixer pumps and their required horsepowers must be accurately estimated based on sludge property measurements to ensure that the sludge will be successfully mobilized. Further, it is desired that over-design of the retrieval systems be avoided to reduce system cost.

Previous sludge mobilization testing has been conducted at various levels of scale (i.e., benchscale, 1/25-scale, and 1/12-scale). These tests suggested that the mobilization resistance of selected sludge simulants may correlate with the measured vane shear strength. However, it was clear from these tests that physical properties in addition to shear strength are probably relevant to sludge mobilization (e.g., sludge cohesiveness). An attempt to quantify sludge cohesiveness was made by measuring the tensile strength of the sludge simulants. In an effort to determine the importance of

(a) Pacific Northwest Laboratory is operated for the U.S. Department of Energy by Battelle Memorial Institute under contract DE-AC06-76 RLO 1830. 
sludge cohesiveness to sludge mobilization and to identify any additional/alternative properties relevant to sludge mobilization, a series of $1 / 25$-scale sludge mobilization tests were conducted during fiscal year 1994.

This document describes the results of $261 / 25$-scale tests conducted during fiscal year 1994 . The tests were assigned test numbers in the form of "nn-yy" in which " $\mathrm{nn}$ " is the sequential test number and "yy" is an alphabetic identifier that indicates what type of simulant was used in the test. For example, if "yy" is "K," then kaolin clay was used as the sludge simulant. Similarly, "B" refers to bentonite clay, "KB" refers to kaolin/bentonite simulant, "BK" refers to bentonite/kaolin simulant, "KP" refers to kaolin/plaster of paris simulant, "KL" refers to kaolin/Ludox simulant, and " $\mathrm{KN}$ " refers to kaolin $/ \mathrm{NaCl}_{(\mathrm{aq})}$. Bentonite in the "BK" simulants comprises $33 \mathrm{wt} \%$ of the total solids, while bentonite is only $2 \mathrm{wt} \%$ of the solids in the "KB" simulants.

Following this introduction, conclusions drawn from the testing and the recommendations for future direction of the sludge mobilization correlation development efforts are presented in Section 2.0. The experimental apparatus and procedures used during the 1/25-scale testing are described in Section 3.0. Section 4.0 presents the data obtained from the $1 / 25$-scale sludge mobilization testing, and Section 5.0 lists the references. ECR, ECR/ $\mathrm{U}_{0} \mathrm{D}$, slurry temperature, and slurry density data are presented in Appendix A. Appendix B contains sketches of the sludge bank profiles as seen from under the tank at various times during testing. The test plan and results of $1 / 25$-scale tests investigating the effects of nozzle diameter and nozzle design on the ECR are attached as Appendix C. 


\subsection{Conclusions and Recommendations}

The fiscal year 1994 1/25-scale testing of DST sludge simulants has improved the understanding of the relationship between mixer pump performance and waste simulant properties. A variety of different simulant types were tested and found to support the results of the fiscal year 1993 1/25-scale testing, which indicated sludge cohesion is the primary force responsible for resistance to mobilization by submerged fluid jets. The results of the present testing allow the development of sludge mobilization correlations to proceed with improved confidence that the relevant sludge physical properties have been identified. Testing is planned for $1 / 12$ scale and eventually $1 / 4$ scale to provide the data required for the development of correlations between the ECR and sludge properties. The following conclusions can be drawn based on the results of all sludge mobilization testing conducted to date:

- There appears to be a single relationship between sludge mobilization resistance and vane shear strength for cohesive sludge simulants. If the tank sludge can be shown to obtain most of its shear strength from cohesive rather than frictional forces, then the DST sludge mobilization dependence on shear strength would be expected to follow that of the cohesive sludge simulants. It may be possible to determine the cohesiveness of the DST sludge through measurement of specific surface area and/or viscoelastic characterization in combination with vane shear strength measurements.

- Tensile strength provides a direct measure of sludge cohesion; however, it is very difficult to measure tensile strength on sludge-like materials. Several techniques have been developed for the measurement of sludge simulant tensile strength. Extruding the simulant vertically seems to be the best approach from a repeatability standpoint, but to avoid complicating effects the extrusion must be performed very slowly. None of the techniques developed thus far, however, are easily applied to tank sludge either in a hot cell or inside the tank. Further development of sludge tensile strength measurement techniques is needed.

- It is not certain whether sludge mobilization will be improved by removing the high-salt tank supernate and replacing it with a low-salt supernate before mobilization. Testing of sludge simulants under these conditions indicated that no benefit is derived from the postulated osmotic permeation effect. It is not expected, however, that the use of a lower salt concentration eroding fluid would result in lower than expected ECRs.

- Tests were done to determine the importance of mixer pump nozzle design on ECR, and it was initially found the ECR was independent of the tested nozzle designs, but further investigations revealed that nozzle design can significantly affect the ECR. In particular, it was determined that care must be taken to minimize swirl in the fluid issuing from the jet nozzle. The swirling flow acts to cause a more rapid dissipation of the jet energy with increasing downstream distance. Jet flows with poor nozzle designs and nozzle entrance conditions were found to result in ECRs as much as 50\% smaller than the ECRs of well-designed nozzles. This result demonstrates that well-designed nozzles are needed for the full-scale mixer pumps. 
- Tests conducted with a 0.9 -cm-diameter nozzle instead of the $0.6-\mathrm{cm}$ nozzle used for most tests indicated that the ECR is directly proportional to the magnitude of $U_{0} D$ provided that wellformed jets are used. Some of the tests revealed that the $0.9-\mathrm{cm}$ nozzles produced smaller ECRs than the $0.6-\mathrm{cm}$ nozzles at equal $U_{0} D$ 's, but further testing indicated that this was due to differences in the uniformity of the jet fluid velocity exit profiles rather than nozzle diameter differences.

- Slurry rheology can significantly impact the ECR obtained. A test was done in which the mobilization of a simulant was accomplished using a near-Newtonian, low viscosity slurry and then a non-Newtonian, high apparent viscosity slurry. The effect of the non-Newtonian slurry rheology was to increase the mobilization resistance of the sludge simulant. This effect is thought to be due to the presence of a thin layer of high apparent viscosity slurry near the sludge/slurry interface that serves to partially protect the sludge from the mobilizing action of the jet. The available jet velocity decay data for non-Newtonian fluids imply that the result of this test was not due to an increased rate of jet velocity decay.

- A commercially available dispersant was found to be capable of improving the ECR generated by the $1 / 25$-scale mixer pump. Dispersants work by decreasing the attractive forces between particles by surface adsorption. If the mobilization resistance of DST sludge is the result of such attractive forces, then ECR growth may be improved through the use of dispersants. The compatibility of such dispersants with the downstream processing of the waste must be examined before the feasibility of using dispersants can be assessed.

- Two tests were conducted in which the continuous oscillation of the mixer pump column was stopped to investigate whether the effectiveness of the mixer pump jets is improved. Stopping the movement of the mixer pump in this manner is referred to as jet indexing. The tests show that any improvement in ECR that might result from jet indexing is on the order of the uncertainty in the 1/25-scale ECR measurements or smaller. The jet indexing effect, if it exists, will be more evident at larger scale due to the reduced relative uncertainty in ECR measurements.

The analysis of the $1 / 25$-scale sludge mobilization data presented in this document has generated several recommendations for the future direction of the sludge mobilization correlation development efforts:

- Perform sludge mobilization tests at $1 / 12$ scale for the purpose of developing a correlation between the ECR and sludge simulant properties. Correlation development is more suited to $1 / 12$ scale than $1 / 25$ scale due to the relatively large uncertainty in ECR measurements made at $1 / 25$ scale that result from non-circular sludge bank profiles. More nearly circular sludge bank profiles are expected at $1 / 12$ scale. Further, it is important to determine the validity of the current understanding of mobilization data scaleup.

- Aggressively pursue the development of techniques that can be used to determine the specific surface area of DST sludge solids. Specific surface area provides a measure of the relative importance of cohesive and frictional contributions to sludge shear strength. The $1 / 25$-scale data indicate that if the DST sludge specific surface area is greater than about $25-35 \mathrm{~m}^{2} / \mathrm{g}$, then the relationship between mobilization resistance and sludge shear strength should be similar to that of the cohesive sludge simulants used. 
- Continue to investigate the viscoelastic properties of the sludge simulants used for mobilization testing. Preliminary indications are that the viscoelastic loss modulus of sludge simulants provides a measure of the relative importance of cohesion and friction. Loss modulus is measured by oscillating the plate in a cone-and-plate rheometer through a small angular amplitude. The resulting stress that is transmitted through the sludge to the cone is used to calculate the relative importance of elastic and frictional forces in the sample. The capability to perform these types of measurements on sludge samples in a radioactive hot-cell is currently being developed by WHC personnel.

- Continue the development of techniques for measuring the tensile strength of sludge and sludge simulants. Tensile strength may provide the most direct measure of mobilization resistance, but it has proven difficult to measure.

- Evaluate the potential for the formation of non-Newtonian slurries during DST sludge mobilization. The present testing has shown that non-Newtonian rheology can significantly affect the ECR obtained by a mixer pump. It may be important to include slurry rheology effects when future sludge mobilization tests are performed for the purpose of ECR correlation development. A correlation that does not include non-Newtonian slurry effects could provide non-conservative ECR predictions. 


\subsection{Experimental Method}

The experimental apparatus and procedures used during the $1 / 25$-scale testing are described in this section. Also given are the compositions and physical properties of the simulants prepared for $1 / 25$-scale sludge mobilization testing.

\subsection{1/25-Scale Test Facility Description}

The $1 / 25$-scale testing was conducted in a $91-\mathrm{cm}(3 \mathrm{ft})$ diameter plexiglass tank. Before testing, the bottom of the tank was marked with concentric circles spaced at 2-cm intervals. Eight radial lines (spaced at $45^{\circ}$ intervals) were drawn from the tank center to the tank wall and labeled A, B, C, ..., and $\mathrm{H}$, respectively. During testing, the location of the sludge/slurry interface was measured along each. of these eight lines using the concentric circles to determine the radial distance between the tank center and the interface. Figure 3.1 is a view of the empty tank showing the concentric circles on the tank . bottom.

A single, simulated mixer pump was positioned in the center of the tank for each test. One of the existing 1/12-scale mixer pumps was modified for use in the $1 / 25$-scale facility. In the $1 / 12$-scale and full-scale mixer pump designs, the pump suction is located below the nozzles. It was not feasible to operate the $1 / 25$-scale mixer pump in this way and still maintain a scaled distance between the nozzles. The distance between the nozzle tips was judged to be the more important than the bottom suction, so the $1 / 25$-scale mixer pump suction is located above the nozzle discharge elevation. Figure 3.2 is a sketch of the $1 / 25$-scale mixer pump and the associated piping.

The slurry enters the suction of the simulated mixer pump and travels up the annular space between a $2.54-\mathrm{cm}(1 \mathrm{in}$.) and a $5.08-\mathrm{cm}(2 \mathrm{in}$.) stainless steel tube. The slurry then flows through flexible hose to the intake of the centrifugal pumps. The flow out of the pumps is monitored with a magnetic flow meter and manually controlled by a ball valve. The pressurized slurry flows down the central $2.54 \mathrm{~cm}(1 \mathrm{in}$.) tube of the mixer pump and out the horizontal, diametrically opposed nozzles (see Figure 3.3).

The mixer pump nozzles were located such that their centerline distance above the tank floor was $1 / 25$ th of the full-scale distance of $46 \mathrm{~cm}$ (18 in.). The nozzles were machined from tool steel and thermally hardened. The nozzles were designed such that the nozzle exit velocity profile would be reasonably uniform. The entrance region of each nozzle was angled at $40^{\circ}$ (20 half-angle) for a horizontal distance about equal to the nozzle diameter. The entrance region was followed by a straight section about 1.7 nozzle diameters long. The target nozzle diameter was $0.61 \mathrm{~cm}(0.24 \mathrm{in}$.). The fabricated nozzles had $0.60-\mathrm{cm}(0.236$ in.) diameters. A cross-section sketch of the $1 / 25$-scale nozzles used for most tests is given in Figure 3.4. 


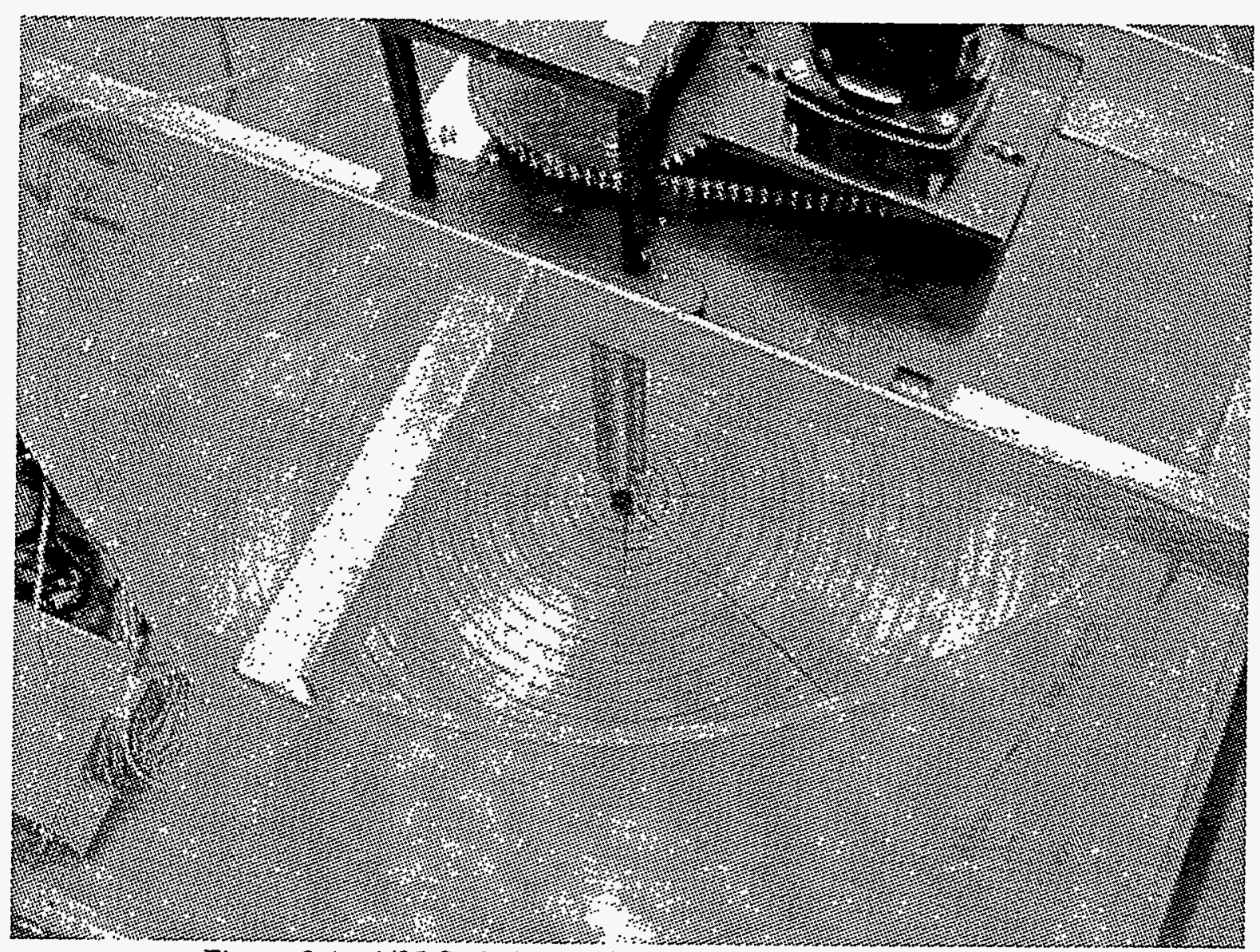

Figure 3.1. 1/25-Scale Tank with Mixer Pump Assembly in place 



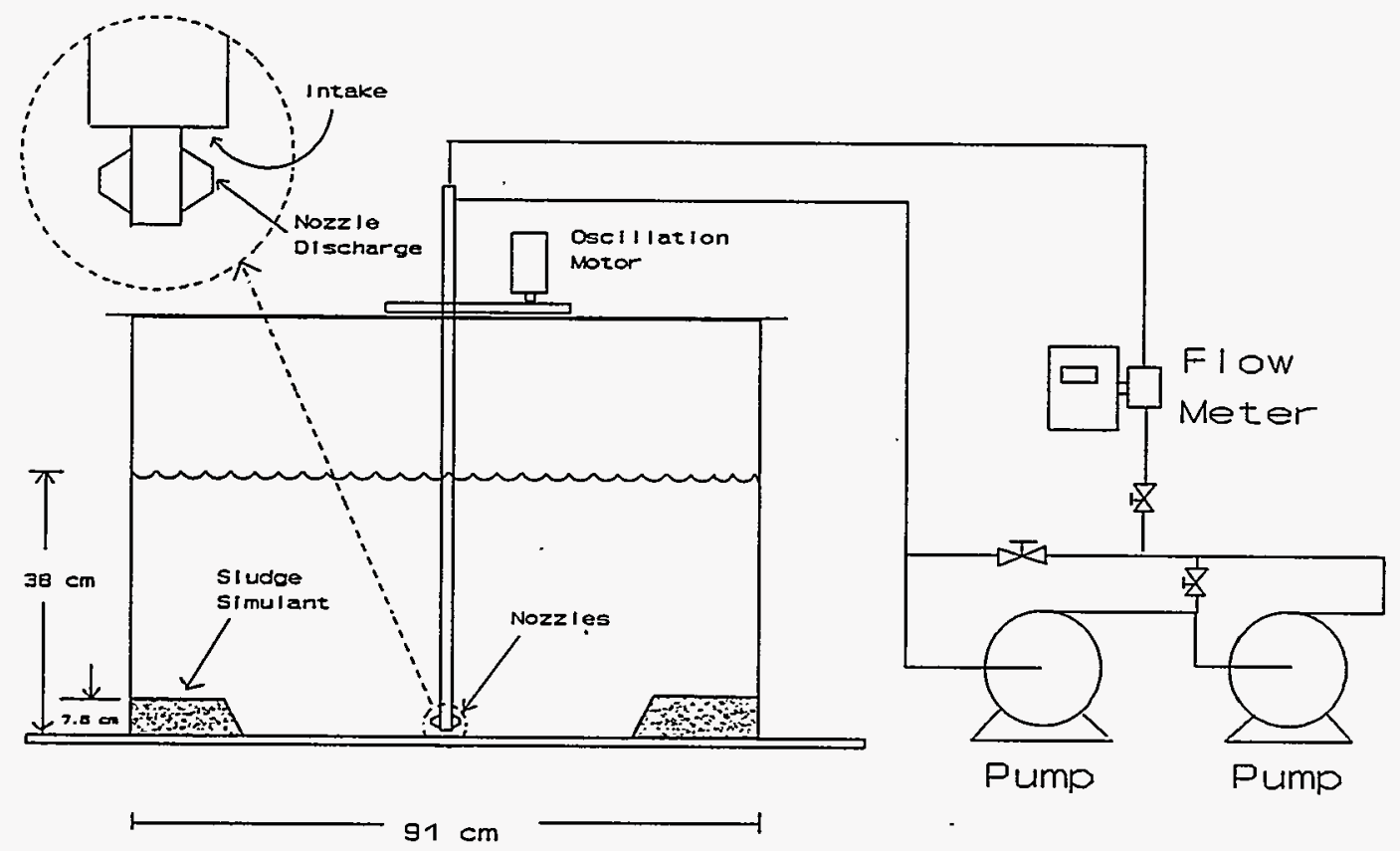

Figure 3.2. Sketch of $1 / 25$-Scale Facility 
$L^{\circ} \mathcal{\varepsilon}$

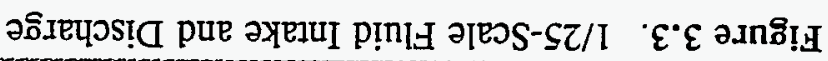

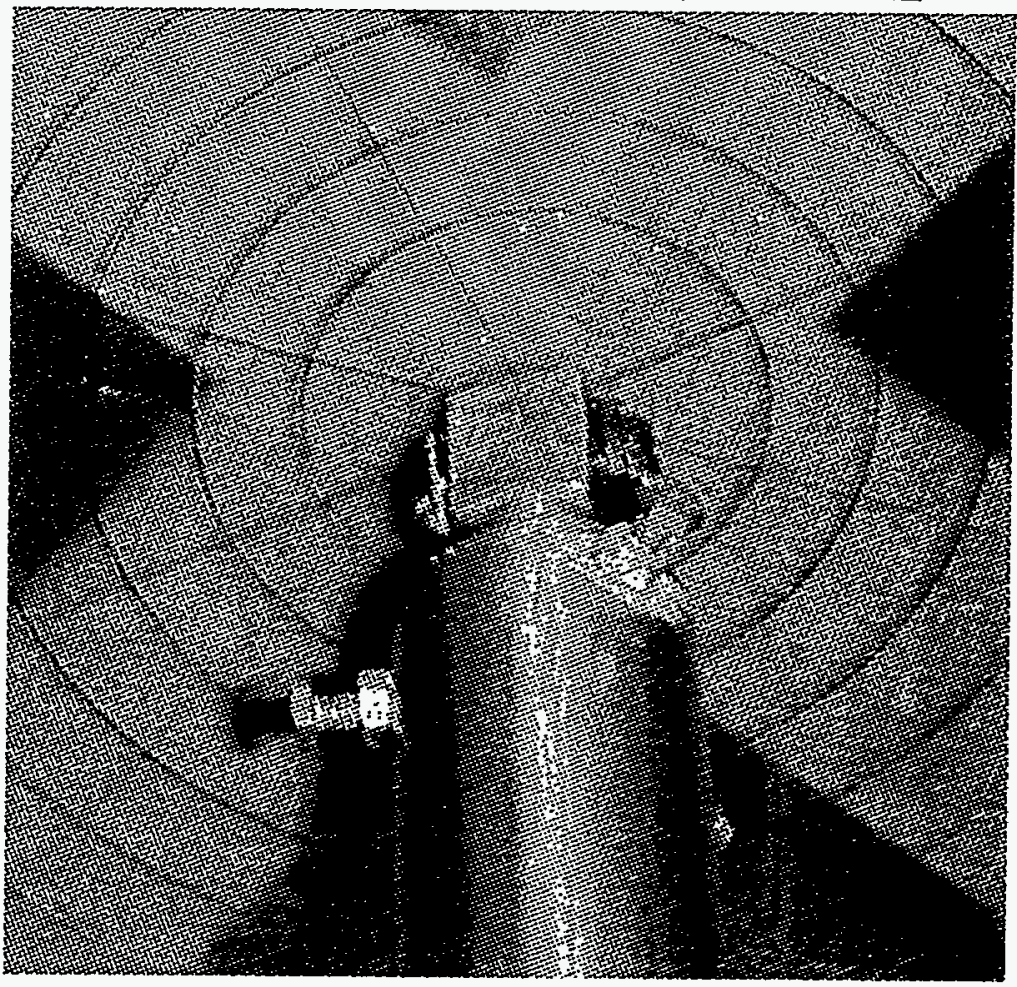





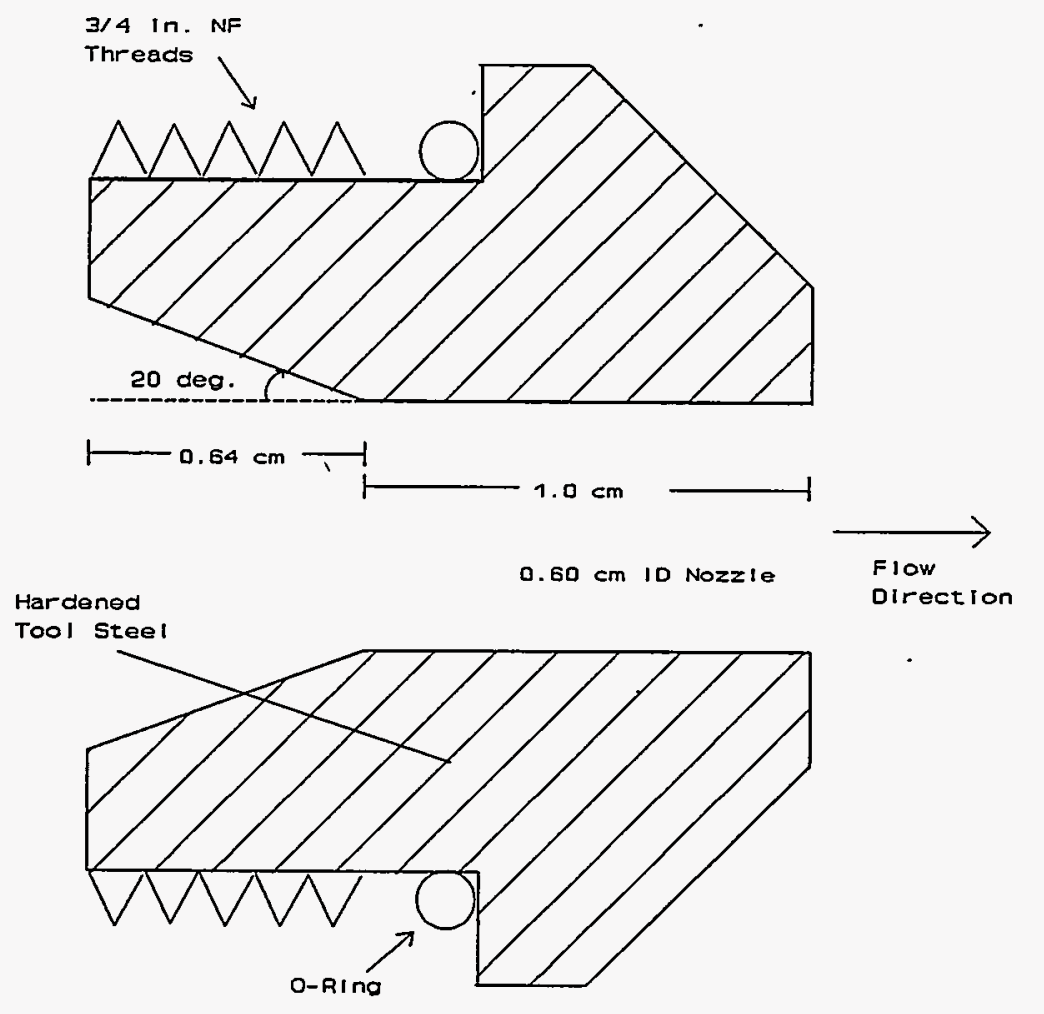

Figure 3.4. $1 / 25$-Scale Nozzle Design (Nominal Nozzle) 


\subsection{Experimental Procedure for 1/25-Scale Tests}

The $1 / 25$-scale tests were conducted as generally described in this section. The procedure described below was followed for most of the tests. Those cases when deviations from this procedure occurred are noted in the text. Some of the 1/25-scale tests included additional steps not described below. These additional steps, when applicable, are described in Section 4.0. This section is intended to provide a general description of the test procedure.

A mass corresponding to approximately $50 \mathrm{~L}$ (13.2 gal) of sludge simulant was placed into the $1 / 25$-scale tank and smoothed to a uniform thickness of about $7.5 \mathrm{~cm}(3 \mathrm{in}$.) as shown in Figure 3.5 . About $3 \mathrm{~L}$ of simulant was reserved for physical property measurements. The $1 / 25$-scale mixer pump assembly was then positioned in the tank such that the mixer pump centerline coincided with the tank centerline. Two-hundred liters of simulated supernate (in most tests this was water) was then pumped into the tank using a drum pump. The resulting liquid surface was approximately $38 \mathrm{~cm}$ (15 in.) above the tank bottom (see Figure 3.6). Care was taken to avoid disturbing the sludge bed while adding the supernate. The $1 / 25$-scale facility centrifugal pumps were then primed with a small auxiliary pump to force tank supernate through the piping. This activity did not disrupt the sludge because the flow direction was reversed while priming the pump and a plastic bag was positioned between the mixer pump and the sludge (visible near the base of the mixer: pump in Figure 3.6).

The mixer pump assembly was continuously oscillated through $180^{\circ}$ of rotation at a rate of 4.2 rpm during the tests. This rate is scaled based on an assumed $0.17 \mathrm{rpm}$ full-scale rotation rate. ${ }^{\text {(a) }}$ To begin the test, one of the centrifugal pumps was turned on and the flow control valve opened to obtain the desired flow rate. The time at which the pump was activated is assigned the value of 0 minutes. Every minute thereafter for the first 10 minutes, the ECR was measured along each of the eight radial lines marked on the tank bottom. The location of the sludge/slurry interface visible from underneath the tank was recorded as the ECR. ${ }^{(b)}$ After 10 minutes, the ECRs were recorded every 5 minutes until 60 minutes had passed since the pump was started. The ECRs were measured periodically thereafter until either the flow rate was changed or the test ended. Every time the ECRs were measured, measurements of the slurry density were also made with either a mechanical oscillation digital density meter, a stainless steel liquid density flask, or both. The slurry temperature was also recorded.

Effective cleaning radius, temperature, and slurry density measurement continued until the average of the eight ECRs was observed to either stabilize or reach a constant rate of growth. Once this requirement was met, a sketch ${ }^{(c)}$ of the ECR profile visible from under the tank was made. In some cases the flow rate was then increased and measurements taken as described above until the ECR growth criterion was again met. Another sketch of the ECR profile was then prepared. The slurry was pumped out of the tank to expose the sludge bank, which was photographed (see Figure 3.7). The weight of the slurry and the remaining sludge were measured and used to compute the weight percent of the sludge mobilized.

(a) The scaling of sludge mobilization experiments is described in Proposed Test Strategy for the Evaluation of Double-Shell Tank Sludge Mobilization by M. R. Powell, C. L. Fow, G. A. Whyatt, P. A. Scott, and C. M. Ruecker. 1990. A letter report prepared for Westinghouse Hanford Company. Pacific Northwest Laboratory. Richland, Washington.

(b) Before analyzing the data, the distance from the tank center to the nozzle exit (approx. $2.2 \mathrm{~cm}$ ) was subtracted from the ECR data.

(c) The data from these sketches are presented in Appendix B. 


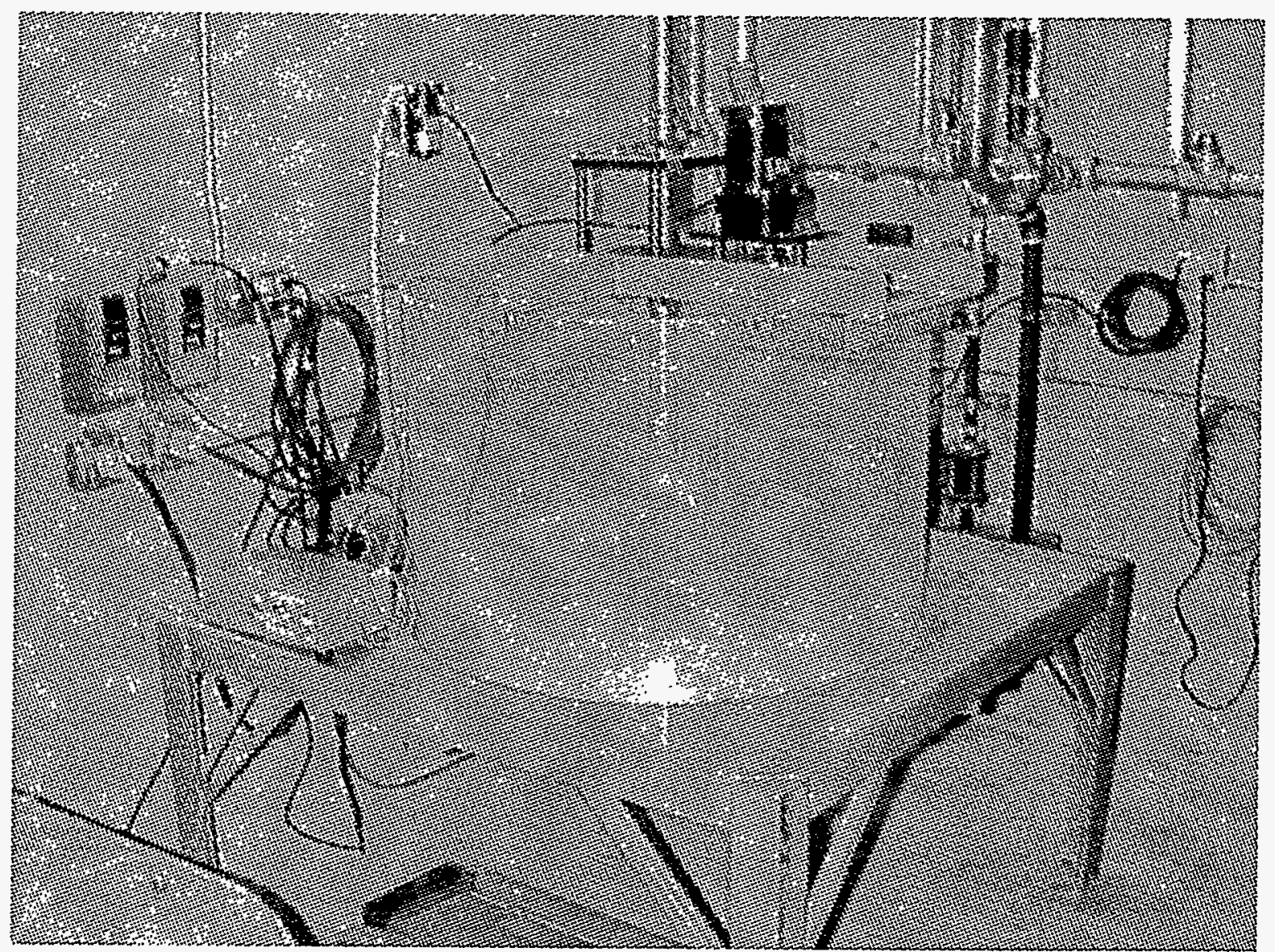

Figure 3.5. 1/25-Scale Tank Loaded with 50 liters of Sludge Simulant (Test 1-K) 



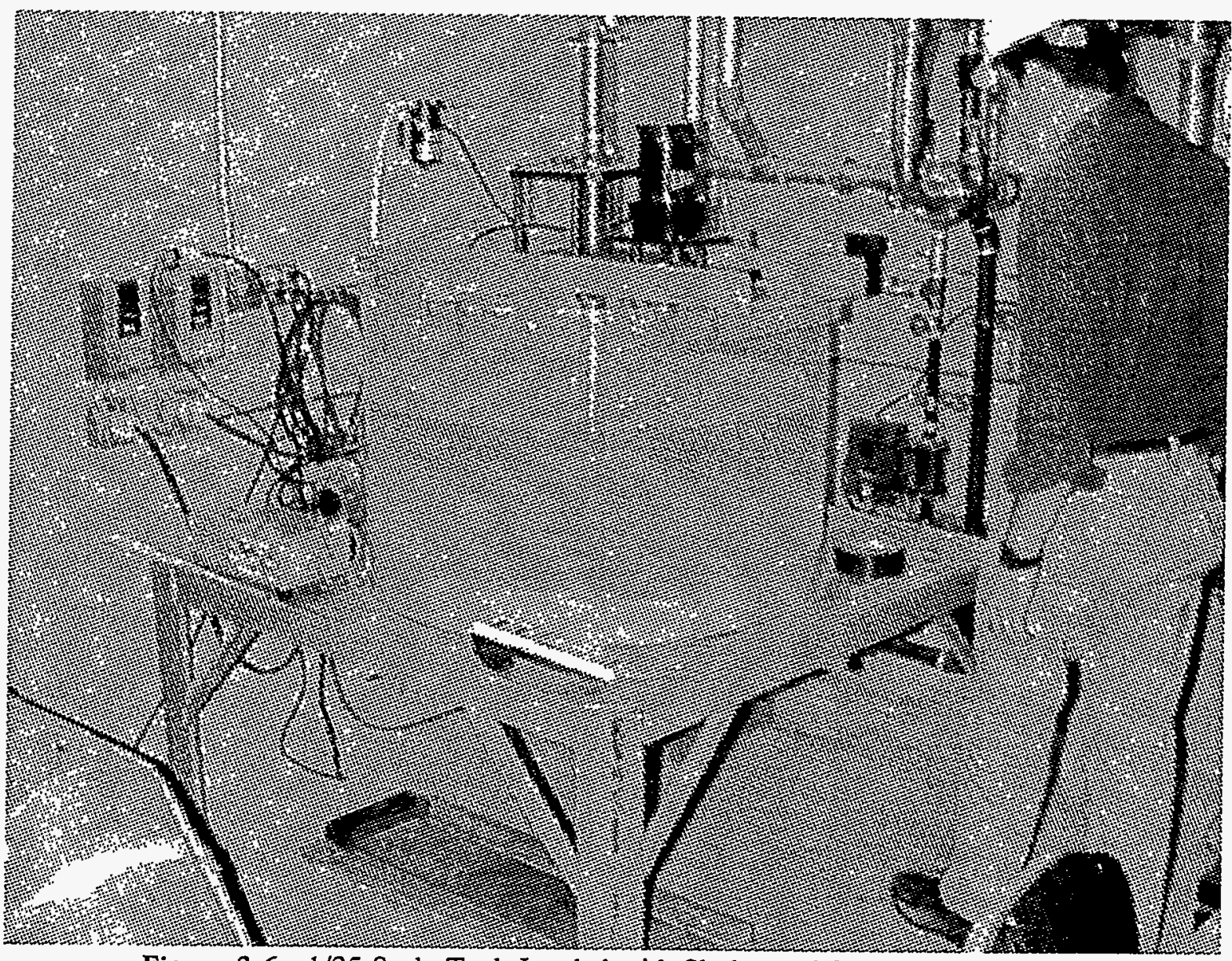

Figure 3.6. 1/25-Scale Tank Loaded with Sludge and Supernate Simulants 



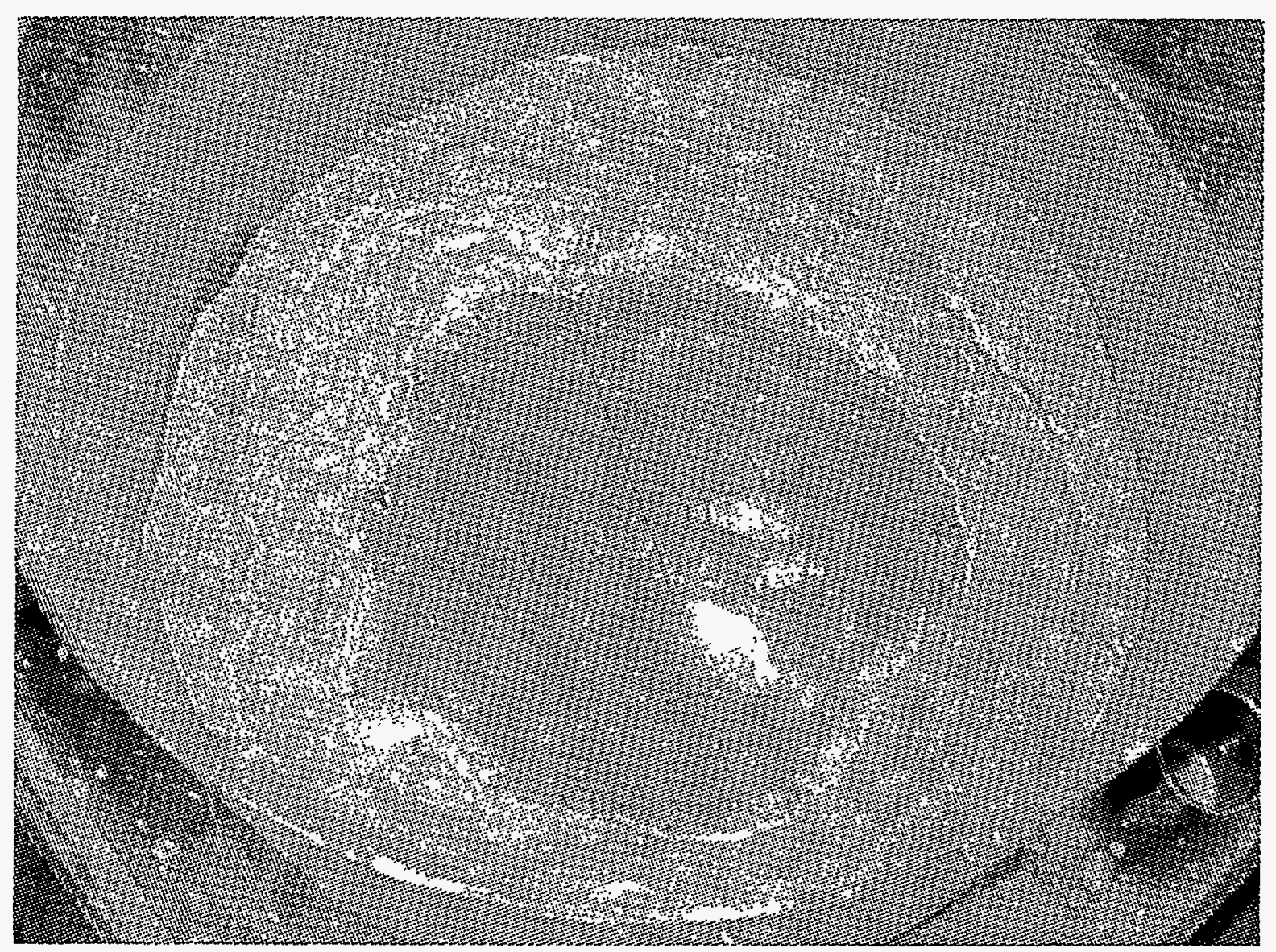

Figure 3.7. Sludge Remaining in Tank after Test $1-\mathrm{K}$ 



\subsection{Measurement and Test Equipment}

This section provides a brief description of each of the devices used to obtain the data provided in this report.

\section{ECR Measurements}

The ECR recorded during testing was the radial distance between the tank centerline and the sludge/slurry interface. This distance was quantified with the assistance of the concentric circles scribed on the tank bottom using a meterstick before testing. Before analysis of the data, the distance between the tank centerline and the nozzle exit was subtracted from all ECR measurements. This distance was $2.2 \mathrm{~cm}$ for the nominal nozzles shown in Figure 3.4.

\section{Slurry Flow Rate}

The flow of slurry through the discharge nozzles was measured with a Schlumberger Industries (Greenwood, South Carolina) Model FM100 pulsed dc magnetic flowmeter. The flowmeter was calibrated with tap water. It was observed during calibration and testing that the flow rate could be maintained at moderate levels (less than about $32 \mathrm{Lpm}$ ) to within $\pm 0.4 \mathrm{Lpm}(0.1 \mathrm{gpm})$ of the desired flow rate. This corresponds to about $a \pm 7 \mathrm{~cm}^{2} / \mathrm{s}$ uncertainty in the $U_{0} D$ values. At higher flow rates (up to $53 \mathrm{Lpm}$ ) the variation in the flow increased to as high as about $\pm 1.2 \mathrm{Lpm}(0.3 \mathrm{gpm})$.

\section{Sluriy Density}

- An Anton Paar (Austria) Model DMA35 mechanical oscillation digital density meter was used to monitor slurry density during the $1 / 25$-scale tests. This device calculates density based on the oscillation period of a small glass tube filled with the sample liquid. The stated accuracy of this device is $\pm 0.001 \mathrm{~g} / \mathrm{mL}$. Its calibration was verified by comparing the measured densities of degassed water and $10.0 \mathrm{wt} \% \mathrm{NaCl}$ solutions at known temperatures with their published densities.

- A Gardco Corp. (Pompano Beach, Florida) stainless steel density flask was used periodically as a check on the operation of the digital density meter. The flask is filled to give a precise volume of sample, which is then weighed to determine the liquid density. This flask has a stated volume of $100 \pm 0.5 \mathrm{~mL}$. Using this volume and the same calibration liquids as used for the digital density meter, the density flask gave densities $0.005 \mathrm{~g} / \mathrm{mL}$ too high. This is within the stated accuracy of the density flask.

\section{Weights}

- An Arlyn Scales model 310M 0-454 kg digital platform scale was used to prepare all simulants and to weigh the amount of sludge and supernate added to and removed from the tank. Accuracy $= \pm 0.5 \mathrm{~kg}$, Resolution $= \pm 0.1 \mathrm{~kg}$.

- A Sartorius (Waukegan, Illinois) 0 to 2100.00-gram digital platform balance was used to measure the weight of the density flask (filled and empty). This balance is accurate to \pm 0.02 grams. 


\section{Slurry Temperature}

A Cole-Parmer (Chicago, Illinois) Digi-Sense Platinum RTD Thermometer (Model 93400-00) was used to monitor the slurry temperature during most tests. The temperature readout displays the temperature with $\pm 0.1^{\circ} \mathrm{C}$ resolution. The stated accuracy of this device is better than $\pm 0.5^{\circ} \mathrm{C}$.

\section{Sludge Rheology}

- A Haake (Karlsruhe, West Germany) Rotovisco viscometer with an M5 measurement head was used for all sludge shear strength measurements. Nearly all shear strength measurements were conducted using a fully-submerged, $0.635-\mathrm{cm}\left(0.25 \mathrm{in}\right.$.) shear vane $\left(\mathrm{H}_{\mathrm{v}}=\mathrm{D}_{\mathrm{v}}\right)$. Where possible, the data obtained using the $0.635-\mathrm{cm}$ vane were verified using a $2.22-\mathrm{cm}(0.875 \mathrm{in}$.) shear vane. The maximum shear strength that can be measured using the $2.22-\mathrm{cm}$ vane is $24 \mathrm{kdyne} / \mathrm{cm}^{2}$. The $0.635-\mathrm{cm}$ vane can measure up to $913 \mathrm{kdyne} / \mathrm{cm}^{2}(490,000$ dyne-cm of torque on submerged $0.635-\mathrm{cm}$ vane).

- A Haake (Karlsruhe, West Germany) Rotovisco viscometer with a CV20 measurement head was used for all slurry rheology measurements.

\section{Sludge Tensile Strength}

Four different techniques were used to measure the tensile strength of the $1 / 25$-scale sludge simulants. These techniques are described below.

- The tensile strength of each sludge simulant was measured using a vertical split-cell tensiometer fabricated from the tops of two $200-\mathrm{mL}$ plastic bottles. The device is shown in Figure 3.8. The sludge simulant sample was loaded into the tensiometer, and a tensile force was then applied at a rate of $98 \pm 5 \mathrm{kdyne} / \mathrm{min}$ (equivalent to a water addition rate of $100 \pm 5 \mathrm{~mL} / \mathrm{min}$ ). Following failure of the specimen in a tensile mode, the mass the water and 1000-mL plastic bottle (M) and the mass of the upper portion of the tensiometer including the contained sludge $\left(M_{t}\right)$ were measured. These data, along with a small allowance for pulley friction (20 grams) and the failure plane diameter $\left(D_{t}\right)$ were used to compute the tensile strength $\left(S_{t}\right)$ according to the equation:

$$
\mathrm{S}_{\mathrm{t}}=\frac{4\left(\mathrm{M}-\mathrm{M}_{\mathrm{t}}-20 \mathrm{grarns}\right)\left(980 \mathrm{~cm} / \mathrm{s}^{2}\right)}{\pi D_{t}^{2}}
$$

- The tensile strength of each sludge simulant was measured in two ways using a horizontal/vertical extrusion device made from a $2.65-\mathrm{cm}$ inside diarneter copper tube, a plunger assembly, and an electric motor. The device is shown in its horizontal configuration in Figure 3.9. The same device was used for both vertical and horizontal extrusion tensile strength tests. The samples were extruded at approximately $3.9 \mathrm{~cm} / \mathrm{min}$. The extrusion was continued until a piece of sample detached and fell into a collection vessel. The average mass of multiple measurements was used to calculate the tensile strength as follows:

Vertical Extrusion: The weight of the pieces that break off divided by the cross-sectional area of the tube give the vertical extrusion tensile strength. 
Horizontal Extrusion: The horizontal extrusion tensile strength is calculated based on a static force analysis of the sample as a cantilevered beam. Based on the mass of the pieces that break free $\left(M_{h}\right)$, the sample density $\left(\rho_{\text {sludge }}\right)$, and the extrusion tube diameter $\left(D_{t}\right)$, the tensile strength is calculated by:

$$
S_{t}=\frac{64 M_{h}^{2} g}{\pi^{2} D_{t}^{5} \rho_{\text {sludge }}}+\frac{8 M_{h} g}{3 \pi D_{t}^{2}}\left[\frac{0.925}{1.04}\right]
$$

The derivation of this equation assumes that no appreciable bending of the sample occurs before failure and that the sample undergoes a brittle elastic failure rather than a plastic failure. This might not be a realistic mechanical behavior expectation for either the DST sludge or some of the sludge mobilization simulants.

- A horizontal split-cell tensiometer was constructed from two 2.21-cm ID stainless steel tubes and a force measurement device as shown in Figure 3.10. The force measurement was accomplished by connecting a spring to a TA-XT2 Texture Analyzer (Stable Micro Systems, Surrey, England). The texture analyzer moves upward vertically at a selectable rate while measuring the tensile force on the spring. The two 18 -cm-long tubes are initially clamped together to form a single $36-$ $\mathrm{cm}$-long tube. The simulant is then loaded into this $36-\mathrm{cm}$-long tube. The connected tube assembly is referred to as the horizontal split-cell tensiometer. Once the split-cell tensiometer is positioned into the cell supports and connected through a pulley to the texture analyzer spring, the texture analyzer head is raised at a constant rate of $0.1 \mathrm{~mm} / \mathrm{s}$, which corresponds to 353 $\mathrm{kdyn} / \mathrm{min}$. The force required to separate the two halves of the split-cell tensiometer is corrected for frictional effects and then divided by the cross-sectional area of the $2.21-\mathrm{cm}$ ID tube to give the tensile strength. 


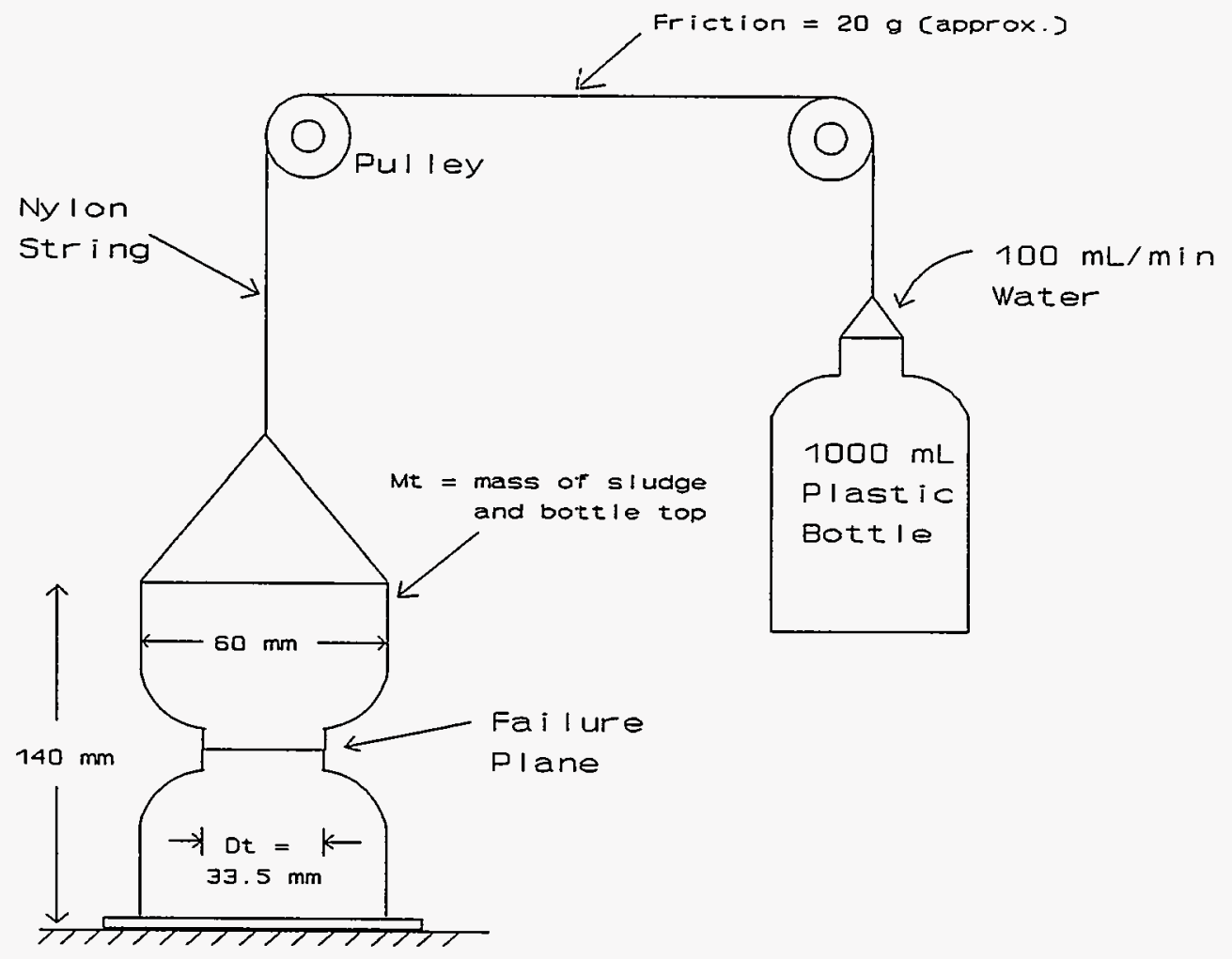

Figure 3.8. Vertical Split-Cell Tensile Strength Measurement Device 


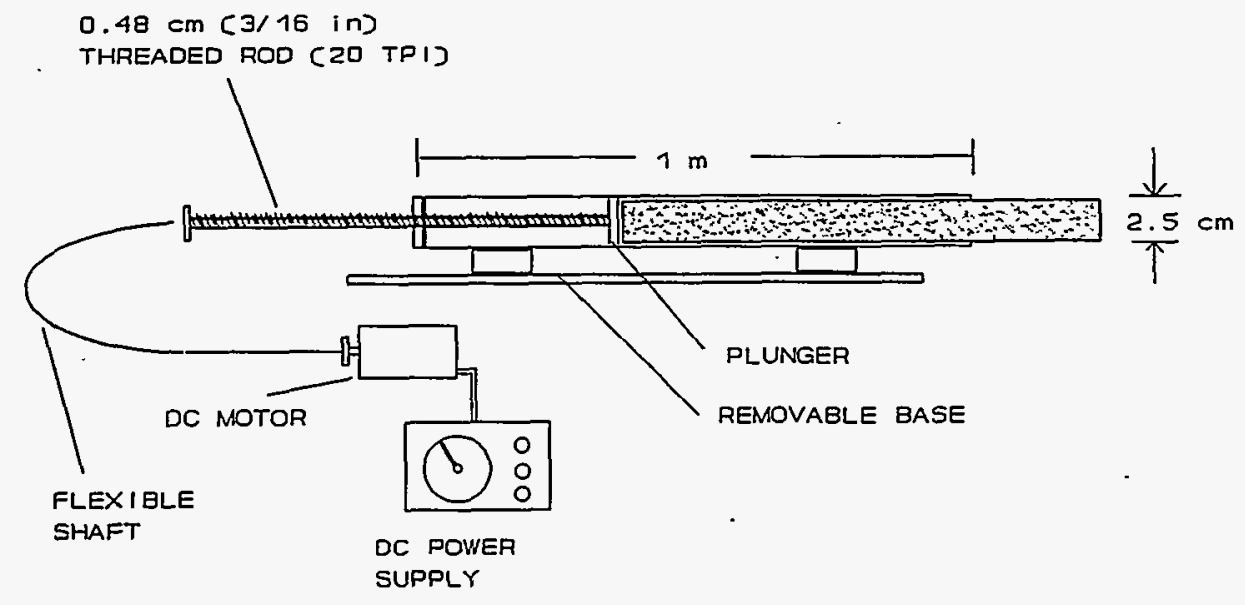

Figure 3.9. Sketch of Horizontal and Vertical Extrusion Tensiometer Apparatus 


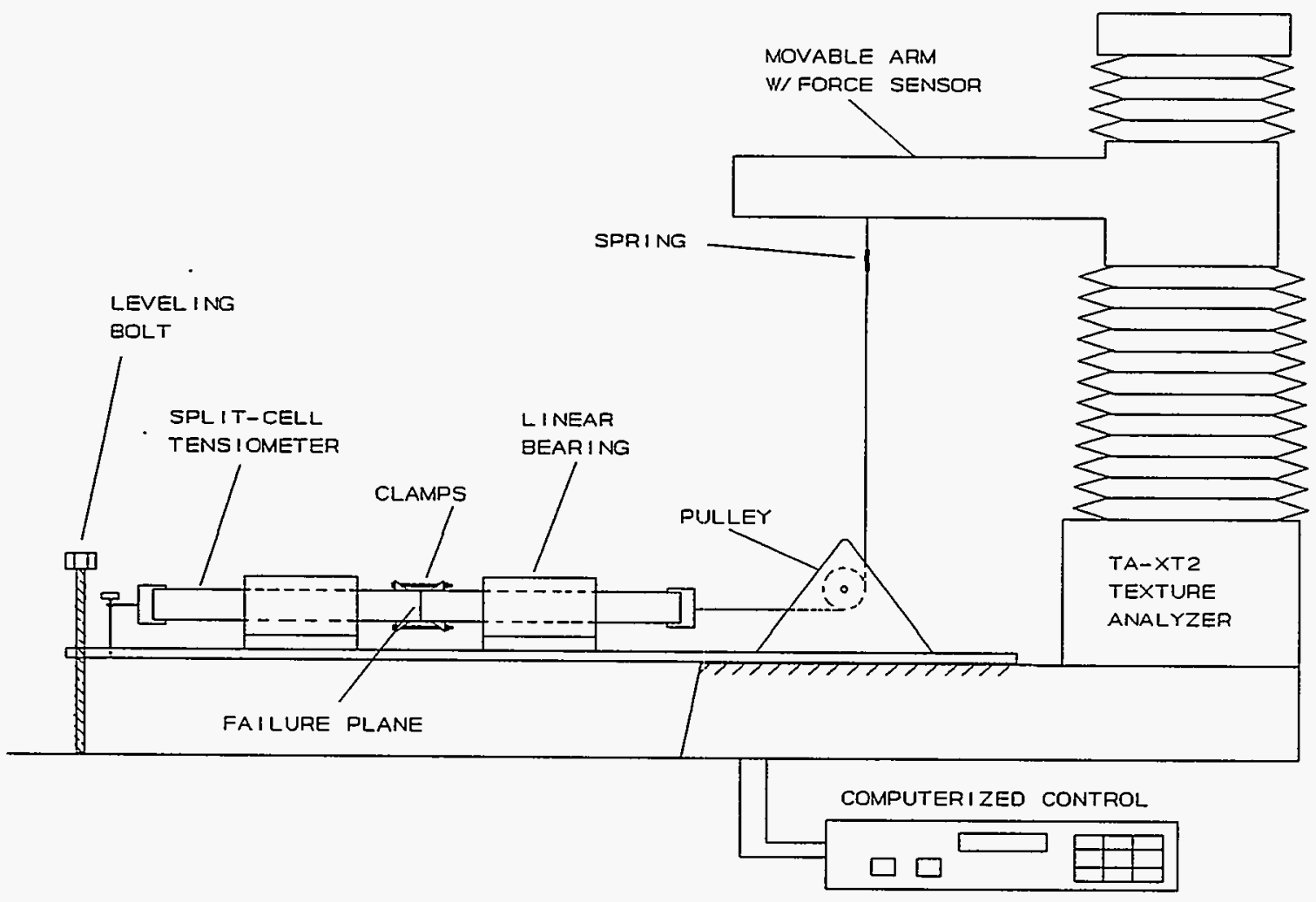

Figure 3.10. Sketch of Horizontal Split-Cell Tensiometer 


\subsection{Simulants used for $1 / 25$-Scale Testing}

Seven types of sludge simulants were used during the fiscal year $19941 / 25$-scale testing. The simulants were selected to provide variations in the key properties thought to govern sludge mobilization.

All the simulants were prepared in a similar manner. The required mass of each component was weighed out before mixing. The dry materials were then added to the Littleford Mixer followed by the water. The simulants were mixed for 20 to 30 minutes before being placed into covered, 5-gallon buckets. Simulants were routinely loaded into the tank following this mixing. Enough simulant was added to the tank to produce $50 \mathrm{~L}$ of sludge. If the simulant was to be in the tank for longer than about 10 minutes before supernate addition, a plastic cover was placed over the simulant surface to prevent evaporation.

The compositions of the sludge simulants used in the $1 / 25$-scale testing and their physical properties are given in Table 3.1. Tensile strength data $\left(\mathrm{S}_{\mathrm{t}}\right)$ for both the vertical split cell and vertical extrusion methods are shown as well as vane shear strength $\left(\tau_{\mathrm{g}}\right)$.

Table 3.1. 1/25-Scale Simulant Compositions and Physical Properties

\begin{tabular}{|c|c|c|c|c|c|}
\hline $\begin{array}{r}\text { O } \\
\text { Test } \#\end{array}$ & 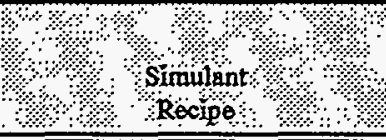 & \%, Messud & 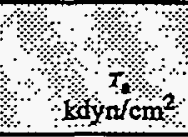 & $\begin{array}{l}\text { क } \\
s_{\mathrm{t}} \text { Split cell } \\
\text { kdyntem }\end{array}$ & $\begin{array}{l}S_{t} \text { Extrusion } \\
\text { (Vertical) } \\
\text { kdyn } / \mathrm{cm}^{2}\end{array}$ \\
\hline $1-K$ & $\begin{array}{l}66.0 \% \text { kgolin } \\
34.0 \% \text { water }\end{array}$ & $64.2 \pm 0.2$ & $20.7 \pm 0.9$ & $29.2 \pm 2.9$ & $32.1 \pm 1.2$ \\
\hline $2-K$ & $\begin{array}{l}54.3 \% \text { krolin } \\
45.7 \% \text { water }\end{array}$ & $54.2 \pm 0.2$ & $3.5 \pm 0.2$ & $10.9 \pm 1.4$ & $4.9 \pm 0.1$ \\
\hline $3-K$ & $\begin{array}{l}\text { 68.9\% kaolin } \\
31.3 \% \text { water }\end{array}$ & $66.4 \cdot \pm 0.3$ & $30.5 \pm 2.1$ & $34.7 \pm 10.7$ & $47.6 \pm 4.7$ \\
\hline $4-B$ & $\begin{array}{l}16.0 \% \text { bentonite } \\
84.0 \% \text { water }\end{array}$ & $15.2 \pm .06$ & $2.7 \pm 0.3$ & $10.0 \pm 0.9$ & $5.8 \pm 0.1$ \\
\hline $5-B$ & $\begin{array}{l}20.0 \% \text { bentonite } \\
80.0 \% \text { water }\end{array}$ & $18.0 \pm 0.3$ & $13.4 \pm 0.4$ & $31.0 \pm 8.1$ & $21.8 \pm 2.5$ \\
\hline $6-B$ & $\begin{array}{l}34.5 \% \text { bentonite } \\
65.5 \% \text { water }\end{array}$ & $32.4 \pm 0.4$ & $66.4 \pm 5.5$ & $109 \pm 11$ & $114 \pm 18$ \\
\hline 7-BK & $\begin{array}{l}18.0 \% \text { bentonite } \\
36.0 \% \text { kaolin } \\
46.0 \% \text { water }\end{array}$ & $52.5 \pm 0.3$ & $66.4 \pm 5.5$ & $100 \pm 32$ & $150 \pm 7$ \\
\hline 8-BK & $\begin{array}{l}14.4 \% \text { bentonite } \\
28.9 \% \text { kaolin } \\
56.7 \% \text { water }\end{array}$ & $42.9 \pm 0.2$ & $24.4 \pm 1.6$ & $55.0 \pm 5.4$ & $43.9 \pm 1.8$ \\
\hline 9-BK & $\begin{array}{l}12.1 \% \text { bentonite } \\
24.8 \% \text { kaolin } \\
63.1 \% \text { water }\end{array}$ & $37.0 \pm 0.1$ & $6.3 \pm 0.4$ & $22.4 \pm 7.3$ & $14.2 \pm 1.4$ \\
\hline
\end{tabular}




\begin{tabular}{|c|c|c|c|c|c|}
\hline Test. \# & $\begin{array}{c}\text { Simulant } \\
\text { Recipe } \\
\end{array}$ & $\begin{array}{l}\text { Measured } \\
\text { wt\%.Sojids: }\end{array}$ & 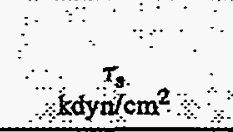 & $\begin{array}{l}\text { sisplit Cell } \\
\text { kdyo } / \mathrm{cm}^{2}\end{array}$ & $\begin{array}{l}s_{t} \text { Extrusion } \\
\text { (Vertical) } \\
\text { kdyn } / \mathrm{cm}^{2}\end{array}$ \\
\hline $10-\mathrm{KP}$ & $\begin{array}{l}50.0 \% \text { kaolin } \\
10.0 \% \text { plaster } \\
40.0 \% \text { water } \\
\text { Supernate: } \\
0.2 \% \text { CaSO }_{4(\mathrm{ag})}\end{array}$ & $59.3 \pm 0.3$ & $9.7 \pm 0.9$ & $22.2 \pm 3.5$ & $17.9 \pm 1.4$ \\
\hline $11-\mathrm{KP}$ & $\begin{array}{l}50.0 \% \text { kaolin } \\
12.0 \% \text { plaster } \\
38.0 \% \text { water } \\
\text { Supernate: } \\
0.2 \% \text { CaSO }_{4(\mathrm{~g})}\end{array}$ & $61.7 \pm 0.2$ & $21.2 \pm 2.2$ & $53.4 \pm 27$ & $37.8 \pm 4.2$ \\
\hline $12-\mathrm{KP}$ & $\begin{array}{l}50.0 \% \text { kaolin } \\
14.0 \% \text { plaster } \\
36.0 \% \text { water } \\
\text { Supernate: } \\
0.2 \% \mathrm{CaSO}_{4(\mathrm{ag})}\end{array}$ & $63.2 \pm 0.2$ & $22.7 \pm 1.0$ & $52.2 \pm 53$ & $33.5 \pm 11$ \\
\hline $13-\mathrm{KL}$ & $\begin{array}{l}\text { 48.6\% kaolin } \\
17.0 \% \text { Ludox } \\
33.7 \% \text { water } \\
0.71 \% \mathrm{NaCl} \\
\text { Supernate: } \\
1.54 \% \mathrm{NaCl}_{(\mathrm{gq})}\end{array}$ & $54.3 \pm 0.1$ & $\begin{array}{l}8.0 \pm 2.0 \\
8.3 \pm 1.4\end{array}$ & $20.5 \pm 19$ & $17.4 \pm 1.3$ \\
\hline $14-\mathrm{KL}$ & $\begin{array}{l}47.1 \% \text { kaolin } \\
27.0 \% \text { Ludox } \\
25.2 \% \text { water } \\
0.69 \% \mathrm{NaCl} \\
\text { Supernate: } \\
1.54 \% \mathrm{NaCl}_{(\mathrm{aq})}\end{array}$ & $55.0 \pm 0.2$ & $\begin{array}{l}75.8 \pm 4.2 \\
95.2 \pm 5.3\end{array}$ & $44 \pm 11$ & $\begin{array}{c}38.9 \pm 3.3 \\
\end{array}$ \\
\hline $15-\mathrm{KL}$ & $\begin{array}{l}47.4 \% \text { kaolin } \\
25.0 \% \text { Ludox } \\
26.9 \% \text { water } \\
0.69 \% \mathrm{NaCl} \\
\text { Supernate: } \\
1.54 \% \mathrm{NaCl}_{\text {(aq) }}\end{array}$ & $55.3 \pm 0.2$ & $\begin{array}{l}47.4 \pm 2.3 \\
64.2 \pm 2.3\end{array}$ & $32 \pm 11$ & $18.6 \pm 4.9$ \\
\hline $16-\mathrm{KN}$ & $\begin{array}{l}63.0 \% \text { ksolin } \\
35.15 \% \text { water } \\
1.85 \% \mathrm{NaCl}\end{array}$ & $64.2 \pm 0.1$ & $15.4 \pm 1.7$ & $27.1 \pm 2.4$ & $20.6 \pm 1.3$ \\
\hline $17-\mathrm{KN}$ & $\begin{array}{l}57.5 \% \text { kaolin } \\
34.0 \% \text { water } \\
8.5 \% \mathrm{NaCl}\end{array}$ & $65.7 \pm 0.1$ & $11.5 \pm 0.8$ & $23.7 \pm 0.6$ & $14.6 \pm 0.3$ \\
\hline $18-\mathrm{KN}$ & $\begin{array}{l}63.0 \% \text { kaolin } \\
35.15 \% \text { water } \\
1.85 \% \mathrm{NaCl} \\
1 \text { st Supernate: } \\
5.0 \% \mathrm{NaCl} \\
95.0 \% \text { water } \\
2 \text { nd Supernate: } \\
100 \% \text { water }\end{array}$ & $64.4 \pm 0.1$ & $14.6 \pm 0.3$ & $22.1 \pm 1.5$ & $17.9 \pm 1.3$ \\
\hline $19-\mathrm{K}$ & $\begin{array}{l}66.0 \% \text { kaolin } \\
34.0 \% \text { water }\end{array}$ & $65.3 \pm 0.1$ & $26.0 \pm 1.1$ & $25.0 \pm 2.9$ & $42.4 \pm 1.6$ \\
\hline $20-B$ & $\begin{array}{l}25.0 \% \text { bentonite } \\
75.0 \% \text { water }\end{array}$ & $24.3 \pm 0.2$ & $40.4 \pm 3.5$ & $86.2 \pm 11.9$ & $54.5 \pm 3.4$ \\
\hline
\end{tabular}




\begin{tabular}{|c|c|c|c|c|c|}
\hline Test H: & $\because$ Simulant & Mersured & Kdy & $\begin{array}{l}\mathrm{s}_{\mathrm{t}} \text { Split Cell } \\
\text { kdyn } \mathrm{cm}^{2}\end{array}$ & $\begin{array}{c}\text { si Extrusion } \\
\text { (Vertical) } \\
\text { kdyn } / \mathrm{cm}^{2}\end{array}$ \\
\hline $21-K$ & $\begin{array}{l}58.5 \% \text { kaolin } \\
41.5 \% \text { water }\end{array}$ & $58.1 \pm 0.1$ & $6.4 \pm 0.3$ & $14.8 \pm 1.5$ & $9.4 \pm 1.3$ \\
\hline $22-K$ & $\begin{array}{l}66.0 \% \text { kaolin } \\
34.0 \% \text { water }\end{array}$ & $66.2 \pm 0.2$ & $27.1 \pm 3.6$ & $24.3 \pm 5.5$ & $49.8 \pm 3.2$ \\
\hline 23-KB & $\begin{array}{l}65.0 \% \text { kaolin } \\
33.7 \% \text { water } \\
1.33 \% \text { bentonite }\end{array}$ & $65.8 \pm 0.3$ & $37.1 \pm 1.7$ & $58.9 \pm 11.5$ & $58.4 \pm 6.4$ \\
\hline $24-\mathrm{K}$ & $\begin{array}{l}66.0 \% \text { kaolin } \\
34.0 \% \text { water }\end{array}$ & $65.4 \pm 0.3$ & $26.7 \pm 3.3$ & $21.3 \pm 6.1$ & $\begin{array}{l}\text { not meas. } \\
\text { see tests } \\
1-K \& 19-K\end{array}$ \\
\hline $25-\mathrm{KB}$ & $\begin{array}{l}62.08 \% \text { kaolin } \\
1.27 \% \text { bentonite } \\
34.0 \% \text { water }\end{array}$ & $63.3 \pm 0.3$ & $20.1 \pm 2.1$ & $40.2 \pm 7.9$ & $33.3 \pm 2.2$ \\
\hline $26-\mathrm{KB}$ & $\begin{array}{l}59.87 \% \text { kaolin } \\
1.22 \% \text { bentonite } \\
38.91 \% \text { water }\end{array}$ & $61.0 \pm 0.2$ & $7.1 \pm 0.7$ & $18.6 \pm 2.9$ & $11.7 \pm 0.6$ \\
\hline
\end{tabular}

In each test, $200 \mathrm{~L}$ ( $52.9 \mathrm{gal}$ ) of supernate was added to the $50 \mathrm{~L}$ of sludge placed in the tank. Unless otherwise specified, the supernate was tap water. The supernate solutions for tests 10-KP through 15-KL and 18-KN were salt solutions as specified in Table 3.1.

\subsection{Mixer Pump Operation Data}

As described in Section 3.2, ECR data were recorded periodically throughout each test and typically the mixer pump was operated first at a low flow rate and then at a higher flow rate. The selection of the initial flow rate for each test was made based on the results of previous tests. It was desired that the ECR reach about 20 to $25 \mathrm{~cm}$ from the tank center for the first flow rate. ECRs much less than $20 \mathrm{~cm}$ are subject to larger relative measurement uncertainties. If the initial ECR is much greater than $25 \mathrm{~cm}$, then the second flow rate cannot be made much higher than the initial flow rate without the ECR reaching 35 to $40 \mathrm{~cm}$ where the effects of the tank wall on the slurry flow patterns will likely affect the ECR growth (tank radius is approximately $45 \mathrm{~cm}$ ). The second flow rate, if one was employed, was selected based on the ECR observed from the first flow rate.

The flow rates selected for each test along with the corresponding nozzle exit velocities and $U_{0} D$ values are provided in Table 3.2. Also provided in the table are the measured average ECRs that were recorded at the end of the specified time intervals. The $95 \%$ confidence intervals on the ECR measurements were estimated based on the sample standard deviation about the mean (i.e., sample standard deviation multiplied by the 7 degree of freedom Student's t-value for the 0.975 probability level divided by the square root of 8). The Table 3.2 ECR data are presented as plots in Section 4.0. 


\subsection{Results and Analyses}

The results of the $261 / 25$-scale sludge mobilization tests conducted during fiscal year 1994 are presented in this section. This section is divided into five sub-sections. Section 4.1 addresses the efforts to develop a correlation between various sludge properties and the ECR produced by jet mixer pumps of known hydraulic power. The effects of nozzle design on the mobilization of sludge simulants are discussed in Section 4.2. Section 4.3 details the results of the 1/25-scale tests in which changes to the slurry rheology and density were tested. Mixer pump operation effects such as indexed nozzle movement vs. continuous oscillation and the ability of mixer pumps to mobilize sludge near the tank wall are discussed in Section 4.4. Finally, Section 4.5 presents a list of future tests that are needed to address some of the unresolved issues discussed in Section 4.1 through 4.4.

\subsection{ECR Correlation Development}

The data presented in this section indicate that the cohesiveness of the sludge simulants tested provides a good predictor of their resistance to mobilization by a submerged fluid jet. Measuring cohesiveness has proven challenging, but two viable approaches have been identified. The first approach is to measure the tensile strength of the sludge. For some sludge-like materials, tensile strength provides a direct measure of the strength of interparticle attractive forces. However, tensile strength is difficult to measure accurately. The second approach is to use shear strength data coupled with an estimate of the fraction of the shear strength thought to be due to cohesion. With data from these two methods, it is expected that a reasonably accurate prediction of the ECR could be made.

The $1 / 25$-scale mobilization data imply that it is feasible to develop conservative ECR prediction capabilities based on sludge shear strength measurements. This correlation would accurately predict the ECR of sludge that owes its shear strength to cohesive rather than frictional forces. Such a correlation would likely underpredict the ECR in those cases when the shear strength is not due only to cohesion, but it is not expected that an overprediction of the ECR would occur. The use of such a correlation would help to avoid problems like those recently experienced at the Savannah River Site where the 150 -hp mixer pumps were expected to generate $7.3 \mathrm{~m}$ ( $24 \mathrm{ft}$ ) ECRs, but only about $4.9 \mathrm{~m}$ $(16 \mathrm{ft})$ ECRs were observed. The $7.3 \mathrm{~m}$ ECR prediction was based on kaolin clay simulants. 1/25-scale testing at PNL has shown that kaolin clay obtains only a small fraction of its strength from cohesive forces.

The present data were not developed for the purpose of generating a correlation for making fullscale ECR predictions. The scatter in the ECR data that results from working at such a small scale makes any correlations developed from 1/25-scale test data less accurate than correlations developed at a larger scale. The fact that the areas cleaned by the $1 / 25$-scale mixer pump are not perfect circles is thought to be due to inhomogeneities in the simulant and the simulant adhesion to the tank floor. The absolute magnitude of the scatter in the ECR data that results from these effects is not expected to increase in direct proportion to the scale of the test facility. Thus, at a larger scale the uncertainty in the ECR measurements will be a smaller fraction of the magnitude of the ECRs measured. This allows for the development of more accurate ECR correlations. 
The value of running tests at $1 / 25$ scale is the ability to run many tests in a short time at reduced cost. Running a large number of tests is required to identify the set of sludge simulant properties that have the greatest influence on mobilization. During fiscal year 1994, seven different simulants of varying strength properties were studied in the $1 / 25$-scale tank. The results indicate that the cohesiveness of sludge is the relevant physical property for the prediction of ECR. The next step in ECR correlation development is to run tests at larger scale so that a more accurate correlation can be generated.

\subsubsection{ECR vs. Shear Strength}

The mobilization data for the fiscal year 1994 1/25-scale testing are plotted in Figure 4.1. The ECR data are divided by the quantity $U_{0} D$ to result in a measure of the susceptibility of each simulant to mobilization. $U_{0}$ is the nozzle exit velocity of the mixer pump jet, and $\mathrm{D}$ is the nozzle diameter. Thus, the quantity $U_{0} D$ is a measure of the mobilizing force of the jet. The ECR/U $U_{0} D$ data are plotted vs. simulant shear strength $\left(\tau_{s}\right)$ on a log-log scale in Figure 4.1 .

The ECRs selected for plotting were all ECRs greater than $10 \mathrm{~cm}$. In some cases tests were started using a conservatively low jet flow to avoid mobilizing all the sludge simulant in the tank. Occasionally, this practice resulted in a very small ECR. When this happened, the jet flow was increased so that a larger ECR was obtained. Only ECRs of greater than $10 \mathrm{~cm}$ were considered acceptable for correlation development because ECRs this small cannot be accurately measured in the $1 / 25$-scale tank.

The ECRs used for plotting the data for bentonite/water and bentonite/kaolin simulants are not the final, end-of-test values, but values determined based on the observed shift in mobilization rate from an early, rapid rate to a long-term, linear ECR growth rate. The ECR at which this transition occurs is the ECR used in all plots of the data for these simulants. This was done to account for the osmotic swelling behavior of the bentonite clay. This is discussed further in Section 4.1.1.2.

The solid line drawn on Figure 4.1 represents the correlation between mobilization susceptibility and shear strength derived from 1/12-scale tests conducted in fiscal year 1987 using a silica/soda ash sludge simulant. It is clear that the 1/12-scale correlation under-predicts the ECRs observed at $1 / 25$-scale. There are several possible explanations for this. The favored explanation is that the $1 / 12$-scale correlation is conservative because the silica/soda ash tests were stopped before ECR growth had completed. If the tests had continued until ECR growth was complete, it is possible that the observed correlation would be much closer to the $1 / 25$-scale data. 


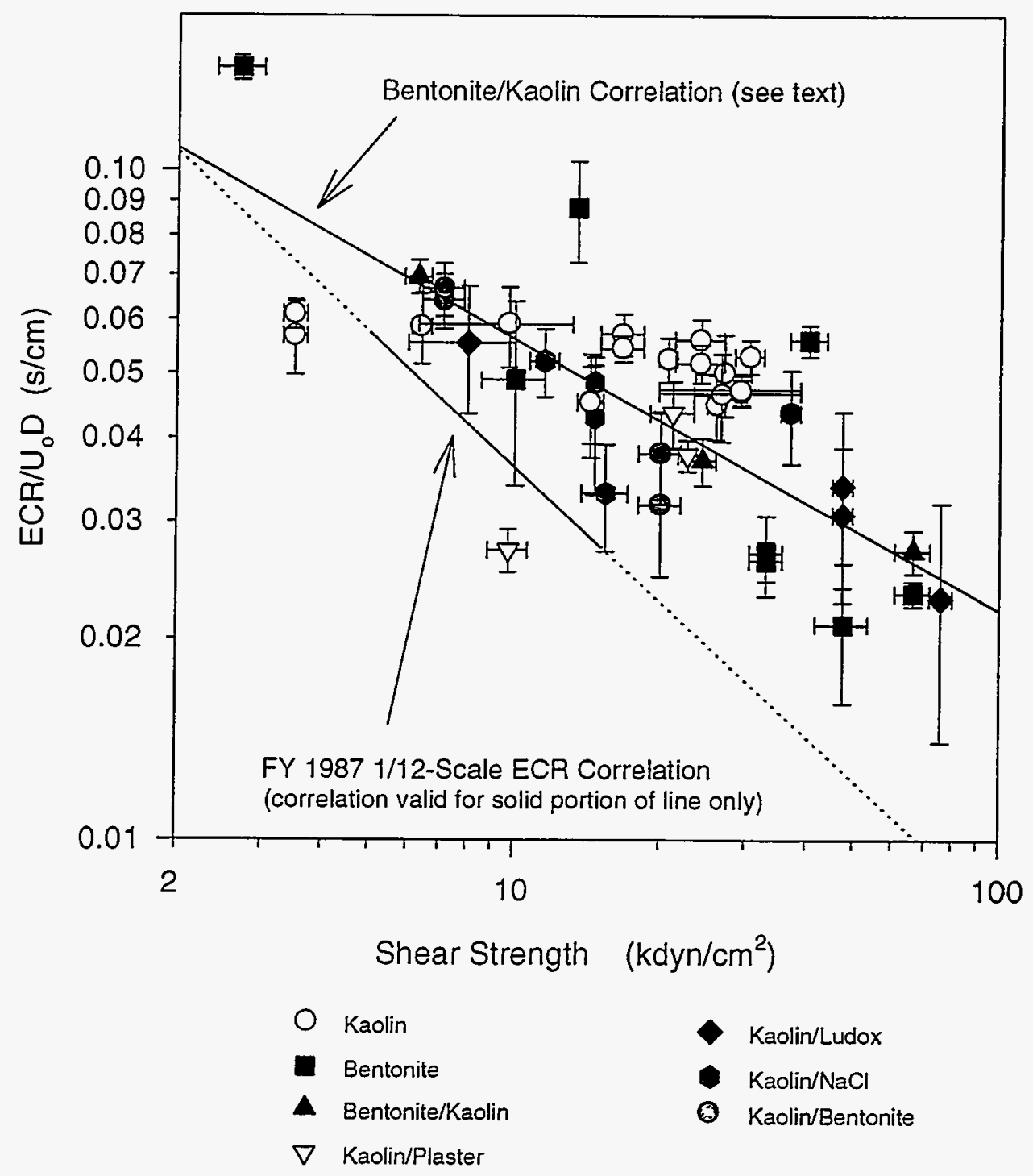

Figure 4.1. 1/25-Scale Simulant ECR vs. Shear Strength Data 
An alternative explanation is that there is an effect of scale on the correlation of mobilization susceptibility with shear strength. If this is so, then it appears that for a given sludge shear strength, the susceptibility of a sludge to mobilization decreases as the size of the jet is increased. This explanation is not viewed as likely at this time. Turbulent jet similarity of scale is reasonably well understood for Newtonian fluids, and jet theory does not predict any such scaleup effect. Future mobilization tests at $1 / 12$-scale are needed to determine whether there is an unexpected scaleup effect for sludge mobilization data.

The fact that the simulant used to develop the fiscal year 1987 correlation was not tested as part of the present work is another possible explanation for the difference. However, silica/soda ash was one of the simulants tested in the 1/25-scale tank during fiscal year 1993. The silica/soda ash simulant ECR growth was initially rapid then transitioned into a slower, but constant, ECR growth rate. This constant growth rate showed no signs of slowing over the 12 hours of the two silica/soda ash tests (Powell et al. 1995). ${ }^{\text {(a) }}$ It is inferred from this that the mechanism of silica/soda ash mobilization at the final ECR probably involves gradual particle-by-particle erosion rather than the jet shear stress overcoming the cohesive strength of the simulant. If this mechanism is accurate, then reasonably large ECRs should be attainable in silica/soda ash simulants provided that the test is run for a long time. Long-term testing was not performed during fiscal year 1993 because the silica rapidly destroyed the pump seals.

Whether the fiscal year 1987 correlation tends to underpredict ECRs for the cohesive sludge simulants used in the present study will be resolved by $1 / 12$-scale sludge mobilization tests that are planned. If the 1987 correlation is too conservative and the $1 / 25$-scale data can be scaled directly to full-scale, then it appears that the actual ECR expected from a $10 \mathrm{kdyn} / \mathrm{cm}^{2}$ shear strength sludge will be about $25 \%$ larger than the 1987 correlation would predict.

\section{Kaolin/Water Sludge Simulant Correlation}

The ECR/U $\mathrm{D}$ vs. shear strength data for kaolin clay sludge simulants are plotted in Figure 4.2. Data from both fiscal year 1993 and 1994 test programs are included to show the consistency. The 1993 tests were stopped sooner than the 1994 tests (before complete ECR growth), but this effect does not appear to have been significant. It is apparent from Figure 4.2 that variations in the shear strength of kaolin clay simulants have only a minor effect on mobilization susceptibility. When the ECR growth rates are considered, however, shear strength does play a role in the mobilization of kaolin simulants. Figure 4.3 shows fiscal year $1994 \mathrm{ECR} / \mathrm{U}_{0} \mathrm{D}$ data plotted versus time for different shear strengths. A systematic progression in ECR growth rate is evident as shear strength decreases. The final ECRs for kaolin simulants are largely independent of shear strength, but the time required to reach the final ECR increases as shear strength increases.

(a) A 1/12-scale test using silica/soda ash was conducted for 14 hours and the ECR was also observed to grow linearly with time after an early, rapid growth period. These tests are discussed further in Powell et al. (1995). 


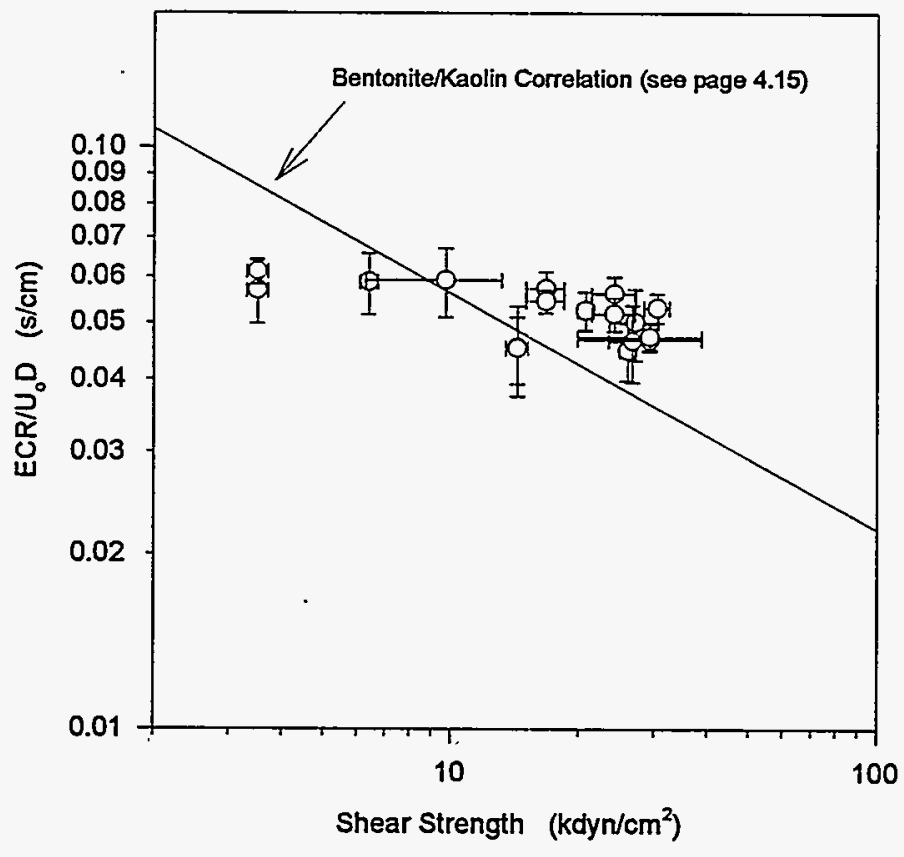

Figure 4.2. Kaolin/Water ECR Data

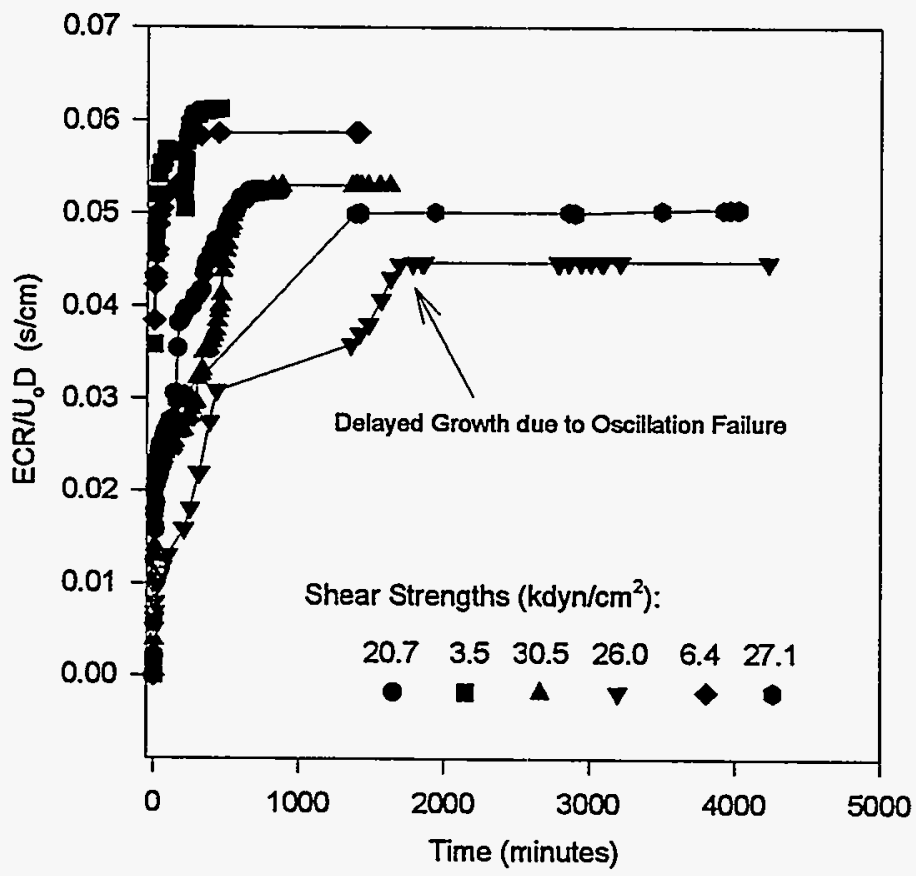

Figure 4.3. Kaolin EC'R vs. Time Data 
This observation is significant in that it provides an explanation for why a much stronger dependence of ECR on shear strength was observed during bench-scale tests ${ }^{(a)}$ conducted in fiscal year 1988. The bench-scale tests were run using a stationary jet impinging on a carefully prepared, vertical sludge bank. The jet flow was increased gradually until mobilization was evident and then allowed to continue at a constant flow for 20-30 minutes. Direct comparison of the time-scales used for the bench-scale work to the $1 / 25$-scale tests is not possible due to the differences in test conditions, but it is worth noting that if the $1 / 25$-scale tests had been stopped after only 100 minutes then a much stronger dependence of ECR on shear strength would be observed. Considering the data in Figure 4.3 and the method in which the bench-scale tests were conducted, it is not at all surprising that a strong correlation of ECR with shear strength was found from the bench-scale data. Of course, the correlation of interest for mobilization testing is that between the final ECR and sludge properties. For kaolin clay sludge simulants, shear strength is of only minor importance in determining the final ECR.

Kaolin clay is unusual in that most of the other simulants tested do exhibit a dependence of ECR on shear strength. The explanation for kaolin's lack of dependence can be found in the manner that kaolin obtains its shear strength. The shear strength of sludge simulants is due to the combination of cohesive and frictional forces. Cohesive forces arise from colloidal attractive forces and bonding between adjacent particles. Frictional forces result when particles encounter each other when the simulant is deformed.

The shear strength of kaolin sludge simulants is principally due to frictional forces. Measurements indicate that roughly $7 \%$ of the shear strength of a $68 \mathrm{wt} \% \mathrm{kaolin} /$ water mixture is due to cohesive forces, and $93 \%$ is due to friction (Gibson 1953). Decreasing the clay/water ratio is expected to alter this split such that cohesive forces become relatively more important because the increased space between adjacent particles will decrease friction. The cohesion of kaolin clay is primarily due to edge-to-face, electrostatic alignment of clay particles rather than to van der Waals attractive forces as is the case for bentonite. The total amount of cohesion obtained from these edge-toface bonds is expected to be linearly related to the total number of such bonds per unit volume of clay. As the wt\% clay is decreased, fewer particles are available for bond formation, so the total cohesion decreases.

While the relationship between cohesion and wt\% clay may be nearly linear, the contribution of frictional forces to the shear strength certainly is not. As the clay fraction is increased, a point will be reached where there is very little void space left. At this point, the addition of even a small amount of clay can cause a large increase in shear strength. This is illustrated in Figure 4.4, which is a plot of kaolin simulant shear strength vs. wt\% kaolin clay. As the wt\% kaolin is increased from 54 to about $62 \mathrm{wt} \%$ clay, the shear strength increases quite gradually. But beyond $62 \mathrm{wt} \%$ clay, the shear strength rapidly increases. This is interpreted as follows. As the wt\% clay is increased from $54 \%$ up to approximately $62 \%$, the modest increase in shear strength that is seen is due primarily to an increase in the number of electrostatic bonds between clay particles. Beyond $62 \mathrm{wt} \%$, increases in wt\% clay still increase the number of bonds, but the void space becomes progressively smaller. Thus, interparticle friction becomes much more important. So important is the friction that by $68 \mathrm{wt} \%$ kaolin cohesion only amounts to about $7 \%$ of the shear strength (Gibson 1953).

(a) Whyatt, G. A., C. L. Fow, T. D. Powell, and P. A. Scott. 1988. FY 1988 Bench-Scale Sludge Mobilization Testing. TW21-88-05. Pacific Northwest Laboratory, Richland, Washington. Technical Report for Westinghouse Hanford Company. 
The shear strength vs. wt\% clay of kaolin contrasts with that of bentonite clay. Figure 4.5 is a plot of bentonite shear strength vs. wt\% bentonite. The bentonite shear strength grows linearly with wt\% clay beyond about $14 \mathrm{wt} \%$ bentonite. At clay concentrations less than $14 \mathrm{wt} \%$, the bentonite particles are too disperse to form a significant shear strength, and the resultant mixture behaves like a fluid rather than a semi-solid sludge. The implication of the linear growth of shear strength is that as the $\mathrm{wt} \%$ clay is increased, the number of interparticle bonds increases in direct proportion. Interparticle friction is not expected to be significant for bentonite simulants as the wt\% clay is low enough that there are plenty of void spaces to accommodate additional clay particles without difficulty. Gibson (1953) determined that for a bentonite clay of approximately $31 \mathrm{wt} \%$ the shear strength is due $80 \%$ to cohesion and only $20 \%$ to friction. By the same argument as presented above for kaolin, the relative importance of friction is expected to diminish as the wt\% clay is decreased, and the clay structure becomes more disperse.

The significance of the kaolin shear strength curve in Figure 4.4 is that it provides insight into why the mobilization resistance of kaolin is nearly indepenclent of shear strength. As the shear strength is increased from a low of $3.5 \mathrm{kdyn} / \mathrm{cm}^{2}$ (test $2-\mathrm{K}$ ) to a high of $40.5 \mathrm{kdyn} / \mathrm{cm}^{2}$ (test S25-3-K, fiscal year 1993), the resulting increase in cohesion is of much smaller magnitude. Assume that at $3.5 \mathrm{kdyn} / \mathrm{cm}^{2}$ the cohesive fraction of the shear strength is approximately $75 \%$, and friction is the remaining $25 \%$. No direct measurements are currently available to support this assumption, but given the nature of kaolin's strength development curve in Figure 4.4, it does not seem unreasonable. Gibson (1953) has determined that the cohesion is only about 7\% of the shear strength for kaolin at about 68 wt\% clay (S25-3-K was $67.2 \pm 0.2 \mathrm{wt} \%)$. The cohesion of the weak simulant (2-K) is computed to be $(0.75)(3.5)=2.6 \mathrm{kdyn} / \mathrm{cm}^{2}$ and the cohesion of the strong simulant (S25-3-K) is computed to be $(0.07)(40.5)=2.8 \mathrm{kdyn} / \mathrm{cm}^{2}$. This analysis demonstrates that it is reasonable for there to be a large difference in shear strength between kaolin simulants and relatively little difference in mobilization resistance, since it is the simulant cohesion that determines mobilization resistance.

Clearly, this analysis depends heavily on the assumption that the shear strength of the weak simulant is $75 \%$ (or so) cohesive. If the shear strength of the weak simulant is $7 \%$ cohesive just like the strong simulant, then the argument is much less convincing because then there is an order of magnitude difference in cohesion between the weak and strong kaolin simulants with little corresponding difference in mobilization resistance. Determining whether selecting $75 \%$ rather than $7 \%$ for the weak simulant can be justified is currently being pursued.

A limited effort along these lines was conducted earlier this year as part of the PNL simulant development efforts. A Bohlin rheometer was used to perform viscoelastic characterizations on several of the archived 1993 1/25-scale sludge simulants. Two kaolin simulants were tested. Using the Bohlin cone-and-plate sensor, the shear strengths of these simulants were measured at $17.5 \mathrm{kdyn} / \mathrm{cm}^{2}$ and $25.0 \mathrm{kdyn} / \mathrm{cm}^{2}$. A low frequency $(0.01 \mathrm{~Hz})$ oscillating cone-and-plate measurement was conducted to determine the viscoelastic nature of these simulants. 


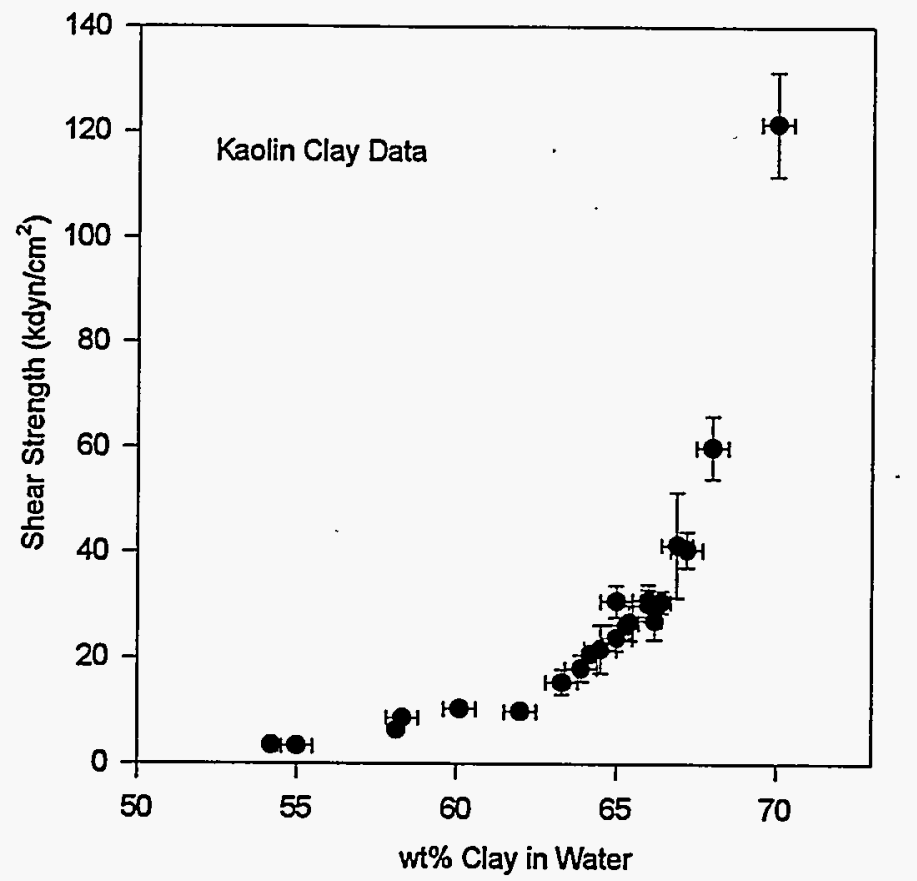

Figure 4.4. Kaolin Shear Strength vs. wt\% Kaolin

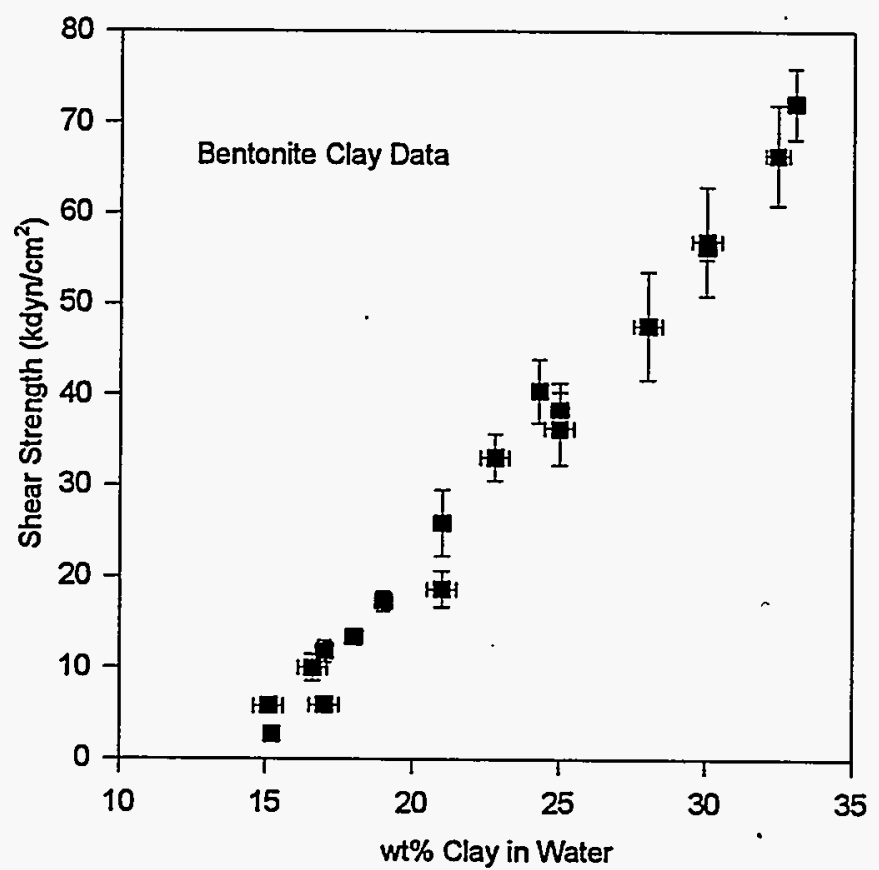

Figure 4.5. Bentonite Shear Strength vs. wt\% Bentonite 
One of the properties measured for each simulant was the loss tangent, which is a measure of the relative importance of frictional and elastic forces within the simulant. ${ }^{\text {(a) }}$ For these simulants, elastic forces are directly analogous to cohesion. ${ }^{\text {(b) }}$ A material with a loss tangent of 1.0 would have approximately equal frictional/viscous and elastic/cohesive characteristics. The $17.5 \mathrm{kdyn} / \mathrm{cm}^{2} \mathrm{kaolin}$ simulant had a loss tangent of 0.38 , and the $25.0 \mathrm{kdyn} / \mathrm{cm}^{2} \mathrm{kaolin}$ simulant had a loss tangent of 0.50 . This is consistent with the supposition that the relative importance of kaolin cohesion increases as the shear strength decreases. For comparison, four bentonite simulants were tested with Bohlin shear strengths of $5.5,5.7,18.0$, and $30.6 \mathrm{kdyn} / \mathrm{cm}^{2}$. The corresponding loss tangents measured were 0.15 , $0.11,0.15$, and 0.14 . The fact that the bentonite loss tangents are low and do not show a systematic variation with increasing shear strength demonstrates that bentonite simulant shear strengths are mostly cohesive, and interparticle friction does not play an increasing role as the clay concentration is increased over the range tested.

Other explanations have been offered for the lack of increase in mobilization resistance with increasing shear strength for kaolin simulants. It was suggested that the kaolin may be absorbing water at its surface, thereby becoming weaker. The weakened material is swept away by the jet to expose a fresh surface, which then absorbs water and weakens before being swept away. Under this scenario, ECR growth continues until the mobilizing power of the jet just equals the mobilization resistance of the weakened sludge layer on the surface of the original, stronger sludge. Because all the kaolin simulants were prepared with the same raw material (kaolin clay), they would all tend to absorb water to reach about the same, reduced wt\% solids near the surface. All the kaolin simulants should have about the same ECRs because they all absorb water to reach the same clay concentration. The mobilization resistance measured in the test is that of the weakened sludge near the sludge/slurry interface, which ultimately becomes the same for all the kaolin simulants regardless of the initial bulk simulant strength.

This water absorption hypothesis is also attractive because it can account for the variation in mobilization rate with shear strength seen in Figure 4.3. The surface of the stronger simulants needs to absorb more water to become sufficiently weak to be swept away. More water is required for the stronger simulants simply because they initially have less water than the weaker simulants. For the stronger simulants to absorb more water takes more time. This results in the stronger simulants taking more time to reach their final ECRs even though these final ECRs are the same as those for the weak simulants. This is exactly what is evident in Figure 4.3.

(a) The viscoelastic characterization is accomplished by sinusoidally oscillating the plate of a coneand-plate rheometer through a small angular deflection at varying frequencies. The resulting stress on the cone is measured. If the cone stress is in-phase with the applied strain, then the sample is a purely elastic body. If the cone stress lags the applied strain by $90^{\circ}$ then the sample is purely viscous (frictional). Most real samples fall in between these two extremes. The loss tangent is a measure of the ratio of measured loss modulus (viscous behavior) to the measured storage modulus (elastic behavior).

(b) An elastic response implies that the applied strain is transmitted through the sample without irrecoverable losses. For this to happen in a sludge simulant, the simulant solids must be arranged in a matrix that is capable of receiving a small applied strain without permanently deforming. Cohesive forces between particles are required to form such a structure. Interparticle friction results in a loss of the applied strain energy (if particles slide past each other), so friction is not measured as part of the elastic modulus. 
To test the water absorption hypothesis, approximately 50 g samples of selected $1 / 25$-scale sludge simulants were packed into $100-\mathrm{ml}$ plastic beakers and carefully weighed. A layer of water was then poured into the beakers taking care not to disrupt the sludge simulant. After $24 \mathrm{~h}$ of exposure to the water layer, the water was removed and the sludge reweighed to determine the extent of any water absorption. Four different kaolin simulants were tested in this manner. The data are presented in Table 4.1. The four kaolin tests show that as the wt\% kaolin is increased between 58.1 and $66.2 \mathrm{wt} \%$, very little absorption of water takes place. It should be noted that the approximately $0.08 \mathrm{~g}$ of water "absorbed" by the kaolin could certainly have been due to a thin film of water on the surface of the clay rather than water actually absorbed. One drop of water weighs about $0.10 \mathrm{~g}$. The $0.08 \mathrm{~g}$ absorption of the 58.1 and $66.2 \mathrm{wt} \%$ kaolin samples should not be considered to be a significant deviation from zero absorption. Beyond $66.2 \mathrm{wt} \%$ kaolin, however, significant absorption of water does take place. The $68.0 \%$ and $70.0 \%$ samples absorbed $0.39 \mathrm{~g}$ and $1.19 \mathrm{~g}$, respectively. The absorption of water by the other simulants listed in Table 4.1 will be addressed in later sections.

That no absorption of water was observed for kaolin simulants at less than about $66.2 \mathrm{wt} \%$ kaolin is significant. This implies that water absorption should not affect sludge mobilization unless the kaolin concentration is greater than $66.2 \mathrm{wt} \%$. During the fiscal year $19941 / 25$-scale mobilization testing all kaolin simulants were less than or equal to $66.4 \mathrm{wt} \%$ kaolin. Water absorption is observed for 68.0 and $70.0 \mathrm{wt} \%$ kaolin simulants, but no $1 / 25$-scale tests were conducted with simulants of this concentration precisely for the reason that it was suspected that water absorption would be a problem.

Table 4.1. Water Absorption Test Results

\begin{tabular}{|c|c|c|c|c||}
\hline Simulant Test \# & wt\% Solids & Final Mass (g) & Initial Mass (g) & Mass Change (g) \\
\hline \hline $21-\mathrm{K}$ & 58.1 & $60.653 \pm 0.003$ & $60.582 \pm 0.144$ & $0.071 \pm 0.144$ \\
\hline $22-\mathrm{K}$ & 66.2 & $55.430 \pm 0.004$ & $55.347 \pm 0.004$ & $0.083 \pm 0.006$ \\
\hline $68 \%$ kaolin & 68.0 & $59.068 \pm 0.004$ & $58.678 \pm 0.004$ & $0.390 \pm 0.006$ \\
\hline $70 \%$ kaolin & 70.0 & $66.469 \pm 0.003$ & $65.282 \pm 0.008$ & $1.187 \pm 0.009$ \\
\hline 4-B & 15.2 & $62.590 \pm 0.007$ & $58.981 \pm 0.009$ & $3.610 \pm 0.011$ \\
\hline 5-B & 18.0 & $51.234 \pm 0.004$ & $46.505 \pm 0.002$ & $4.729 \pm 0.004$ \\
\hline 6-B & 32.4 & $59.250 \pm 0.004$ & $49.006 \pm 0.009$ & $10.244 \pm 0.010$ \\
\hline $7-B K$ & 52.5 & $61.740 \pm 0.005$ & $54.691 \pm 0.005$ & $7.069 \pm 0.007$ \\
\hline 8-BK & 42.9 & $61.335 \pm 0.003$ & $56.553 \pm 0.005$ & $4.782 \pm 0.006$ \\
\hline 9-BK & 37.0 & $70.372 \pm 0.003$ & $66.752 \pm 0.004$ & $3.620 \pm 0.005$ \\
\hline 23-KB & 65.8 & $56.050 \pm 0.003$ & $55.652 \pm 0.004$ & $0.398 \pm 0.005$ \\
\hline
\end{tabular}


White and Pichler (1959) present a study of water absorption by different types of clays. Kaolin, illite, and calcium-bentonite clays were found to absorb water fairly rapidly until the clay reached its liquid limit. The liquid limit is one of the standard "Atterberg Limits" used in soil mechanics to classify different types of soils. Lambe and Whitman (1969) give the liquid limit for sodium kaolinite (the type of clay used for 1/25-scale testing) as $\mathbf{5 3}$ grams of water per 100 grams of clay, which is equivalent to $65.3 \mathrm{wt} \%$ kaolin. According to the White and Pichler study, the $1 / 25$-scale kaolin simulants with more than about $65.3 \mathrm{wt} \%$ kaolin would be expected to absorb water whereas the simulants with less than $65.3 \mathrm{wt} \%$ kaolin would not. This provides a verification of the tests described in Table 4.1.

Based on the lack of observed water absorption by kaolin simulants at less than $66.2 \mathrm{wt} \%$, it is judged unlikely that the absorption of water is relevant to the mobilization of kaolin simulants. The data in Table 4.1 show that the simulants containing bentonite clay absorbed significant quantities of water. This absorption did affect the mobilization of these simulants as discussed below. The most reasonable explanation for the lack of variation of kaolin mobilization resistance with shear strength is that the cohesion of the kaolin simulants is largely independent of the shear strength over the range tested.

\section{Bentonite/Water Sludge Simulant Data}

The $E C R / U_{0} D$ data for bentonite/water simulants are given in Figure 4.6. Data from both 1993 and $19941 / 25$-scale testing are shown. The 1994 simulants appear to show a systematic decrease in mobilization resistance compared to that observed in 1993. The reason for this is that the 1994 tests were allowed to run much longer than those in 1993: DDuring the 1993 test program, most simulants were only allowed about 200 to 250 minutes to reach their final ECRs. Some of the 1994 bentonite/water tests were allowed to run for much longer periods. Figure 4.7 shows ECR/U $D$ vs. time for the 1994 bentonite simulants. During the first 200 minutes mobilization proceeds rapidly. Following this, the mobilization rate slows and transitions into a nearly constant ECR growth rate that for one test continued for at least 3.5 days.

Had the 1993 tests been run for longer periods, it is expected that the observed ECRs would have continued to grow in the same manner that was observed in the 1994 tests.

This continuing ECR growth of the bentonite simulants is due to the osmotic swelling of bentonite

clay. The mechanism of osmotic swelling is described later. Because osmotic swelling might not be important in the mobilization of DST sludge, it was decided that an effort should be made to remove the osmotic swelling effect from the bentonite ECR data. This was done by taking the "corrected" ECR to be that at which the ECR growth rate is observed to transition from the early, rapid growth to the slower, linear ECR growth due to swelling. The corrected ECR/U $\mathrm{O}_{0} \mathrm{D}$ values selected for tests 4-B through $6-\mathrm{B}$ and $20-\mathrm{B}$ are $0.142 \pm 0.006,0.088 \pm 0.015,0.0234 \pm 0.001$, and $0.056 \pm 0.003 \mathrm{~s} / \mathrm{cm}$, respectively. The method used to select these values involved passing a straight line through the data points clearly within the linear ECR growth region on the ECR vs. time plot for each test (see Appendix A). The point at which this straight line was no longer captured by the ECR error bars was taken to be the transition point of interest. The data for tests 6-B through 9-BK and 20-B were treated in this manner. There was not sufficient linear growth data to apply this method to tests 4-B and 5-B, so the final observed ECR was used for these tests. The fiscal year 1994 data plotted in Figure 4.6 are the corrected values. No correction was applied to the 1993 data as these tests were stopped right about at the time the transition to constant ECR growth. rate was reached. 


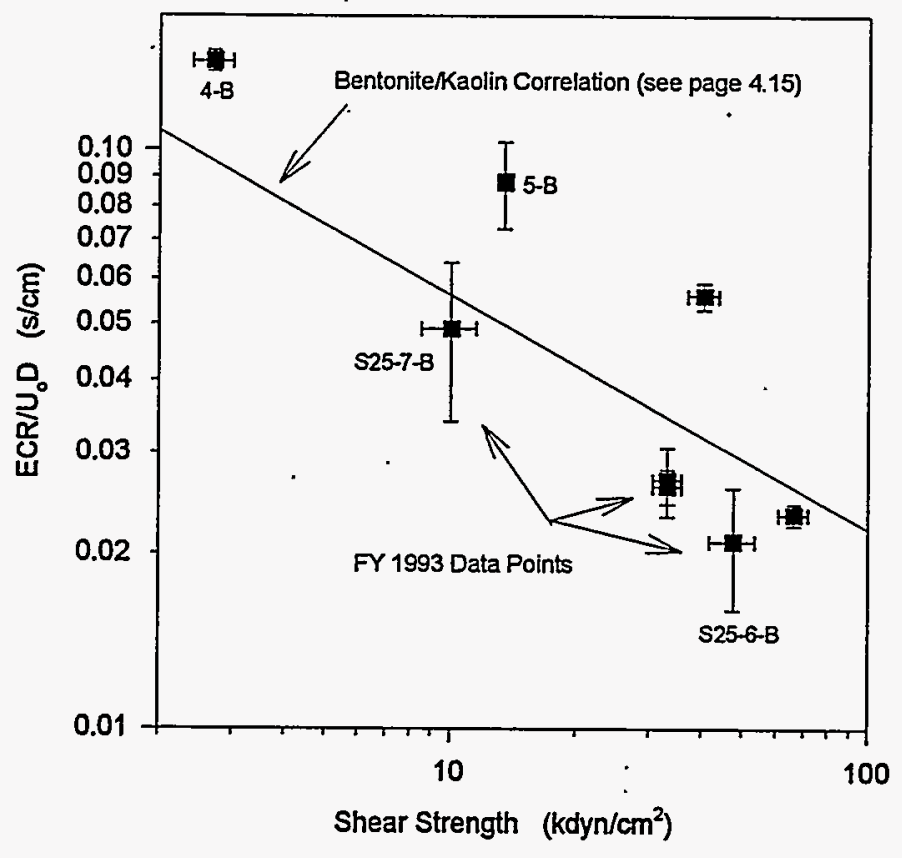

Figure 4.6. Bentonite ECR Data.

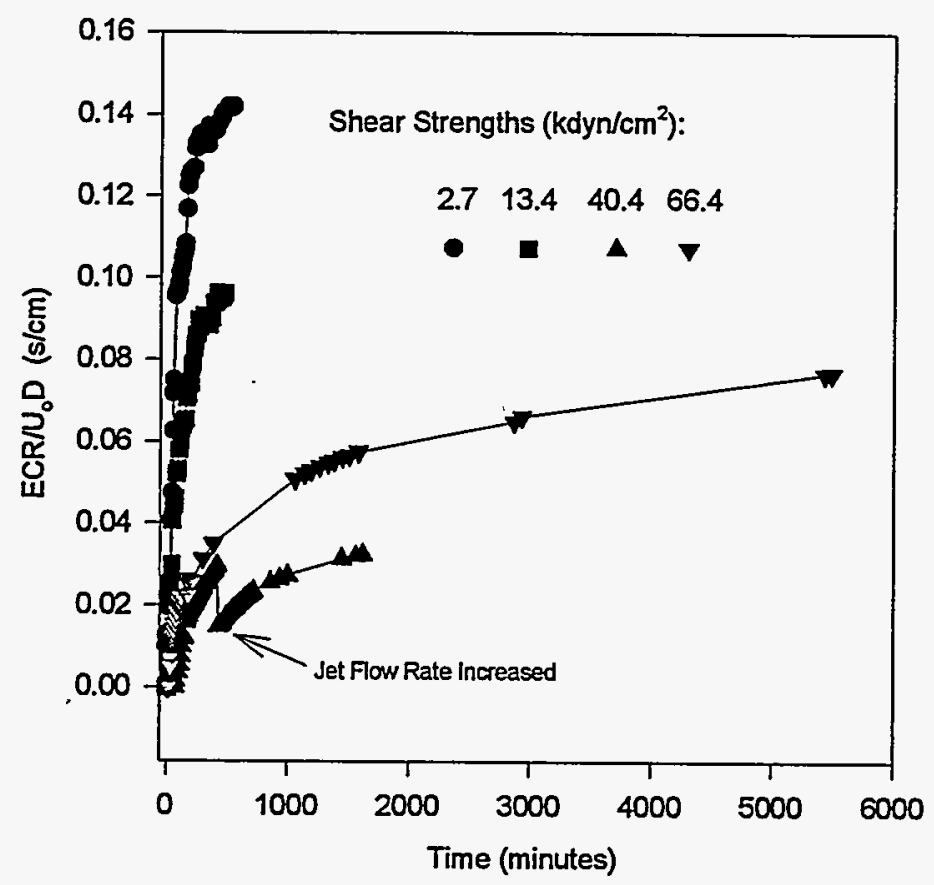

Figure 4.7. Bentonite/water ECR vs. Time 
The line drawn on Figure 4.6 is based on a fit of the data from tests 7-BK through 9-BK (the data points from these tests are not shown on Figure 4.6). The reason for selecting these tests to generate the line shown on Figure 4.6 is given in the next section. The bentonite/kaolin ECR/U $U_{0} D$ vs. shear strength correlation may represent the relationship for a highly cohesive material. It has been included in Figure 4.6 to show that the bentonite/kaolin correlation provides a reasonable, yet conservative fit of the bentonite/water data.

Four of the data points in Figure 4.6 require further explanation. These four points are the ECR data from 1994 tests 4-B and 5-B and 1993 tests S25-6-B and S25-7-B. The 4-B and 5-B points are plotted at shear strengths of 2.7 and $13.4 \mathrm{kdyn} / \mathrm{cm}^{2}$, respectively. The $S 25-6-\mathrm{B}$ and $S 25-7-\mathrm{B}$ points are at $47.6 \mathrm{kdyn} / \mathrm{cm}^{2}$ and $10.0 \mathrm{kdyn} / \mathrm{cm}^{2}$. During these four tests, it was observed that tank slurry was forced underneath the sludge bank early in each test. The bentonite sludge simulants are not very dense, so the force of the mixer pump jet can potentially create a lifting force on the sludge bank early in the test when the sludge bank is undercut by the jet. The elastic nature of the bentonite simulant allows large sections of the bank to flex upwards several centimeters in response to the lifting force of the jet. Once the tank slurry, which is primarily water, is under the bentonite, it no longer adheres to the bottom of the tank. It has been observed that this lack of adhesion can result in a larger ECR than would be obtained otherwise. For a more detailed discussion of this sludge-bank lifting effect, see Powell et al. (1995).

Tank slurry was observed to be under the sludge bank for both tests 4-B and 5-B. This occurred despite efforts to avoid the problem. The jet flow rate was increased very slowly with the hope that each small increase in flow would mobilize some of the sludge without lifting the sludge bank. Unfortunately, in both cases the final flow increase caused the sludge bank to lift. The ECR that was obtained from these two tests may have been biased high as a result of the bank lifting.

Fiscal year 1993 tests S25-6-B and S25-7-B also had bank lifting problems. In this case, however, a sector of the tank was spared from the bank lifting, so the sludge bank continued to adhere to the tank bottom in that area of the tank. At the end of test S25-6-B, for example, the ECRs in the portion of the tank where the sludge had lifted averaged to $38 \mathrm{~cm}$, while the ECRs in the non-lifting portion averaged $24 \mathrm{~cm}$. Because a non-lifting sludge bank is thought to more accurately represent full-scale mobilization, the non-lifting ECRs for these tests have been plotted in Figure 4.6.

The other bentonite tests contained in Figure 4.6 did not have problems with lifting of the sludge bank.

Sludge lifting is not expected to occur during full-scale DST sludge mobilization. That sludge lifting is observed at $1 / 25$-scale is a consequence of the simulant properties used and the manner in which the nozzle flow has been scaled. Mobilization tests are not designed using similitude. As a result, the ratios between different types of forces are different at different scales. For example, at $1 / 25$-scale, the maximum jet stagnation pressures are on the order of $150 \mathrm{kPa}$ ( $22 \mathrm{psi})$. The full-scale jet pressures are also expected to be about $150 \mathrm{kPa}(22 \mathrm{psi})$ for the same nozzle exit velocities. The force required to lift an area of the sludge layer at $1 / 25$-scale is on the order of $1.5 \mathrm{~Pa}$. To lift a sludge layer of scaled thickness at full-scale, however, requires twenty-five times this force or almost $40 \mathrm{~Pa}$. Since the jet stagnation pressures are the same at both scales, there is approximately the same amount of lifting pressure available at both scales. The fact that the pressure required to lift the full-scale sludge is so much greater makes it unlikely that sludge bank lifting would be observed at full-scale. 
The osmotic swelling of the bentonite clay is due to the double-layer repulsion between the surfaces of the bentonite particles. Due to impurities in the crystal lattice of clay minerals, the surface of clay particles are negatively charged under most conditions. This negative surface charge electrostatically attracts a cloud of cations that tend to diminish the electric field of the negative particles. When two bentonite particles are close enough, their respective cation clouds will overlap. This creates a repulsive force because the positively-charged cations electrostatically repel each other. The swelling of the bentonite clay is termed osmotic swelling because the water outside the clay permeates into the region between particles in an effort to equalize the local high cation concentration with that of the water far away from the particles. This influx of water tends to push the particles apart until double-layer overlap is no longer significant (van Olphen 1977).

The degree to which a clay will imbibe water due to osmotic swelling depends on the average double-layer thickness compared to the distance between adjacent clay particles. Double-layer thickness is determined by the clay's surface charge density, which is a function of its mineralogical composition, and by the ionic strength of the fluid surrounding the clay. The distance between clay particles is a function of the weight fraction of clay in the clay/fluid mixture. White and Pichler (1959) studied the rate of water absorption of several different clay types. Beyond the liquid limit of each clay, osmotic swelling was small or non-existent for illite clay, kaolin clay, and calcium-bentonite clay. Sodium-bentonite, however, showed continuing osmotic swelling even when the wt\% clay had fallen to about $12 \mathrm{wt} \%$. The swelling of sodium-bentonite is expected to cease when the particles are so far apart that double-layer repulsions are balanced by the attractive van der Waals and edge-to-face crosslinking forces (van Olphen 1977). Calcium-bentonite does not show the same continuous swelling as the sodium-bentonite due to the ability of the calcium cations to compress the double-layers. In calcium-bentonite, the wt\% clay at which the double-layers cease to overlap is higher than for sodiumbentonite.

Osmotic swelling up to about the liquid limit is commonly observed in concentrated dispersions like clay pastes when the behavior of the particles is principally governed by colloidal effects. It has been suggested that colloidal effects dominate behavior when the total surface area per unit mass of particles exceeds about $25 \mathrm{~m}^{2} / \mathrm{g}$ (Lambe and Whitman 1969). Osmotic swelling is not observed in dispersions of large particles like sand. because colloidal effects do not significantly affect sand particles.

Whether osmotic swelling is a potentially significant mechanism for the mobilization of DST sludge is not known. The permeability of the sludge and the osmotic pressure driving force will determine the rate at which any osmotic swelling could occur. The osmotic pressure driving force will be a function of both the specific surface area of the sludge and the difference in ionic strength between the eroding and interstitial fluids. For osmotic swelling to be a significant effect, the swelling rate of the DST sludge must be high enough that appreciable ECR growth can be obtained in a realistic amount of time. If the waste were to swell at the same rate as the bentonite clay used for $1 / 25$-scale testing, then a full-scale ECR growth rate of only $8 \mathrm{~cm} /$ day would be expected. Depending on how much time can be allocated for sludge mobilization, this rate may be too small to be of much practical interest to DST waste retrieval operations.

The overall conclusion drawn from the bentonite/water simulant mobilization data is that the mobilization resistance of bentonite increases significantly with increasing shear strength. The shear strength of bentonite is primarily due to cohesion, so the variation of ECR/ $U_{0} D$ with shear strength 
implies that sludge cohesion is the force responsible for mobilization resistance. That cohesion provides erosion resistance has also been shown through testing of soils as described in the literature (Raudkivi and Tan 1984; Smalley 1970; Nearing et al. 1991).

\section{Bentonite/Kaolin Sludge Simulant Data}

Three $1 / 25$-scale sludge mobilization tests were conducted using a simulant composed of kaolin clay, bentonite clay, and water. These bentonite/kaolin simulants were formulated such that of the total solids fraction, bentonite clay comprised one-third, and kaolin clay was the remaining two-thirds. To vary the shear and tensile strengths of this simulant, the total wt\% solids was varied between 37 and $52.5 \mathrm{wt} \%$. The ECR/ $\mathrm{U}_{0} \mathrm{D}$ vs. shear strength data for these simulants are plotted in Figure 4.8. Because the bentonite/kaolin ECR growth was affected by the osmotic swelling of bentonite, the $E C R / U_{0} D$ values selected for plotting are those in which the ECR growth rate was observed to transition to a constant value. The procedure used to determine these points is described above in the discussion of the bentonite/water data.

The transition point for test 8-BK had to be estimated by extrapolating the rapid ECR growth curve to determine where the likely transition point occurred. The transition point for this test occurred during the night when ECR growth was not being monitored. Because this method of determining the transition point is likely to introduce additional error, the magnitude of the error bars on the 8-BK ECR/U $\mathrm{D}$ point has been increased. The amount of increase was determined by postulating worst-reasonable-case over-and-underestimations of the transition point location on the ECR vs. time plot (see Appendix A). The selected transition point for test 8-BK was at ECR/U $\mathrm{D}=0.037$ $\pm 0.006 \mathrm{~s} / \mathrm{cm}$. The ECR/U $\mathrm{D}$ vs. time data for all three bentonite/kaolin simulants are given in Figure 4.9. The step change at about 300 minutes in the ECR/ $U_{0} D$ vs. time data for the two higher shear strength simulants is due to the fact that the flow rate was increased at this point during these tests. Since the ECR does not instantly change to reflect the new flow rate, there is an apparent rapid drop in the value of $E C R / U_{0} D$ when the flow rate is increased.

A least-squares fit of the bentonite/kaolin data in Figure 4.8 was used to generate the line shown on the plot. This line is also included on the ECR/ $\mathrm{U}_{\mathrm{o}} \mathrm{D}$ vs. shear strength plots for the other simulants. It was decided that the bentonite/kaolin data set provided mobilization resistance vs. shear strength for a highly cohesive simulant that was not adversely affected by problems with sludge-bank lifting. The bentonite/water simulants used in tests 4-B through 6-B and 20-B also owe a large fraction of their shear strength to cohesion, but the bentonite/water ECR data may have, in some cases, been biased high due to the lifting of the sludge layer. (That the bentonite/kaolin simulant represents a highly cohesive simulant like bentonite is shown by the similarity of the tensile strength vs. shear strength curves for these two simulants shown later in Figure 4.18).

The fit of the bentonite/kaolin data gives a correlation between ECR and shear strength that can be expressed as ECR $(\mathrm{cm})=2.34 \mathrm{U}_{0} \mathrm{D} \tau_{\mathrm{s}}^{-0.405}$ where $\mathrm{U}_{\mathrm{o}} \mathrm{D}$ is expressed in $\mathrm{cm}^{2} / \mathrm{s}$ and shear strength $\left(\tau_{s}\right)$ is in dyn $/ \mathrm{cm}^{2}$. This ECR correlation predicts significantly larger ECRs than the 1987 correlation developed at $1 / 12$-scale using the silica/soda ash simulant. Whether the bentonite/kaolin correlation is valid for $1 / 12$-scale predictions will be determined in future $1 / 12$-scale mobilization tests. For the present time, the usefulness of the bentonite/kaolin correlation is that it provides some indication that the high shear strength DST sludges might be easier to mobilize than has been assumed based on the 1/12-scale silica/soda ash correlation. 


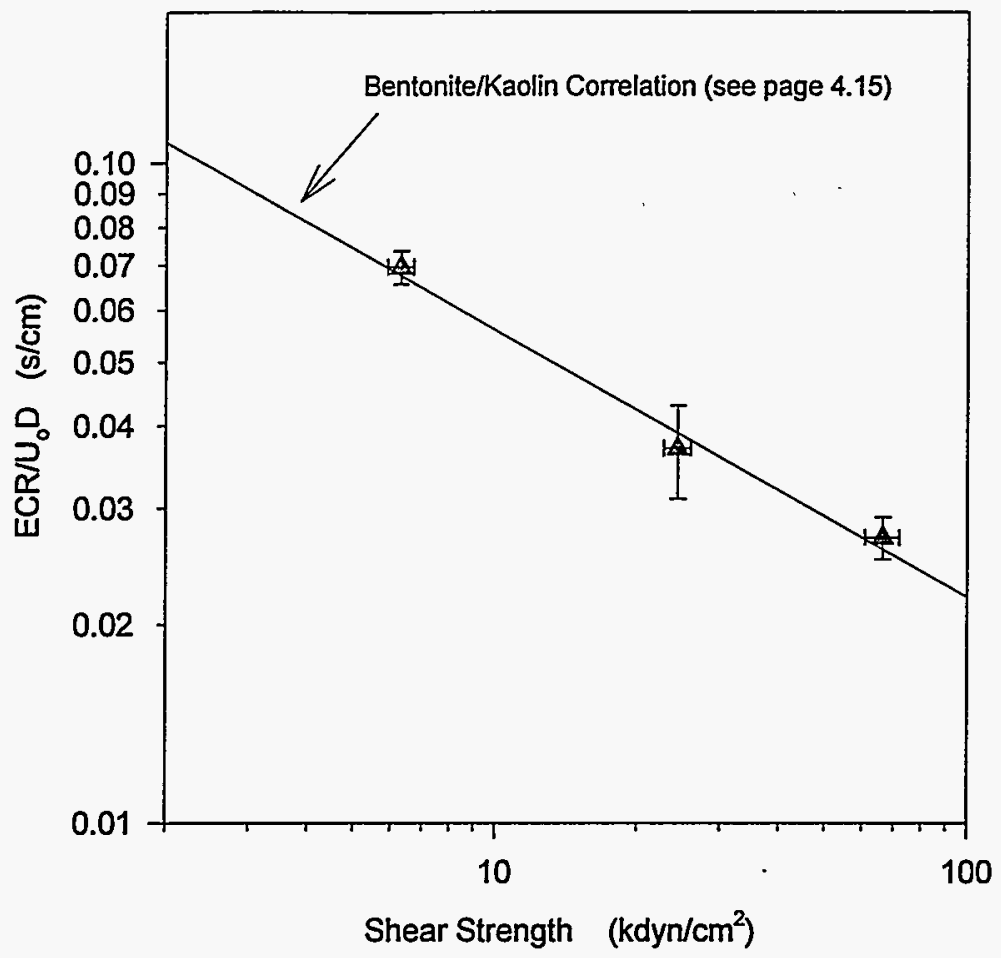

Figure 4.8. Bentonite/Kaolin ECR Data

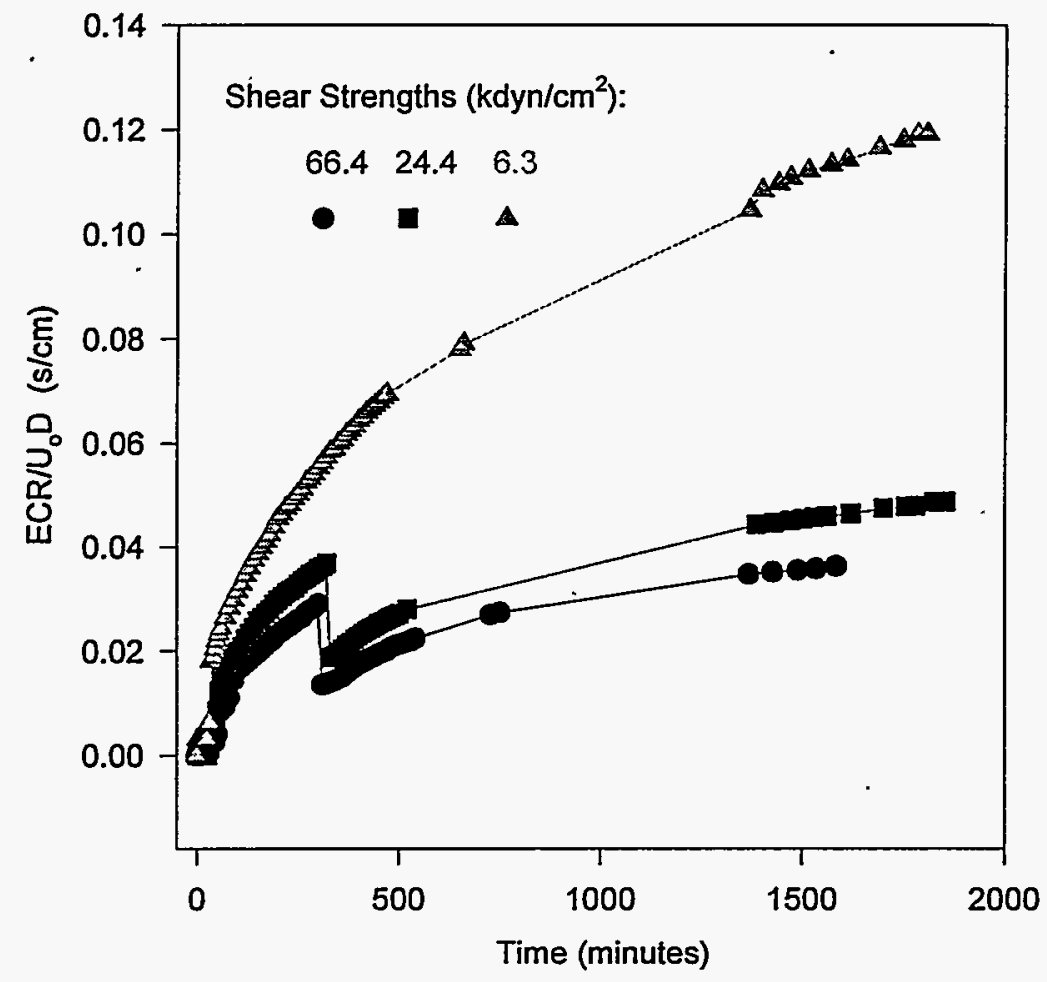

Figure 4.9. Bentonite/Kaolin ECR vs. Time 
The bentonite/kaolin ECR data, once corrected for the effect of osmotic swelling, are thought to provide a measure of the mobilization resistance of sludge simulants that obtain most of their shear strength through cohesive rather than frictional forces. Lambe and Whitman (1969) suggest that the behavior of soils with a specific surface area of more than about $25 \mathrm{~m}^{2} / \mathrm{g}$ is determined primarily by colloidal forces. The specific surface area of bentonite clay is about $800 \mathrm{~m}^{2} / \mathrm{g}$ and that of kaolin is about $15 \mathrm{~m}^{2} / \mathrm{g}$. Thus, the specific surface area of the bentonite/kaolin simulants used in tests 7-BK through $9-B K$ is estimated to be $(0.33)(800)+(0.67)(15)=274 \mathrm{~m}^{2} / \mathrm{g}$. This is clearly in the colloidal range as defined by Lambe and Whitman.

Sludge simulants that have specific surface areas on the order of $25 \mathrm{~m}^{2} / \mathrm{g}$ or less are expected to owe a larger fraction of their shear strengths to frictional forces than the bentonite or bentonite/kaolin simulants. For a given shear strength, lower cohesion simulants ${ }^{(a)}$ are expected to be easier to mobilize than the highly cohesive bentonite/kaolin simulants because interparticle friction is unlikely to contribute to mobilization resistance. Thus, the bentonite/kaolin correlation should represent a lower limit to the ECR expected from any given simulant whose cohesion is less than that of the bentonite/kaolin simulant.

\section{Kaolin/Bentonite Sludge Simulant Data}

In an effort to prepare a sludge simulant whose cohesive fraction of its shear strength was intermediate between that of kaolin and the bentonite/kaolin simulants, a simulant was prepared that contained mostly kaolin and only a small fraction of bentonite. Scoping tests revealed that the tensile strength vs. shear strength relationship for various mixtures of bentonite and kaolin was nearly identical until the bentonite fraction was decreased to about $2 \mathrm{wt} \%$ of the total solids ( $98 \% \mathrm{kaolin})$. Based on these scoping tests, it was decided that tests $23-\mathrm{KB}, 25-\mathrm{KB}$, and $26-\mathrm{KB}$ would be run using a simulant with $2 \mathrm{wt} \%$ of the solids as bentonite and the remaining $98 \mathrm{wt} \%$ as kaolin. These three tests were originally intended to be conducted using illite clay rather than a mixture of kaolin and bentonite, but no suitable vendor was found for illite clay. The intent of using illite was to use a clay with a specific surface area intermediate between those of bentonite and kaolin. This intent was met by using the kaolin/bentonite mixture.

The simulant used in tests $23-\mathrm{KB}, 25-\mathrm{KB}$, and $26-\mathrm{KB}$ are referred to as kaolin/bentonite simulants to distinguish them from the simulants used in 7-BK through 9-BK, which are called bentonite/kaolin simulants. This convention is followed throughout this report.

The ECR/U $\mathrm{D}$ vs. shear strength data for the kaolin/bentonite simulants are plotted in Figure 4.10. The bentonite/kaolin ECR correlation described in the previous section is seen to provide a reasonable fit of the kaolin/bentonite data. The high shear strength point falls above the ECR correlation line while the two lower shear strength points follow the correlation to within the uncertainty of the ECR measurements.

(a) This is true provided that the simulant particles are generally smaller than about 100 microns. Particles larger than 100 microns (e.g., sand and gravel) can be difficult to mobilize because the submerged fluid jet does not develop sufficient lifting force. 


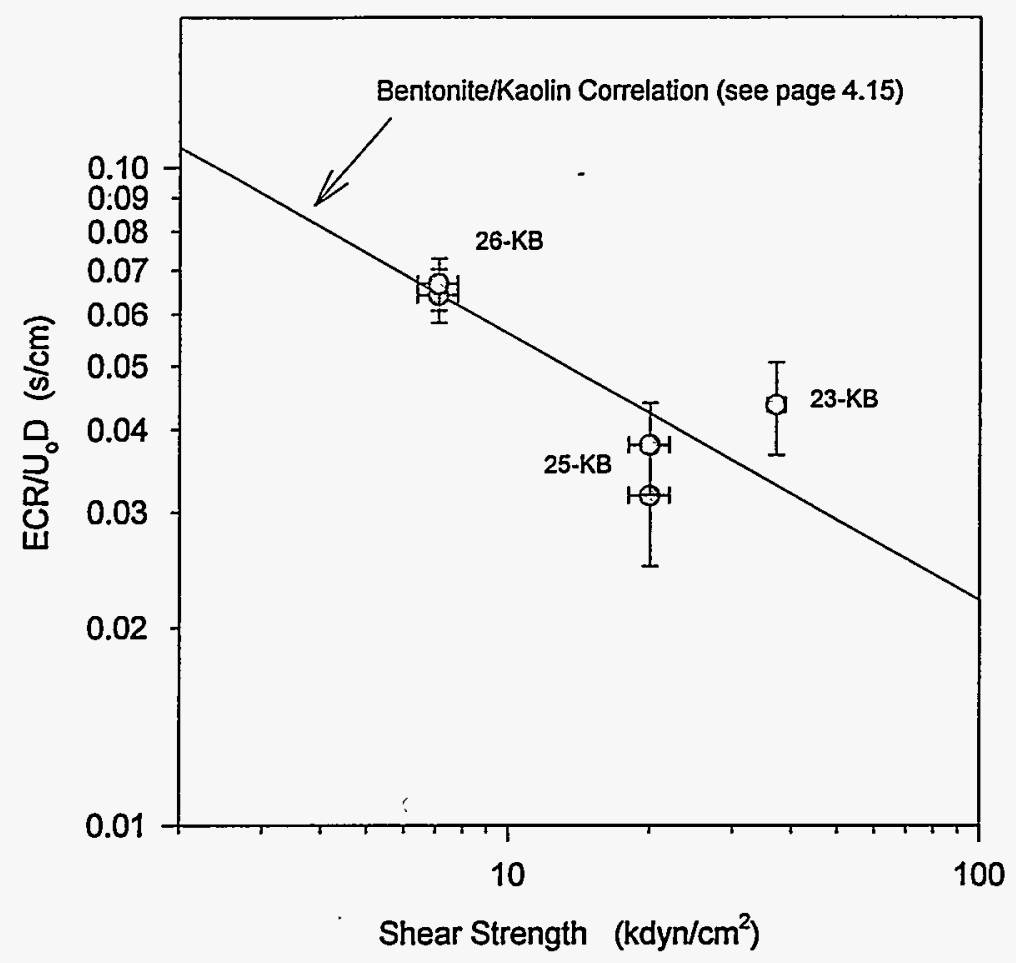

Figure 4.10. Kaolin/Bentonite ECR Data

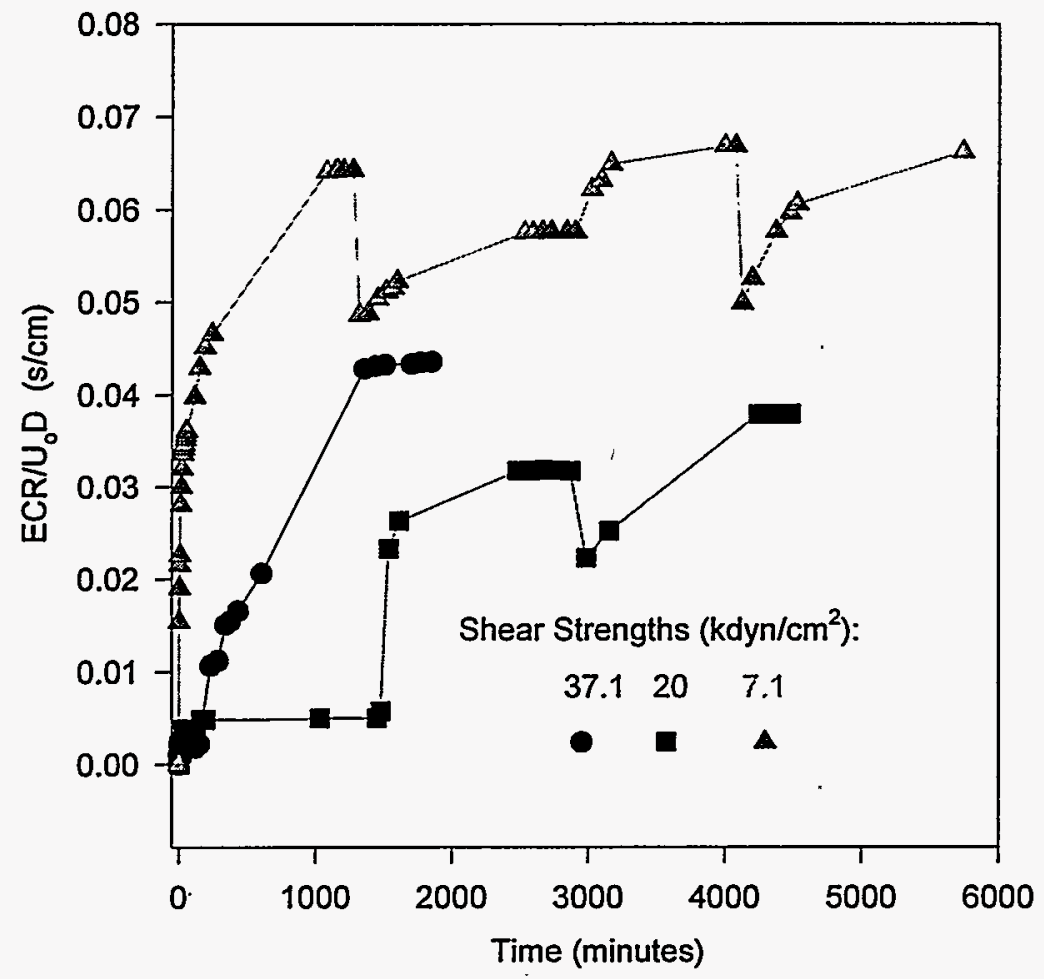

Figure 4.11. Kaolin/Bentonite ECR vs. Time Data 
The high shear strength test was the first of the kaolin/bentonite tests to be run (23-KB). During test $23-\mathrm{KB}$, sand could be observed through the bottom of the tank to be circulating within the mixerpump jets. The sand came from the bentonite clay that was used to make the sludge simulant. The bentonite that was used for test 23-KB contains a small fraction of sand as an impurity. It was speculated that this sand might be improving the effectiveness of the mixer-pump jet by acting as an abrasive on the sludge bank. The simulants used for tests $25-\mathrm{KB}$ and $26-\mathrm{KB}$ were made using a different grade of bentonite clay that contains a smaller fraction of large sand particles. The clay was of the same type (sodium-bentonite).

This change in bentonite grade may have resulted in the observed deviation of the 23-KB test from the bentonite/kaolin ECR correlation. The large sand particles in the 23-KB simulant might have biased the ECR high for this test. Tests $25-\mathrm{KB}$ and $26-\mathrm{KB}$ would have shown this to a lesser extent due to the lack of large sand particles in the simulants for these tests. It was intended that the effect of sand erosion be investigated further during tests $25-\mathrm{KE}$ and $26-\mathrm{KB}$ by adding sand to the tank after ECR growth stopped to determine whether further ECR growth occurred. This was not done because attention was shifted to nozzle diameter effects after test $24-\mathrm{K}$. The nozzle-diameter-effects testing is described in Section 4.2.

Figure 4.11 gives the ECR/U $D$ vs. time data for the kaolin/bentonite simulants. The curves for the two lower strength tests $(25-\mathrm{KB}$ and $26-\mathrm{KB})$ show several step changes to higher and lower values. This is a result of switching the mixer-pump nozzles between the nominal size $(0.6 \mathrm{~cm})$ and the large size $(0.9 \mathrm{~cm})$. The data given in Figure 4.10 are only for the nominal nozzle size.

It is evident in Figure 4.11 that swelling of the bentonite clay did not play a significant role in ECR growth. The ECR growth rates were decreased to zero after about 1000 minutes. Had osmotic swelling been important, continuing ECR growth would have been observed as was the case for the bentonite/water and bentonite/kaolin tests. Table 4.1 also provides evidence that the kaolin/bentonite simulants do not absorb appreciable water. Because water absorption was not judged to be significant for these tests, no correction was applied to the ECR data as was done for the bentonite/water and bentonite/kaolin tests.

The most important implication of the kaolin/bentonite tests is that the addition of just a small amount of bentonite is capable of significantly changing the mobilization resistance of kaolin clay. This result demonstrates the need to adequately characterize the DST sludge particle-size distributions in the submicron range. The specific surface area of the kaolin/bentonite simulants is estimated to be $(800)(.02)+(15)(.98)=31 \mathrm{~m}^{2} / \mathrm{g}$, which indicates that the behavior of this material is governed primarily by colloidal forces. This is contrasted with the mobilization resistance of kaolin clay, which appears to be largely independent of shear strength. The specific surface area of kaolin is about $15 \mathrm{~m}^{2} / \mathrm{g}$, which implies that its behavior is determined by a combination of colloidal forces (e.g., van der Waals attractions, electrostatic bonding) and body forces (e.g., friction, inertia).

It will be important to establish whether the kaolin/bentonite simulant ECRs follow the cohesive simulant correlation developed from the bentonite/kaolin data. The two lower shear-strength data points on Figure 4.10 do follow the bentonite/kaolin correlation, but the high shear-strength point (test 23-KB) lies in between the bentonite/kaolin correlation and the kaolin/water mobilization data. More testing of the kaolin/bentonite simulant should be conducted to establish whether this simulant follows the bentonite/kaolin correlation. Assuming kaolin/bentonite follows the cohesive simulant correlation, 
then it follows that if the specific surface area is greater than about $25 \mathrm{~m}^{2} / \mathrm{g}$, then the simulant shear strength is primarily due to cohesive forces, and the mobilization resistance can be adequately predicted on the basis of shear strength.

The implication of this for the prediction of ECRs in the full-scale tanks is that it may be possible to make ECR predictions based on shear strength and specific surface area measurements. For example, if a sludge is found to have a specific surface area of $40 \mathrm{~m}^{2} / \mathrm{g}$, then its ECR can be predicted using the correlation between ECR and shear strength for cohesive simulants. Whether a sludge is cohesive depends on whether its specific surface area is greater than about $25 \mathrm{~m}^{2} / \mathrm{g}$. A sludge with a specific surface area of $10 \mathrm{~m}^{2} / \mathrm{g}$ would be expected to exhibit a lower resistance to mobilization than would be predicted by the cohesive simulant correlation, but the cohesive simulant correlation should provide a lower limit to the ECR than can be expected.

This approach of using specific surface area and shear strength to predict ECRs relies on the assumption that the only cohesive forces acting in tank sludge are colloidal. Chemical bonding between particles provides mobilization resistance much in the same way that van der Waals attractive forces do. A sludge might have a specific surface area of only $1 \mathrm{~m}^{2} / \mathrm{g}$, which would imply that colloidal forces are not very important, but that same sludge could acquire substantial mobilization resistance through the formation of bonds between particles. It is not currently known whether the relationship between mobilization resistance and shear strength for sludges with extensive interparticle bonding is similar to that same relationship for sludges that acquire cohesion from colloidal forces. It is possible that for a given shear strength, the mobilization resistance of a sludge with extensive interparticle bonding is greater than that of colloidally bonded material like the bentonite/kaolin simulant. If this is the case then an ECR correlation based on colloidally bonded simulants would overpredict ECRs for chemically bonded sludges. The determination of the relationship between ECR and shear strength for chemically bonded simulants is a goal of future work.

\section{Kaolin/Plaster Sludge Simulant Data}

To determine whether the ECR vs. shear strength correlation for colloidally bonded simulants applies to simulants that obtain cohesion through other mechanisms, simulants composed of kaolin clay and plaster of Paris were prepared. Scoping tests were performed to establish the compositions of the kaolin/plaster simulants used in the tests. The scoping tests indicated that if the kaolin fraction was held constant at $50 \mathrm{wt} \%$ and the plaster fractions were $10 \mathrm{wt} \%, 12 \mathrm{wt} \%$, and $14 \mathrm{wt} \%$ then shear strengths of approximately 10,20 , and $40 \mathrm{kdyn} / \mathrm{cm}^{2}$ would be obtained after one day of curing. The scoping tests also indicated that the shear strength did not increase appreciably after one day of curing. Mobilization tests 10-KP through 12-KP were conducted using the kaolin/plaster simulants with 10, 12, and $14 \mathrm{wt} \%$ plaster.

The shear strength of the 12-KP simulant, however, did not reach the target $40 \mathrm{kdyn} / \mathrm{cm}^{2}$. It is not known why this happened. Samples prepared to the same composition before the test reached the target of $40 \mathrm{kdyn} / \mathrm{cm}^{2}$. It is possible that differences in the simulant mixing procedure or perhaps disruption of the 12-KP shear strength sample before measurement could account for the lower than expected shear strength.

The ECR/ $\mathrm{U}_{0} \mathrm{D}$ data for the kaolin/plaster simulants are shown in Figure 4.12. Also shown on the plot is the cohesive simulant ECR correlation derived from the bentonite/kaolin data as described earlier. The two data points at about $20 \mathrm{kdyn} / \mathrm{cm}^{2}$ (tests $11-\mathrm{KP}$ and 12-KP) are seen to be reasonably well fit by the bentonite/kaolin correlation. The test $10-\mathrm{KP}$ data point at about $10 \mathrm{kdyn} / \mathrm{cm}^{2}$ lies well 
below the cohesive simulant correlation. As is noted in the figure, however, test 10-KP was stopped before ECR growth was completed. During test 10-KP, the nearly constant ECR growth rate beyond about 800 minutes was interpreted as possibly being due to some sort of swelling behavior as was observed for the bentonite/water simulants. After the test, however, this was reconsidered. Swelling or dissolution of the cured plaster crystals was dismissed as a possible mechanism because the eroding fluid (tank supernate) was initially prepared to be saturated with calcium sulfate specifically to avoid these effects. It was decided that tests $11-\mathrm{KP}$ and $12-\mathrm{KP}$ should be continued until ECR growth stopped.

The ECR/ $\mathrm{U}_{0} \mathrm{D}$ vs. time data for the kaolin/plaster simulants are given in Figure 4.13. The data for test $10-\mathrm{KP}\left(9.7 \mathrm{kdyn} / \mathrm{cm}^{2}\right)$ are seen to terminate after about 1800 minutes, whereas the $11-\mathrm{KP}$ and 12-KP data sets continue for more than 3000 minutes. The 10-KP ECRs were clearly continuing to grow when the test was stopped. Test $12-\mathrm{KP}\left(22.7 \mathrm{kdyn} / \mathrm{cm}^{2}\right)$ was stopped after no significant ECR growth was observed between 2000 and 3000 minutes.

Test $11-\mathrm{KP}$ was continued for nearly 5000 minutes, but some time between the 3000 minute reading and the 4932 minute reading a malfunction stopped the mixer-pump nozzle oscillation. The malfunction could not be fixed for at least one day, so it was decided that the test would be stopped. Because the 4932-minute data point may have been affected by the lack of nozzle oscillation, the ECR measurement taken at 3190 minutes rather than that at 4932 minutes has been plotted in Figure 4.12. The ECR growth observed between 3190 and 4932 minutes is confusing. No significant ECR growth was observed along five of the eight radial lines along which ECRs are measured. The ECR along one direction grew from $30 \mathrm{~cm}$ to about $36 \mathrm{~cm}$, and along the remaining two radial lines the ECR grew from about $32 \mathrm{~cm}$ to the tank wall $(E C R=42.8 \mathrm{~cm})$. It is not clear why this might have happened. Further, the nozzles stopped oscillating while oriented such that one nozzle was pointed in the direction. of one of the ECRs that grew to the tank wall, and the other nozzle was pointed in a direction that showed no ECR growth. That neither nozzle was partially plugged was visually verified after draining the tank and after fluid jets of roughly equal strength were felt in the tank just before stopping the test.

The test 12-KP ECR vs. time data indicate that the ECR had stopped growing. The fact that ECR growth continued in test 11-KP suggests that more ECR growth might have been observed had test $12-\mathrm{KP}$ been continued. Certainly more ECR growth would be expected from test 10-KP had it been continued. Whether the additional growth would have been sufficient to move the test $10-\mathrm{KP}$ $E C R / U_{0} D$ value up to the cohesive ECR correlation line on Figure 4.12 is not known. Additional long-term tests of the kaolin/plaster simulant are needed to determine when ECR growth for this simulant actually stops. 


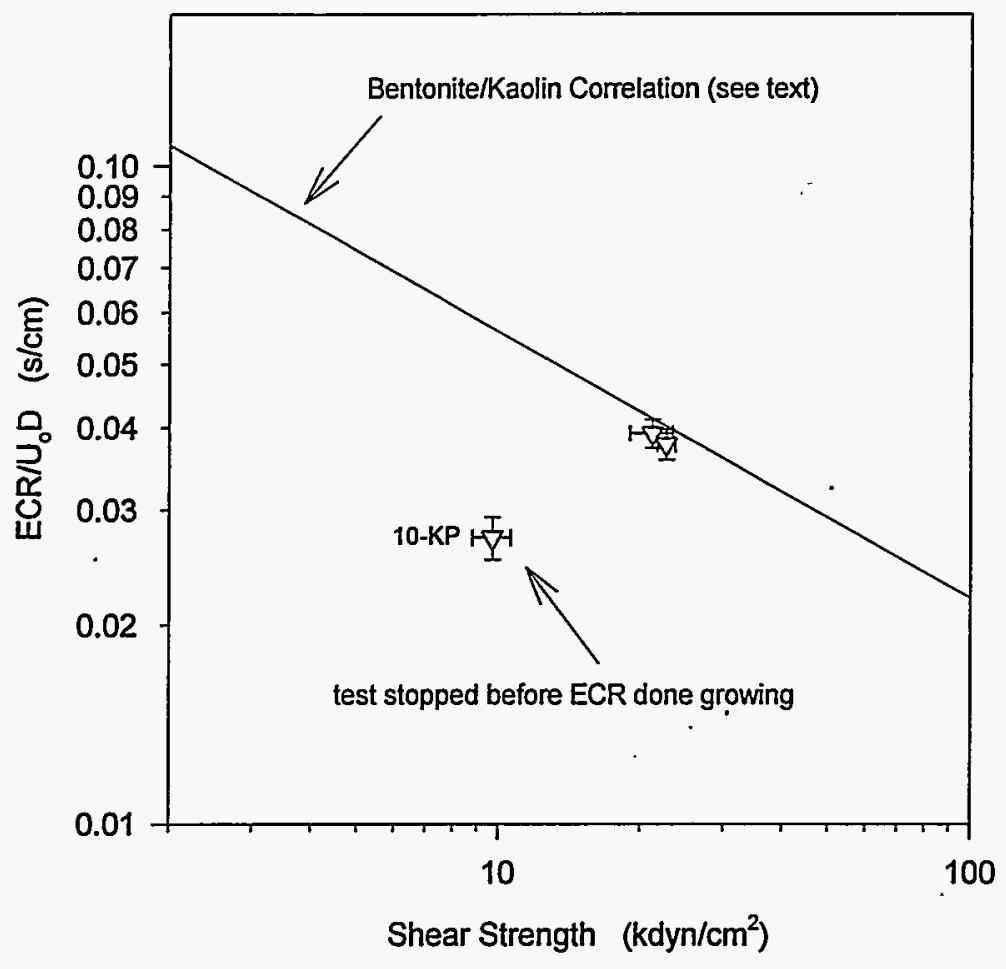

Figure 4.12. Kaolin/Plaster ECR Data

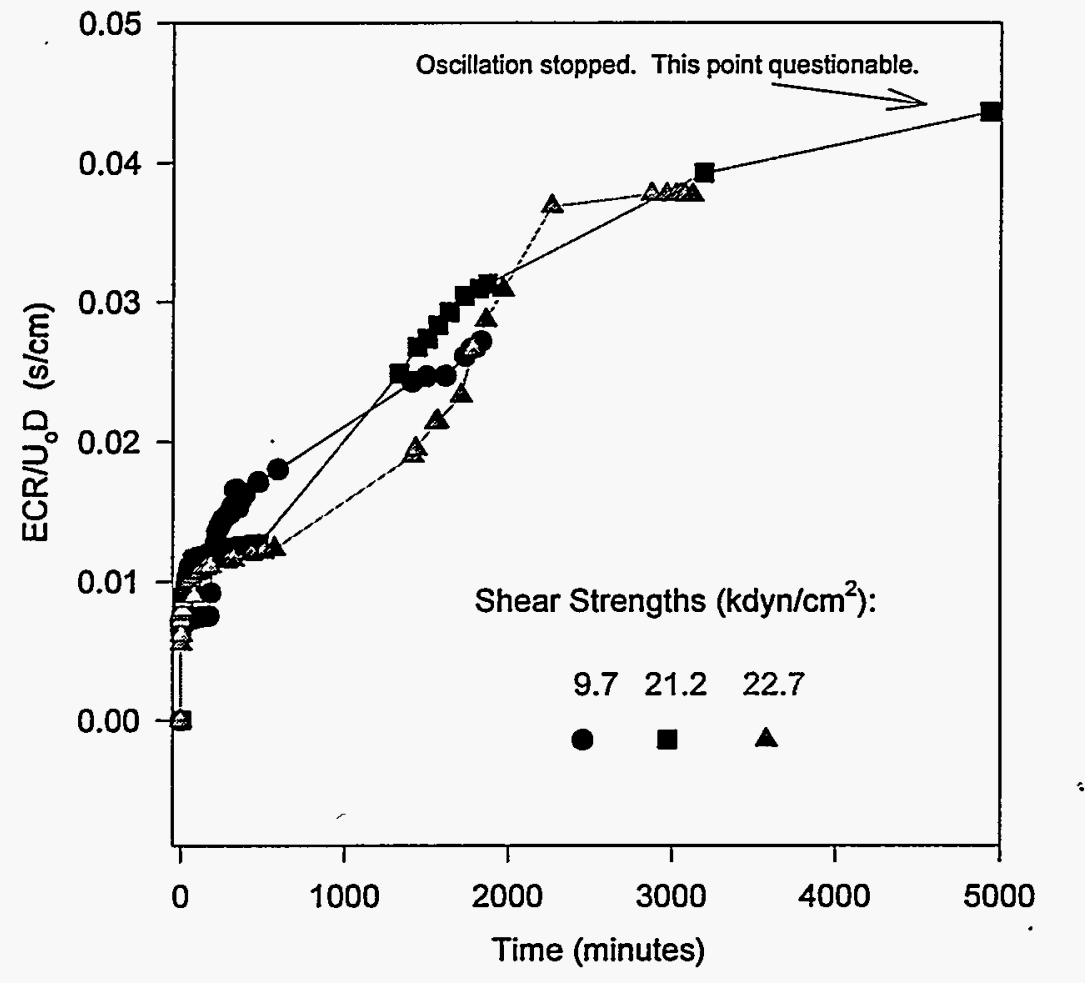

Figure 4.13. Kaolin/Plaster ECR vs. Time Data 
Understanding the mobilization of the kaolin/plaster simulant is very important because the mechanism by which this simulant obtains much of its strength may also influence the strength of DST sludge. The kaolin/plaster simulant has a shear strength on the order of $25 \%$ to $50 \%$ of its cured strength when it is first prepared. This initial strength is due to the combination of the kaolin clay cohesion and friction as well as the frictional contribution of the plaster particles. As the plaster of Paris cures, the calcium sulfate hemihydrate $\left(2 \mathrm{CaSO}_{4} \cdot \mathrm{H}_{2} \mathrm{O}\right)$ complexes with additional water molecules to form interlocking crystals of gypsum $\left(\mathrm{CaSO}_{4} \cdot 2 \mathrm{H}_{2} \mathrm{O}\right)$. These crystals grow between and around the kaolin particles as they grow together and interlock. The growth of interlocking crystals between insoluble sludge particles has been suggested as a possible mechanism for strength development in some DST sludges. This is based on the observation that the shear strength of the sludge from DST 101-SY decreases markedly as the temperature is increased (Herting 1992). The increase in temperature, it is postulated, results in the dissolution of some of the salts, thereby decreasing the degree of interlocking.

\section{Kaolin/Ludox ${ }^{\circ}$ Sludge Simulant Data}

Following the 1/12-scale tests conducted in fiscal year 1987 using the silica/soda ash sludge simulant, a series of six 1/12-scale tests were performed using a simulant composed of kaolin clay, water, salt, and colloidal silica. In 1987 it was desired that mobilization tests be conducted using sludge simulants with higher shear strengths than those practically attainable using the silica/soda ash simulant. To meet this need, a new simulant was developed. This simulant used the gelation of colloidal silica to create strength. The colloidal silica chosen is sold under the trade name Ludox ${ }^{\circ}$ HS-30. Kaolin clay was added to give the gel the target sludge density of $1.5 \mathrm{~g} / \mathrm{ml}$. This simulant was convenient to use for $1 / 12$-scale tests because it could be mixed up as a slurry and pumped into the tank where it cured to form a sludge. The shear strength of the sludge and the curing time are predictably controlled by the Ludox ${ }^{\circ}$ and salt concentrations used. This simulant is referred to as kaolin/Ludox .

The results of the six mobilization tests conducted using this simulant, however, contradicted the silica/soda ash ECR correlation. The kaolin/Ludox ${ }^{\circ}$ simulant exhibited no discernible dependence of ECR on shear strength.

Three 1/25-scale tests were conducted during fiscal year 1994 in an effort to determine why the kaolin/Ludox simulant did not show a dependence of ECR on shear strength during the 1987 $1 / 12$-scale tests. The ECR/U $\mathrm{O}_{\mathrm{O}} \mathrm{D}$ vs. shear strength data collected at $1 / 25$-scale are presented in Figure 4.14. The $1 / 25$-scale data do indicate that the mobilization resistance of kaolin/Ludox is a function of shear strength. In fact, the kaolin/Ludox ${ }^{\circ}$ data fit the bentonite/kaolin ECR correlation for cohesive simulants as shown on the graph. Two different shear strengths are plotted for test 14-KL and two are plotted for $15-\mathrm{KL}$. This was done because the shear strength of the kaolin/Ludox ${ }^{\circ}$ simulant increased during the test. The plotted points represent shear strength measurements taken at the time the ECR growth was observed to stop. Only a single shear strength was used for the $13-\mathrm{KL}$ data because the shear strength of the 13-KL simulant did not change appreciably during the test period. 


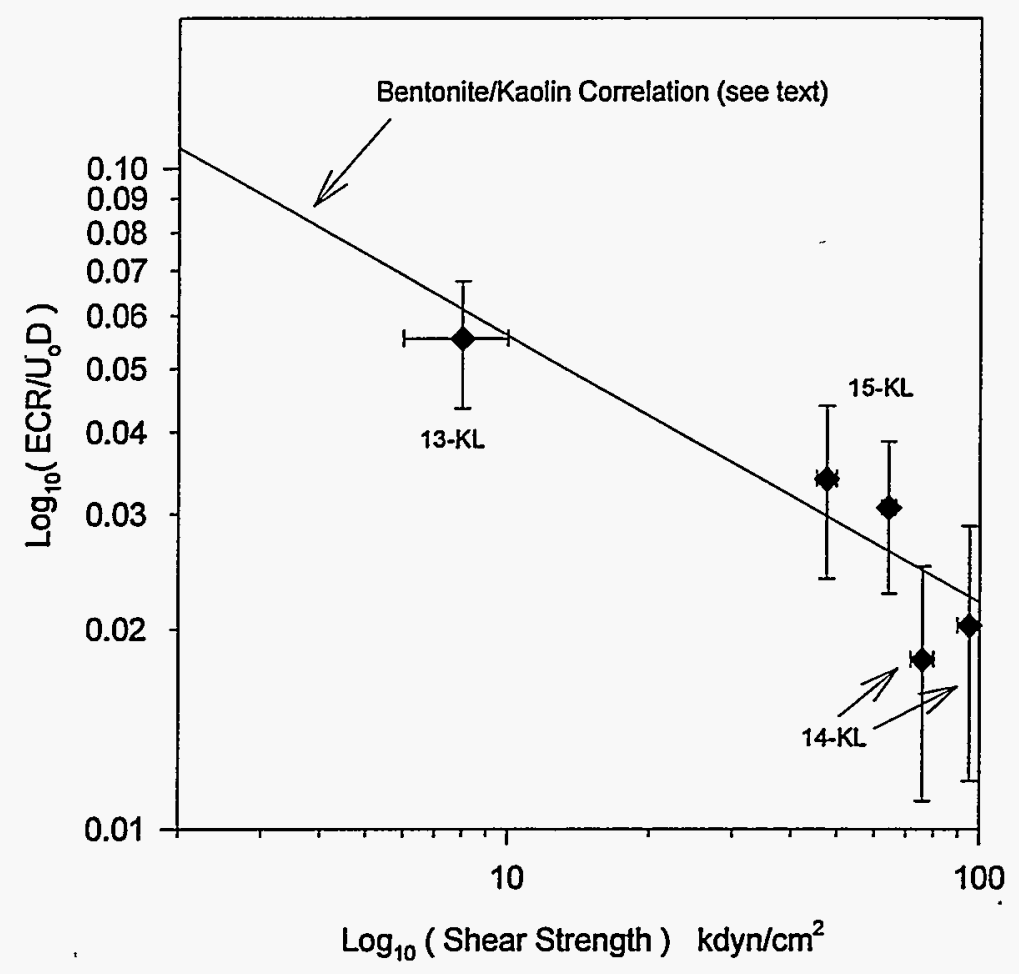

Figure 4.14. Kaolin/Ludox ECR Data

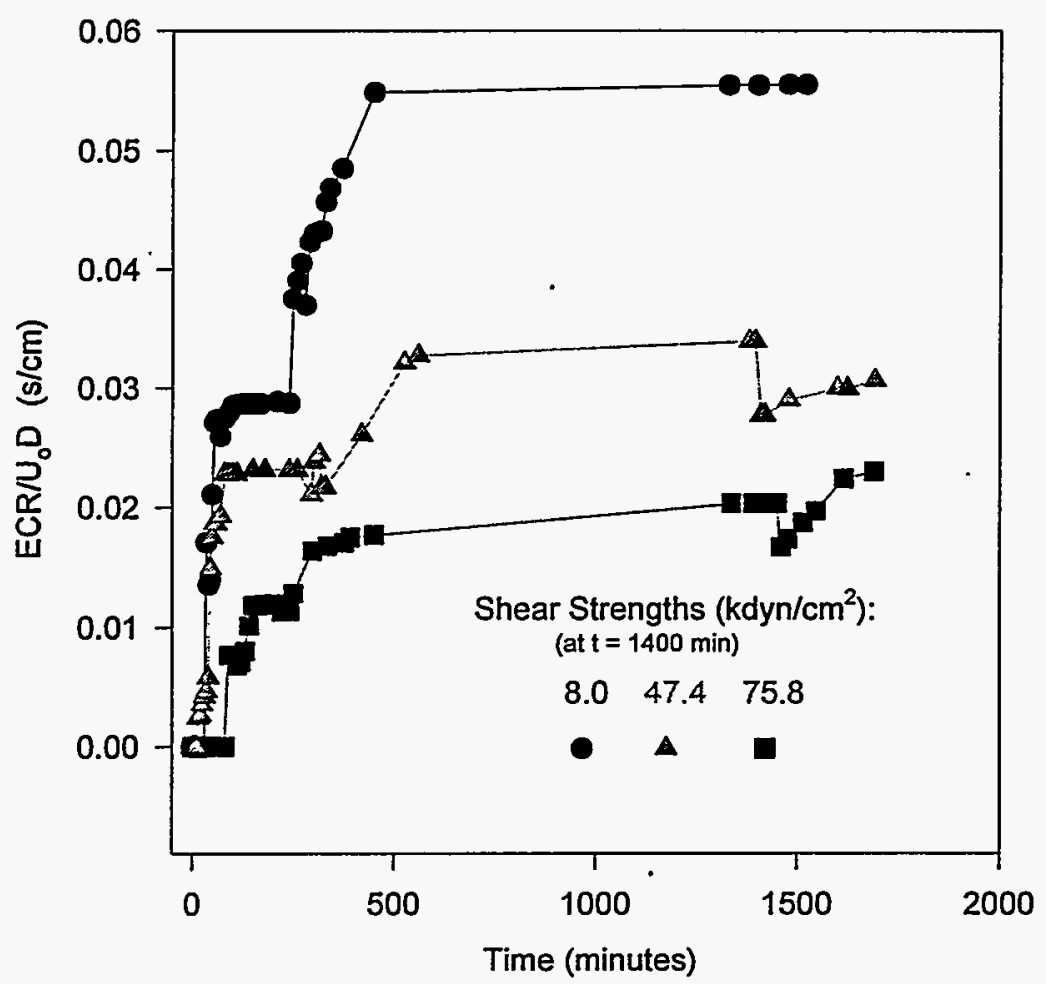

Figure 4.15. Kaolin/Ludox ${ }^{\star}$ ECR vs. Time Data 
The likely explanation for the discrepancy between the $1 / 25$-scale and the $1 / 12$-scale kaolin/Ludox ${ }^{\circ}$ results was revealed during the first $1 / 25$-scale kaolin/Ludox ${ }^{\circ}$ test $(13-\mathrm{KL})$. When the flow rate was increased so that an ECR larger than $10 \mathrm{~cm}$ was obtained, a portion of the sludge bank was observed to lift in the same way that the bentonite/water simulants did, as described previously. In the region of the tank where the sludge had lifted, the final average ECR was $27.5 \pm 12.6 \mathrm{~cm}$. The average ECR for the remainder of the tank was $23.9 \pm 7.4 \mathrm{~cm}$. Sludge bank lifting also was observed to facilitate the mobilization of bentonite/water simulants.

The sludge lifting in test 13-KL occurred despite efforts to avoid this problem. Because of the flexible nature of kaolin/Ludox ${ }^{\star}$, the potential for sludge lifting was anticipated, so the test was started by slowly increasing the mixer-pump-jet flow rate until sufficient mobilization was noted. It has been previously observed that sludge bank lifting can be induced in bentonite/water simulants by rapidly increasing the jet flow rate when the ECR is small (Powell et al. 1995). The 1987 1/12-scale kaolin/Ludox ${ }^{\odot}$ tests were started by lowering the mixer pump into the sludge bank so that the initial ECR was essentially $0 \mathrm{~cm}$, then the mixer pump flow was rapidly established. Based on the $1 / 25$-scale test results, this procedure would be expected to result in sludge lifting, which facilitates sludge mobilization.

A review of the data collected during the 1987 1/12-scale tests provides further evidence that the $1 / 12$-scale kaolin/Ludox ${ }^{\circ}$ tests were affected by sludge lifting. At the end of several of the tests, very non-circular sludge-bank profiles were observed. Along some radial directions the tank floor was cleaned all the way to the tank wall, and along other directions a substantial sludge bank remained. This is consistent with the hypothesis that sludge lifting occurred. In the regions of the tank where lifting occurred the sludge would be easier to mobilize.

It cannot be proven that sludge-bank lifting was responsible for the $1 / 12$-scale kaolin/Ludox observations, but the evidence collected both at $1 / 25$-scale and at $1 / 12$-scale point to sludge lifting as likely.

After sludge lifting was observed in test 13-KL, greater care was taken while running tests $14-\mathrm{KL}$ and $15-\mathrm{KL}$ so that sludge lifting could be avoided. No sludge lifting was observed in either test. The sludge lifting that was observed in test. 13-KL is estimated to have resulted in the average ECR being larger than it would have been otherwise. However, this does not invalidate the fit of the $1 / 25$-scale kaolin/Ludox ${ }^{\odot}$ data to the bentonite/kaolin ECR correlation as shown in Figure 4.14. If the data from the portion of the tank where lifting did not occur are used instead of the average of all the ECRs, then the resulting ECR/ $\mathrm{U}_{\mathrm{o}} \mathrm{D}$ for test $13-\mathrm{KL}$ is $0.051 \pm 0.016 \mathrm{~s} / \mathrm{cm}$. The vertical error bar of this point still captures the bentonite/kaolin correlation. To remain consistent with the other ECR/ $U_{0} D$ plots, the value for test 13-KL plotted in Figure 4.14 is the average of all eight ECR readings rather than just the four from the portion of the tank where the sludge did not lift.

The fact that the kaolin/Ludox ${ }^{\oplus}$ data are reasonably fit by the bentonite/kaolin ECR correlation is encouraging because kaolin/Ludox is also a highly cohesive simulant. The shear strength of kaolin/Ludox ${ }^{\circ}$ is derived from the formation of a three-dimensional gel structure formed by colloidally bonded silica particles. The kaolin clay does not contribute significantly to the shear strength. When kaolin/Ludox is first prepared it has the consistency of a milk shake. At this point the silica has not gelled so the lack of strength from kaolin is quite evident. 
The correlation between cohesive behavior and specific surface area is also seen for the kaolin/Ludox simulant. The colloidal silica used in Ludox ${ }^{\oplus}$ has a specific surface area of about $230 \mathrm{~m}^{2} / \mathrm{g}$. The specific surface area for the $13-\mathrm{KL}$ kaolin/Ludox simulant is estimated to be $(0.095)(230)+(.905)(15)=35 \mathrm{~m}^{2} / \mathrm{g}$. For $14-\mathrm{KL}$ and $15-\mathrm{KL}$ the specific areas are 47 and $44 \mathrm{~m}^{2} / \mathrm{g}$, respectively. ${ }^{(a)}$

Figure 4.15 gives the ECR/U $\mathrm{D}$ vs. time data for each of the three kaolin/Ludox ${ }^{\circ}$ tests. The mobilization of kaolin/Ludox ${ }^{\circ}$ is seen to be very rapid. The final ECR is reached very quickly compared to some of the other simulants tested. This is likely due to the manner in which kaolin/Ludox ${ }^{\circ}$ mobilizes. The kaolin/Ludox ${ }^{\circ}$ was observed to break off from the sludge bank as 0.5 to 2.0-cm-sized pieces. Other simulants, like kaolin, break off from the sludge bank as 0.2 to $0.5-\mathrm{cm}-$ sized pieces. The explanation for this difference is not known.

\section{$\mathrm{Kaolin} / \mathrm{NaCl}_{(\mathrm{aq})}$ Sludge Simulant Data}

Three $1 / 25$-scale tests were conducted to investigate whether a difference in ionic strength between the tank supernate and the sludge interstitial fluid might affect mobilization. The effects of the salt concentration differences are addressed in Section 4.1.3. In this section, consideration will be given only to the observed mobilization resistance as a function of shear strength.

The ECR/ $\mathrm{U}_{0} \mathrm{D}$ vs. shear strength data for test $16-\mathrm{KN}$ through $18-\mathrm{KN}$ are presented in Figure 4.16. The intent of these tests was to run all three tests at nearly the same shear strength. As a result, conclusions cannot be drawn from these data about the dependence of ECR on shear strength for these simulants. The bentonite/kaolin cohesive simulant ECR correlation has been included in Figure 4.16 to show that the data are reasonably fit. However, the bentonite/kaolin correlation also fits the $\mathrm{kaolin} /$ water simulant data in the 10 to $15-\mathrm{kdyn} / \mathrm{cm}^{2}$ shear strength range (see Figure 4.2 ). Because of this, it is not clear whether the kaolin $/ \mathrm{NaCl}_{(\mathrm{aq})}$ simulants follow the bentonite/kaolin correlation.

Figure 4.17 shows the ECR/U $\mathrm{D}$ vs. time curves for tests $16-\mathrm{KN}$ through $18-\mathrm{KN}$. It is not known why the simulant in test $16-\mathrm{KN}\left(15.4 \pm 1.7 \mathrm{kdyn} / \mathrm{cm}^{2}\right)$ exhibited a greater mobilization resistance than that of test $18-\mathrm{KN}\left(14.6 \pm 0: 3 \mathrm{kdyn} / \mathrm{cm}^{2}\right)$. Both simulants were prepared according to the same composition, and the difference in shear strengths is not statistically significant. More tests using this simulant would be required to resolve whether the test $16-\mathrm{KN}$ ECR/U $\mathrm{O}$ data are uncharacteristically low.

(a) These specific surface areas are estimated from the mass-fraction weighted average of the specific surface areas of each component in the mixture (e.g., kaolin and Ludox $)^{9}$. It is not known whether it is sufficient to calculate the specific surface area this way. For example, two simulants with different particle-size distributions might both have a specific surface area of 40 $\mathrm{m}^{2} / \mathrm{g}$. One simulant could contain particles of all the same size and shape while the other simulant could be composed of a mixture of large and small particles. Whether the mobilization resistance of both simulants would be equal (for equal shear strengths) is not certain. 


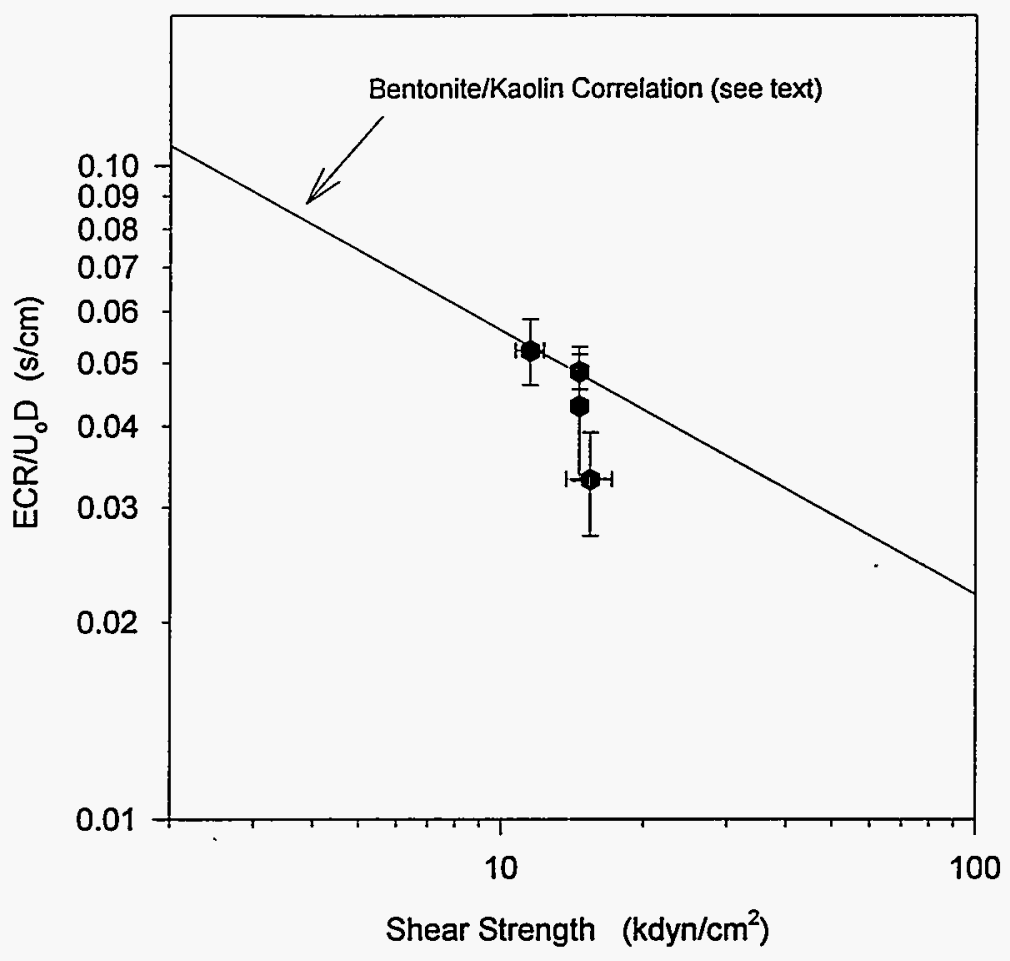

Figure 4.16. $\mathrm{Kaolin} / \mathrm{NaCl}_{(a q)} \mathrm{ECR}$ Data

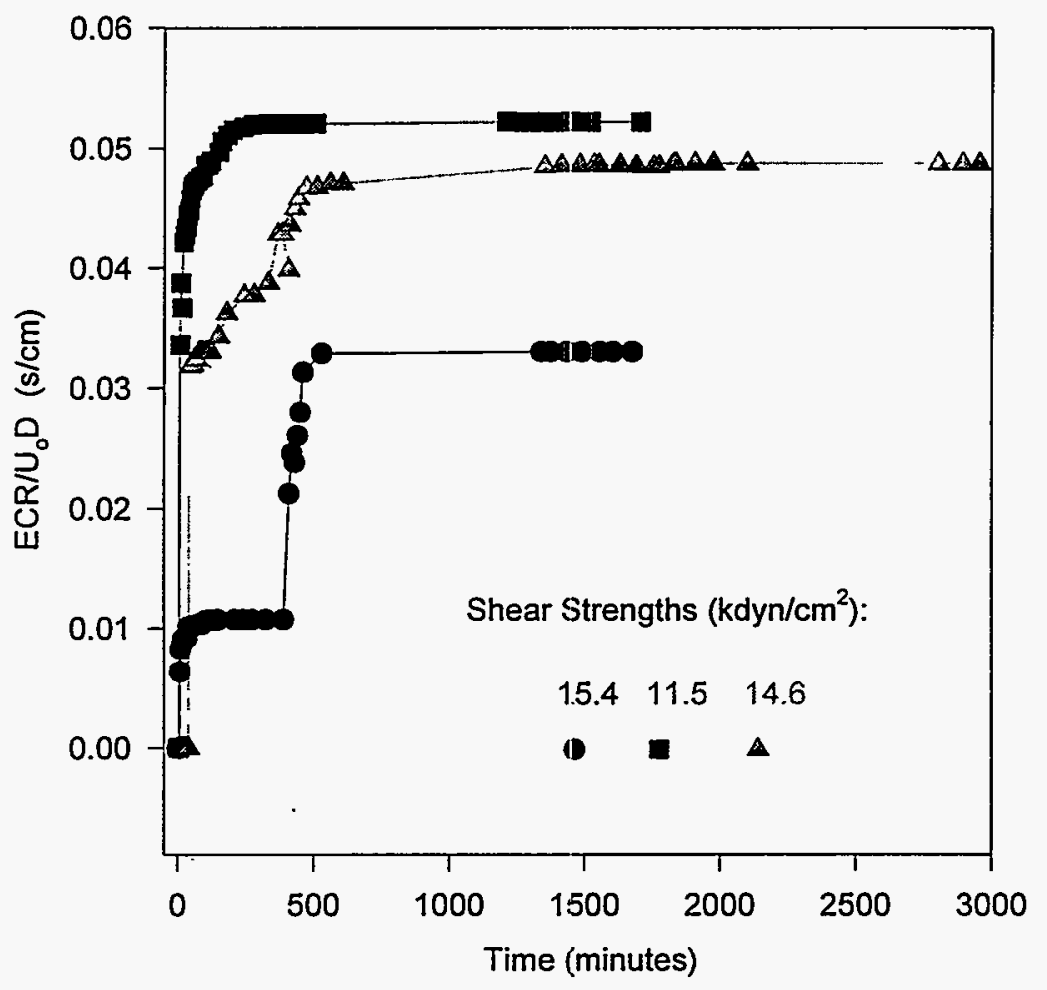

Figure 4.17. Kaolin/ $/ \mathrm{NaCl}_{(\mathrm{aq})} \mathrm{ECR}$ vs. Time Data 


\subsubsection{ECR vs. Tensile Strength}

The use of tensile strength as a direct measure of cohesion has been suggested by others in the literature (Nearing et al. 1991; Leavell and Peters 1987; Smalley 1970; Searle and Grimshaw 1959). That tensile strength might correlate with erosion resistance to turbulent flow was perhaps first suggested by Martin (1962) in his review of the paper by Moore and Masch (1962), which was one of the first attempts to correlate the erosion resistance of soils with physical properties. The use of tensile strength as an erosion predictor, however, has only recently received renewed attention (Nearing 1991). This apparent oversight is more likely an implicit recognition of the difficulty in obtaining tensile strength measurements on saturated soils. Currently no standard tensile strength measurement technique exists for soils with shear strengths in the range expected for DST sludge. Relationships between shear strength, tensile strength, and mobilization resistance are discussed in this section.

\section{Tensile Strength vs. Shear Strength Relationships}

The sludge simulant tensile strength measurement techniques described in-Section 3.0 were applied to the $1 / 25$-scale mobilization-testing simulants. The simulant tensile strengths are plotted vs. shear strength in Figures 4.18 through 4.20. The data in each of the three figures were collected using a different tensile strength measurement technique. Figure 4.18 contains the data from the vertical split-cell tensiometer, Figure 4.19 data were created using the vertical extrusion method, and the data in Figure 4.20 are from the horizontal split-cell tensiometer connected to the texture analyzer for force measurement. The vertical split-cell tensiometer data for kaolin/water and bentonite/water simulants collected during 1993 1/25-scale testing (Powell et al. 1995) have been included in Figure 4.18. Vertical extrusion and horizontal split-cell tests were not conducted before the present study.

The vertical split-cell tensiometer data in Figure 4.18 show two distinct correlations. The first is a nearly linear correlation of tensile strength with shear strength that has a slope of about 1.70 . All the sludge simulants except for kaolin/water, kaolin/ $/ \mathrm{NaCl}_{(\mathrm{aq})}$, and kaolin/Ludox follow this correlation reasonably well. As discussed earlier, these remaining simulants are thought to owe large fractions of their shear strengths to cohesive forces. Since cohesive forces contribute directly to tensile strength (Smalley 1970), it is expected that a strong relationship between tensile and shear strengths exists for these simulants. It is encouraging that all these simulants appear to follow roughly the same trend despite differences in composition. This implies that there might be a single relationship between shear strength and tensile strength for cohesive materials. If this is so, then ECR predictions for DST sludge mobilization could be made based on shear strength for sludge that is determined to be cohesive.

The second correlation is that followed by the kaolin/water and kaolin/Ludox ${ }^{\oplus}$ simulants. Increases in shear strength beyond about $20 \mathrm{kdyn} / \mathrm{cm}^{2}$ do not result in significant increases in the $\mathrm{kaolin} / \mathrm{water}$ or kaolin/Ludox tensile strengths. It is suspected, however, that the kaolin/Ludox ${ }^{\circ}$ measurements are not representative of the true relationship between shear and tensile strength for kaolin/Ludox ${ }^{\oplus}$. Most of the sludge simulants tested showed a small amount of deformation as the tensile load on the specimen was increased. The kaolin/Ludox samples, however, exhibited no observable strain before tensile failure. This behavior tends to make kaolin/Ludox samples highly sensitive to any misalignment of the split-cell tensiometer. 


\subsection{0}




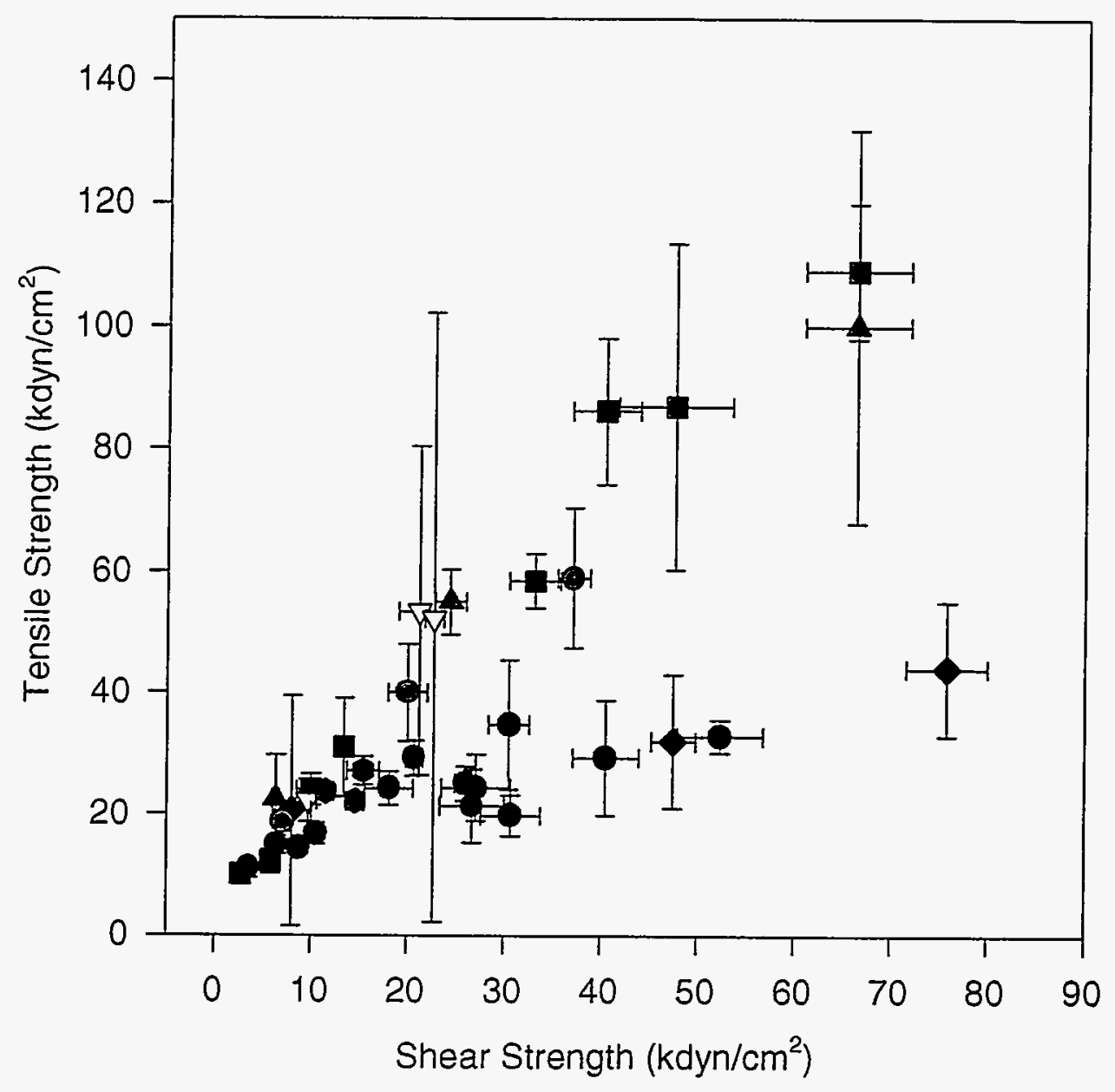
- Kaolin
- Bentonite
A Bentonite/Kaolin
Kaolin/Ludox
$\nabla$ Kaolin/Plaster
- Kaolin/Bentonite

Figure 4.18. Split-Cell Tensile Strength vs. Shear Strength 

If the tensile load is applied in any direction other than perpendicular to the pre-determined failure plane of the vertical split-cell tensiometer, then a stress concentration results along one edge of the sample. Clay samples (bentonite and kaolin), it is postulated, can relieve this stress concentration by undergoing a small amount of strain in the region of concentrated stress. This results in a redistribution of the tensile stress so that it is uniform across the failure plane. Clay pastes can undergo small strains without substantial changes in tensile properties because the van der Waals and electrostatic forces that determine tensile strength are re-established very quickly following any sort of disruption. Kaolin/Ludox ${ }^{\circledR}$, however, is not able to relieve stress concentrations by undergoing a small strain because even small strains result in damage to the three-dimensional gel structure of silica particles that gives the kaolin/Ludox ${ }^{\circ}$ simulant its cohesion. The damage to the gel structure is not repaired (through the formation of new interparticle bonds) quickly enough.

The time-scale for the regeneration of the silica gel structure is on the order of days rather than seconds as is the case for clays. To illustrate this point, consider the behavior of a kaolin/water and a kaolin/Ludox ${ }^{\circ}$ sample in response to being mixed. If a sample of kaolin/water is vigorously mixed (to disrupt the cohesive bonds) and its shear strength then quickly measured, the measured shear strength is not significantly ${ }^{(a)}$ different from that of a kaolin/water sample that has not been disrupted for several days. ${ }^{(b)}$ The behavior of bentonite clay is similar. Mixing a kaolin/Ludox sample, however, destroys the silica gel structure, and the shear strength drops to nearly zero even if the undisturbed strength was as high as $100 \mathrm{kdyn} / \mathrm{cm}^{2}$. The mixed kaolin/Ludox sample will retain a slurry-like consistency for several minutes to several hours depending on the exact composition of the simulant. Several days may be required for the mixed kaolin/Ludox to regain most of its former strength.

The rate of force application used for the vertical split-cell tensile strength tests is such that tensile failure is obtained in 2 to 10 minutes. This is probably slow enough to allow the clays to recover from small strains induced by stress concentrations resulting from a small misalignment of the tensiometer. However, this is probably not slow enough for the kaolin/Ludox simulants to recover from such strains. Kaolin/Ludox ${ }^{\Phi}$ tensile tests would probably require several days per test to avoid the effect of misalignment.

Because the kaolin/Ludox ${ }^{\oplus}$ tensile strength measurements probably were biased low by premature failure induced by stress concentration, it is not certain whether the kaolin/Ludox ${ }^{\circledR}$ tensile strength vs. shear strength relationship actually follows the kaolin/water trend as would be indicated by

(a) Minor increases in shear strength with time have been observed for the kaolin and bentonite simulants used for $1 / 25$-scale testing. These effects are relatively small with a shear strength increase on the order of $20 \%$ over two weeks being not unusual. The fractional increase over the first few days after mixing is on the order of $10 \%$, which is also about the amount of scatter seen in repeated shear strength measurements on "identical" samples.

(b) An interesting test was recently performed as part of the PNL simulant development efforts in which the shear strengths of kaolin and bentonite simulants were measured while a highamplitude, sonic-frequency (approx. $50 \mathrm{~Hz}$ ) vibration was applied to the samples. The shear strength of both types of clay was observed to be much lower with the vibration applied than without the vibration. Once the vibration was terminated, the shear strength recovered to its original value within a few seconds. It is inferred from this that the time-scale for the establishment of cohesive bonds in the kaolin and bentonite simulants tested is probably on the order of 1 second or less. 
Figure 4.18. Considering the nature of the forces that control the tensile strength of kaolin/Ludox ${ }^{\ominus}$, it is judged to be more likely that kaolin/Ludox follows a trend similar to that of the other cohesive simulants (bentonite/water, bentonite/kaolin, etc.).

There is not a compelling reason, however, to suppose that the kaolin/water tensile strength data obtained from the vertical split-cell tensiometer are biased low. By the argument given above, stress concentration should not be a significant problem for the kaolin clays tested. The lack of increase in tensile strength with increasing shear strength for kaolin/water is consistent with the data presented earlier in Section 4.1.1. It was observed that increases in kaolin/water shear strength did not result in appreciable increases in mobilization resistance. Since cohesion is thought to be the primary indicator of mobilization resistance, and tensile strength measures cohesion, the kaolin/water data in Figure 4.18 support the argument that increases in kaolin/water shear strength beyond $20 \mathrm{kdyn} / \mathrm{cm}^{2}$ are primarily due to friction.

The kaolin/water tensile strength data indicate that the kaolin/water cohesion decreases with decreasing tensile strength below about $20 \mathrm{kdyn} / \mathrm{cm}^{2}$. The ECR/ $\mathrm{U}_{\mathrm{o}} \mathrm{D}$ data given in Figure 4.2 , however, indicate that the cohesion should not show such a large decrease in this range. It was noted during tensile testing of all the simulants in the $<10 \mathrm{kdyn} / \mathrm{cm}^{2}$ shear-strength range that these simulants did not fail by the same mechanism as the simulants with larger shear strengths. The stronger simulants tended to break cleanly across a flat surface perpendicular to the applied tensile stress. The weaker simulants showed signs of flowing and "necking down" before complete failure. The originally cylindrical failure zone was observed to develop an hourglass shape over about 5 seconds. The narrow portion of the hourglass shape rapidly becomes narrower until the two halves separate. This is interpreted as being the result of some combination of shear and tensile failure modes. If a tensiometer could be designed such that a purely uniform tensile stress was applied to the sample, then this might not occur. Unfortunately, most means of gripping the ends or sides of the test specimen distort the tensile stress distribution and apply shearing forces to the sample. This problem becomes especially difficult to avoid when testing weak samples like those with shear strengths less than $10 \mathrm{kdyn} / \mathrm{cm}^{2}$.

Because of the possibility that shear failure may have affected the tensile strength measurements of the weak simulants, the data in this range should be carefully interpreted. The tensile failures of the stronger simulants, however, exhibited no signs of shear failure so those data are thought to be valid.

Whether the kaolin/ $/ \mathrm{NaCl}_{(\mathrm{aq})}$ simulant follows the kaolin/water trend or that of the cohesive simulants is unclear. The addition of salt to the fluid between the kaolin particles is expected to result in a compression of the double-layers, and this should allow more extensive face-to-face bonding of the kaolin platelets while not adversely affecting the edge-to-face linkages that are thought to be the principal source of cohesion in the kaolin/water simulants. This argument would predict that the $\mathrm{kaolin} / \mathrm{NaCl}_{(\mathrm{ag})}$ simulant would owe a greater fraction of its shear strength to cohesion than the kaolin/water simulant. However, as has been noted previously, the specific surface area of kaolin clay is about $15 \mathrm{~m}^{2} / \mathrm{g}$, which would indicate that double-layer effects are less important than in other clays. Whether the double-layer compression effect is significant enough to cause a deviation of the tensilestrength trend for kaolin/ $/ \mathrm{NaCl}_{(\mathrm{aq})}$ from that of kaolin/water is not known. Tensile testing of the $\mathrm{kaolin} / \mathrm{NaCl}_{(\mathrm{aq})}$ simulant at higher shear strengths would be needed to resolve this.

The tensile-strength data obtained using the vertical extrusion method are presented in Figure 4.19. Nearly all the data fall along a straight line with a slope of 1.7 , which is consistent with the tensile-strength data obtained from the vertical split-cell tensiometer (see Figure 4.18). As in 
Figure 4.18, the kaolin/Ludox ${ }^{\oplus}$ tensile-strength data do not follow the cohesive simulant correlation as would be expected for this simulant based on its estimated specific surface area $\left(>35 \mathrm{~m}^{2} / \mathrm{g}\right)$. This is believed to have been due to misalignment of the extrusion tube with the tensile force (provided by gravity), which resulted in premature failure due to stress concentration as discussed above. Efforts were made to position the extrusion tube plumb vertical, but even if this had been achieved, the small horizontal movements. of the extrusion tube that occurred as the plunger was forced down the tube may have been sufficient to induce failure.

The primary difference between Figures 4.18 and 4.19 is the behavior of the kaolin/water data. The vertical extrusion tensile strengths for kaolin seem to follow the correlation exhibited by the highly cohesive simulants like bentonite/water and bentonite/kaolin. This contradictory result is believed to be due to the frictional nature of the kaolin/water simulants as explained below.

The vertical extrusion tensile-strength measurement technique involves extruding a cylindrical specimen vertically downward until the weight of the extruded sample exceeds the sample's tensile strength. At any given time during the test, the maximum tensile force applied by the hanging mass of sample is proportional to the weight of the sample that has already been extruded. This maximum tensile force is applied across the sample cross-section that is most near the extrusion tube. Thus, the tensile failure observed in the vertical extrusion test occurs in the most recently extruded material. This contrasts with the vertical split-cell technique, in which the tensile stress is always applied to the same portion of the sample (that nearest the interface between the two halves of the tensiometer).

The significance of this difference is that the tensile strength of kaolin/water is expected to be a function of the rate of tensile force application. In the vertical extrusion test, the portion of the sample that ultimately fails very quickly goes from experiencing relatively little tensile stress while inside the extrusion tube to having to support the weight of all the previously-extruded sample. The time scale over which this occurs was held constant for all the vertical extrusion tests and is estimated to be on the order of 30 seconds or less (extrusion rate was $3.9 \mathrm{~cm} / \mathrm{min}$ ). In the vertical split-cell test, the tensile stress is applied to a predetermined failure plane at a constant rate of about $100 \mathrm{kdyn} / \mathrm{min}$. Thus, the time required to obtain tensile failure was directly proportional to the tensile strength and typically ranged from about 2 to 10 minutes.

Many concentrated dispersions of solid particles exhibit dilatancy. Dilatancy is the tendency of a sample to increase its volume in response to an applied strain. This is typical of systems in which the particles are packed closely together. For the sample to flow, particles must move past each other. For a tightly packed system of particles, the only way for this to happen quickly is for the bed volume to increase so that the average interparticle distance increases. When a liquid occupies the space between particles a further complication is introduced. As the volume increases in response to an applied strain, liquid must flow from outside the bed or from non-deforming regions of the bed to fill this newly created volume. Because the liquid has a finite viscosity, it cannot do this instantly. The amount of time required for the liquid to equalize the apparent suction that is created in a deforming region of the sample depends on various liquid and solid characteristics. For coarse solids, like sand, this time is on the order of tenths of seconds, whereas systems of much smaller particles can require hours for the water to equalize the suction. A dilatant material will resist rapid strain application with great force due to the inability of the water to neutralize the resulting pore suction fast enough. Slowly applied strains, however, encounter very little resistance, as the water is able to flow quickly enough to keep up with the slowly changing bed volume. 


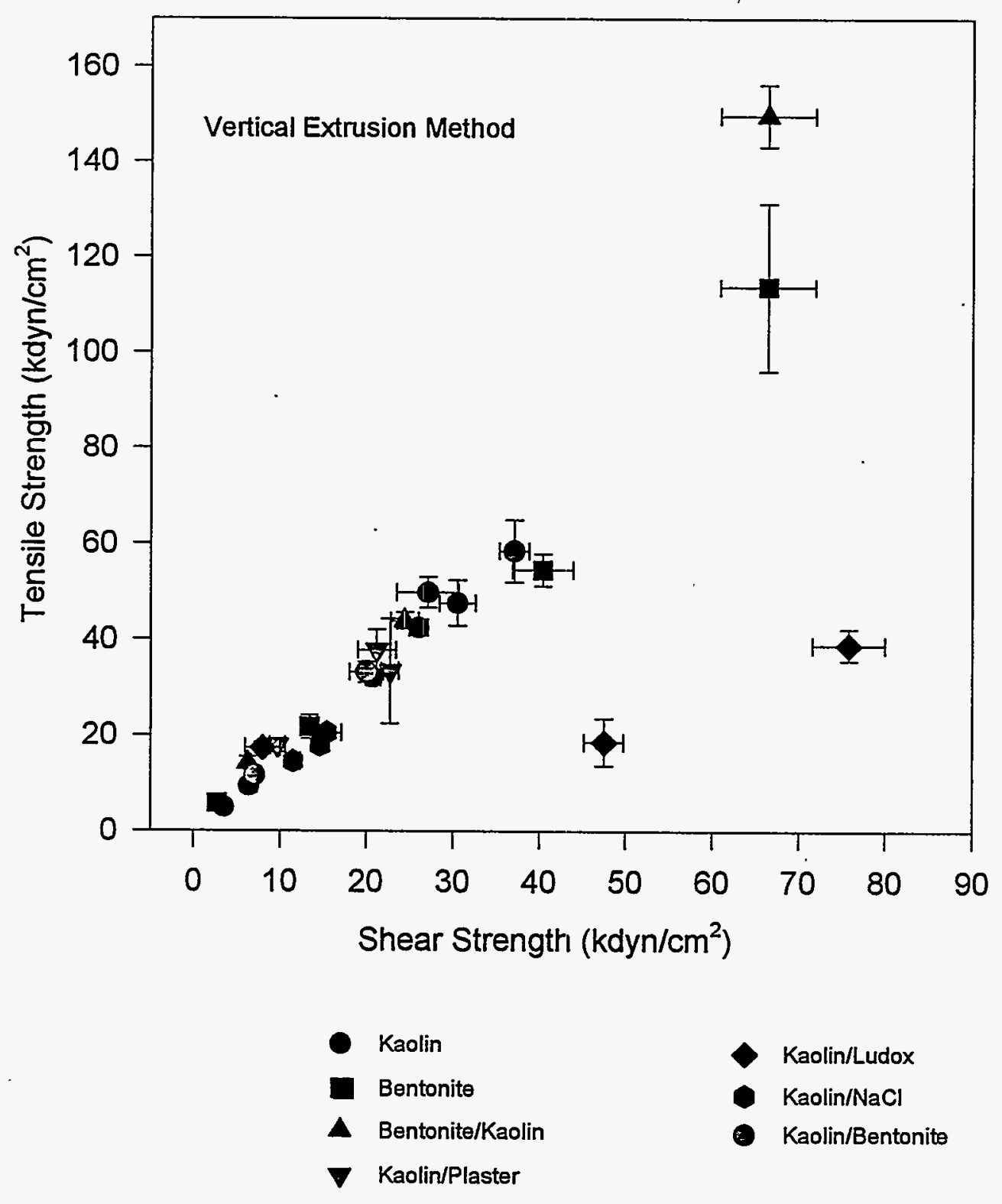

Figure 4.19. Vertical Extrusion Tensile Strength vs. Shear Strength 

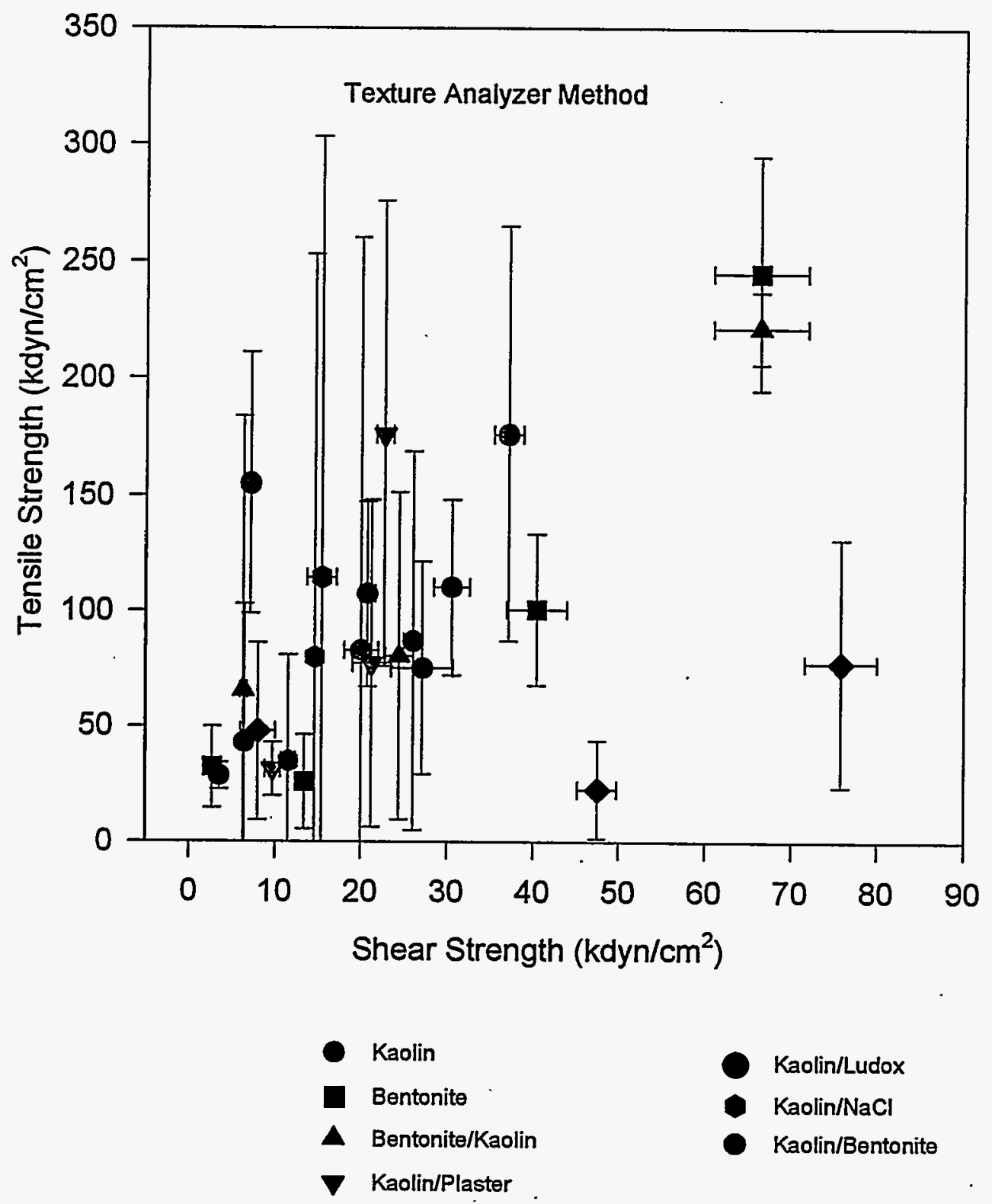

Kaolin/Ludox

- Kaolin/ $\mathrm{NaCl}$

- Kaolin/Bentonite

Figure 4.20. Horizontal Split-Cell Tensile Strength vs. Shear Strength 
Evidence was presented in Section 4.1.1 that indicates the stronger kaolin/water simulants owe much of their strength to the friction that results from the particles being closer together. As dilatancy is not uncommon in concentrated dispersions, it is plausible that the stronger kaolin/water simulants exhibit some degree of dilatancy.

As further supporting evidence for dilatancy in kaolin/water, consider the dependence of $\mathrm{kaolin} /$ water vane shear strength on shear vane rotation speed. Tests performed in fiscal year 1992 demonstrate that the shear strength of kaolin tends to increase as the vane rotation speed is increased. (a) The data that support this are presented in Figures 4.21 and 4.22. It is seen in Figure 4.21 that the magnitude of the strength increase (with respect to increasing vane speed) increases as the wt \% kaolin is increased. This is consistent with the hypothesis that dilatancy affects the kaolin/water simulant behavior. Further, it is seen in Figure 4.22 that no such trend is evident for bentonite/water simulants. This is consistent with the assertion that bentonite does not suffer from the dilatancy effects as does kaolin.

Viscoelastic characterization of kaolin/water simulants also implies that kaolin/water exhibits dilatancy. During tests at low frequency $(0.01 \mathrm{~Hz})$, the measurements imply that kaolin behaves as though its shear resistance is due to a combination of frictional/viscous and cohesive/elastic forces. When the frequency of the cone-and-plate oscillation was increased to $1 \mathrm{~Hz}$, the kaolin response became more like that of an elastic substance. This would be expected from a dilatant material. At the higher strain application rate of $1 \mathrm{~Hz}$, the pore fluid is unable to keep up with the changing sample volume so pore suctions are generated that serve to hold the kaolin particles tightly together. The applied strain is transmitted through the matrix of touching kaolin particles held together by pore suction. The particles are held together so tightly that very little of the applied strain is irreversibly lost to interparticle friction. This is interpreted by the rheometer as elastic behavior because the measured stress is in phase with the applied strain. In contrast to the kaolin/water results, bentonite/water was found to respond elastically regardless of oscillation rate. This implies that dilatancy is important for kaolin, but not for bentonite.

Since the effect of dilatancy is to increase the apparent strain resistance of a material, dilatancy could have biased the kaolin/water vertical extrusion tensile strengths high such that they appear to follow the correlation for the more cohesive simulants. Further testing is planned to determine whether the vertical extrusion tensile strength of kaolin/water decreases as the extrusion rate is decreased. The evidence collected thus far, however, indicates that the kaolin/water vertical extrusion data are suspect. Because the vertical split-cell tensiometer kaolin/water measurements are less likely to have been affected by any dilatancy effects, the split-cell measurements are judged to be more reliable than the vertical extrusion data.

Because the vertical extrusion kaolin/water data are suspect, the vertical split-cell tensile strength measurements are used for all plots of kaolin/water ECR/ $\mathrm{U}_{0} \mathrm{D}$ vs. tensile strength presented below. The vertical extrusion tensile strength data are used for the $E C R / U_{0} D$ data for the other simulants because there is less scatter for these data than for the split-cell data, and dilatancy effects probably were not important (except, possibly for the kaolin/ $\mathrm{NaCl}_{(\mathrm{aq})}$ simulant).

(a) Powell, M. R. FY 1992 Laboratory-Scale Sludge Mobilization Simulant Testing. A Letter Report prepared for Westinghouse Hanford Company by the Pacific Northwest Laboratory, Richland, Washington. June 1993. 


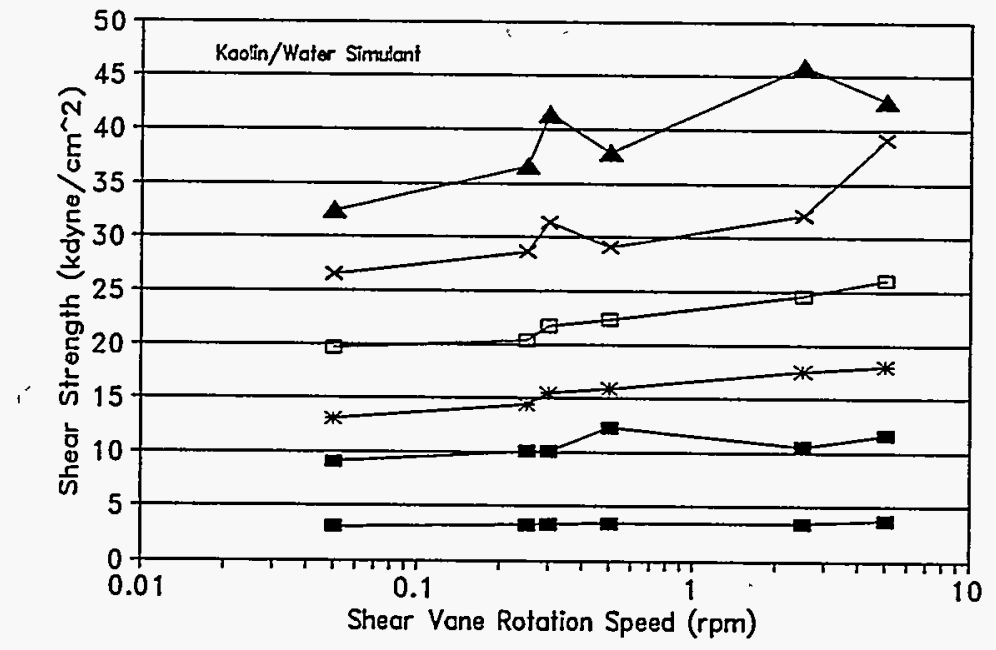

Figure 4.21. Shear Strength vs. Vane Rotation Speed for Kaolin/Water (see footnote on page 4.35)

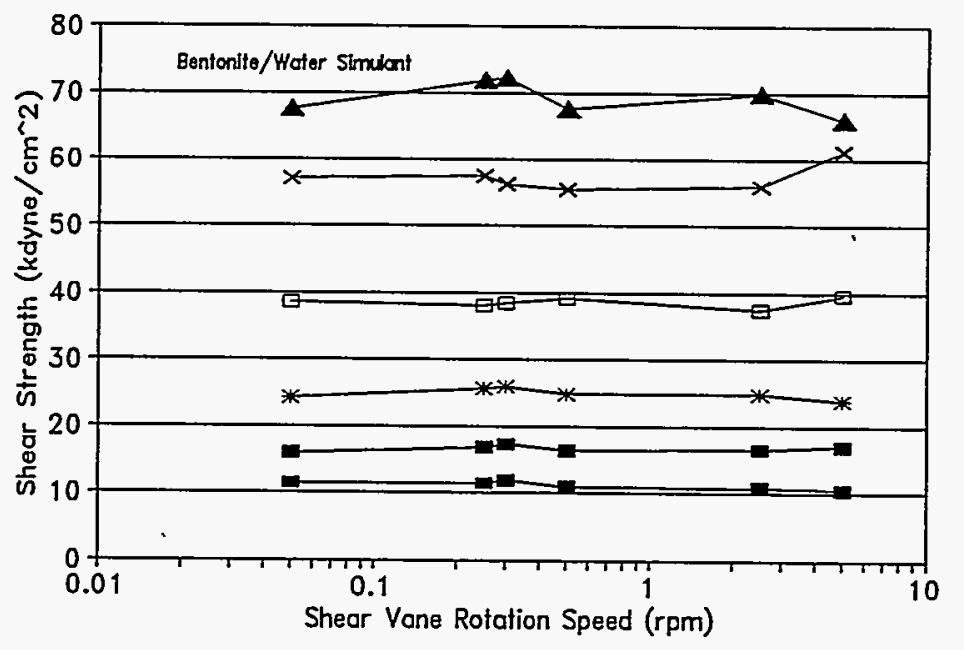

Figure 4.22. Shear Strength vs. Vane Rotation Speed for Bentonite/Water (see footnote on page 4.35) 
The horizontal split-cell tensile strength measurement technique, also referred to as the texture analyzer method, was used to generate the tensile strength data given in Figure 4.20. The trend is similar to that shown in Figures 4.18 and 4.19 , but there is considerably more scatter in the tensile strength measurements. Problems were encountered using this technique that included disruption of the failure plane before testing, simulant in between the mating surfaces of the two cell halves, and friction between the tensiometer cell and the cell supports. These effects combined to produce the observed scatter. These results serve to emphasize some of the difficulties that can be encountered when trying to measure tensile strength.

Measurements were also made of the amounts of each simulant that could be extruded horizontally before failure as described in Section 3.0. The data are not presented here because most of the results were adversely affected by slumping downward of the simulant before failure instead of maintaining a horizontal, cylindrical shape. This behavior invalidates the equation used to compute tensile strength from the horizontal extrusion data. An example of this slumping behavior is shown in Figure 4.23. In many cases, the slumping was considerably more severe than that shown in Figure 4.23. Slumping is indicative of shear failure. To get a reliable measurement of tensile strength using the horizontal extrusion method, the sample must fail due to a tensile stress concentration within the upper portion of the extruded cylinder.

Because stress concentration is an important element of the horizontal extrusion technique, simulants that are capable of relieving the tensile stress without failing completely tend to slump rather than fail cleanly. Examples of such simulants are kaolin and bentonite clays. The kaolin/Ludox simulant, on the other hand, does not relieve stress concentrations, so the horizontal extrusion technique may be particularly well-suited to the measurement of kaolin/Ludox tensile strengths. It is worth noting that the horizontal extrusion tensile strength data for the kaolin/Ludox simulant are reasonably close to the bentonite/water data on Figures 4.18 and 4.19. However, some of the observations made during the the testing imply that these samples may also have been failing in shear rather than tension, so these results must be viewed as tentative. The horizontal extrusion tensile strength data for tests $13-\mathrm{KL}$ through $15-\mathrm{KL}$ are calculated as $32.3 \pm 5.7,95.5 \pm 8.0$, and $41.6 \pm 4.3 \mathrm{kdyn} / \mathrm{cm}^{2}$, respectively. These data points are reasonably close to the bentonite/water correlation.

\section{Tensile Strength vs. Mobilization Resistance Relationships}

The ECR/U $/ \mathrm{O}_{0}$ vs. tensile strength data for the $1 / 25$-scale simulants are presented in Figures 4.24 and 4.25. The tensile strength data used to generate Figure 4.24 were those obtained using the vertical split-cell tensiometer. Also included in Figure 4.24 are the results of the fiscal year 1993 1/25-scale tests using kaolin/water and bentonite/water sludge simulants. Figure 4.25 uses the vertical extrusion tensile strength data for all simulants except kaolin/water. The kaolin/water vertical extrusion tensile strength data are suspect as was discussed in the previous section. The kaolin/water data plotted in Figure 4.25 were generated using the vertical split-cell tensiometer. Since the vertical extrusion tensiometer was not used during the 1993 testing, no 1993 bentonite/water data are included in Figure 4.25 . 


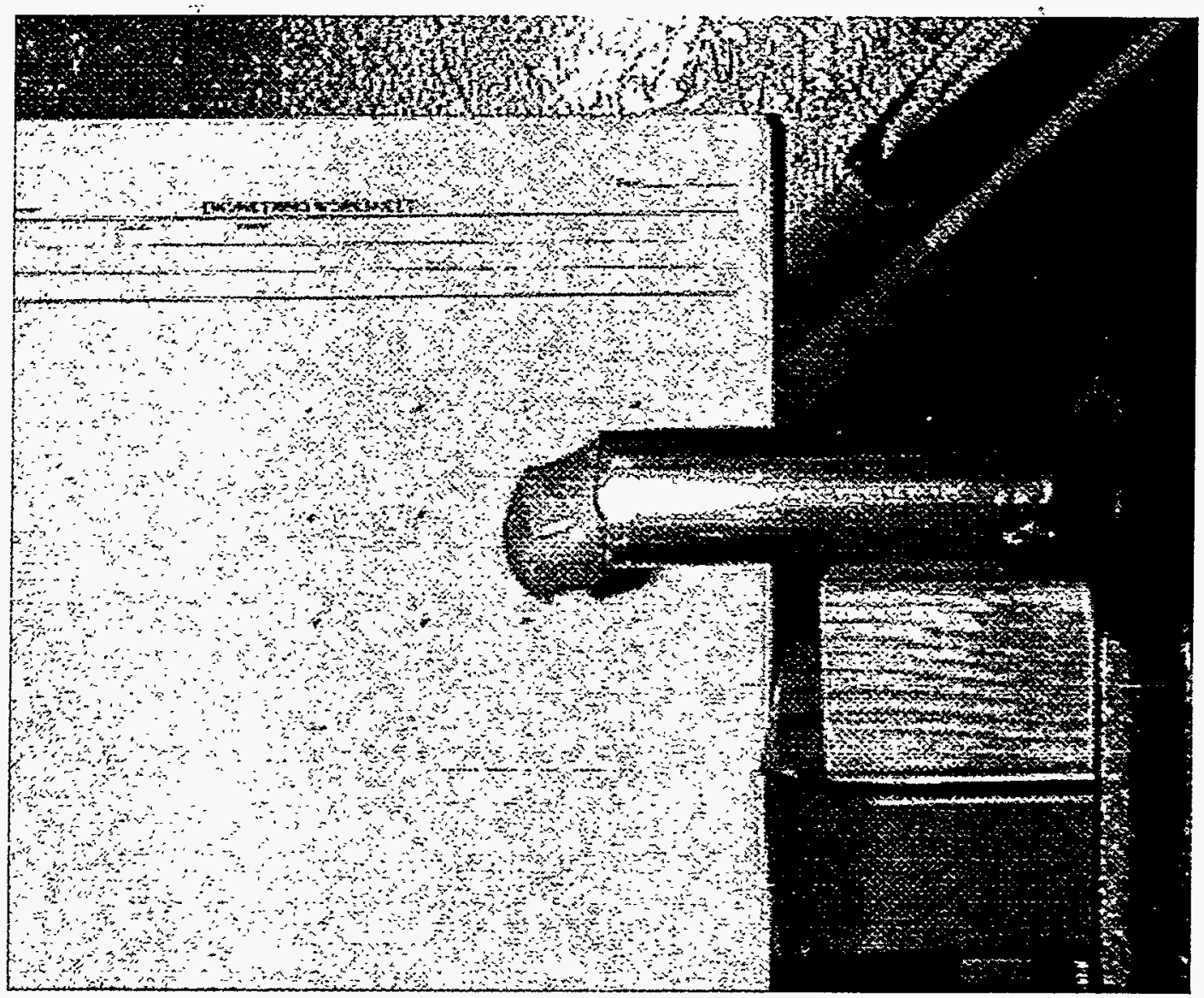

Figure 4.23. Simulant Slumping During Horizontal Extrusion Test 
$-$ 


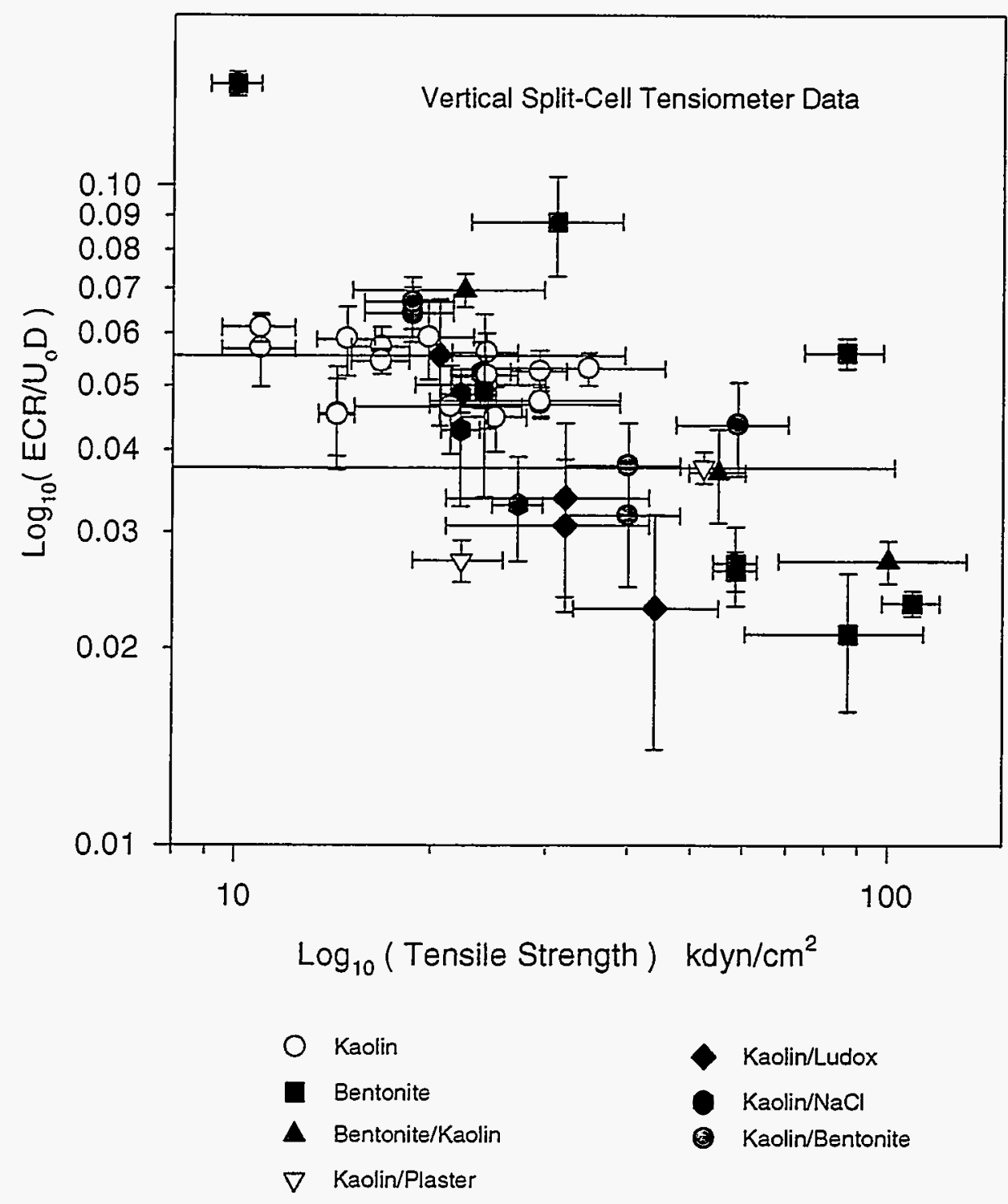

Figure 4.24. ECR Data vs. Split-Cell Tensile Strength 



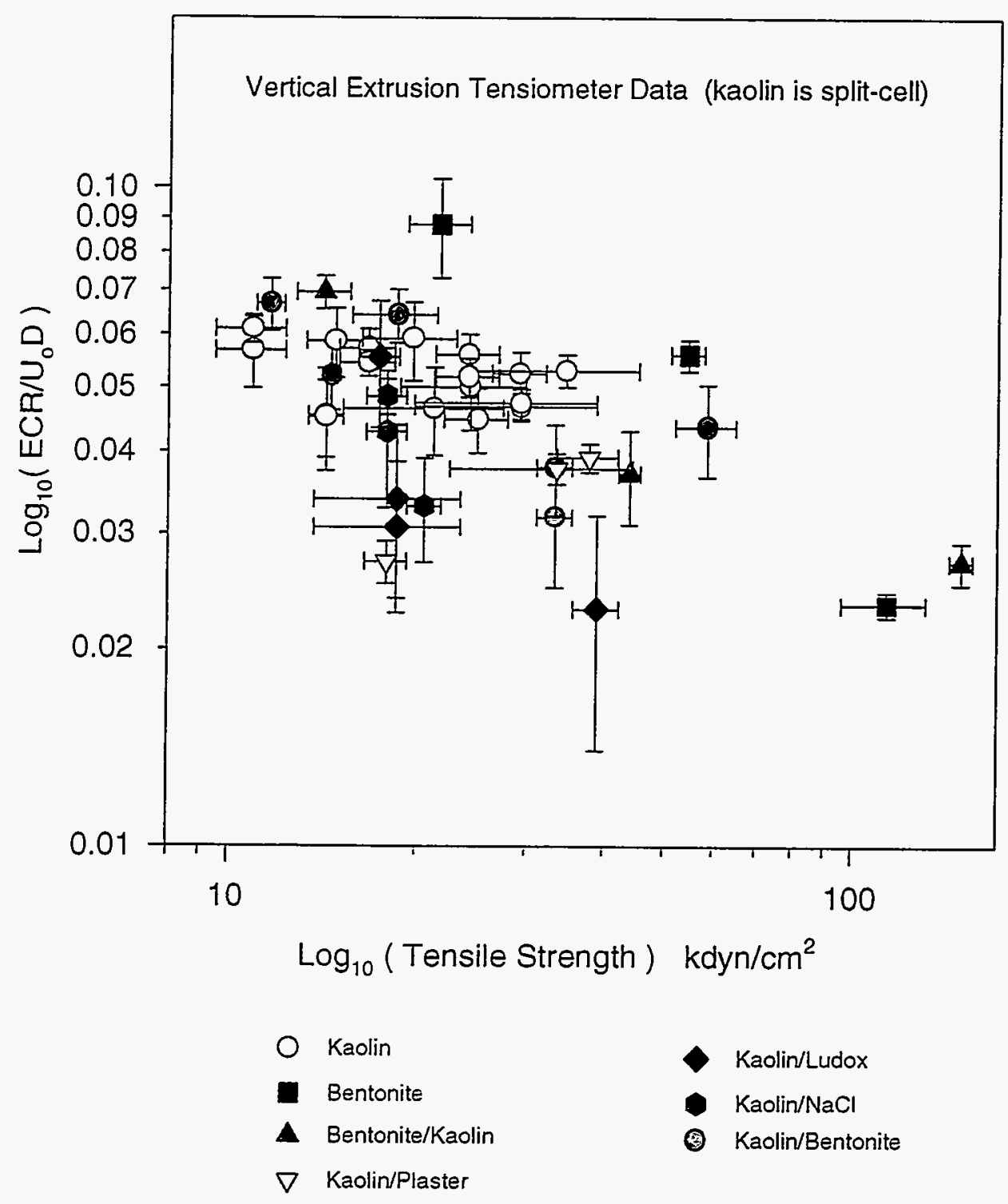

Figure 4.25. ECR Data vs. Vertical Extrusion Tensile Strength 

Both figures show generally increasing mobilization resistance (decreasing ECR/U $\mathrm{D}$ ) with increasing tensile strength. There is more scatter in Figure 4.24 than in Figure 4.25 because the vertical extrusion tensile strength measurements are more repeatable than the vertical split-cell measurements. The data show that increasing cohesion results in decreased ECRs, but it is also evident that the scatter in the tensile strength measurements makes it difficult to generate a reliable correlation between ECR and tensile strength. This situation can be improved through the development of improved methods for tensile strength characterization.

Correlation development is also hampered by the relatively large uncertainty in the ECR/ $U_{0} D$ values for many tests. This applies both to tensile strength and shear strength correlations. It must be reiterated that the $1 / 25$-scale tests were conducted with the goal of identifying the key physical properties that govern the mobilization resistance of sludge-like materials. Within certain limits this goal has been accomplished. It was recognized before $1 / 25$-scale testing that the uncertainty in ECR measurement at such a small scale would make developing correlations difficult. For this reason, it has always been intended that ECR correlation development would take place at $1 / 12$ scale or larger. At these larger scales, the $\pm 5-\mathrm{cm}$ variations in ECR that are observed due to sludge inhomogeneities represent a smaller fraction of the absolute ECR measurement. The error bars on the ECR/ $\mathrm{U}_{0} \mathrm{D}$ values are likely to become correspondingly smaller as the scale of the test is increased. Data collected at these larger scales will have smaller uncertainty and will, therefore, be more suitable for ECR correlation development.

\subsubsection{Salt Gradient Effects on Mobilization}

Three $1 / 25$-scale tests were conducted with the express goal of estimating the amount of additional ECR growth that could be expected when the salt concentration of the eroding fluid is lower than that of the fluid between the sludge simulant particles. It has been postulated that when such a concentration difference exists, water will permeate into the sludge in an effort to equalize the salt concentration in the sludge with that of the slurry. The additional water would be expected to decrease the cohesive strength of the sludge near the sludge surface by decreasing the local solids concentration in that region. Tests $16-\mathrm{KN}, 17-\mathrm{KN}$, and $18-\mathrm{KN}$ were designed to evaluate the importance of this saltinduced sludge swelling effect.

Whether such a mechanism actually occurs is of interest because some current DST waste retrieval plans call for removal of the high salt concentration tank supernate before mobilization. A more dilute supernate is added to the tank before activating the mixer pumps. This will result in the ionic strength (a measure of salt concentration) of the eroding fluid being lower than that of the interstitial fluid surrounding the solids that make up the sludge bank.

The three tests conducted to study this effect indicated that no additional ECR growth should be expected to result from the ionic strength gradient. It is likely that an effect can be observed given the appropriate sludge simulant properties, but no effect was found for the simulants that were tested. Further, consideration of the waste properties thought to determine whether such an effect might be found leads to the conclusion that tank waste is unlikely to exhibit an increased ECR due to these salt effects.

Test 16-KN involved the use of a sludge simulant prepared from kaolin clay and a $5 \mathrm{wt} \%$ sodium chloride solution. This simulant was mobilized using tap water as the initial tank supernate. It was intended that the final ECR/ $U_{0} \mathrm{D}$ for test $16-\mathrm{KN}$ would be compared to that expected based on the kaolin/water simulant tests at the same shear strength to determine the amount by which the salt effect 
increases the ECR. Unexpectedly, the mobilization resistance of the $16-\mathrm{KN}$ simulant was measured as being greater than that of the appropriate kaolin/water simulants.

Test $17-\mathrm{KN}$ was conducted similarly to test $16-\mathrm{KN}$ with the exception that the sludge simulant contained $20 \mathrm{wt} \%$ sodium chloride solution instead of the $5 \mathrm{wt} \%$ solution used for test 16-KN. Tap water was used as the eroding fluid. It was expected that the large difference in ionic strength between the eroding fluid and the sludge interstitial fluid would result in some decrease in mobilization resistance compared to that of kaolin/water of the same shear strength. No significant difference was found.

The test 18-KN sludge simulant was prepared according to the same composition as was used for test $16-\mathrm{KN}$. This was done to determine whether the same ECR/U $\mathrm{O}_{0} \mathrm{D}$ would be obtained. The test $16-\mathrm{KN}$ mobilization resistance, as stated above, was higher than that of the salt-free kaolin/water simulants. The test $18-\mathrm{KN}$ initial supernate was not tap water as was used in tests $16-\mathrm{KN}$ and $17-\mathrm{KN}$. Instead, a $5 \mathrm{wt} \%$ sodium chloride solution was used as the initial supernate. This was done to determine the mobilization resistance of the 18-KN simulant in the absence of the postulated swelling effects. The ECR/U $\mathrm{U}_{0} \mathrm{D}$ obtained was within the range typical of kaolin/water simulants rather than lower as was $16-\mathrm{KN}$. Based on the typical colloidal effects of salts on cohesive forces, the use of a salt solution as the eroding fluid would be expected to increase mobilization resistance. Since the $E C R / U_{0} D$ observed was greater than that of $16-\mathrm{KN}$, it is judged likely that if test $16-\mathrm{KN}$ was repeated several more times the average $\mathrm{ECR} / \mathrm{U}_{0} \mathrm{D}$ obtained would be closer to that of test $18-\mathrm{KN}$ than that recorded in test $16-\mathrm{KN}$.

Once ECR growth had stopped in test $18-\mathrm{KN}$, the slurry was removed from the tank and replaced with fresh tap water. The mixer pump was restarted and adjusted to the same flow rate as was used for the first half of test $18-\mathrm{KN}$. No further ECR growth was observed over a period of more than 1000 minutes. The conclusion from this test is that the ionic strength gradient between the eroding fluid and the kaolin/ $/ \mathrm{NaCl}_{(\mathrm{aq})}$ sludge simulants does not affect the ECR.

Tests conducted at 1/25-scale during fiscal year 1993 demonstrated that additional ECR growth on the order of $50 \%$ might be obtained when the sludge partially dissolves during mobilization (Powell et al. 1995). These tests used simulants composed of kaolin clay, water, and sodium chloride. Enough sodium chloride was used in these tests so that about $5 \mathrm{wt} \%$ of solid sodium chloride remained undissolved within the sludge before mobilization. Tap water was used to mobilize these simulants and the ECRs that resulted were approximately $50 \%$ greater than those of kaolin/water simulants of the same shear strength. (a) Considering the fiscal year 1994 data described above, this improvement in ECR is attributed to the dissolution of exposed pieces of solid sodium chloride rather than to a saltinduced swelling effect as described above. It is hypothesized that as exposed pieces of sodium chloride crystals become exposed to the eroding slurry, they dissolve leaving small craters where they used to be. These craters serve to decrease the mobilization resistance of the sludge surface because the crater edges tend to concentrate the force of the jet along their edges. As the cratered surface is smoothed by the jet, more salt crystals become exposed and form yet more craters. This could be a credible mobilization mechanism for DST sludge in which a portion of the sludge solids are soluble in the eroding fluid.

(a) The uncertainty in the ECR measurements was large enough that the estimated $50 \%$ increase in ECR should be viewed as a very rough estimate of the magnitude of this effect. See Powell et al. (1995) for a description of this work. 
The applicability of the test $16-\mathrm{KN}$ through test $18-\mathrm{KN}$ data to the mobilization of DST sludge must be considered. It is possible that the properties of the $\mathrm{kaolin} / \mathrm{NaCl}_{(\mathrm{aq})}$ simulants are such that ionic gradient effects are unimportant, while for DST waste these effects are important. It is postulated that the rate at which fresh water can penetrate into the sludge bank determines whether the mobilization resistance of a sludge is significantly affected by a sludge/slurry ionic strength gradient. When the permeation rate is very small, the rate of ECR growth due to the ionic strength effect is correspondingly small and probably not of practical interest for DST sludge mobilization. Alternatively, a high permeation rate would be expected to result in a correspondingly high ECR growth rate.

The rate of fresh water permeation into the sludge is a function of the driving force for the permeation and the ability of the sludge to resist permeation. The permeation driving force is the salt concentration gradient between the low salt concentration eroding fluid and the high salt concentration sludge interstitial fluid. The resistance to the water permeation is quantified by the hydraulic conductivity of the sludge. Cohesion between sludge particles also serves to resist the swelling that the permeating water creates, but the relative importance of cohesion is not known.

Test $17-\mathrm{KN}$ used a large difference in salt concentration between the eroding fluid (initially saltfree) and the interstitial fluid of the sludge ( $20 \mathrm{wt} \%$ sodium chloride). Because $20 \mathrm{wt} \%$ is near saturation for sodium chloride, it is unlikely that ionic strength differences greater than this will be encountered during DST waste retrieval. Thus, the salt concentration gradient driving forces encountered during DST retrieval operations will be on the same order or less than those encountered during test $17-\mathrm{KN}$.

Since the permeation driving force is about the same for DST sludge and the test 17-KN $\mathrm{kaolin} / \mathrm{NaCl}_{(\mathrm{aq})}$ simulant, whether the salt-induced swelling effect is likely to be significant for DST sludge depends on whether the permeability of tank sludge is greater than that of the kaolin simulants tested.

The water permeability of kaolin clay at approximately $63 \mathrm{wt} \%$ clay is given by Lambe and Whitman (1969) as $1.5 \times 10^{-6} \mathrm{~cm} / \mathrm{s}$. Few, if any, permeability measurements have been made on tank sludge. A recent WHC study involved measuring the permeability of chemically simulated wastes. (a) A water conductivity for the simulant of $4 \times 10^{-7} \mathrm{~cm} / \mathrm{s}$ was reported (Jeppson and Wong 1993). The permeability of the sludge simulant used in the WHC study was found to be lower than that given above for kaolin clay. (b) This implies that, for a given water permeation driving force, the rate of water permeation into tank sludge will be even slower than that of water into a $\mathrm{kaolin} / \mathrm{NaCl}(\mathrm{aq})$ simulant.

(a) The waste simulant was prepared based on the In Farm scavenging process. In Farm processing waste is stored in several of the C-farm storage tanks at the.Hanford Site. See Jeppson and Wong (1993) for a detailed description of the simulant and of the In Farm scavenging process.

(b) If the DST sludge permeability is lower than that of kaolin, then there is reason to believe that the specific surface area of DST sludge is higher than that of kaolin. This suggests that the DST sludge is more cohesive than kaolin. The permeability of saturated soils can be estimated using the Kozeny-Carman equation in which permeability varies proportionally to the inversesquare of the soil's specific surface area (Lambe and Whitman 1969). If the permeability of DST sludge is lower than that of kaolin, then the Kozeny-Carman equation implies that DST sludge has a specific surface area larger than that of kaolin. This is not certain, however, because differences in particle shape and fluid properties can affect permeability as well. 
If the DST sludge permeability is less than that of kaolin clay, then the expected ionic strength difference between the sludge and the tank supernate is not expected to result in a larger ECR than that obtained in the absence of salt effects. If portions of the sludge solids dissolve during mobilization, however, an enhanced ECR may result as demonstrated by the 1993 1/25-scale testing described above.

It should be noted that if the ECR is growing principally due to water permeation or sludge dissolution effects, then the rate of ECR growth will be approximately the same in an absolute sense regardless of scale. Since the dissolution and permeation occur at the same, rather than scaled, rates, a $0.5 \mathrm{~cm} / \mathrm{h}$ ECR growth rate at $1 / 25$-scale that is due to these effects will probably directly correspond to a $0.5 \mathrm{~cm} / \mathrm{h}$ ECR growth rate at full scale. While $0.5 \mathrm{~cm} / \mathrm{h}$ is a significant growth rate at $1 / 25$-scale, at full scale it is of reduced interest. To illustrate this point, if it is assumed that ECR growth is controlled by water permeation and a $1 / 25$-scale test requires 24 hours for the ECR growth to stop, then it is expected that about 25 days of mixer-pump operation would be required to reach the final ECR. Whether such a slow ECR growth rate is acceptable depends on the amount of time available for mixer-pump operation during sludge mobilization.

\subsection{Nozzle Design Effects}

Some of the effects of mixer-pump nozzle design on sludge mobilization are discussed in this section. Tests were done to examine the impacts of changes in certain nozzle design features.

\subsubsection{Nozzle Length-to-Diameter Ratio}

It has been shown that free jets produced by straight nozzles of different length-to-diameter ratios (L/D) can entrain the surrounding fluid at different rates (Trabold et al. 1987; Obot et al. 1984, 1986). Free jets produced by nozzles with relatively large $L / D$ ratios $(L / D>5)$ exhibit slower decay rates in mean centerline velocity than free jets produced by nozzles with relatively small $L / D$ ratios $(\mathrm{L} / \mathrm{D}=1)$. With this in mind, three different nozzzles were designed for $1 / 25$-scale testing. The L/D ratios of these nozzles were $0.53,1.7$, and 5. A schematic of each nozzle is shown in Figures 4.26, 4.27, and 4.28. In addition, the shape of the nozzle entrance region has been shown to influence the jet velocity profiles (Obot et al. 1979). Smooth entrances result in a slower rate of maximum centerline velocity decay than do sharp-edged entrances. The entrance to the short nozzle $(L / D=0.53)$ was designed with a sharp-edged entrance, and the other two nozzles were designed with a $20^{\circ}$ sloped entrance. These nozzles were employed in two $1 / 25$-scale tests (19-K and 20-B) to investigate the effect nozzle design has on ECR growth.

Test 19-K, utilizing a kaolin/water simulant, was started with the short nozzle $(L / D=0.53)$ first and run until no further growth in ECR was observed. This resulted in an ECR of about $22.3 \pm 2.5 \mathrm{~cm}$. The test was stopped and the short nozzles were replaced with the nominal nozzles $(L / D=1.7)$. The flow was re-established at the same flow rate used for the $L / D=0.53$ nozzle and the ECR monitored for 300 minutes. The $L / D=1.7$ nozzles did not offer any significant improvement in ECR over the $L / D=0.53$ nozzles. Finally, the long nozzles $(L / D=5)$ were installed to see if this nozzle design would offer any improvement in ECR over the other two nozzle designs. Following installation of the $\mathrm{L} / \mathrm{D}=5$ nozzles, the ECR was monitored for more than 19 hours. No further ECR 


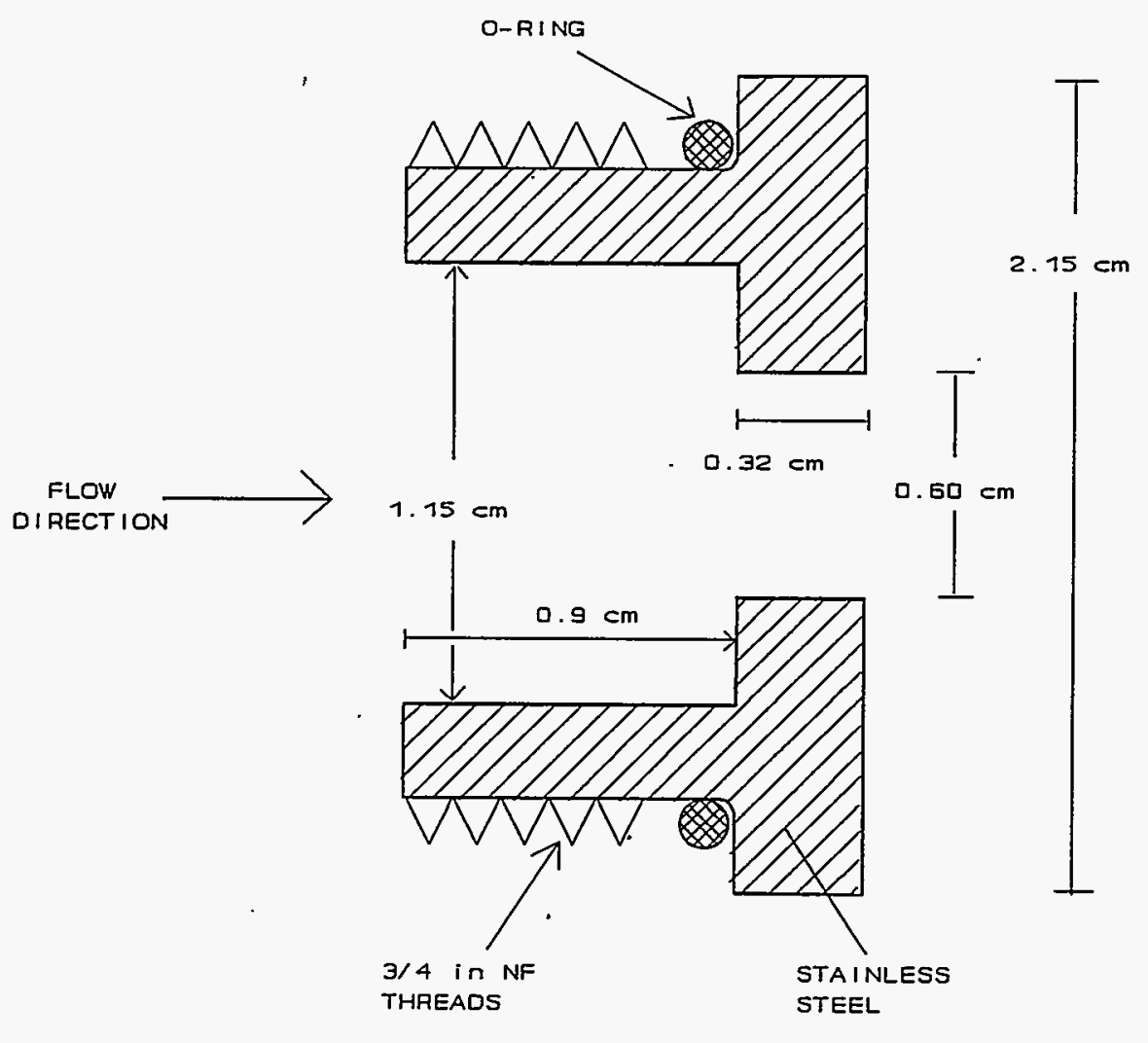

Figure 4.26. $L / D=0.53$ Nozzle Design 


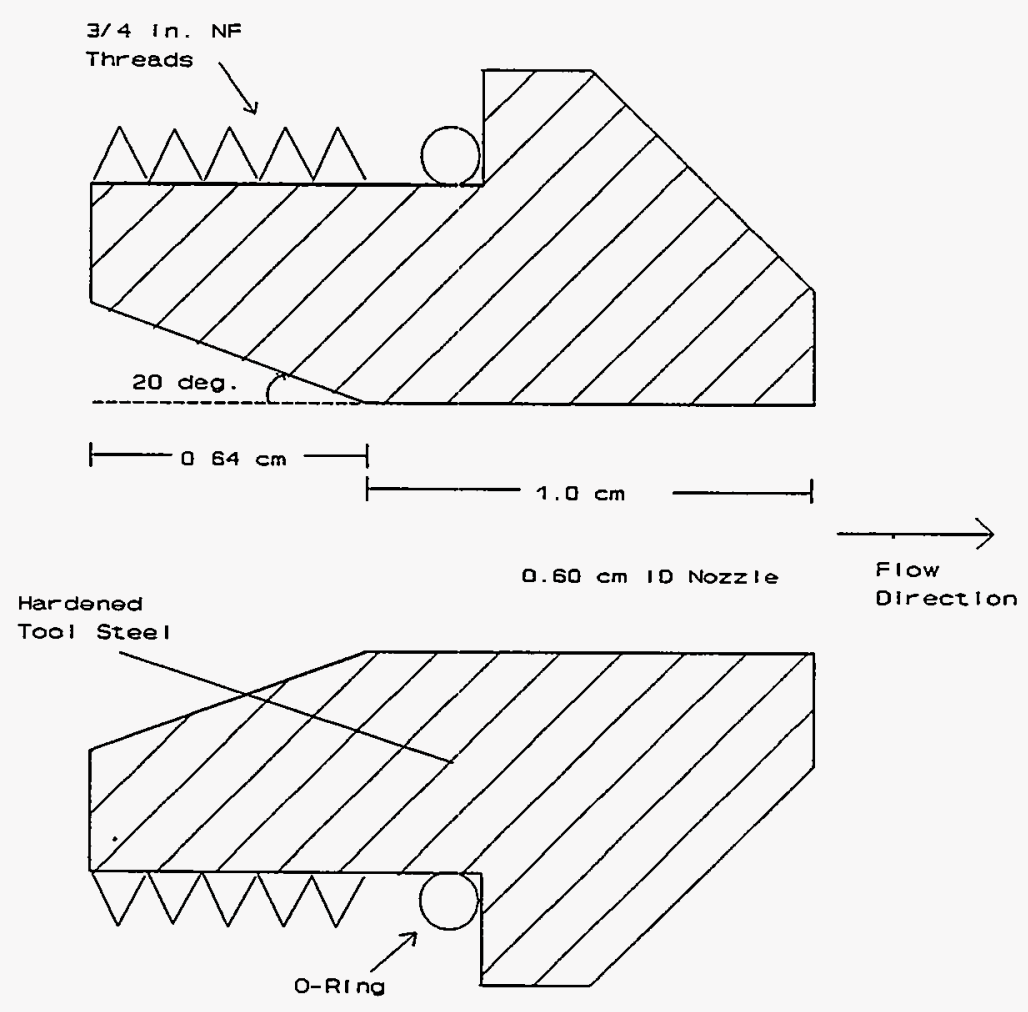

Figure 4.27. $L / D=1.7$ Nozzle Design 


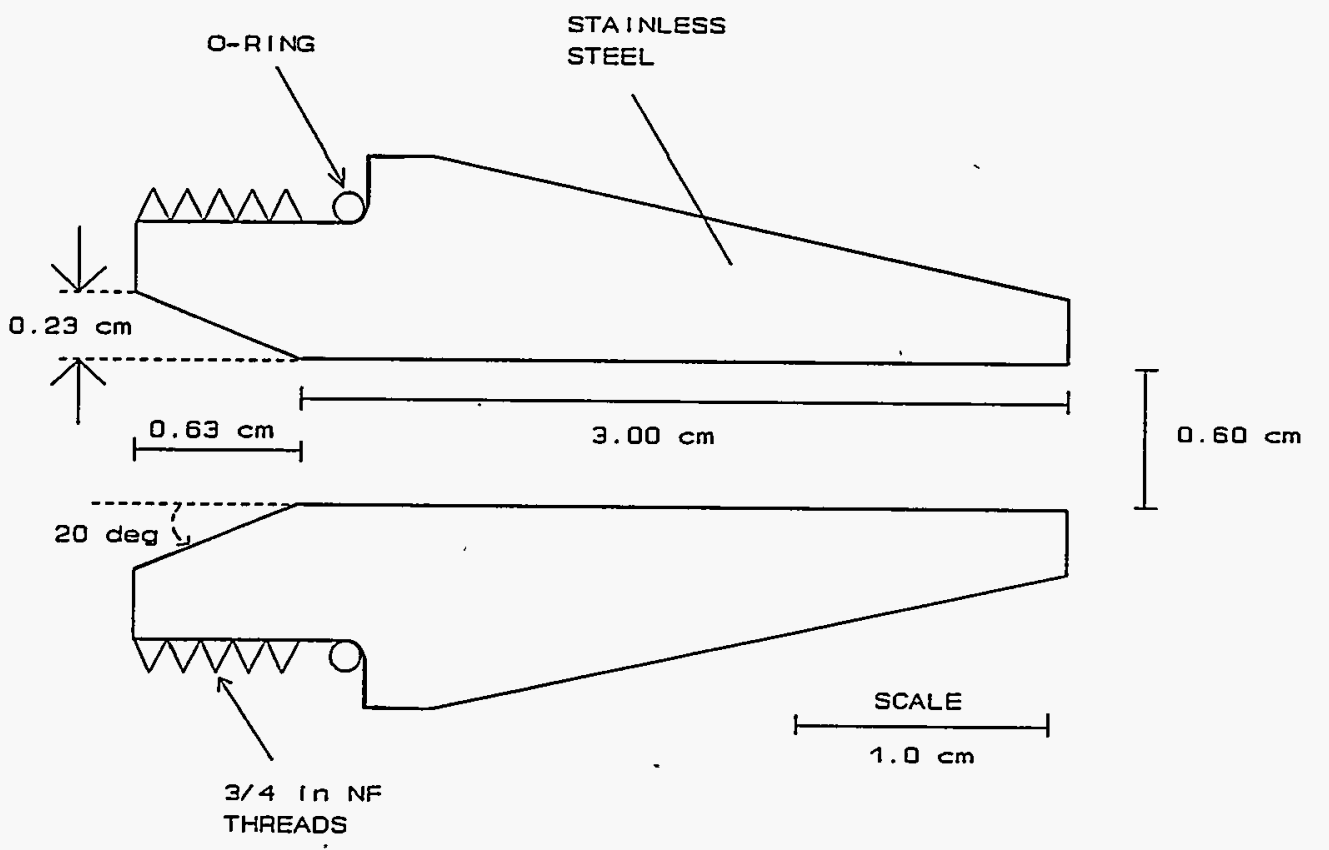

Figure 4.28. $\mathrm{L} / \mathrm{D}=5$ Nozzle Design 
growth was observed. The results from this test indicate that the short nozzles are just as effective at mobilizing the sludge as are the longer nozzles with a tapered entrance region.

Test 20-B, using a bentonite/water simulant, was run to support the findings of test 19-K. The test was run with the $\mathrm{L} / \mathrm{D}=0.53$ nozzles installed first. Because the bentonite-based simulants tend to continue mobilizing at a constant rate after an initial rapid mobilization period (See Section 4.1.1.2), the criteria for changing the nozzles was set to the time when this rate of constant growth was reached. At an ECR of $20.9 \pm 1.1 \mathrm{~cm}$, the $\mathrm{L} / \mathrm{D}=0.53$ nozzles were replaced with the $L / D=1.7$ nozzles and the test continued. No significant change in ECR growth rate was observed. This implies that the $\mathrm{L} / \mathrm{D}=1.7$ nozzle is no more effective than the $\mathrm{L} / \mathrm{D}=0.53$ nozzle. Since no appreciable difference was seen in test $19-\mathrm{K}$ between the nozzles with L/D's of 1.7 and 5 , only the nominal nozzles were used in this test.

The results from the above two tests suggest that nozzle L/D ratios have little effect on the final ECR achieved in each case. It was anticipated that the nozzle with the larger L/D would maintain a larger centerline velocity for a given distance from the nozzle exit resulting in a larger ECR. This was not seen in these two tests. At first inspection, this seems to contradict the results published in the cited literature (Trabold et al. 1987; Obot et al. 1986, 1984). The literature data cited represent the jet velocity up to approximately 24-nozzle-diameter lengths from the nozzle exit. In this region $(x / D<24)$, the difference between the rate of maximum centerline velocity decay for a jet discharging from a nozzle with a $L / D$ of 1 and a jet discharging from a nozzle with a $L / D$ of 12 can differ by as much as $20 \%$ (Figure 4.29). In addition, it should be noted that forcing liquid through a 90-degree bend just before the nozzle exit, as was done in the 1/25-scale mixer pump, can increase the rate of decay of maximum centerline velocity as shown in Figure 4.30 (Sudo et al. 1987).

There was some concern over the apparent contradiction between the $1 / 25$-scale test results and the literature. A series of three additional $1 / 25$-scale tests were conducted to further examine the effects of nozzle design and nozzle diameter on the ECR. These tests are described in detail in Appendix C. Through these tests it was determined that the sharp bend in the flow pattern immediately preceding the nozzle entrance of the $1 / 25$-scale mixer pump was inducing substantial swirl and other undesirable flow patterns in the jet fluid. These flow pattern disturbances were severe enough that the water-in-air jet breakup patterns $^{\left({ }^{(a)}\right.}$ for the nozzles shown in Figure 4.26 through 4.28 were nearly identical. In all three cases, the jets were observed to rapidly spread apart into a coarse mist upon exiting the nozzles. The L/D ratio did not appear to have a significant effect on the water-in-air jets. While the decay mechanisms of water-in-air and submerbed jets are very different, it is reasonable to conclude from the water-in-air jet tests that the effects of changing the L/D ratios for the ECR tests may have been masked by the relatively poor velocity distibution of the fluid entering the nozzles.

Nozzles should be designed to limit the amount of swirl introduced to the fluid jet. A fluid jet is said to possess some degree of swirl if there exists some bulk motion of the fluid in the angular direction. The effect of swirl is to spread the jet more rapidly causing the jet centerline velocity to decay much faster. It has been shown (Pani and Rajaramam 1975) that the centerline velocity of a

(a) Several scoping tests were done in which the $1 / 25$-scale mixer-pump assembly was suspended in the air. Water was supplied to the mixer pump so that jets issued from the nozzles into the surrounding air. The coherence of these water-in-air jets was used to judge the effectiveness of various techniques for improving the jet flows. See Appendix $\mathrm{C}$ for further details. 


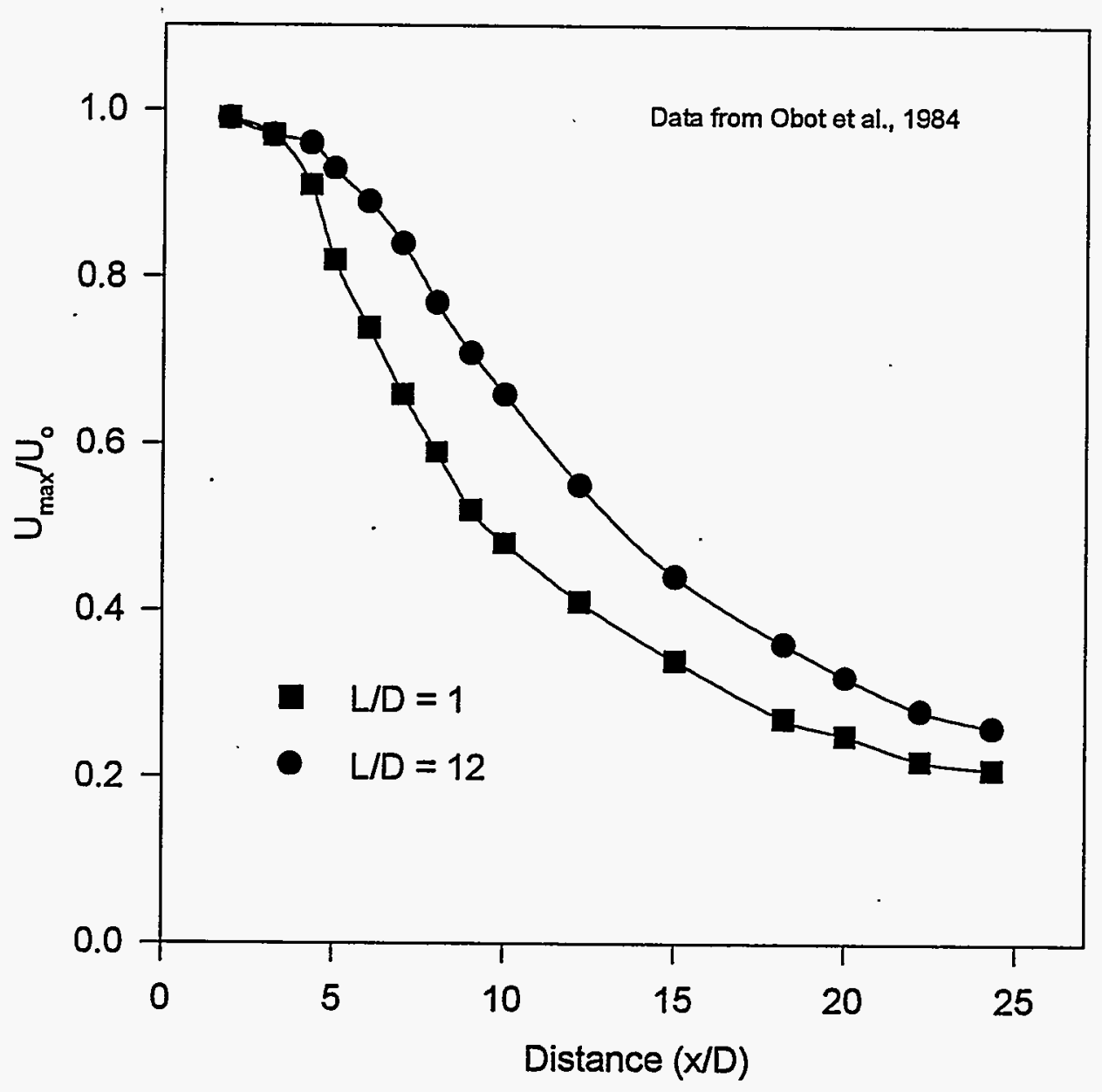

Figure 4.29. Effect of Nozzle L/D Ratio (from Obot et al. 1984) 


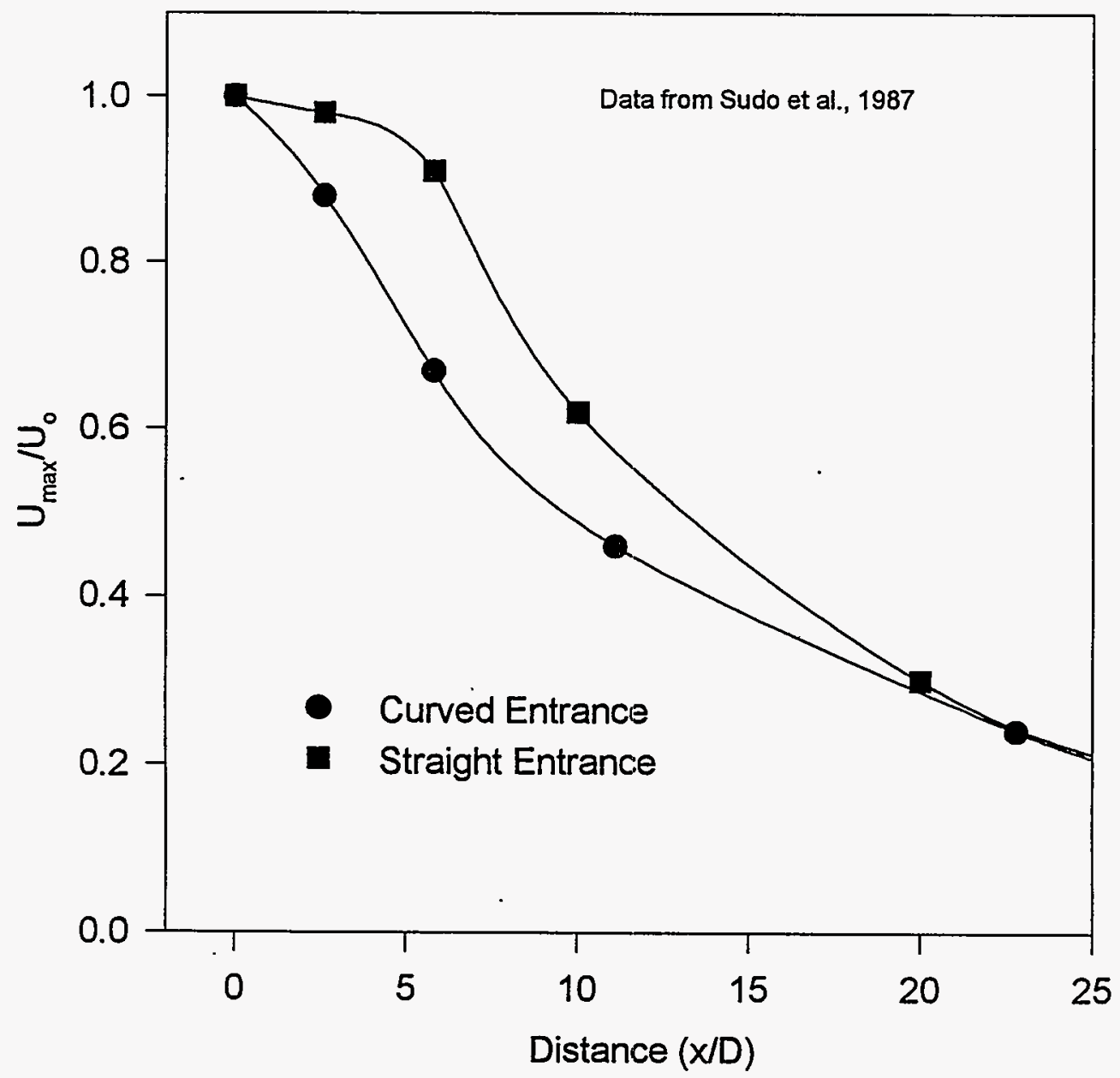

Figure 4.30. Nozzle Entrance Effects (from Sudo et al. 1987) 
non-swirling jet can be nearly $50 \%$ larger than that of a swirling jet at a dimensionless downstream distance $(\mathrm{x} / \mathrm{D})$ of 50 .

Efforts were made to improve the jet flows of the $1 / 25$-scale mixer pump. It was found that the water-in-air jet flows were substantially improved by installing a flow divider within the discharge tube body and extending the nozzles radially outward using a tube that contained flow-straightening vanes. These modifications are described in Appendix C. A comparison of the ECRs obtained using the nominal nozzle size of $0.6 \mathrm{~cm}$ in diameter, both with and without the improved jet flows, revealed that the improved jets resulted in ECRs about 10 to $20 \%$ larger than the ECRs produced by the $0.6-\mathrm{cm}$ nozzles without the flow improvements. Since most of the work presented in this report (except tests $24-\mathrm{K}$ through $26-\mathrm{KB}$ ) exclusively used the $0.6-\mathrm{cm}$ nozzles without the flow straighteners, it is likely that about a $10 \%$ to $20 \%$ increase in the measured ECRs would be expected if improved jet flows were used. This does not significantly impact any of the major conclusions of this report. It is worth noting at this point that a much larger difference in ECRs was observed for the 0.9 -cm-diameter jets. This is addressed in Section 4.2.2.

\subsubsection{Nozzle Diameter Effects}

The literature indicates that the behavior of a turbulent Newtonian fluid jet is determined from the nozzle diameter (D) and the jet exit velocity $\left(U_{0}\right)$ (Rajaratnam 1976). That is, for a constant value of $U_{0} D$, the same jet behavior can be obtained for different combinations of $U_{0}$ and $D$. This phenomenon allows for flexibility in choosing jet exit velocity and nozzle diameter provided the product, $U_{0} D$, is large enough to provide the desired axial jet velocities. Three tests were designed to explore this $U_{0} D$ relationship using two nozzles of different diameters. Nozzle entrance geometry and length-to-diameter ratio were kept constant between the two nozzles. Tests $24-\mathrm{K}, 25-\mathrm{KB}$, and $26-\mathrm{KB}$ used these two nozzle designs to investigate the relationship between $U_{0} D$ and ECR. The small diameter nozzle has already been shown in Figure 4.27. A schematic of the large diameter nozzle is given in Figure 4.31.

Test 24-K, utilizing a kaolin/water simulant, was initiated with the 0.894-cm-diameter nozzles at a flow rate of $41.9 \mathrm{~L} / \mathrm{min}$. This resulted in a $U_{o} D$ of $498 \pm 7 \mathrm{~cm}^{2} / \mathrm{s}$ for each nozzle. This nozzle and $\mathrm{U}_{\mathrm{o}} \mathrm{D}$ achieved an ECR of $12.3 \pm 2.0 \mathrm{~cm}$, then the test remained stable for more than 5 hours. Before changing to the $0.597-\mathrm{cm}$-diameter nozzles, a surfactant ${ }^{(a)}$ was added to the tank slurry in the amount of $16.6 \mathrm{grams} / \mathrm{liter}$ of slurry. The flow rate was maintained at $42.4 \mathrm{~L} / \mathrm{min}$ for this portion of the test. It was postulated that the surfactant would enhance sludge mobilization by wetting the clay particles at the sludge/slurry interface thereby weakening the forces that resist mobilization (see Section 4.3.3). ECR growth was monitored for approximately another 21 hours before the ECR stabilized at $16.25 \pm 2.5 \mathrm{~cm}$. These data suggest that the wetting action of the surfactant provided about a $30 \%$ increase in ECR.

The $0.894-\mathrm{cm}$-diameter nozzles were replaced by the $0.597-\mathrm{cm}$-diameter nozzles after test $24-\mathrm{K}$ had stabilized from the addition of the surfactant. The flow rate was reduced to $28.0 \mathrm{~L} / \mathrm{min}$, which resulted in the same $U_{0} D$ of $498 \pm 7 \mathrm{~cm}^{2} / \mathrm{s}$. The ECR growth was monitored for another 25 hours before it stabilized at $23.2 \pm 4.6 \mathrm{~cm}$. The $0.597-\mathrm{cm}$-diameter nozzles achieved an ECR at least $40 \%$ larger than that of the $0.894-\mathrm{cm}$-diameter nozzles for the same $U_{0} D$. This result is in apparent contradiction with the assumption that the ECR is directly proportional to $U_{0} D$.

(a) The surfactant used was a commercially available clay dispersant. See Section 4.3 .3 for further discussion of the effects of the dispersant. 

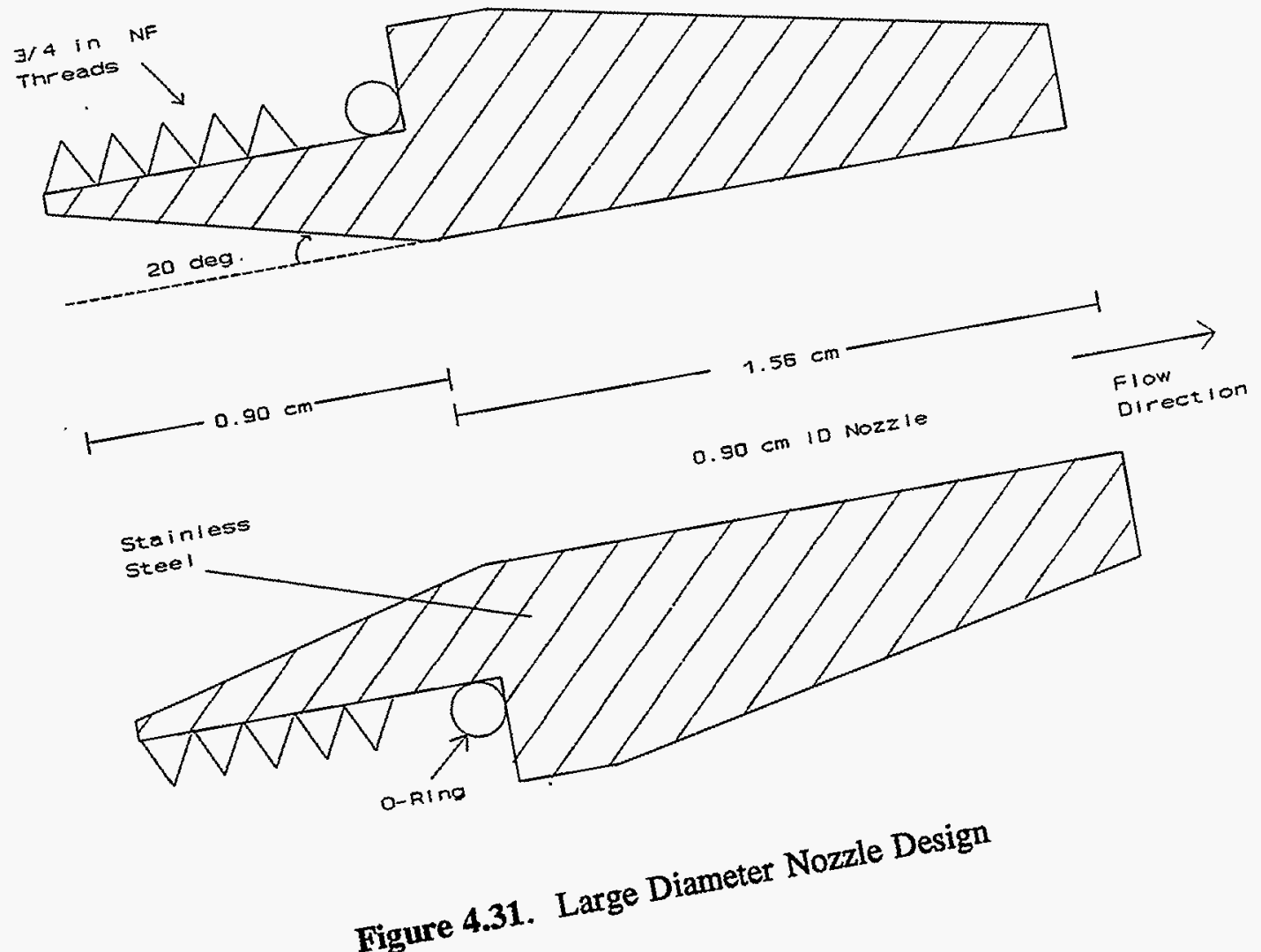
Test 25-KB, using a kaolin/bentonite simulant, was performed to further examine whether ECR is directly proportional to the quantity $U_{0} D$. The $0.894-\mathrm{cm}$-diameter nozzles were installed first, and the flow rate was established at $41.9 \mathrm{~L} / \mathrm{min}\left(\mathrm{U}_{\mathrm{o}} \mathrm{D}=498 \pm 7 \mathrm{~cm}^{2} / \mathrm{s}\right)$. The ECR growth was monitored for 24 hours before it stabilized at $2.5 \pm 1.8 \mathrm{~cm}$. It was noted that the sludge bank angle was low at 20 to 30 degrees. For a sludge bank angle of 30 degrees, the top of the sludge bank would have been around $16 \mathrm{~cm}$ from the nozzle exit. In addition, the slurry density predicted an ECR of $12.8 \mathrm{~cm}$ at this time. The ECR measured by looking at the bottom of the tank clearly underestimated the true extent of mobilization.

The 0.597-cm-diameter nozzles were installed after the ECR growth had stabilized with the 0.894-cm-diameter nozzles. The flow rate was adjusted to $28.0 \mathrm{~L} / \mathrm{min}\left(\mathrm{U}_{\mathrm{o}} \mathrm{D}=498 \pm 7 \mathrm{~cm}^{2} / \mathrm{s}\right)$. The ECR was monitored for 22 hours before it stabilized at $15.8 \pm 3.6 \mathrm{~cm}$. It was noted that $75 \%$ of the sludge bank was now at an angle of 80 to 90 degrees. The remaining $25 \%$ of sludge bank was at approximately 45 degrees. In addition, the slurry density did not change during this portion of the test. Therefore, the ECR calculated from slurry density remained at $12.8 \mathrm{~cm}$. It appears the $0.597-\mathrm{cm}-$ diameter nozzles were effective at re-establishing a more vertical sludge bank.

The 0.894-cm-diameter nozzles were then reinstalled. The flow rate was increased until ECR growth was observed $(59.9 \mathrm{~L} / \mathrm{min})$. This resulted in a $U_{0} D$ of $711 \pm 21 \mathrm{~cm}^{2} / \mathrm{s}$. ECR growth was monitored for 26 hours, and it stabilized at $27.1 \pm 4.6 \mathrm{~cm}$. In order to compare this ECR with the previous ECR from the $0.597-\mathrm{cm}$-diameter nozzle, the ECRs were divided by their respective $U_{0} D$ 's. For the 0.894 - and the $0.597-\mathrm{cm}$-diameter nozzles, the ECR $/ \mathrm{U}_{\mathrm{o}} \mathrm{D}$ quantities were $0.038 \pm 0.007 \mathrm{~s} / \mathrm{cm}$ and $0.032 \pm 0.007 \mathrm{~s} / \mathrm{cm}$, respectively. When the $95 \%$ confidence intervals are considered, it is clear that the difference between these two values is not statistically significant. The initial ECR of $2.5 \pm 1.8 \mathrm{~cm}$ was not included in this comparison due to the uncertainty in its validity.

Test 26-KB, using a kaolin/bentonite simulant, was designed to confirm the findings of test $25-\mathrm{KB}$. In this test, the $0.597-\mathrm{cm}$-diameter nozzles were installed first, and the flow rate was established at $18.6 \mathrm{~L} / \mathrm{min}\left(\mathrm{U}_{\mathrm{o}} \mathrm{D}=330 \pm 7 \mathrm{~cm}^{2} / \mathrm{s}\right)$. The ECR growth was monitored for 21 hours before it stabilized $21.2 \pm 2.1 \mathrm{~cm}$. Before replacing the $0.597-\mathrm{cm}$-diameter nozzles with the $0.894 \mathrm{~cm}$ diameter nozzles, it was noted that the sludge bank was fairly vertical (60 to 90 degrees). With the 0.894-cm-diameter nozzles installed, the test continued with a flow rate of $37.4 \mathrm{~L} / \mathrm{min}\left(\mathrm{U}_{\mathrm{o}} \mathrm{D}=445 \pm\right.$ $14 \mathrm{~cm}^{2} / \mathrm{s}$ ). The ECR growth was monitored for another 27 hours and it stabilized at $25.6 \pm 2.7 \mathrm{~cm}$. To collect one more point for comparison, the $0.597-\mathrm{cm}$-diameter nozzles were re-installed, and the flow rate was established at $24.6 \mathrm{~L} / \mathrm{min}\left(\mathrm{U}_{\mathrm{o}} \mathrm{D}=438 \pm 14 \mathrm{~cm}^{2} / \mathrm{s}\right)$. For the next 20 hours, the ECR growth was monitored. The ECR stabilized at $29.3 \pm 2.8 \mathrm{~cm}$. The ECRs from both nozzles were divided by the corresponding $U_{0} D$ 's for comparison. For the $0.597-\mathrm{cm}$-diameter nozzles at 18.6 $\mathrm{L} / \mathrm{min}$, the $0.894-\mathrm{cm}$-diameter nozzles at $37.4 \mathrm{~L} / \mathrm{min}$, and the $0.597-\mathrm{cm}$-diameter nozzles at 24.6 $\mathrm{L} / \mathrm{min}$, the ECR/U $\mathrm{D}$ quantities were $0.064 \pm 0.006,0.058 \pm 0.006$, and $0.067 \pm 0.006$, respectively. The difference between these $\mathrm{ECR} / \mathrm{U}_{0} \mathrm{D}$ values is not statistically significant because the $95 \%$ confidence intervals overlap.

The results from tests $25-\mathrm{KB}$ and $26-\mathrm{KB}$ support the theory that jet behavior is dependent on the quantity $\mathrm{U}_{0} \mathrm{D}$, while the results from test $24-\mathrm{K}$ do not. Tests $24-\mathrm{K}$ and $25-\mathrm{KB}$ were started using the 0.894-cm-diameter nozzles, and a gradual sloping sludge bank (20-30 degrees) was observed. A gradual sloping sludge bank was not seen in test $26-\mathrm{KB}$, which employed the $0.597-\mathrm{cm}$-diameter nozzles first. 
The results of test $24-\mathrm{K}$ implied that ECR might not be proportional to $\mathrm{U}_{0} \mathrm{D}$. This result was disturbing because a $U_{0} D$ criterion is being used to specify full-scale mixer-pump performance for procurement purposes. If, for a given $U_{0} D$, there was reason to go with a smaller nozzle diameter for improved mobilization performance, then that had to be known and incorporated into the full-scale pump specifications. To further investigate the relationship between $U_{0} D$ and ECR at different nozzle diameters, three additional $1 / 25$-scale tests were performed. These tests are described in Appendix C and are not included in the data analyses presented elsewhere in this report (except for Section 4.2.1). Through these additional tests, it was demonstrated that the larger nozzle size $(0.9 \mathrm{~cm})$ produced an ECR at least as large as that produced by smaller nozzles at the same $U_{0} D$. Thus, confidence in the linear proportionality between ECR and $\mathrm{U}_{0} \mathrm{D}$ was re-established.

The reduced performance of the $0.9-\mathrm{cm}$ nozzles relative to the $0.6-\mathrm{cm}$ nozzles as noted in tests 24-K through $26-\mathrm{KB}$ must have been due to effects other than solely the difference in nozzle diameters. The most likely explanation is that the jets produced by the larger nozzle were more susceptible to the disruptive flow patterns and swirl induced by the $1 / 25$-scale mixer-pump nozzle assembly. A larger diameter nozzle will allow proportionally larger eddies and other macroscopic fluid motions to pass through its exit. It is hypothesized that the $0.6-\mathrm{cm}$ nozzles were small enough that some of the flow disturbances were effectively damped out within the nozzle. This is further evidenced by the observation that the $0.6-\mathrm{cm}$ nozzles with flow straighteners and without flow straighteners gave nearly identical ECRs, while a very large difference in ECRs resulted when the 0.9-cm nozzles were used with and without flow straighteners. The $0.9-\mathrm{cm}$ nozzles with flow straighteners gave ECR/ $U_{0} D$ values comparable to those of the $0.6-\mathrm{cm}$ nozzles both with and without flow straighteners (see Appendix C).

\subsubsection{Nozzle Inclination Angle Effects}

Test 3-K, using a kaolin/water simulant, was designed to explore the effect on sludge mobilization of nozzle-inclination angle with respect to the tank floor. The nominal nozzles with a diameter of $0.597 \mathrm{~cm}$ and an $\mathrm{L} / \mathrm{D}$ ratio of 1.7 were installed for test 3-K. The flow rate was established at $28.0 \mathrm{~L} / \mathrm{min}\left(\mathrm{U}_{\mathrm{o}} \mathrm{D}=498 \pm 7 \mathrm{~cm}^{2} / \mathrm{s}\right)$. Before changing the angle of the nozzles, test $3-\mathrm{K}$ was allowed to reach a stable ECR with the nozzles in the horizontal position. After monitoring the ECR growth for 14.6 hours, the ECR stabilized at $26.4 \pm 1.6 \mathrm{~cm}$. For the next 8.6 hours the ECR growth was monitored, and no significant growth was observed. After 23.2 hours of operation, the west pump support was raised up with a $1-\mathrm{cm}$ shim. This generated an angle of approximately 0.65 degrees between the nozzle centerline and the tank floor. The eastward nozzle was aimed downward at the tank floor, while the westward nozzle was aimed above the tank floor. The ECR was monitored for another 3.8 hours before the test was ended. A 0.65 -degree change in nozzle inclination appeared to have no influence on the final ECR.

At an angle of 0.65 degrees, the centerline of the jet was only moved approximately $0.3 \mathrm{~cm}$ from horizontal at an ECR of $26.4 \pm 1.6 \mathrm{~cm}$. It is speculated that larger angles of incline are necessary if measurable differences in ECR are to be seen. Angles of 3 to 5 degrees would direct the jet centerline to the sludge/tank bottom interface at ECRs between 22 and $36 \mathrm{~cm}(1 / 25$-scale). Angles of incline greater than 5 degrees may hinder mobilization by directing the jet into the tank floor before the desired ECR is achieved. The current apparatus did not allow for angles greater than 0.65 degrees to be investigated. Modification to the apparatus will need to be made if future studies are to be performed with larger angles of incline. 


\subsection{Slurry Effects on Mobilization}

Several 1/25-scale tests were conducted with the goal of investigating the effects of changes in the characteristics of the eroding fluid on sludge mobilization. Changes in slurry rheology and density were studied to determine the importance of these properties to ECR correlation development. A test was also conducted to examine whether surfactants might aid the mobilization of tank sludge. Understanding the relevance of slurry properties to sludge mobilization is an essential part of designing appropriate waste simulants for use in ECR correlation development. A significant effect of slurry rheology on ECR growth, for example, might mean that the simulants used for testing must match the expected DST slurry rheology. Alternatively, if rheological properties are not very important, then simulant selection is made easier because fewer waste properties must be matched.

The testing of various slurry properties as described later in this section resulted in the following conclusions that are relevant to future ECR correlation development work using simulants. Test $21-\mathrm{K}$ demonstrated conclusively that slurry rheology can have very important effects on mobilization. NonNewtonian slurry rheology can result in an increase in the apparent mobilization resistance of the sludge. Changing the rheology of the test $21-\mathrm{K}$ slurry from near Newtonian to an approximate Bingham-plastic resulted in roughly a $30 \%$ decrease in the ECR/U $\mathrm{O}_{0} \mathrm{D}$ for the sludge tested.

Changes in slurry density are expected to affect the ECR. Test 22-K was conducted to examine the magnitude of the density effect. The magnitude of the observed increase in ECR with increasing density was on the order of that expected based on the current understanding of the relationship between slurry density and ECR. However, the uncertainty in the ECR measurement was large compared to this change, so it cannot be claimed that test $22-\mathrm{K}$ validates the current understanding.

A commercially available dispersant used in the oil drilling industry (CON-DET ${ }^{\circ}$, NL Baroid) was added to the tank slurry after ECR growth had stopped in test 24-K. A small but significant increase in ECR was observed following addition of the dispersant. This implies that the mobilization of some DST sludges could be enhanced through the addition of additives. Whether this is practical, however, will depend on not only the effectiveness of the dispersant, but on whether the dispersant addition is compatible with the waste and with downstream treatment of the waste.

\subsubsection{Slurry Rheology Effects}

The functional dependence of the ECR on slurry density and viscosity is not known. For the purposes of simulant development, the approach has been to use simulants that have densities and viscosities similar to those of the expected DST slurries. To allow the extrapolation of sludge mobilization data from one set of slurry properties to others, an understanding of the dependence of ECR on viscosity and density is required.

As a first approximation, the relationship between the ECR and the slurry density and viscosity can be estimated by calculating the effects of density and viscosity on the drag force at the sludge/slurry interface. Assuming a 1/7-power turbulent boundary layer velocity distribution, Bird et al. (1960) give the drag force for a turbulent fluid flowing parallel to a planar solid as:

$$
\mathrm{F}_{\mathrm{d}}=0.037 \rho_{\text {slurry }} \mathrm{U}^{2} \mathrm{WL}\left(\frac{\mathrm{LU} \rho_{\text {slurry }}}{\mu}\right)^{-0.2}
$$


where

$$
\begin{aligned}
F_{d} & =\text { drag force on a flat plate, dyne } \\
\rho_{\text {slurry }} & =\text { density of the fluid, } \mathrm{g} / \mathrm{cm}^{3} \\
\mu & =\text { viscosity of the fluid, } \mathrm{g} / \mathrm{cm}^{3} \\
L & =\text { length of the plate, } \mathrm{cm} \\
W & =\text { width of the plate, } \mathrm{cm} \\
U & =\text { bulk fluid velocity, } \mathrm{cm} / \mathrm{s}
\end{aligned}
$$

This equation represents a simplification of the sludge mobilization problem because the fluid jet approach is not parallel to the sludge, and the sludge bank is not long and flat. Assuming that the drag force imposed on the sludge at the final ECR is equal to the resistive force of the sludge (which will be assumed proportional to tensile strength, $S_{t}$, for this exercise) and that the mixer pump jet velocity decays similarly to a free jet, the following equation results:

$$
\mathrm{ECR}=\mathrm{K} \mathrm{U} \mathrm{o}\left(\rho_{\text {slurry }} 4 \mu\right)^{1 / 9} \mathrm{~S}_{\mathrm{t}}^{-5 / 9}
$$

Based on this equation it is predicted that the ECR will vary with slurry density to the 4/9-power and slurry viscosity to the $1 / 9$-power.

Test 21-K was conducted with the goal of determining whether the expected relationship between ECR and slurry viscosity could be observed. Based on the assumed 1/9-power dependence, it was calculated that the slurry viscosity would need to be increased to about $20 \mathrm{cp}$ so that a significant increase in ECR would be observed. Unfortunately, it is very difficult to obtain a 20-cp slurry viscosity without adding salts or resorting to a non-Newtonian viscosifier. The addition of salt was avoided because the salt could potentially affect the mobilization resistance of the sludge simulant. It was decided that a xanthan gum solution would be used to increase the slurry viscosity. Xanthan gum is not surface-active (so it does not affect mobilization resistance through colloidal effects), it is nonhazardous, and relatively small quantities are capable of producing high viscosity fluids. Unfortunately, these fluids are non-Newtonian. The 1/9-power dependence on viscosity assumes that a Newtonian slurry is used, so the use of a non-Newtonian slurry complicates the interpretation of the test results.

A relatively weak kaolin/water sludge simulant was used for test 21-K. Initially, the tank supernate was water. The mixer pump was run until ECR growth stopped. The ECR/U $D$ at this point was $0.059 \pm 0.007 \mathrm{~s} / \mathrm{cm}$, and the slurry in the tank was near-Newtonian with a viscosity of about $2 \mathrm{cp}$.

A xanthan gum solution containing $400 \mathrm{~g}$ of xanthan gum was then added to the tank. The mixerpump flow rate was maintained at the same level as was used before xanthan gum addition. No ECR growth was observed at this flow over a period of 250 minutes, so the flow rate was increased gradually until some ECR growth was observed. ECR growth was allowed to continue at this elevated flow for another 1000 minutes to ensure that complete ECR growth was observed. The final ECR with the xanthan gum in the tank resulted in a ECR/ $U_{0} \mathrm{D}$ value of $0.042 \pm 0.004 \mathrm{~s} / \mathrm{cm}$. The slurry at the end of the test was yield-pseudoplastic with an apparent yield stress of approximately $1.2 \mathrm{~Pa}$. Rheograms for the test $21-\mathrm{K}$ slurries are shown in Figure 4.32. 


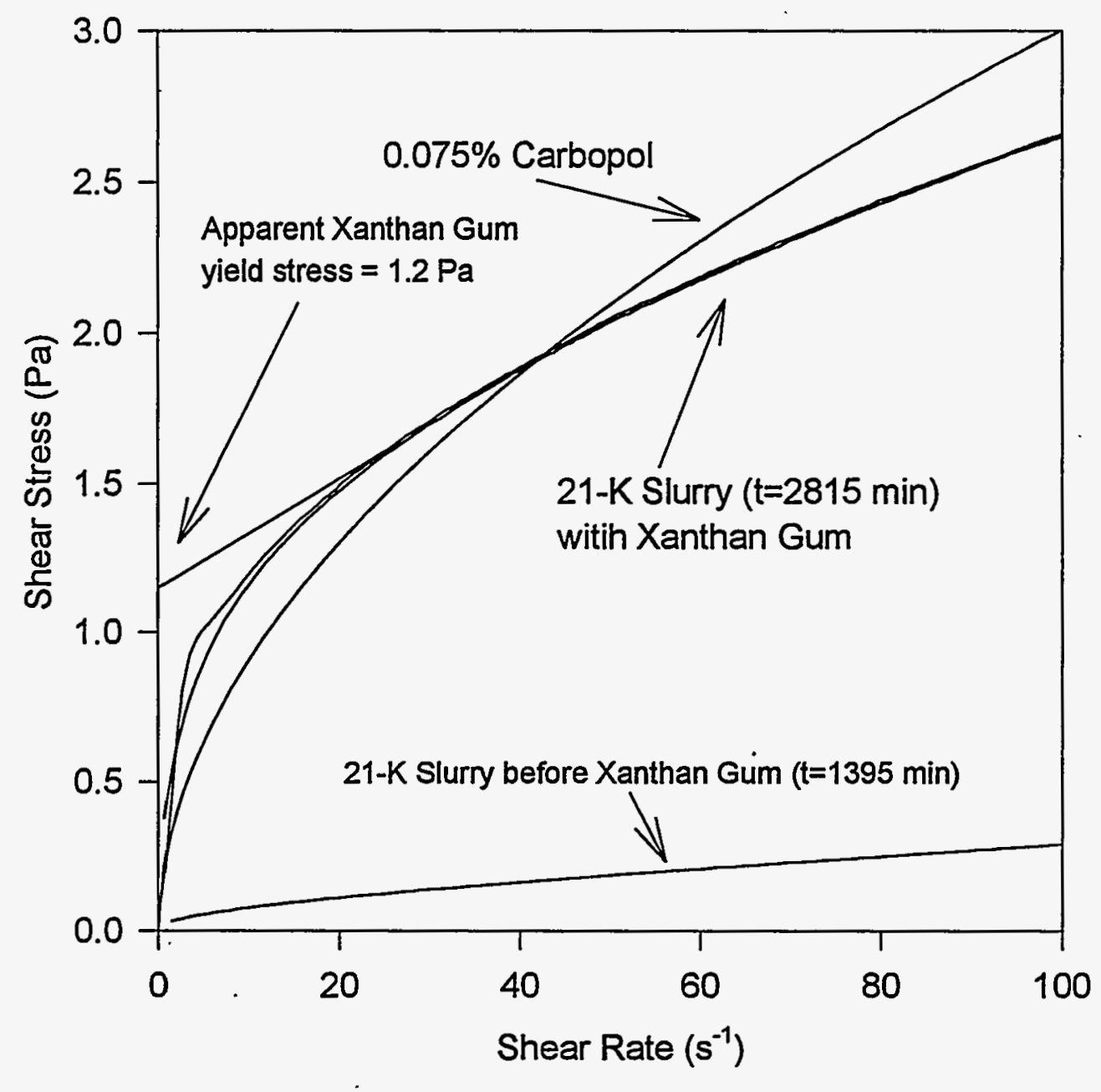

Figure 4.32. Rheogram for Test 21-K Slurries and 0.075\% Carbopol 
Clearly, the reduced $E C R / U_{0} D$ obtained with xanthan gum does not confirm the expected 1/9-power dependence of ECR on viscosity. The addition of the xanthan gum served to increase the mobilization resistance of the simulant rather than decrease it. Further, the magnitude of this increase is quite large. That the 1/9-power relationship was not observed is not surprising given the nonNewtonian theology of the xanthan gum/kaolin slurry. The non-Newtonian rheology was expected before test $21-\mathrm{K}$, but it was decided that xanthan gum would be used because non-Newtonian slurry effects on mobilization are equal or greater interest than the effects of Newtonian viscosity increases. It is possible that non-Newtonian slurries will be generated during the mobilization of some tank wastes. For this reason it is important to understand the relationship between non-Newtonian slurry rheology and sludge mobilization.

The change in slurry rheology from Newtonian to non-Newtonian had a significant effect on the apparent mobilization resistance of the sludge. Based on the measured $E C R / U_{0} D$ values, a jet of the non-Newtonian test slurry requires a $40 \%$ higher flow rate to achieve the same ECR as the Newtonian slurry. Possible explanations for this difference include non-Newtonian effects that can change the rate of jet velocity decay and/or the protection of the sludge/slurry interface from the turbulence of the jet by a thin layer of yield-pseudoplastic fluid at the sludge surface. These possibilities are explored below.

Recent work by Shekarriz et al. (1995) indicates that non-Newtonian fiuid rheology can impact the rate of jet velocity decay under certain conditions. The work of Shekarriz includes a determination of the rate of velocity decay for a submerged, free jet of $0.075 \mathrm{wt} \%$ Carbopol solution. A rheogram for the $0.075 \mathrm{wt} \%$ Carbopol is included in Figure 4.32. It is seen that this fluid is rheologically similar to that in the $1 / 25$-scale tank at the end of test $21-\mathrm{K}$. (a) The work by Shekarriz indicates that a free jet of this fluid will decay approximately at the same rate as a Newtonian jet, provided that the nozzle exit velocity from a $0.6-\mathrm{cm}$ nozzle is higher than about $3 \mathrm{~m} / \mathrm{s} .{ }^{\text {(b) }}$ The nozzle exit velocities used during test $21-\mathrm{K}$ ranged from 8.4 to $15.7 \mathrm{~m} / \mathrm{s}$, so non-Newtonian effects on the rate of jet velocity decay were not likely significant during test $21-\mathrm{K}$.

Another possible explanation for the apparent increase in test $21-\mathrm{K}$ simulant mobilization resistance is the protection of the sludge surface by a layer of tank slurry. It is suggested that the results of test $21-\mathrm{K}$ are attributable to a layer of high apparent viscosity fluid near the eroding sludge surface. This fluid resists the turbulent eddy bursts from the mixer-pump jet that are primarily responsible for eroding the sludge. This high apparent viscosity fluid is the same fluid as the mixer pump jet, but due to its proximity to the immobile sluclge bank, it experiences a lower shear rate than the jet fluid. Because of the curved nature of the rheogram for the test $21-\mathrm{K}$ slurry as shown in Figure

(a) The apparent yield stresses of the xanthan gum slurry and the carbopol slurry are both on the order of $1 \mathrm{~Pa}$. Yield stresses of as high as $1.3 \mathrm{~Pa}$ have been observed on slurries of DST waste (30 wt\% solids slurry of 101-AZ waste). See Characterization of the Second Core Sample of Neutralized Current Acid Waste from Double-Shell Tank 101-AZ. by W. J. Gray, M. E. Peterson, R. D. Scheele, and J. M. Tingey. September 1990. Pacific Northwest Laboratory, Richland, Washington.

(b) Lower nozzle exit velocities were found to result in jets that differed markedly from Newtonian jets. Close to the nozzle, the non-Newtonian jet velocities decayed more slowly than Newtonian jets, but a point was reached where the jet velocity rapidly decayed to zero. This point is interpreted as being the downstream distance where the turbulent stresses within the jet are no longer sufficient to overcome the apparent yield stress of the fluid. 
lower shear rate fluid can have a much higher apparent viscosity than the higher shear-rate fluid within the fluid jet. Thus, the non-Newtonian slurry serves to increase mobilization resistance by providing resistance to penetration by the mixer-pump jets. To get the sludge to mobilize, the jet must overcome the viscosity of the slurry and then overcome the sludge cohesion.

A measure of the relative importance of the slurry rheology and the sludge cohesion is provided from a consideration of the apparent slurry yield stress and the critical shear stress of the sludge. The apparent yield stress is estimated by extrapolating the slurry shear stress data from higher shear rates back to zero shear rate. This extrapolation as shown in Figure 4.32 results in an estimated yield stress of $1.2 \mathrm{~Pa}$ for the end-of-test $21-\mathrm{K}$ slurry. Critical shear stress is defined as the minimum stress needed to induce the erosion of the sludge. A technique for estimating critical shear stress based on sludge mobilization ECR data is presented in Powell et al. (1995). Using this technique, the critical shear stress for the $21-\mathrm{K}$ sludge is estimated to be $5.1 \pm 1.7 \mathrm{~Pa}$ for the first half of the test in which a near Newtonian slurry was used. At the end of the test, the ECR data indicate a critical shear stress of $11.0 \pm 2.4 \mathrm{~Pa}$. The difference between these two critical shear stresses is $5.9 \pm 3.0 \mathrm{~Pa}$.

The magnitude of the increase in critical shear stress that resulted from xanthan gum addition is on the same order as the apparent yield stress of the slurry. This fact supports the hypothesis that the effectiveness is being diminished by the layer of slurry near the sludge surface.

The conclusion drawn from Test $21-\mathrm{K}$ is that non-Newtonian slurry behavior is likely to be detrimental to sludge mobilization. It appears that the apparent yield stress of the slurry might be the key variable that determines the magnitude of the effect. A higher apparent yield stress should result in a higher effective critical shear stress for the sludge, which is manifested as a lower ECR. If slurries with significant yield stress are expected during the mobilization of DST sludge, then it will be important to include the effect of the slurry rheology when making ECR predictions for the purposes of retrieval system design.

\subsubsection{Slurry-Density Effects on Mobilization}

It is expected that the ECR will vary with slurry density to approximately the 4/9-power. The development of this expected relationship is described in Section 4.3.1. Test 22-K was conducted in an effort to determine whether the expected 4/9-power relationship holds. A kaolin/water sludge simulant was mobilized using water as the initial mobilizing fluid. The test was continued normally until ECR growth stopped. At this point, $23 \mathrm{~kg}(50 \mathrm{lb})$ of dry kaolin clay was added to the tank slurry. This increased the slurry density from its initial value of 1.071 to $1.153 \mathrm{~g} / \mathrm{mL}$.

Based on the expected 4/9-power relationship, this increase in density should have resulted in about a $3.3 \%$ increase in the ECR. The ECR before addition of the dry kaolin was $25.0 \pm 3.6 \mathrm{~cm}$. After kaolin addition, the average ECR grew to $25.2 \pm 3.6 \mathrm{~cm}$. If the 4/9-power relationship holds, the expected final ECR is $25.8 \mathrm{~cm}$. Considering the uncertainties in the ECR measurements, the small observed increase does not necessarily imply that the 4/9-power relationship is valid. Further, the ECR was only observed to grow along one of the eight ECR lines following kaolin addition. This implies that the observed growth was not actually due to the increased slurry density, but may have been the result of a sludge inhomogeneity or disruption of the sludge bank as the dry kaolin was being mixed into the tank slurry. 
After addition of the kaolin, the apparent yield stress of the tank slurry increased from 0.5 to about 6.2 Pa. The non-Newtonian slurry effects discussed in Section 4.3.1 probably prevented any real ECR growth as a result of the slurry density increase. It would have been instructional to increase the test $22-\mathrm{K}$ jet flow rate after no ECR growth was observed following the increase in slurry density. The amount of additional flow necessary to effect mobilization could have provided further insight into the non-Newtonian effects on mobilization. The testing schedule did not permit this addition to test $22-\mathrm{K}$.

The test $22-\mathrm{K}$ data are consistent with the current understanding of the effects of slurry density and rheology on mobilization. However, the non-Newtonian rheology of the concentrated kaolin slurry may have hidden any unexpected density effects.

\subsubsection{Mobilization Enhancement by Dispersants}

Dispersants are surface active agents (surfactants) that tend to coat the surfaces of particles and prevent or reduce cohesive bonding. Dispersants are used in the oil drilling industry to promote the break-up of clay deposits and to reduce clay stickiness. Dispersants such as these may aid in the mobilization of DST sludge by reducing the cohesion at the sludge/slurry interface. In the extreme example, a highly effective dispersant could conceivably provide enough reduction in cohesion that only one mixer pump would be required to mobilize all the sludge in a DST.

A secondary goal of test $24-\mathrm{K}$ was to investigate the ability of a commercially available dispersant to improve the mobilization of a kaolin/water sludge simulant. The mixer pump was run and ECR growth monitored until ECR growth stopped. With the mixer pump operating at the same flow rate, $3314 \mathrm{~g}$ of CON-DET ${ }^{\circ}$ dispersant was added to the tank. CON-DET ${ }^{\circ}$ is manufactured by NL Baroid Corp. (Houston, Texas). Following addition of the surfactant, the ECR was observed to grow from $12.3 \pm 2 \mathrm{~cm}$ to $16.3 \pm 2.5 \mathrm{~cm}$.

This result indicates that surfactants can improve the ability of fluid jets to mobilize sludge. It had been postulated that surfactants would be ineffective because the surfactant molecules must permeate into the sludge to affect the cohesion between the particles. The test $24-\mathrm{K}$ results demonstrate that the permeation is apparently sufficient to result in additional sludge mobilization.

An alternative explanation of the $24-\mathrm{K}$ result is that the surfactant affected the slurry rheology in such a way that the jet became more effective. This explanation is not judged likely, however, because rheological measurements made on slurry collected before and after surfactant addition do not show appreciable differences.

The application of dispersants to DST sludge retrieval activities requires more study before its feasibility can be determined. Test $24-\mathrm{K}$ indicates that the potential exists for a beneficial effect. However, the compatibility of the surfactant with downstream treatment of the waste must be carefully considered. It is possible, for example, that the surfactant will hinder the settling of the sludge solids following in-tank washing operations. 


\subsection{Mixer-Pump Operation Effects on Mobilization}

Several of the fiscal year 1994 1/25-scale tests were performed with secondary objectives of determining whether indexed jet movement provides larger ECRs than oscillating jets. Other tests were conducted to investigate the ability of the mixer-pump jets to mobilize sludge near the tank wall. In the $1 / 25$-scale tests, measurements were made of the actual amount of sludge that was suspended in the tank slurry. This quantity is of interest because it is only the pumpable slurry that can be removed from the tank using a transfer pump. The results of these investigations are given in this section.

\subsubsection{Indexed vs. Oscillating Nozzle Movement}

Jet indexing was examined as part of tests $18-\mathrm{KN}$ and $19-\mathrm{K}$. Test $18-\mathrm{KN}$ was run with the mixer pump initially oscillating through a $180^{\circ}$ arc at a speed of 2 to $4 \mathrm{rpm}$. After ECR growth had stopped with the jets oscillating, the mixer-pump rotation was stopped with the jets aligned along ECR measurement lines $B$ and $F^{(a)}$ ECR growth along these lines was monitored for more than 250 minutes. No further ECR growth was observed along either line B or F. Some growth was observed, however, along a line about $20^{\circ}$ to the $\mathrm{E}$ side of $\mathrm{F}$ where the ECR was observed to grow from 34 to $38 \mathrm{~cm}$. No corresponding growth was observed in the region surrounding ECR line B.

Because the jets aligned with B and F did not show ECR growth in both directions, it was decided that a different nozzle orientation would be tested. The nozzles were oriented midway between ECR lines $B$ and $C$ in one half of the tank and $F$ and $G$ in the other half. No further ECR growth was observed with the nozzles indexed along this path. The ECR growth was monitored for more than 250 minutes before the test was stopped.

Test 19-K was not intended to examine nozzle indexing, but while the tank was running unattended overnight the direction-switching relay failed and the mixer-pump oscillation stopped with the nozzles oriented mid-way between ECR lines $C$ and D in one side of the tank ( $G$ and $H$ in the other side). This problem was corrected in the morning, but the ECRs in the direction of the jets had reached 26 to $28 \mathrm{~cm}$, while ECRs in the rest of the tank were approximately $20 \mathrm{~cm}$. After the oscillation was resumed, the average ECR grew to $22.3 \pm 2.5 \mathrm{~cm}$. The fact that the ECRs along the directions' where the pump was stopped are larger than the final average ECR implies that there might be some benefit to indexing the nozzles in this way. However, the magnitude of this effect, if it exists, is on the order of the uncertainties in the ECR measurements, so it cannot be stated confidently that indexing increased the ECRs. Further, the test 19-K simulant composition was identical to that used in test $1-\mathrm{K}$ where, at the same jet flow rate, an average ECR of $26.2 \pm 1.8 \mathrm{~cm}$ was attained.

Indexed jet tests have been performed at 1/25-scale during fiscal years 1993 and 1994 . In both cases, it was found that the magnitude of the ECR improvement that results from indexing is on the order of the uncertainty in the 1/25-scale ECR measurements. Based on the 1/25-scale data collected thus far, it is not clear whether any benefit is expected from indexing the nozzle movement rather than continuously oscillating or rotating at a slow rate. What is clear, however, is that if the jet indexing effect exists it is not large enough to be conclusively seen at $1 / 25$-scale. Testing at larger scales may be necessary to determine the magnitude of the indexed nozzle movement effect.

(a) The 1/25-scale ECRs are usually measured along each of eight radial lines drawn on the bottom of the tank. These lines are labeled A through H. See Appendix B for schematic representations of these radial lines. 
The additional 1/25-scale tests described in Appendix $\mathrm{C}$ were conducted at pump-column rotation rates of about $0.25 \mathrm{rpm}$ instead of the 2 to $4 \mathrm{rpm}$ used for the remainder of the tests described in this report. The fact that the observed ECRs for the $0.6-\mathrm{cm}$ jets rotated at $0.25 \mathrm{rpm}$ were consistent with those in the remainder of this report ( 2 to $4 \mathrm{rpm}$ ) implies that the ECR is relatively insensitive to changes in the column rotation rate over this range. Clearly, if the pump-column rotation rate is increased sufficiently, a point will be reached where significantly reduced ECRs are observed. The $1 / 25$-scale data gathered thus far indicate that a rotation rate of greater than $4 \mathrm{rpm}$ is required to reach this point of reduced performance at $1 / 25$ scale.

\subsubsection{Mobilization Near the Tank Wall}

At the end of $1 / 25$-scale tests $2-\mathrm{K}$ and $26-\mathrm{KB}$, the mixer-pump flow was increased to determine the ability of the jet to clean the region near the tank wall. It has been speculated that the jet flow in the region near the wall might not be sufficient to mobilize sludge effectively. Following the completion of ECR growth for test 2-K, the measured ECR/ $\mathrm{U}_{0} \mathrm{D}$ values were used to estimate how much mixer-pump flow would be necessary to obtain an ECR of about $47 \mathrm{~cm}$. An ECR of $42.8 \mathrm{~cm}$ reaches the tank wall, so this flow is about $10 \%$ higher than that predicted to be necessary to reach the tank wall based strictly on ECR vs. $U_{0} D$ proportionality. This flow rate was observed to mobilize all the sludge simulant in the tank.

Test 26-KN was conducted similarly with the exception that the flow was increased by the amount predicted to make the ECR just reach the tank wall $(E C R=42.8 \mathrm{~cm})$. Once again, all of the simulant was mobilized by the fluid jet.

These tests indicate that the flow patterns of the jet near the tank wall might not be too different from the flow patterns near the base of the sludge bank. Whether these data can be scaled is not presently clear. The jet flow patterns near the tank wall should be similar between $1 / 25$ scale and full scale. However, it is possible that at $1 / 25$ scale the mechanism of tank-knuckle cleaning involves wearing down the sludge until the weight of the remaining sludge is low, and it gets swept into the flow. At full scale, the scaled size of this sludge is $25^{3}=15,625$ times larger so its weight is also much greater. Based on this possibility, the relationship between ECR and tank-knuckle cleaning needs to be tested at a much larger scale to obtain reliable data. Testing at $1 / 4$-scale will probably be required to assess tank cleaning.

\subsubsection{Amount of Sludge Retrieved vs. ECR}

At the completion of each $1 / 25$-scale test, all of the slurry was removed from the tank and weighed. The un-mobilized sludge and any dislodged pieces of sludge were not collected in this slurry. The wt $\%$ solids of this slurry was measured by drying. These data were used along with the measured wt\% solids of the sludge simulant and the mass of sludge initially placed in the tank to compute the fraction of the sludge that was retrieved in the slurry. The purpose of doing this was to provide some indication of the combined effects of non-vertical bank angles and sludge that is mobilized but resettles. The weight fraction of sludge retrieved in the form of a slurry is plotted versus the weight fraction mobilized as predicted by the ECR in Figure 4.33. The weight fraction mobilized is predicted by assuming a vertical sludge bank and no settling of mobilized solids. 


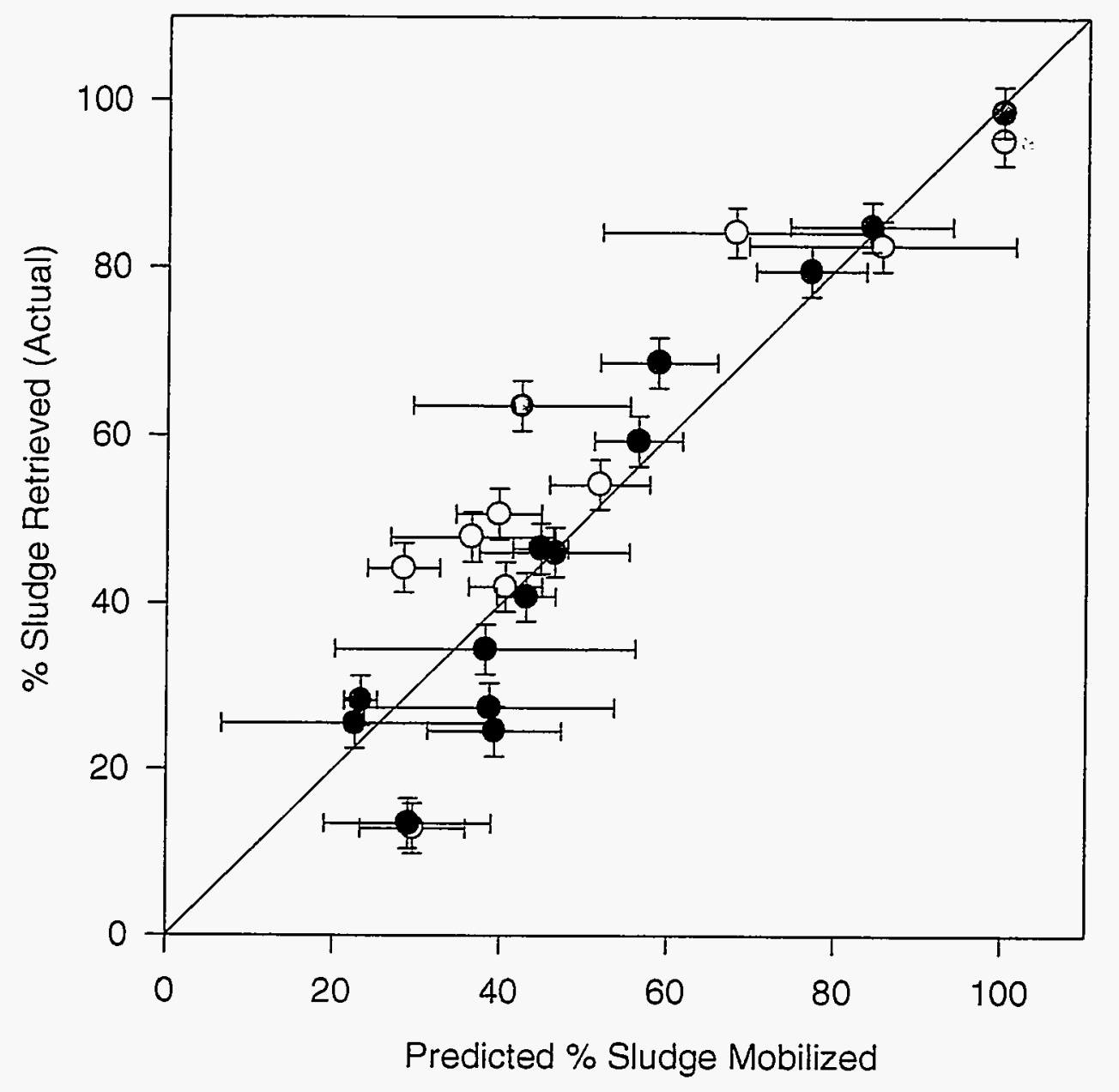
Kaolin
- Bentonite
- Bentonite/Kaolin
O Kaolin/Plaster

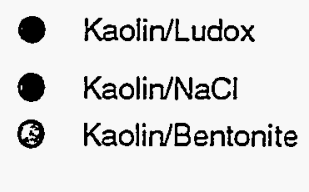

Figure 4.33. Fraction of Sludge Actually Retrieved vs. Fraction Predicted by ECR 
It was observed during $1 / 25$-scale testing that when the ECR is small, the bank angle tends to be vertical or even slightly undercut. Also at small ECRs, the region of the tank near the walls does not get mixed very well so some settling of previously dislodged material takes place. These effects can combine to result in the ECR measurement overpredicting the amount of sludge that will be retrieved when the slurry is pumped out of the tank. At larger ECRs, the bank angles tend to be sloped towards the wall. In many cases, the banks are sloped at $30^{\circ}$ to $45^{\circ}$. This gradual slope not only means that more of the sludge has been mobilized than the ECR indicates, but the gradual slope allows more of the jet energy to be directed into regions of the tank that are not well mixed at smaller ECRs. This results in the re-entrainment of sludge particles that may have settled near the tank wall while the ECR was smaller.

These observations are supported by the data in Figure 4.33. The figure shows that the actual fraction of sludge retrieved tends to be greater than the ECR predicts when the ECR is large and somewhat less than the ECR predicts when the ECR is small.

\subsection{Recommended Future Mobilization Testing}

The present $1 / 25$-scale work has revealed additional questions that will require further testing to answer. The tests recommended to address these questions are described below.

The most important issue to be investigated that was raised through $1 / 25$-scale testing is that of mobilization data scaleup. When the fiscal years 1993 and $19941 / 25$-scale data are compared to the fiscal year 1987 ECR correlation developed at $1 / 12$ scale, the $1 / 25$-scale data are seen to predict systematically higher ECRs. This difference might just be because the 1/12-scale tests were stopped before the final ECR was reached, but it is also possible that an unanticipated scale-up effect exists between $1 / 25$ scale and $1 / 12$ scale. This same effect could also be applicable when 1/12-scale data are scaled to full scale. Because this possible scale-up effect tends to decrease the ECRs, it is essential that this issue be fully investigated. To begin this investigation, it is recommended that mobilization tests be conducted at $1 / 12$ scale with simulants identical to those used at $1 / 25$-scale. These tests should either provide confidence in the current scaling methodology or point to scale-up effects that have heretofore been neglected. These types of tests are currently planned for fiscal year 1995.

Another issue is that of the difference between the vertical extrusion and vertical split-cell tensilestrength measurements for kaolin/water simulants. As discussed in section 4.1.2, this difference is attributed to dilatant behavior in concentrated kaolin/water mixtures. Vertical extrusion tensile-strength measurements conducted at different speeds should show increasing strength with increasing extrusion rate if this explanation is valid. An alternative test would be to extrude a segment of kaolin/water simulant such that its weight is intermediate between that observed to give failure during vertical extrusion testing and the weight predicted to give failure by split-cell measurements. If extrusion is stopped at this point, then it is predicted that a piece will break free after several minutes.

The kaolin/Ludox ${ }^{\circledR}$ tensile strength data also required that some assumptions be made to defend why the mobilization behavior of kaolin/Ludox does not violate the conclusion that cohesion controls mobilization resistance. Horizontal extrusion testing of several kaolin/Ludox simulants using a smaller tube diameter than that used in this study should be sufficient to determine the actual relationship between kaolin/Ludox ${ }^{\circ}$ tensile strength and shear strength. 
Some of the testing has indicated that measurement of the viscoelastic loss-modulus can provide an indication of the relative importance of the cohesive and frictional forces that determine shear strength. This is encouraging because techniques for measuring loss modulus are much better developed than those for measuring tensile strength of sludge-like materials. Further, WHC recently acquired an instrument capable of performing these measurements that is destined for radioactive hotcell use. It is recommended that viscoelastic characterization be applied to a wider range of sludge simulants to determine whether the loss modulus data is consistent with the existing $1 / 25$-scale sludge mobilization data.

With the exception of the kaolin/plaster simulants, all the 1/25-scale simulants tested thus far obtain their cohesiveness through either van der Waals or electrostatic attractive forces. Additional strength development mechanisms may be relevant to tank waste. In particular, chemical bonding between sludge particles may have taken place given the length of time the sludge has been in the tanks. Whether the relationship between shear strength and mobilization resistance is the same for chemically bonded particles as it is for those held together by van der Waals forces is not yet known. The kaolin/plaster data imply that this relationship may be similar, but the fact that test 10-KP was stopped before ECR growth had stopped makes the results inconclusive. It is recommended that further testing at $1 / 25$ scale and $1 / 12$ scale be conducted using simulants that obtain their cohesive strength through interparticle bonds at the particle contact points. Any other likely sludge-strength development mechanisms should also be investigated in a similar manner. 


\subsection{References}

Bird, R. B., W. E. Stewart, and E. N. Lightfoot. 1960. Transport Phenomena. John Wiley \& Sons, New York.

Gibson, R. E. 1953. "Experimental Determination of the True Cohesion and True Angle of Internal Friction in Clays." Proc. Int. Congr. Soil Mech., 3rd., I:126-130.

Herting, D. L. 1992. Laboratory Characterization of Samples Taken in May 1991 from Hanford Waste Tank 241-SY-101. WHC-SD-WM-DTR-024. Westinghouse Hanford Company. P. O. Box 1970, Richland, Washington.

Jeppson, D. W., and J. J. Wong. 1993. "Ferrocyanide Waste Simulant Characterization." WHC-EP0631, Westinghouse Hanford Company, P. O. Box 1970, Richland, Washington.

Lambe, T. W. and R. V. Whitman. 1969. Soil Mechanics. John Wiley and Sons, New York.

Leavell, D. A. and J. F. Peters. 1987. Uniaxial Tensile Test for Soil. Dept. of the Army, Waterways Experiment Station, Vicksburg, Mississippi. Geotechnical Laboratory. Final Report GL-87-10. April 1987.

Martin, R. T. 1962. "Discussion of Paper by Walter L. Moore and Frank D. Masch, Jr., 'Experiments on the Scour Resistance of Cohesive Sediments.'" J. Geophysical Research. 67(4):1447-1449.

Moore, W. L. and F. D. Masch. 1962. "Experiments on the Scour Resistance of Cohesive Sediments." J. Geophysical Research. 67(4):1437-1446.

Nearing, M. A., S. C. Parker, J. M. Bradford, and W. J. Elliot. 1991. "Tensile Strength of ThirtyThree Saturated Repacked Soils." Soil Sci. Am. J. 55:1546-1551.

Obot, N. T., T. A. Trabold, M. L. Graska, and F. Gandhi. 1986. "Velocity and Temperature fields in Turbulent Jets Issuing from Sharp-Edged Inlet Round Nozzles." Ind. Eng. Chem. Fundam. 25:425-433.

Obot, N. T., M. L. Graska, and T. A. Trabold. 1984. "The Near Field Behavior of Round Jets at Moderate Reynolds Numbers." Can. J. Chem. Eng. 62:587-593.

Obot, N. T., A. S. Majumdar, and W. J. M. Douglas. 1979. "The Effect of Nozzle Geometry on Impingement Heat Transfer under a Round Turbulent Jet." ASME Paper 79-WA/HT-53.

Pani, B. S., and N. Rajaratnam. 1975. "Turbulent Circular Wall Jets with Swirl." Technical Report, Department of Civil Engineering, Univ. of Alberta, Edmonton, Canada. 
Powell, M. R., G. R. Golcar, C. R. Hymas, and R. L. McKay. 1995. FY 1993 1/25-Scale Sludge Mobilization Testing. PNL-10464. Prepared by Pacific Northwest Laboratory, Richland, Washington. April 1995.

Rajaratnam, N. 1976. Turbulent Jets. Elsevier Scientific Publishing Co., New York

Raudkivi, A. J. and S. K. Tan. 1984. "Erosion of Cohesive Soils." J. Hydraulic Research. 22(4):217-233.

Searle, A. B., and R. W. Grimshaw. 1959. The Chemistry and Physics of Clays and Other Ceramic Materials. 3rd ed. Interscience Publishers, Inc. New York.

Shekarriz, A., G. Douillard, T. Weir, and C. D. Richards. 1995. "Rheology and Reynolds Number Effects on the Velocity Field of a Yield-Pseudoplastic Jet." ' Submitted for presentation at the ASME Fluids Engineering Division Summer Meeting, Hilton Head, South Carolina, August 13-18, 1995.

Smalley, I. J. 1970. "Cohesion of Soil Particles and the Intrinsic Resistance of Simple Soil Systems to Wind Erosion." J. Soil Science. 21(1):154-161.

Sudo, Kozo, Toshihiro Takami, and Hideki Hibara. 1987. "Jet Issuing from $90^{\circ}$ Curved Nozzle." Nippon Kikai Gakki Ronbunshu B. Hen. 53(487):839-842.

Trabold, T. A., E. B. Esen, and N. T. Obot. 1987. "Entrainment by Turbulent Jets Issuing from Sharp-Edged Inlet Round Nozzles." Trans. ASME. 109:248-254.

van Olphen, H. 1977. An Introduction to Clay Colloid Chemistry. John Wiley and Sons. New York.

White, W. A. and E. Pichler. 1959. Water sorption characteristics of clay minerals. Illinois State Geol. Surv., Circ., 266. 
Appendix A

1/25-Scale Test Data 


\section{Appendix A}

\section{1/25-Scale Test Data}

This appendix contains plots of the data collected during each 1/25-scale test. Four graphs have been generated for each test. The first is a plot of the measured ECR vs. time. Error bars are computed based on the observed scatter in the eight ECR measurements taken for each point. The second graph is ECR/U $\mathrm{O}_{0} \mathrm{D}$ v. time. The third graph is a plot of the observed ECRs along with the ECR as predicted, based on a mass balance and assuming vertical sludge banks and no settling of dislodged material. The equation used for this computation is:

$$
E C R=R_{\text {tank }} \sqrt{\frac{V_{\text {super }} \rho_{\text {slurry }}-M_{\text {super }}}{M_{\text {sludge }}-V_{\text {sludge }} \rho_{\text {slurry }}}}-a
$$

where $E C R=$ estimate of distance from nozzle tip to sludge bank (assumed vertical bank)

$V_{\text {super }}=$ initial supernate volume, liters

$V_{\text {sludge }}=$ initial sludge volume, liters

$\rho_{s \text { surry }}=$ measured slurry density, $\mathrm{kg} /$ liter

$M_{\text {super }}=$ initial supernate mass, $\mathrm{kg}$

$M_{\text {sludge }}=$ initial sludge mass, $\mathrm{kg}$

$R_{\text {tank }}=$ tank radius, meters

$a=$ distance between mixer-pump centerline and nozzle discharge, meters

The fourth graph provided for each set of test data is that of the measured slurry density and temperature as a function of time. 


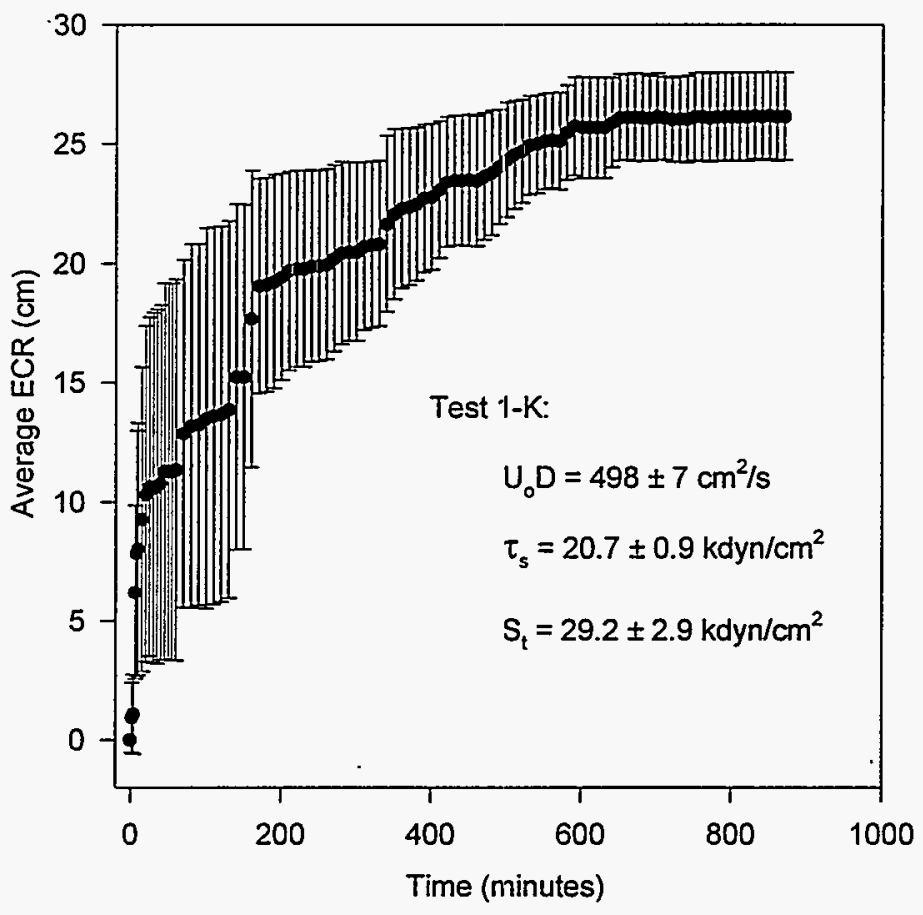

Figure A.1. Test 1-K ECR vs. Time

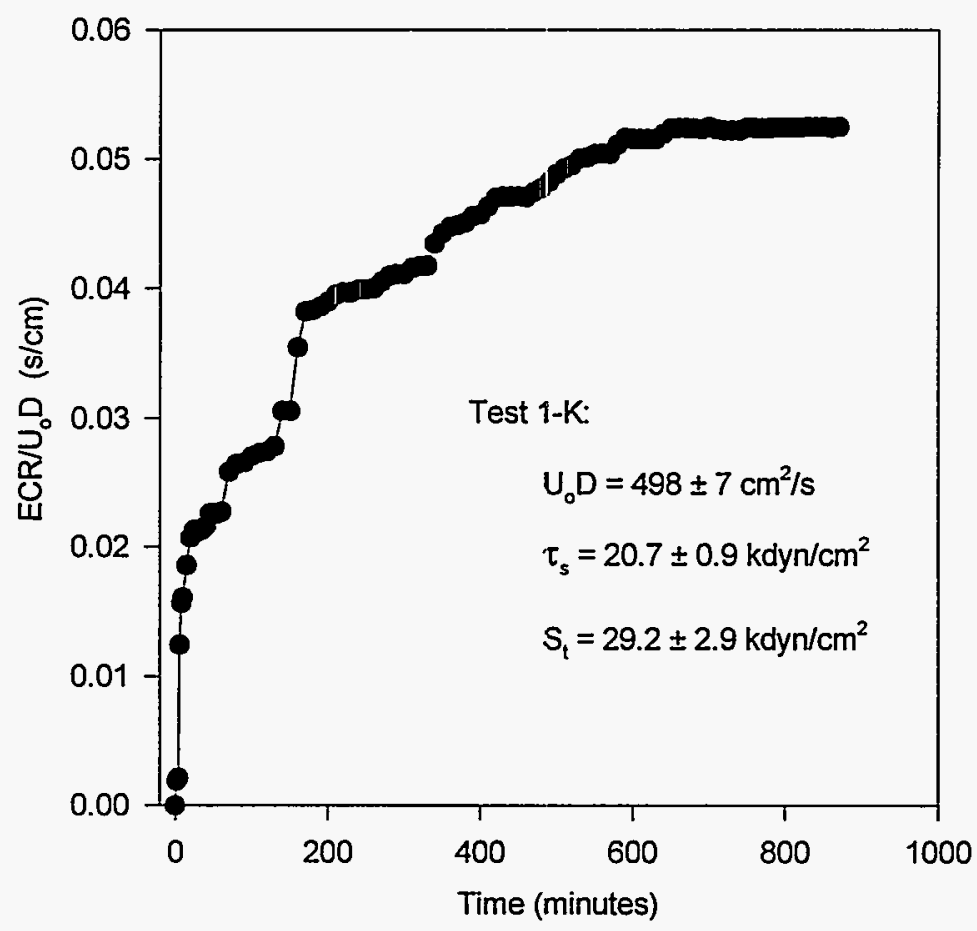

Figure A.2. Test $1-\mathrm{K} E C R / \mathrm{U}_{0} \mathrm{D}$ vs. Time 


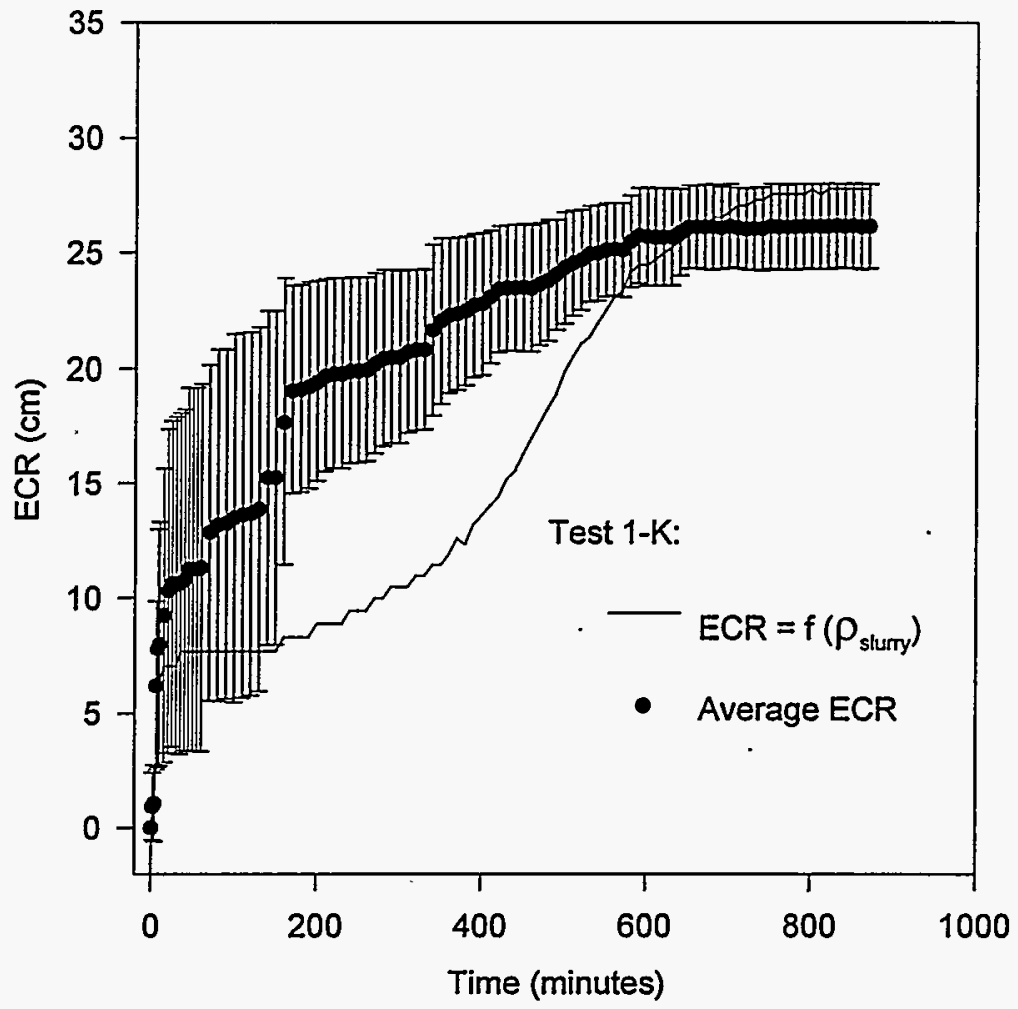

Figure A.3. Test 1-K ECR Calculated from Density

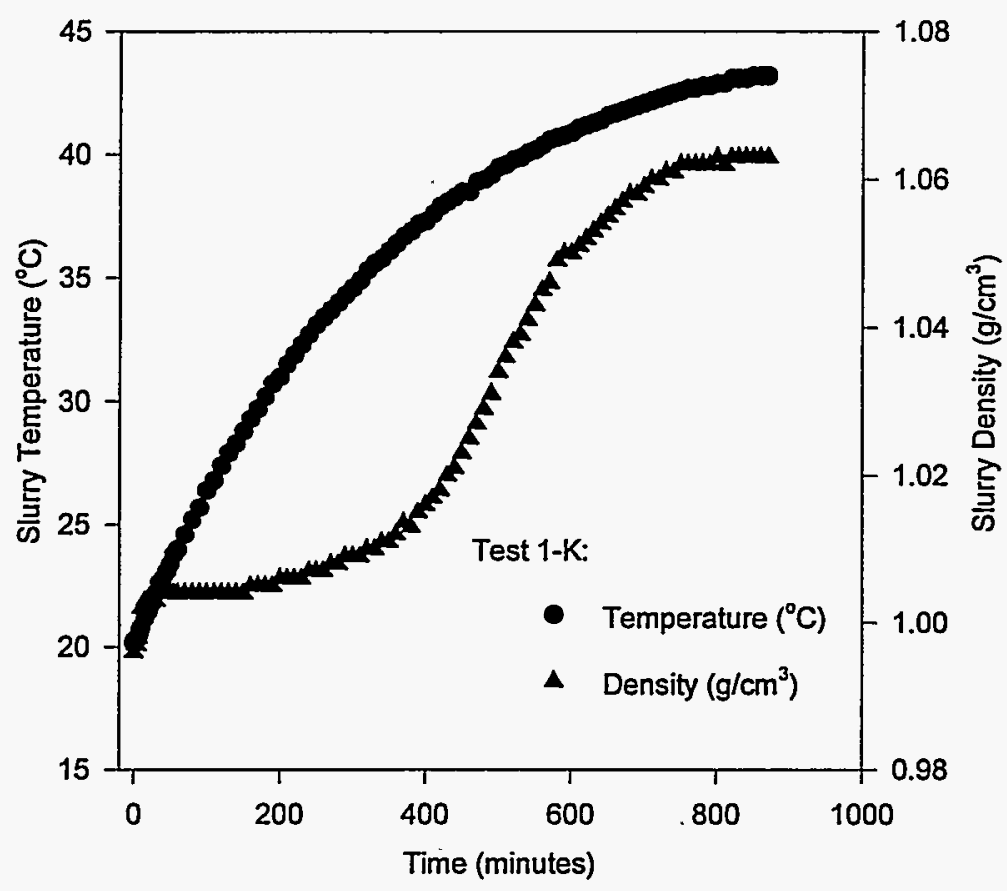

Figure A.4. Test 1-K Slurry Temperature and Density 


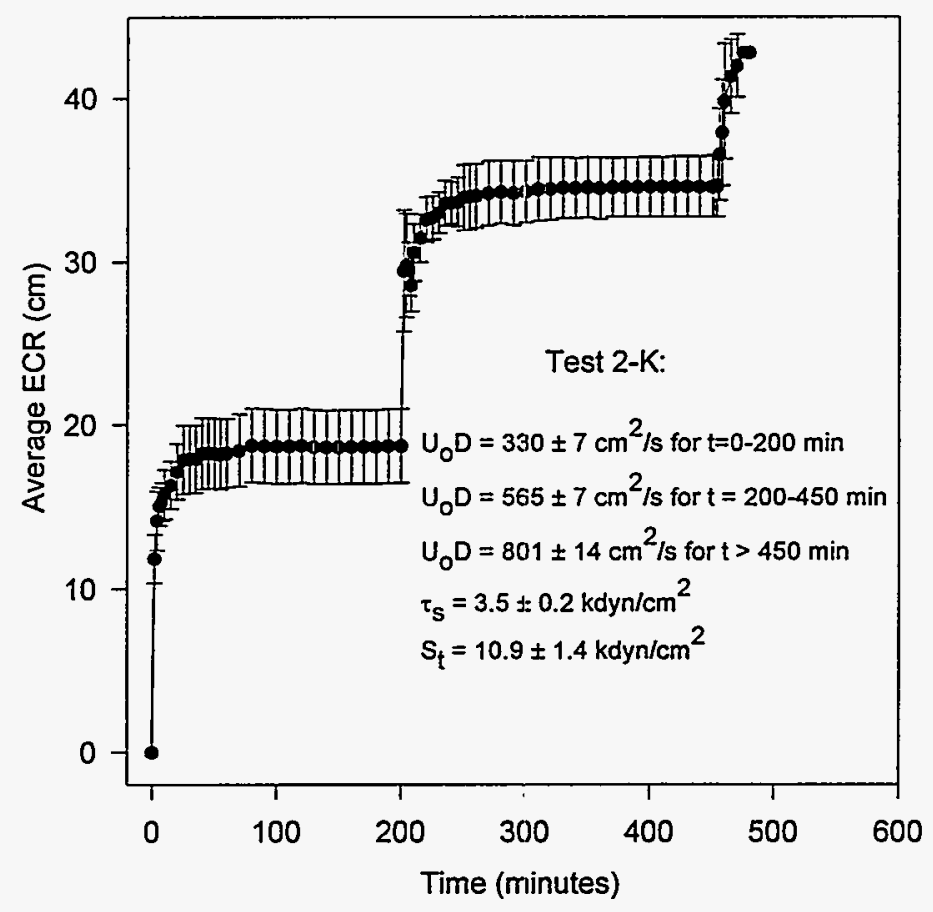

Figure A.5. Test 2-K ECR vs. Time

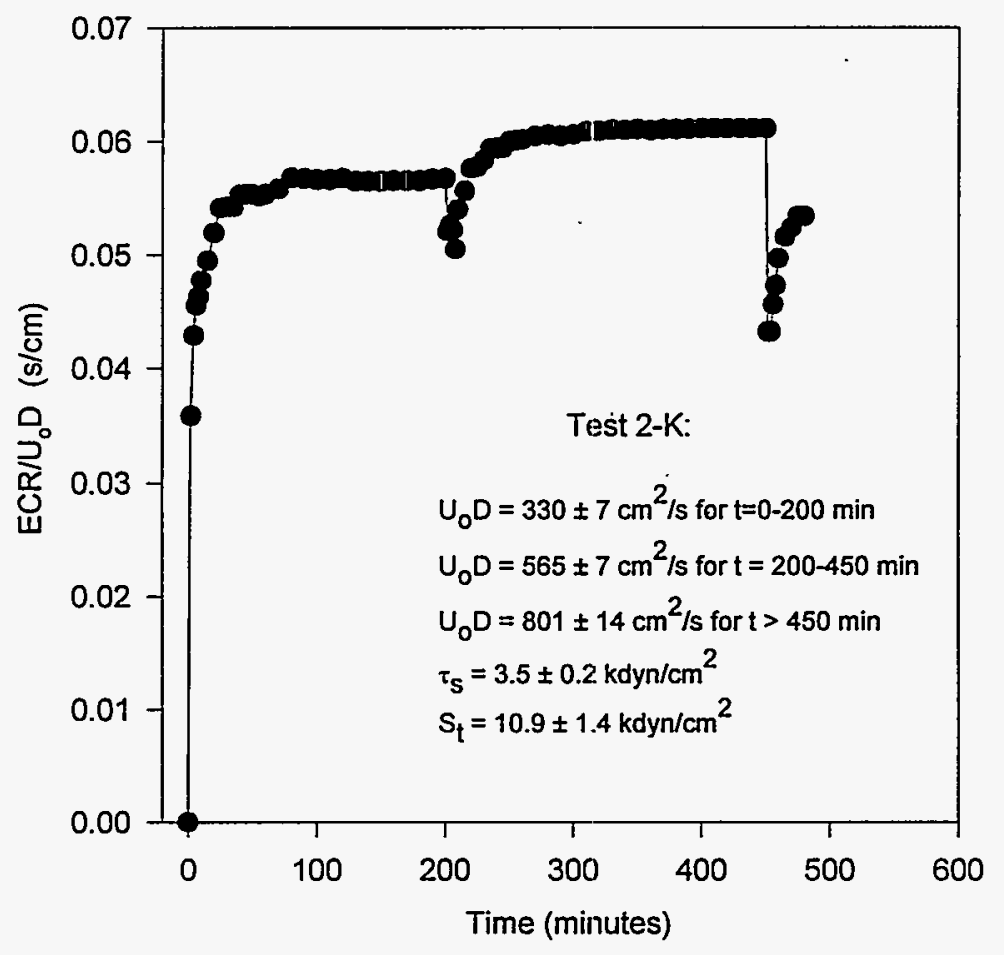

Figure A.6. Test $2-\mathrm{K} E C R / U_{0} D$ vs. Time 


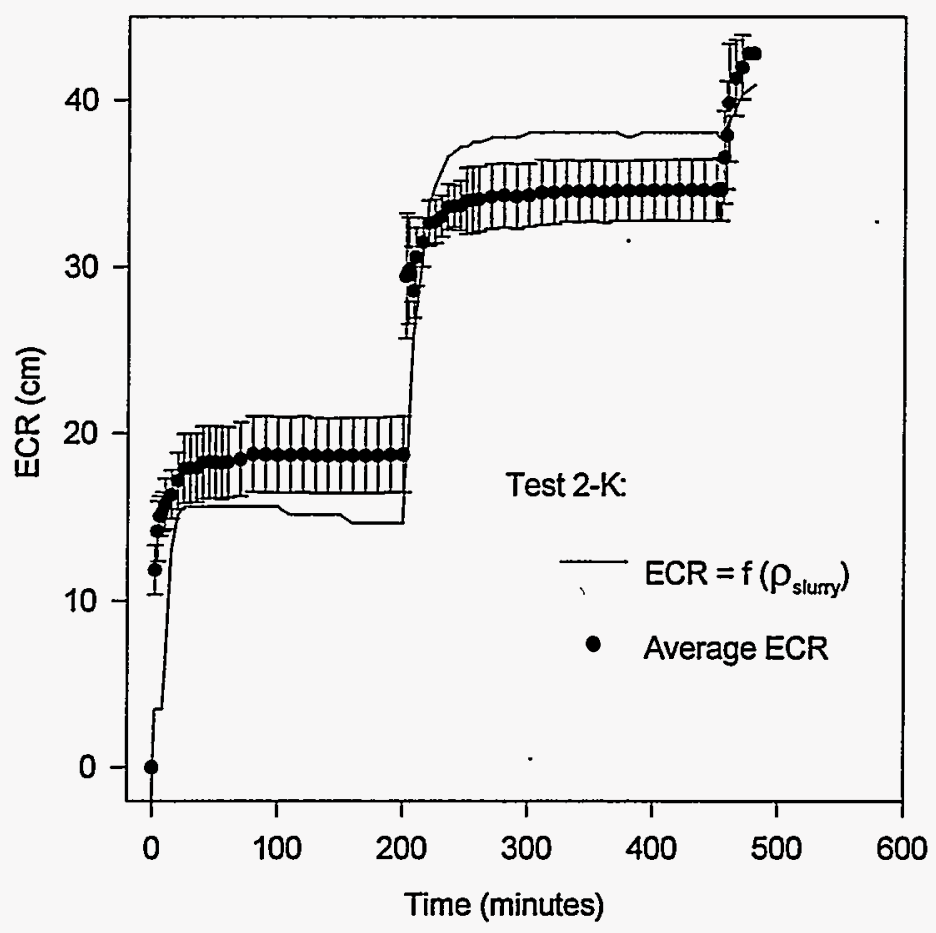

Figure A.7. Test 2-K ECR Calculated from Density

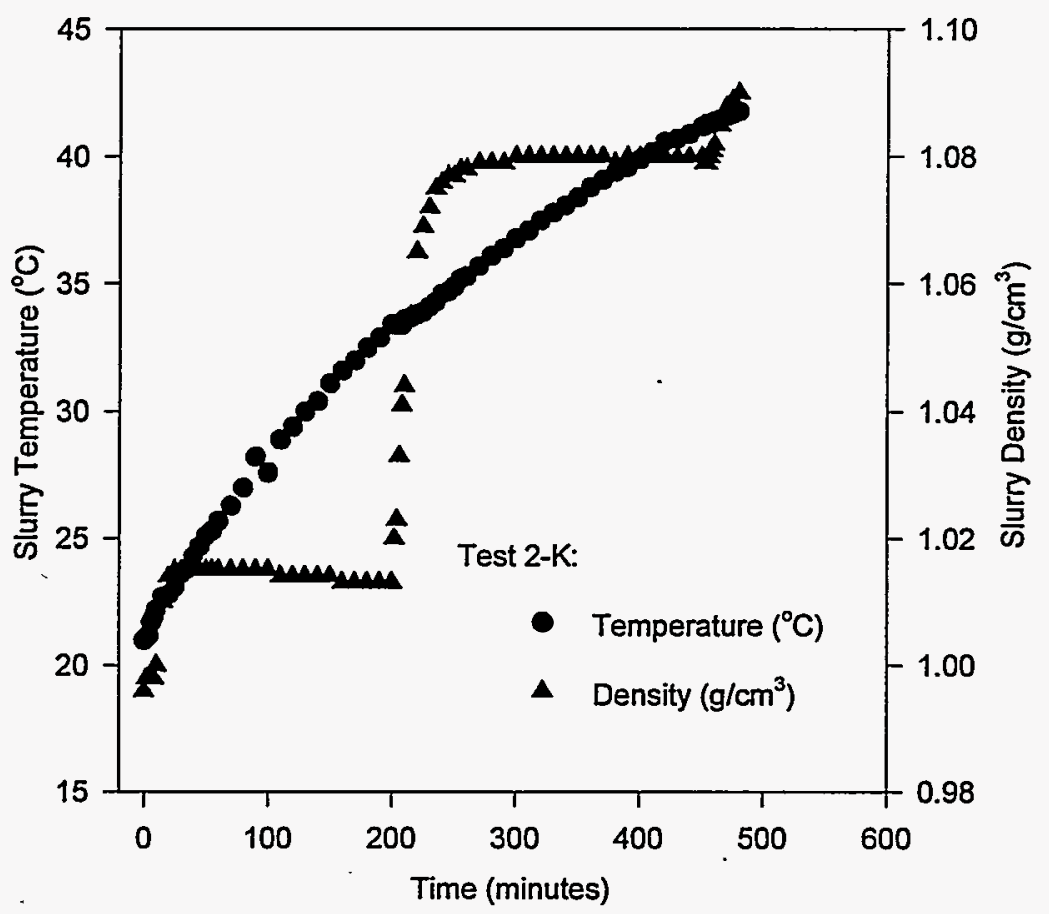

Figure A.8. Test 2-K Slurry Temperature and Density 


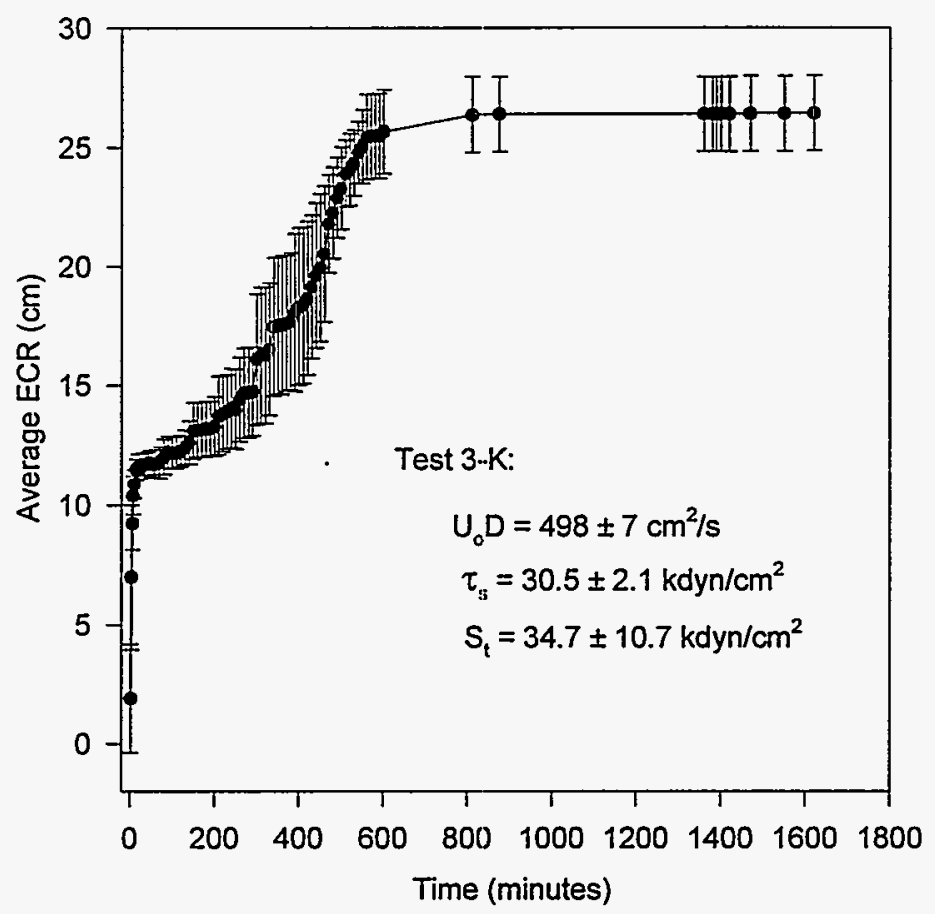

Figure A.9. Test 3-K ECR vs. Time

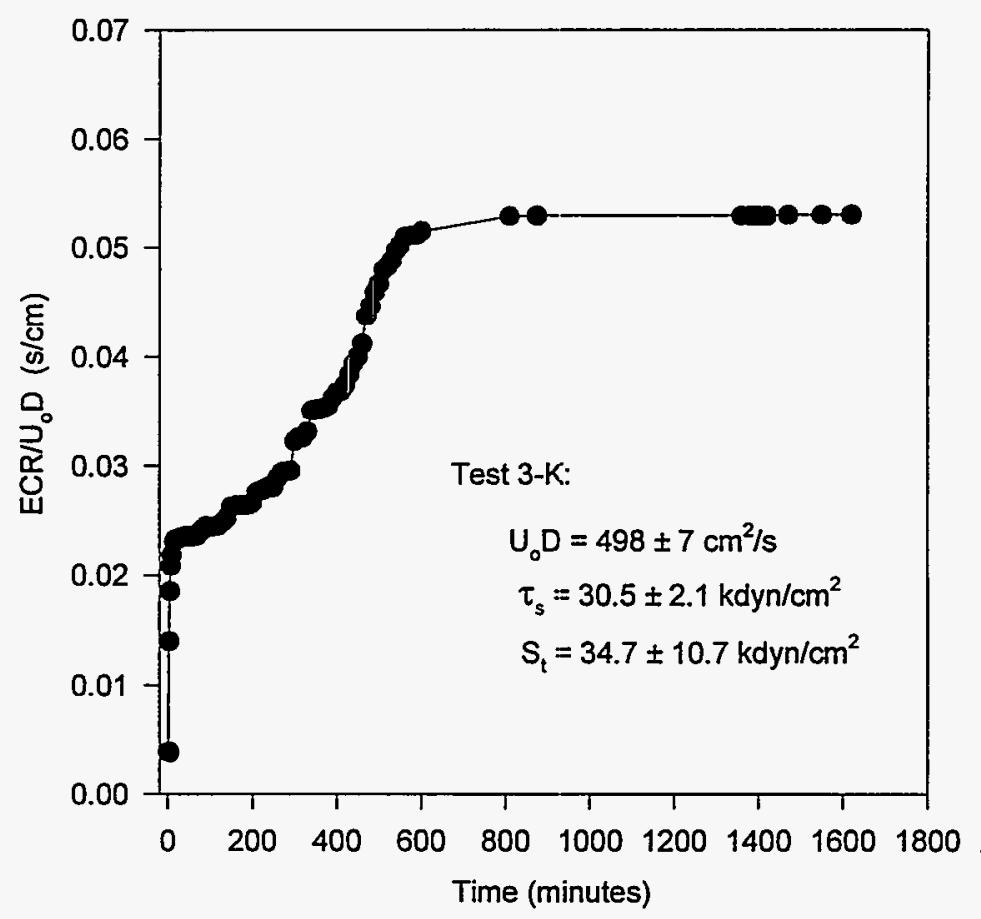

Figure A.10. Test 3-K. ECR/ $\mathrm{U}_{0} \mathrm{D}$ vs. Time 


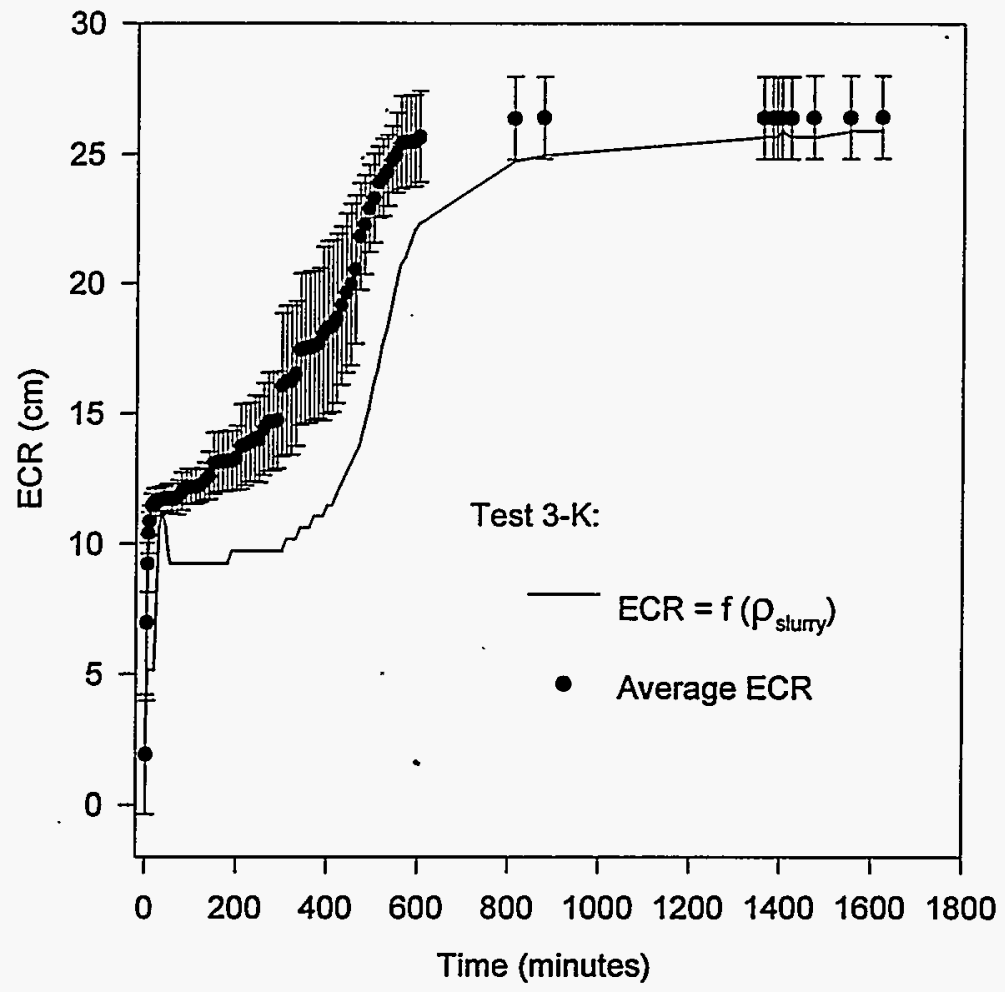

Figure A.11. Test 3-K ECR Calculated from Density

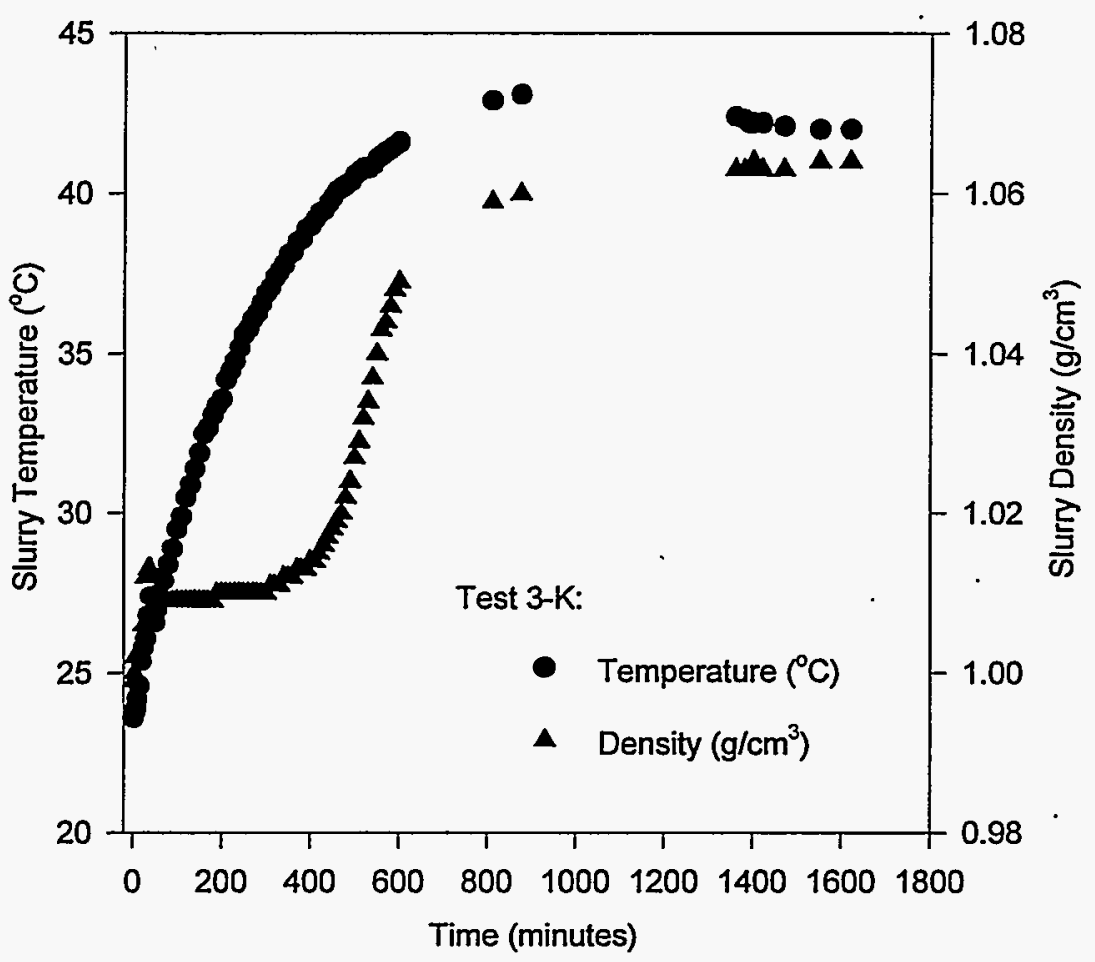

Figure A.12. Test 3-K Slurry Temperature and Density

A.7 


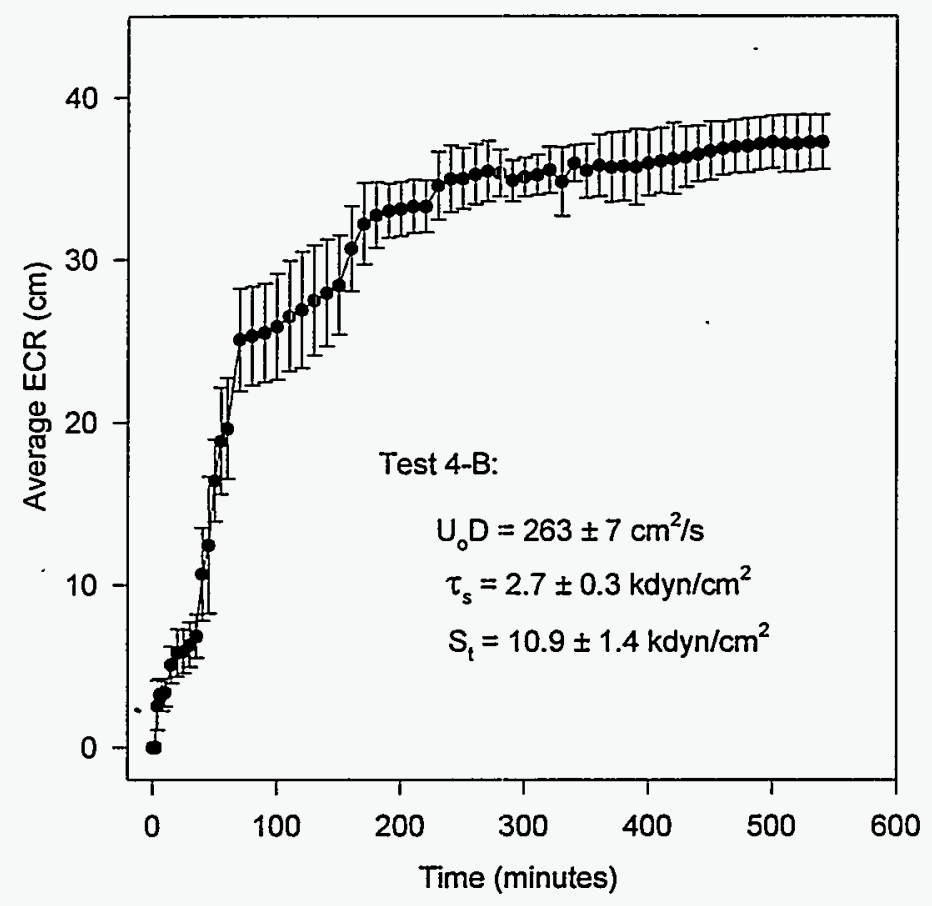

Figure A.13. Test 4-B ECR vs. Time

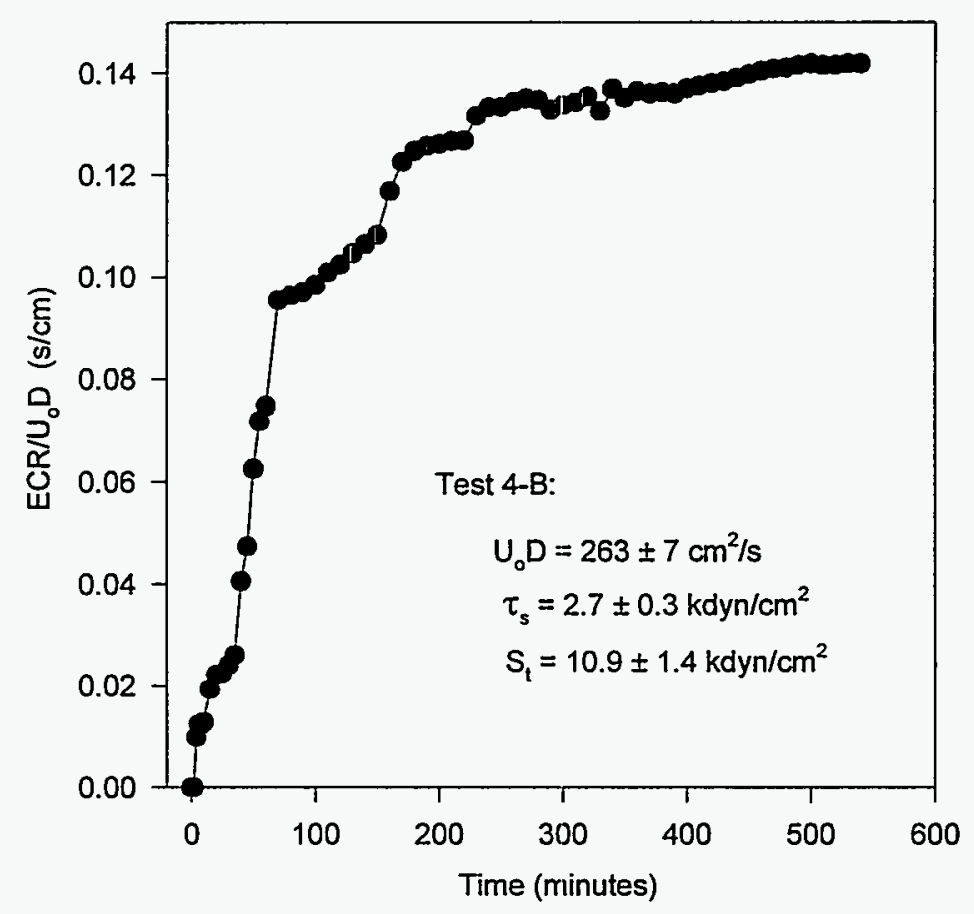

Figure A.14. Test 4-B ECR/U $\mathrm{D}$ vs. Time 


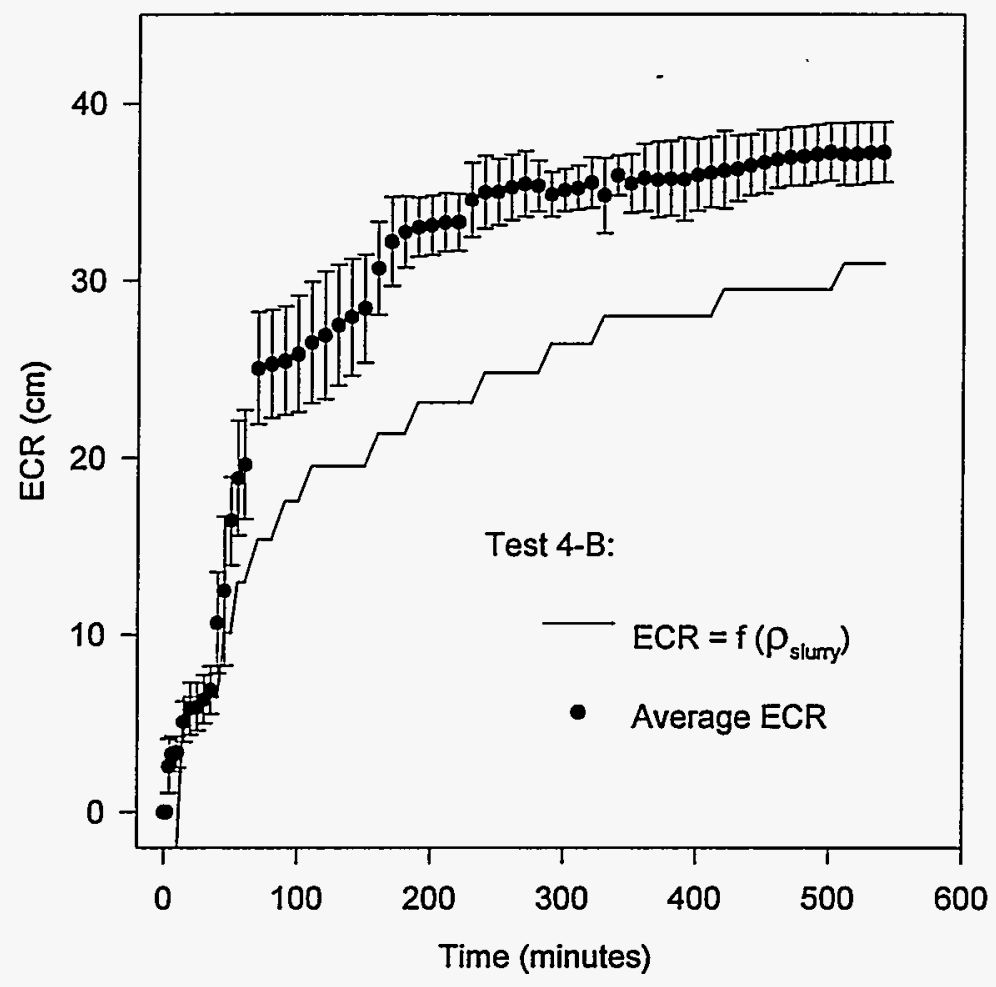

Figure A.15. Test 4-B ECR Calculated from Density

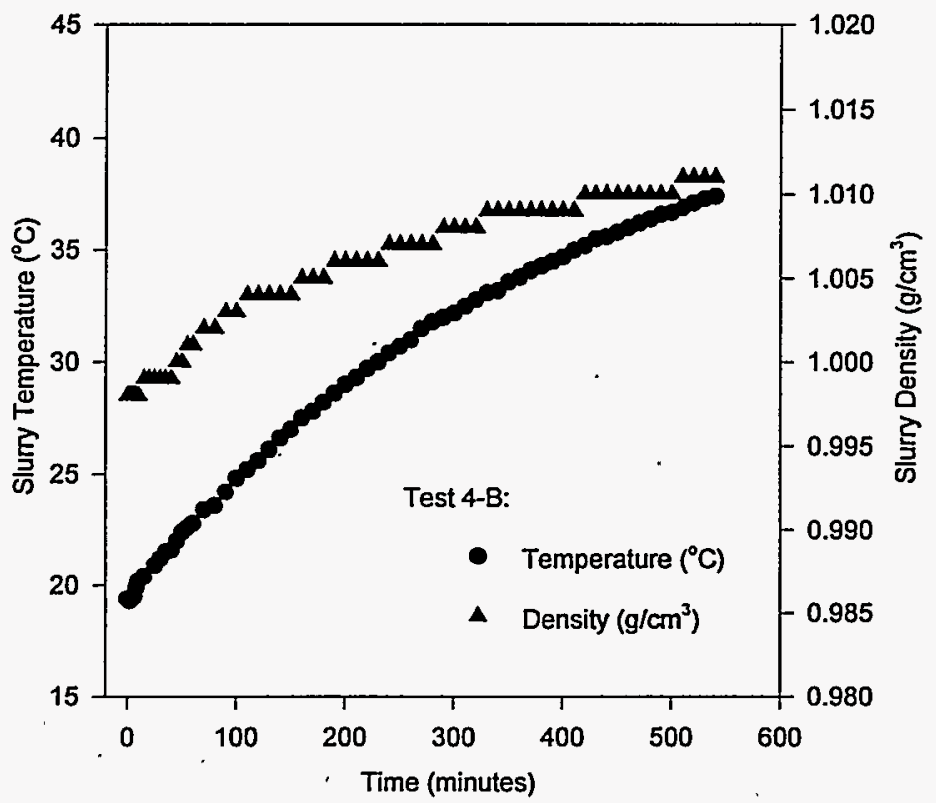

Figure A.16. Test 4-B Slurry Temperature and Density

A.9 


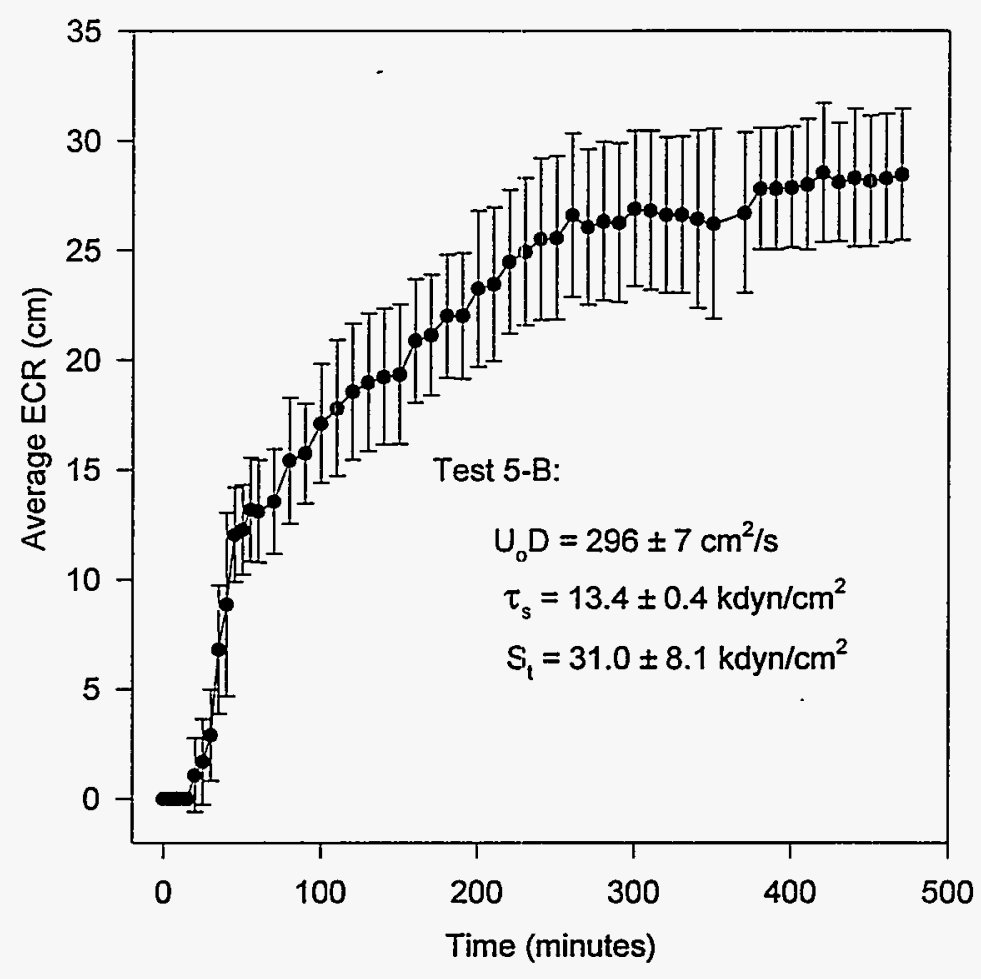

Figure A.17. Test 5-B ECR vs. Time

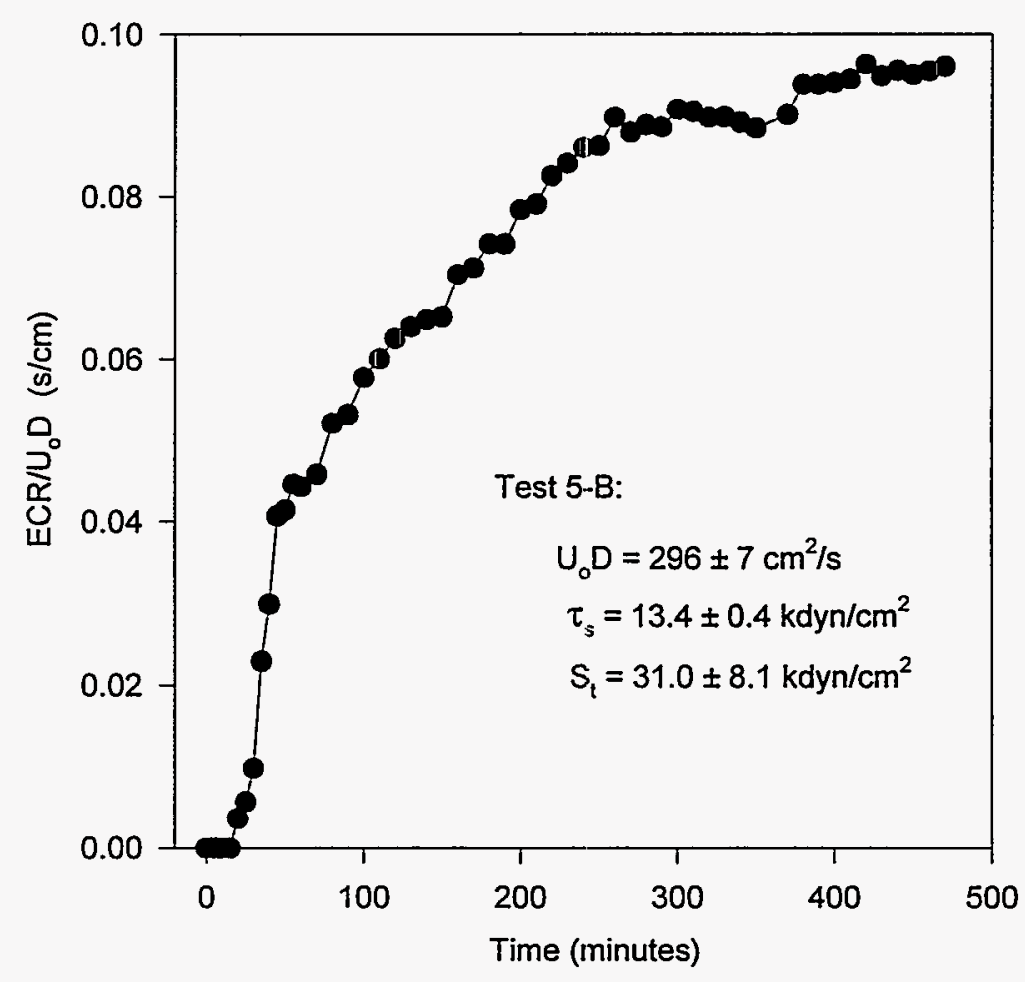

Figure A.18. Test $5-B E C R / U_{0} D$ vs. Time 


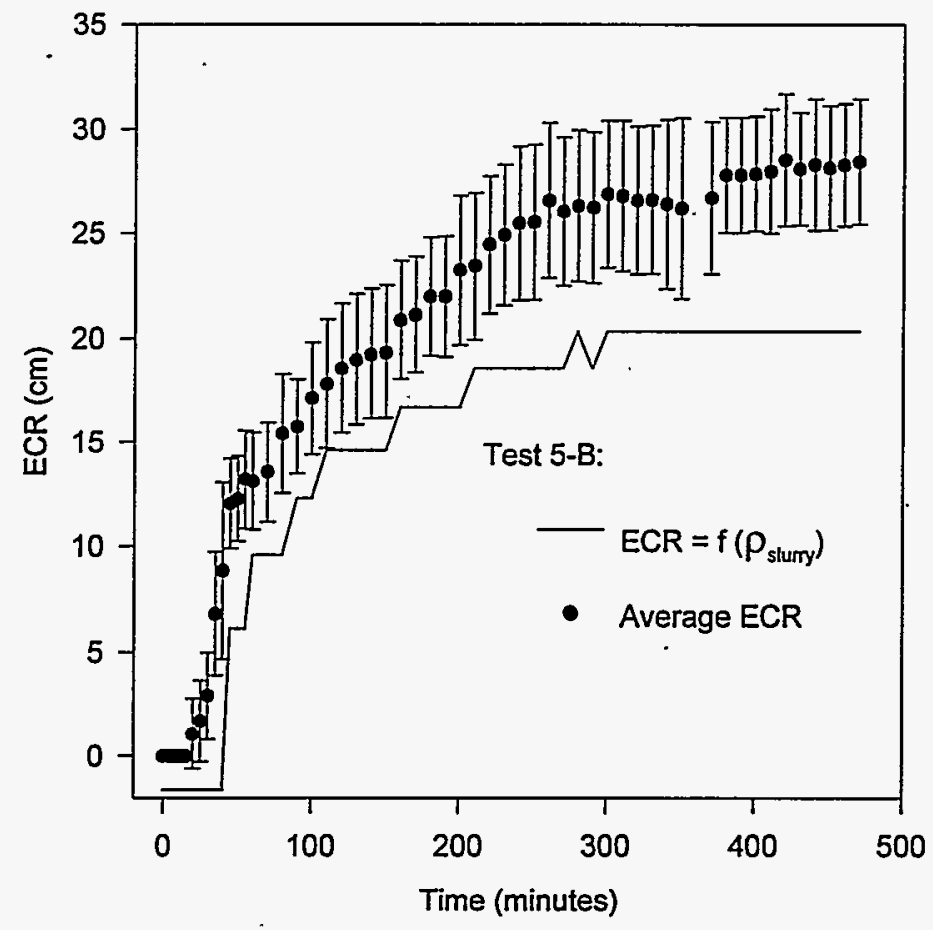

Figure A.19. Test 5-B ECR Calculated from Density

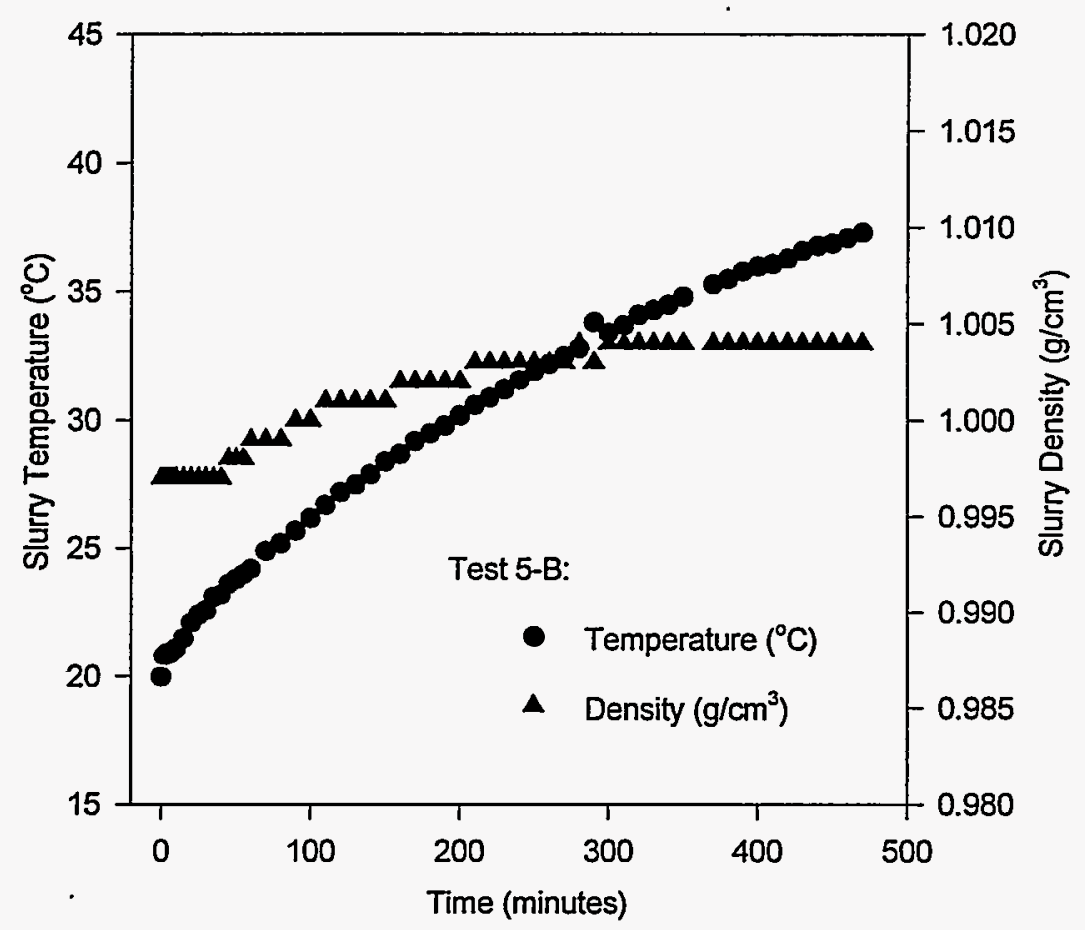

Figure A.20. Test 5-B Slurry Temperature and Density

\section{A. 11}




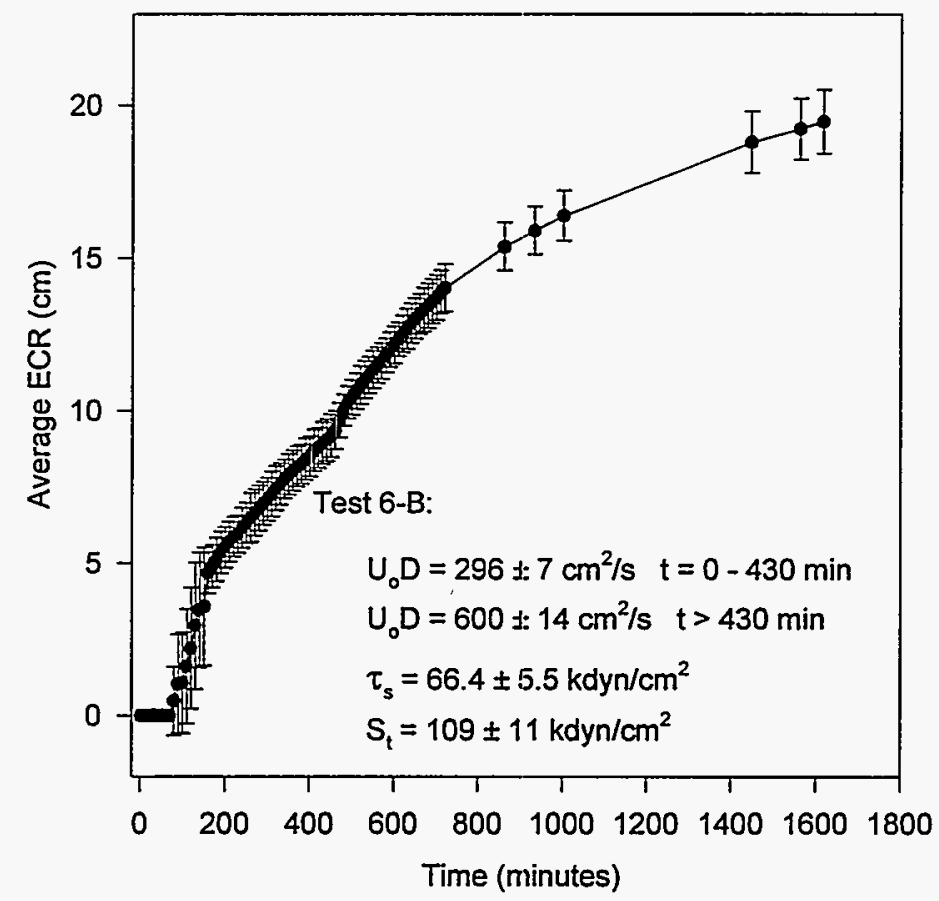

Figure A.21. Test 6-B ECR vs. Time

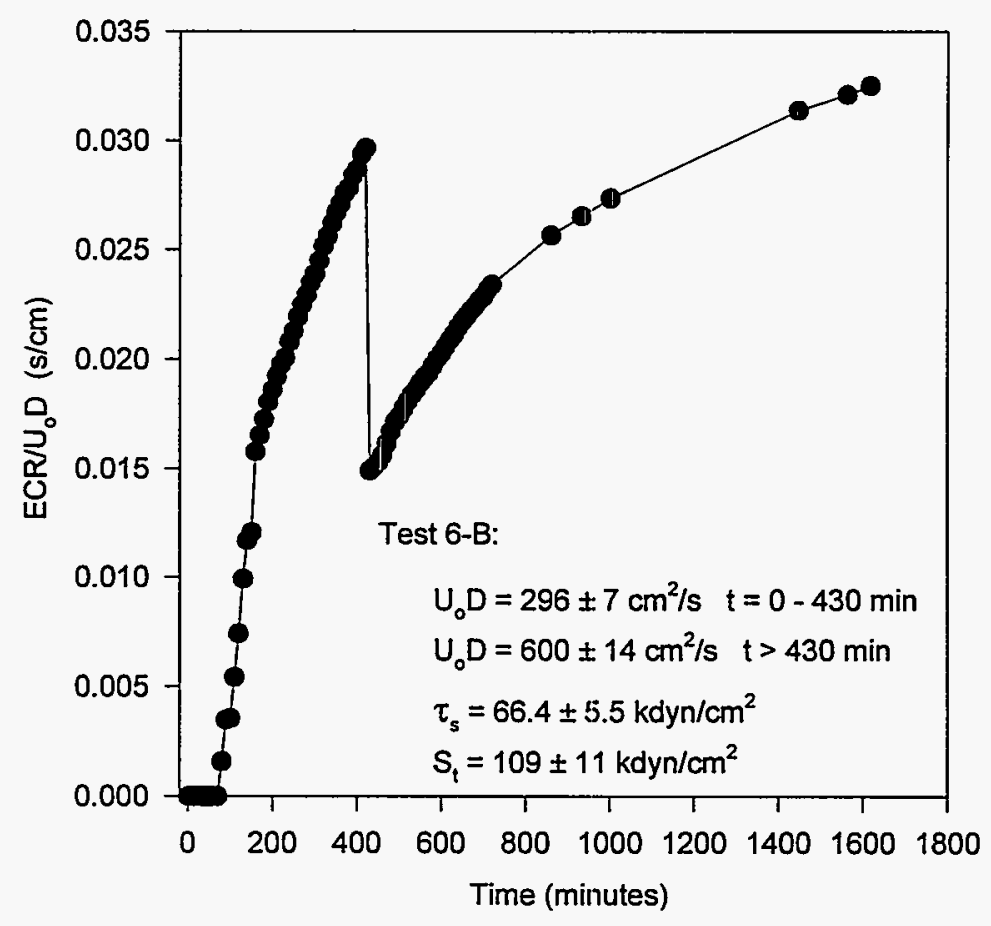

Figure A.22. Test 6-B ECR/ $\mathrm{U}_{0} \mathrm{D}$ vs. Time 


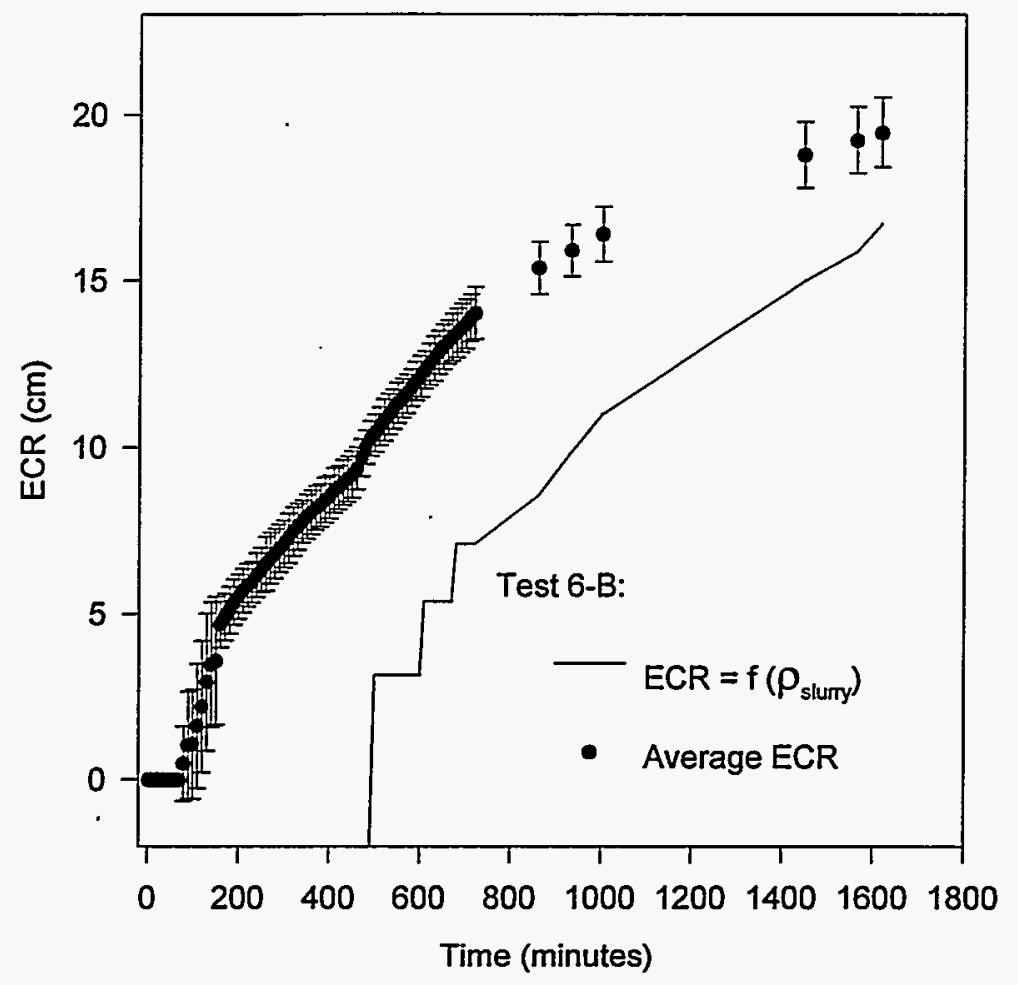

Figure A.23. Test 6-B ECR Calculated from Density

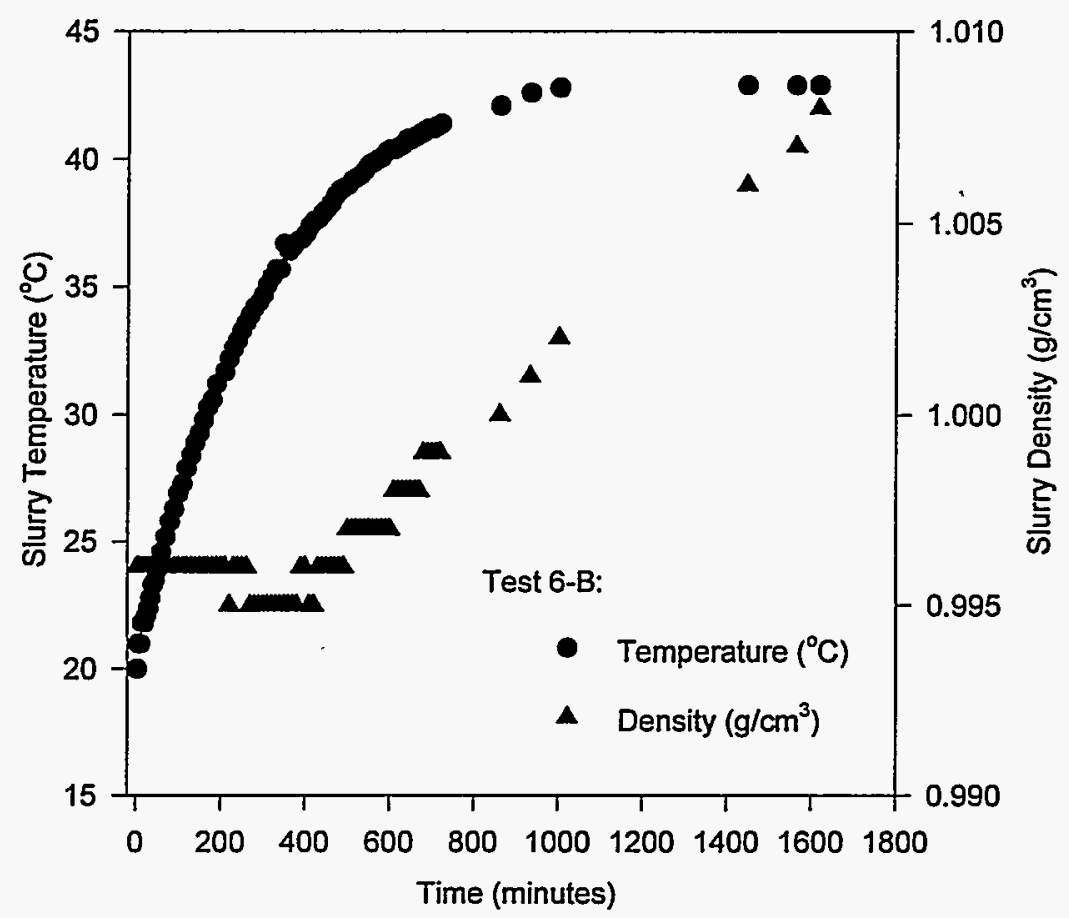

Figure A.24. Test 6-B Slurry Temperature and Density

\section{A. 13}




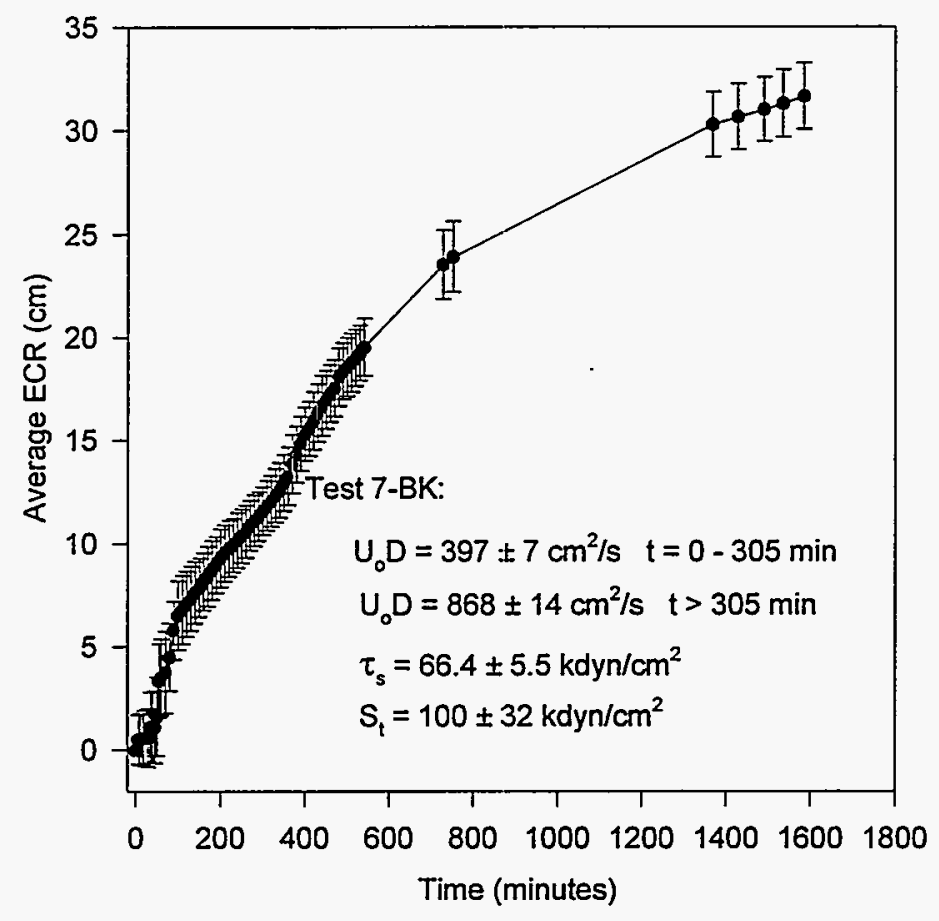

Figure A.25. Test 7-BK ECR vs. Time

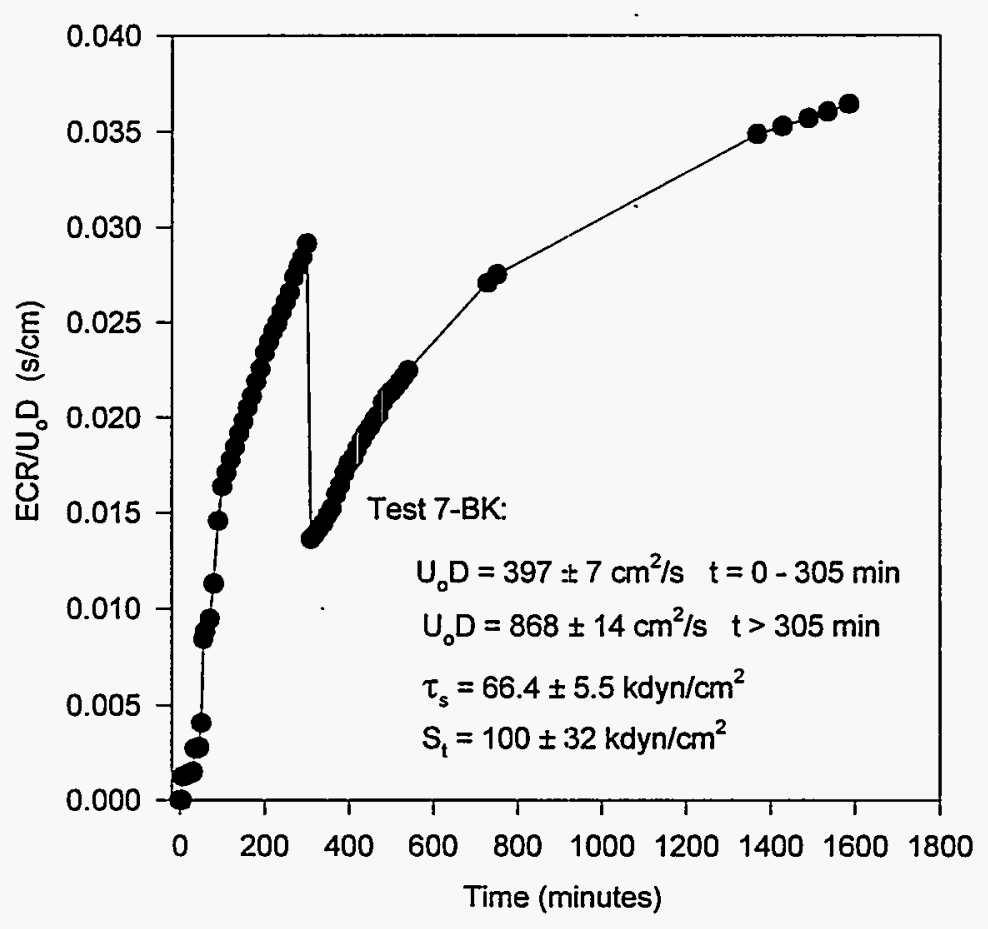

Figure A.26. Test 7-BK ECR/ $\mathrm{U}_{0} \mathrm{D}$ vs. Time

A. 14 


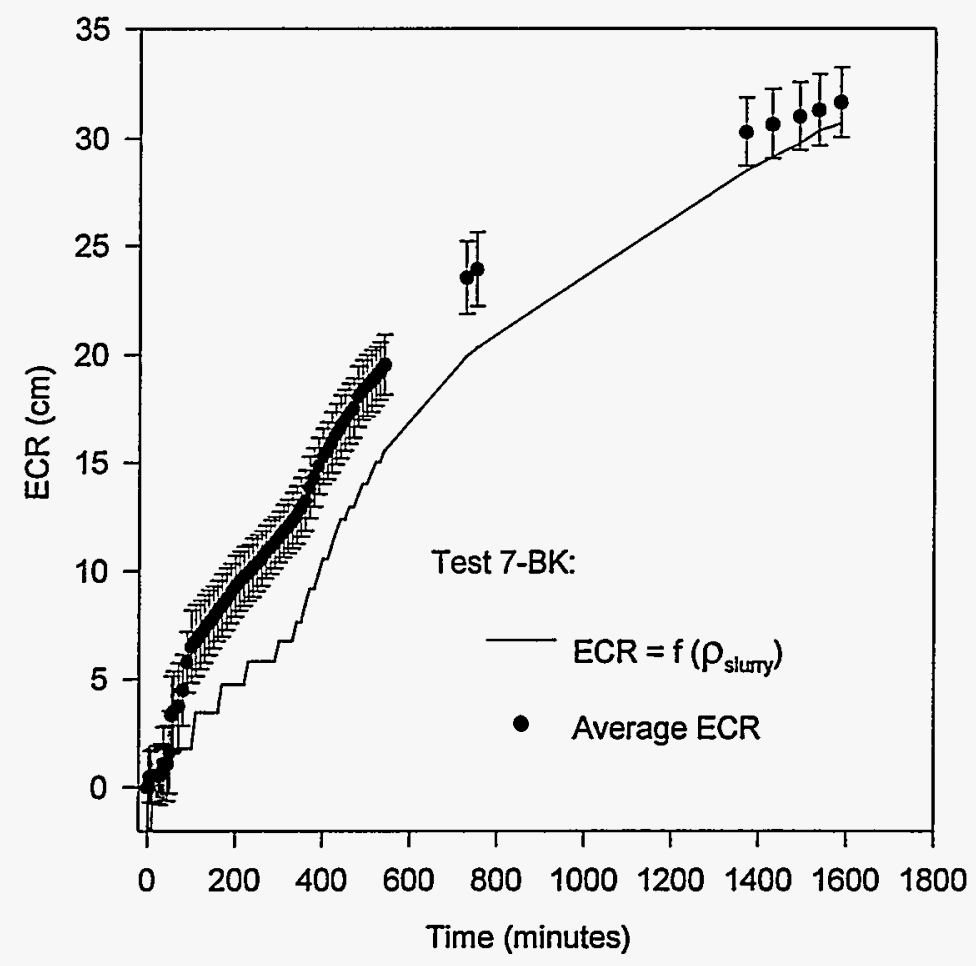

Figure A.27. Test 7-BK ECR Calculated from Density

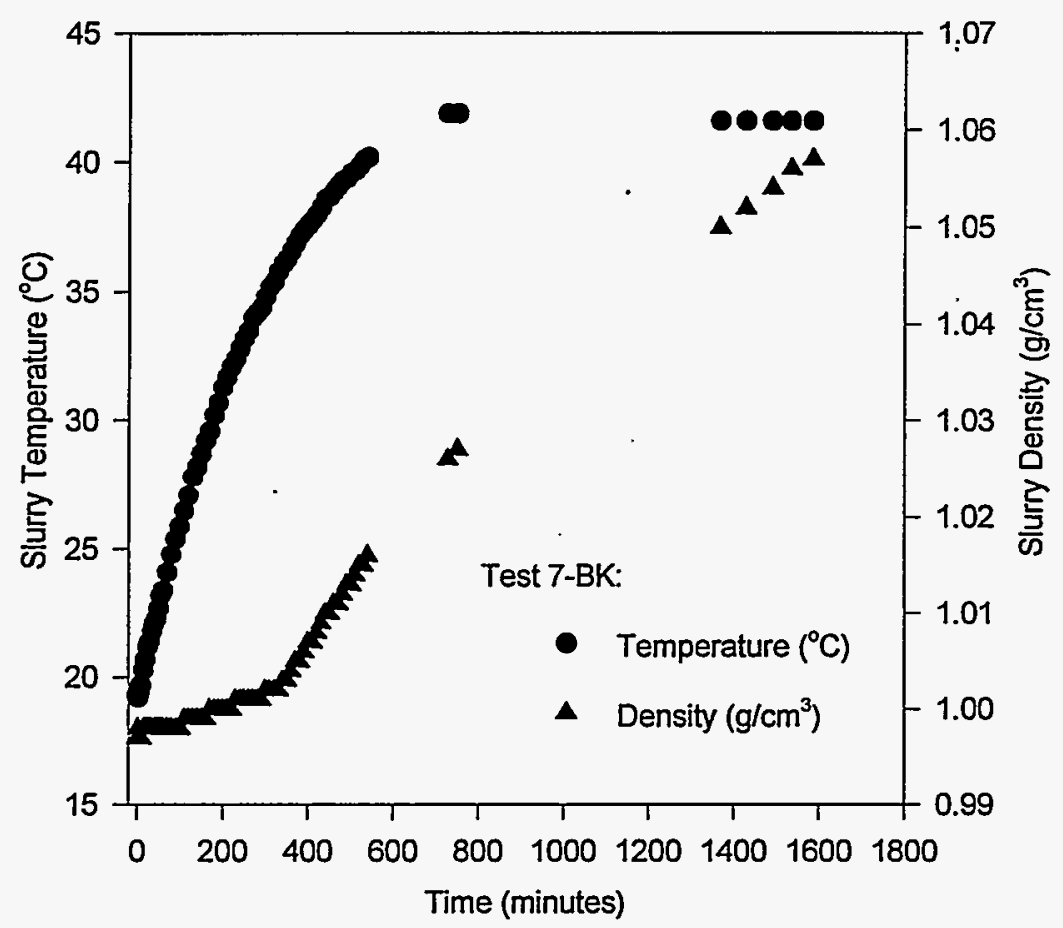

Figure A.28. Test 7-BK Slurry Temperature and Density

\section{A. 15}




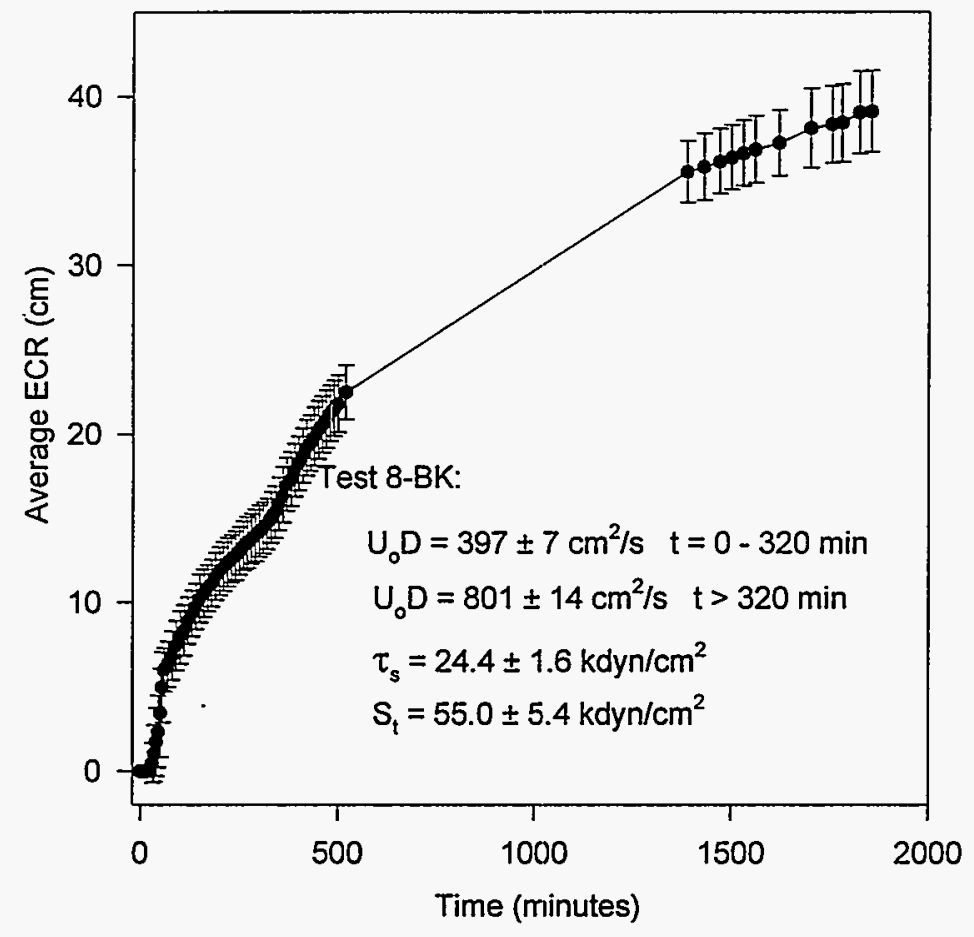

Figure A.29. Test 8-BK ECR vs. Time

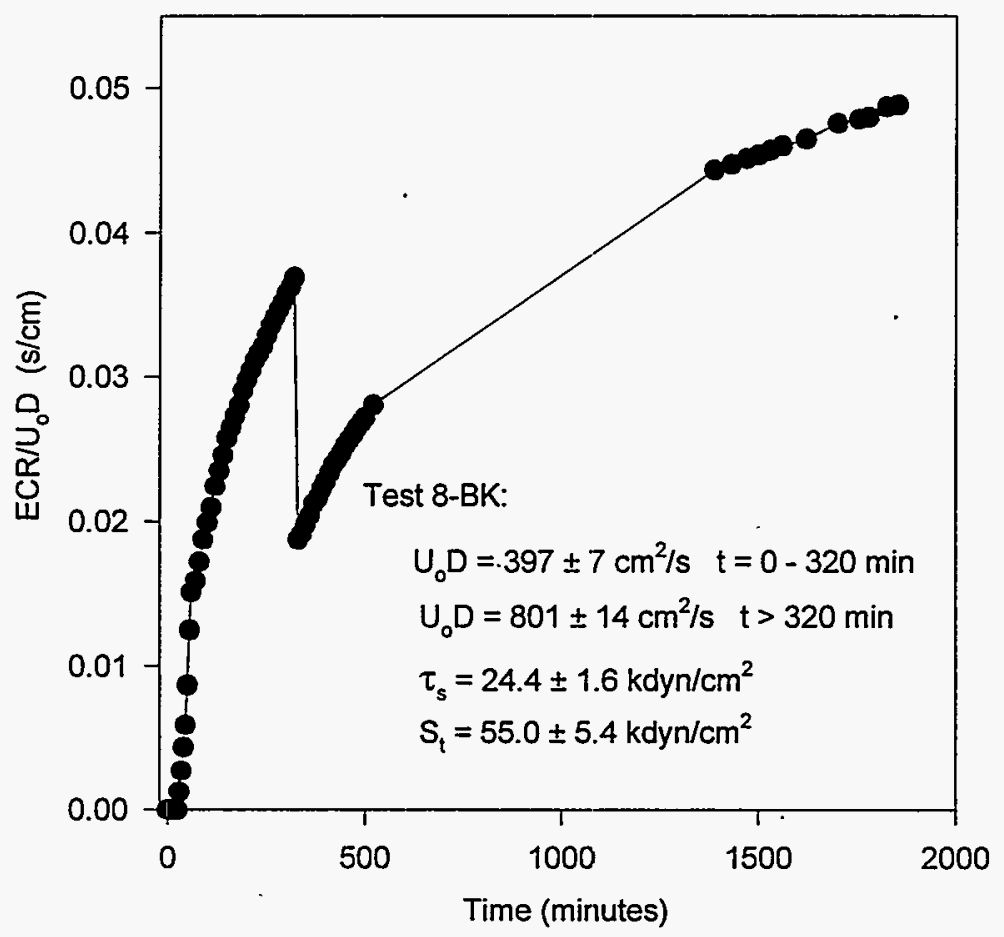

Figure A.30. Test 8-BK ECR/U $D$ vs. Time 


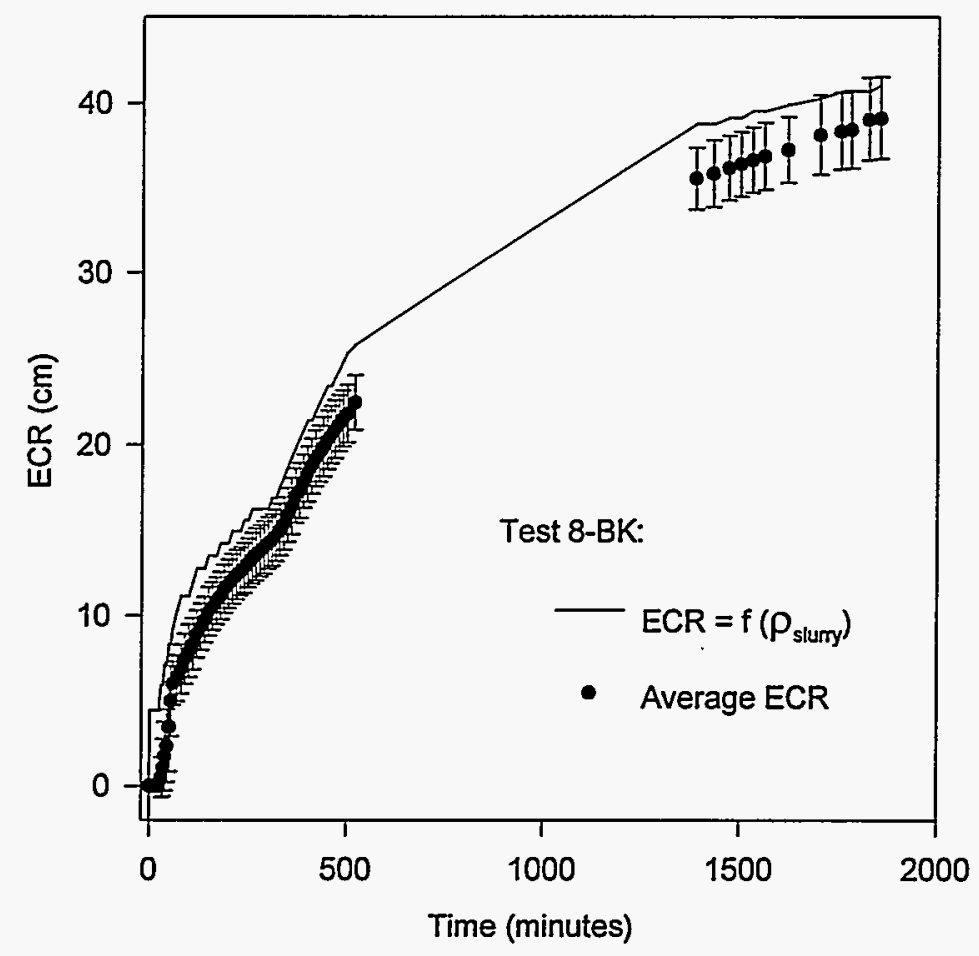

Figure A.31. Test 8-BK ECR Calculated from Density

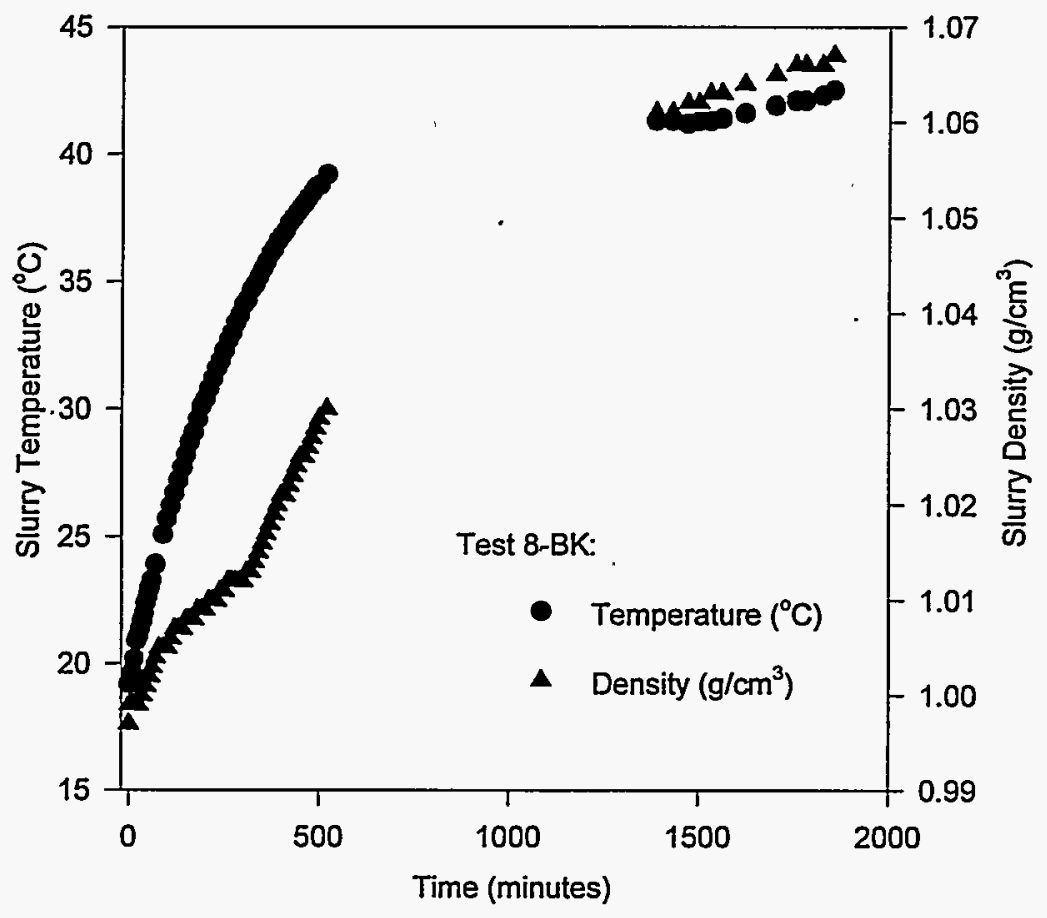

Figure A.32. Test 8-BK Slurry Temperature and Density 


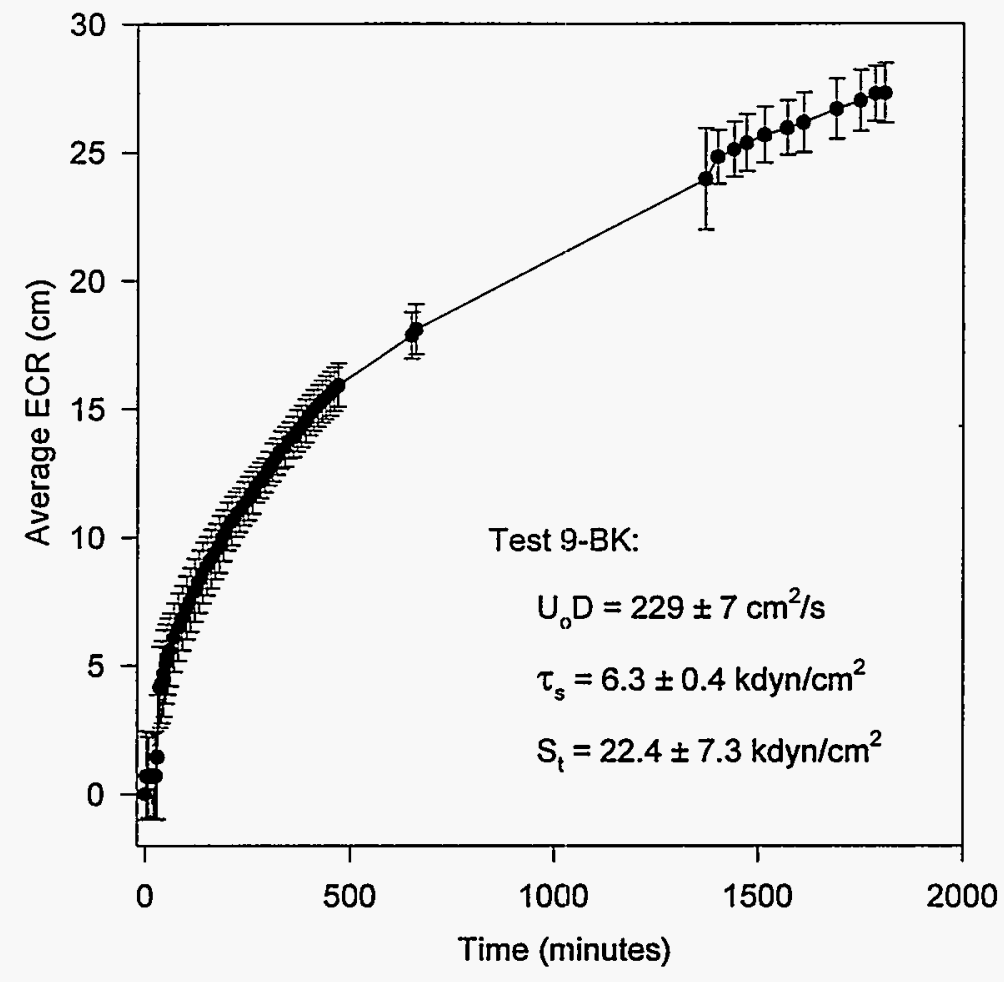

Figure A.33. Test 9-13K ECR vs. Time

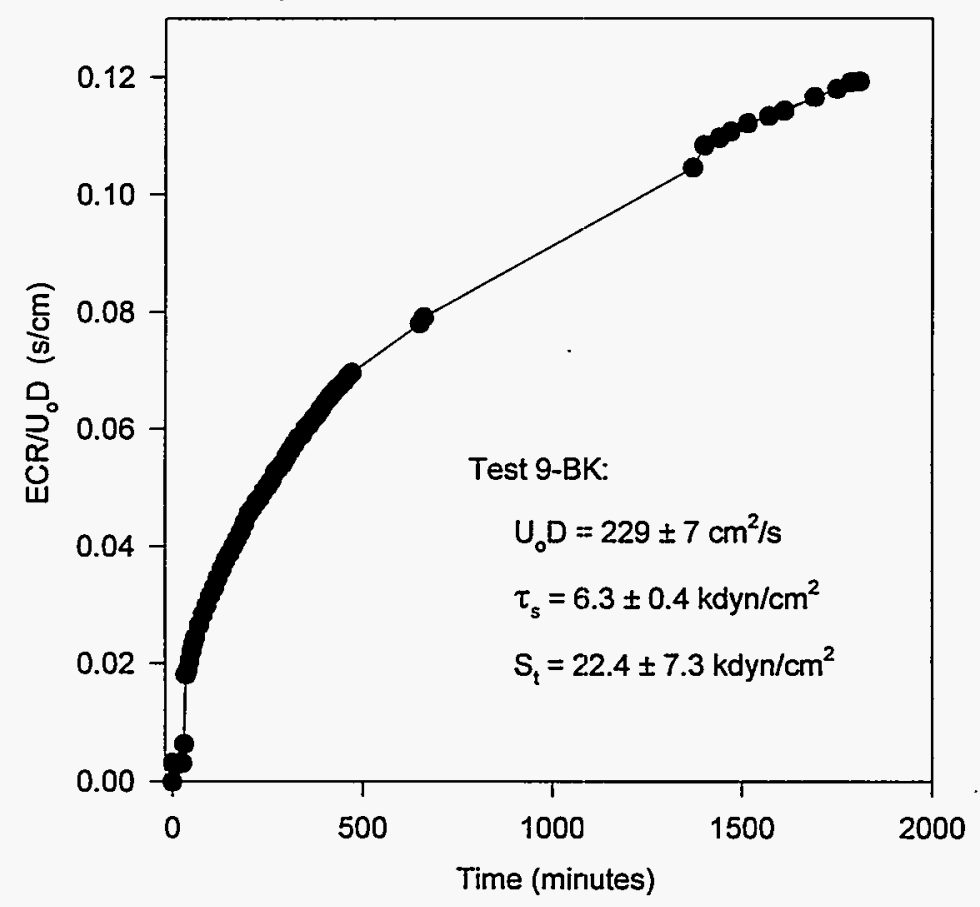

Figure A.34. Test 9-BK ECR/ $\mathrm{U}_{0} \mathrm{D}$ vs. Time 


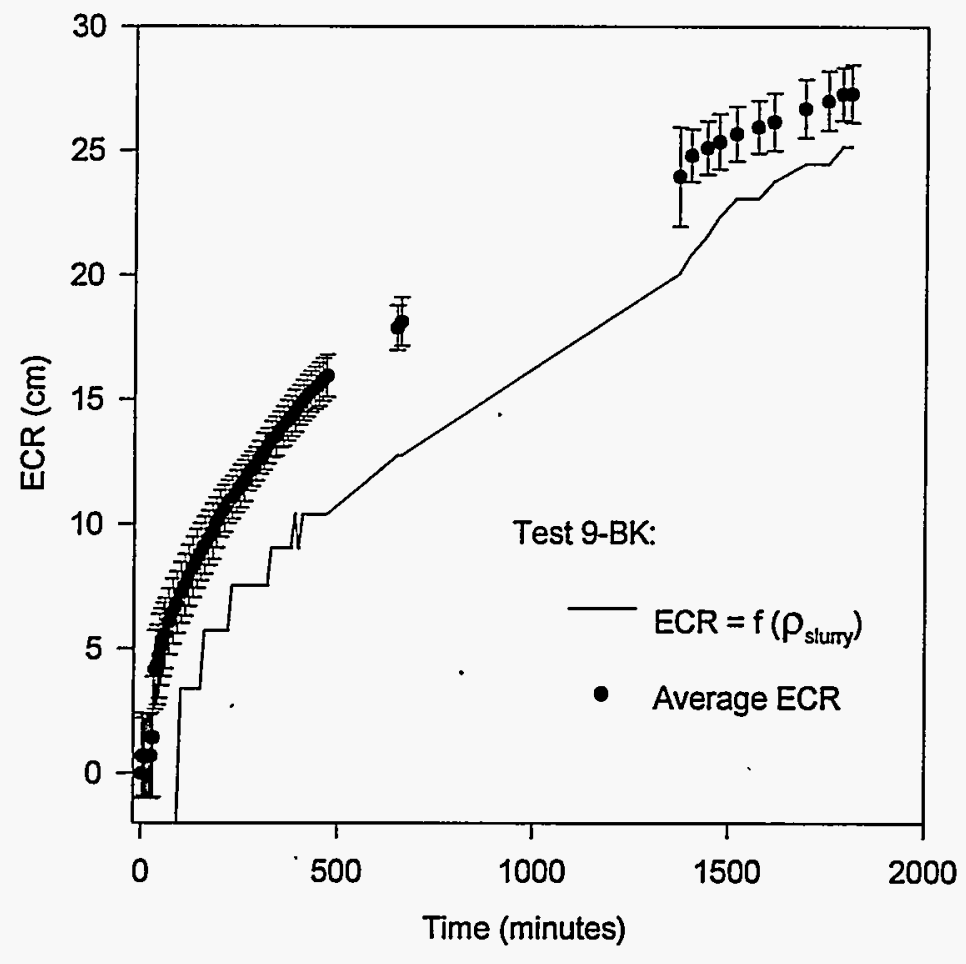

Figure A.35. Test 9-BK ECR Calculated from Density

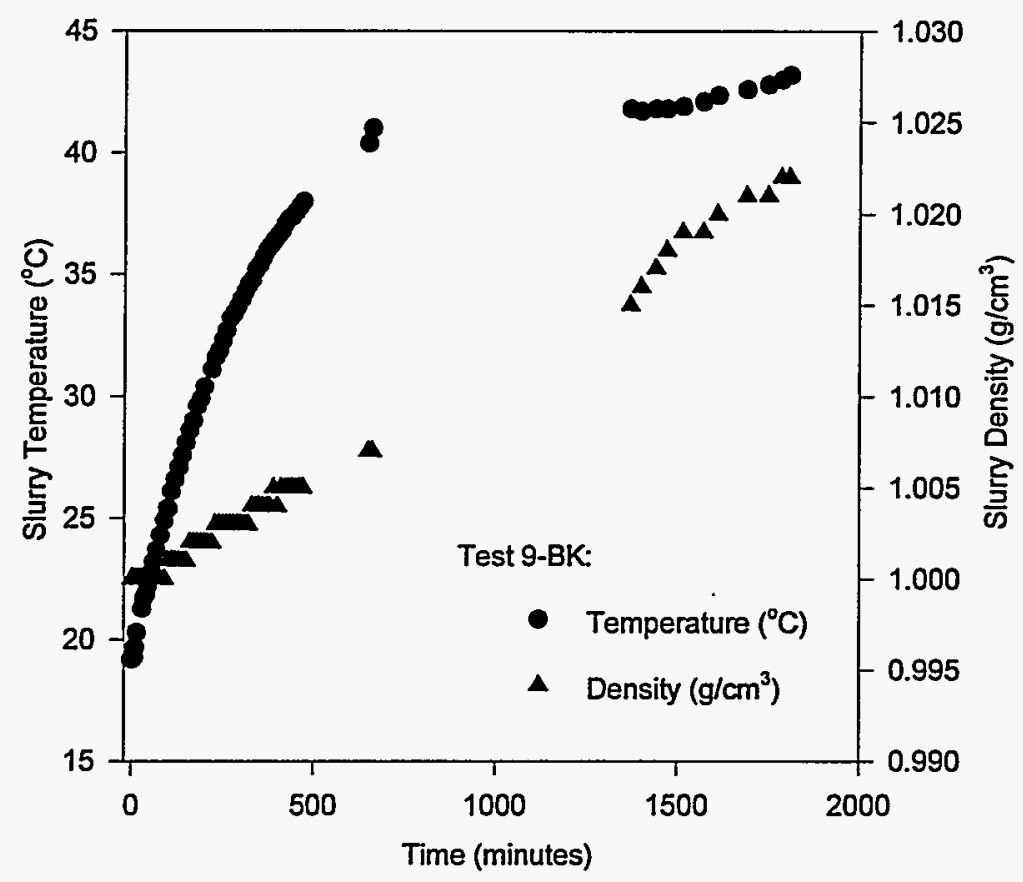

Figure A.36. Test 9-BK Slurry Temperature and Density 


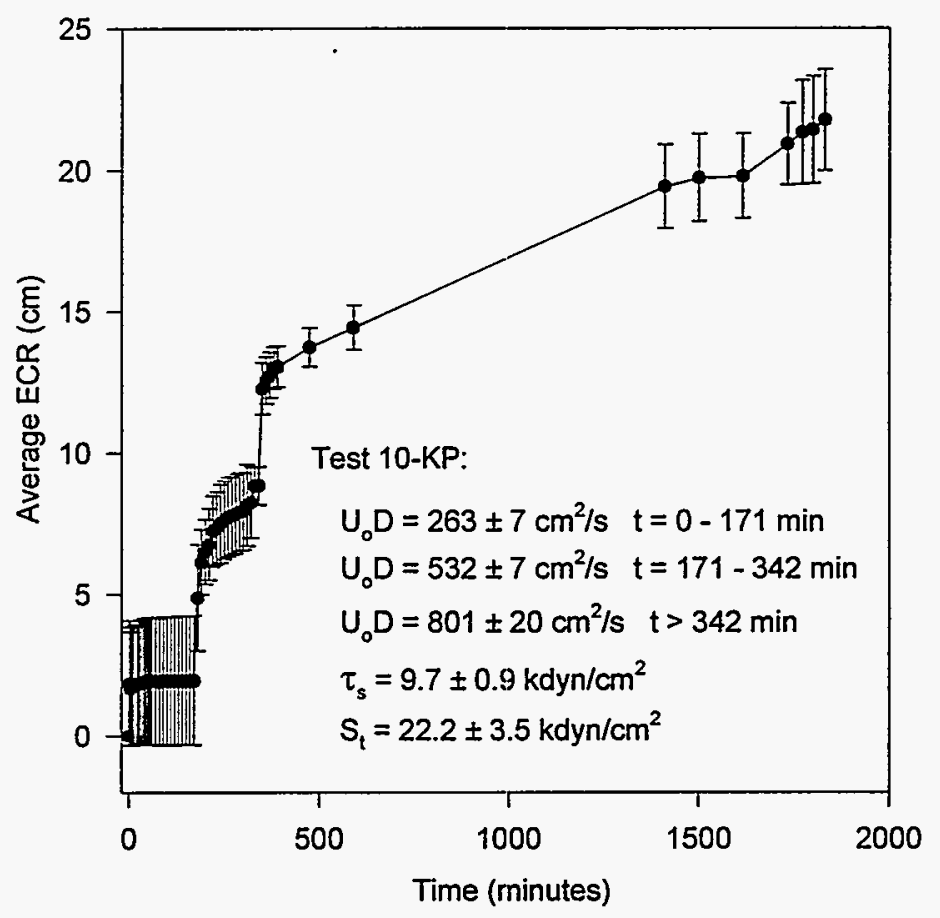

Figure A.37. Test 10-KP ECR vs. Time

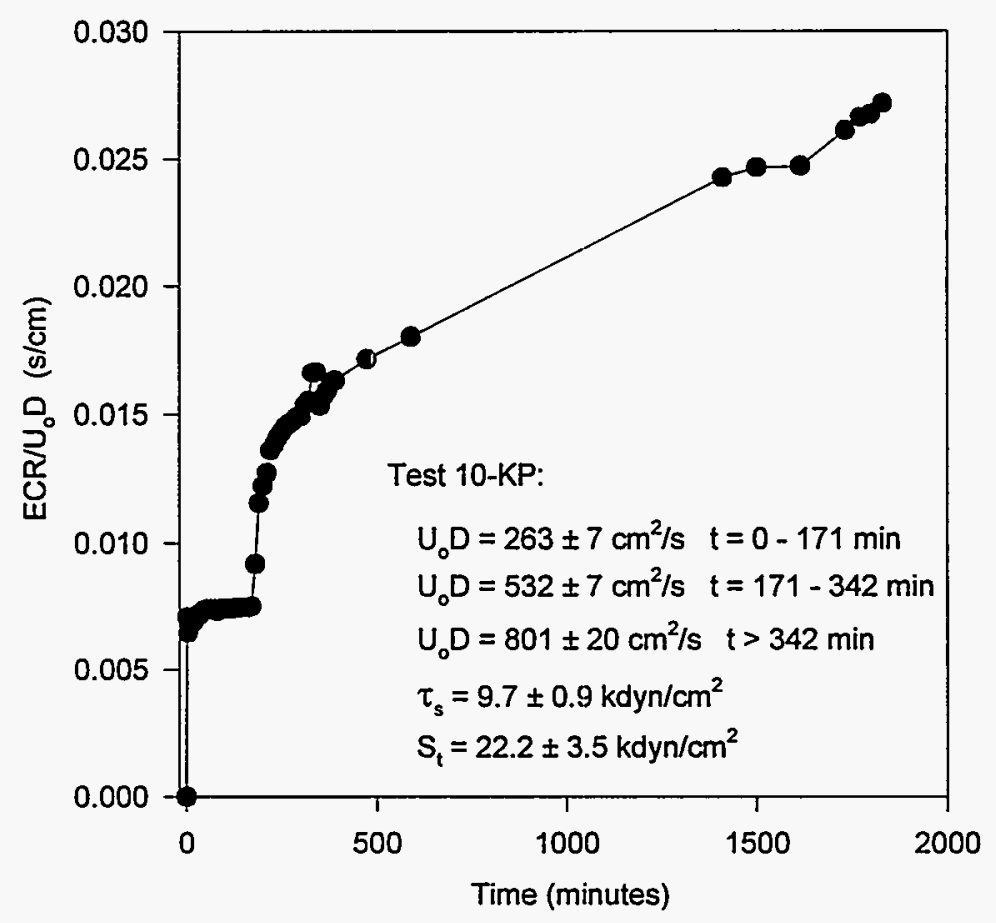

Figure A.38. Test $10-\mathrm{KP} E C R / \mathrm{U}_{0} \mathrm{D}$ vs. Time 


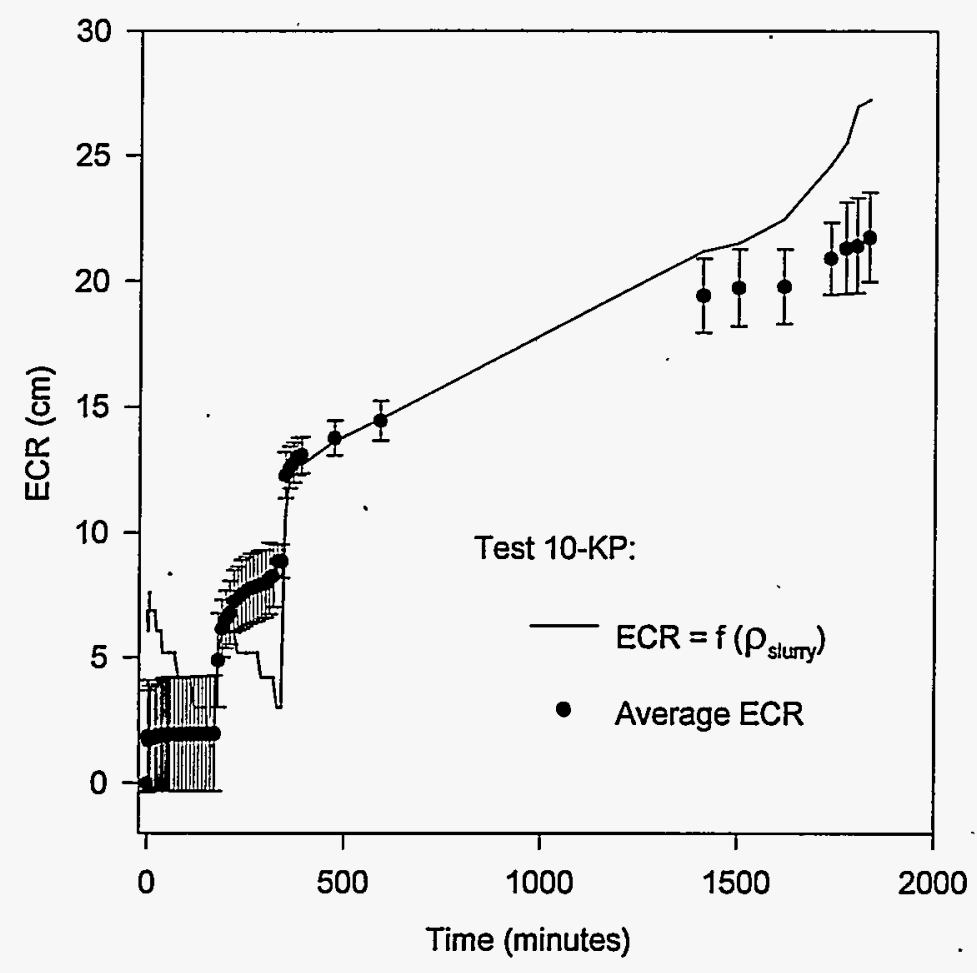

Figure A.39. Test 10-KP ECR Calculated from Density

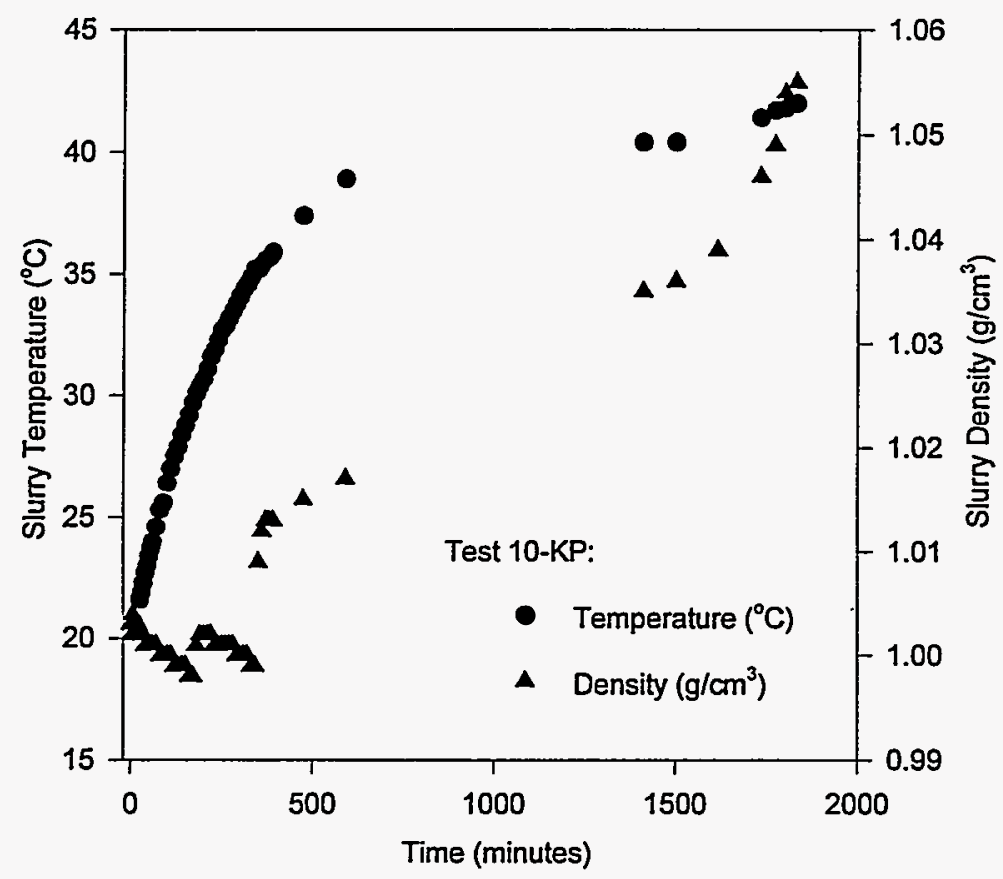

Figure A.40. Test 10-KP Slurry Temperature and Density 


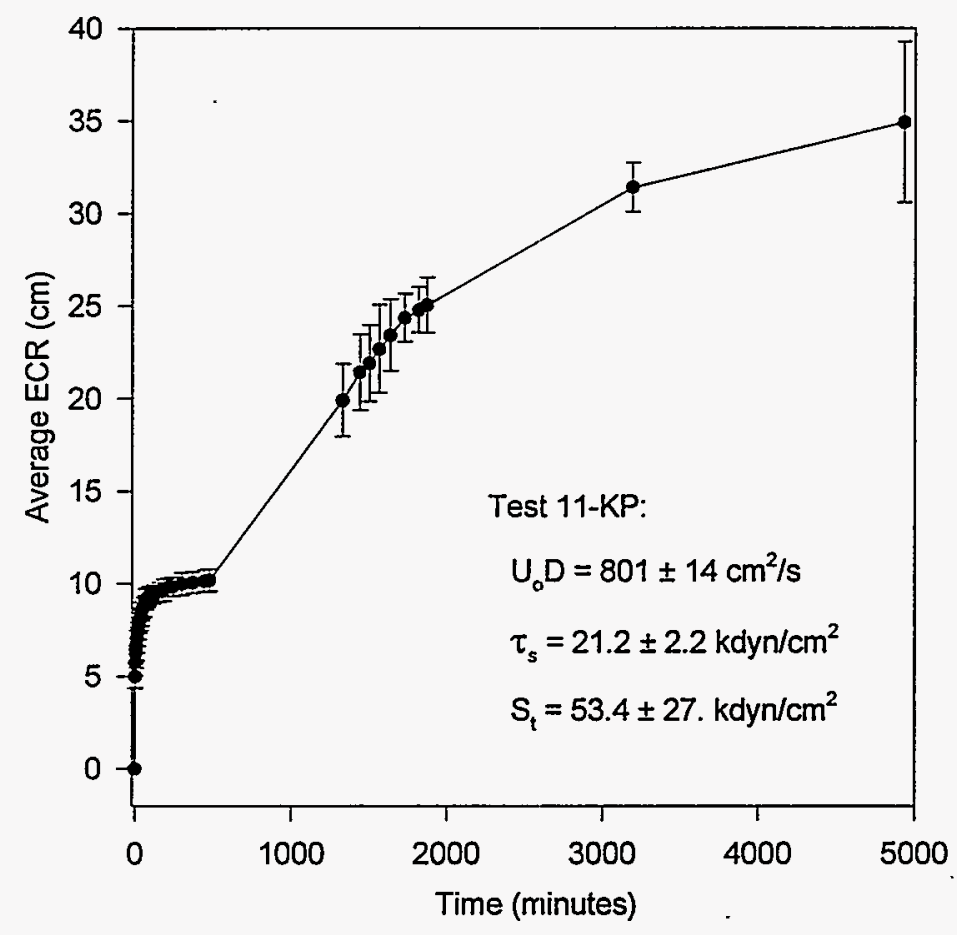

Figure A.41. Test 11-KP ECR vs. Time

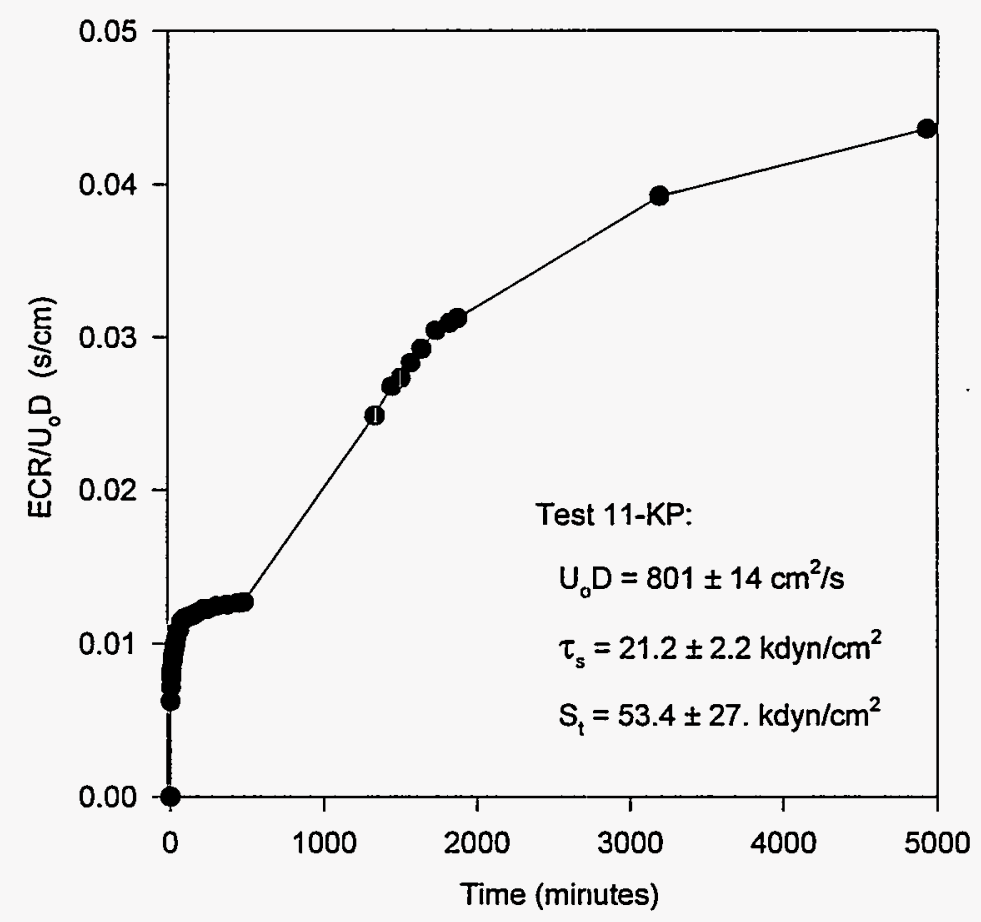

Figure A.42. Test $11-\mathrm{KP} E C R / \mathrm{U}_{0} \mathrm{D}$ vs. Time 


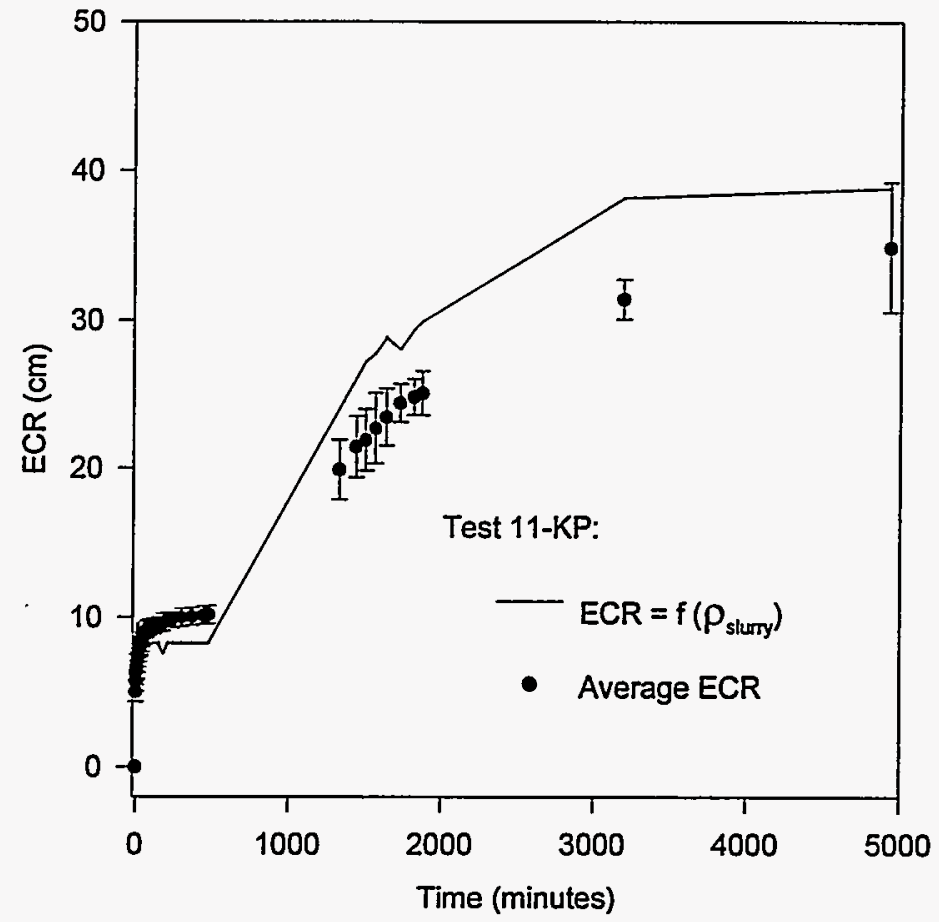

Figure A.43. Test 11-KP ECR Calculated from Density

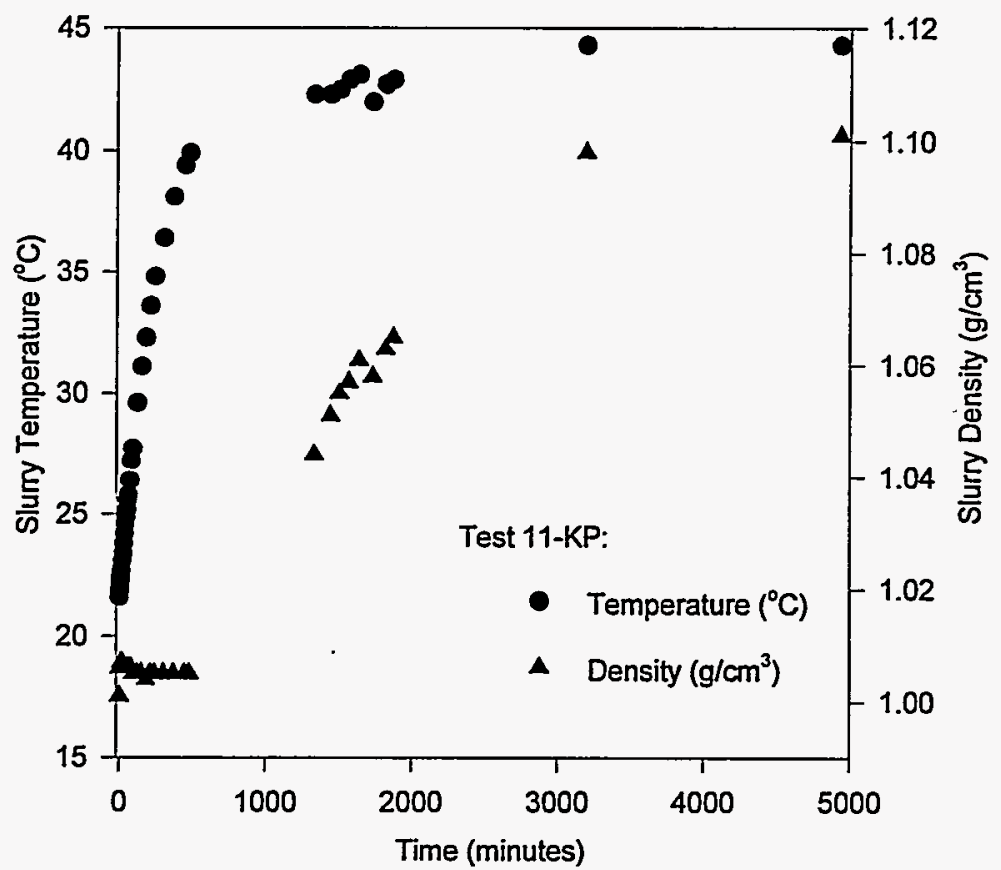

Figure A.44. Test 11-KP Slurry Temperature and Density 


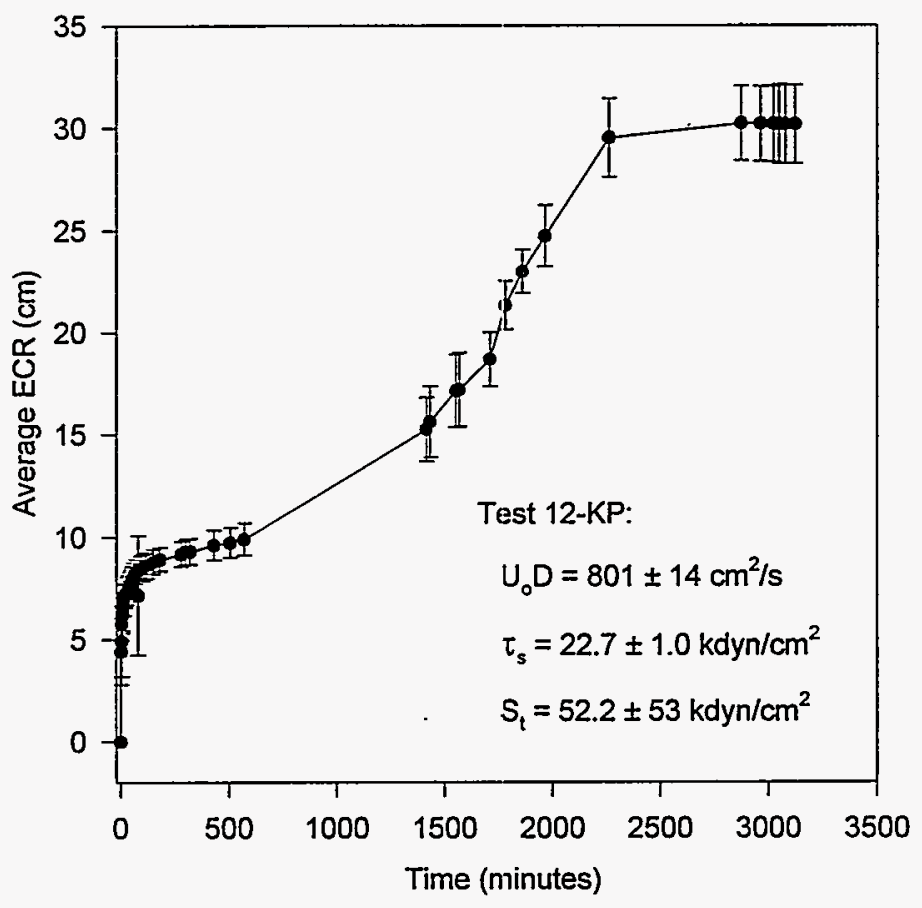

Figure A.45. Test 12-KP ECR vs. Time

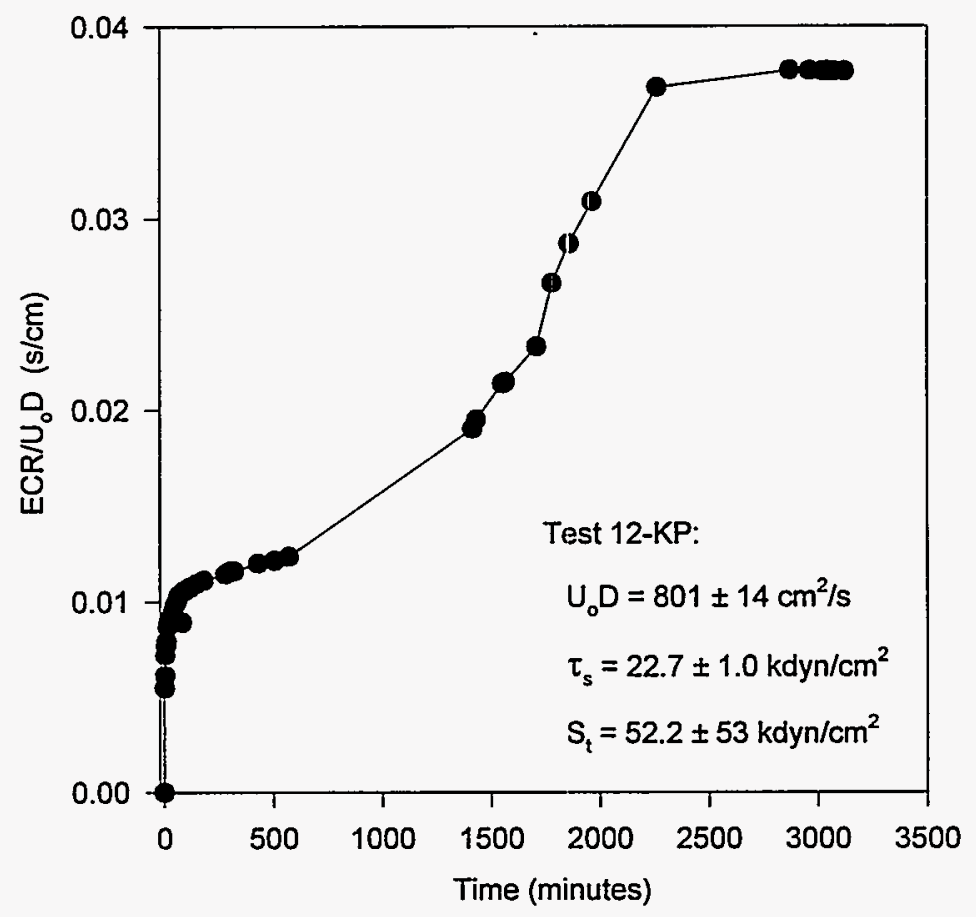

Figure A.46. Test $12-\mathrm{KP} E C R / \mathrm{U}_{0} \mathrm{D}$ vs. Time

\section{A. 24}




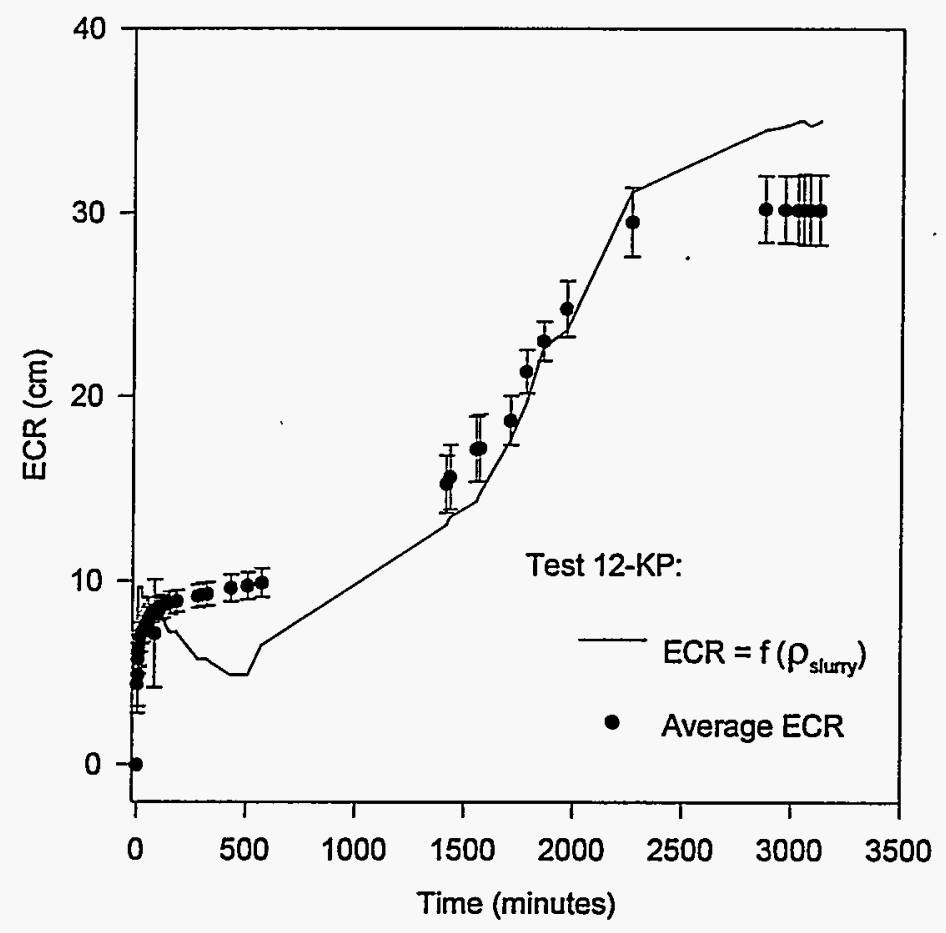

Figure A.47. Test 12-KP ECR Calculated from Density

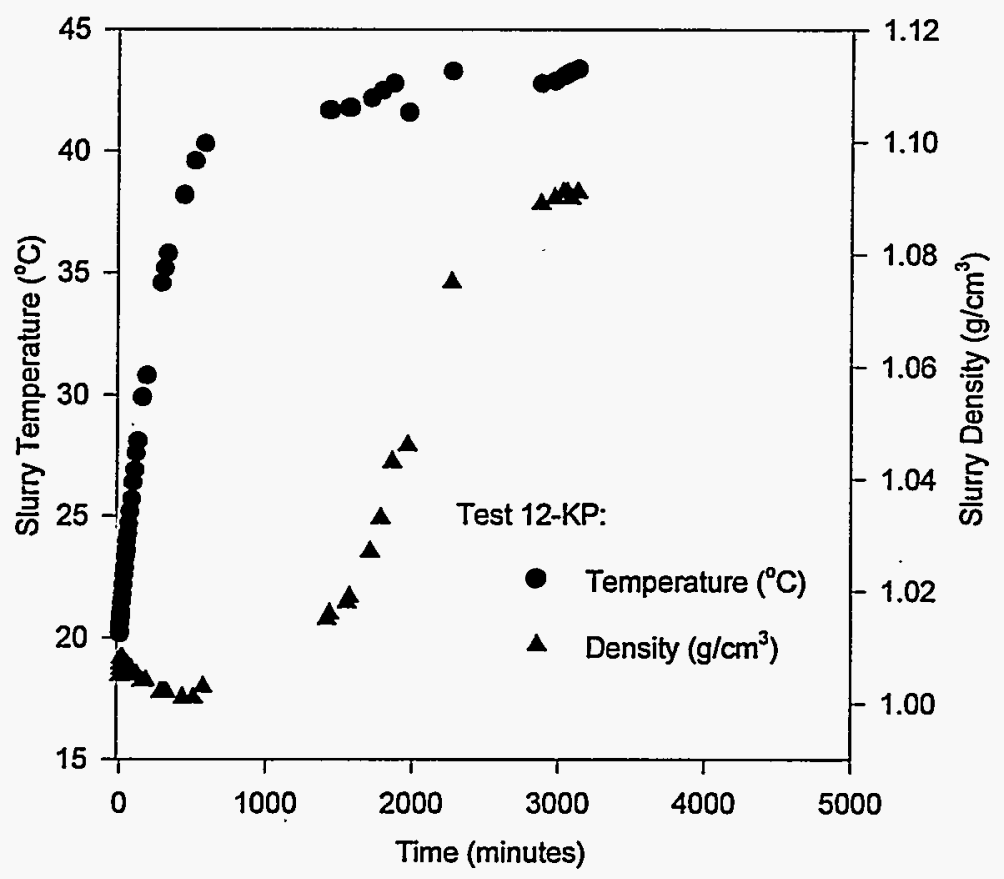

Figure A.48. Test 12-KP Slurry Temperature and Density 


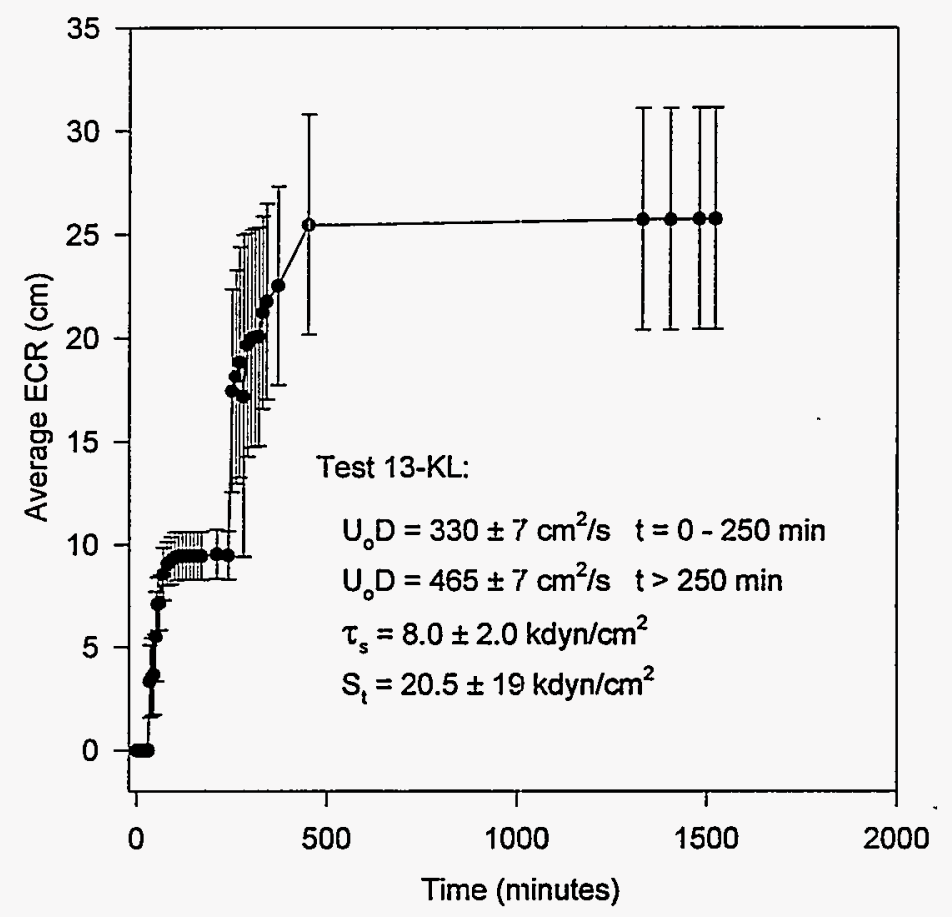

Figure A.49. Test $13-\mathrm{KL}$ ECR vs. Time

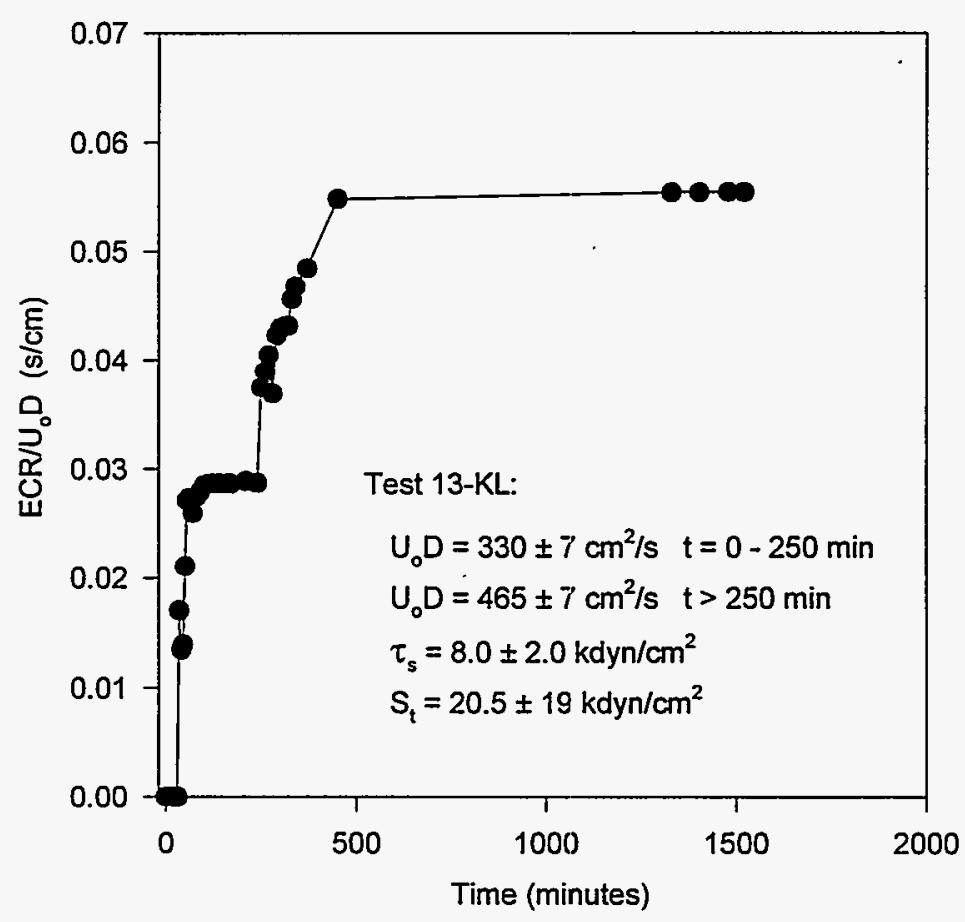

Figure A.50. Test $13-\mathrm{KL} L \mathrm{ECR} / \mathrm{U}_{0} \mathrm{D}$ vs. Time 


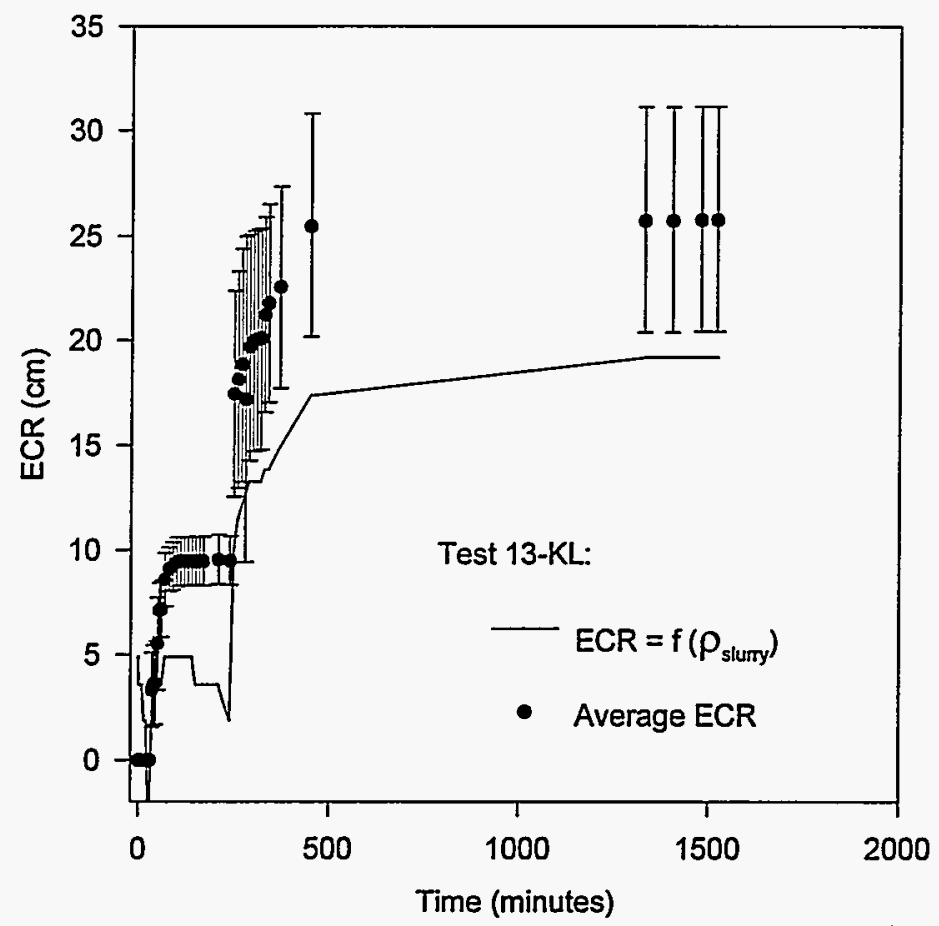

Figure A.51. Test 13-KI ECR Calculated from Density

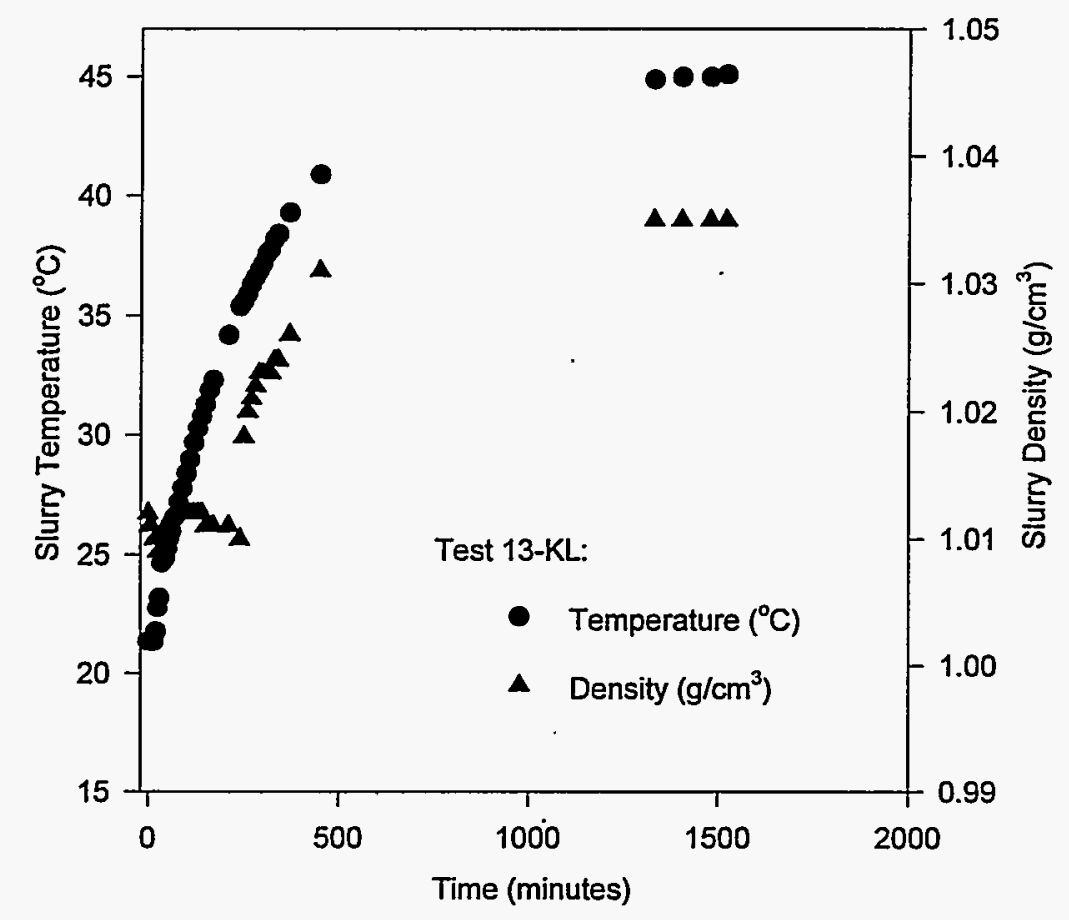

Figure A.52. Test 13-KL Slurry Temperature and Density 


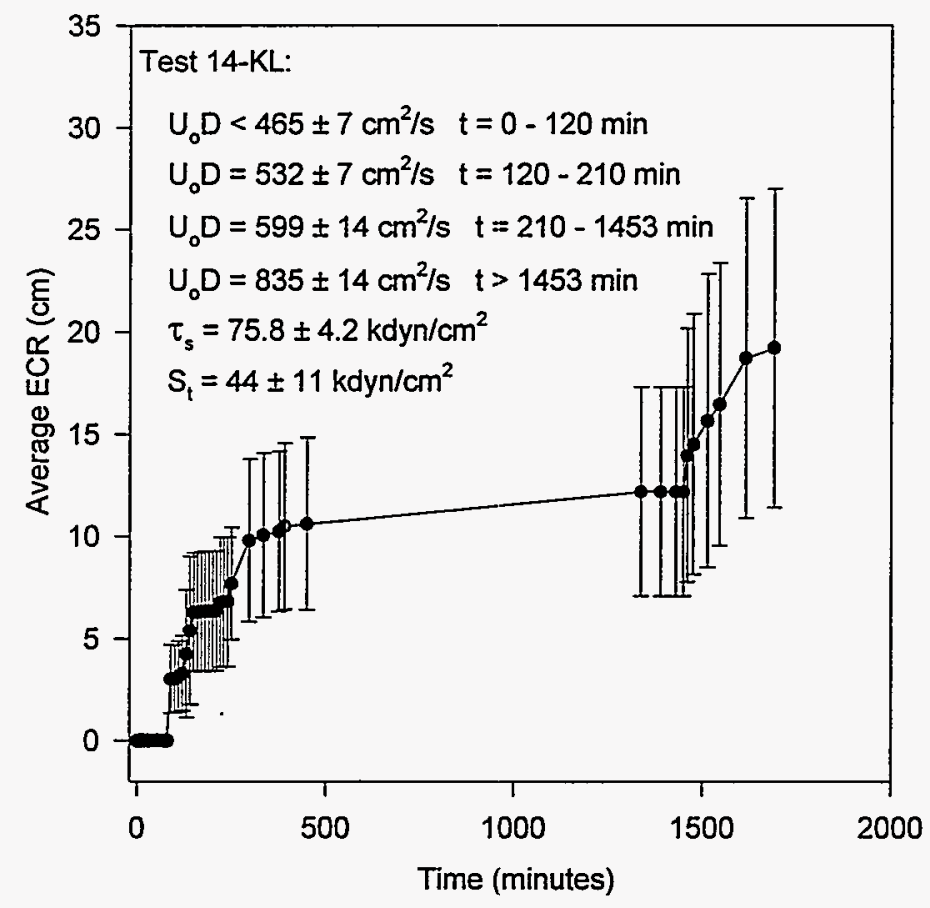

Figure A.53. Test $14-\mathrm{KL}$ ECR vs. Time

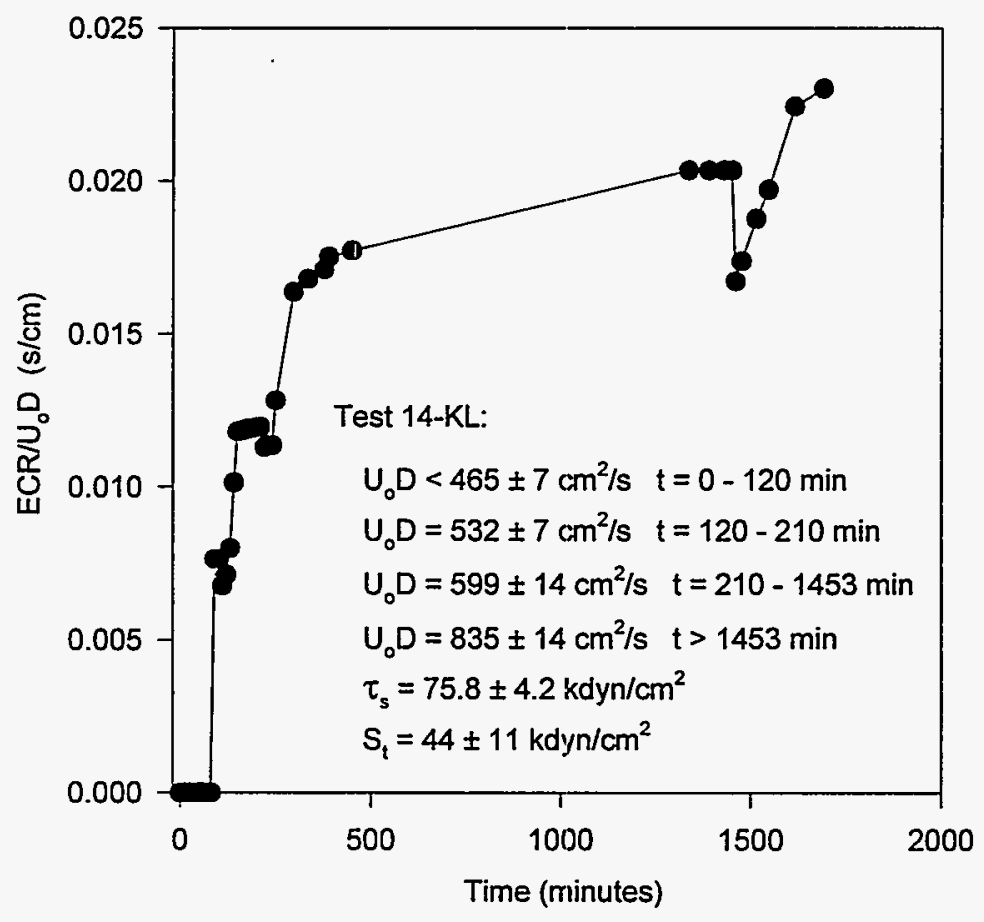

Figure A.54. Test $14-\mathrm{KL}$ ECR/ $\mathrm{U}_{0} \mathrm{D}$ vs. Time 


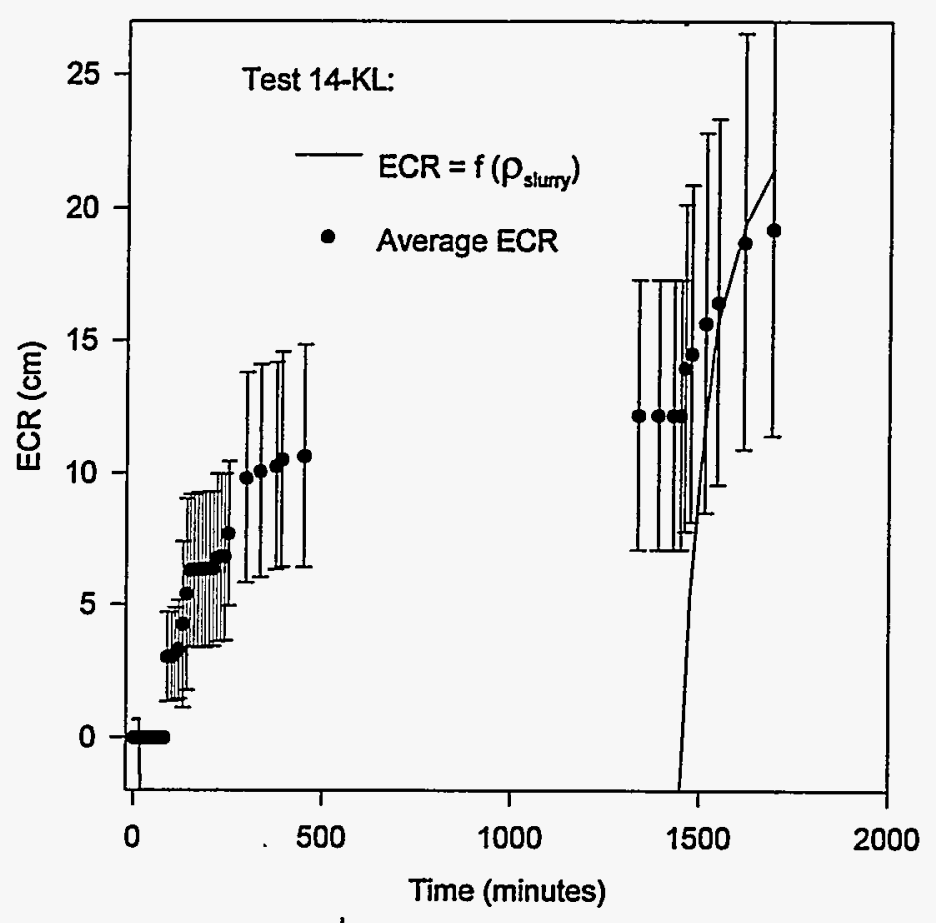

Figure A.55. Test 14-KL ECR Calculated from Density

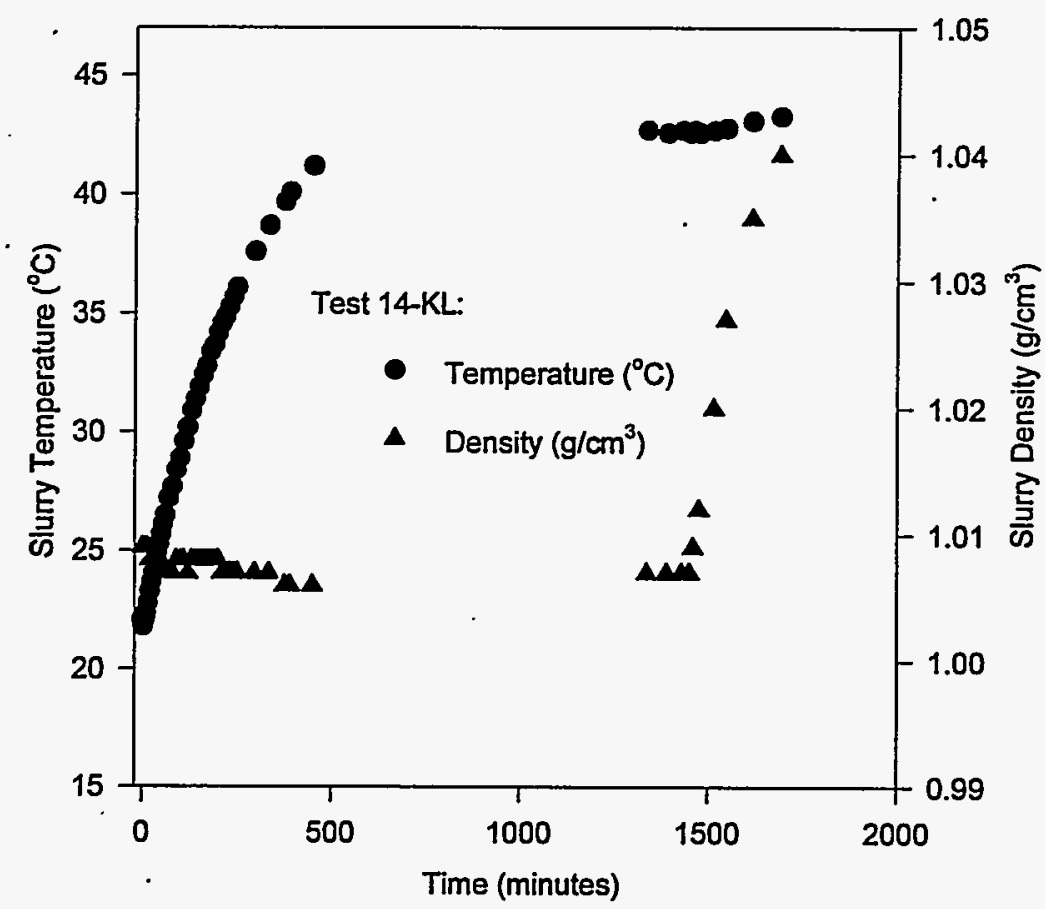

Figure A.56. Test 14-KL Slurry Temperature and Density 


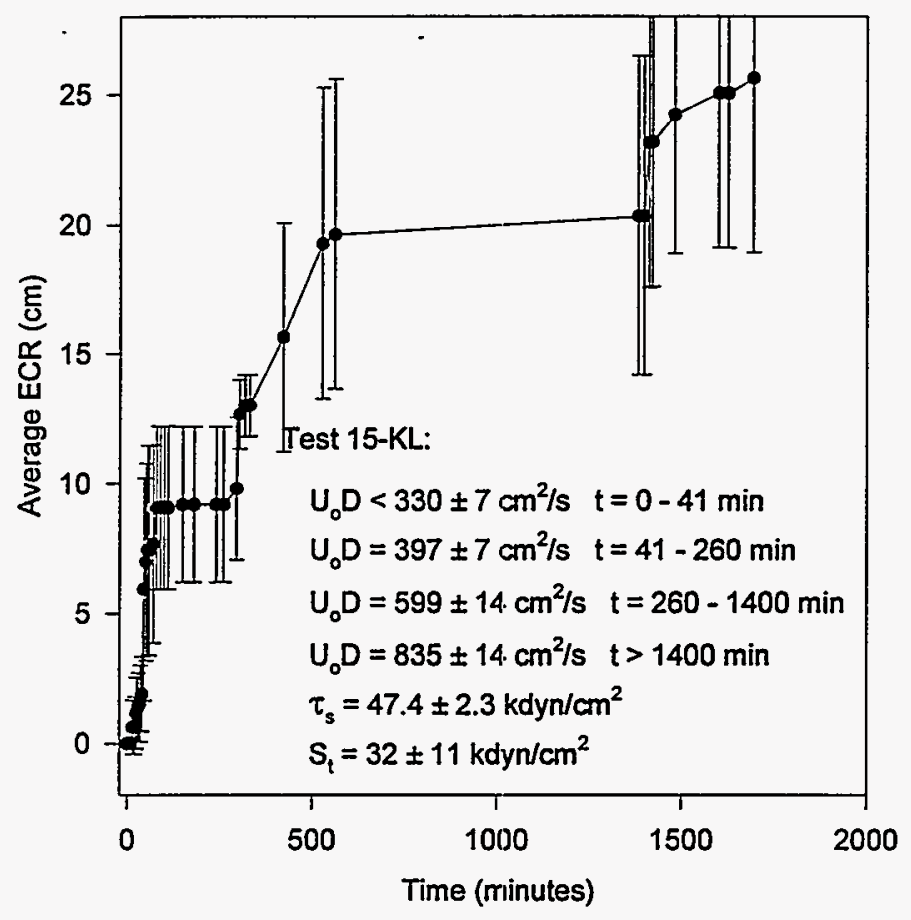

Figure A.57. Test $15-\mathbb{K L}$ ECR vs. Time

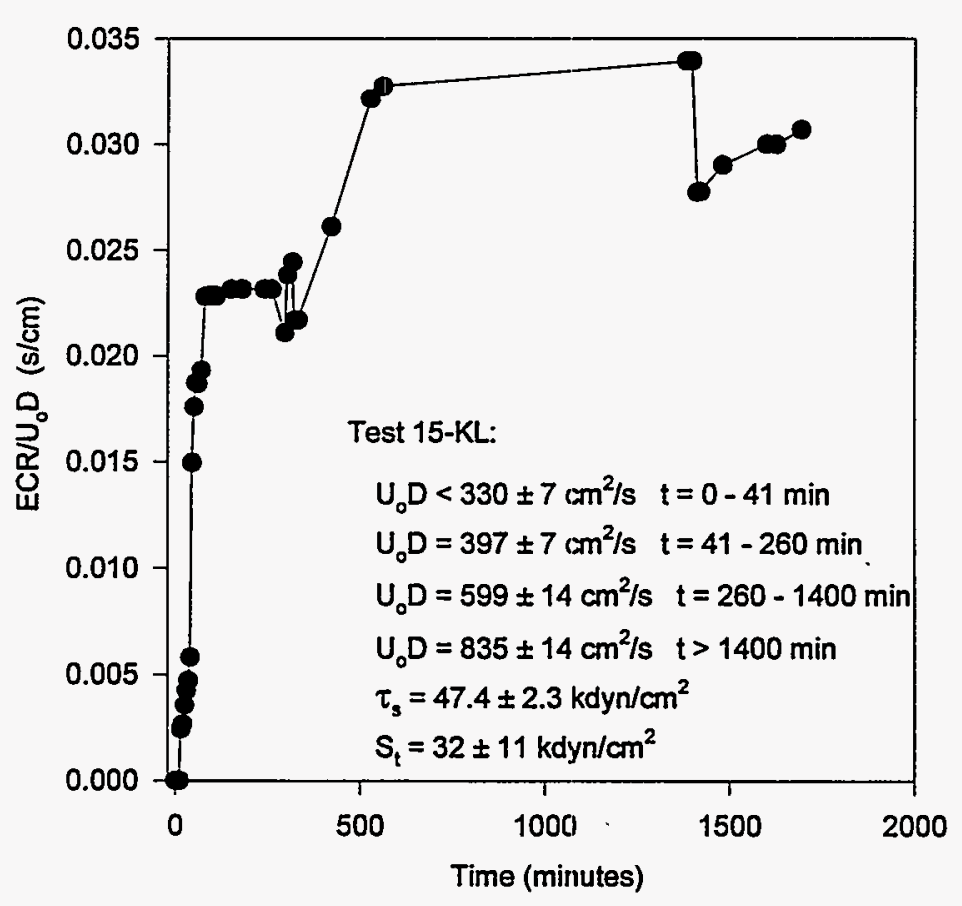

Figure A.58. Test $15-\mathrm{KL}, \mathrm{ECR} / \mathrm{U}_{0} \mathrm{D}$ vs. Time 


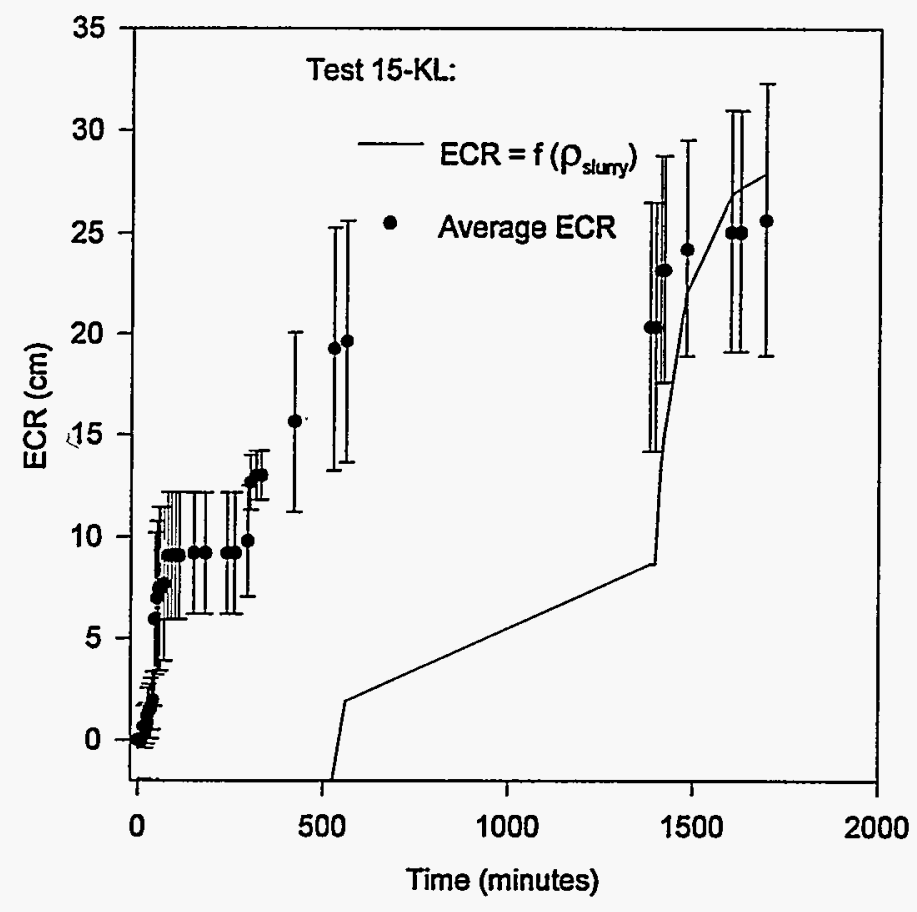

Figure A.59. Test 15-KL ECR Calculated from Density

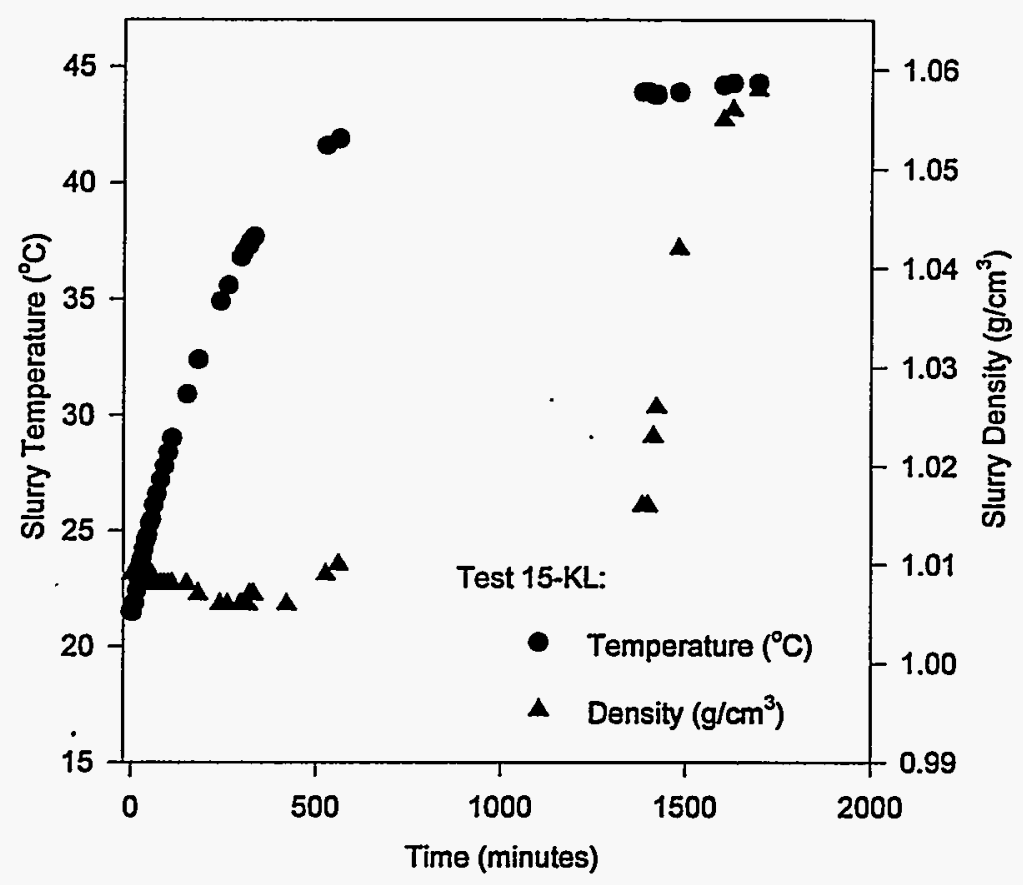

Figure A.60. Test 15-KL Slurry Temperature and Density

\section{A. 31}




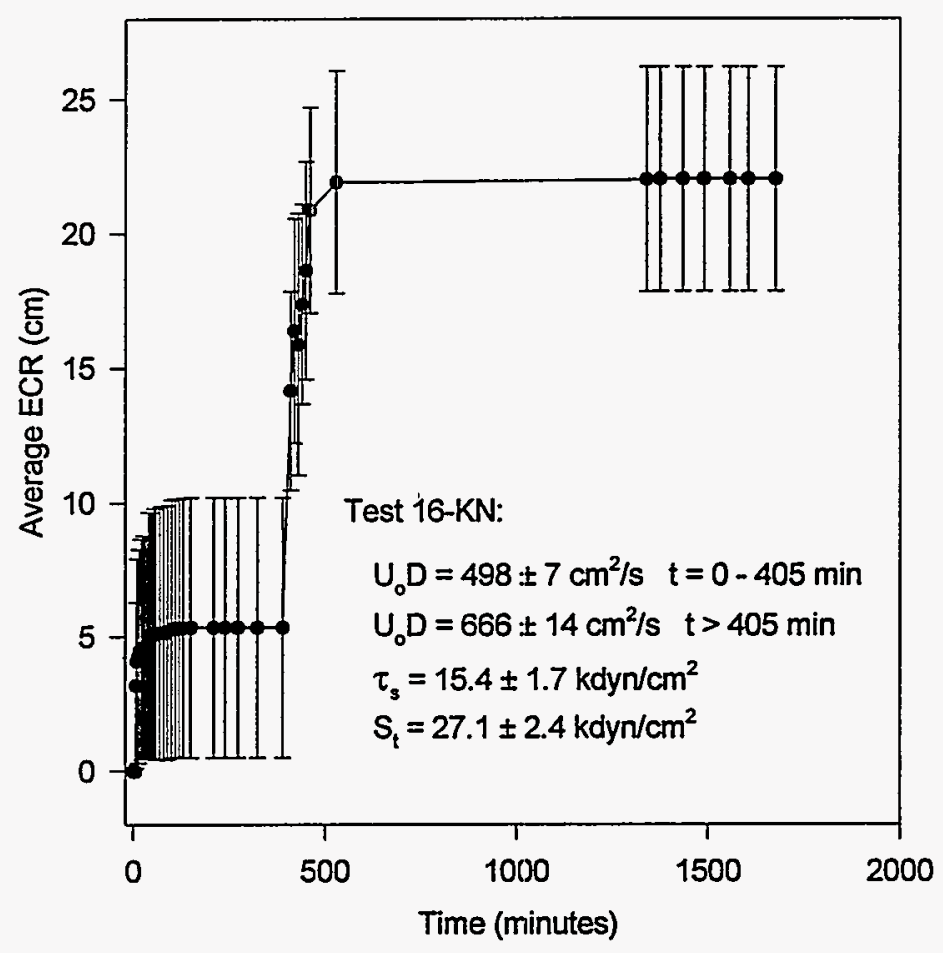

Figure A.61. Test $16-\mathrm{KNN}$ ECR vs. Time

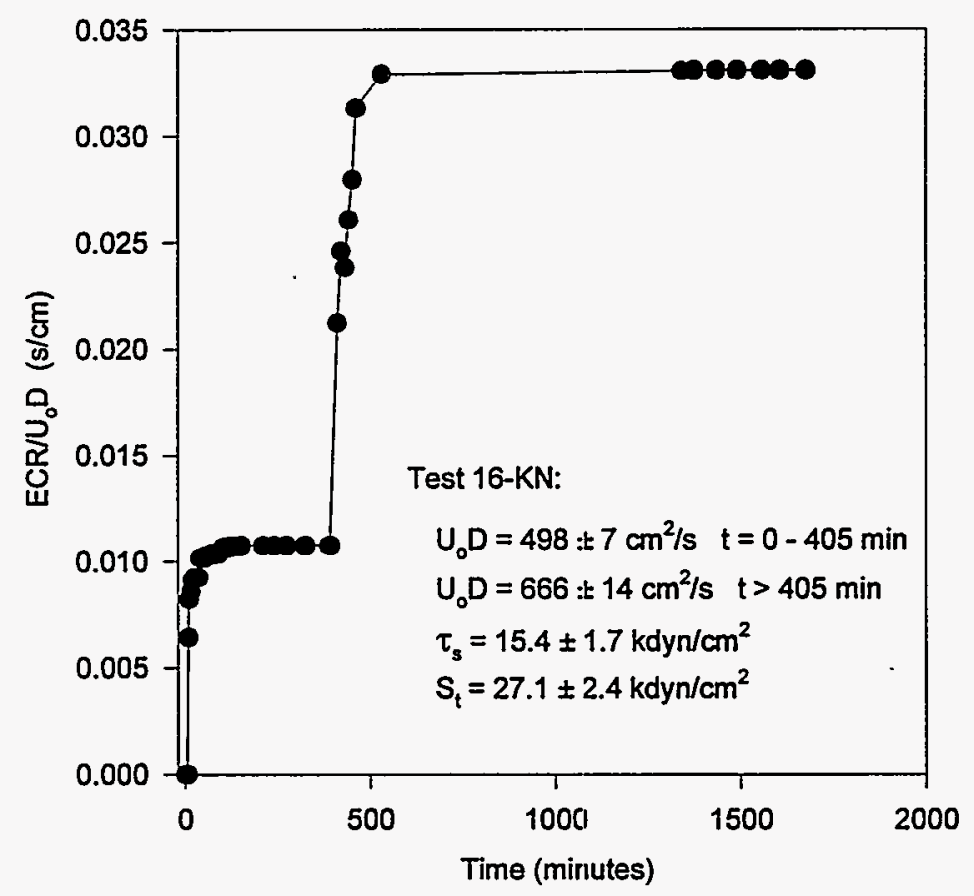

Figure A.62. Test $16-\mathrm{KN}$ ECR/U $\mathrm{D}$ vs. Time 


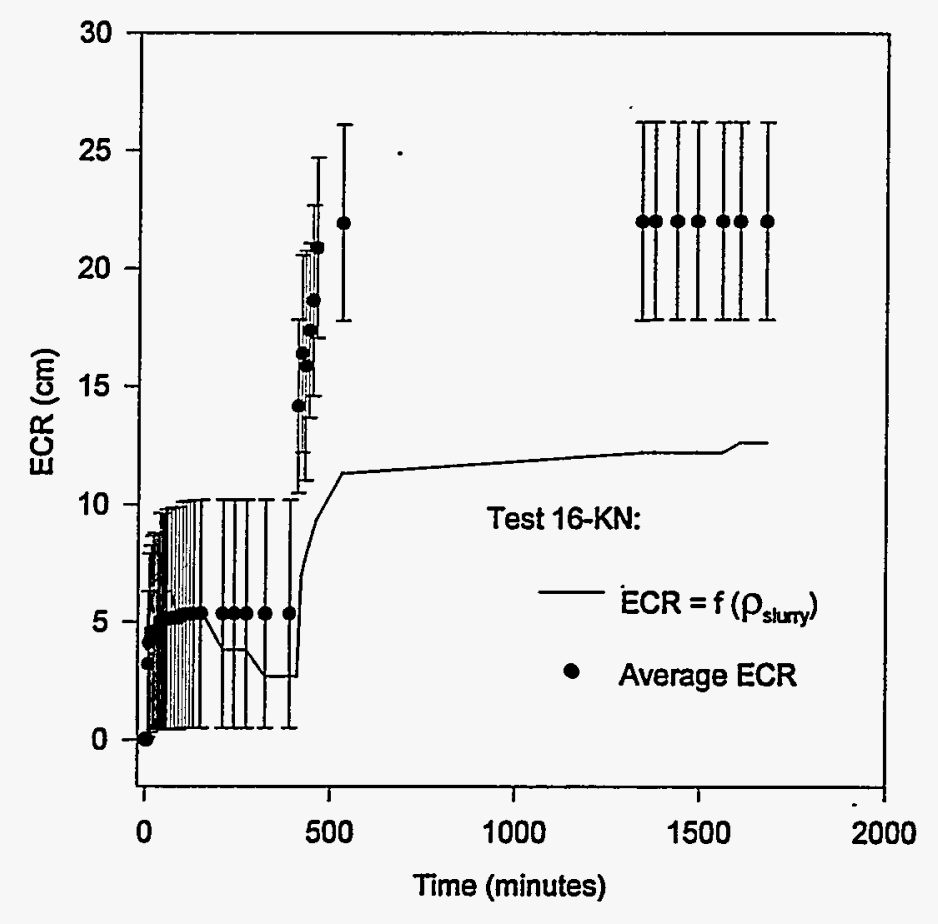

Figure A.63. Test 16-KN ECR Calculated from Density

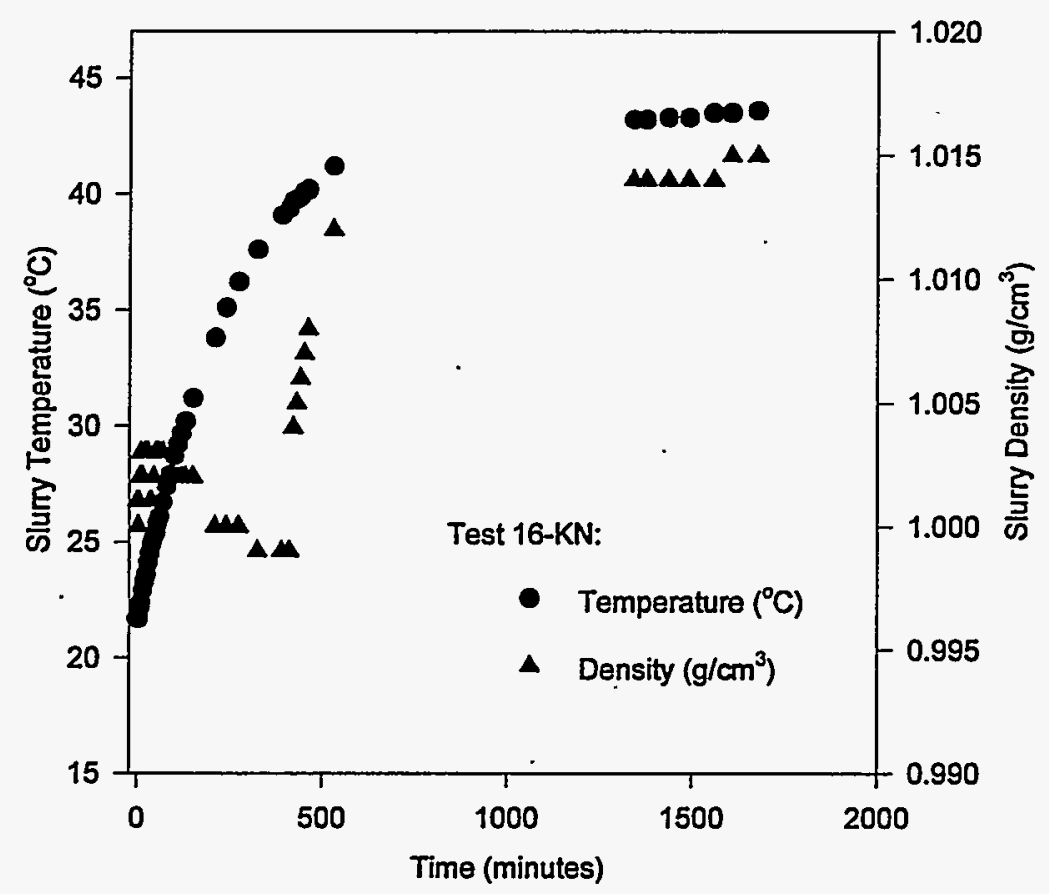

Figure A.64. Test 16-KN Slurry Temperature and Density 


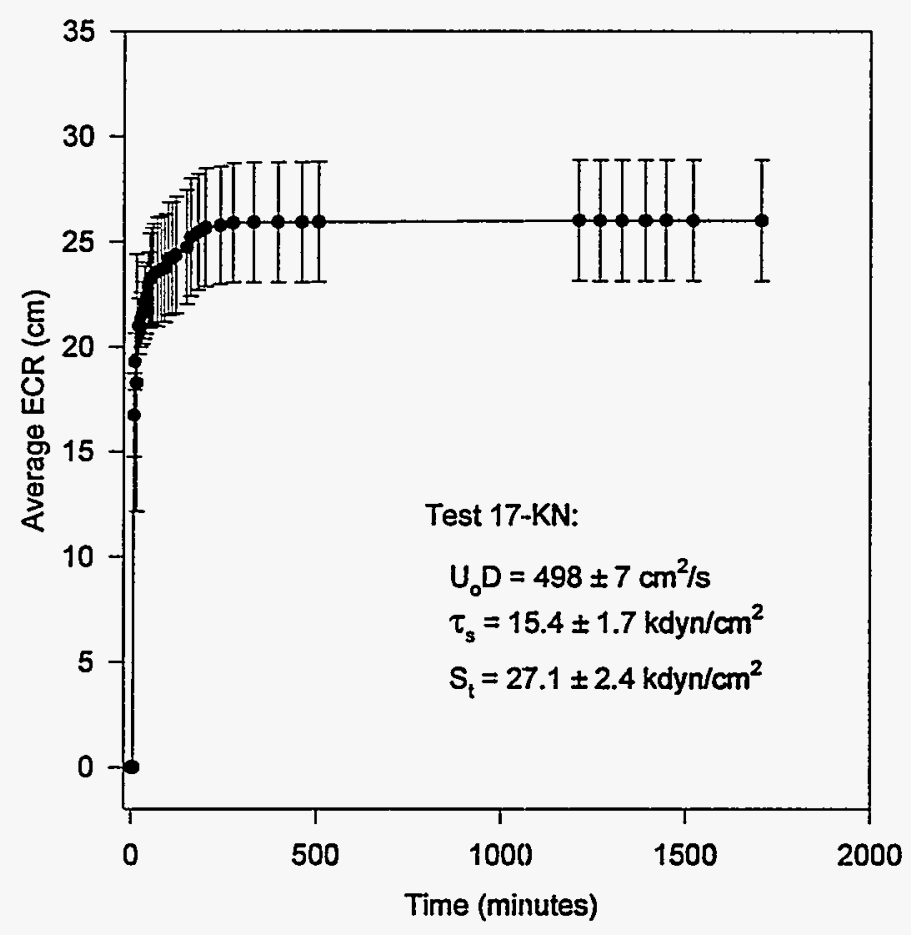

Figure A.65. Test $17-\mathrm{KN}$ ECR vs. Time

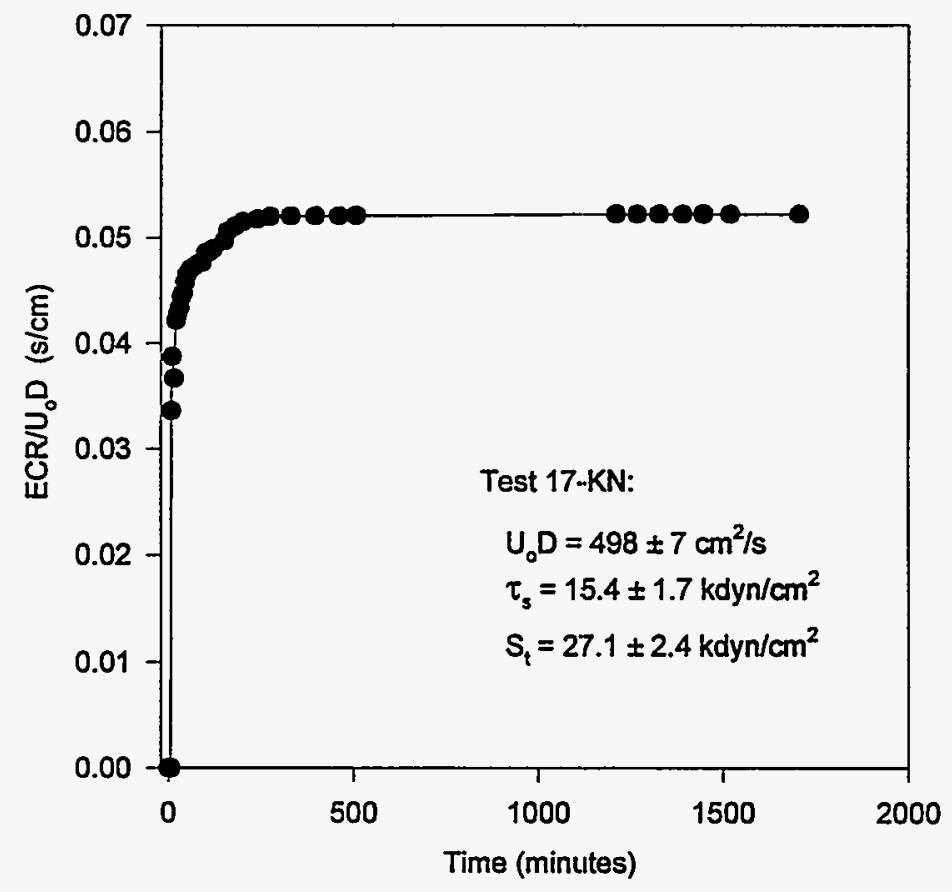

Figure A.66. Test $17-\mathrm{KN}$ ECR/U ${ }_{0} \mathrm{D}$ vs. Time 


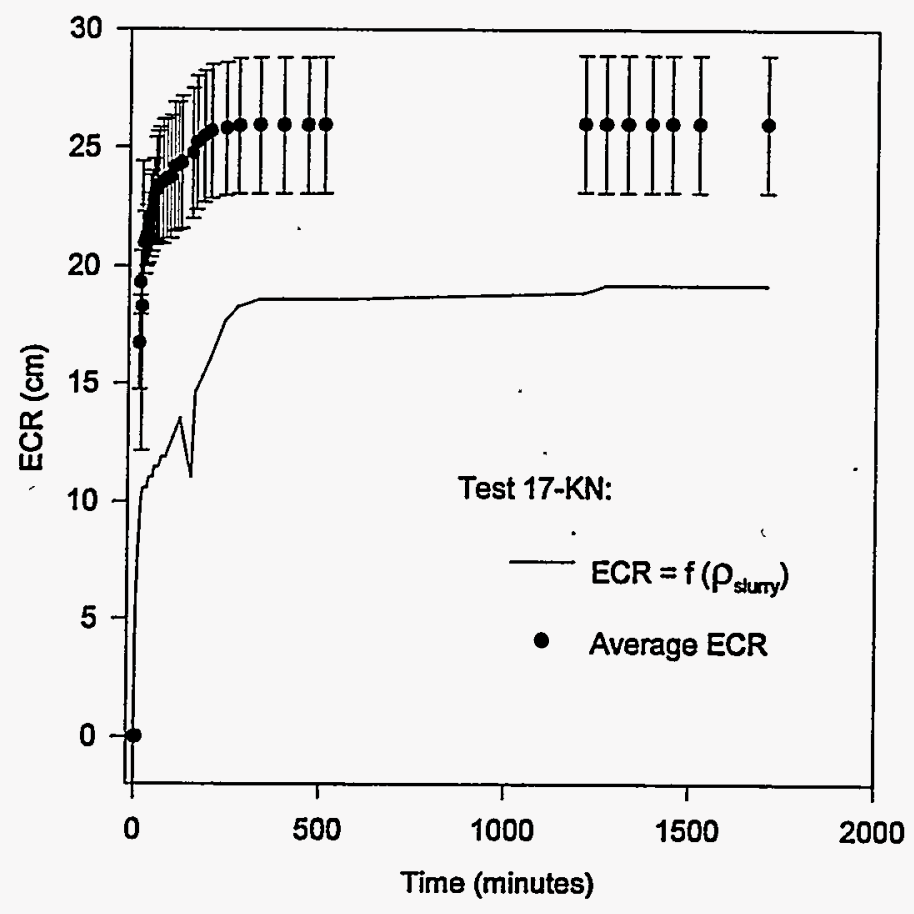

Figure A.67. Test 17-KN ECR Calculated from Density 1

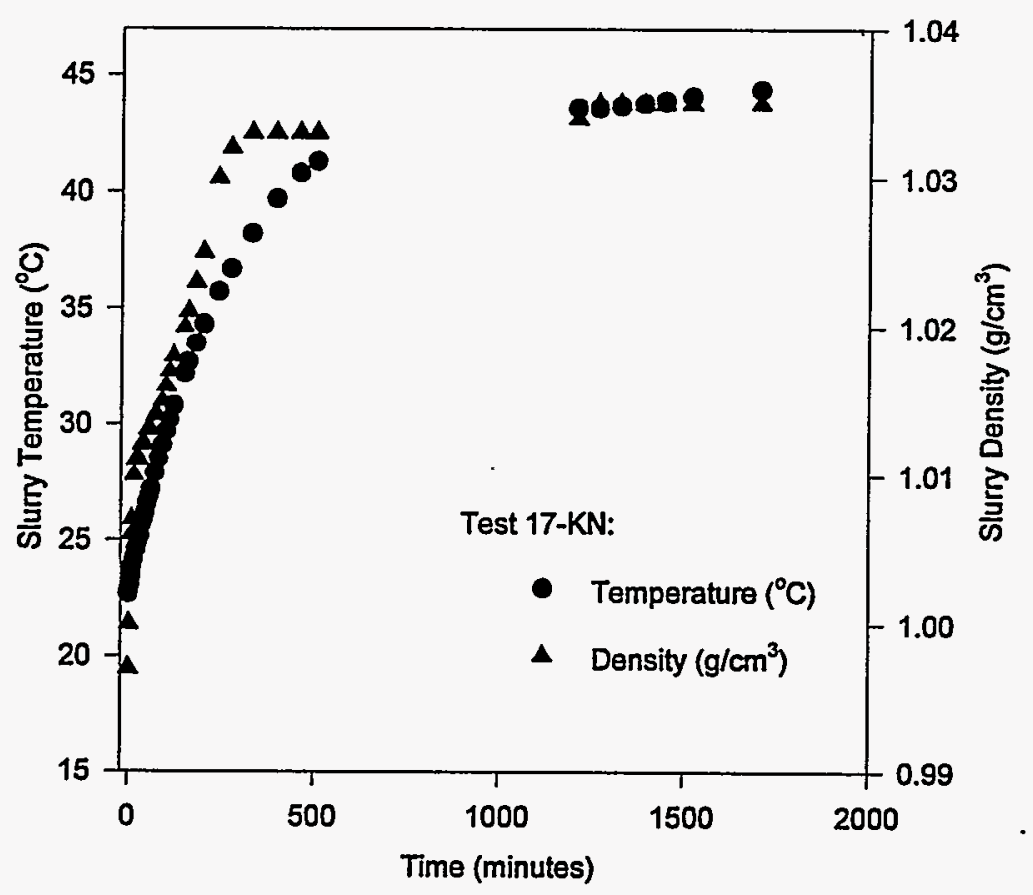

Figure A.68. Test 17-KN Slurry Temperature and Density 


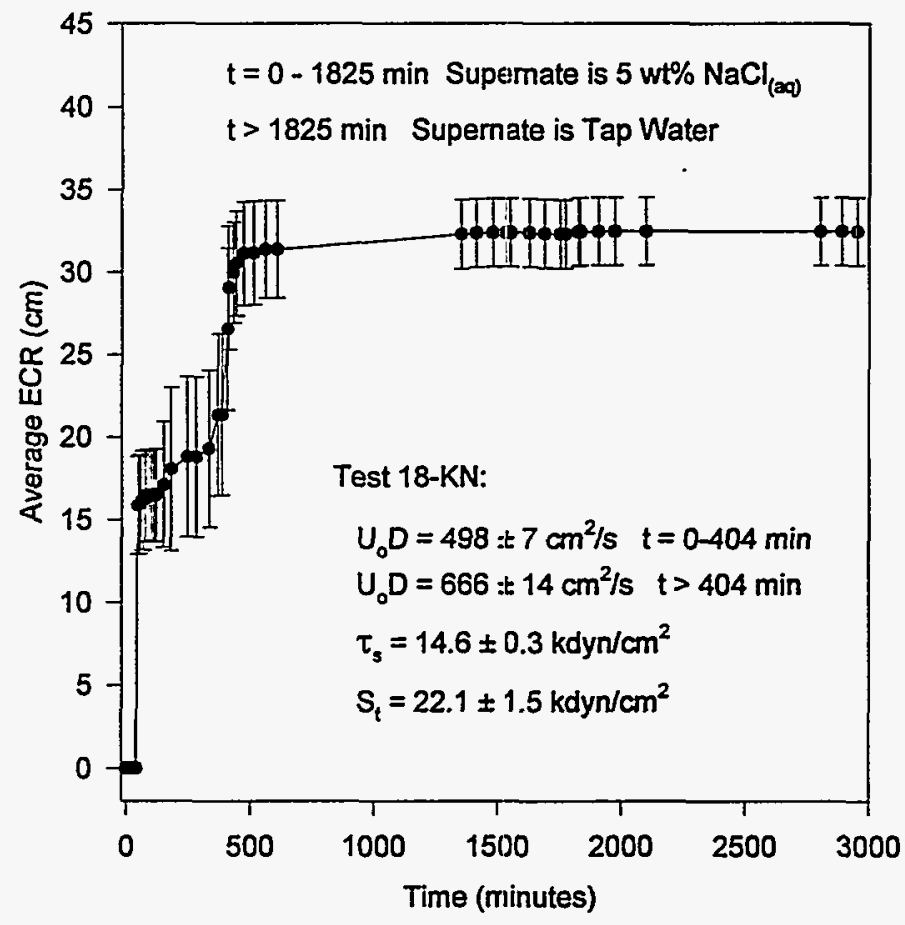

Figure A.69. Test 18-KN ECR vs. Time

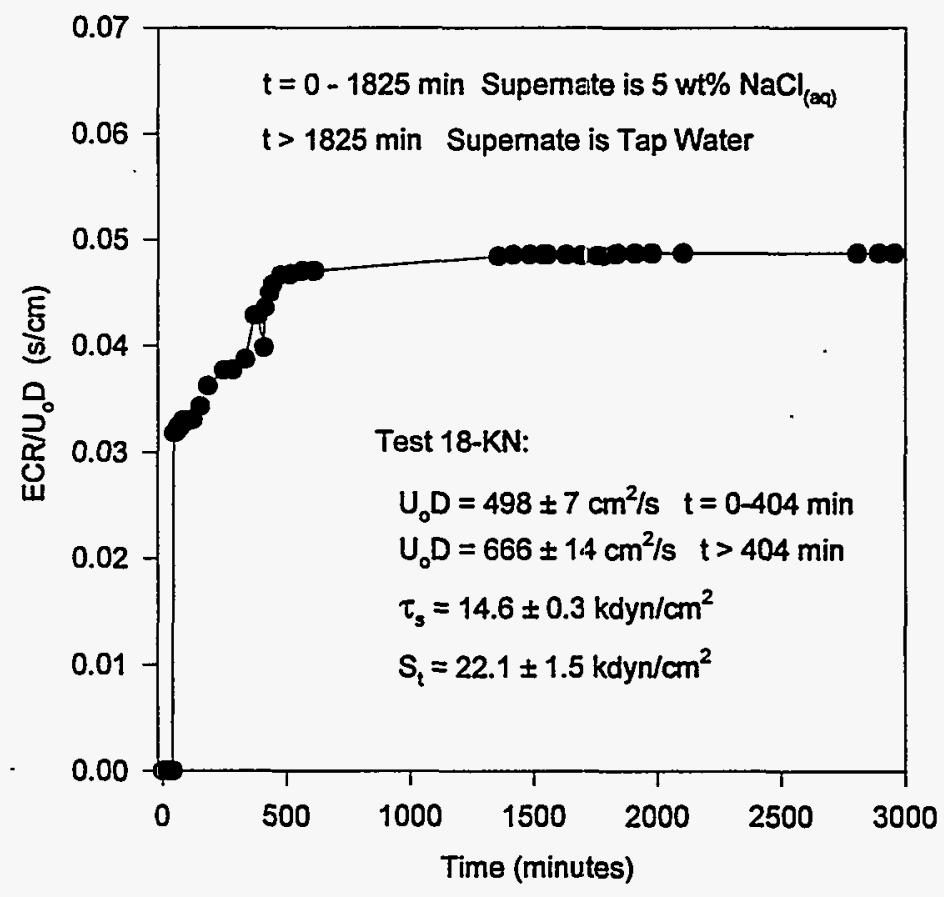

Figure A.70. Test $18-\mathrm{KN} / \mathrm{ECR} / \mathrm{U}_{\circ} \mathrm{D}$ vs. Time

\section{A.36}




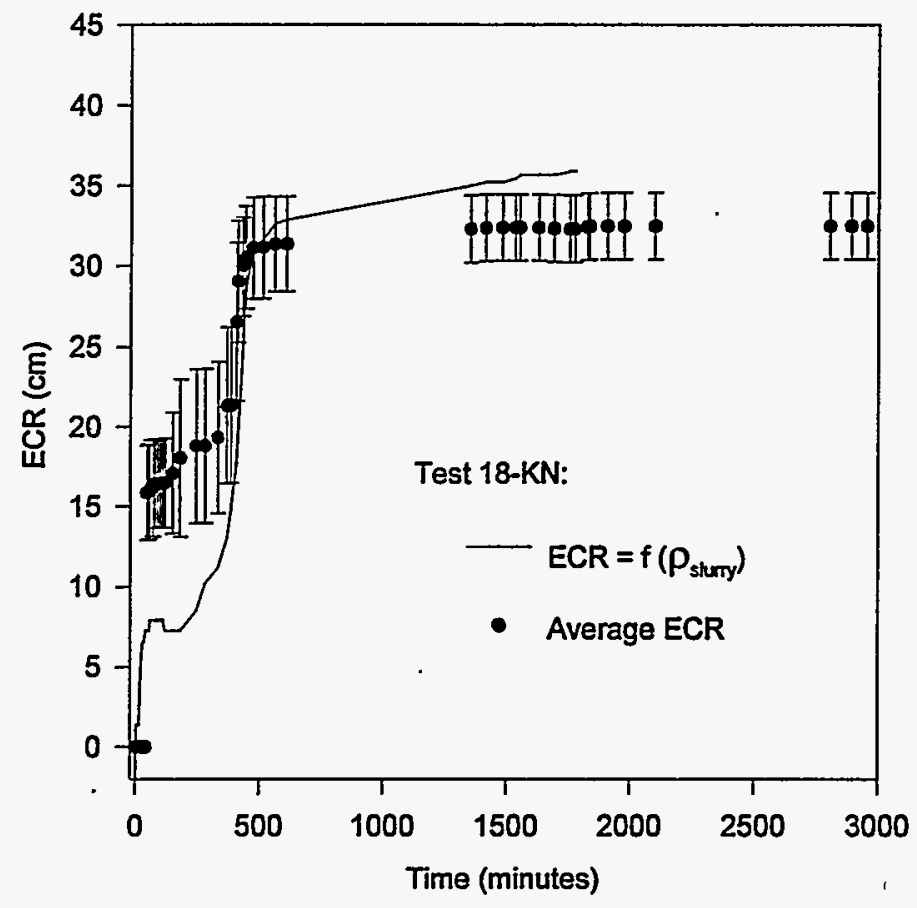

Figure A.71. Test 18-KN ECR Calculated from Density

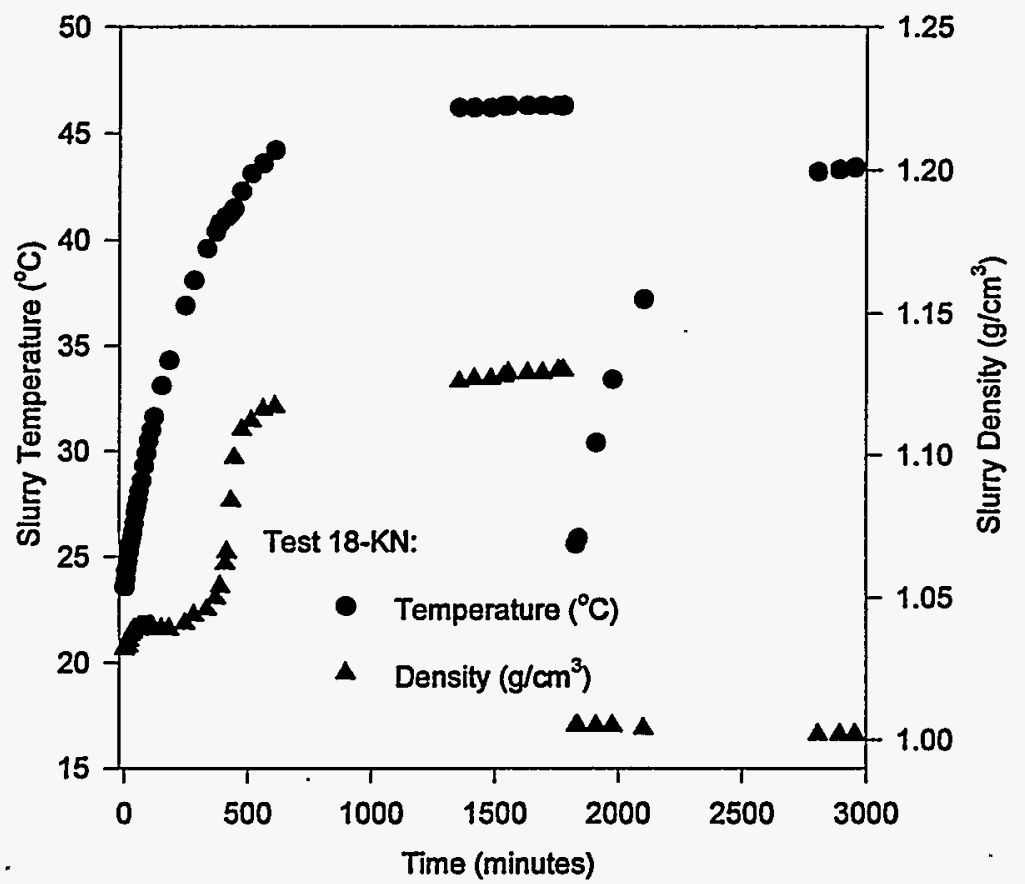

Figure A.72. Test $18-\mathrm{KN}$ Slurry Temperature and Density 


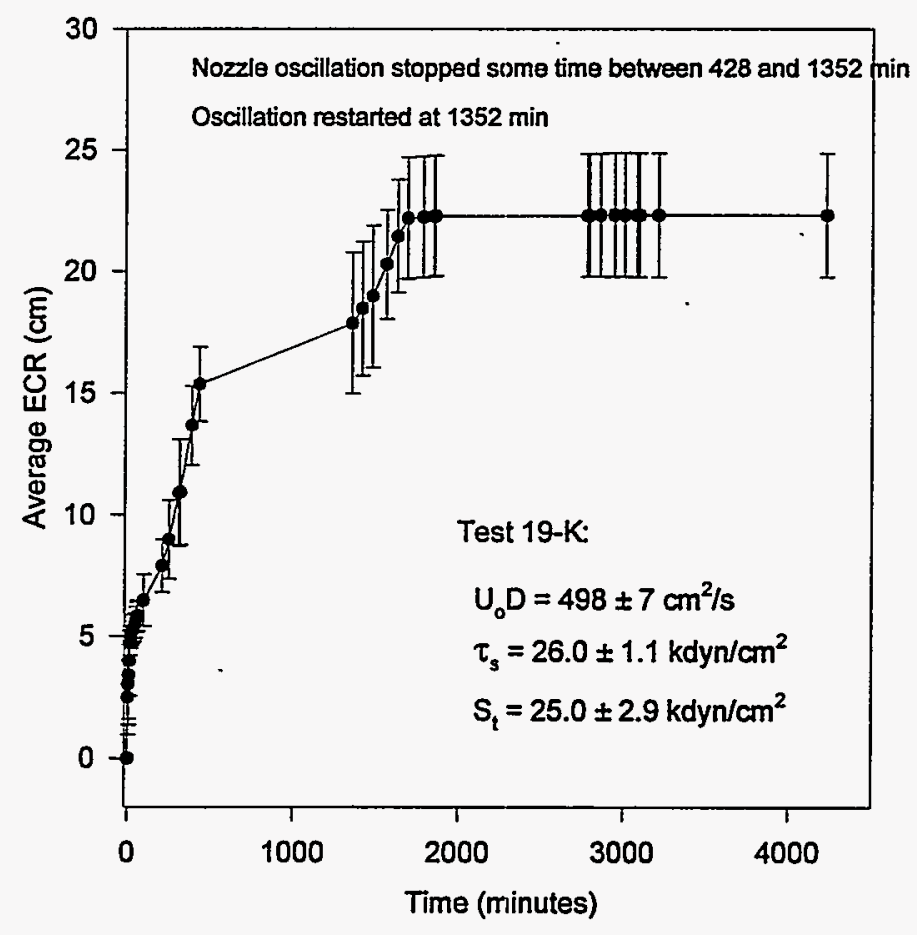

Figure A.73. Test 19-K ECR vs. Time

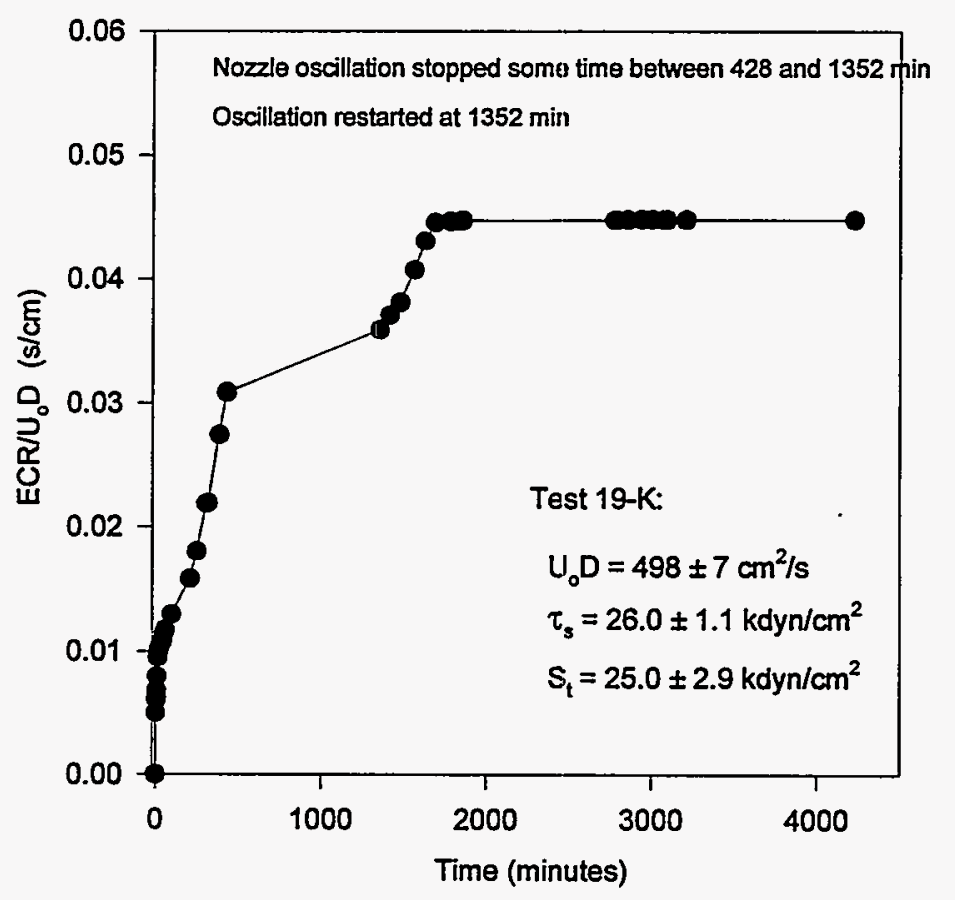

Figure A.74. Test $19-\mathrm{K} E C R / \mathrm{U}_{0} \mathrm{D}$ vs. Time 


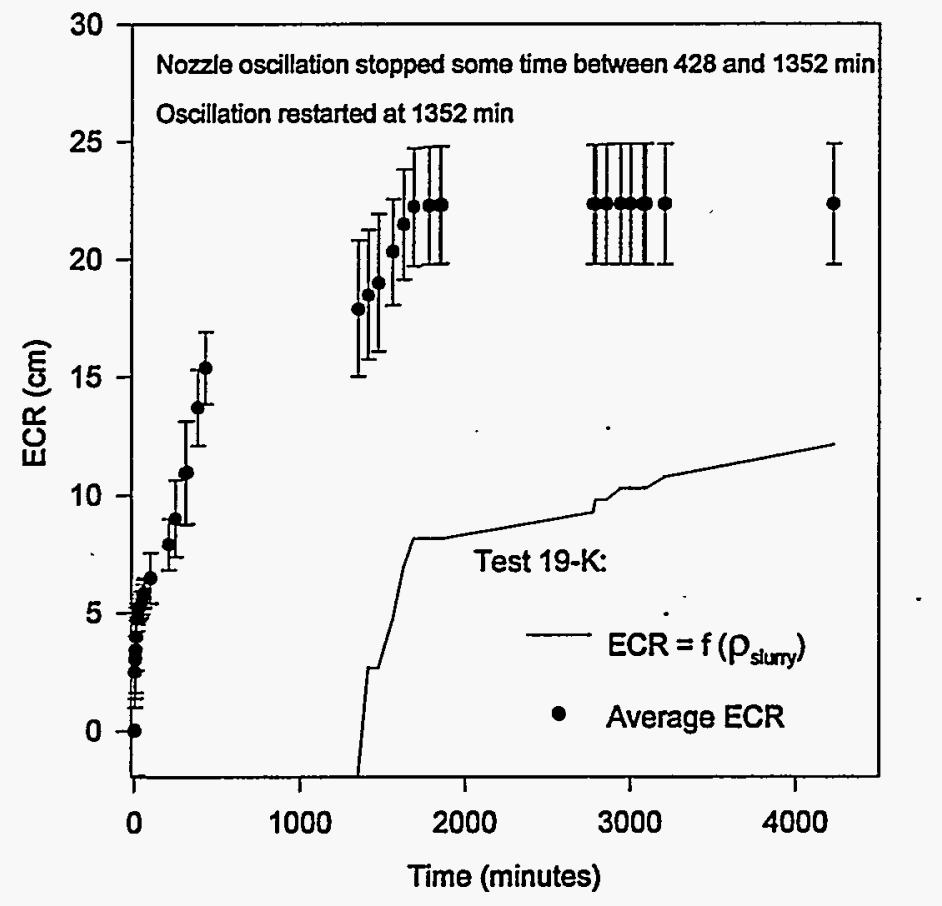

Figure A.75. Test 19-K ECR Calculated from Density

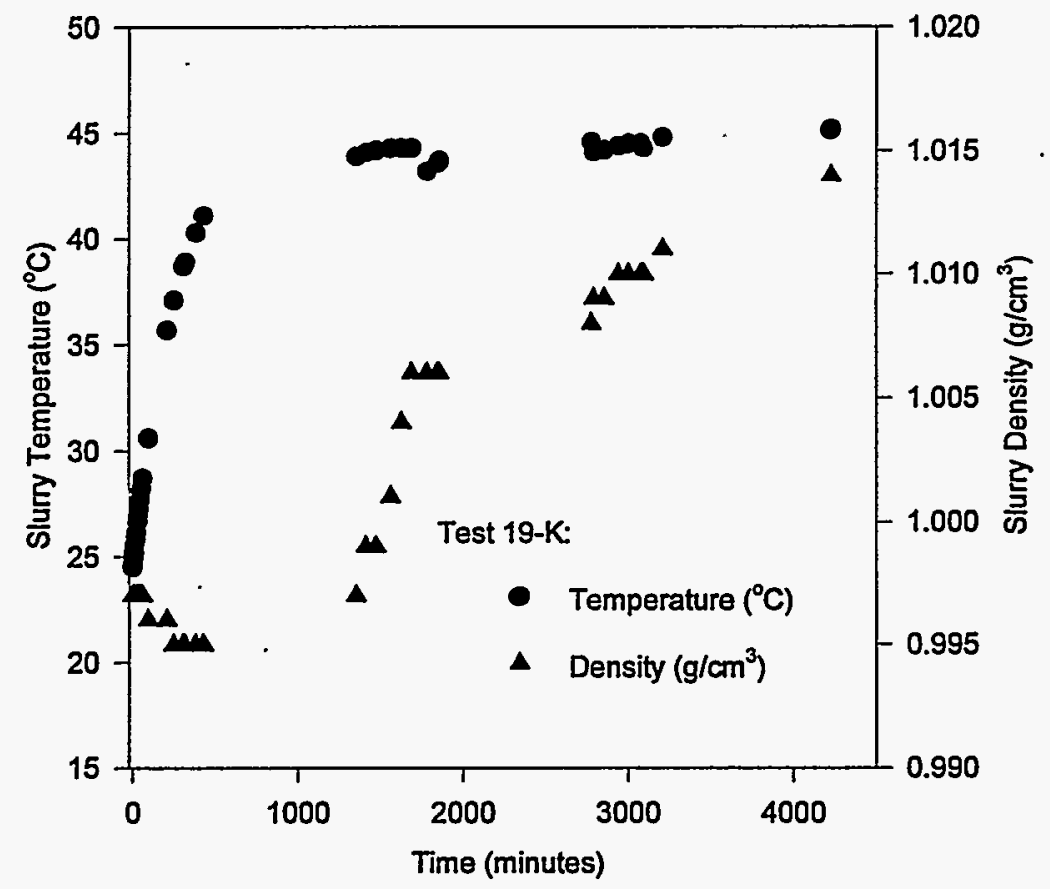

Figure A.76. Test 19-K Slurry Temperature and Density 


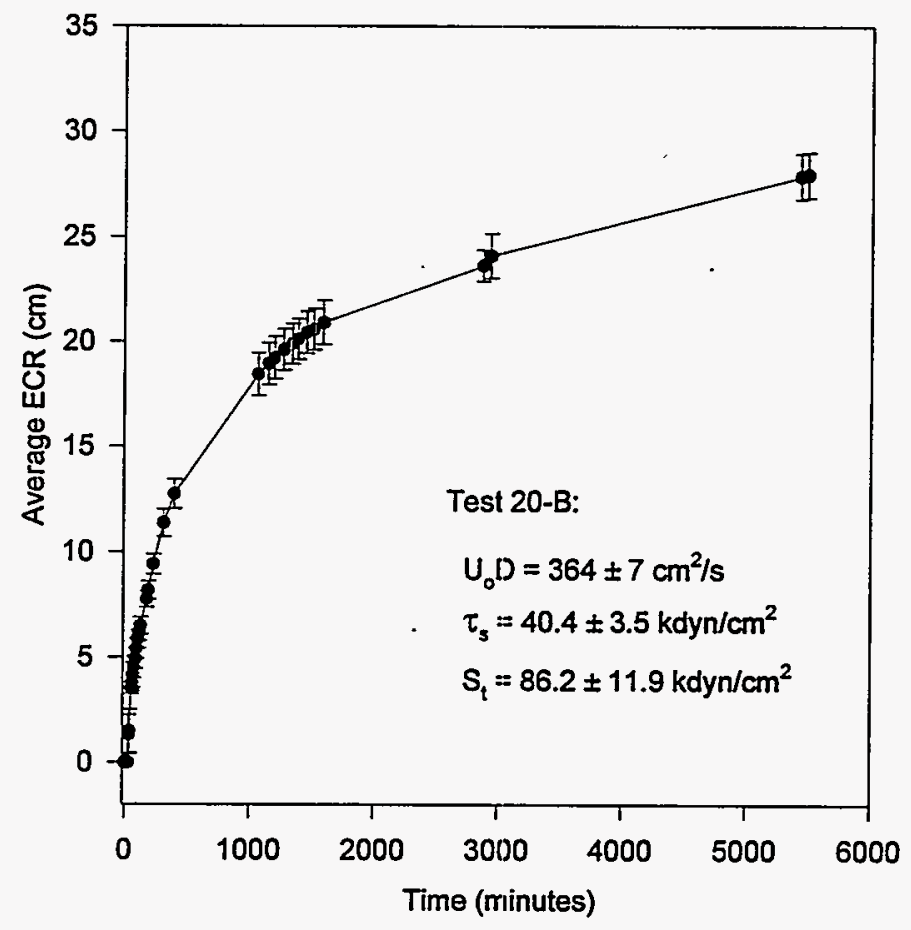

Figure A.77. Test 20-B ECR vs. Time

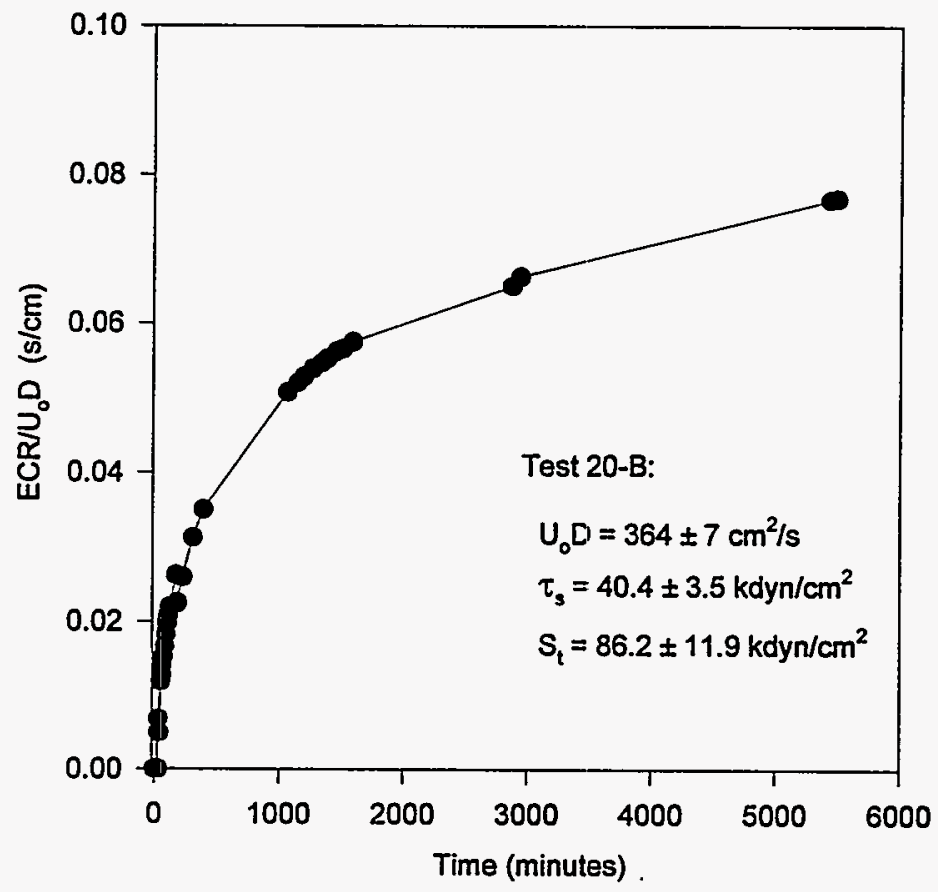

Figure A.78. Test $20-B \quad E C R / U_{0} D$ vs. Time 


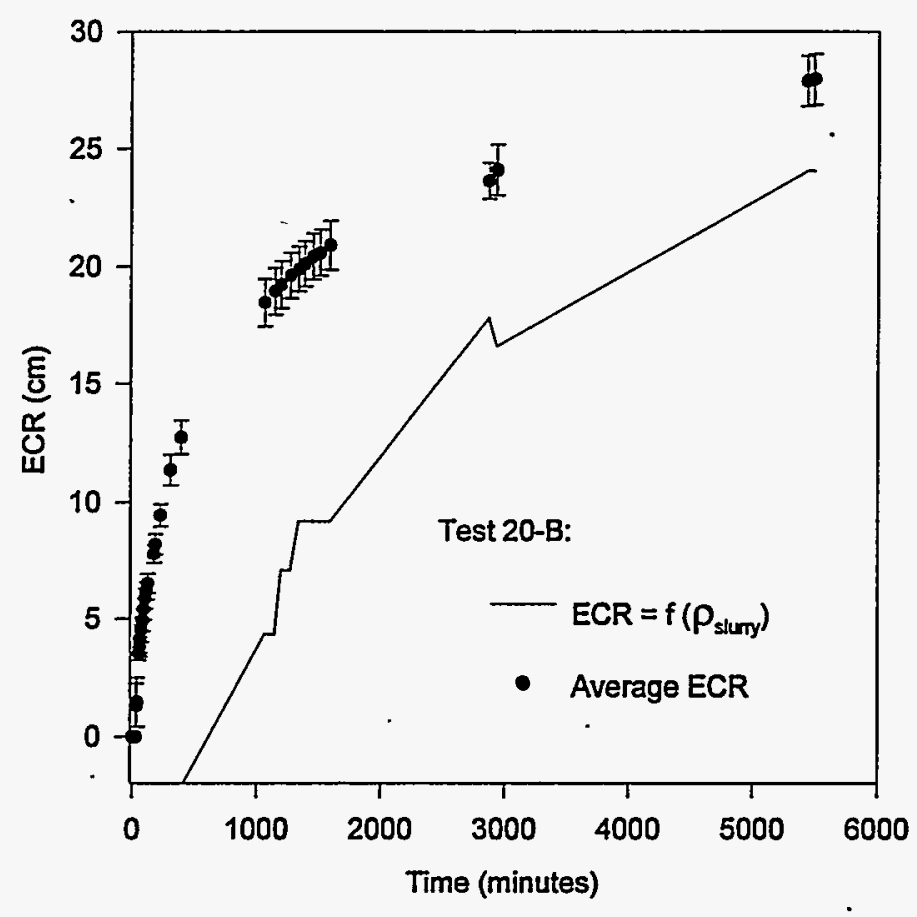

Figure A.79. Test 20-B ECR Calculated from Density

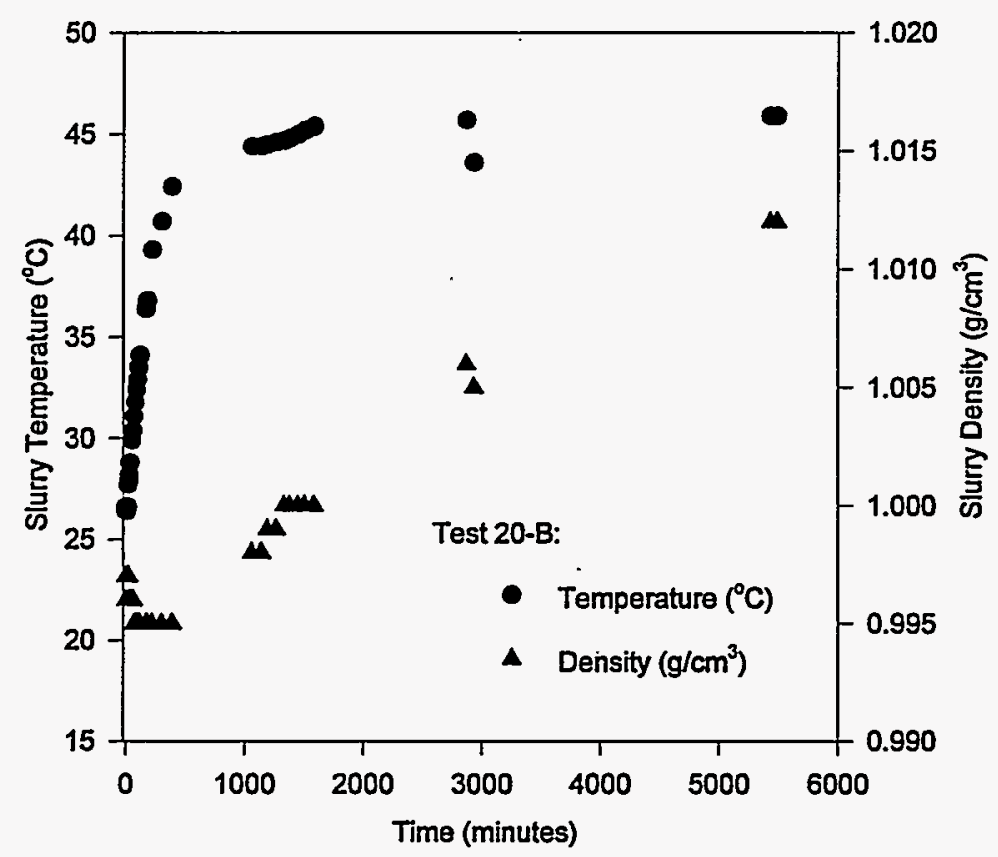

Figure A.80. Test 20-B Slurry Temperature and Density 


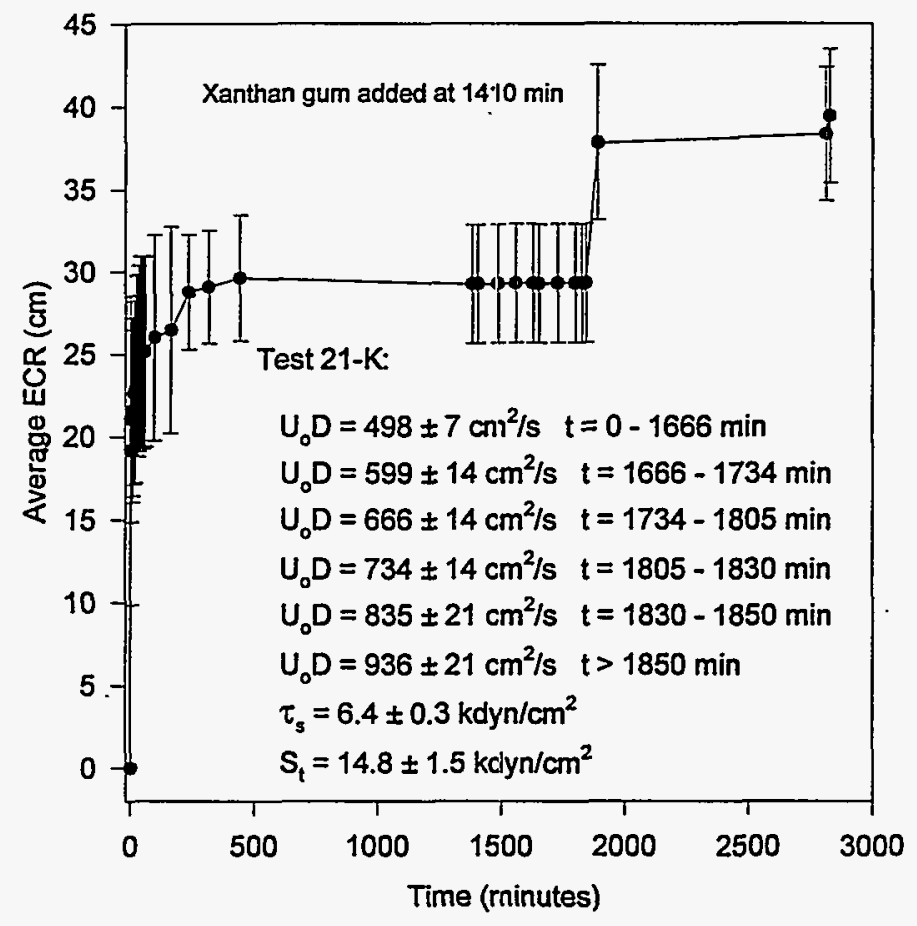

Figure A.81. Test $21-\mathrm{K}$ ECR vs. Time

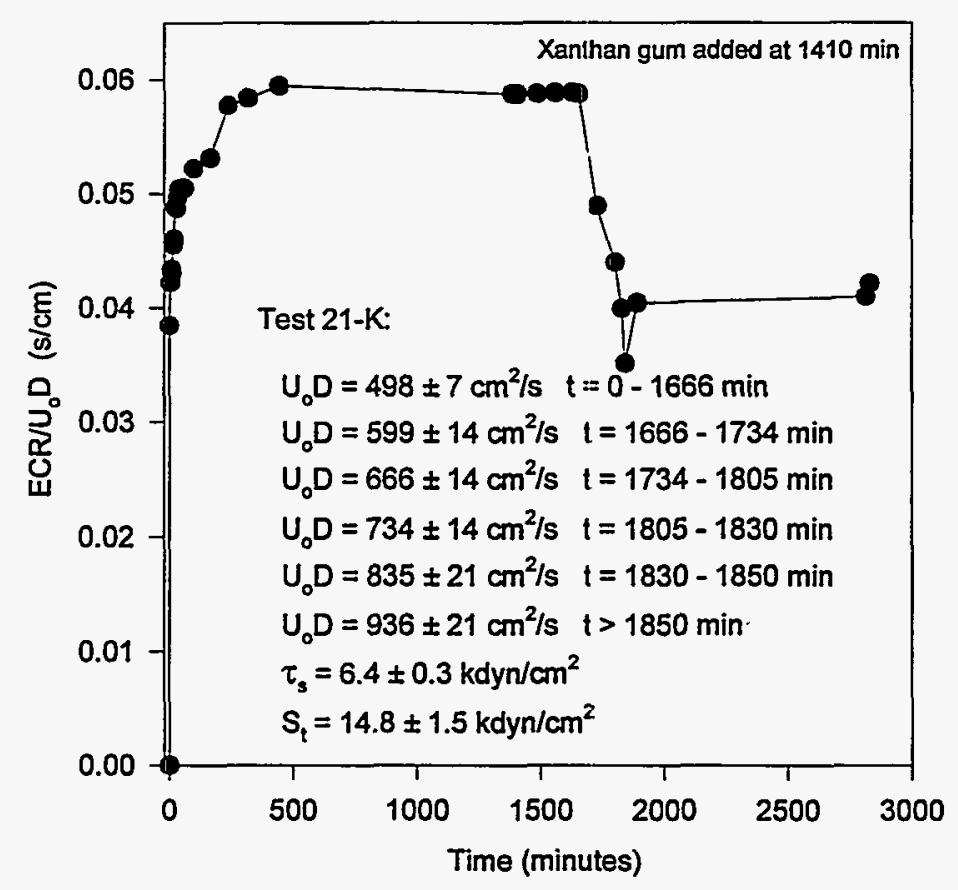

Figure A.82. Test $21-\mathrm{K} E C R / \mathrm{U}_{0} \mathrm{D}$ vs. Time 


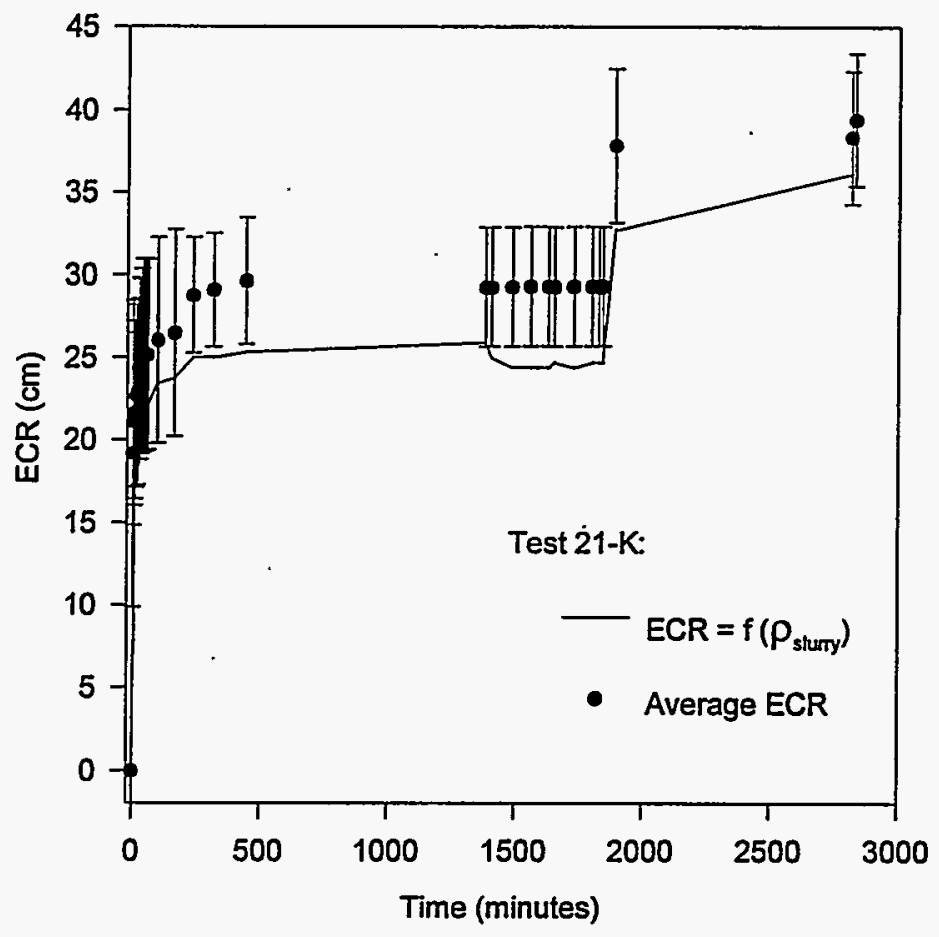

Figure A.83. Test 21-K ECR Calculated from Density

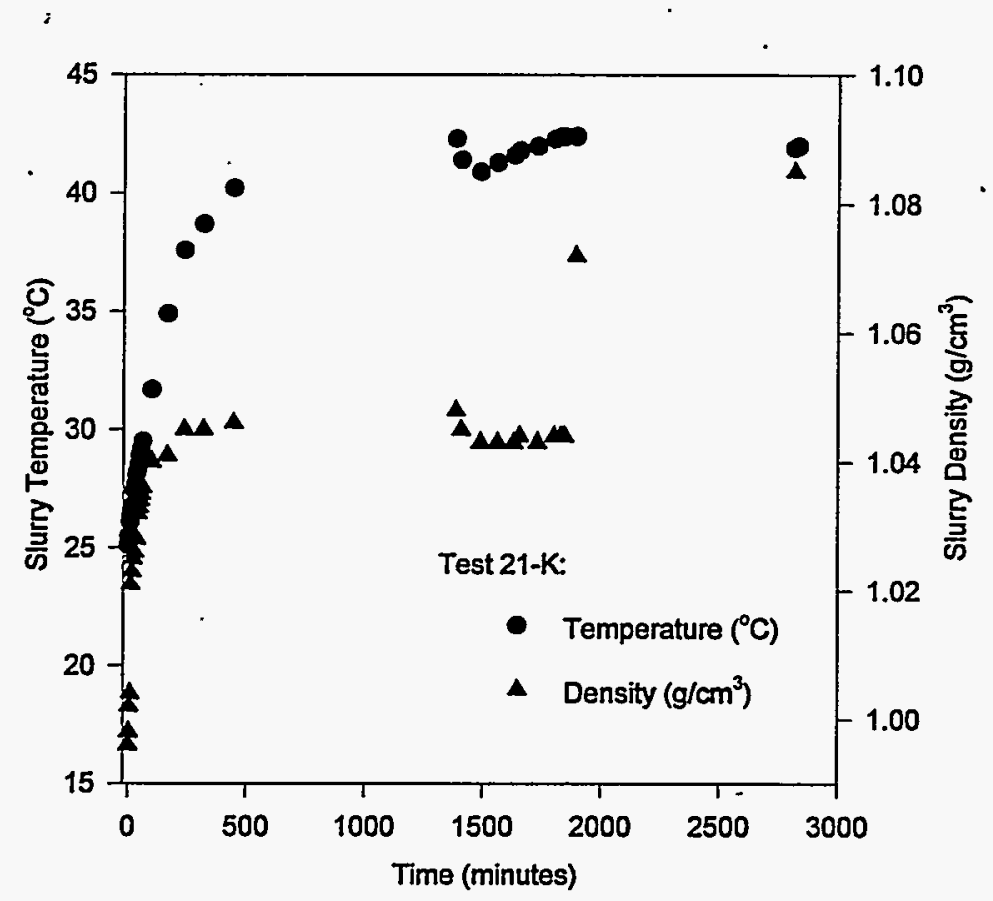

Figure A.84. Test 21-K Slurry Temperature and Density 


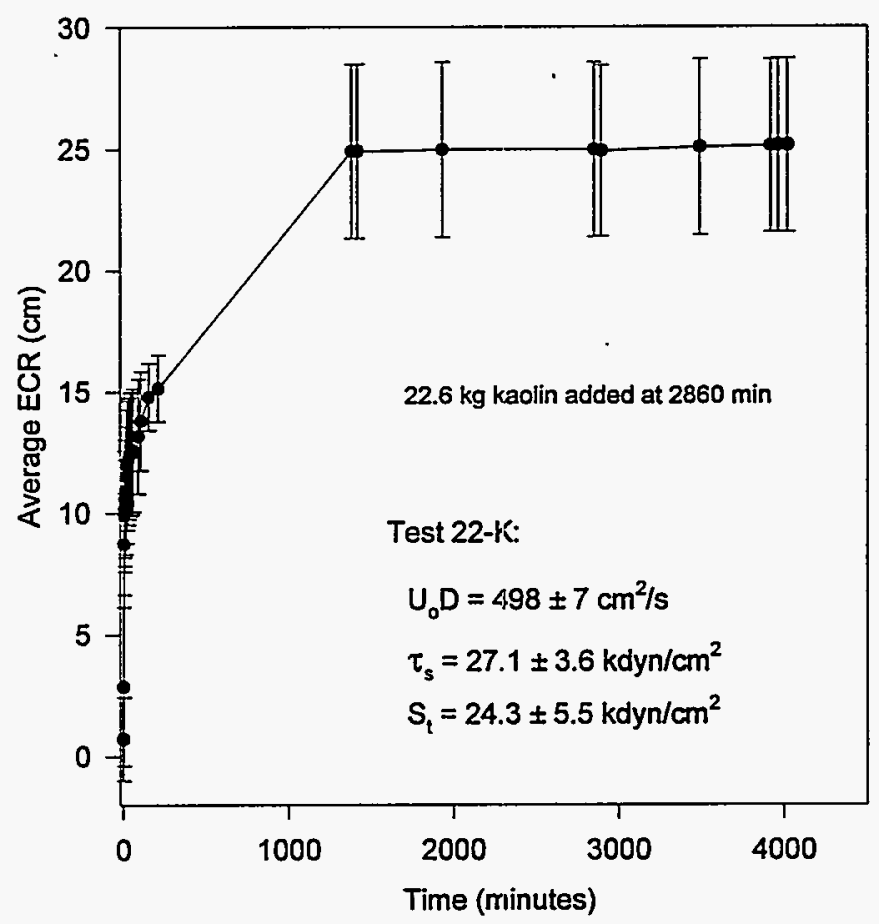

Figure A.85. Test $22-\mathrm{K}$ ECR vs. Time

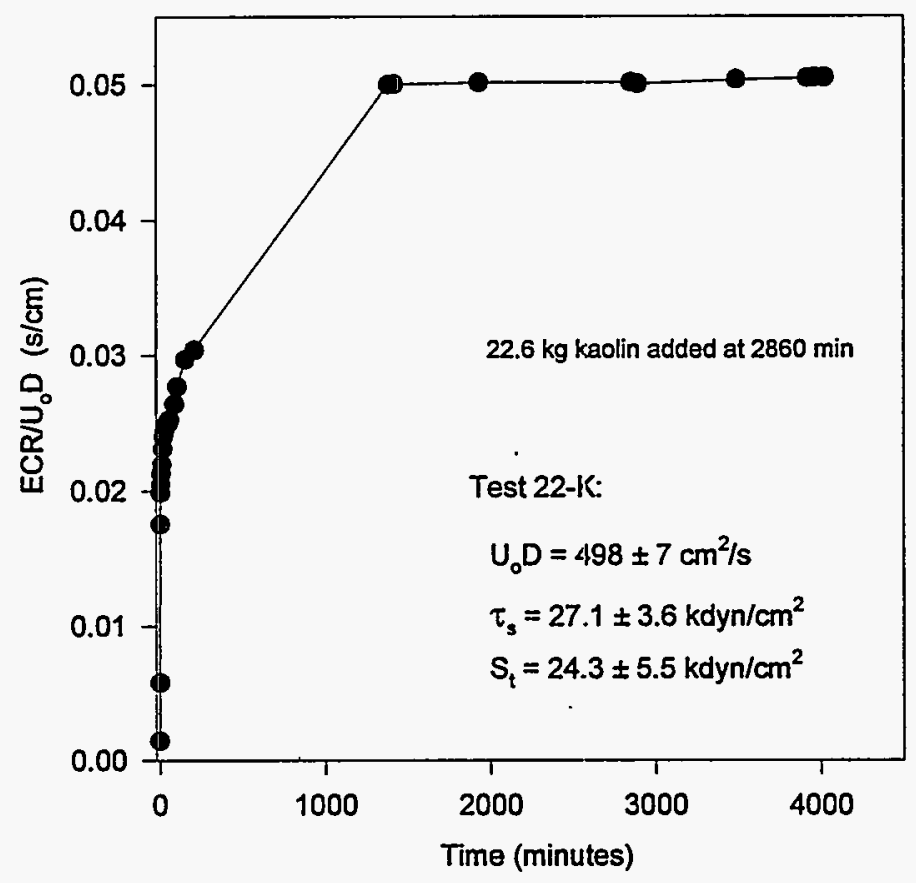

Figure A.86. Test $22-K$ ECR/U $\mathrm{U}_{0} \mathrm{D}$ vs. Time

\section{A. 44}




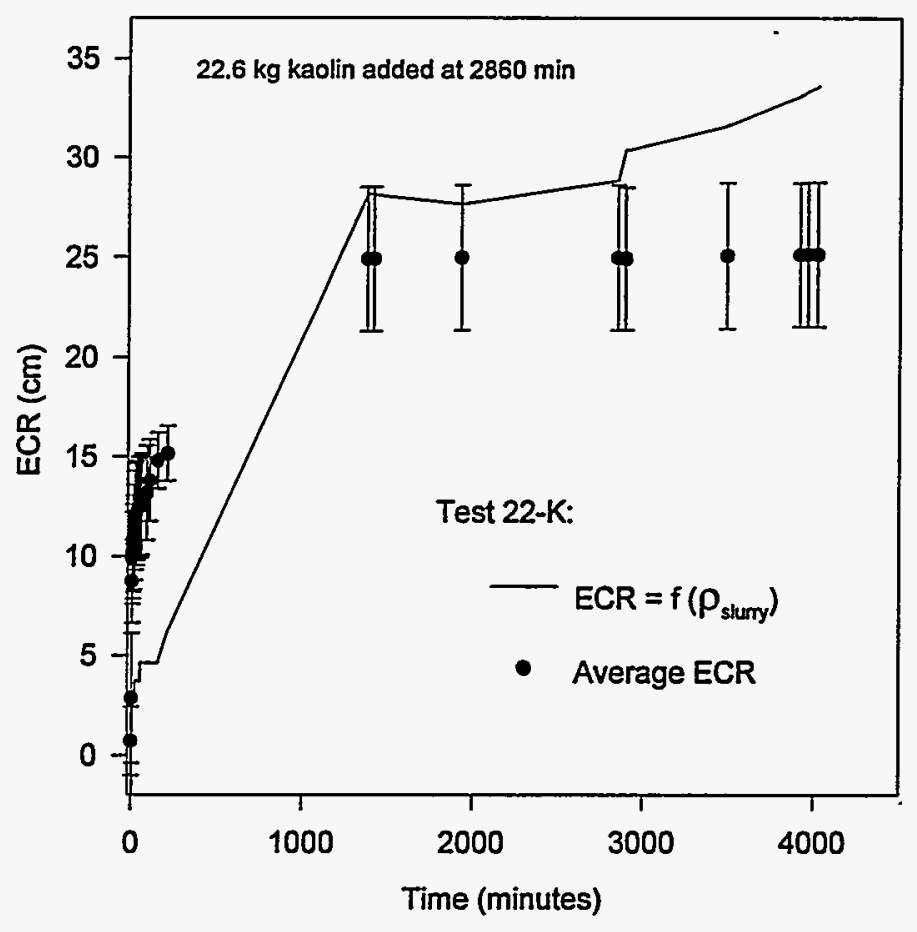

Figure A.87. Test 22-K ECR Calculated from Density

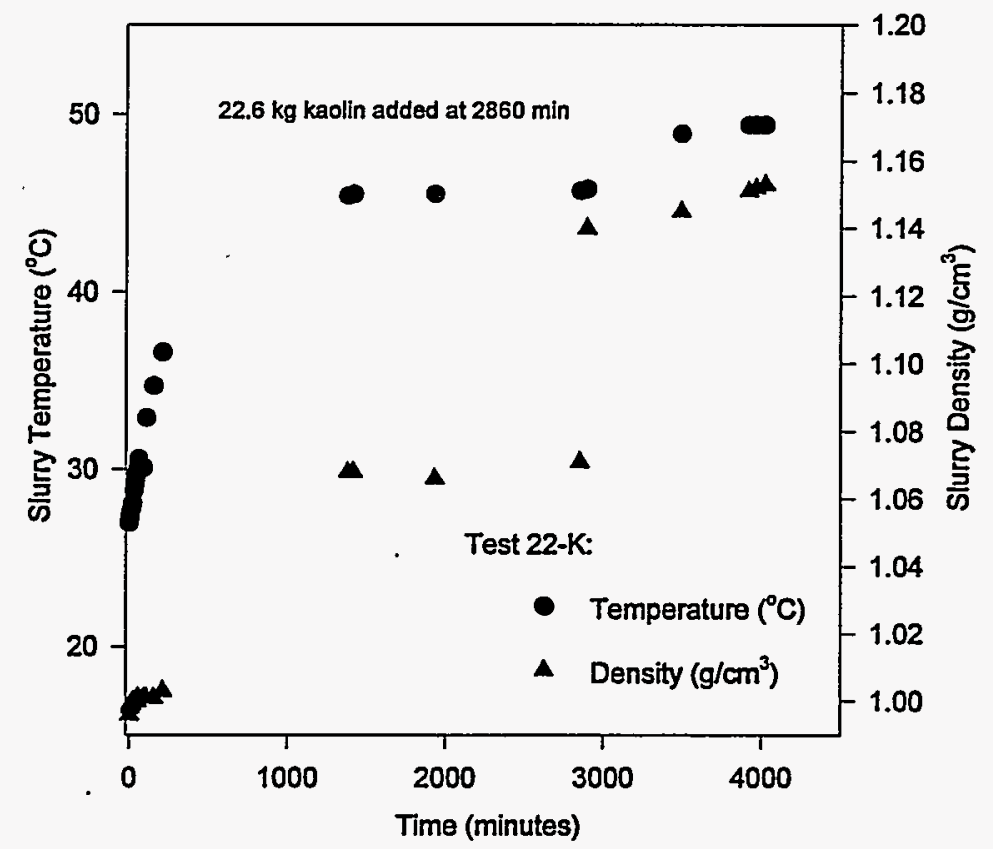

Figure A.88. Test 22-K Slurry Temperature and Density 


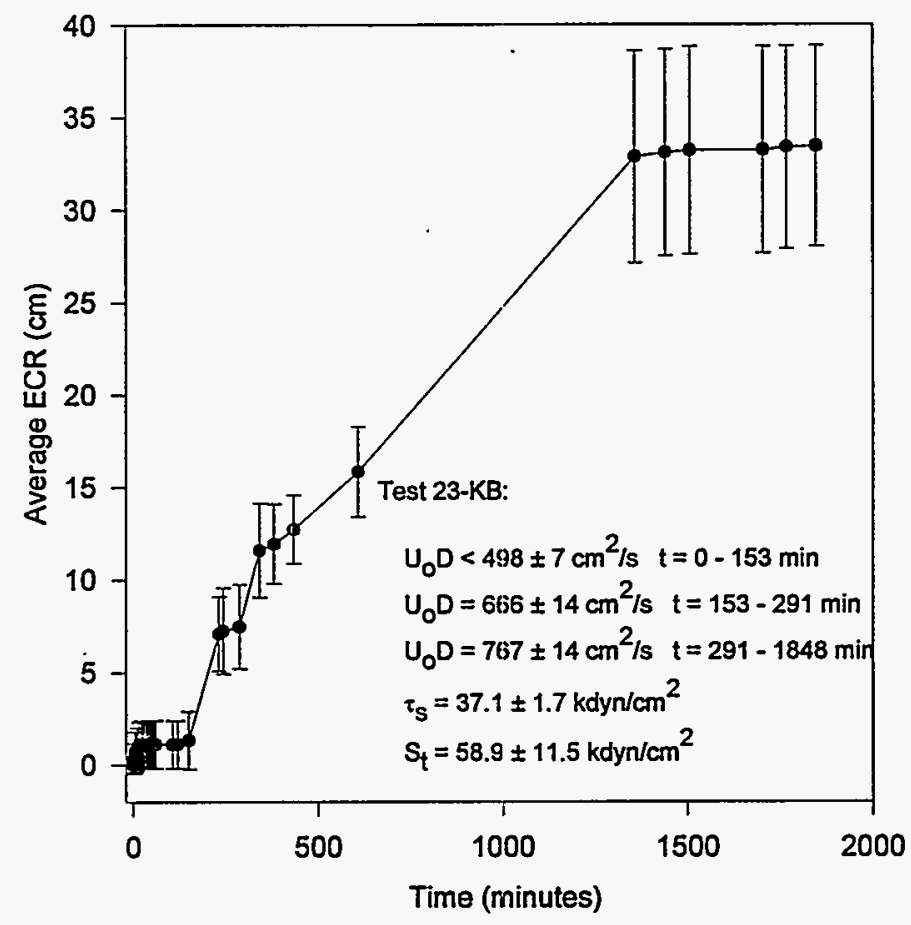

Figure A.89. Test 23-KB ECR vs. Time

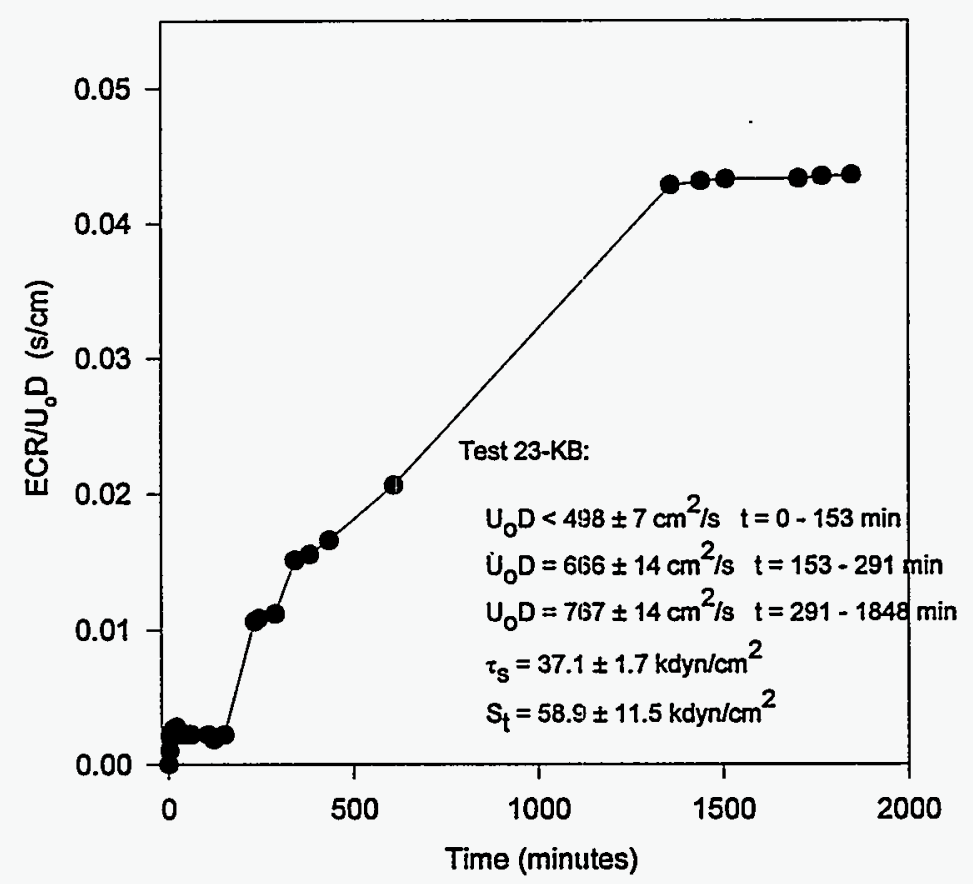

Figure A.90. Test $23-\mathrm{KB} / \mathrm{ECR} / \mathrm{U}_{0} \mathrm{D}$ vs. Time

\section{A.46}




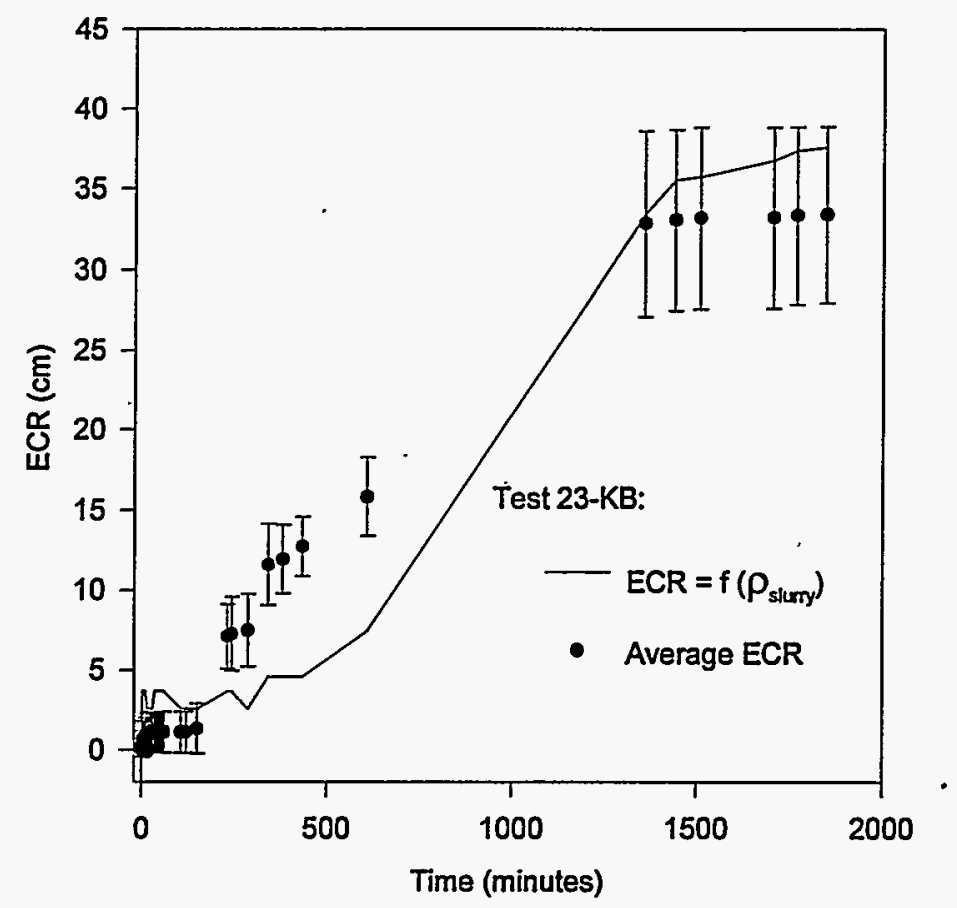

Figure A.91. Test 23-KB ECR Calculated from Density

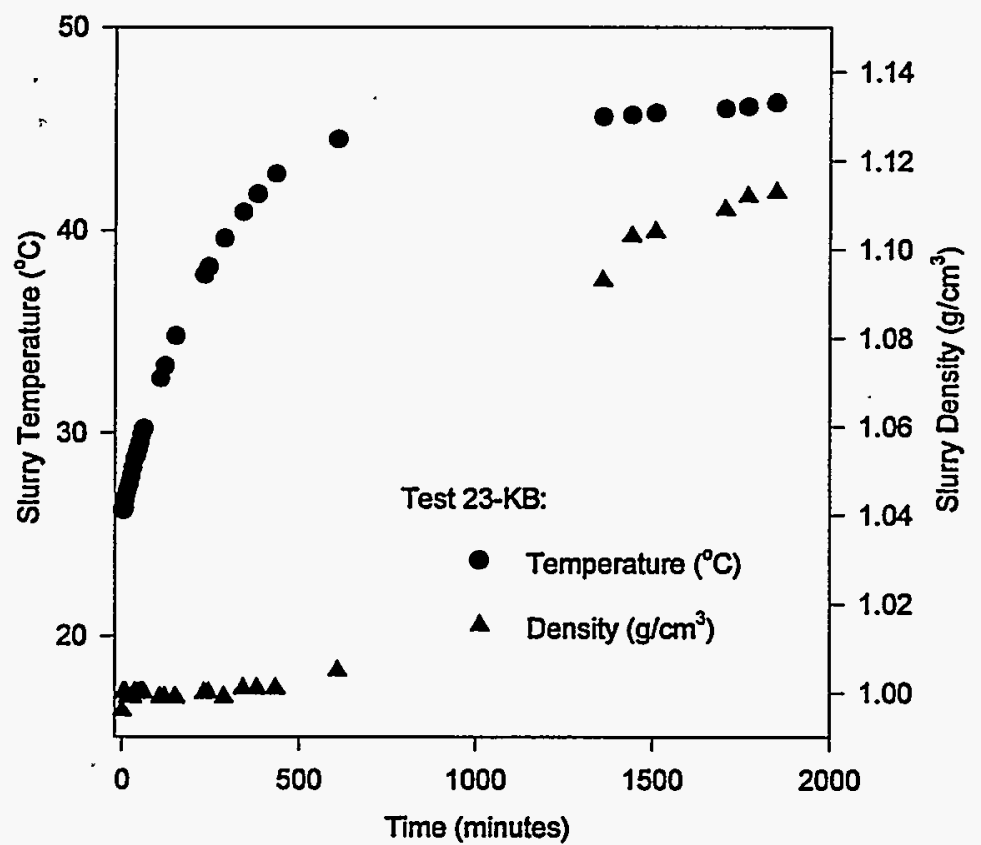

Figure A.92. Test 23-KB Slurry Temperature and Density 


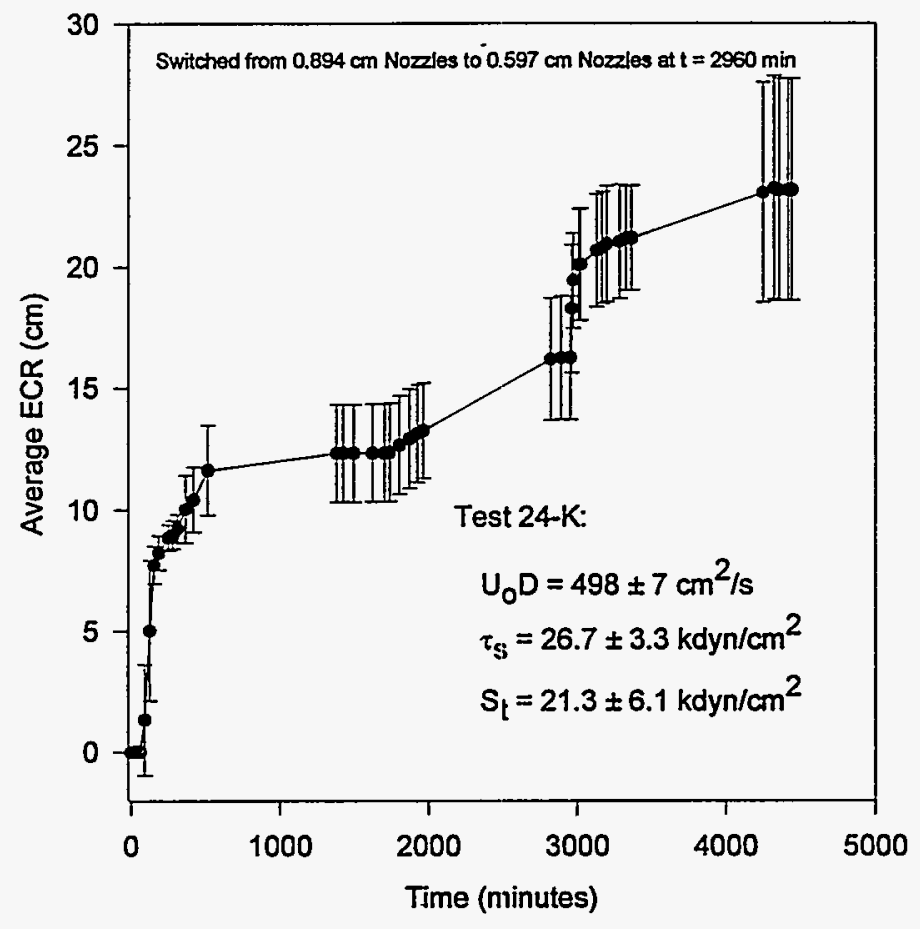

Figure A.93. Test 24-K ECR vs. Time

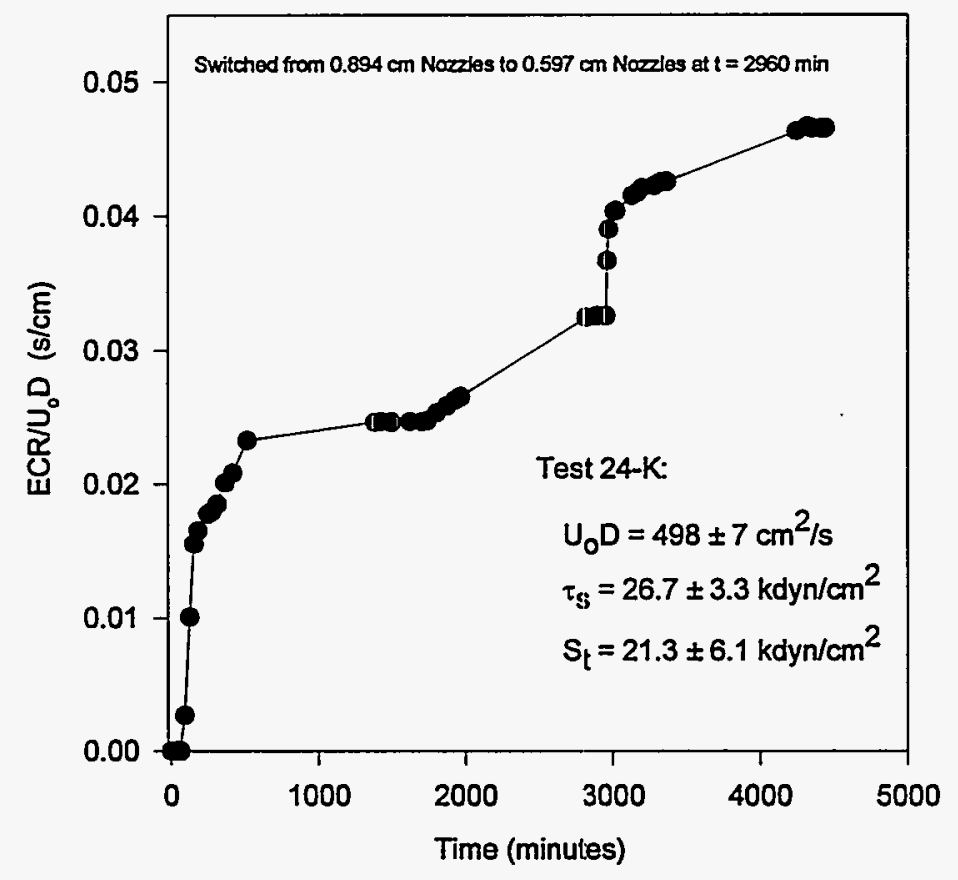

Figure A.94. Test $24-K E C R / U_{0} D$ vs. Time 


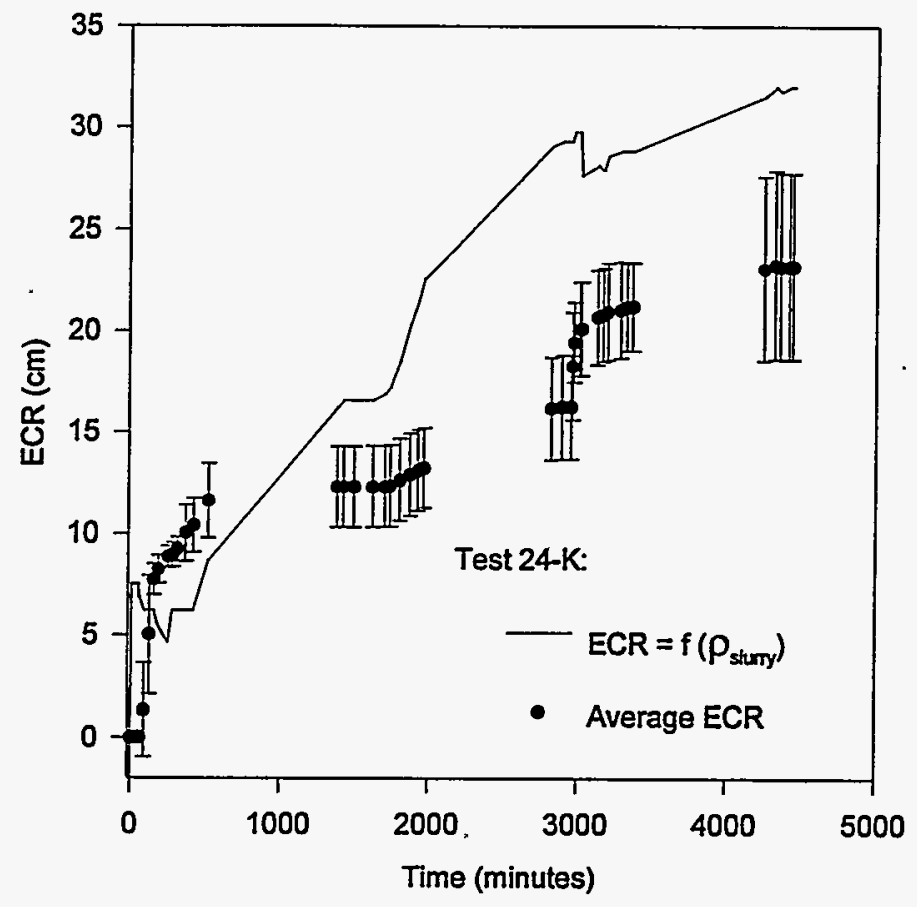

Figure A.95. Test 24-K ECR Calculated from Density

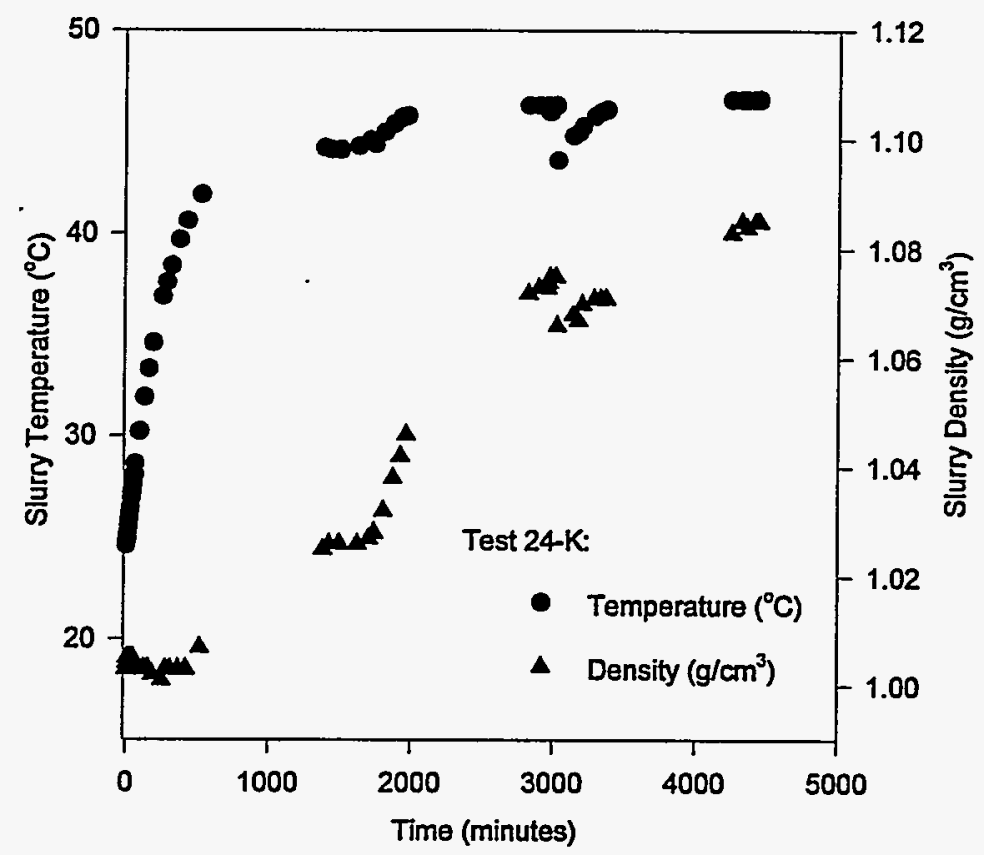

Figure A.96. Test 24-K Slurry Temperature and Density 


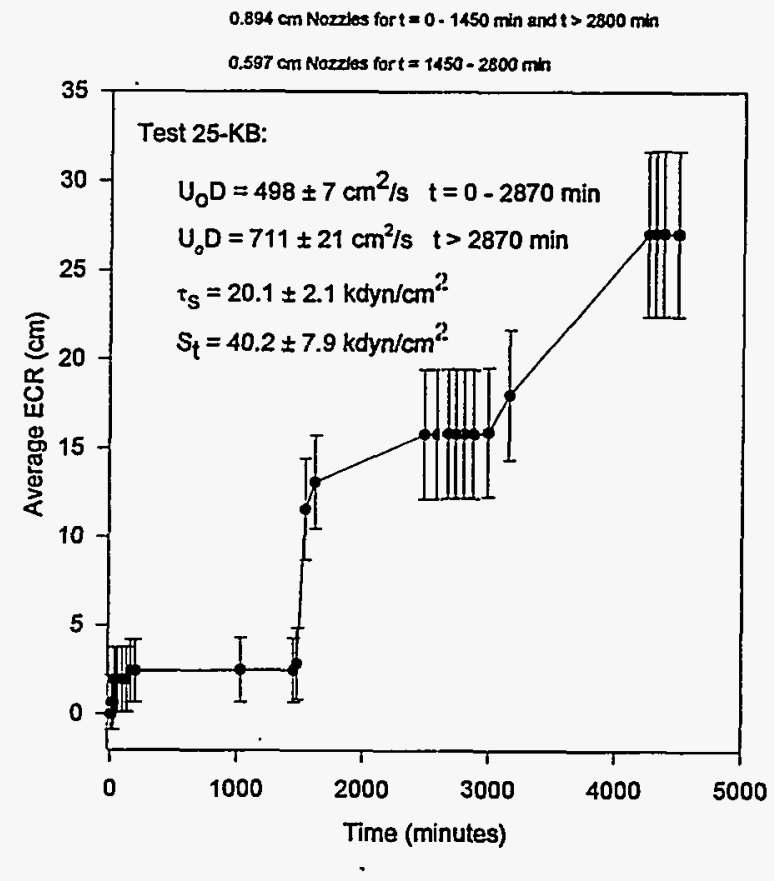

Figure A.97. Test 25-IKB ECR vs. Time

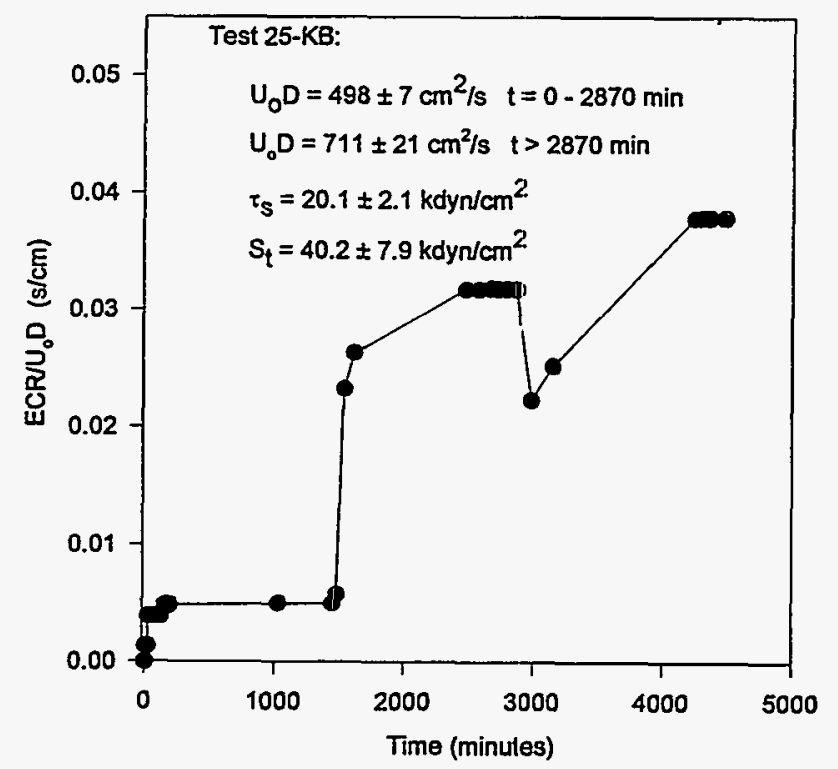

Figure A.98. Test $25-\mathrm{KB} E C R / \mathrm{U}_{0} \mathrm{D}$ vs. Time 


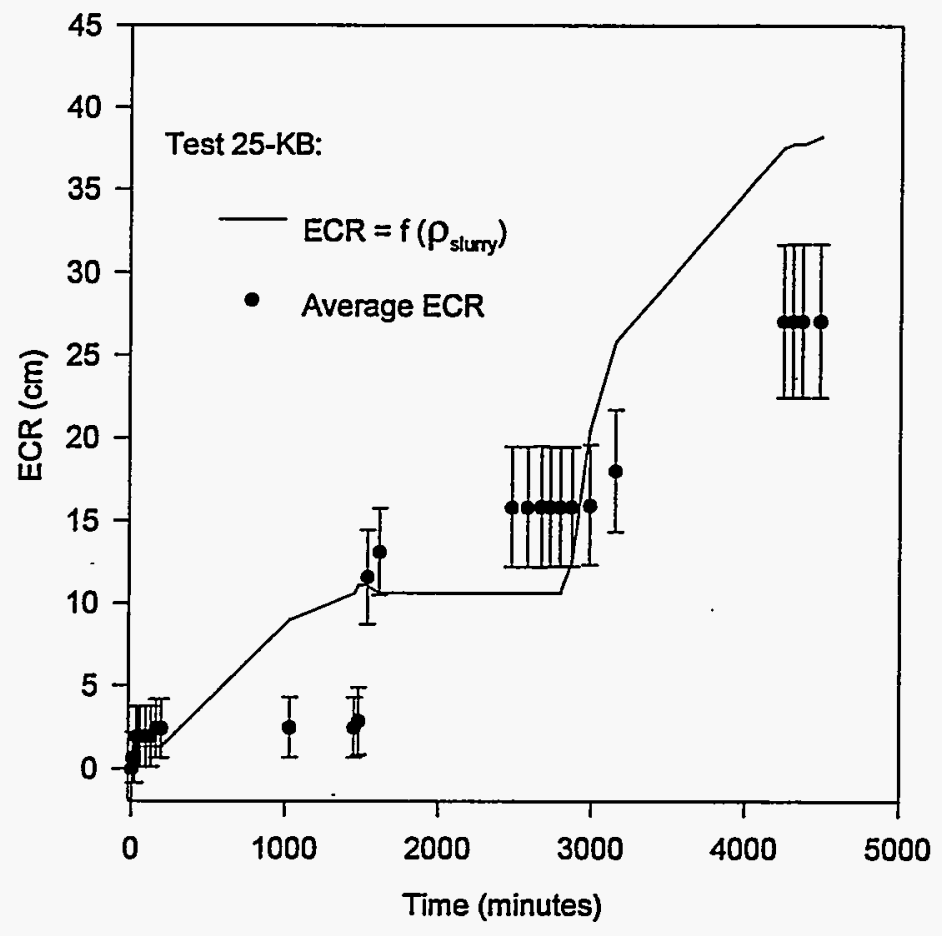

Figure A.99. Test 25-KB ECR Calculated from Density

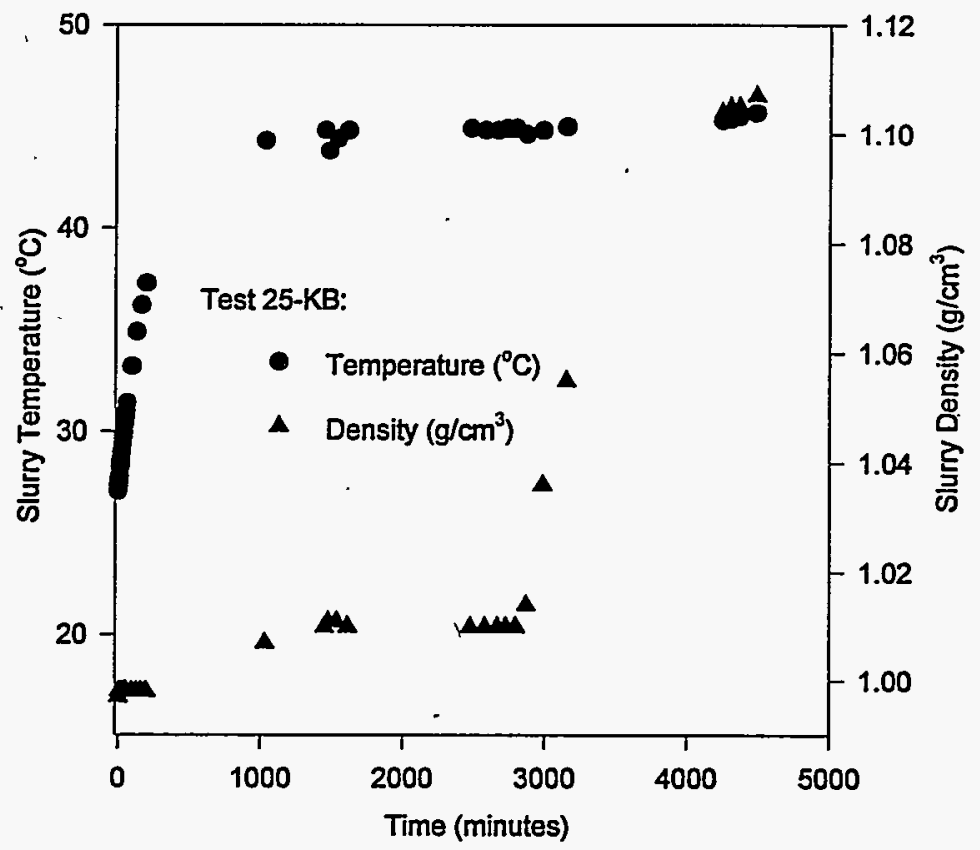

Figure A.100. Test 25-KB Slurry Temperature and Density 


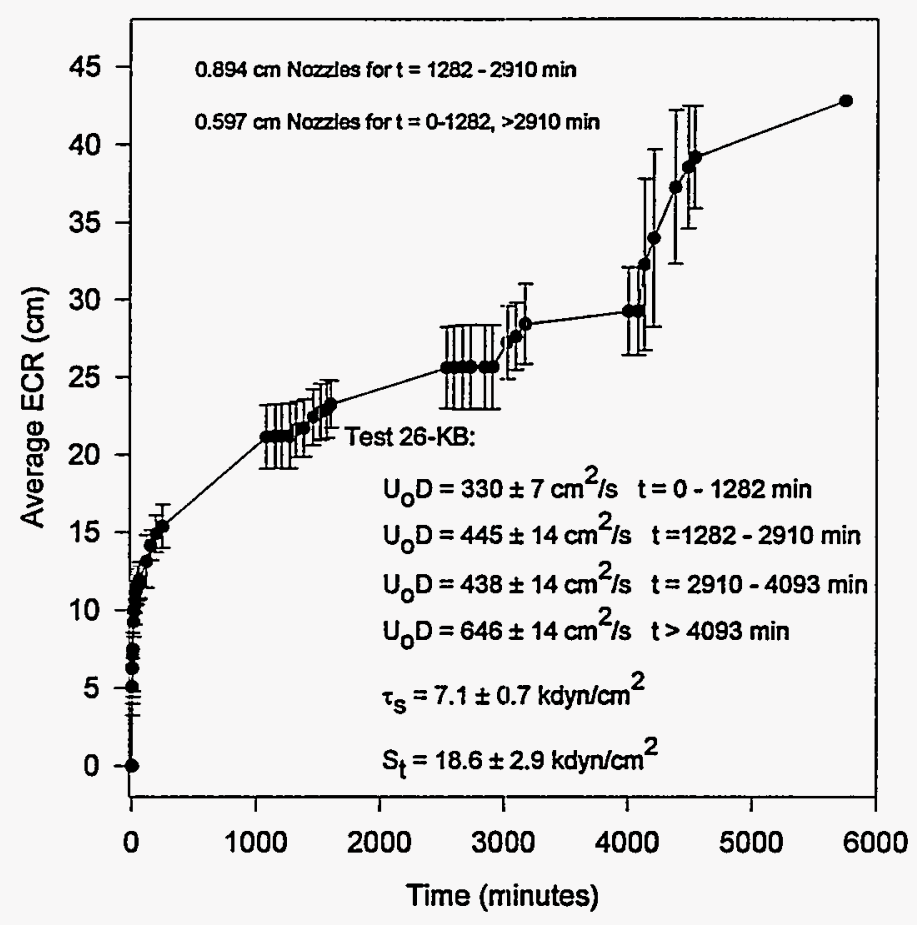

Figure A.101. Test 26-KB ECR vs. Time

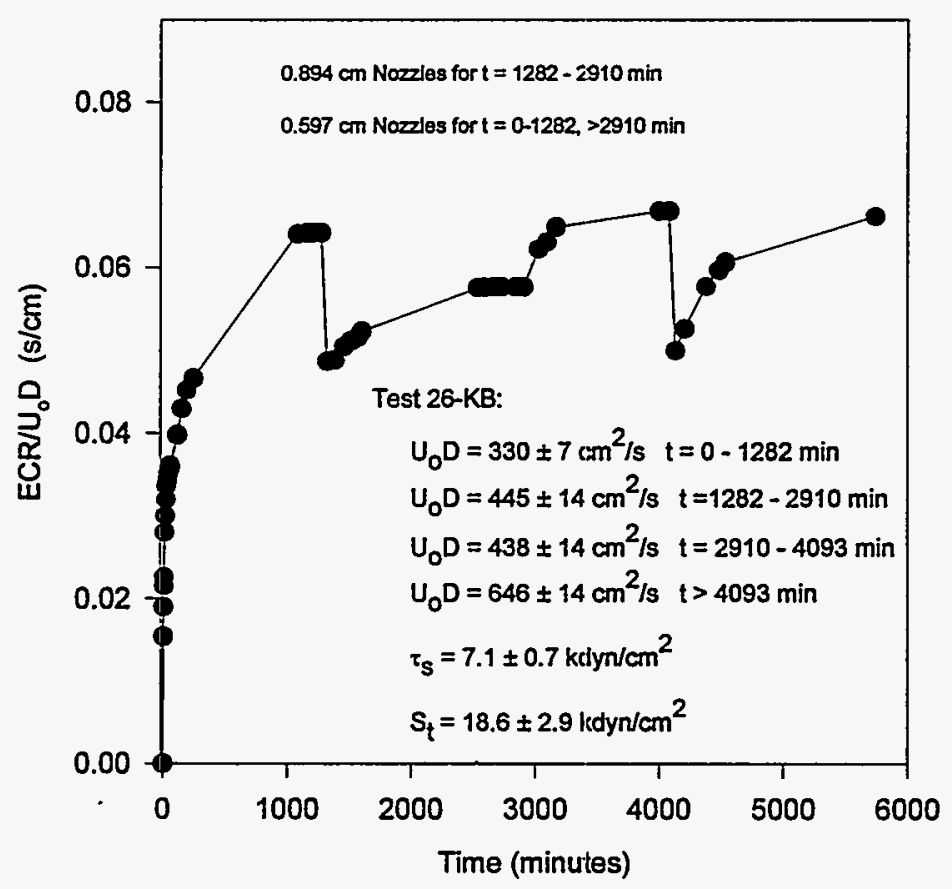

Figure A.102. Test $26-\mathrm{KB} E C R / \mathrm{U}_{0} \mathrm{D}$ vs. Time 


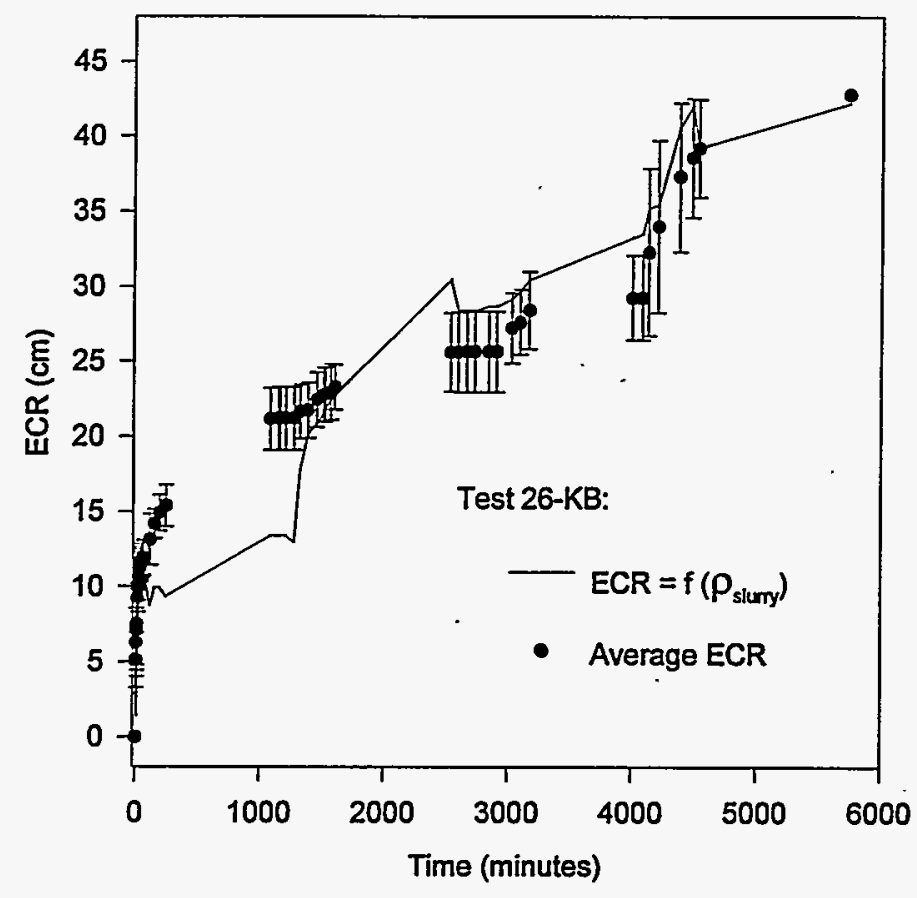

Figure A.103. Test 26-KB ECR Calculated from Density

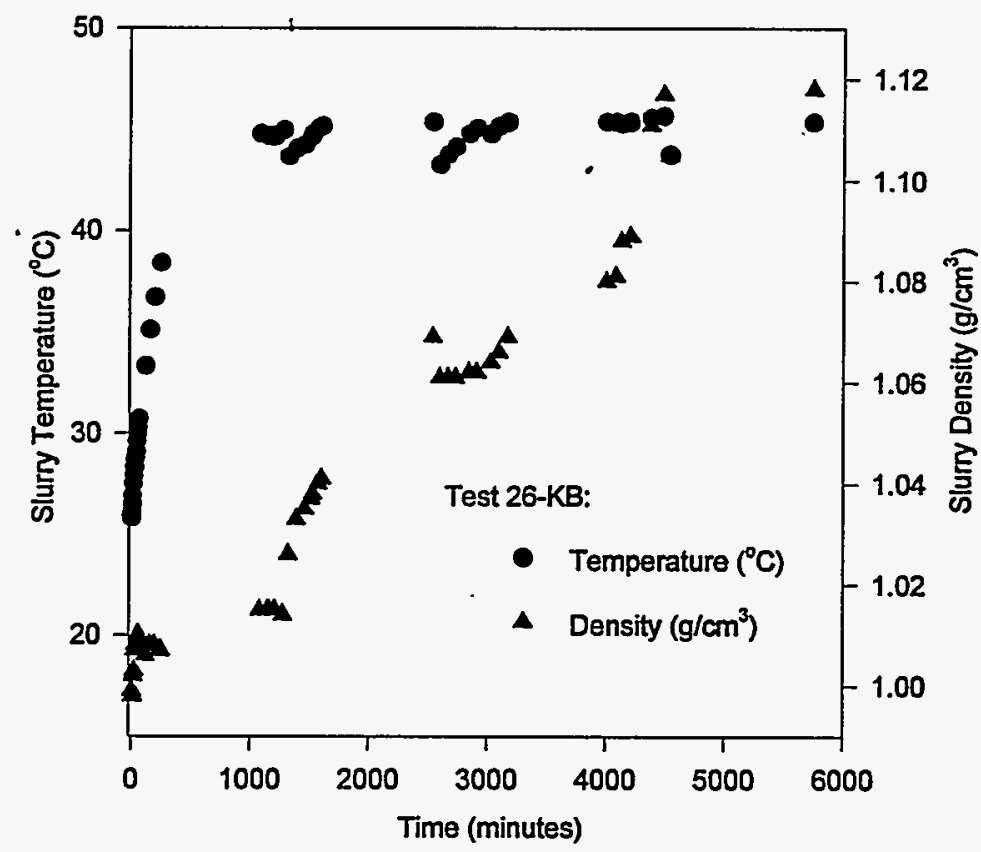

Figure A.104. Test 26-KB Slurry Temperature and Density 
Appendix B

ECR Profile Sketches 


\section{Appendix B}

\section{ECR Profile Sketches}

Sketches were made of the sludge/slurry interface as seen from under the $1 / 25$-scale tank. These data are given herein. At least one of these ECR profile sketches was prepared for each test run with the exception of test 11-KP, which was inadvertently skipped. These sketches provide a visual representation of the magnitude of the uncertainty in ECR measurements made at $1 / 25$-scale. 


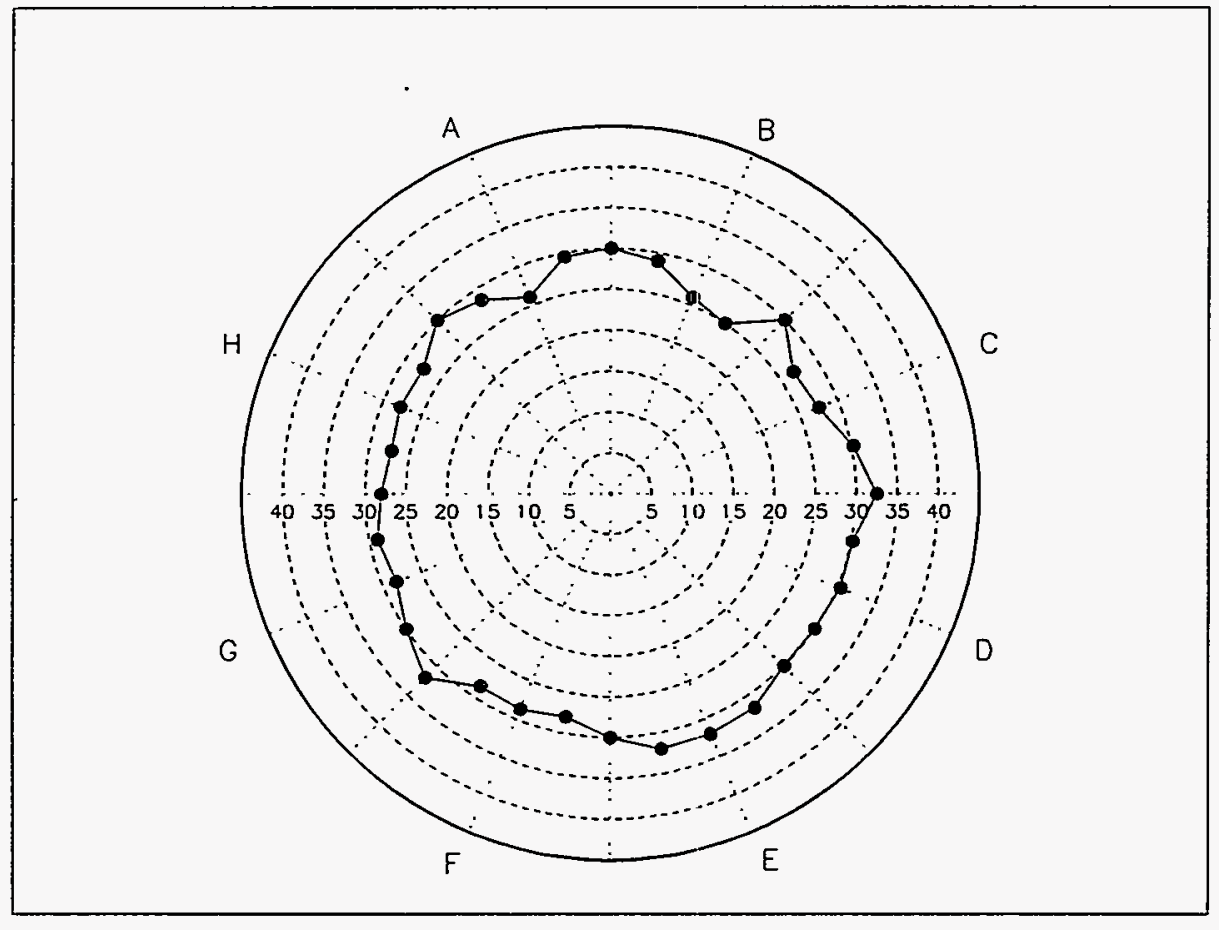

Figure B.1. Test $1-\mathrm{K}$ at $868 \mathrm{~min}$ 


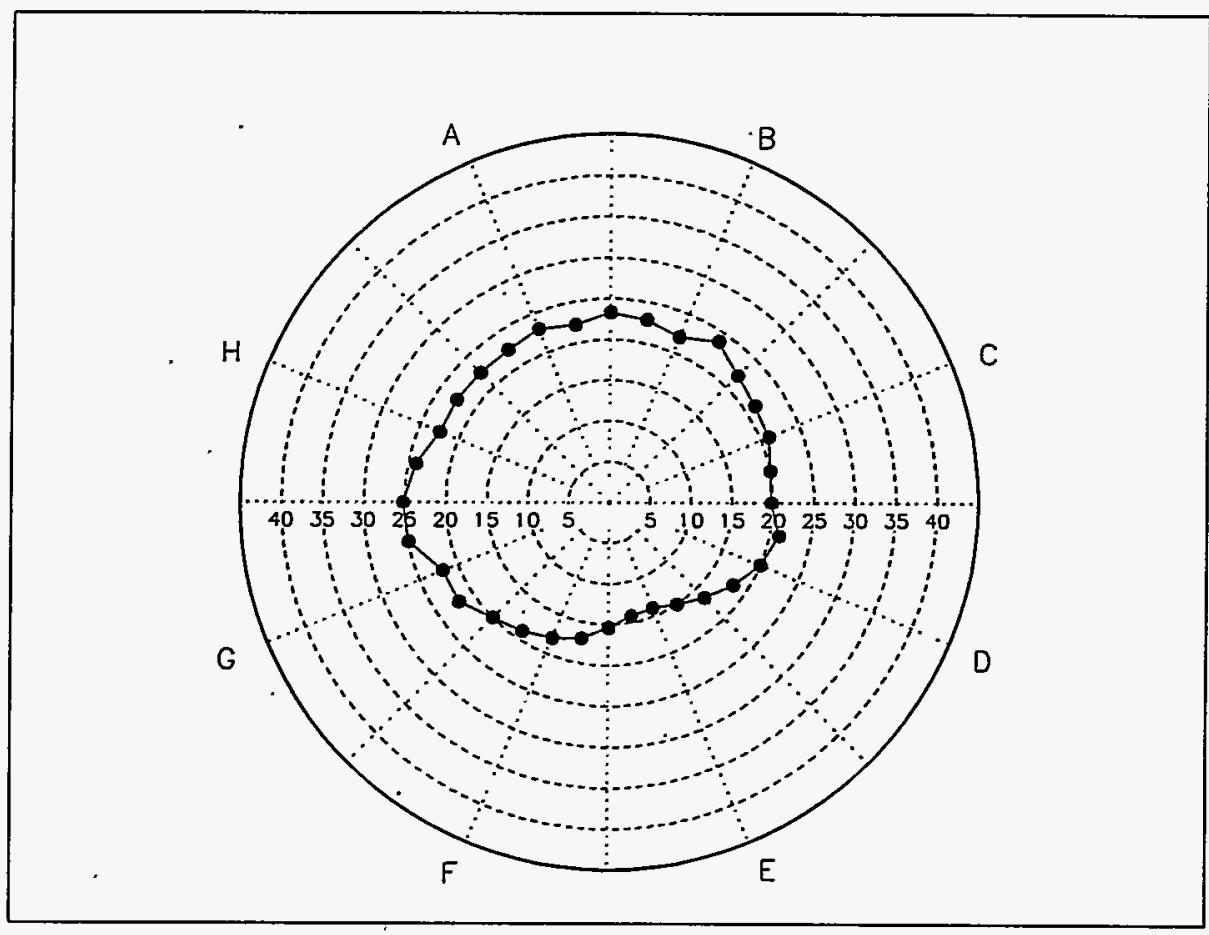

Figure B.2. Test $2-K$ at $245 \mathrm{~min}$ 


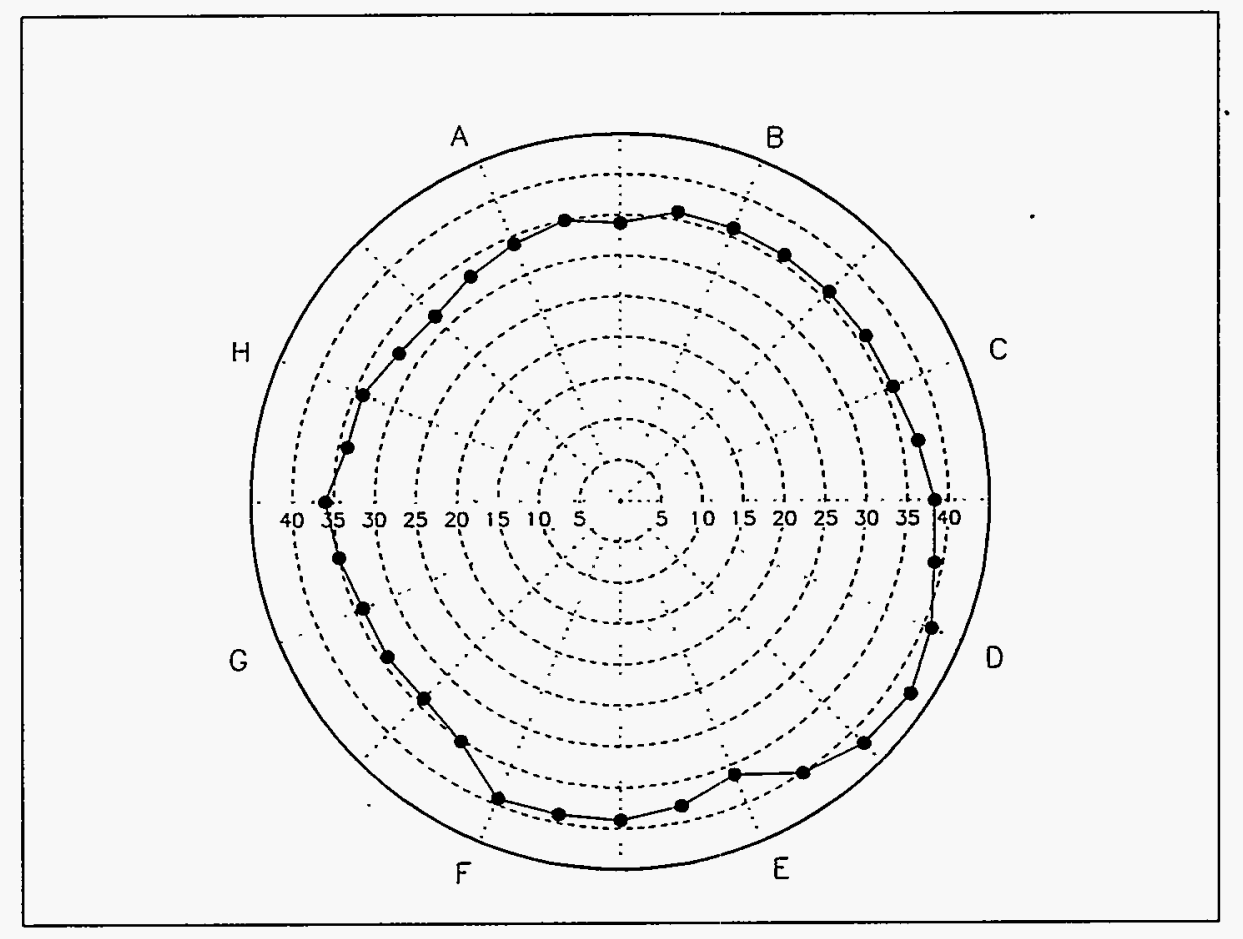

Figure B.3. Test 2-K at $245 \mathrm{~min}$

\section{B. 4}




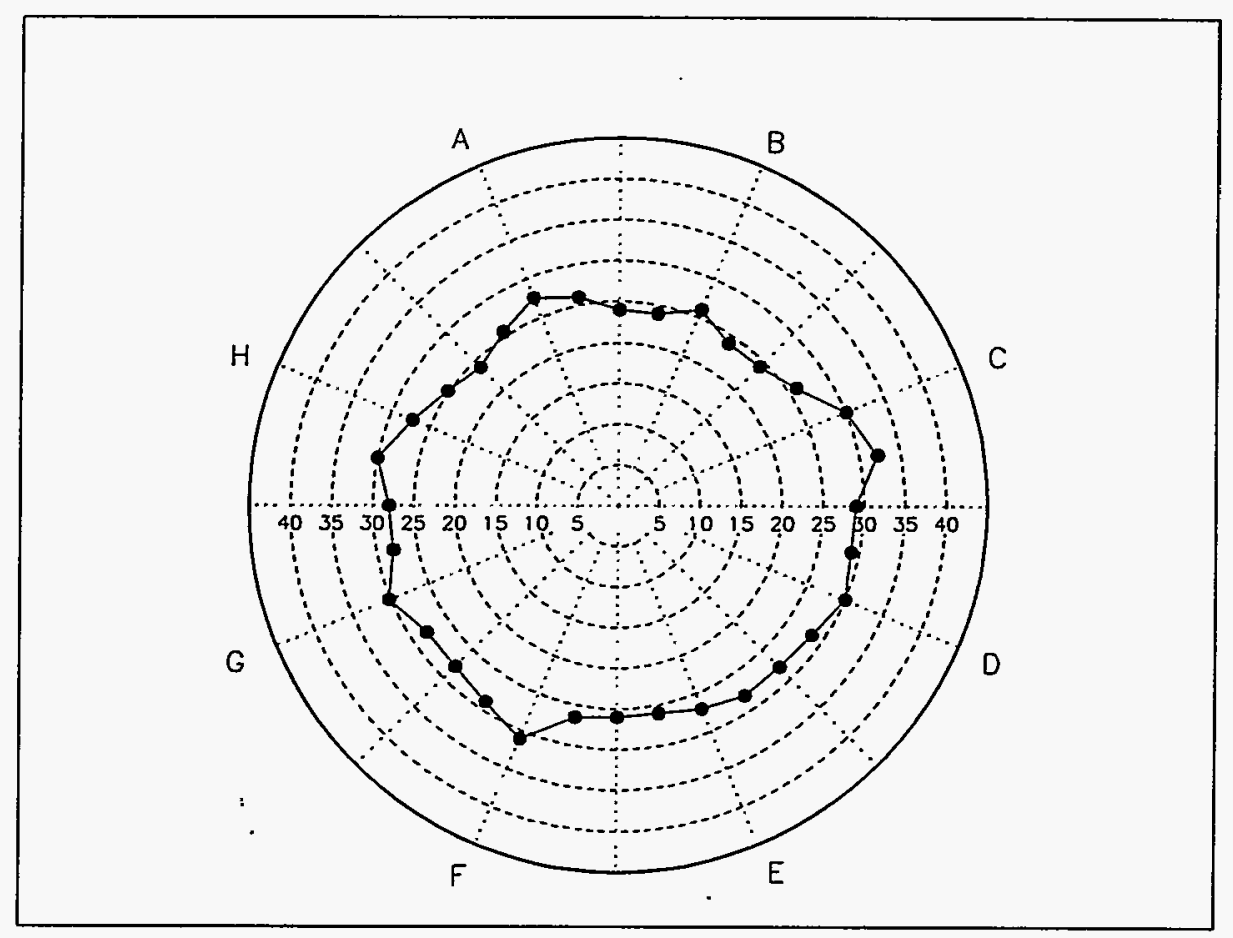

Figure B.4. Test 3-K at $1380 \mathrm{~min}$ 


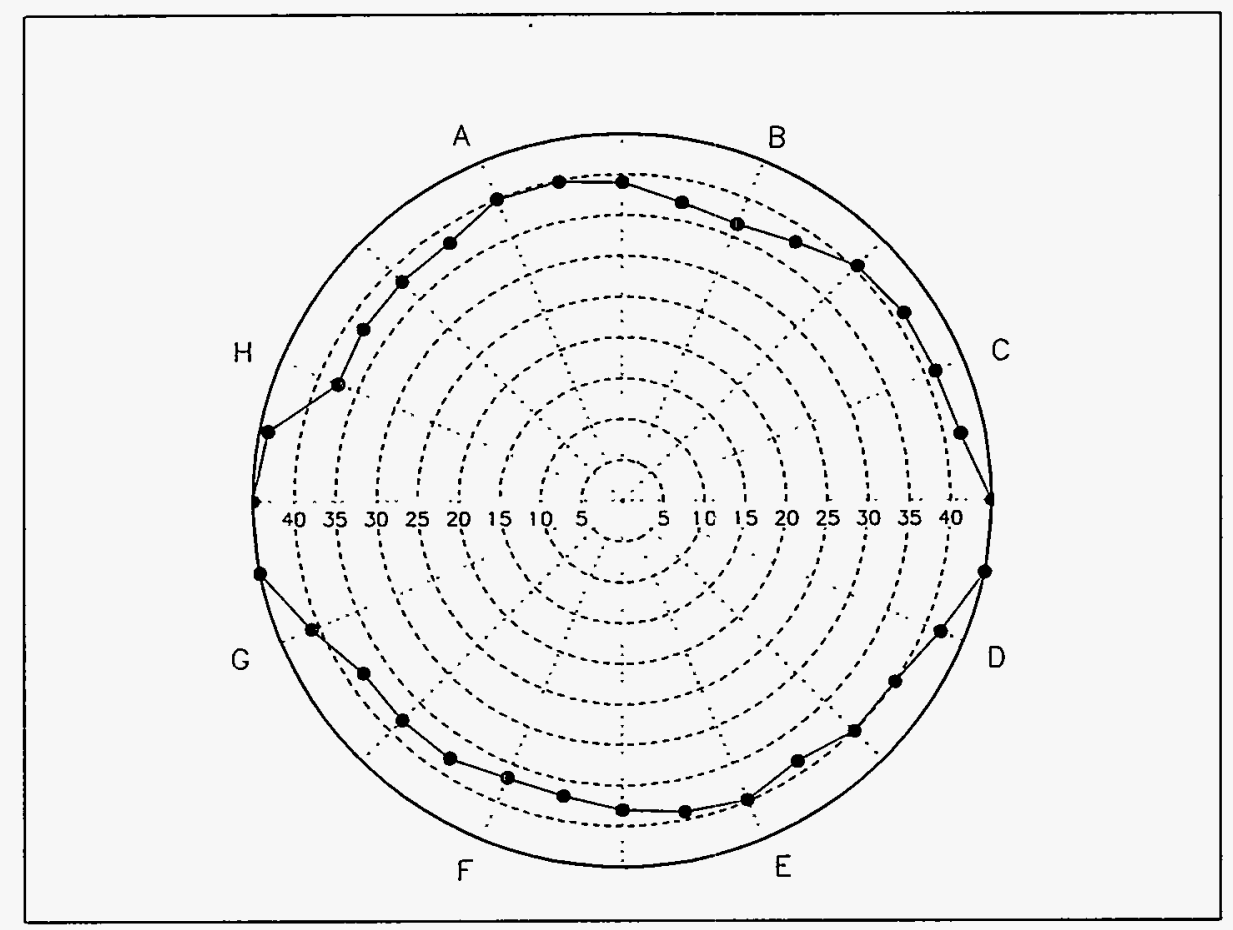

Figure B.5. Test 4-B at $540 \mathrm{~min}$ 


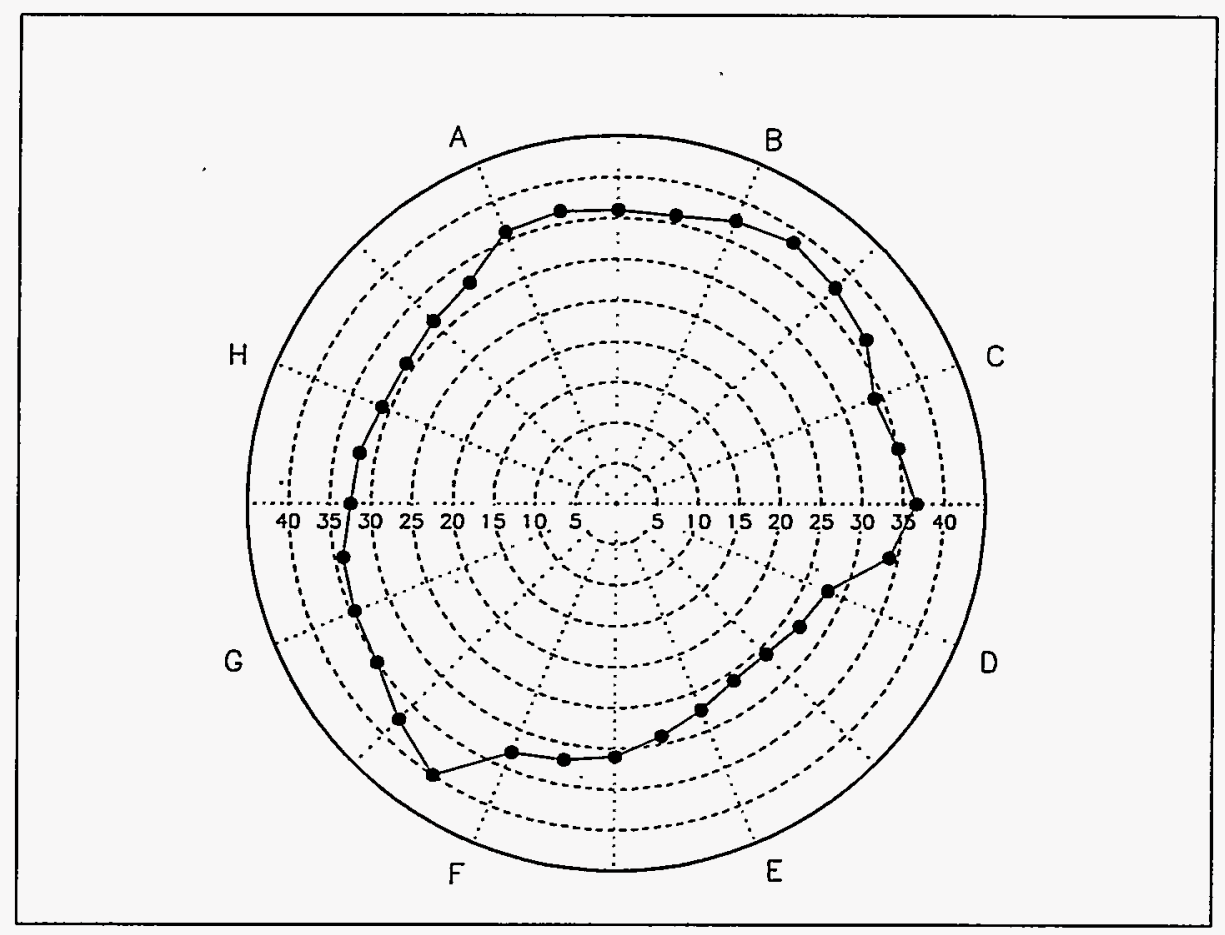

Figure B.6. Test 5-B at $470 \mathrm{~min}$ 


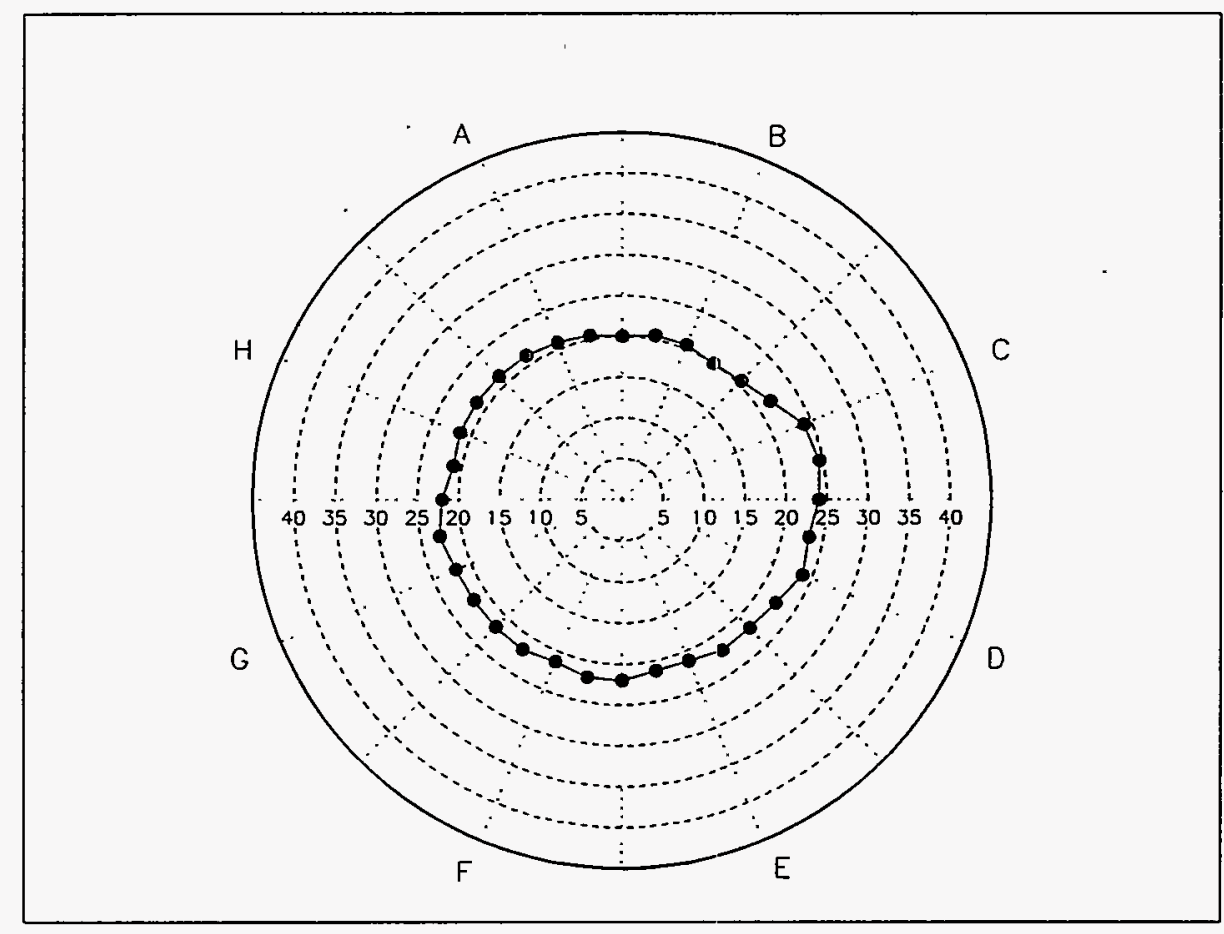

Figure B.7. Test 6-B at $1670 \mathrm{~min}$ 


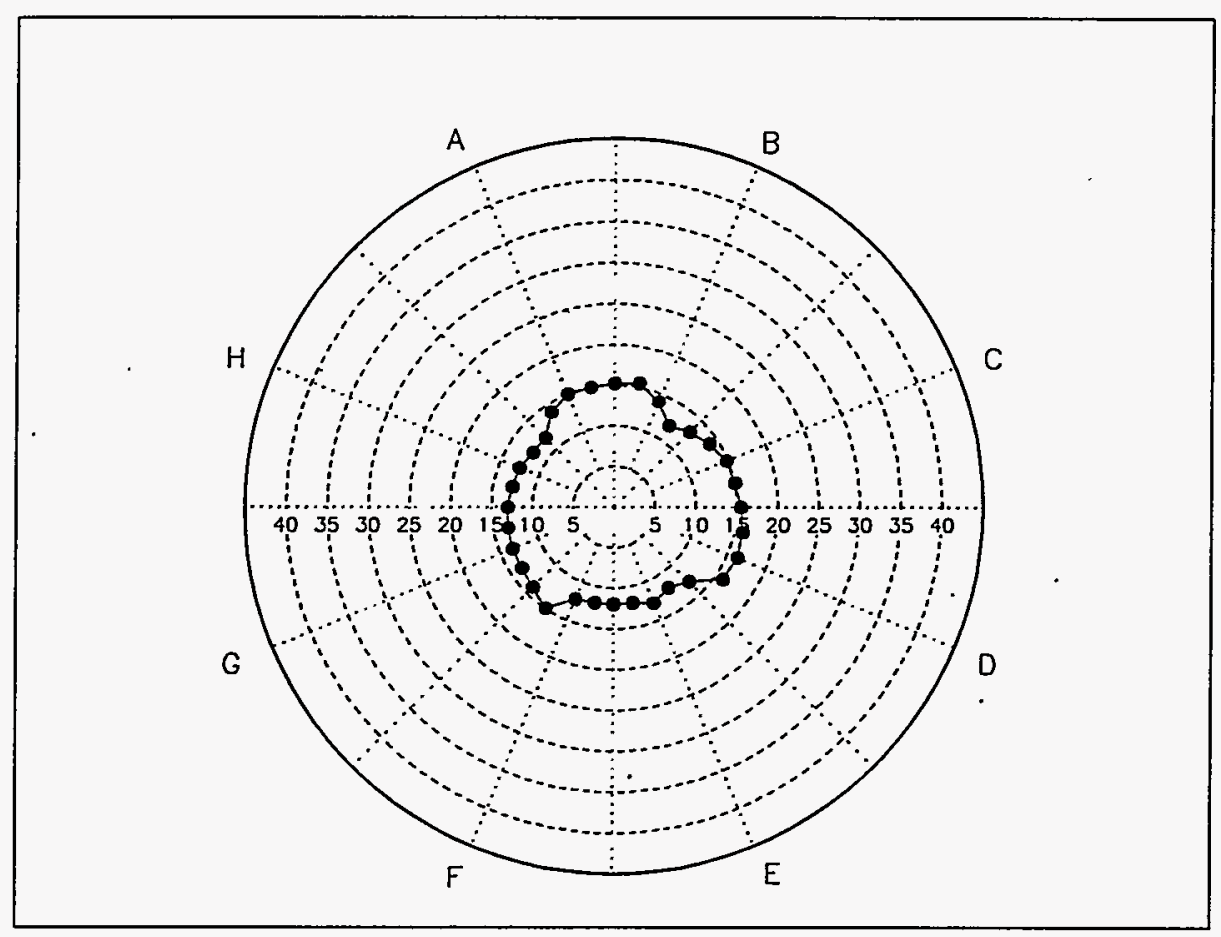

Figure B.8. Test 7-BK at $300 \mathrm{~min}$ 


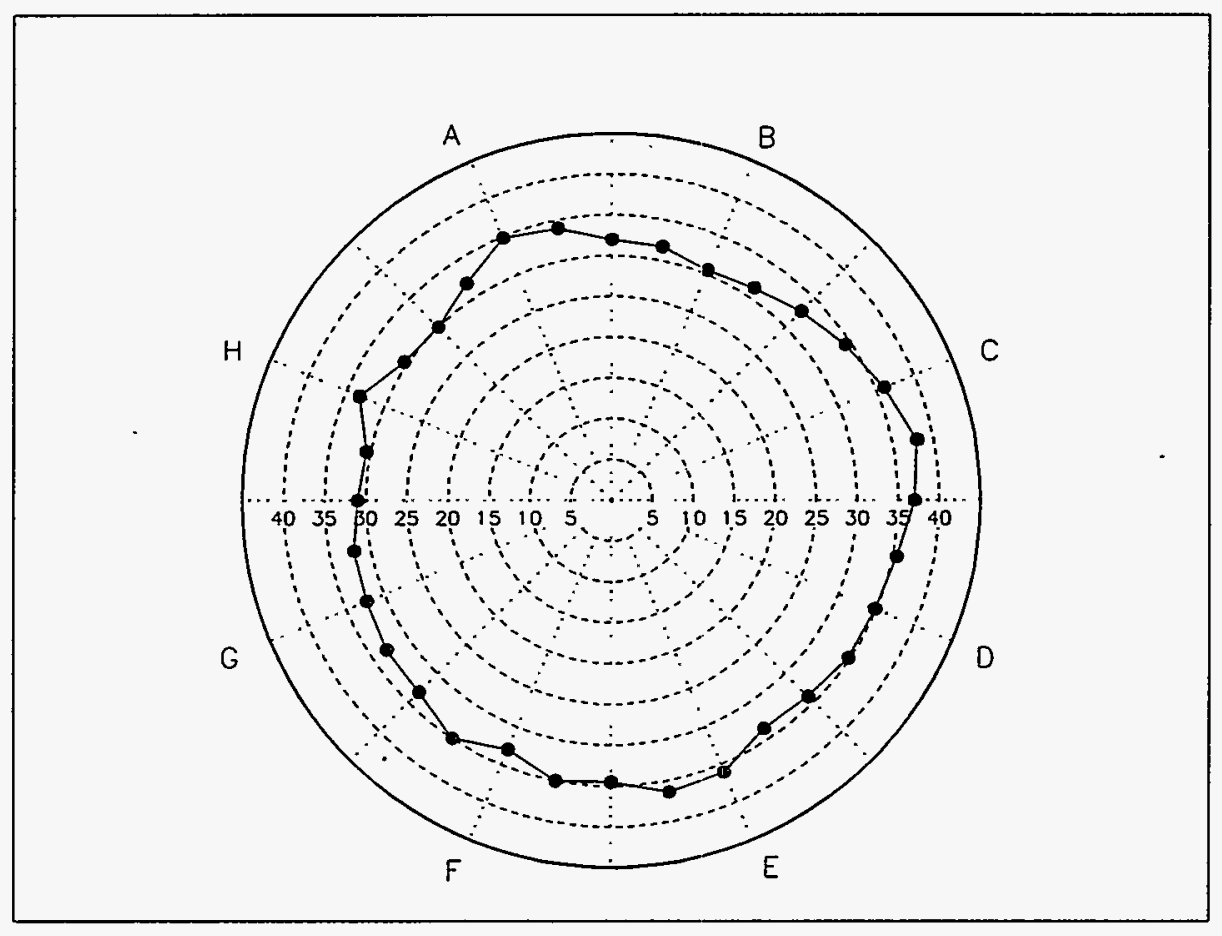

Figure B.9. Test 7-BK at $1585 \mathrm{~min}$ 


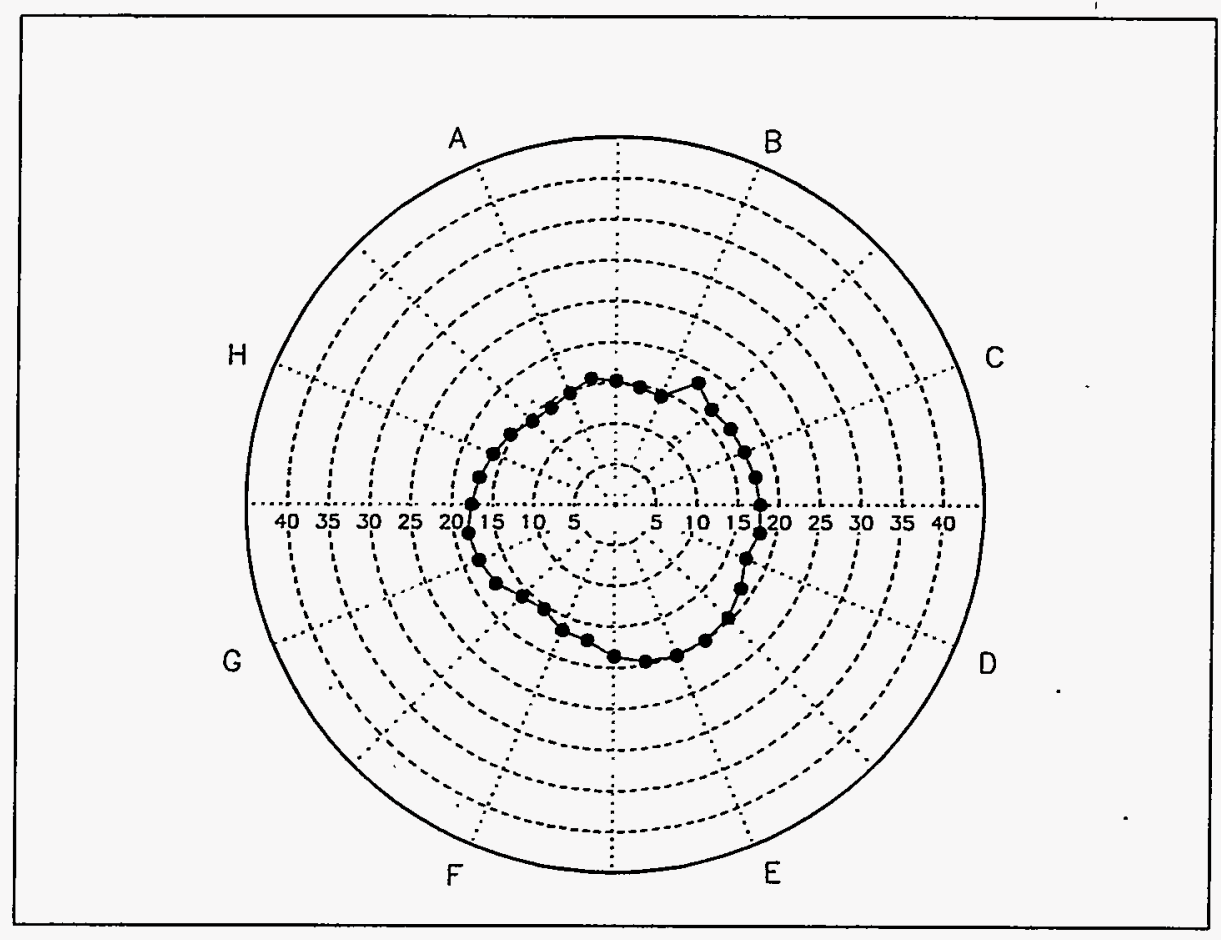

Figure B.10. Test $8-B K$ at $313 \mathrm{~min}$ 


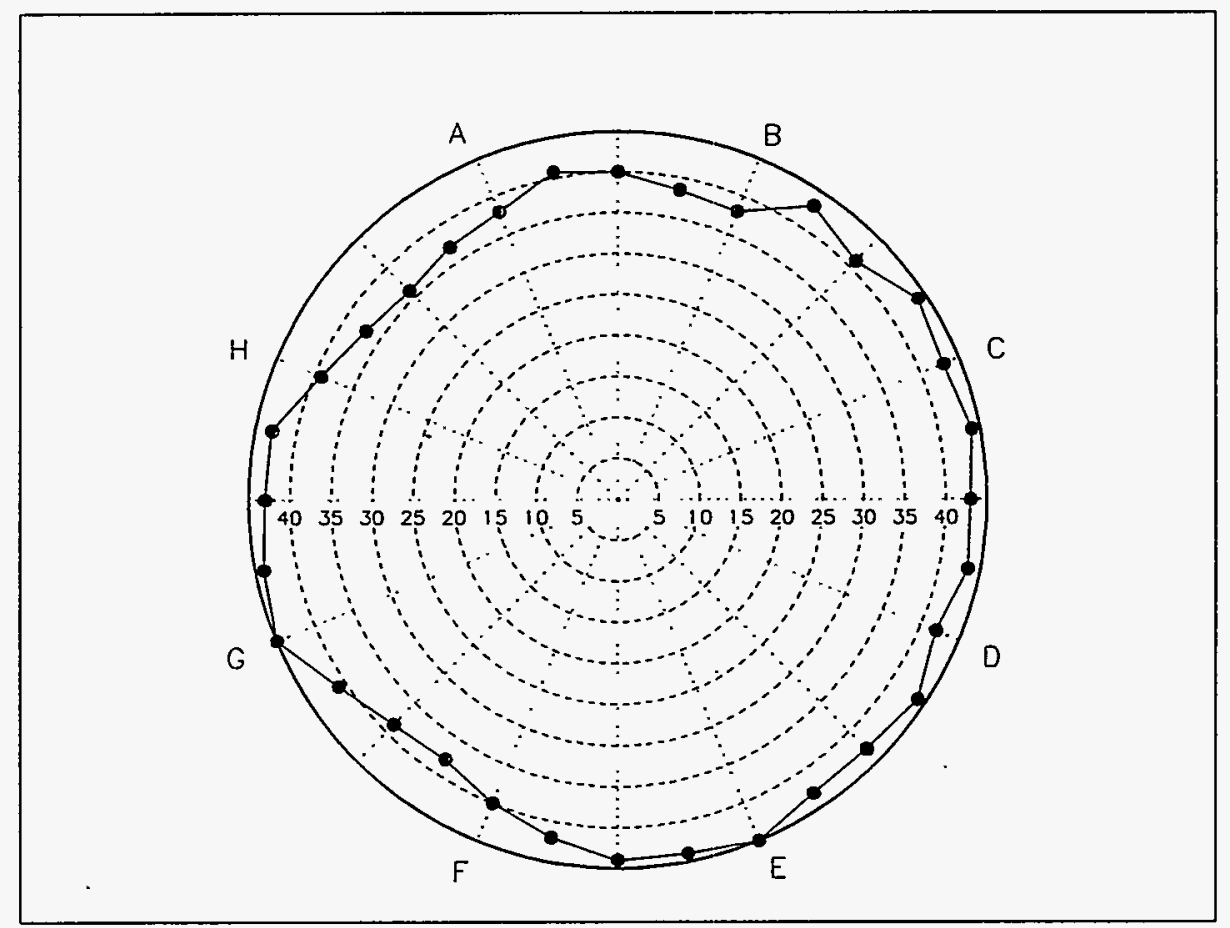

Figure B.11. Test $8-\mathrm{BBK}$ at $1850 \mathrm{~min}$ 


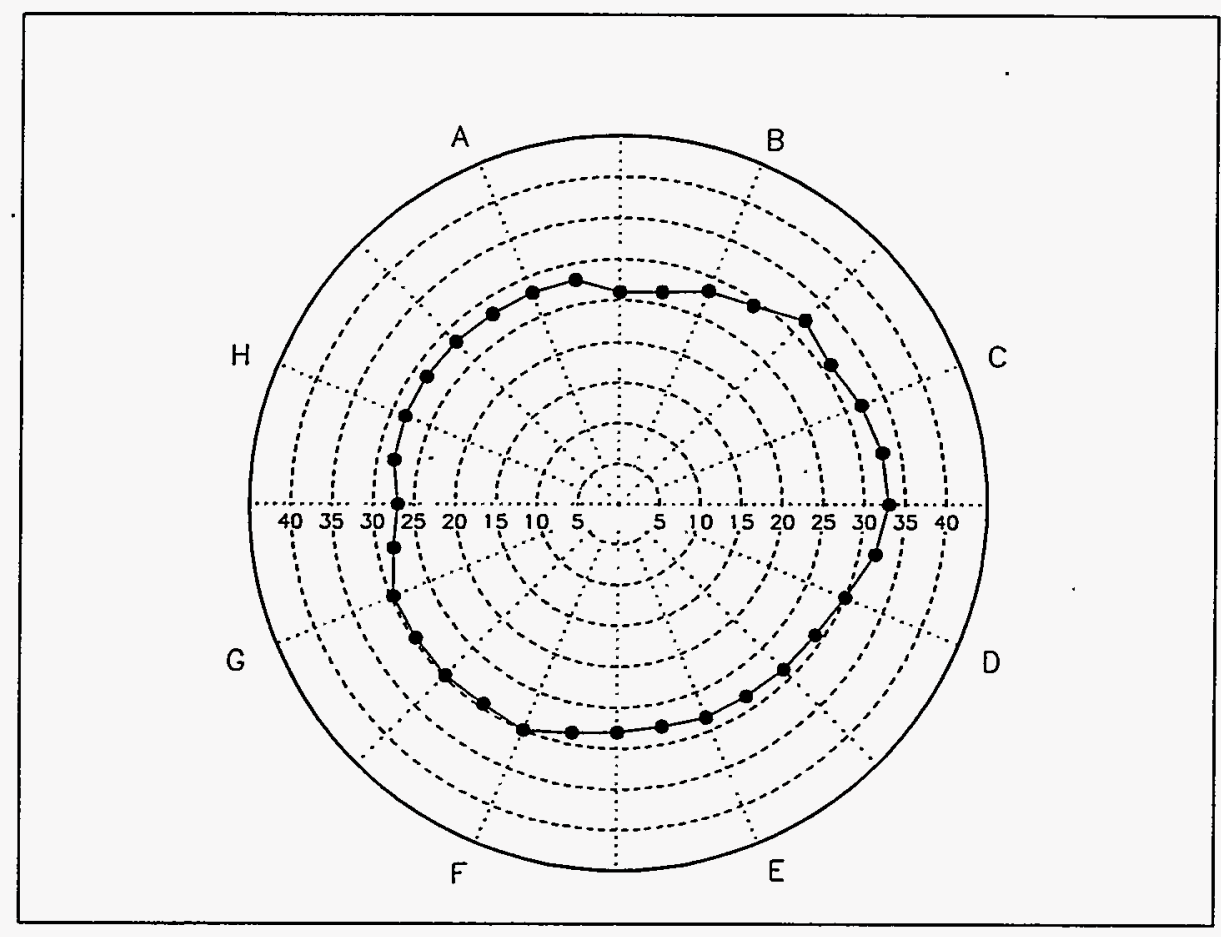

Figure B.12. Test 9-BK at $1815 \mathrm{~min}$ 


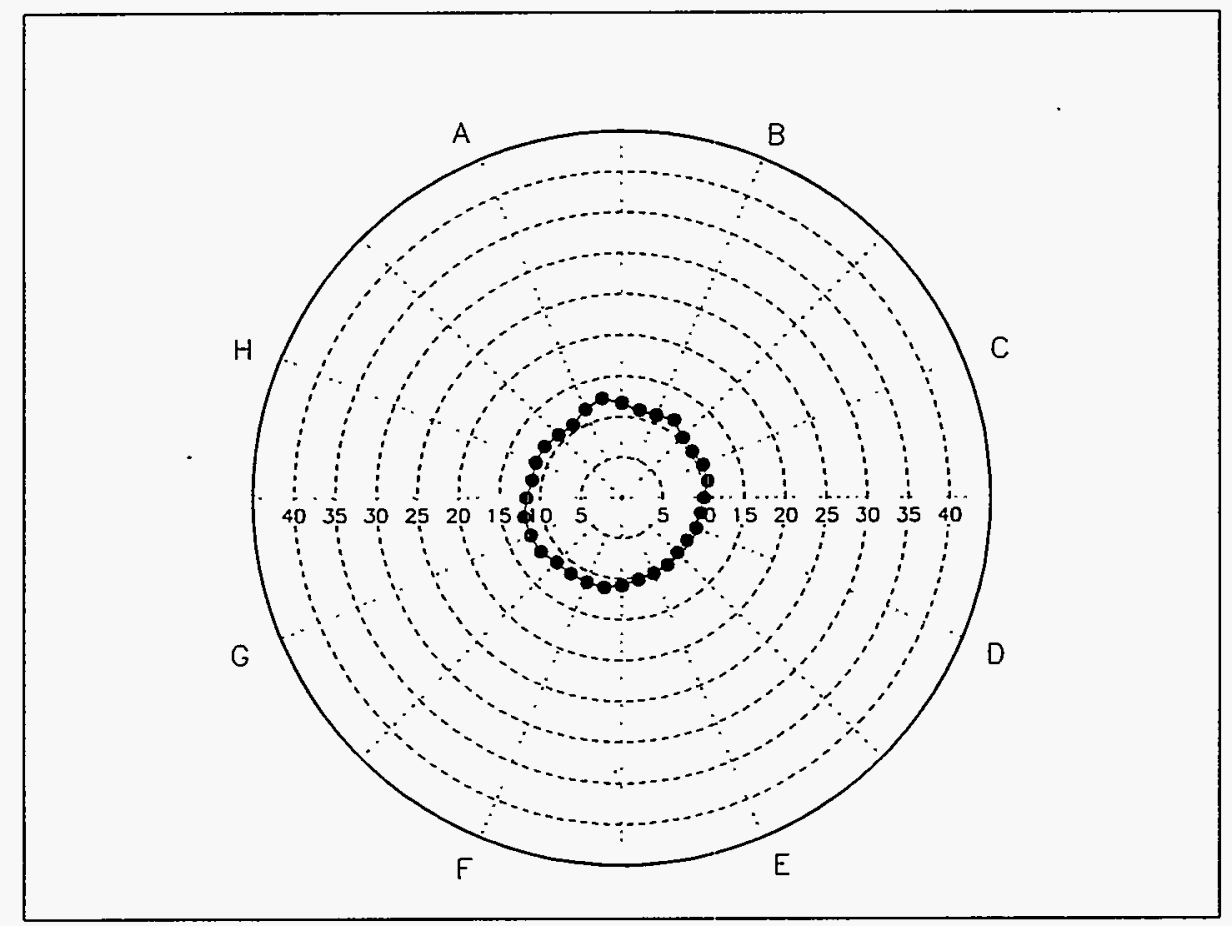

Figure B.13. Test $10-\mathrm{KP}$ at $340 \mathrm{~min}$ 


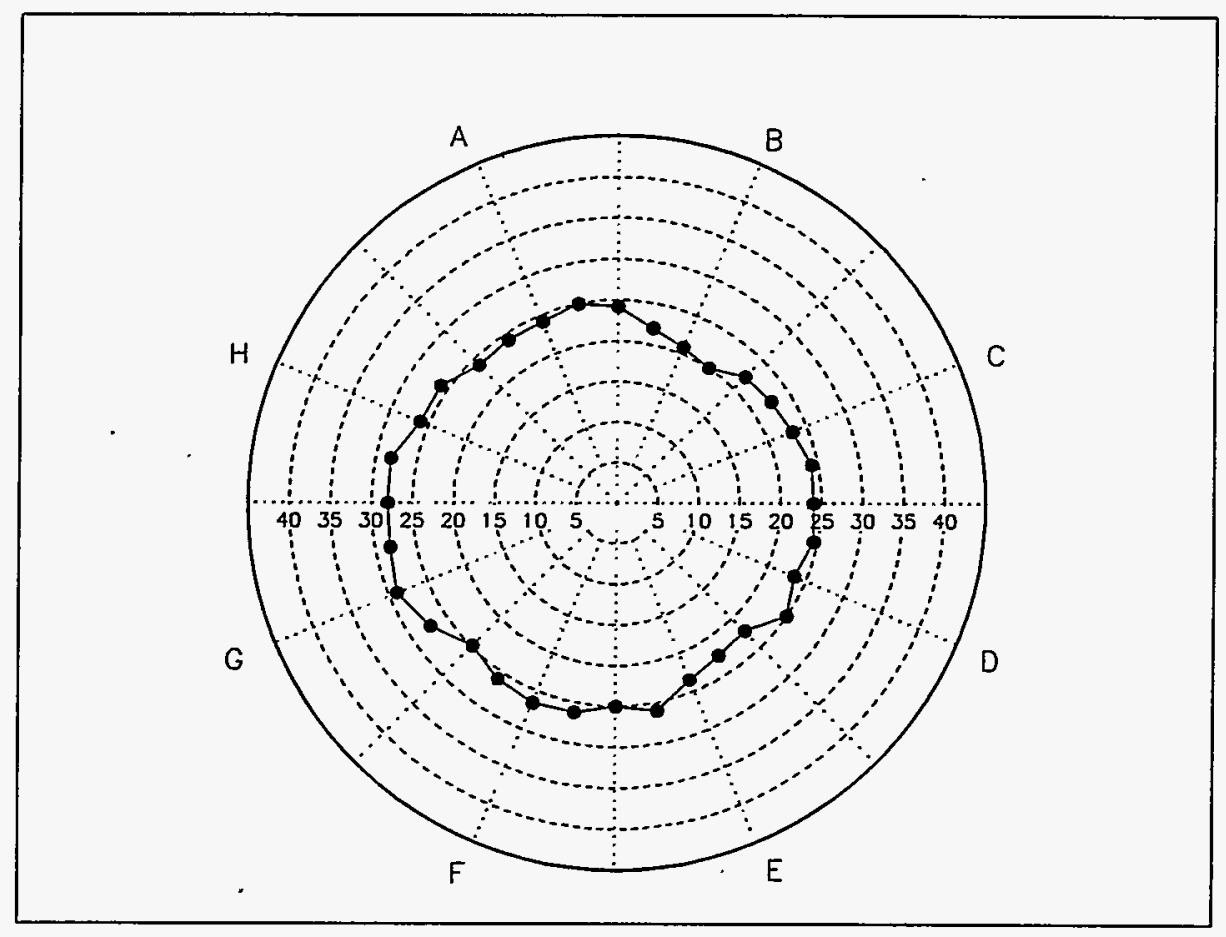

Figure B.14. Test $10-\mathrm{KP}$ at $1844 \mathrm{~min}$ 


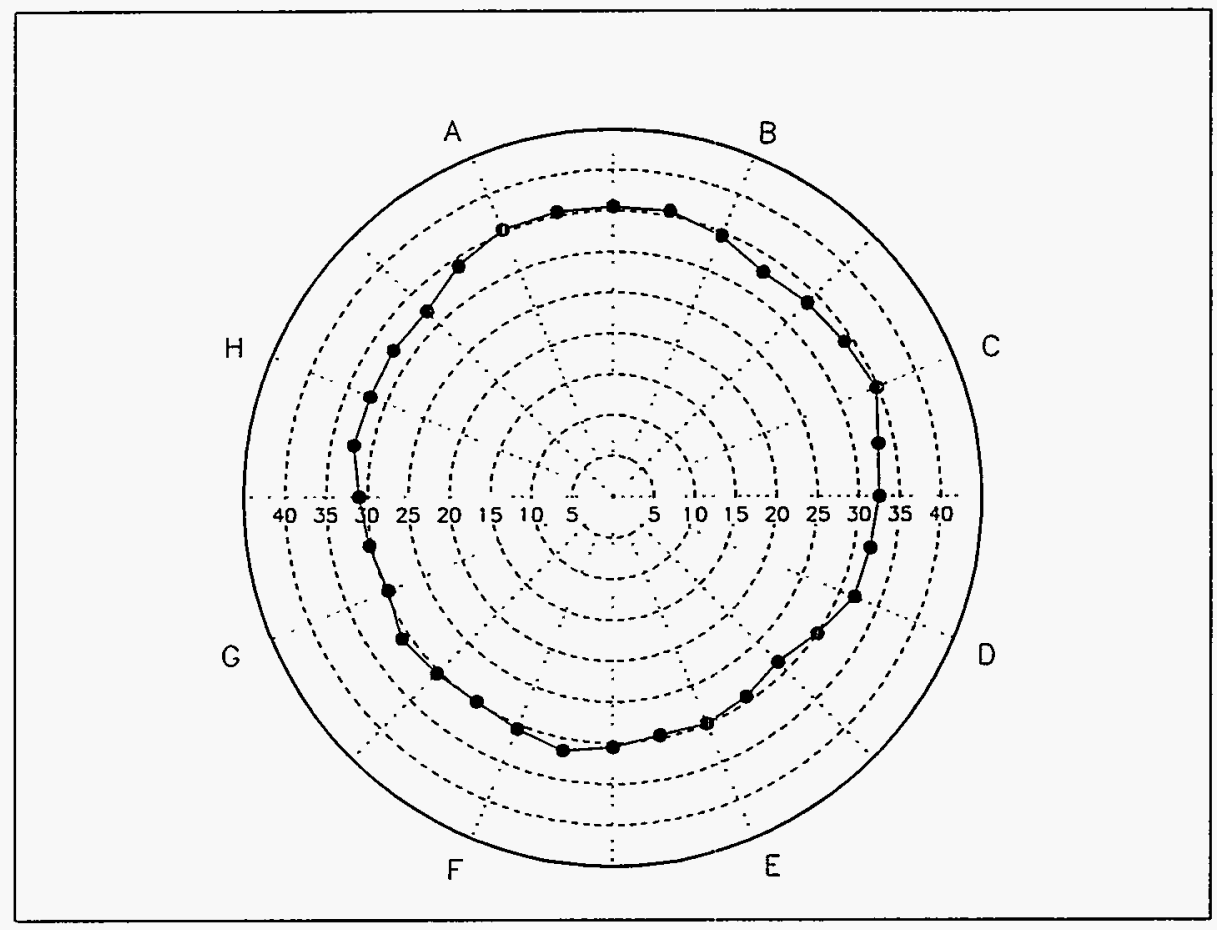

Figure B.15. Test $12-\mathrm{KP}$ at $3127 \mathrm{~min}$ 


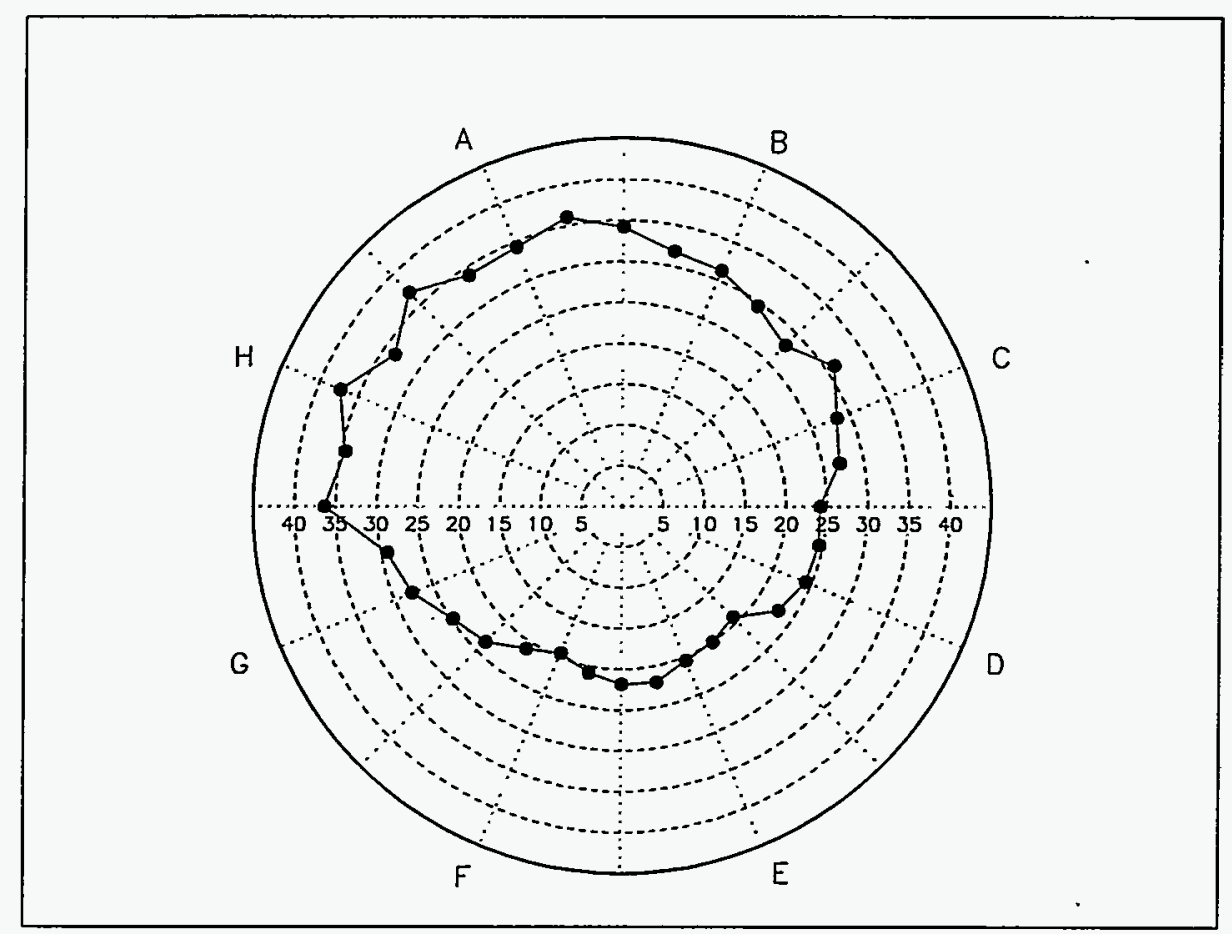

Figure B.16. Test $13-\mathrm{KL}$ at $1525 \mathrm{~min}$ 


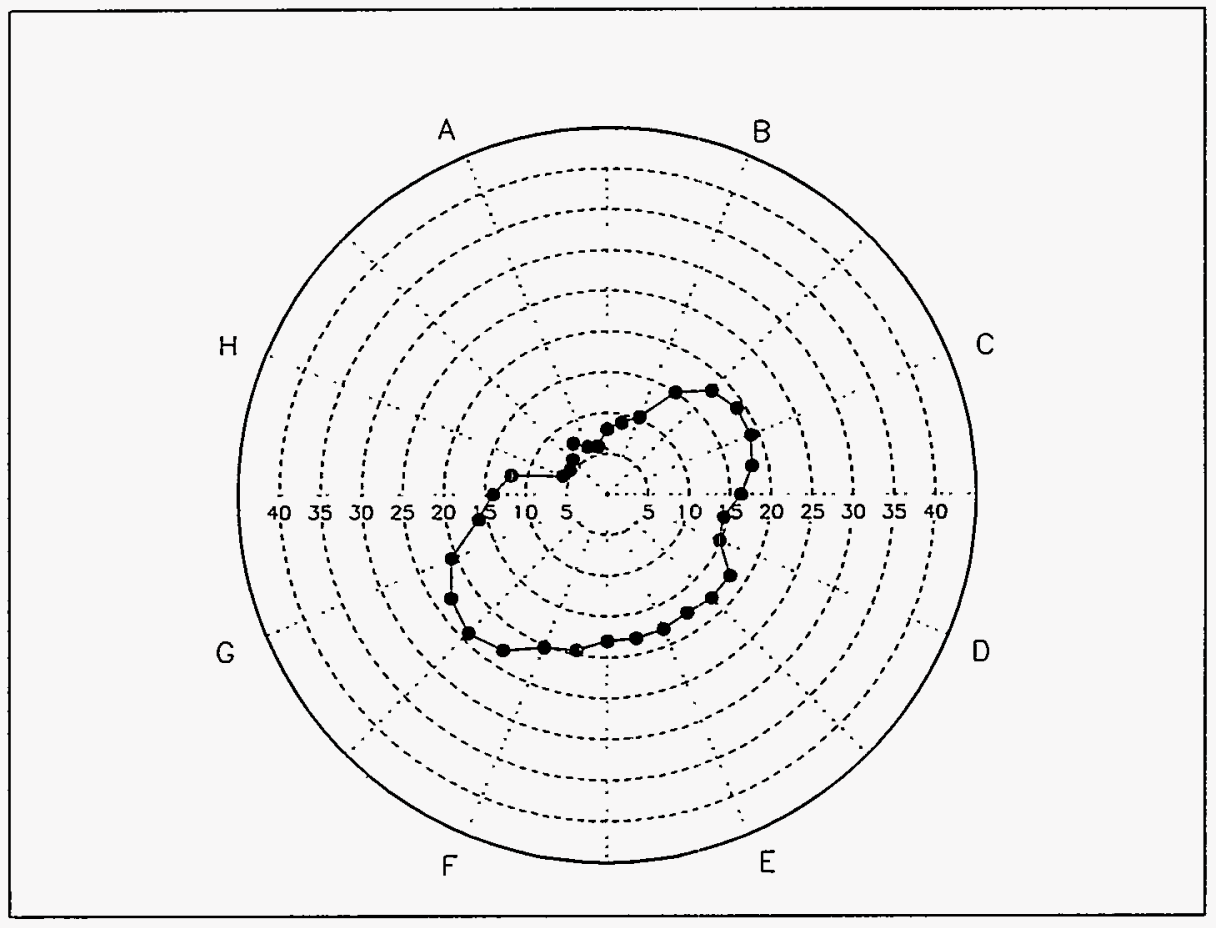

Figure B.17. Test $14-\mathrm{KL}$ at $1450 \mathrm{~min}$ 


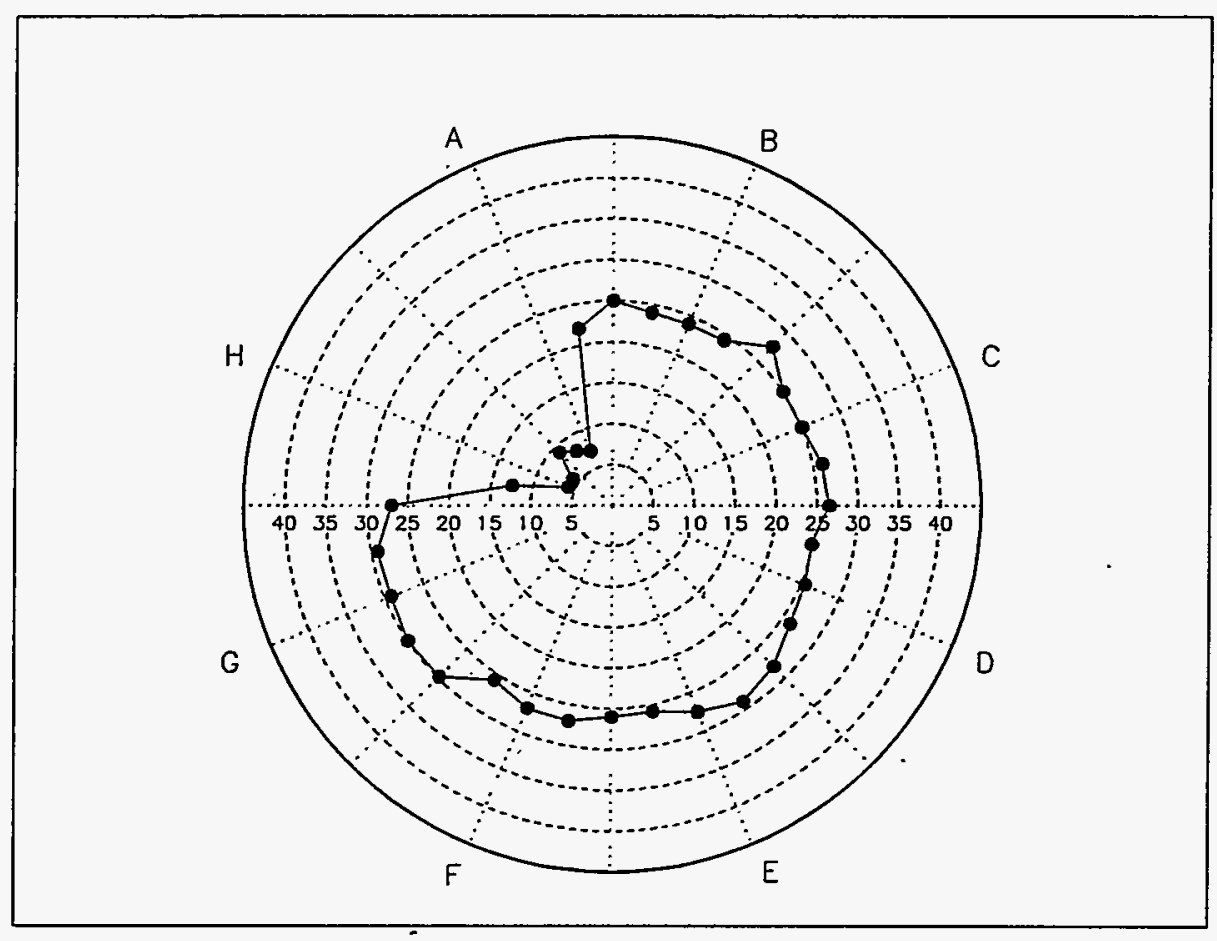

Figure B.18. Test $14-\mathrm{KL}$ at $1690 \mathrm{~min}$

B.19 


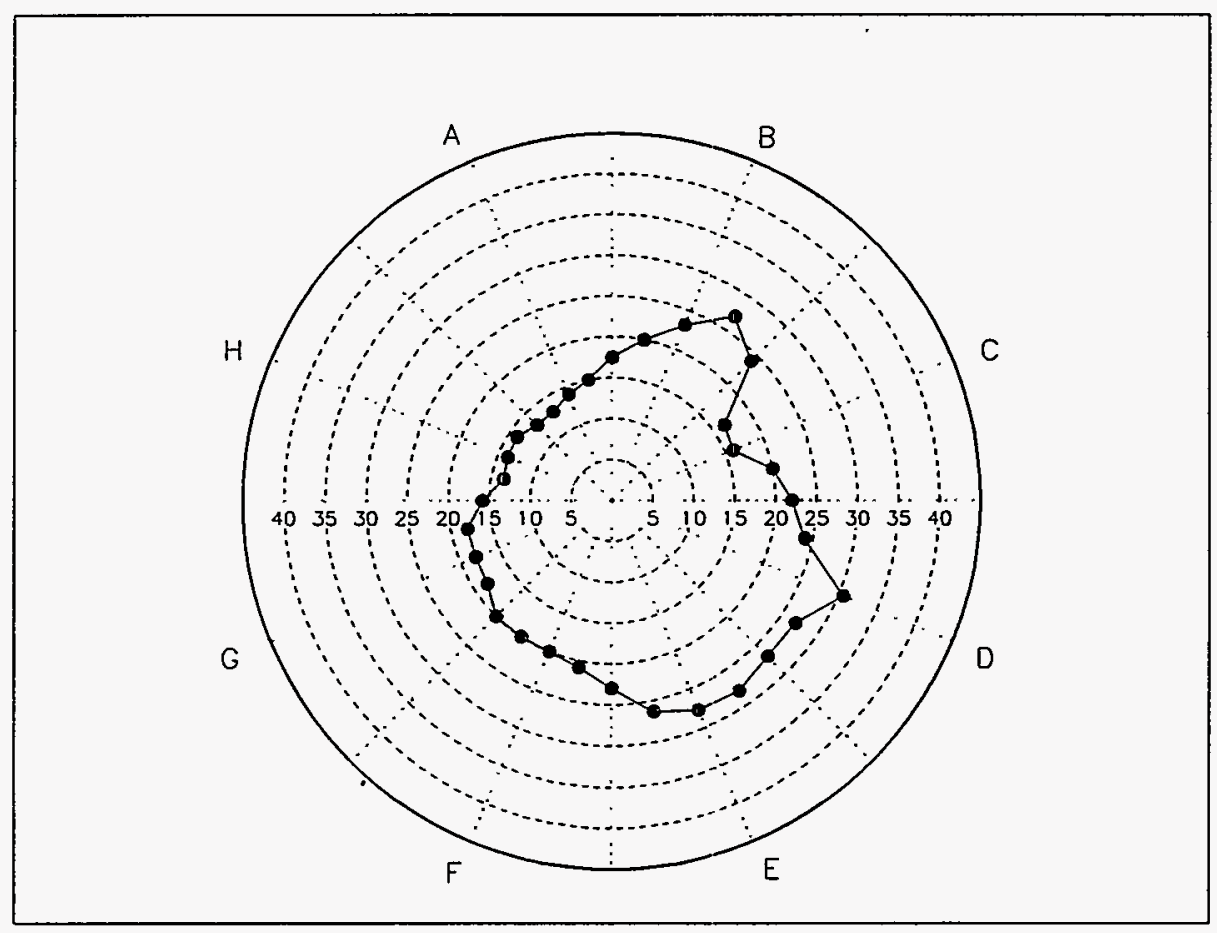

Figure B.19. Test $15-\mathrm{KL}$ at $1385 \mathrm{~min}$ 


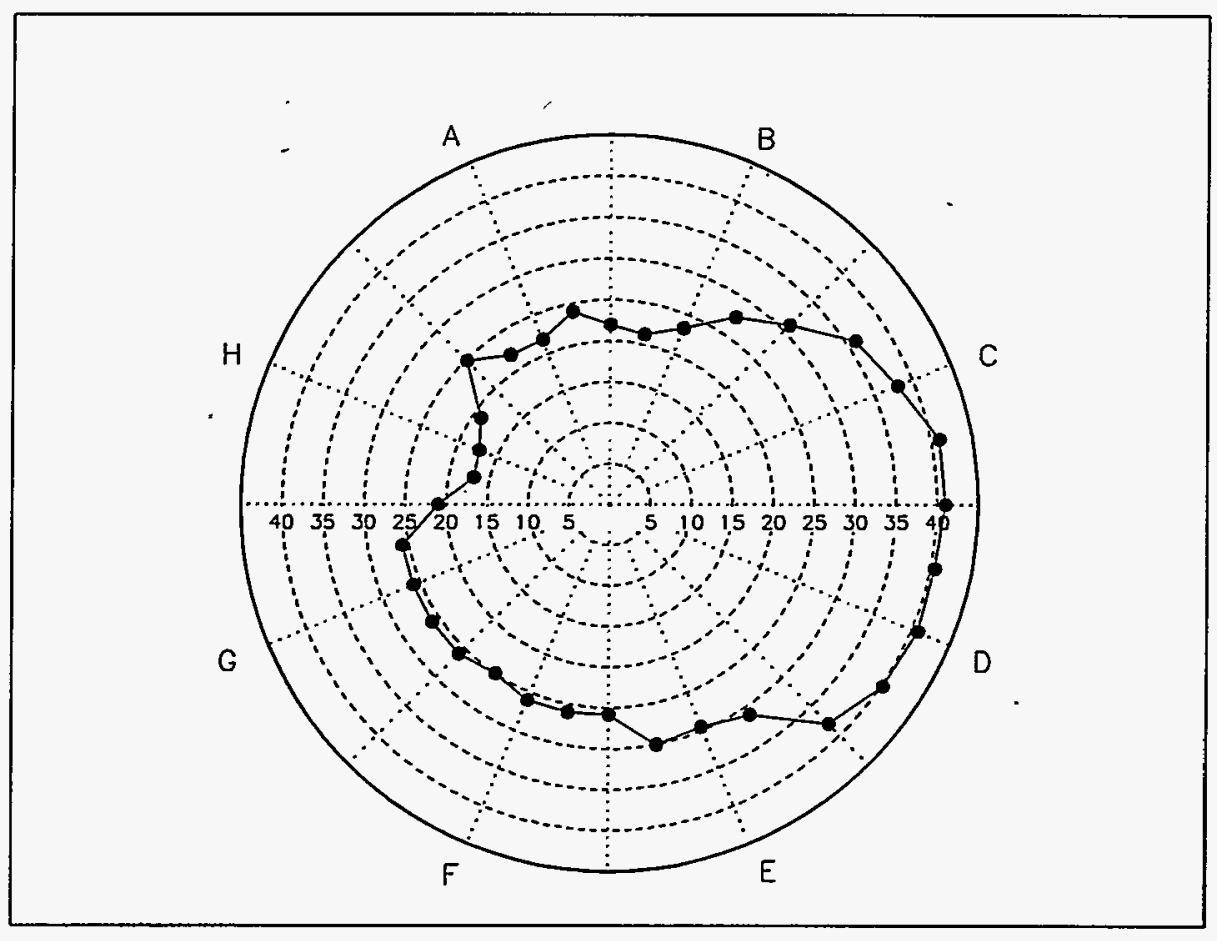

Figure B.20. Test $15-\mathrm{KL}$ at $1693 \mathrm{~min}$ 


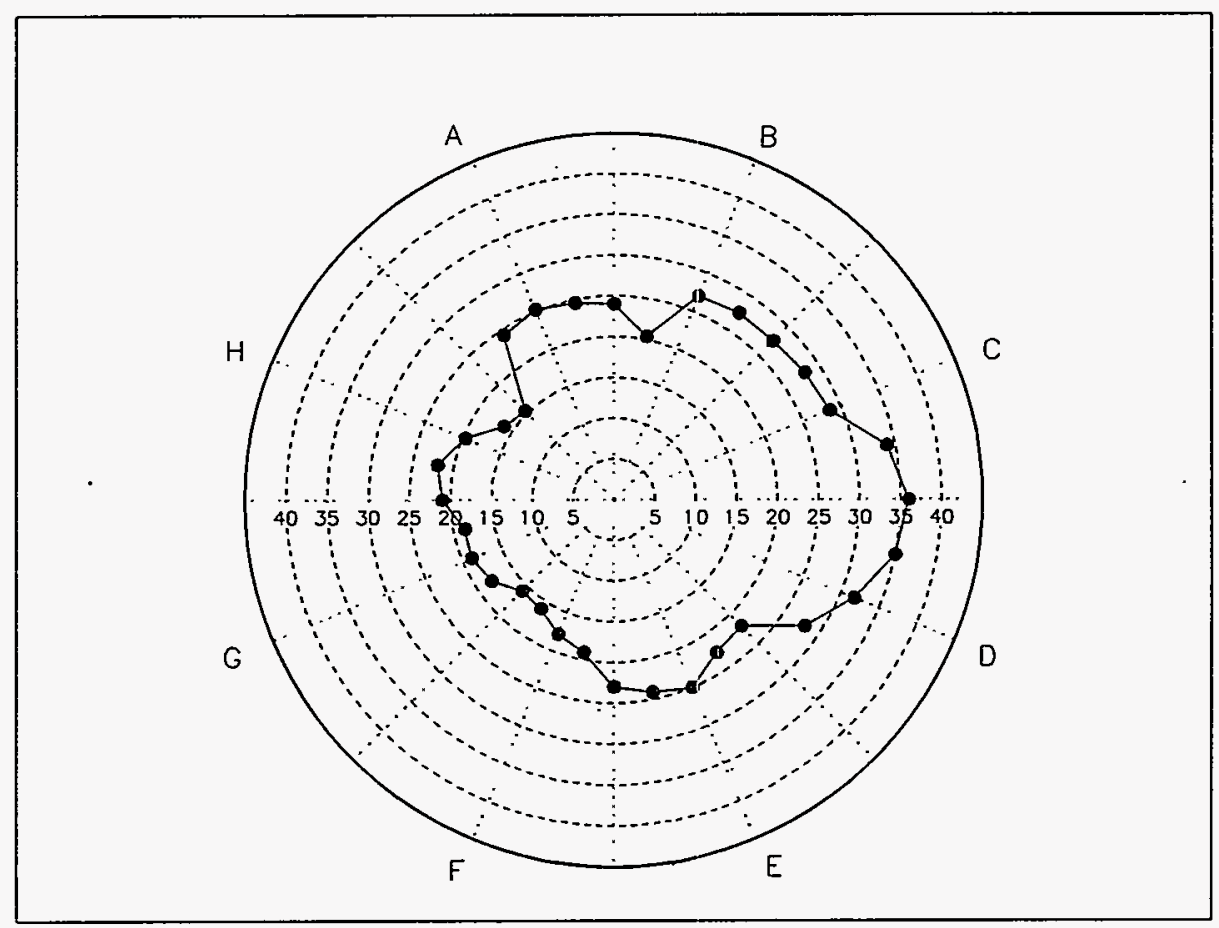

Figure B.21: Test $16-\mathrm{KN}$ at $1676 \mathrm{~min}$ 


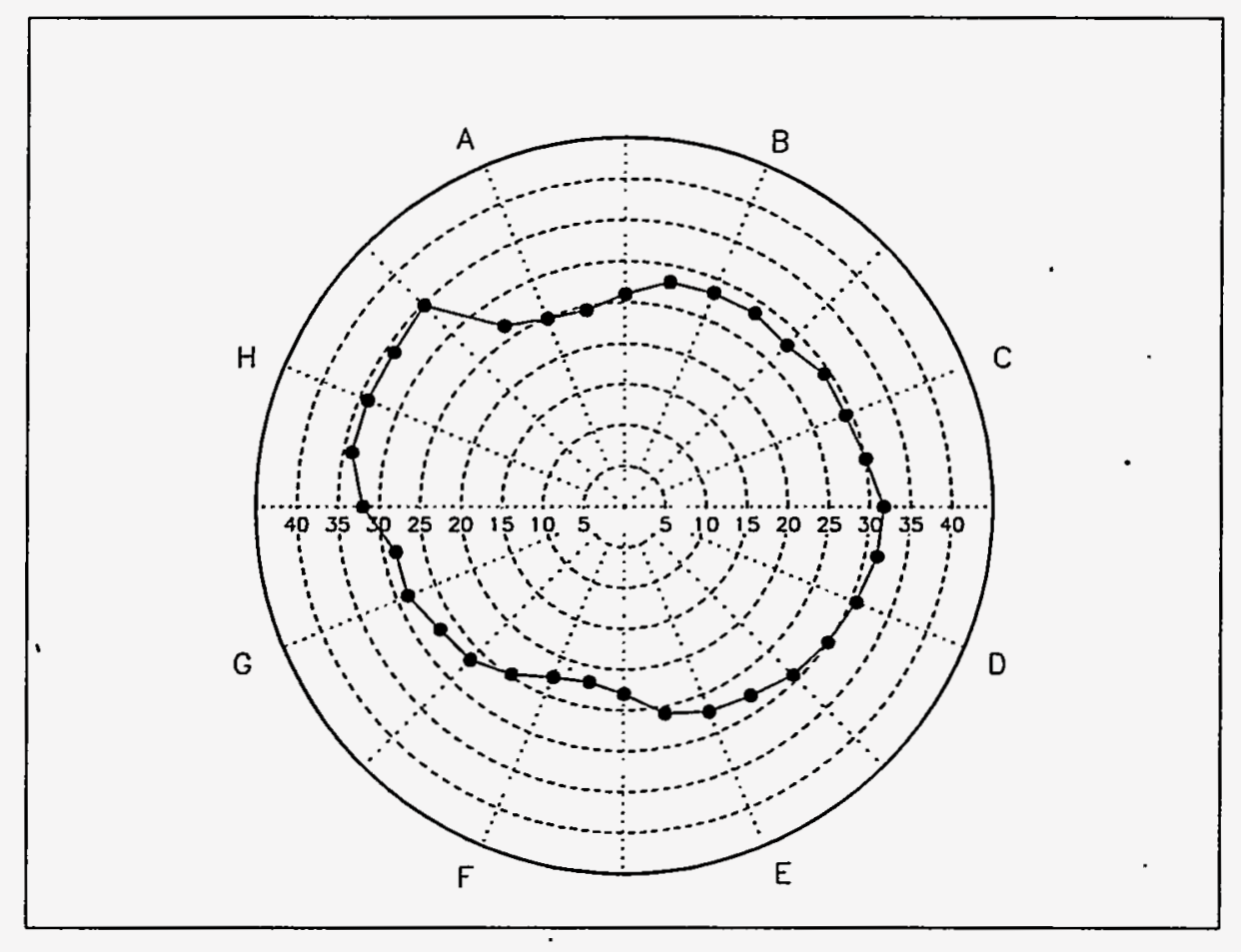

Figure B.22. Test $17-\mathrm{KN}$ at $1704 \mathrm{~min}$ 


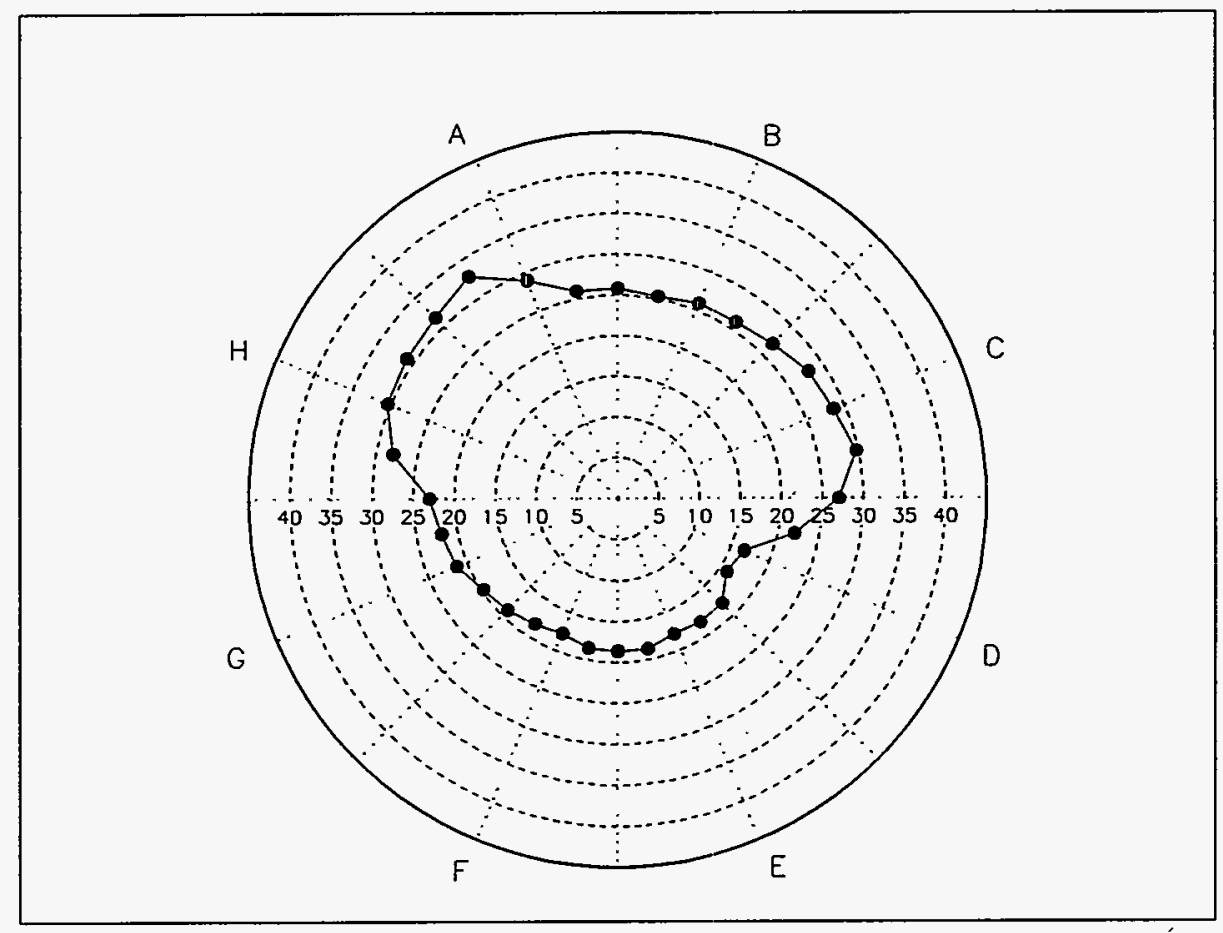

Figure B.23. Test $18-\mathrm{KN}$ at $385 \mathrm{~min}$ 


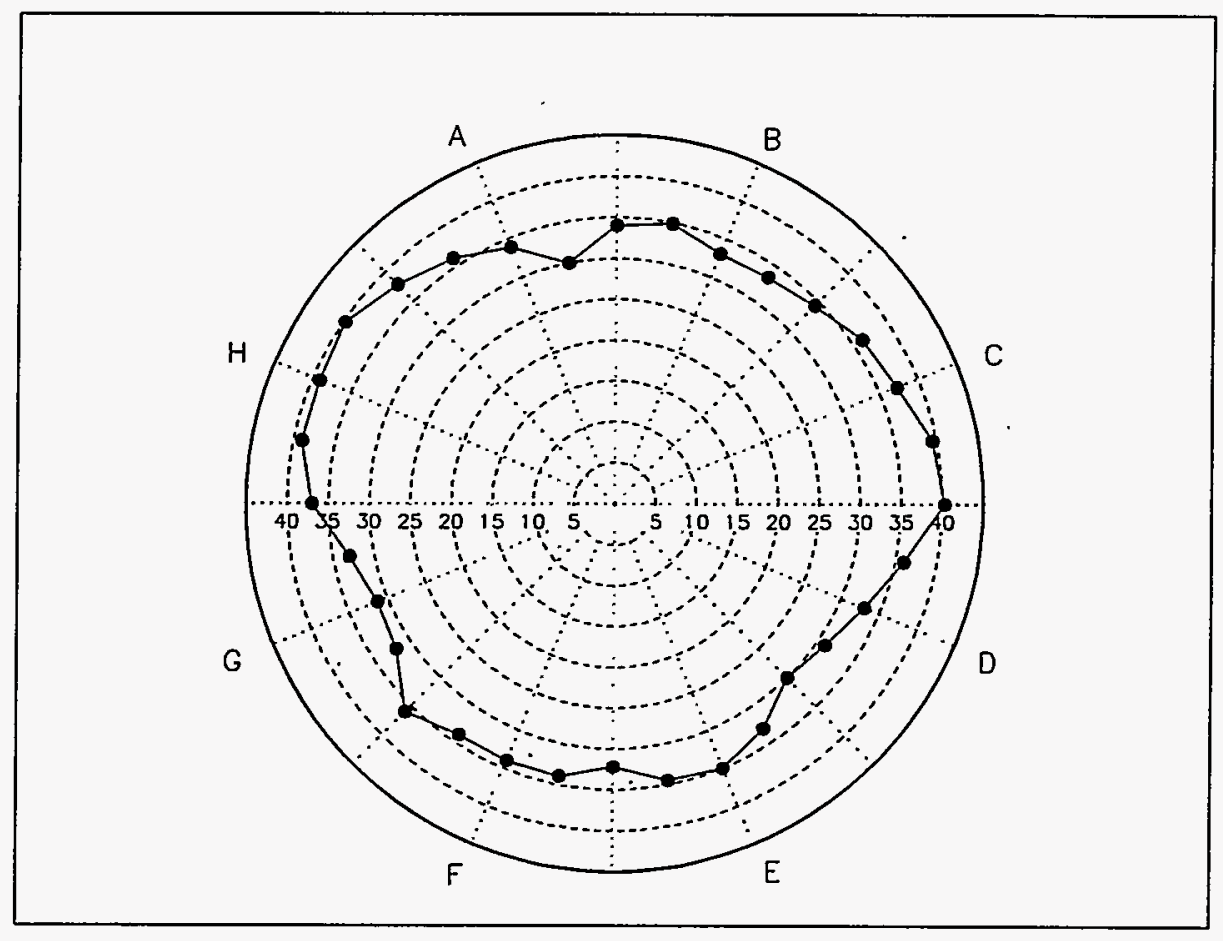

Figure B.24. Test $18-\mathrm{KN}$ at $1535 \mathrm{~min}$ 


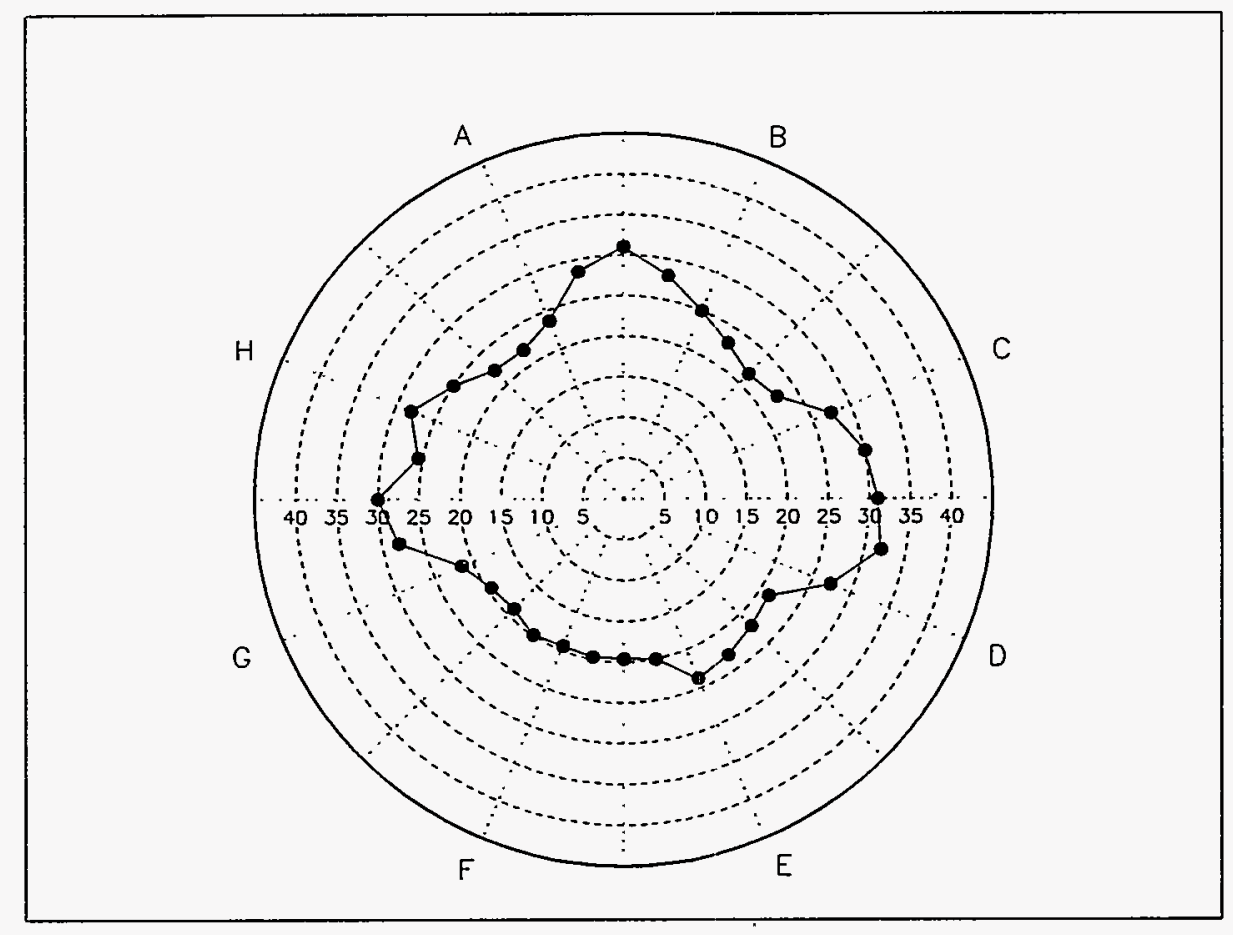

Figure B.25. Test $19-\mathrm{K}$ at $4228 \mathrm{~min}$ 


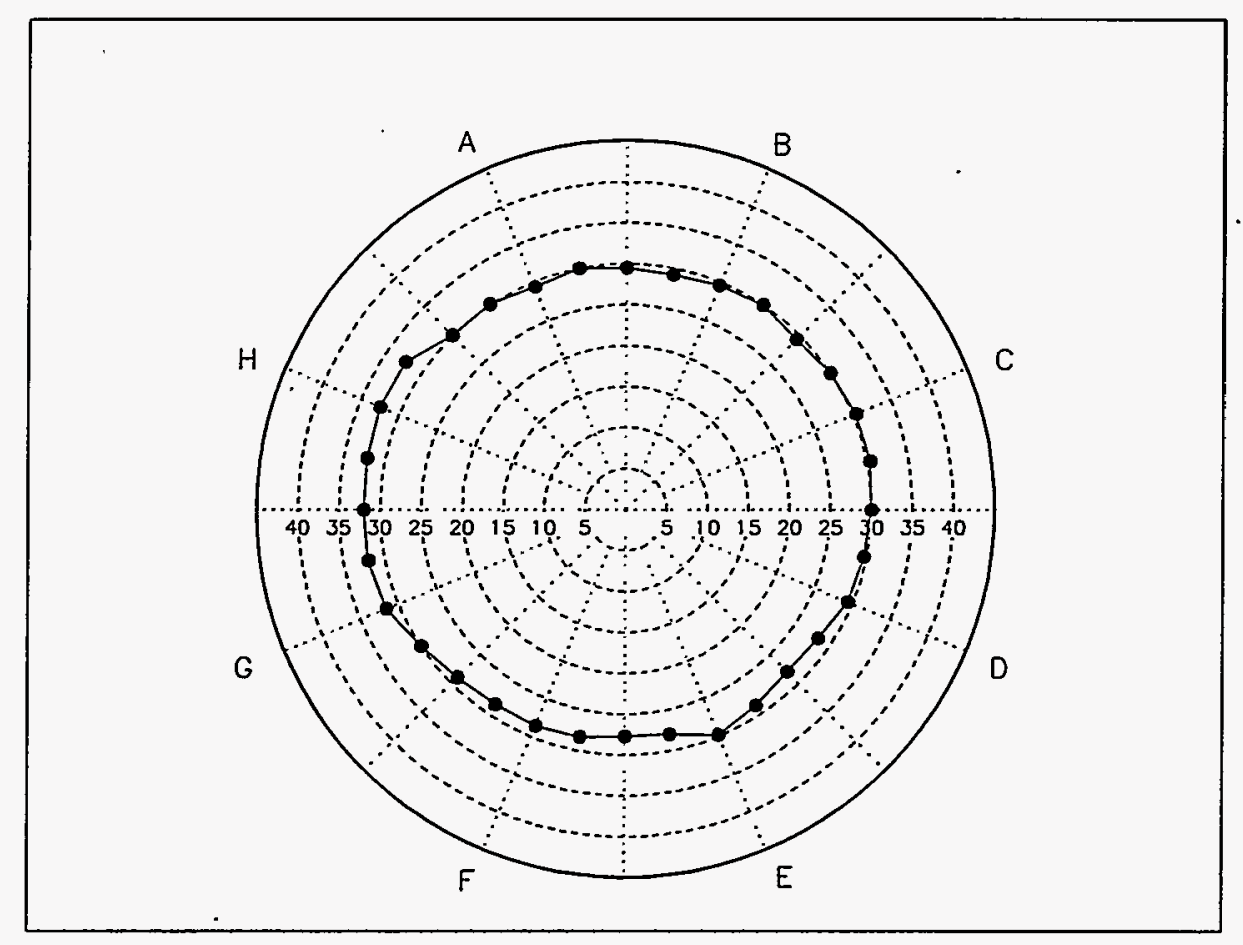

Figure B.26. Test $20-\mathrm{B}$ at $5497 \mathrm{~min}$ 


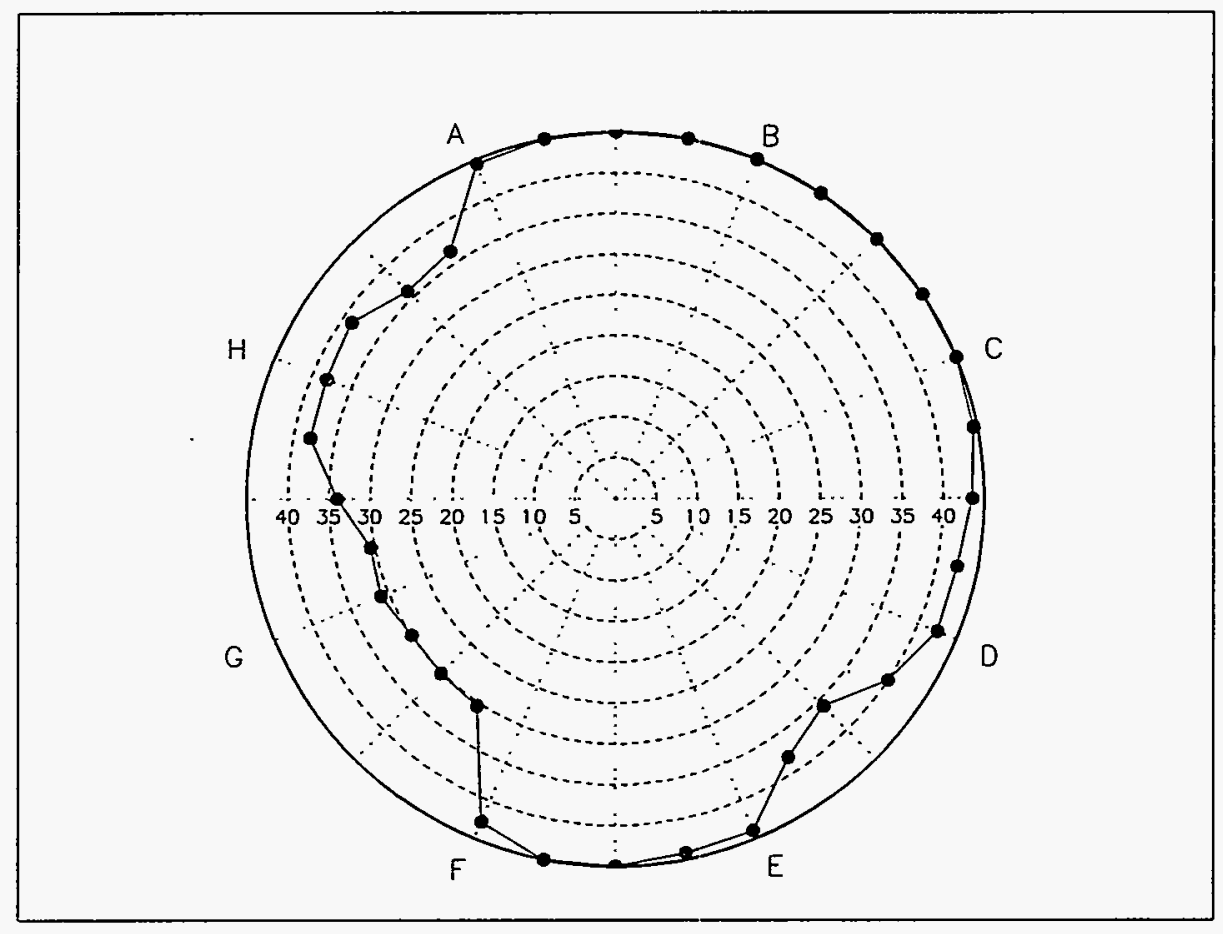

Figure B.27. Test $21-\mathrm{K}$ at $2830 \mathrm{~min}$ 


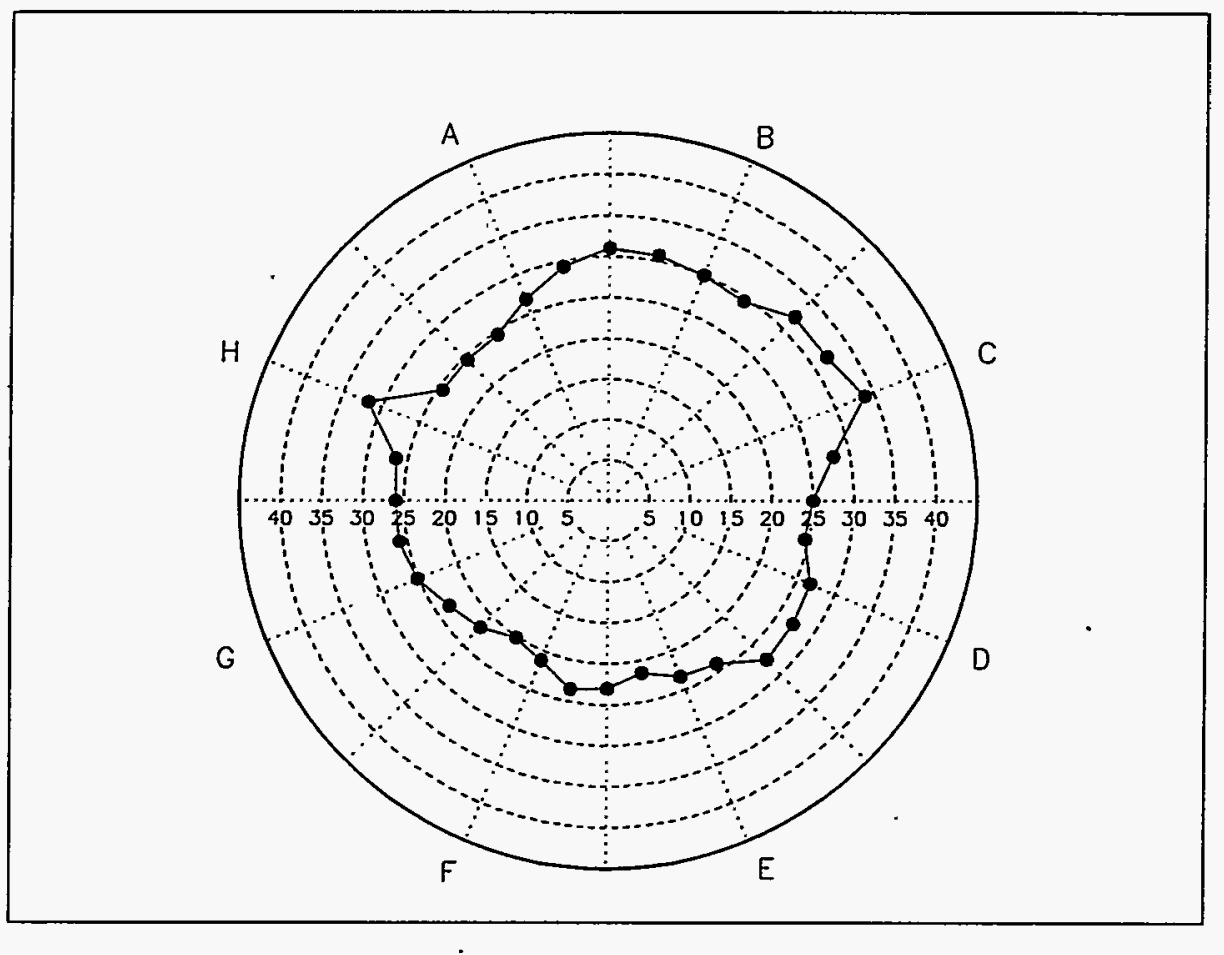

Figure B.28. Test $22-\mathrm{K}$ at $4020 \mathrm{~min}$ 


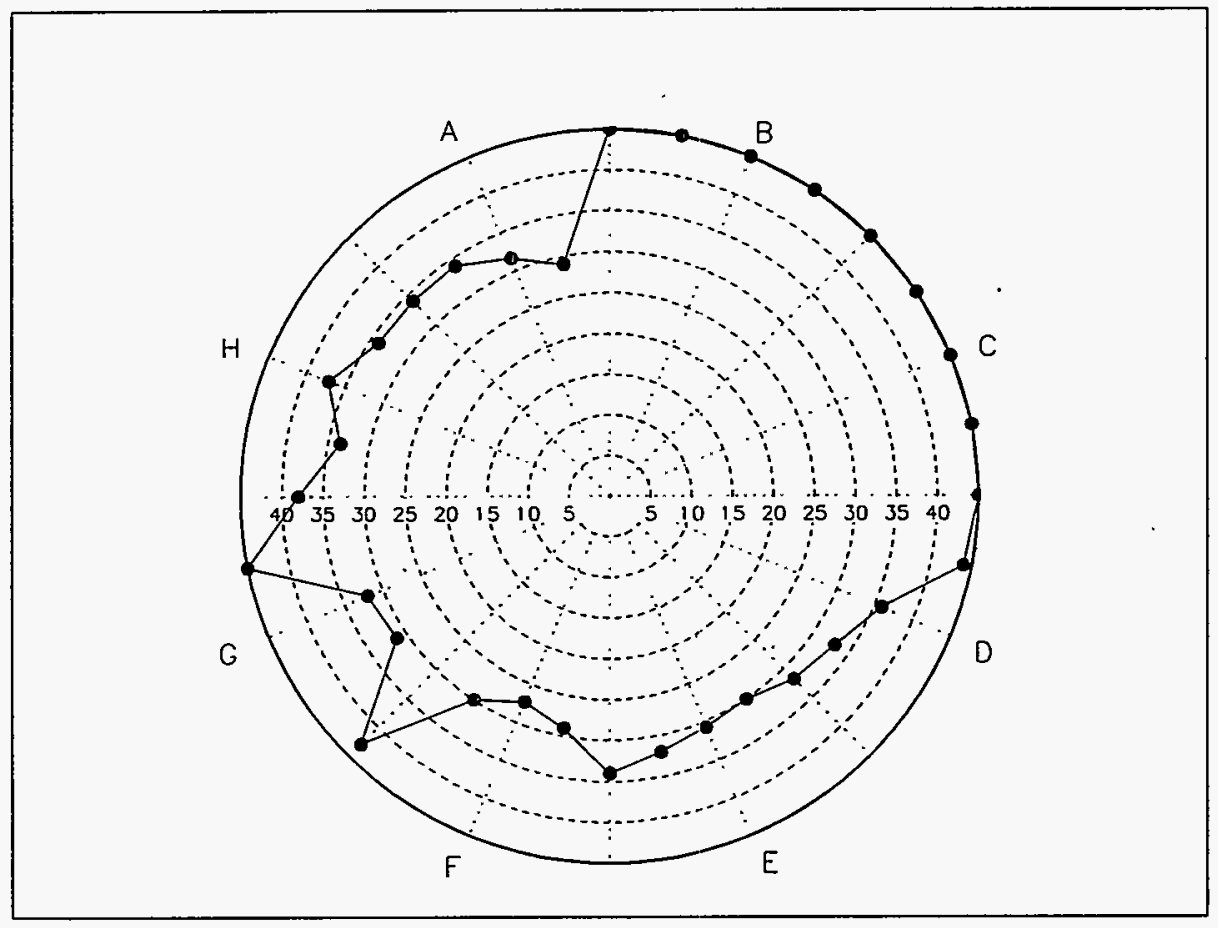

Figure B.29. Test $23-\mathrm{K}$ at $1850 \mathrm{~min}$ 


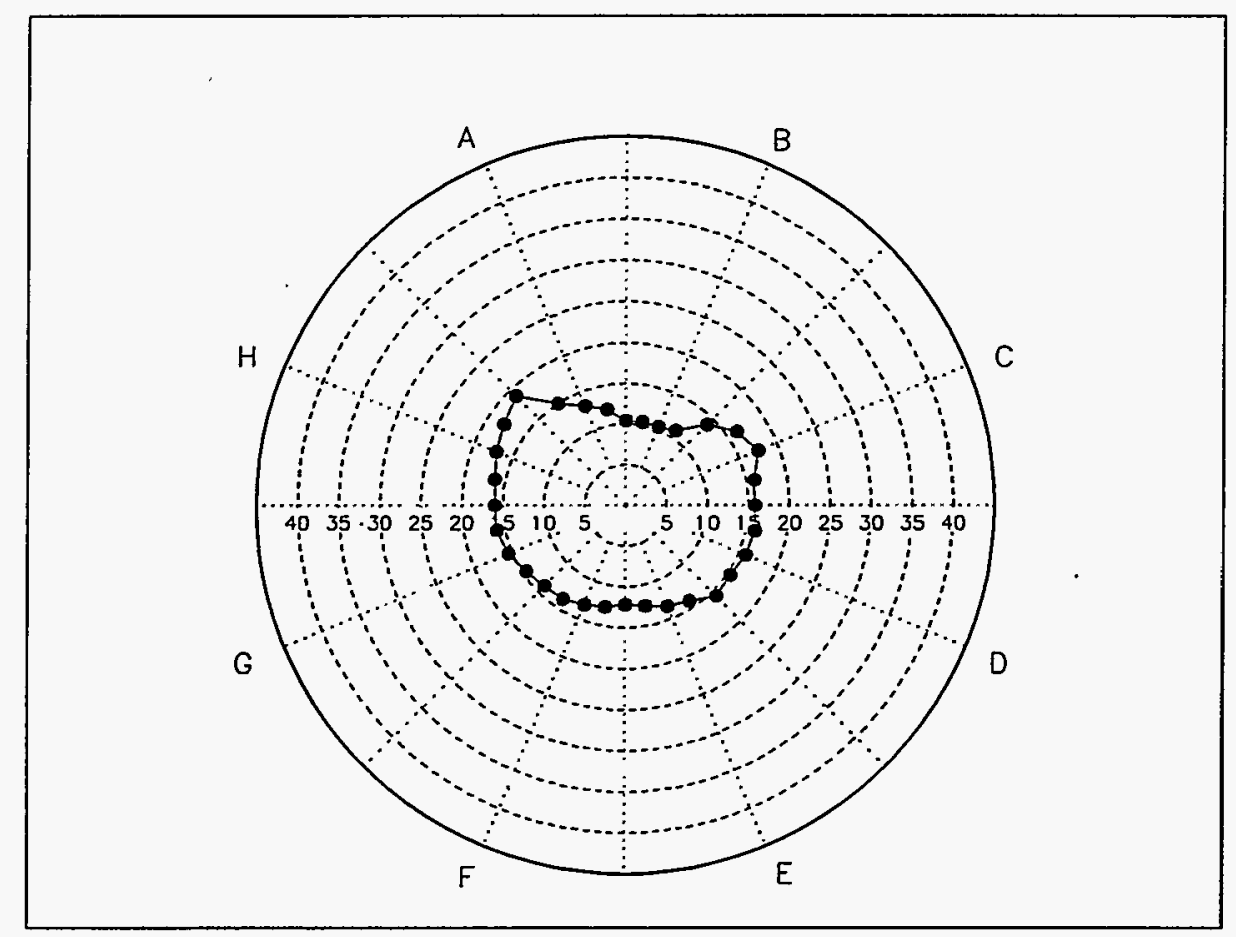

Figure B.30. Test $24-\mathrm{K}$ at $1702 \mathrm{~min}$ 


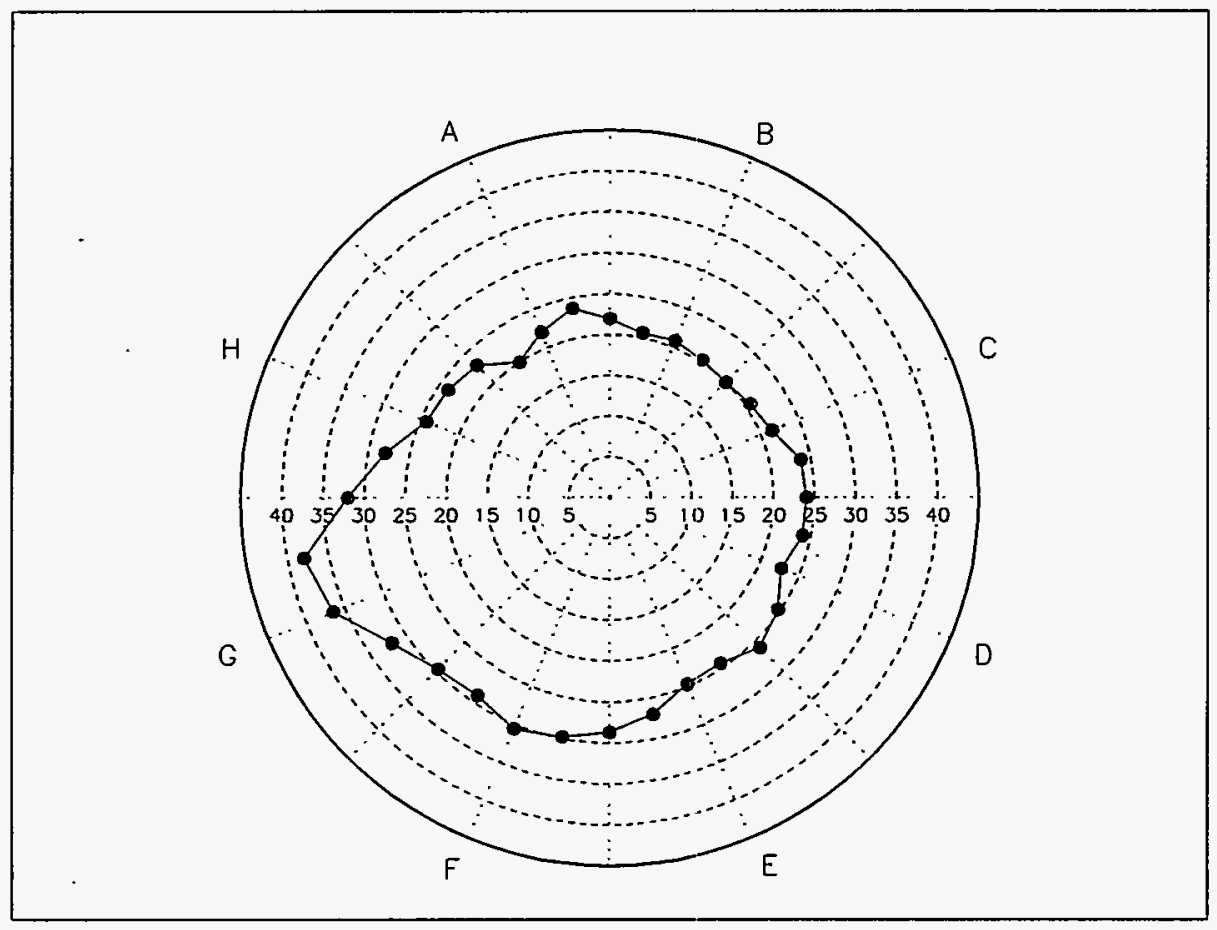

Figure B.31. Test $24-\mathrm{K}$ at $4440 \mathrm{~min}$ 


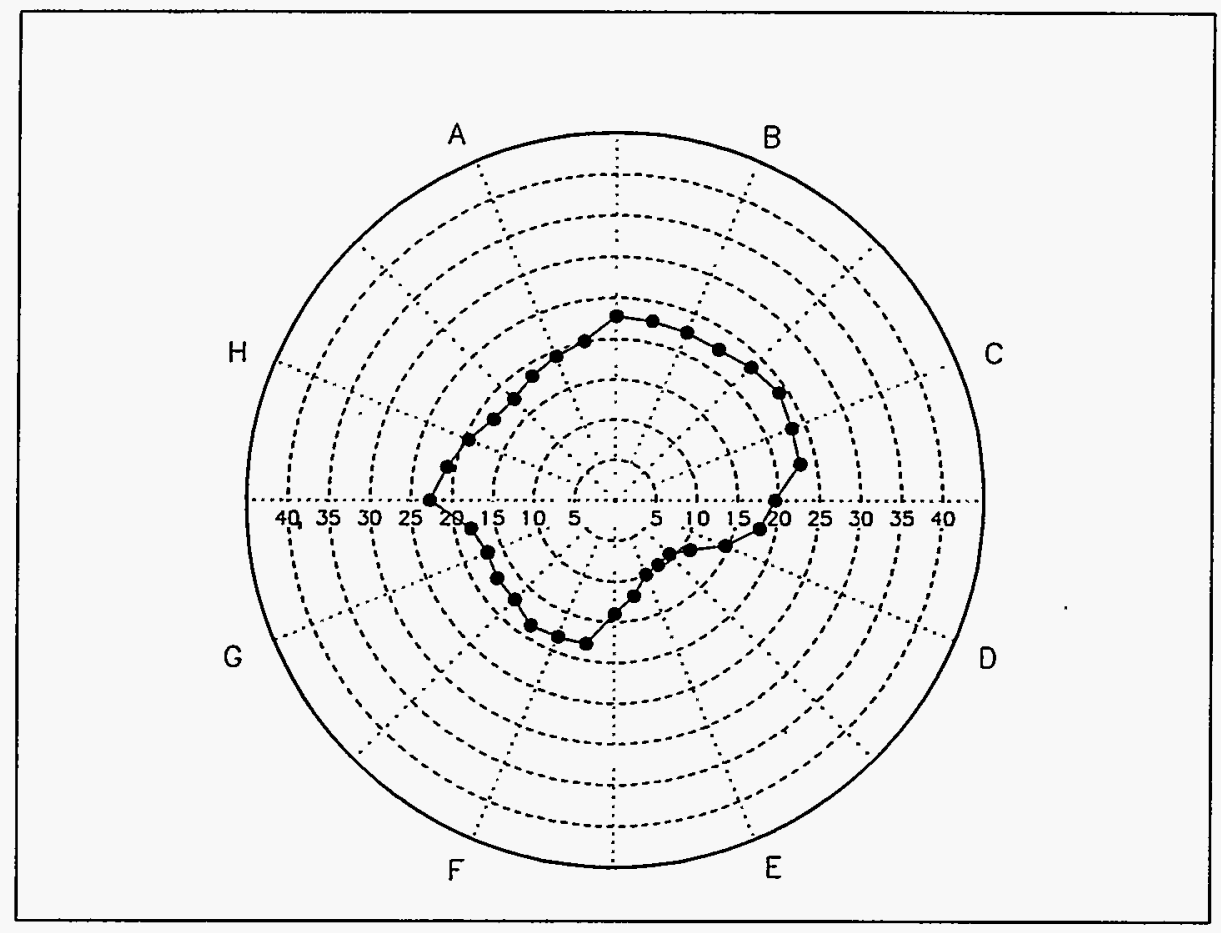

Figure B.32. Test $25-\mathrm{K}$ at $2793 \mathrm{~min}$ 


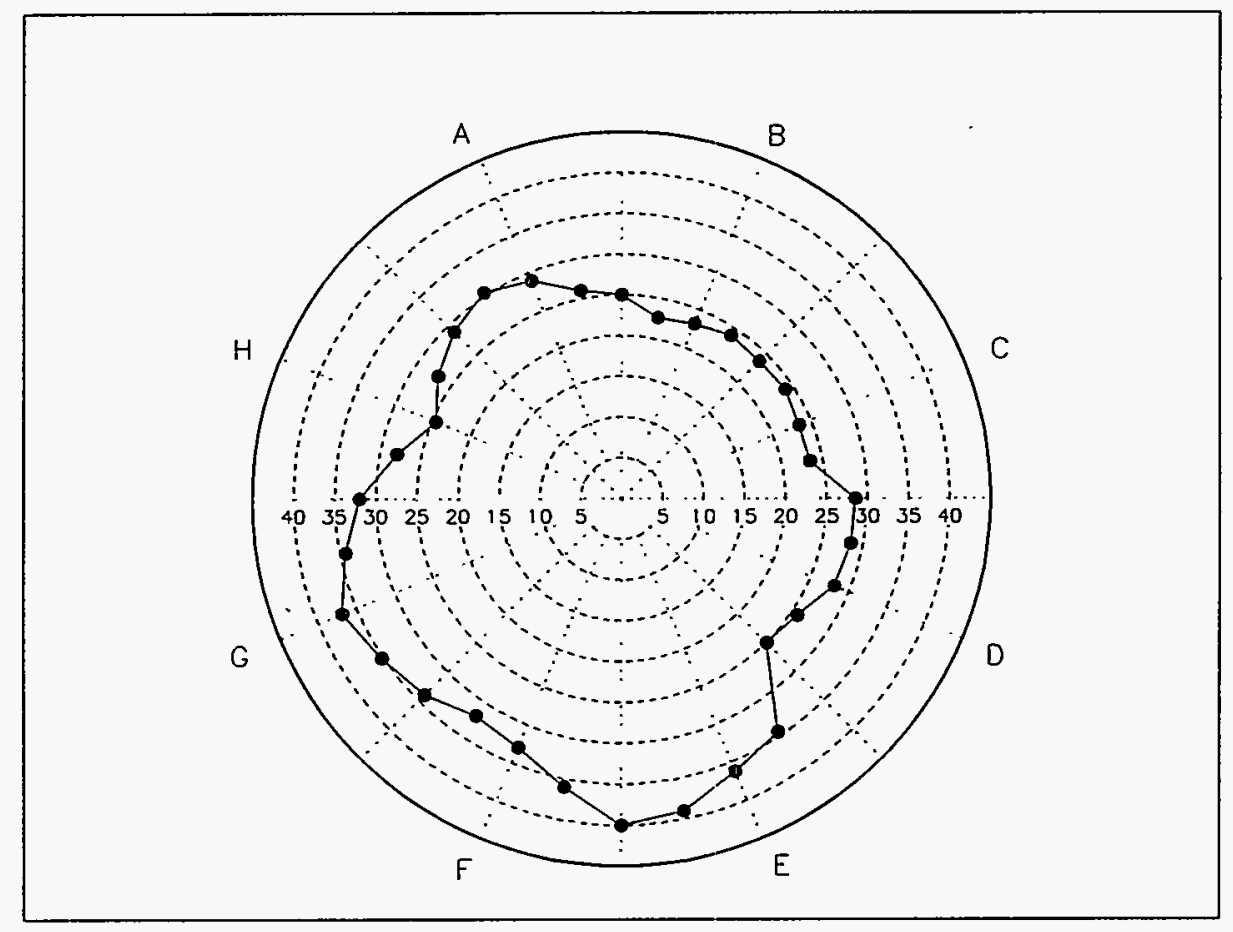

Figure B.33. Test $25-\mathrm{K}$ at $4486 \mathrm{~min}$ 


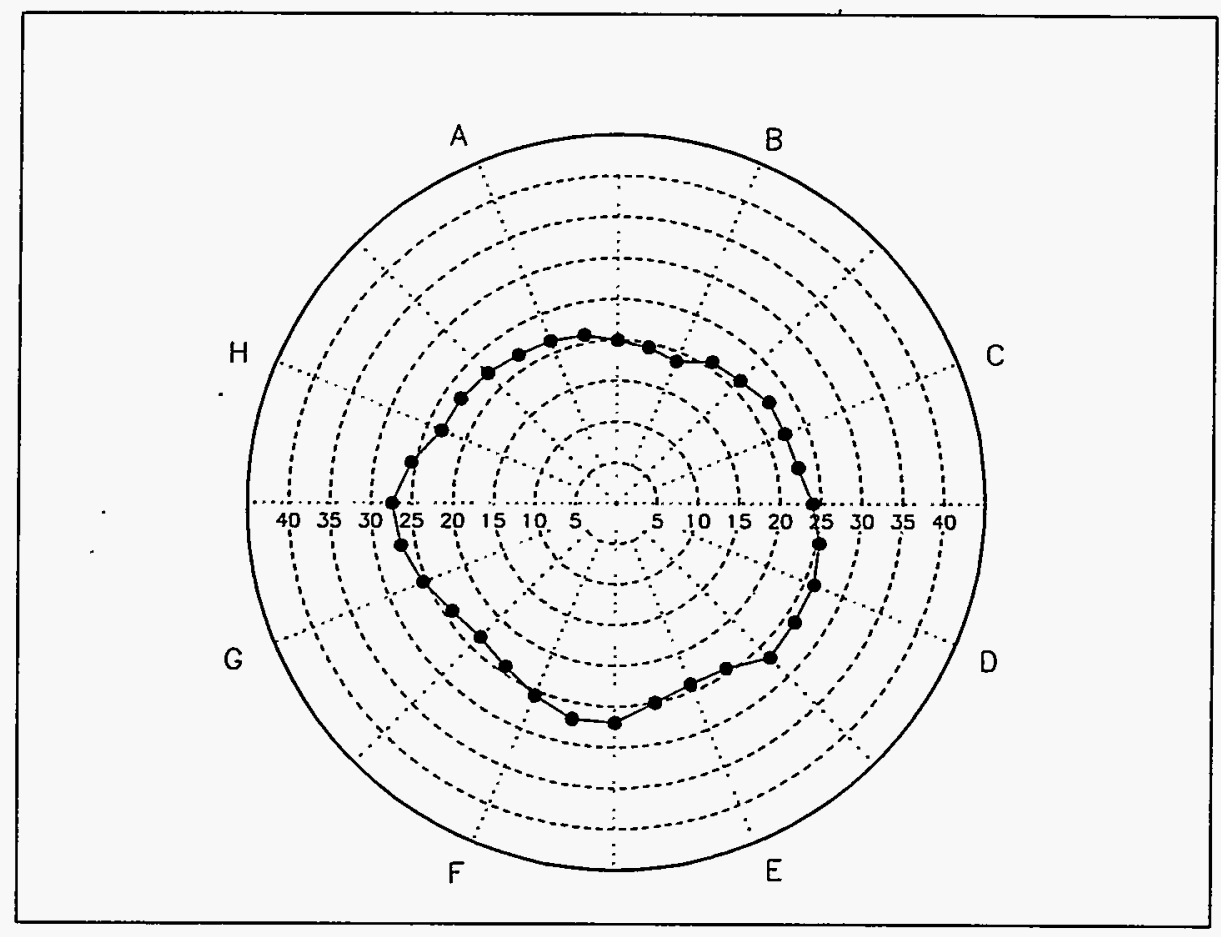

Figure B.34. Test $26-\mathrm{KB}$ at $1275 \mathrm{~min}$ 


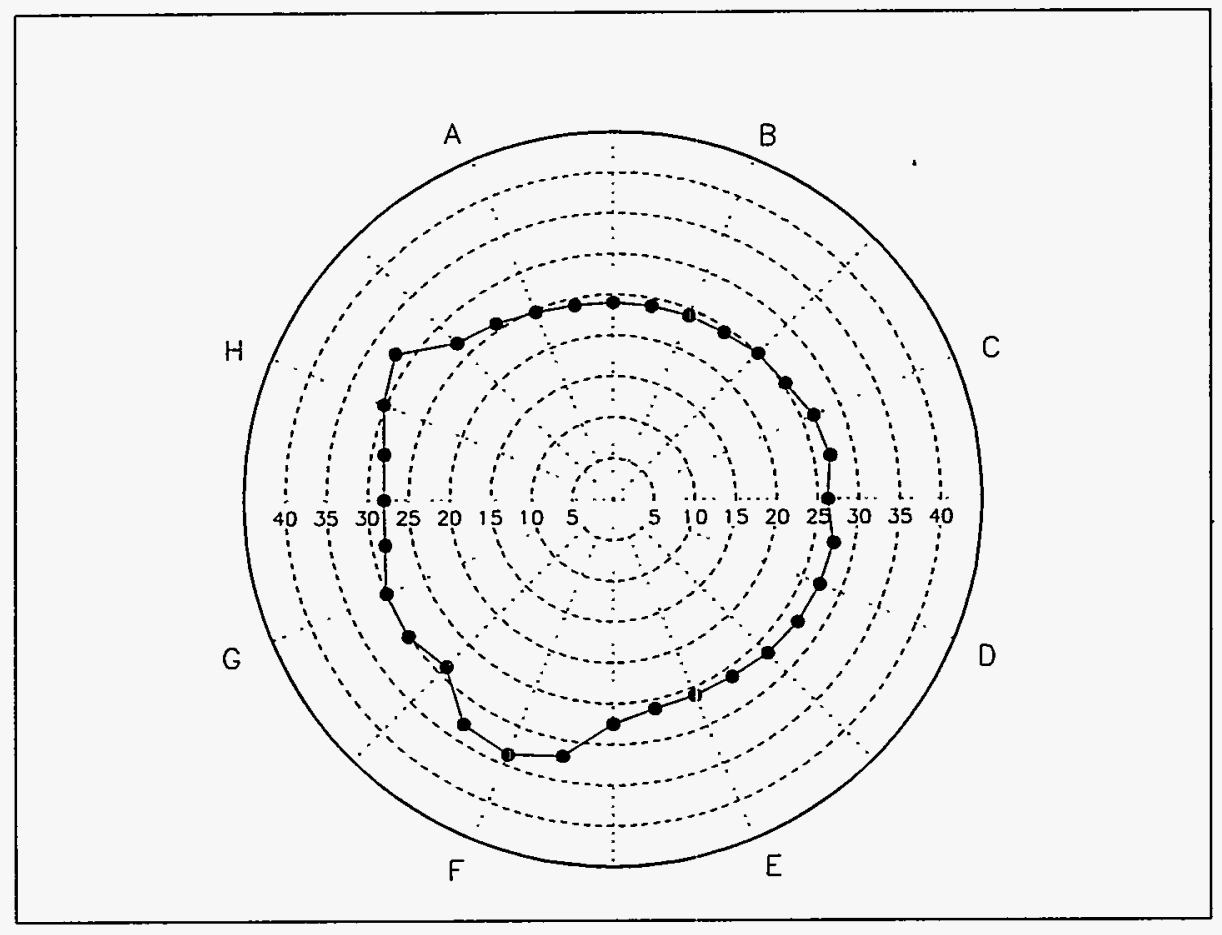

Figure B.35. Test $26-\mathrm{KB}$ at $2904 \mathrm{~min}$ 


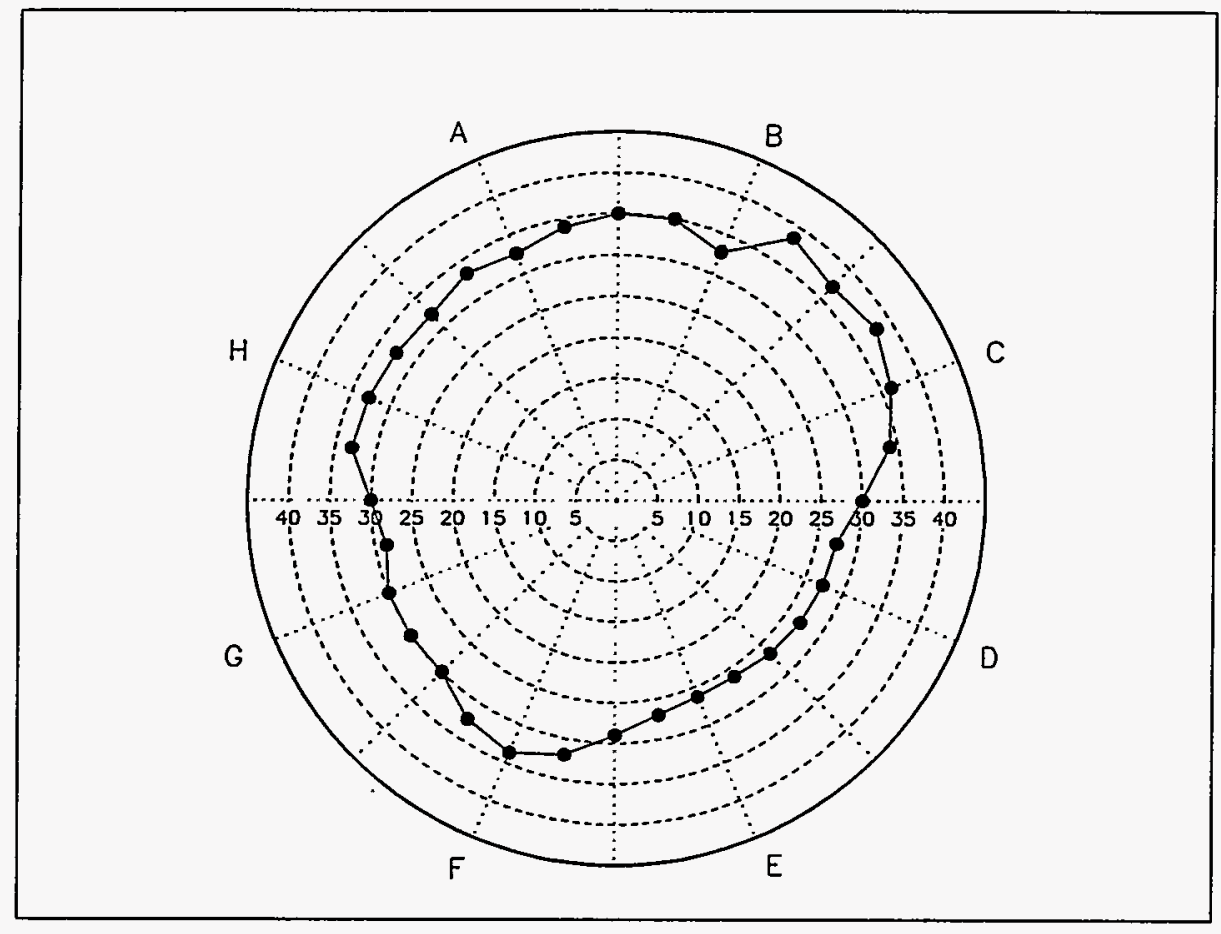

Figure B.36. Test $26-\mathrm{KB}$ at $4486 \mathrm{~min}$ 
Appendix C

Nozzle Diameter Effects Testing Results 


\section{Appendix C}

\section{Nozzle Diameter Effects Testing Results}

The nozzle diameter effects testing described in test plan DSTRTP-FY95-SM1, Rev. 0 are presented below. The test plan describing this work is attached as Appendix D of this document. All deviations from the test plan are noted in the text below.

\section{Summary}

Based on the results of the nozzle diameter effects testing, it is concluded that the mobilization performance of a large diameter jet is at least as good as a small diameter jet operated with a proportionally higher nozzle exit velocity. Stated another way, the effective cleaning radius (ECR) is directly proportional to the product of nozzle diameter (D) and exit velocity $\left(U_{0}\right)$.

The reduced performance of larger diameter nozzles observed during fiscal year 1994 1/25scale testing was most likely due to the effect of induced swirl on the jet direction and decay rates. The jets produced by larger diameter nozzles are thought to be more susceptible to this problem than the smaller diameter jets. Efforts were made to control the swirling flow during the nozzle diameter effects tests and the performance of $0.9-\mathrm{cm}$ nozzles was found to at least equal that of $0.4-\mathrm{cm}$ nozzles operated at the same $U_{0} D$.

Provided the necessary $U_{0} D$ criterion is met, nozzle diameter need not be a consideration when determining the sludge mobilization capabilities of a mixer pump. However, there are reasons for considering nozzle diameter that do not relate specifically to mobilization. The required fluid horsepower, for example, is reduced as nozzle diameter increases for a constant $U_{0} D$.

This testing has served to illustrate the importance of good nozzle design for the full-scale mixer pumps. By improving the flow issuing from the $1 / 25$-scale $0.9-\mathrm{cm}$ nozzles, roughly a $50 \%$ increase in ECR was obtained. The improvement in ECR for the nominal 0.6-cm nozzles was much less pronounced. These data clearly indicate that the fluid velocity profile at the nozzle exit can have a very significant effect on ECR. Considering that the total amount of sludge mobilized is roughly proportional to the square of the ECR, a 50\% increase in ECR could be the difference between $100 \%$ of the sludge mobilized and only $47 \%$ of the sludge mobilized by a centrally-located mixer pump. Careful consideration of mixer-pump nozzle design is strongly recommended.

Finally, it should be pointed out that operation of the $1 / 25$-scale mixer pump at a level corresponding to full power for the full-scale mixer pumps resulted in the complete mobilization of the kaolin/water sludge simulant. The scaling of mobilization test results have not yet been verified, but if the results are assumed to scale linearly then it is predicted that a single, centrally-located mixer pump of $29.4 \mathrm{ft}^{2} / \mathrm{s} U_{o} \mathrm{D}$ should be more than sufficient to mobilize all the sludge in a tank with properties similar to the kaolin simulant. The importance of this is that it implies there may be DSTs where only one mixer pump is required. 
Portions of the test data as well as the results of some limited submerged jet velocity measurements are presented below.

\section{Test Methods and Results}

The following is a brief description of the three tests that were performed in early fiscal year 1995 by PNL to determine whether mixer pump nozzle diameter affects the effective cleaning radius (ECR) in an unexpected manner. A detailed description of these tests as well as the justification for each is given in the Test Plan for TWRS Retrieval Technology Development Project 1/25-Scale Nozzle Diameter Effects Testing (Test Plan Number DSTRTP-FI95-SM1, Rev. 0, 10/24/94), which is appended to this report as Appendix D.

Two conclusions were drawn from this work. The first is that the ECR is directly proportional to the product of nozzle diameter (D) and fluid exit velocity $\left(\mathrm{U}_{\mathrm{o}}\right)$ if the swirl in the nozzle is not significant. Thus, larger nozzle sizes can be selected without affecting mobilization performance, provided that a given $U_{0} D$ criterion is met. The second conclusion is that nozzle design can significantly affect the downstream jet velocities and, hence, the ECR. The relatively poor performance of larger diameter nozzles noted during FY1994 testing is attributed to the lack of a purely axial fluid velocity profile at the nozzle exit. The data used to draw these conclusions are given in tables C. 1 through C.5 below.

Table C.1. Nozzle Diameter Effects Tests Simulant Data

\begin{tabular}{|c|c|c|c|}
\hline 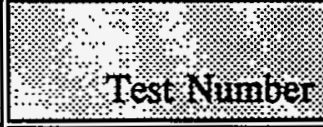 & Metasured shingu & Measured sludger, & 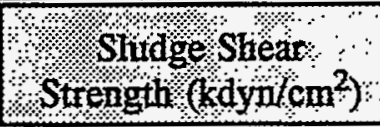 \\
\hline$N-1$ & $19.49 \pm 0.04$ & $64.69 \pm 0.19$ & $16.6 \pm 1.4$ \\
\hline $\mathrm{N}-2$ & $17.38 \pm 0.01$ & $64.32 \pm 0.18$ & $14.5 \pm 1.6$ \\
\hline $\mathrm{N}-3$ & not measured & $63.85 \pm 0.18$ & $12.8 \pm 1.2$ \\
\hline
\end{tabular}

NOTE: $\quad$ The target wt\% solids for all sludge simulants was $65.0 \mathrm{wt} \%$. Deviations from this target are due to weighing uncertainties and, more importantly, the tendency of the stronger portion of the mix (higher wt\% solids) to stick to the mixer internals thereby biasing the bulk composition wt\% solids low. The final wt\% solids of the test N-3 slurry has not yet been measured. Variations in the sludge shear strengths resulted from changes in the wt\% solids, but this does not affect the results of these tests as no comparisons between tests were required. 
Table C.2. Nozzle Size Measurements

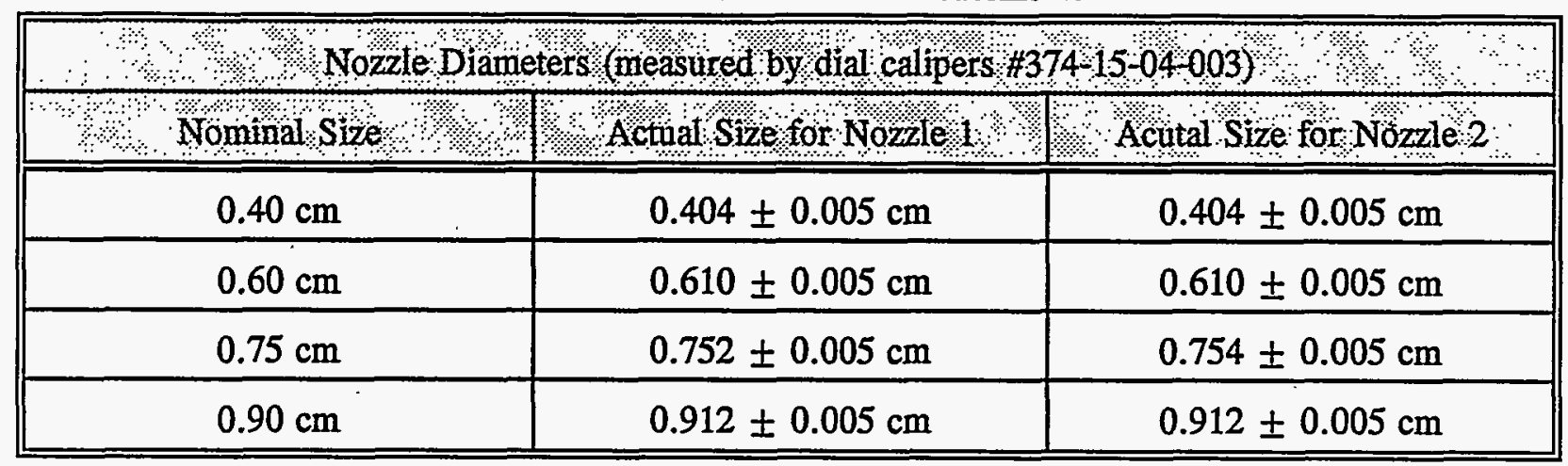

Table C.3. Test $\mathrm{N}-1$ Operation Data

\begin{tabular}{|c|c|c|c|c|}
\hline \multicolumn{5}{|c|}{ (\%) } \\
\hline $\begin{array}{l}\text { Time } \\
\text { (min) }\end{array}$ & \% & $4\left(+1-\mathrm{cm}^{2} / \mathrm{s}\right)$ & (cm) & $\begin{array}{l}\mathrm{ECR} / \mathrm{O}_{\mathrm{O}}^{\mathrm{D}} \\
\mathrm{( \textrm {S } / \mathrm { cm } )}\end{array}$ \\
\hline $0-1685$ & Both 0.9-cm nozzles, NFS & 492 & $19.6 \pm 1.5$ & $0.040 \pm .003$ \\
\hline $1685-3142$ & One 0.9-cm nozzle, w/FS & 492 & $32.4 \pm 6.6$ & $0.066 \pm .013$ \\
\hline $3142-3283$ & Both 0.9-cm nozzles, NFS & 1082 & $>41.8$ & $>0.039$ \\
\hline
\end{tabular}

NOTE: $\quad$ NFS $=$ No Flow Straighteners used for nozzles

$\mathrm{w} / \mathrm{FS}=$ Flow Straighteners used to improve jet flow

Table C.4. Test N-2 Operation Data

\begin{tabular}{|c|c|c|c|c|}
\hline \multicolumn{5}{|c|}{ 3. } \\
\hline (Time & $4 \%$ ( & $\left( \pm / 1 \mathrm{U}^{\mathrm{B}}, 2 / \mathrm{cm}\right)$ & $\frac{\mathrm{ECR}}{(\mathrm{cm})}$ & $\begin{array}{l}\mathrm{ECR} / \mathrm{U} \mathrm{D} \\
\quad(\mathrm{s} / \mathrm{cm})\end{array}$ \\
\hline $0-1660$ & Both 0.9-cm nozzles, w/FS & 395 & $19.2 \pm 2.1$ & $0.049 \pm .005$ \\
\hline \multirow[t]{2}{*}{$1660-3060$} & Both $0.6-\mathrm{cm}$ nozzles, w/FS & 392 & $20.9 \pm 2.7$ & $0.053 \pm .007$ \\
\hline & Both 0.9-cm nozzles, w/FS & 572 & $36.7 \pm 3.3$ & $0.064 \pm .006$ \\
\hline
\end{tabular}

NOTE: $\quad$ w/FS $=$ Flow Straighteners used to improve jet flow 
Table C.5. Test N-3 Operation Data

\begin{tabular}{|c|c|c|c|c|}
\hline Time & \& Nozzte & $\left(\mathrm{U} / \mathrm{UPm}^{2} / \mathrm{s}\right)$ & ECR & $\begin{array}{l}\text { ECR/U } D \\
(\mathrm{~s} / \mathrm{cm})\end{array}$ \\
\hline $0-3187$ & Both 0.9-cm nozzles, w/FS & 395 & $21.9 \pm 1.8$ & $0.055 \pm .005$ \\
\hline $3187-4500$ & Both 0.75 -cm nozzles, w/FS & 395 & $22.7 \pm 1.9$ & $0.057 \pm .005$ \\
\hline $4500-4757$ & Both 0.6-cm nozzles, w/FS & 395 & $22.7 \pm 1.9$ & $0.057 \pm .005$ \\
\hline $4757-5747$ & Both 0.4-cm nozzles, w/FS & 395 & $22.7 \pm 1.9$ & $0.057 \pm .005$ \\
\hline $5747-7427$ & Both 0.9-cm nozzles, w/FS & 501 & $22.7 \pm 1.9$ & $0.045 \pm .004$ \\
\hline $7427-8825$ & Both 0.9-cm nozzles, w/FS & 550 & $25.7 \pm 2.7$ & $0.047 \pm .005$ \\
\hline $8825-10241$ & Both $0.75-\mathrm{cm}$ nozzles, w/FS & 550 & $26.2 \pm 2.6$ & $0.048 \pm .005$ \\
\hline $10241-11618$ & Both 0.6-cm nozzles, w/FS & 550 & $26.2 \pm 2.6$ & $0.048 \pm .005$ \\
\hline $11618-13242$ & Both $0.4-\mathrm{cm}$ nozzles, w/FS & 550 & $26.2 \pm 2.6$ & $0.048 \pm .005$ \\
\hline
\end{tabular}

NOTE: $\quad$ w/FS $=$ Flow Straighteners used to improve jet flow No additional ECR growth was observed during $5747-7427$ min with the $0.9 \mathrm{~cm}$ nozzles at $501 \mathrm{~cm}^{2} / \mathrm{s}$. An increase in the slurry density, however indicated that some additional mobilization was taking place along the $8 \mathrm{ECR}$ measurement lines. The flow was increased to $550 \mathrm{~cm}^{2} / \mathrm{s}$ to result in a measureable increase in ECR for the elevated flow.

\section{Test N-1 Narrative Description:}

Test N-1 was started using the $0.9-\mathrm{cm}$-diameter nozzles operated at $492 \mathrm{~cm}^{2} / \mathrm{s}$ without flow straighteners to improve the flow. An ECR of $19.6 \mathrm{~cm}$ was obtained, which is considerably smaller than the 27-cm ECR that has been observed for similar simulants using the $0.6-\mathrm{cm}$ nozzles during previous testing at the same $U_{0} D$. One of the $0.9-\mathrm{cm}$ nozzles was then plugged and the flow straighteners installed in the other nozzle. These flow straighteners consist of short stainless steel fittings with flow-straightening vanes inserted inside. These straightening vanes were constructed from a 2-cm-wide strip of thin stainless steel sheet metal bent to form a figure-8 when viewed on edge. The vane separates the flow into four parts which serves to reduce the scale of swirling flow before the fluid enters the nozzle. These flow-straightening elements add about $4 \mathrm{~cm}$ to the distance between pump centerline and nozzle tip. This increased distance has been taken into account when computing ECRs. The resulting ECR was $32.4 \mathrm{~cm}$. This implies that the reduced performance of the $0.9-\mathrm{cm}$ nozzle noted in previous tests $(24-\mathrm{K}, 25-\mathrm{KB}$, and $26-\mathrm{KB})$ and in the first portion of test $\mathrm{N}-1$ was due to the less-than-ideal fluid velocity profile at the nozzle exit. Using the flow straightener improves this situation so that the observed performance equals (even slightly exceeds) that of the $0.6-\mathrm{cm}$ nozzles without straighteners. 
The fact that the reduced performance of the $0.9-\mathrm{cm}$ nozzles was observed when the flow straighteners were not used implies that the previously-observed reduced 0.9 -cm-nozzle performance is not due to the fact that the mixer pump column rotation, was slower in these tests than in the fiscal year 1994 tests. All three nozzle diameter effects tests used a pump column rotation rate of $0.25 \mathrm{rpm}$. Previous tests have employed rotation rates in the range of 2 to $4 \mathrm{rpm}$. The lack of significant rotation rate effect is further supported by the $0.6-\mathrm{cm}$ data. Regardless of whether the flow- straightening vanes were in place, the $0.6-\mathrm{cm}$ nozzles produced $\mathrm{ECR} / \mathrm{U}_{0} \mathrm{D}$ values of $0.055 \pm 0.005 \mathrm{~s} / \mathrm{cm}$ (for kaolin/water sludge simulants) whether the mixer-pump was rotated at $0.25 \mathrm{rpm}$ or at 2 to $4 \mathrm{rpm}$. Taken by itself, the fact that a $19.6-\mathrm{cm}$ ECR was observed using the 0.9-m nozzles (no flow straighteners) during test $\mathrm{N}-1$ instead of the previously-observed $12.3-\mathrm{cm}$ ECR (test 24-K) implies roughly a $60 \%$ increase in ECR resulted because of the slower pump-column rotation rate. Decreasing the $1 / 25$-scale pump-column rotation rate from 2 to $4 \mathrm{rpm}$ to $0.25 \mathrm{rpm}$ may increase the ECRs as the comparison of the test $24-\mathrm{K}$ and $\mathrm{N}-1$ data indicates, but the increase is expected to be, on the average, much smaller than $60 \%$ considering all of the $0.6-\mathrm{cm}$ mobilization data which has not demonstrated any statistically significant improvement. To avoid data interpretation problems in the future, however, it is recommended that future $1 / 25$-scale tests be conducted using the 0.25 -rpm column rotation rate.

In the final portion of test $\mathrm{N}-2$, the flow straightener was removed and both $0.9 \mathrm{~cm}$ nozzles were re-installed and operated at $1082 \mathrm{~cm}^{2} / \mathrm{s}$. This $U_{0} D$ represents approximately full-power operation of the planned full-scale mixer pumps. It is worth noting that all of the sludge simulant was mobilized at this flow. Although scaleup remains to be verified, this result implies that a single, centrally-located mixer pump may provide sufficient mixing for some of the DSTs. Reducing the number of mixer pumps installed could result in considerable cost savings.

The ECR, slurry density, and temperature data for test $\mathrm{N}-1$ are provided in the form of plots in Figures C.1 through C.3.

\section{Test N-2 Narrative Description:}

This test was started with the 0.9-cm nozzles with flow straighteners in place. Before starting the test, sludge was removed from the south side of the tank out to a radial distance of $20 \mathrm{~cm}$ from the pump centerline (initial ECR of about $13 \mathrm{~cm}$ ). The sludge layer in the north side of the tank was left intact. Mobilization was started at a $U_{0} D$ of $395 \mathrm{~cm}^{2} / \mathrm{s}$. The ECR in the north side of the tank grew to $18.9 \pm 1.6 \mathrm{~cm}$, and in the south side the ECR grew to $19.4 \pm 5.9 \mathrm{~cm}$. The lack of significant difference between these numbers indicates that the final ECR in this test was not sensitive to the proximity of the initial sludge bank as was hypothesized in the test plan. Further, because the mobilization performance observed in this test was consistent with that observed previously using $0.6-\mathrm{cm}$ nozzles and the same sludge simulant, it is implied that the flow straighteners have eliminated the apparent reduced performance of the $0.9-\mathrm{cm}$ nozzles.

After ECR growth using the 0.9-cm nozzles stopped, the 0.6-cm nozzles with flow straighteners were then installed and operated at $392 \mathrm{~cm}^{2} / \mathrm{s}$. The final ECR reached $20.9 \pm 2.7 \mathrm{~cm}$, which is not significantly greater than that observed using the $0.9-\mathrm{cm}$ nozzles. Finally, the $0.9-\mathrm{cm}$ nozzles were re-installed and the flow increased to $572 \mathrm{~cm}^{2} / \mathrm{s}$ to obtain an ECR of $36.7 \pm 3.3 \mathrm{~cm}$. Six of the eight ECR measurements were at the tank wall. The data collected during test $\mathrm{N}-2$ are presented in Figures C. 4 through C.6. 


\section{Test N-3:}

The tank was loaded with sludge simulant by the normal-procedure (i.e., regions of sludge were not removed as was done in test $\mathrm{N}-2$ ). Using a $U_{0} D$ of $395 \mathrm{~cm}^{2} / \mathrm{s}$, each of the four different nozzle sizes was used starting with the $0.9-\mathrm{cm}$ nozzles down to the $0.4-\mathrm{cm}$ nozzles (descending order of size). As seen in Table C.5 above for test N-3, no significant ECR growth occurred as the nozzle size was decreased. This same nozzle-size sequence was repeated for a $U_{0} D$ of $550 \mathrm{~cm}^{2} / \mathrm{s}$, and again, no significant ECR growth was observed following that produced by the $0.9-\mathrm{cm}$ nozzle at the increased $U_{0} D$. The conclusion of this is that the larger nozzles at least equal the performance of the smaller nozzles operated at the same $U_{0} D$. The flow straighteners were used for all portions of this test. The test data are presented in Figures C.7 and C.8. 


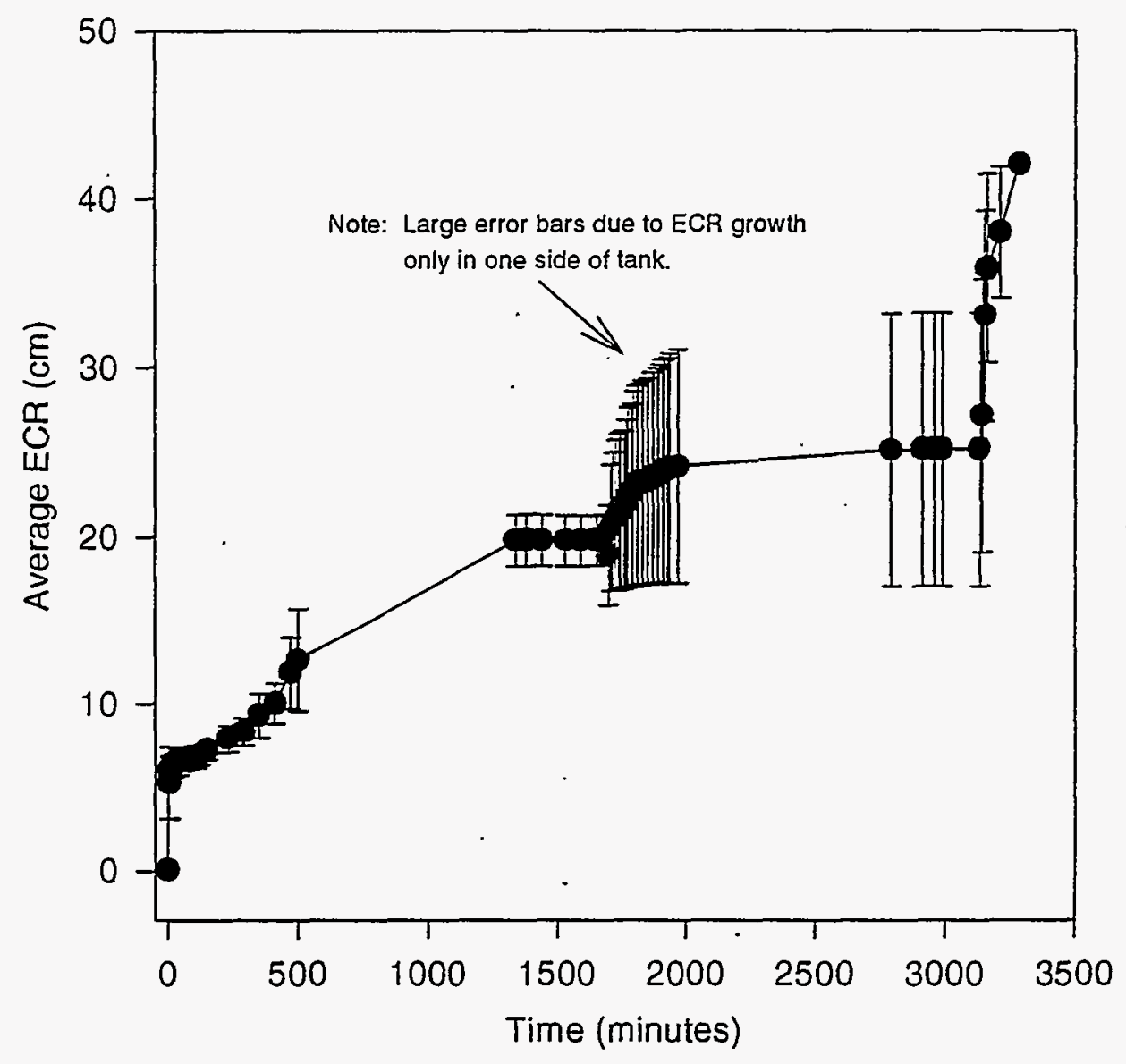

Time (min)

Description of Test Conditions

$0-1685 \quad 0.9 \mathrm{~cm}$ Nozzles at $492 \pm 7 \mathrm{~cm}^{2} / \mathrm{s}$ (no flow straighteners)

$1685-3142 \quad 0.9 \mathrm{~cm}$ Nozzle at $492 \mathrm{~cm}^{2} / \mathrm{s}$ for West Side of Tank

Flow Straighteners Installed for West Side Nozzle

Nozzle Plugged in East Side of Tank

$3142-3283 \quad 0.9 \mathrm{~cm}$ Nozzles (both) at $1082 \pm 21 \mathrm{~cm}^{2} / \mathrm{s}$ (no flow straighteners)

3283 Test Stopped. All Sludge Mobilized $(E C R=42 \pm 0 \mathrm{~cm})$

Figure C.1. Test N-1 Average ECR vs. Time Data

C. 7 


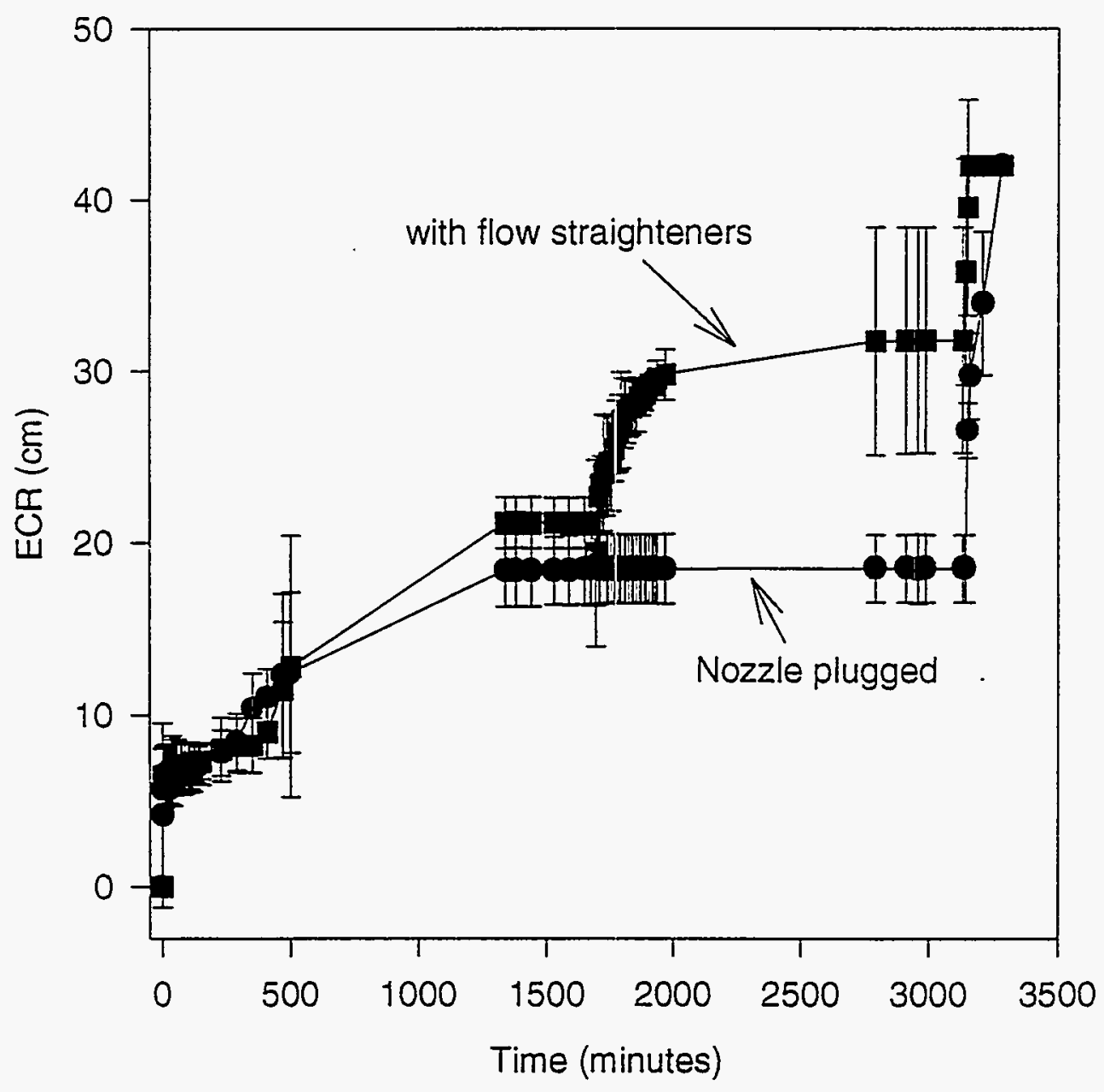

- East Nozzle ECRs West Nozzle ECRs

Figure C.2. Test $N-1$ ECRs in East and West Sides of Tank 


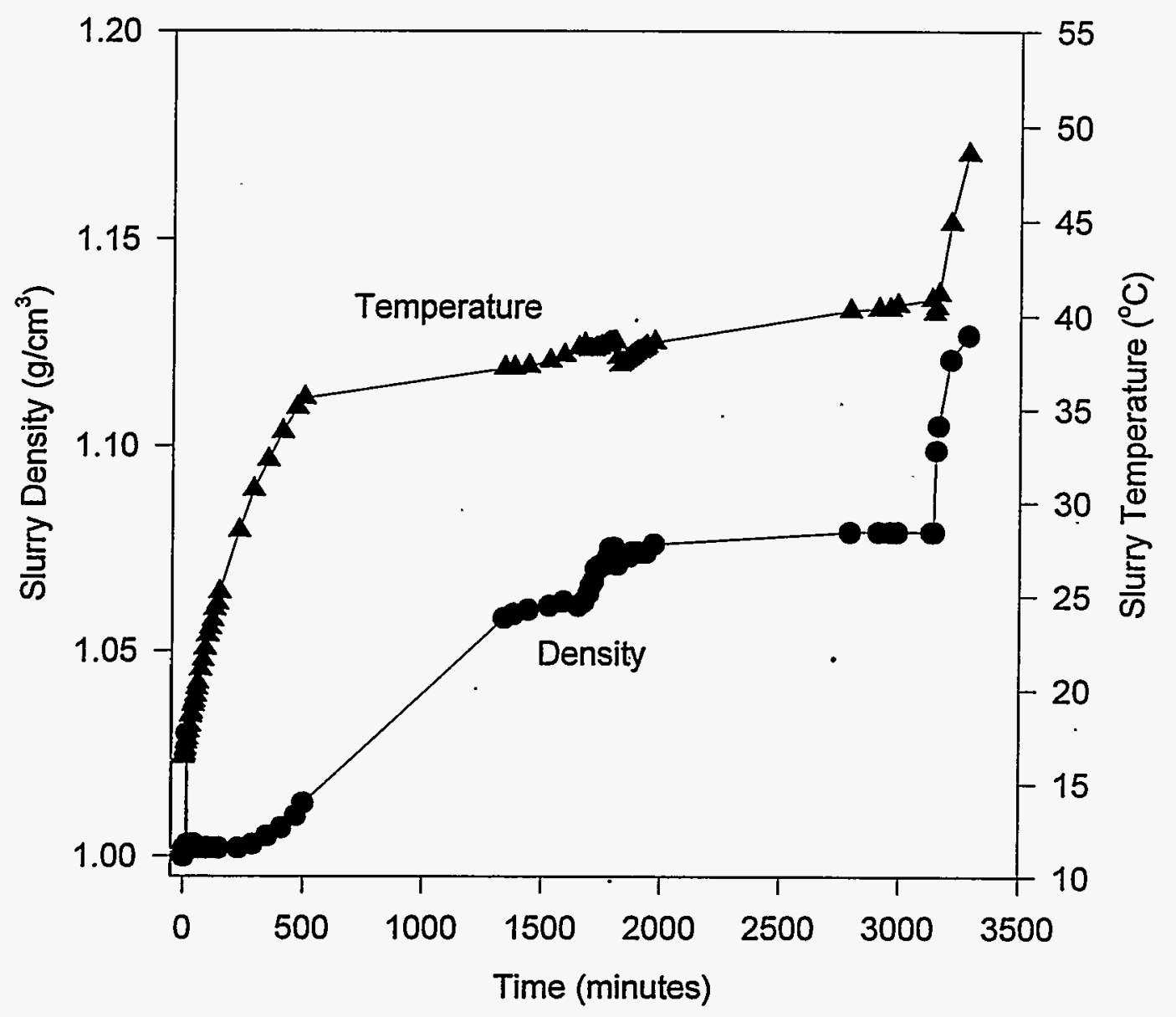

Figure C.3. Test N-1 Temperature and Density Data

C.9 


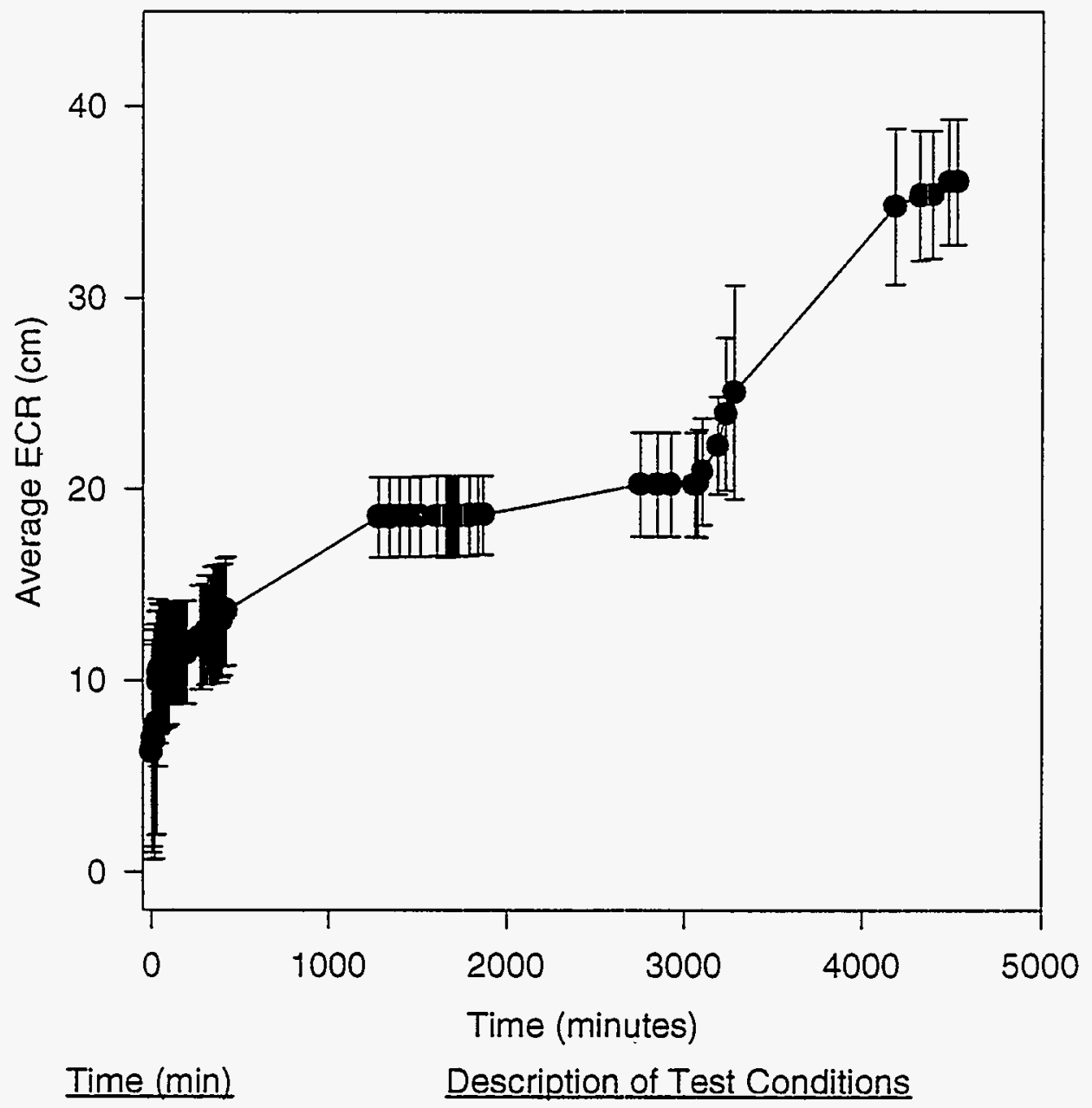

$0-1660 \quad 0.9 \mathrm{~cm}$ Nozzles at $395 \pm 7 \mathrm{~cm}^{2} / \mathrm{s}$. South side of tank initially cleared to an ECR of $13 \mathrm{~cm}$ (radial distance of $20 \mathrm{~cm}$ ).

$1660-30600.6 \mathrm{~cm}$ Nozzles at $U_{0} D=392 \pm 7 \mathrm{~cm}^{2} / \mathrm{s}$

$3060-4530 \quad 0.9 \mathrm{~cm}$ Nozzles at $U_{0} D=572 \pm 14 \mathrm{~cm}^{2} / \mathrm{s}$

Figure C.4. Test N-2 Average ECR Data

C. 10 


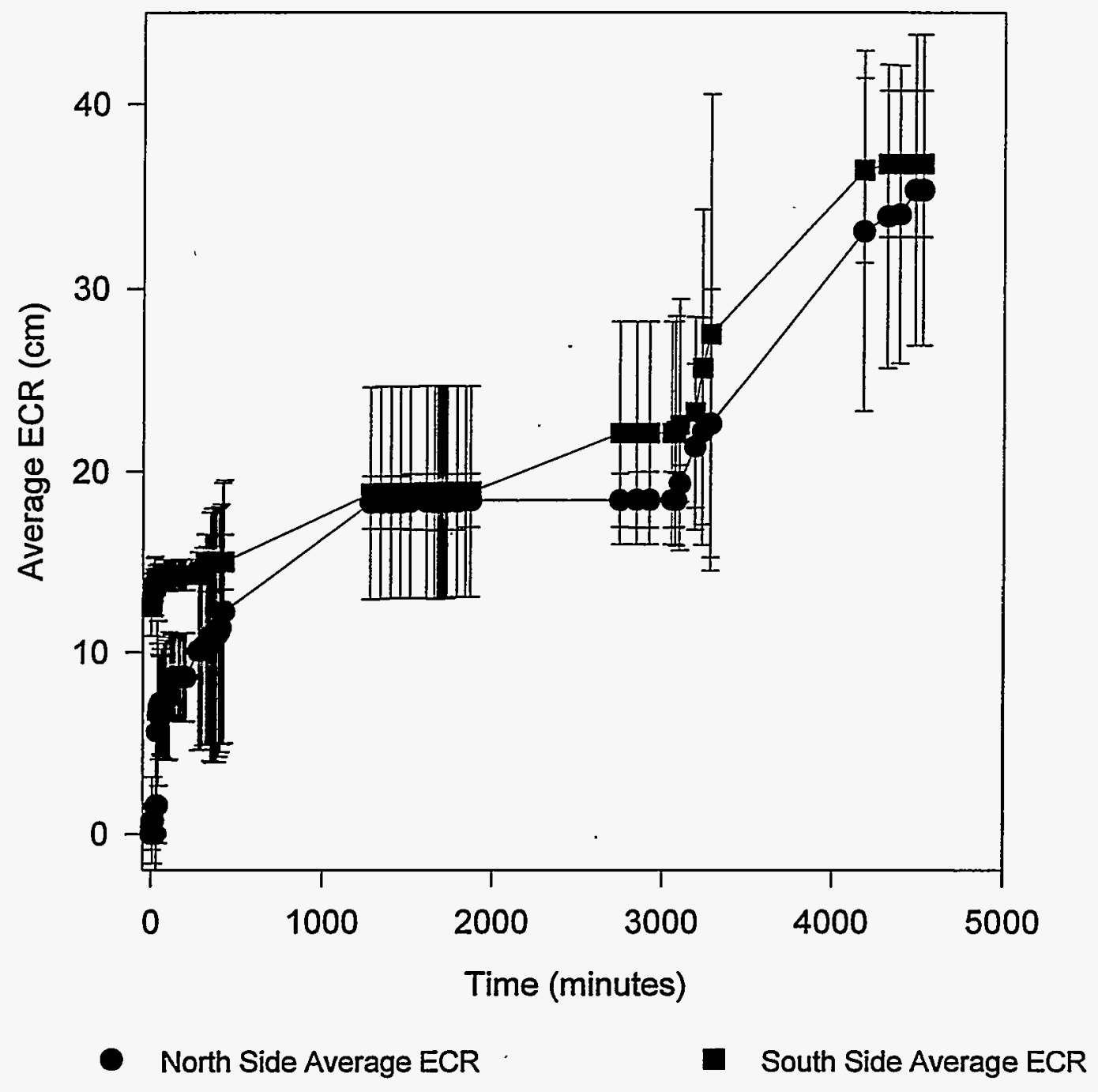

Figure C.5. Test N-2 Average ECRs in North and South Sides of Tank C.11. 


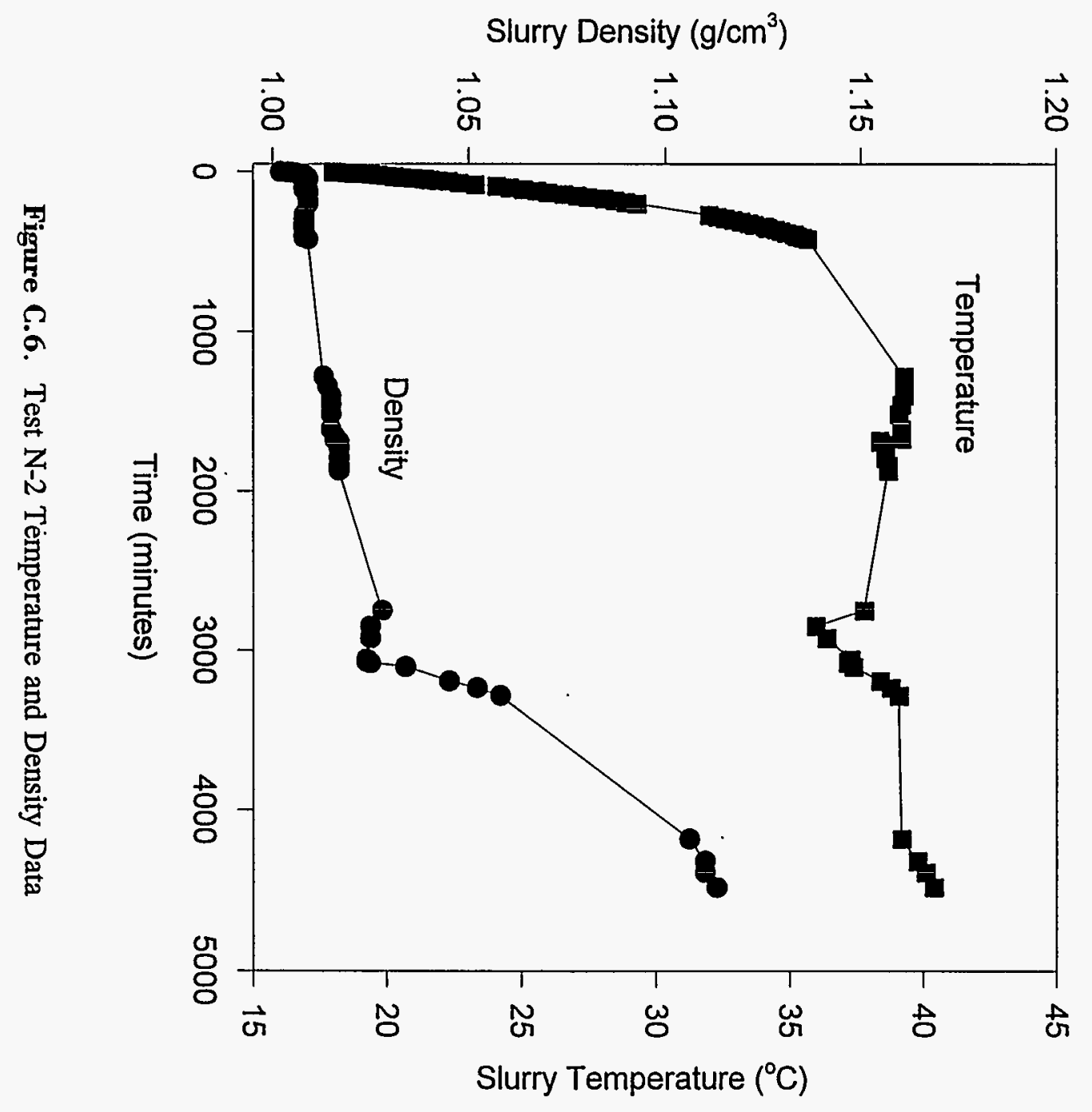




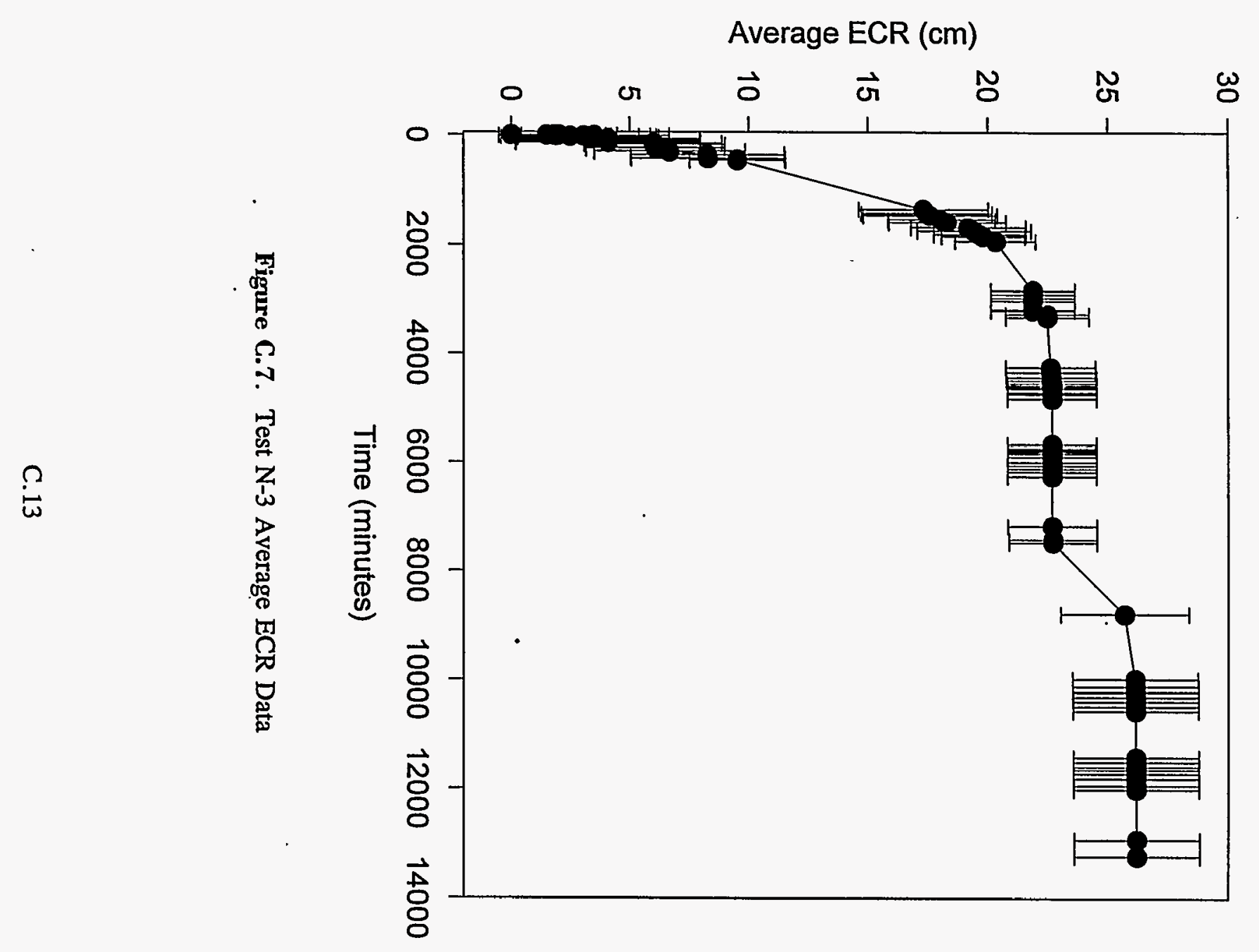




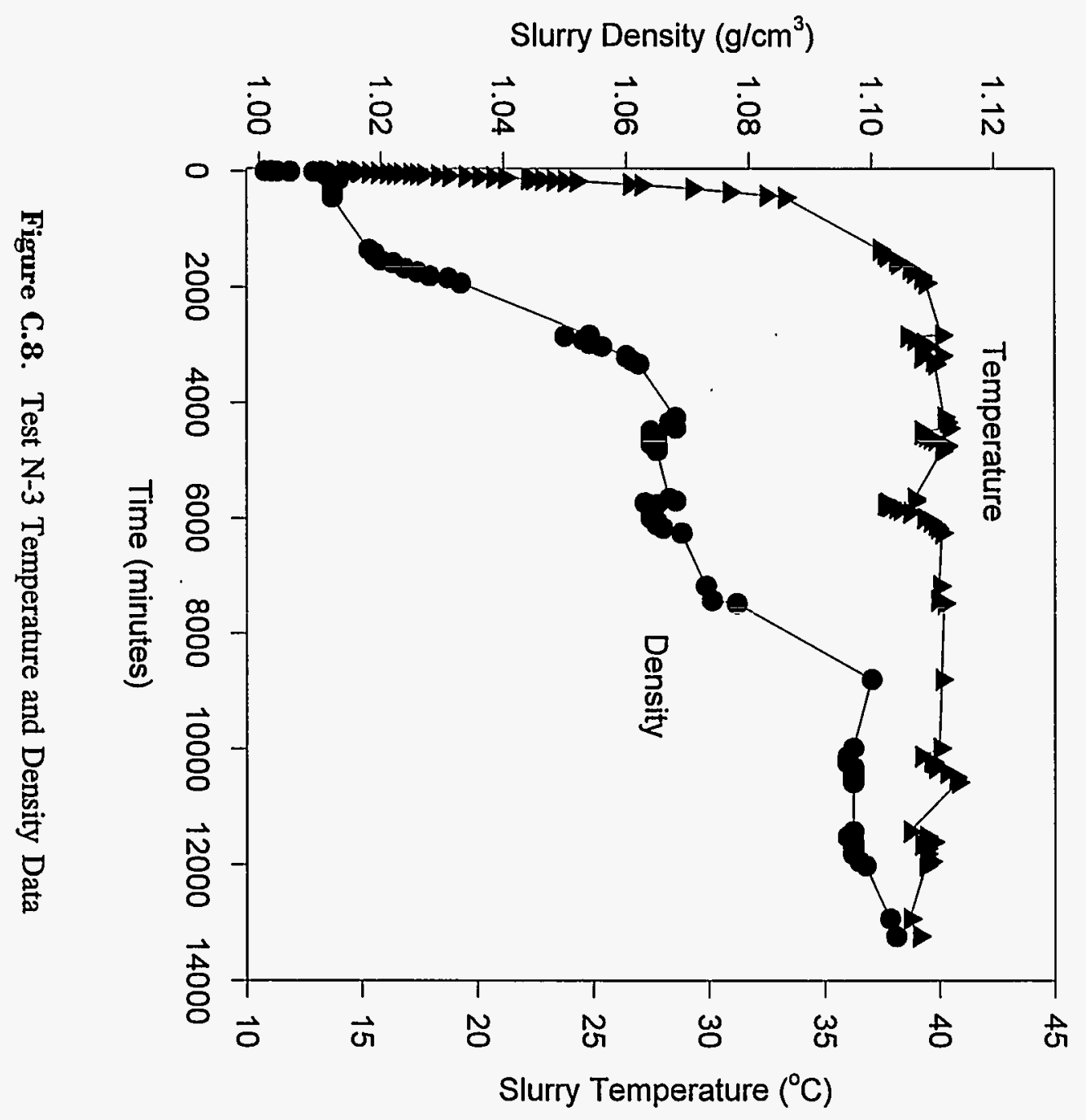




\section{Appendix D}

Nozzle Diameter Effects Test Plan 


\section{Appendix D}

\section{Nozzle Diameter Effects Test Plan}

Contained in Appendix D is a copy of the test plan that was prepared before nozzle diameter effects testing started (tests $\mathrm{N}-1$ through $\mathrm{N}-3$ ). The test plan (DSTRTP-FY95-SM1) describes the justification for the tests that were conducted as well as the procedures that were followed. All deviations from the test plan given in this appendix are noted in Appendix C. 
Test Plan for

TWRS Retrieval Technology Development Project

1/25-Scale Nozzle Diameter Effects Testing

Test Plan No. DSTRTP-FY95-SM1, Revision 0

October 24, 1994

Prepared by:

M. R. Powell, PNL, Principal Investigator

Date

Approvals:

P. A. Scott, PNL, TWRS Retrieval Technology Project Manager

Date

R.C. Schrotke, PNL, Quality Assurance

Date

Safety Review:

The work described in this test plan is a continuation of work described in test plan DSTRTP-CY94-SM2, Rev. 0, which received safety and building management concurrence on April 26, 1994. Because the testing in current: test plan (DSTRTP-FY95-SM1, Rev. 0) utilizes the same test facility, operating procedures, and test materials used in the previouslyapproved test plan, it is not necessary to route this procedure through PNL Laboratory Safety and 336 Building Management for review.

Concurrence with Safety Review Decision:

M. R. Powell, Principal Investigator

Date

E. V. Morrey, Level 3 Manager

Date

D.2 


\section{Limited Distribution Notice}

This document is made available to the U.S. Department of Energy (DOE) and its contractors in confidence solely for use in performance of work under contracts with DOE. This document is not to be published or referenced in other publications, nor its contents otherwise disseminated or used for purposes other than specified above, without determination of final review authority. If the information contained herein is incorporated in any other documents, such documents shall receive appropriate Pacific Northwest Laboratory and DOE clearance. 


\subsection{Introduction}

This test plan describes three tests to be conducted in a $1 / 25$-scale plexiglass tank in the 336 building. These tests are being done to determine the effect of nozzle diameter on the ability of mixer pumps to resuspend simulated sludge layers in tanks. These tests will utilize non-hazardous clay-water slurries to simulate the mechanical and rheological properties of the Hanford tank waste. No radioactive materials will be used in the work described in this test plan.

Several tests conducted at $1 / 25$-scale during fiscal year 1994 indicated that nozzle diameter might influence sludge mobilization in unexpected ways. The three tests described in this test plan are designed to provide a better understanding of the fiscal year 1994 test results. This work is being done to support the review of vendor-proposed mixer pump designs by Westinghouse Hanford Company. The proposal review schedule requires that the work described in this test plan be completed by mid-November 1994 .

\subsection{Background}

Millions of gallons of radioactive liquid and solid wastes are being temporarily stored in double-shell tanks (DSTs) on the Hanford Site in southeastern Washington. There are approximately seven different types of wastes stored in varying amounts in the 28 DSTs. These wastes must eventually be retrieved and processed to create immobile waste forms suitable for permanent disposal. Solids in some of these tanks have been settling for many years creating a sludge layer on the tank floor. This sludge must be dispersed into the supernatant liquid to facilitate retrieval of solids from the tank. 
The technology needed to mobilize the sludge layer must be developed and demonstrated to ensure successful retrieval of radioactive waste from the DSTs. The current plan for sludge mobilization uses mixer pumps to create submerged jets of tank fluid. The two diametrically-opposed jets on each mixer pump are directed at the settled sludge to mobilize and mix the solids with the waste fluid. The mixer pump body and discharge nozzles are rotated creating moving jets of high-momentum fluid that mobilize the settled solids.

Pacific Northwest Laboratory (PNL) has been developing waste retrieval technology using a 1/12-scale DST test facility, a 1/25-scale test facility, and other bench-scale test equipment. The $1 / 25$-scale facility is similar to the $1 / 12$-scale facility with the exception that the $1 / 25$-scale tank is.made from plexiglass, which allows for the visual measurement of the effective cleaning radius (ECR), which is the distance between the nozzle exit and the sludge bank.

Recent mobilization testing has raised questions about whether the effects of nozzle exit velocity $\left(\mathrm{U}_{0}\right)$ and nozzle diameter $(D)$ are understood. Prior to the recent testing, it was accepted that the ECR produced by a mixer pump operating on a given sludge is directly proportional to the product of nozzle exit velocity and nozzle diameter. This product, written as $U_{0} D$, has been shown to be proportional to the ECR both through previous sludge mobilization testing and by the theoretical equations that describe submerged fluid jets. Starting with the equation for the centerline velocity of a free jet, a relationship between the ECR and various jet and sludge properties can be derived. ${ }^{a}$ This relationship predicts that the ECR should be directly proportional to the quantity $U_{0} D$.

aThis derivation is provided in "Proposed Test Strategy for the Evaluation of DoubleShell Tank Sludge Mobilization." by M. R. Powell, C. L. Fow, G. A. Whyatt, P. A. Scott, and C. M. Ruecker. November 1990. A letter report for Westinghouse Hanford Company prepared by Pacific Northwest Laboratory, Richland, Washington. 
In addition to the derived relationship, sludge mobilization testing using mixer pumps has also revealed a linear proportionality between the ECR and $U_{0} D$. This testing is described below.

In FY87, a 1/12-scale sludge mobilization test was carried out using two mixer pumps simultaneously operating on a silica/soda ash sludge simulant. One mixer pump had $0.53 \mathrm{~cm}$ nozzles and the other had $0.79 \mathrm{~cm}$ nozzles. The nozzle exit velocities for these two pumps were $21.6 \mathrm{~m} / \mathrm{s}$ and $14.3 \mathrm{~m} / \mathrm{s}$, respectively, so that both mixer pumps had equal $\mathrm{U}_{0} \mathrm{D}^{\prime} \mathrm{s}$ of $1140 \mathrm{~cm}^{2} / \mathrm{s}$. The mixer pumps were operated simultaneously and the ECRs measured periodically over a period of $14 \mathrm{~h}$. It was observed that the ECR of each pump reached about $54 \mathrm{~cm}$. The ECR data collected during this test are shown in Figure 2.1. It is seen that the ECR produced by the larger nozzle size lags that of the smaller nozzle by about $5 \mathrm{~cm}$ early in the test, but both ECRs are within about $1 \mathrm{~cm}$ by the end of the test. Based on the data presented in Figure 2.1, along with the derived relationship between ECR and $U_{0} D$, it was concluded that the ECR for a given sludge is proportional to $\mathrm{U}_{0} \mathrm{D}$.

Testing of full-scale mixer pumps at the Savannah River Laboratory (SRL) has also been done to examine the ECR vs $U_{0} D$ relationship. Churnetski (1982) reports that the ECR varies linearly with $U_{0} D$ for a given simulant (kaolin clay mixed with water at constant weight fraction). Churnetski's data are shown in Figure 2.2. Seven ECRs were measured using a $3.81 \mathrm{~cm}$ nozzle and one ECR was measured using a $7.62 \mathrm{~cm}$ nozzle. ${ }^{2}$ Based on Figure 2.2 it appears that the $U_{0} D$ proportionality holds even with a doubling of the nozzle diameter (and corresponding halving of the nozzle exit velocity). No ECR growth data are given by Churnetski.

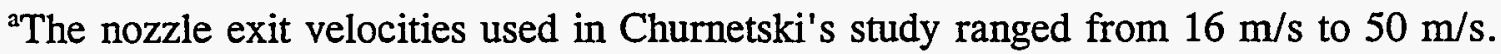




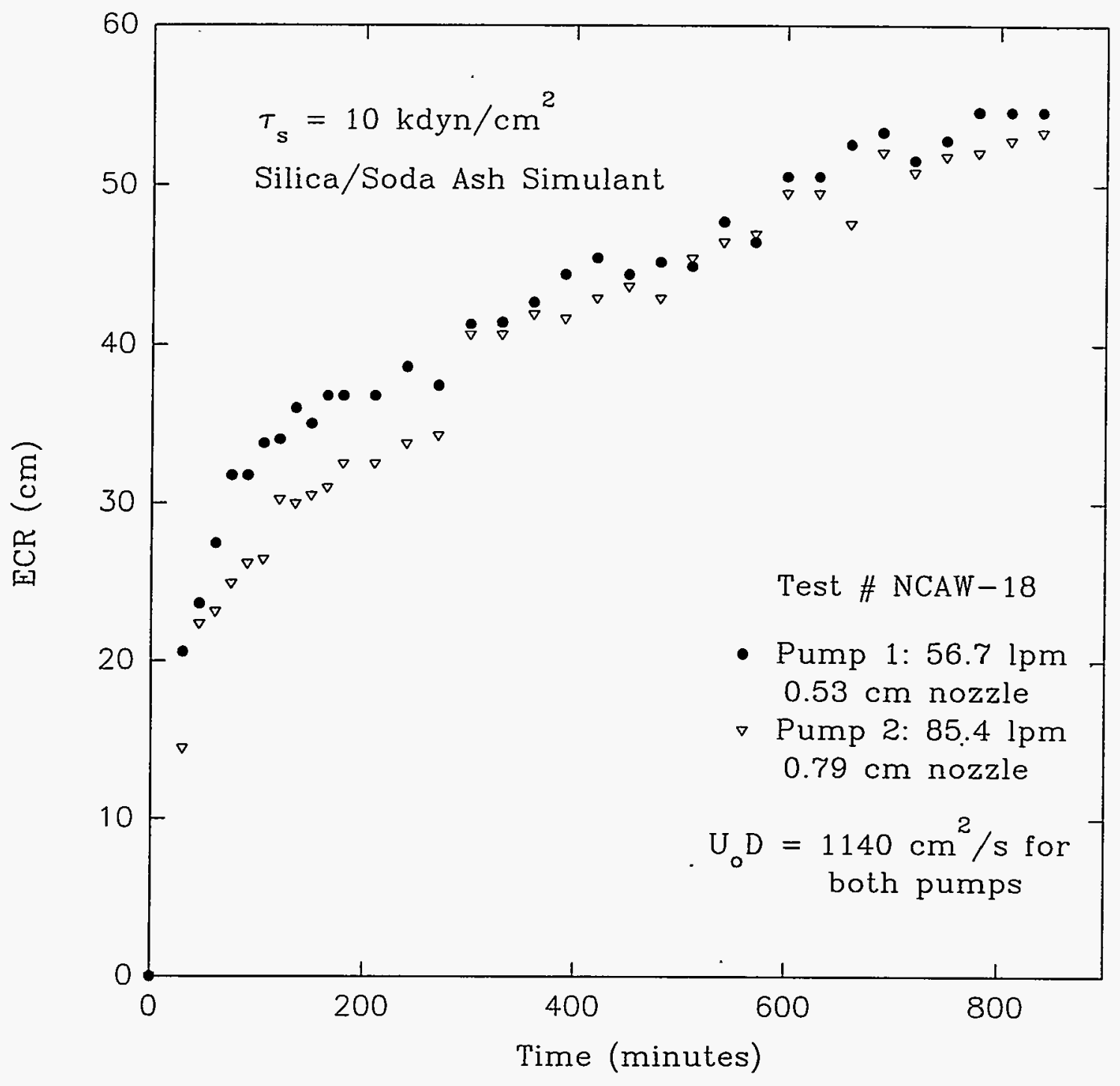

Figure 2.1: ECR Growth Data from 1/12-Scale Test NCAW-18 


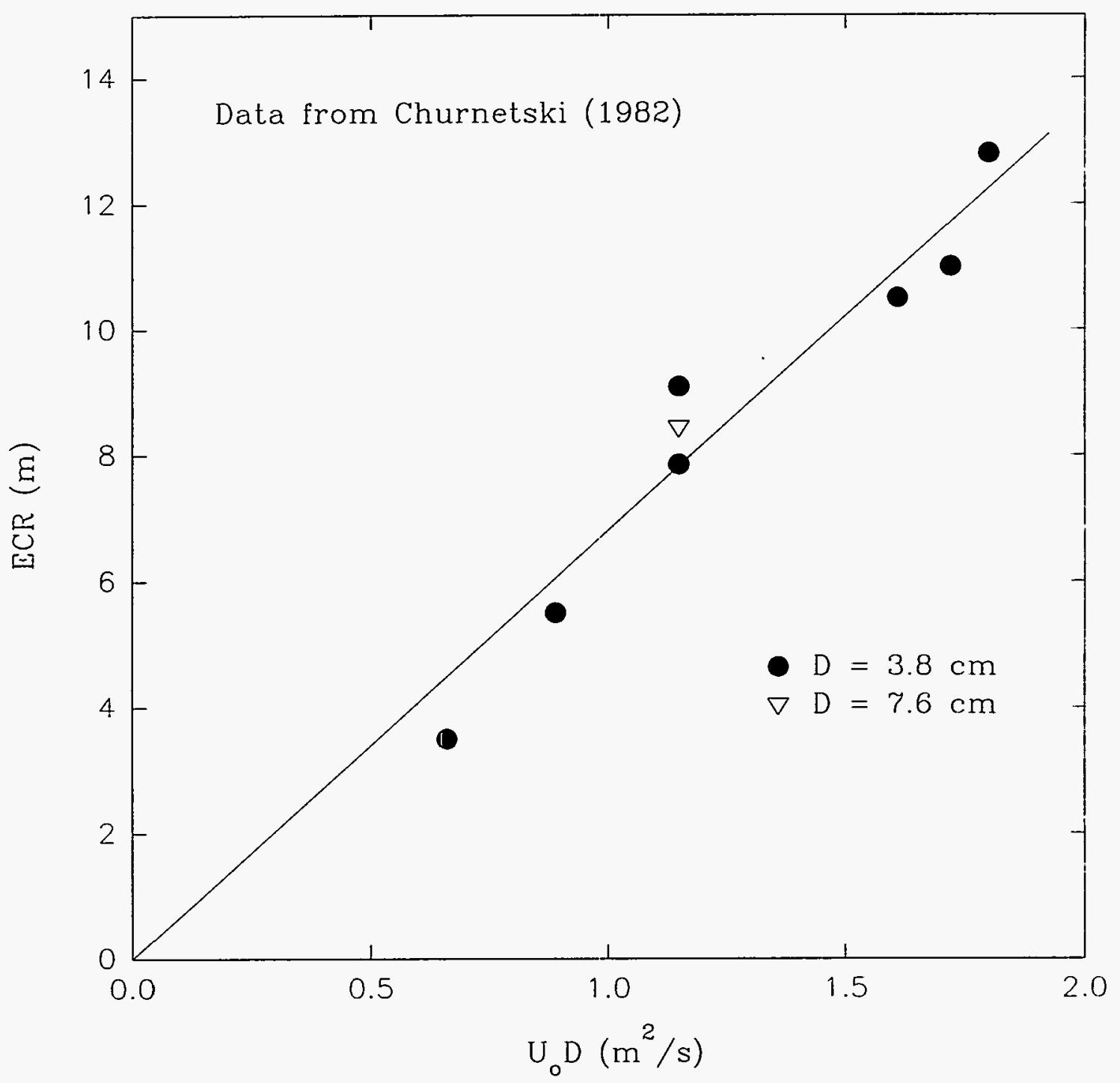

Figure 2.2. $E C R$ vs $U_{0} D$ data from Churnetski (1982)

D. 8 
Testing at $1 / 25$-scale in FY93 and FY94 also indicated that the ECR is proportional to $\mathrm{U}_{\mathrm{o}}$ for a given sludge simulant and a nozzle diameter of $0.6 \mathrm{~cm}{ }^{2}$ In many of these tests, the ECR was allowed to reach its final value with the flow at a relatively low rate before the flow rate was increased and the resulting ECR growth observed. The ratio of the low flow ECR to the high flow ECR was found to be equal to the ratio of the low flow $U_{0} D$ to the high flow $U_{0} D$ (within experimental error).

The experimental data discussed thus far all indicate that the ECR is directly proportional to $U_{0} D$. It must be pointed out, however, that all this testing was done assuming full-scale nozzle diameters of 6 inches $(15.2 \mathrm{~cm})$ or smaller. As a result, the nozzle exit velocities tested tend to be relatively high. Tests were performed at $1 / 25$-scale during FY1994 in which $0.9 \mathrm{~cm}$ nozzles were used. These nozzles represent approximately 9 inch $(22.9 \mathrm{~cm})$ full-scale nozzles. These $0.9 \mathrm{~cm}$ nozzle tests are discussed in the paragraphs that follow.

Sludge mobilization testing conducted at $1 / 25$-scale during fiscal year 1994 was performed with the primary goal of identifying the sludge properties that govern sludge mobilization. One of the secondary goals of the testing was to verify that a larger nozzle diameter operated with a proportionally lower nozzle exit velocity results in the same degree of sludge mobilization as a smaller nozzle with a larger exit velocity. The degree of sludge mobilization is measured by the effective cleaning radius (ECR), which is defined as the distance from the nozzle exit to the sludge bank. For a given sludge, the ECR has been taken to be directly proportional to the product of nozzle exit velocity and diameter, which is written symbolically as $U_{0} D$.

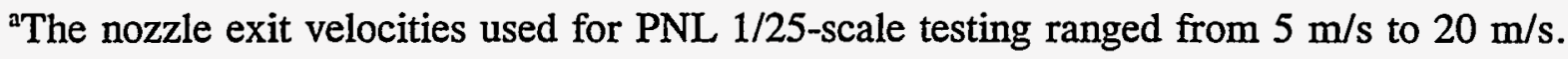
D.9 
Three fiscal year 1994 tests were conducted to investigate the relationship between $E C R$ and $U_{0} D$ for nozzles of two different diameters. During these tests, the ECRs produced by $0.6 \mathrm{~cm}$ nozzles were compared to those produced by $0.9 \mathrm{~cm}$ nozzles. In the first of these tests it was found that for a given $U_{0} D$ the larger nozzles resulted in ECRs much smaller than those of the smaller nozzles. The two tests following this also showed that the smaller nozzles performed better, although the difference was much smaller than that observed in the first test. It is worth noting that a different type of sludge simulant was used for the first test. These 1/25-scale tests are described in detail in Powell et al., 1994. ${ }^{2}$

It is the objective of the study described in this test plan to resolve whether the mobilization of sludge simulants is a function of the jet $U_{0} D$ or if the jet $U_{0}$ and nozzle $D$ are each independently important.

This is a question of practical interest and great importance. Mixer pumps are being designed assuming that the jet behavior is determined by the value of $U_{0} D$. The individual exit velocity $\left(U_{0}\right)$ and nozzle diameter $(D)$ selected are assumed to not be important provided that a specified value of $U_{0} D$ is attained. There are operational reasons for maximizing the nozzle diameter while maintaining the largest achievable $U_{0} D$. For example, for a constant $\mathrm{U}_{0} \mathrm{D}$ the required horsepower is reduced by increasing the nozzle diameter. If the implications of the recent $1 / 25$-scale data are correct, however, increasing nozzle diameter may result in reduced sludge mobilization. Because mixer pump procurement activities are proceeding upon what is potentially an incorrect assumption, it is important that the study described in this test plan be completed rapidly. The current mixer pump procurement schedule requires that this work be completed by mid-November 1994 .

${ }^{2}$ Powell, M. R., C. M. Gates, C. R. Hymas, and M. A. Sprecher. September 1994. Fiscal Year 1994 1/25-Scale Sludge Mobilization Testing. Draft report prepared by Pacific Northwest Laboratory, Richland, Washington 99352. 
This test plan provides the methodology for performing $1 / 25$-scale tests to determine the effects of nozzle diameter on sludge mobilization. These tests will be used to support the selection of a design for DST mixer pumps.

\subsection{Objective}

The work described in this test plan is designed to determine whether the expected proportionality between ECR and $\mathrm{U}_{0} \mathrm{D}$ holds for nozzle diameters up to those representing $22.9 \mathrm{~cm}$ (9 inches) at full-scale. Specifically, it must be determined why the recent $1 / 25$ scale test using a $0.9 \mathrm{~cm}$ nozzle gave smaller than expected ECRs. If it can be shown that the larger nozzle diameters give ECRs at least as large as those produced by smaller nozzles, then full-scale mixer pump design specification can proceed with the current plan to utilize large diameter nozzles.

\subsection{Approach}

The nozzle diameter effects tests will be conducted in the $1 / 25$-scale test facility located in the 336 building. This is the same facility that was used to conduct the FY93 and FY94 1/25-scale test programs. The approach that will be used to investigate the nozzle diameter effects on sludge mobilization is described in this section.

It has been hypothesized that the poor mobilization by the $0.9 \mathrm{~cm}$ nozzles observed at 1/25-scale during FY 1994 resulted from the inability of the larger nozzles at their lower $U_{0}$ 's to mobilize the sludge near the tank floor. This resulted in the formation of a sloped sludge bank that served to redirect much of the jet energy upwards away from the sludge. The smaller jet, by contrast, more efficiently scours the tank floor in the region directly under the nozzles. This prevents the development of a low angle sludge bank like that observed to 
form using the larger nozzle. The improved scouring of the smaller nozzle is due to the higher $U_{o}$ used. A higher $U_{0}$ results in greater local fluid velocities in the region near the nozzles. Turbulent jet $\mathrm{U}_{0} \mathrm{D}$ similarity does not strictly hold in the region near the nozzles (i.e., at downstream distances of about 10 nozzle diameters or less).

The lack of turbulent jet similarity in the near-field region (i.e., at $x / D<10$ ) is shown in Figures 5.1 and 5.2. Figure 5.1 contains the data collected by Sudou and Takami (1990) for wall-adjacent air jets. The air jets were directed horizontally over a planar surface and the downstream jet velocities determined using a hot wire anemometer. Plotted in Figure 5.1 are the maximum jet velocity data $\left(U_{\max }\right)$ divided by $U_{0}$ as a function of dimensionless downstream distance $(x / D)$. The data for two wall-adjacent jet configurations are presented. The configurations tested were with the nozzle centerline located 2 nozzle diameters above the planar surface $(L / D=2)$ and with the centerline 3 nozzle diameters above the surface $(\mathrm{L} / \mathrm{D}=3)$. Conveniently, these are the same $\mathrm{L} / \mathrm{D}$ 's that were used when the $0.9 \mathrm{~cm}(\mathrm{~L} / \mathrm{D}=$ 2) and $0.6 \mathrm{~cm}(\mathrm{~L} / \mathrm{D}=3)$ nozzles were used for mobilization testing during FY 1994. Applying the data of Sudou and Takami to the FY 1994 mobilization test where the mobilization effectiveness of a $0.9 \mathrm{~cm}$ nozzle at $U_{0}=5.6 \mathrm{~m} / \mathrm{s}$ was compared to that of a 0.6 $\mathrm{cm}$ nozzle at $U_{o}=8.4 \mathrm{~m} / \mathrm{s}$, it is found that there is a near-field difference in the jet velocities despite the fact that both nozzles have the same $U_{0} D$. This difference is shown in Figure 5.2. 


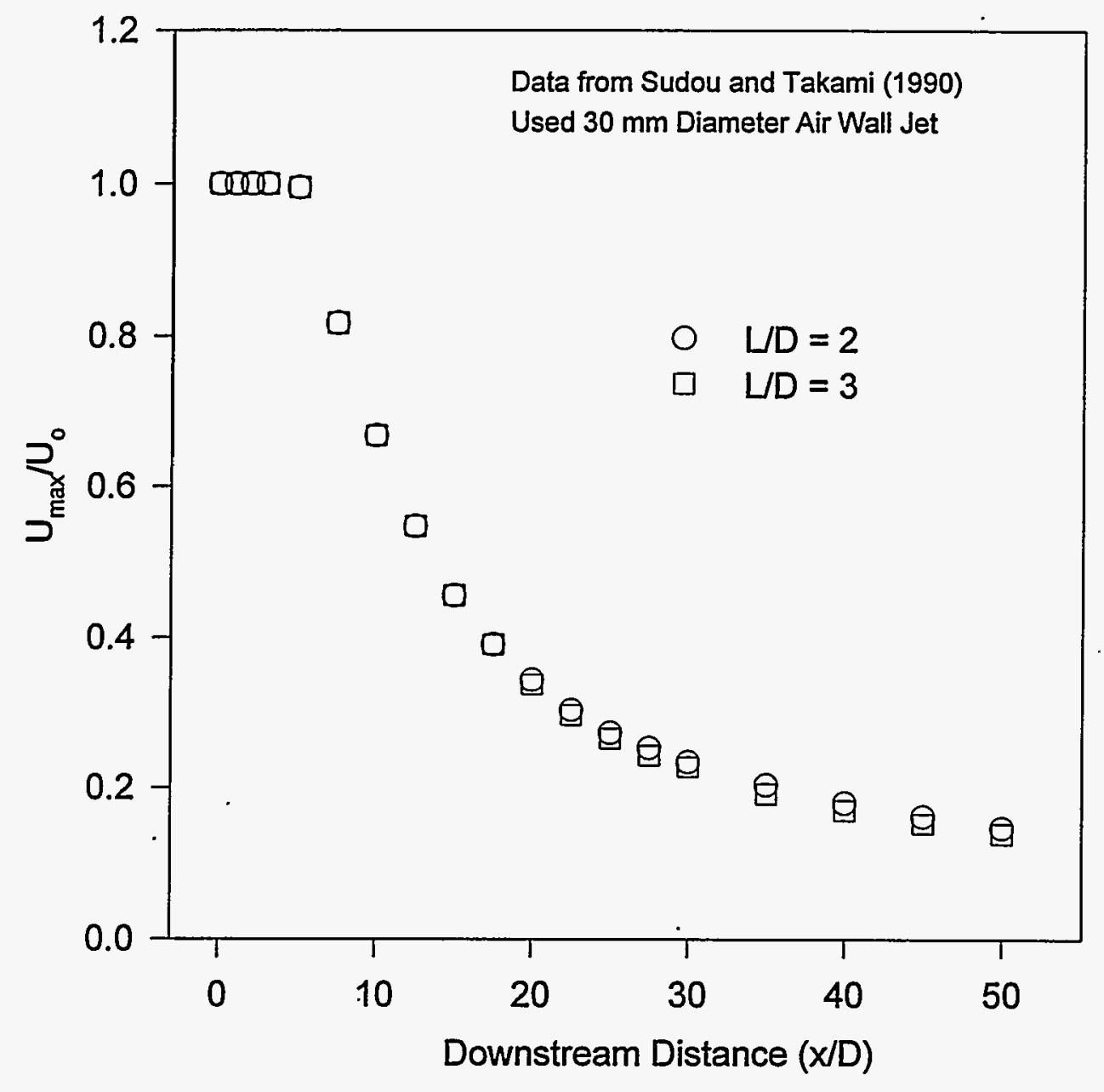

Figure 5.1. Maximum Wall Jet Velocity Decay

D.13 


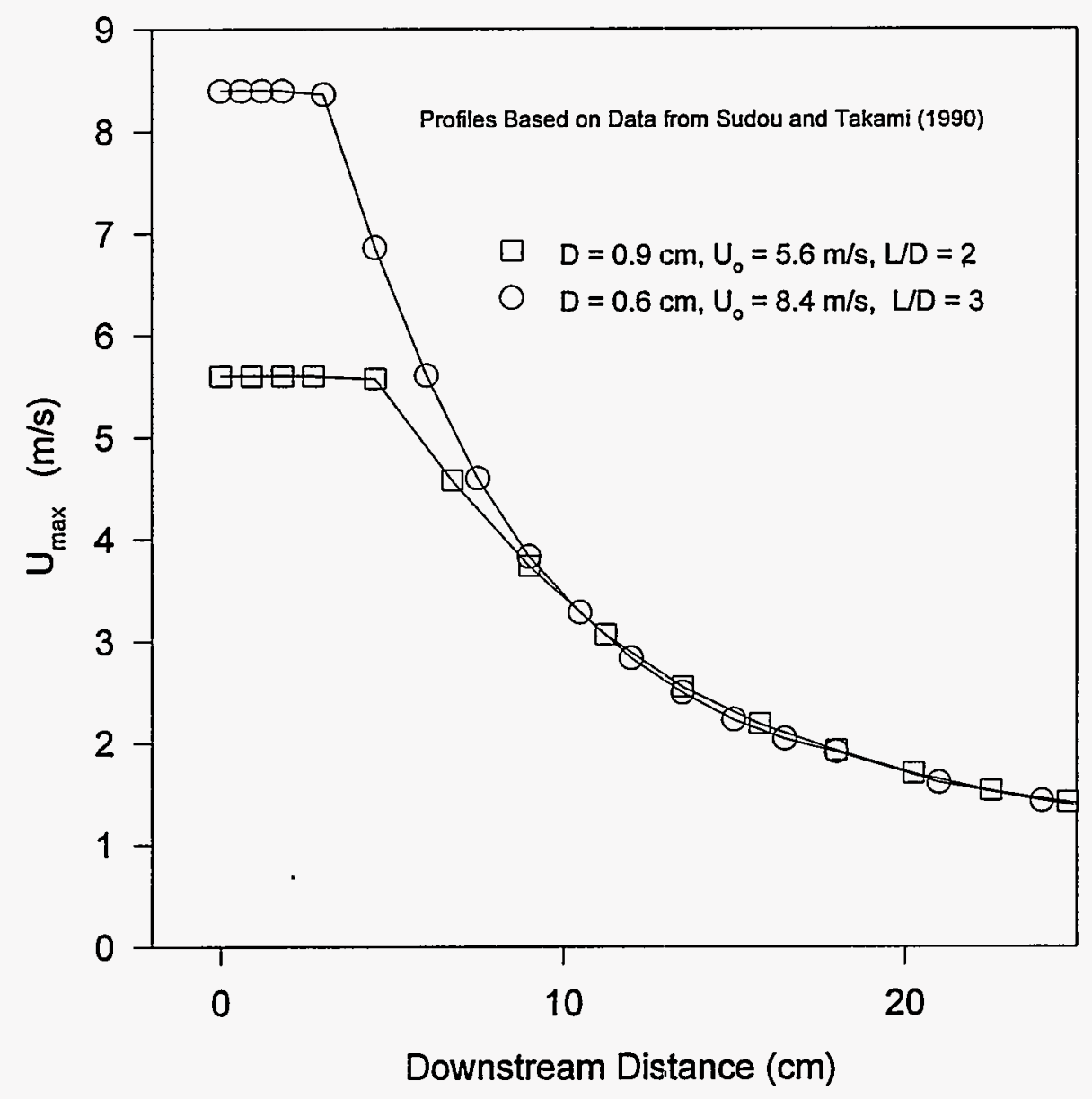

Figure 5.2. Estimated Maximum Velocity Profiles based on Sodou and Takami Data 
The near-field $(x / D<10)$ velocity difference shown in Figure 5.2, it is postulated, was responsible for the formation of the sloped sludge bank observed during $\mathrm{D}=0.9 \mathrm{~cm}$ testing in FY 1994. This sloped sludge bank resulted in a smaller ECR for the $D=0.9 \mathrm{~cm}$ nozzle because the sloped bank tends to redirect much of the jet energy away from the sludge bank. The difference in bank angles obtained in the FY94 tests is depicted schematically in Figure 5.3 .

An alternative explanation fọr the poor mobilization performance of the $0.9 \mathrm{~cm}$ nozzles relative to the $0.6 \mathrm{~cm}$ nozzles has been developed based on qualitative observations of the rate of jet spread observed when water-in-air jets are generated using the $1 / 25$-scale mixer pump assembly. It has long been suspected that the design of the 1/25-scale nozzle assembly results in a disruption of the fluid streamlines that may influence the uniformity of the fluid velocity profile at the nozzle exit. After the slurry is forced down the central tube of the $1 / 25$-scale mixer pump, it is subjected to a right-angle turn just prior to reaching the tapered entrance of the nozzles. The hypothesis is that this flow disruption may have been sufficient to result in an upwards-angled net jet flow and/or a more rapid rate of jet velocity decay. Either of these effects could result in the reduced mobilization performance observed from the $0.9 \mathrm{~cm}$ nozzles.

Tests of the $1 / 25$-scale nozzles were conducted in which water-in-air fluid jets were generated. The nozzles were tested both in the standard $1 / 25$-scale configuration and separately (i.e., connected to the end of a long, straight hose). These tests indicated that the velocity profile uniformity of the $1 / 25$-scale jets is worse than that obtained when the nozzles are preceded by a section of straight pipe. A typical jet produced by the $1 / 25$-scale jets is shown in Figure 5.4. Compare this rapidly-spreading jet to that produced by the well-formed jet shown in Figure 5.5. Clearly the water-in-air jet shown in Figure 5.5 is more coherent than that of the $1 / 25$-scale mixer pump assembly. 


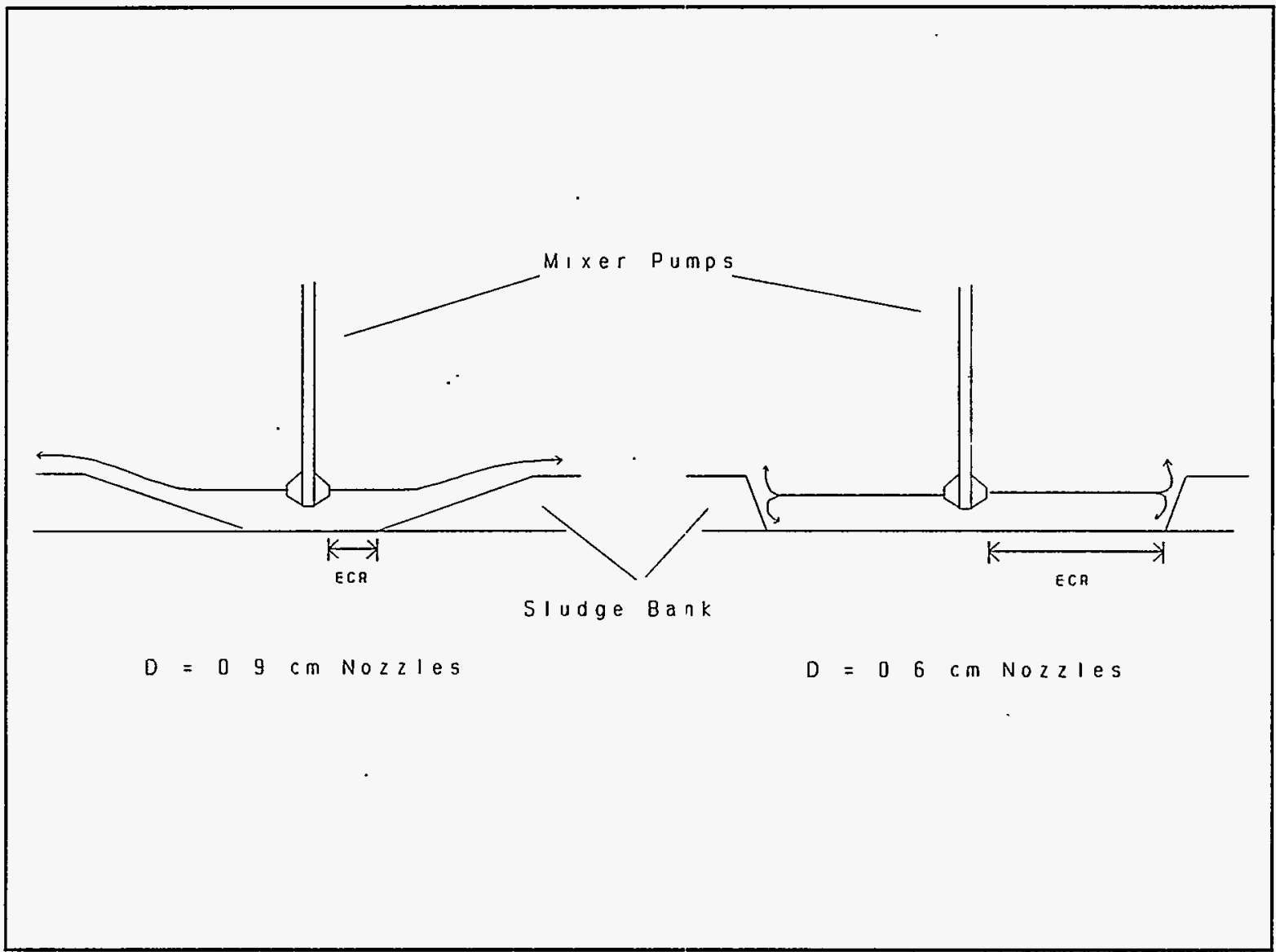

Figure 5.3. Sludge Bank Angles Obtained in FY94 Tests for D=0.9 cm and D=0.6 cm Nozzles 


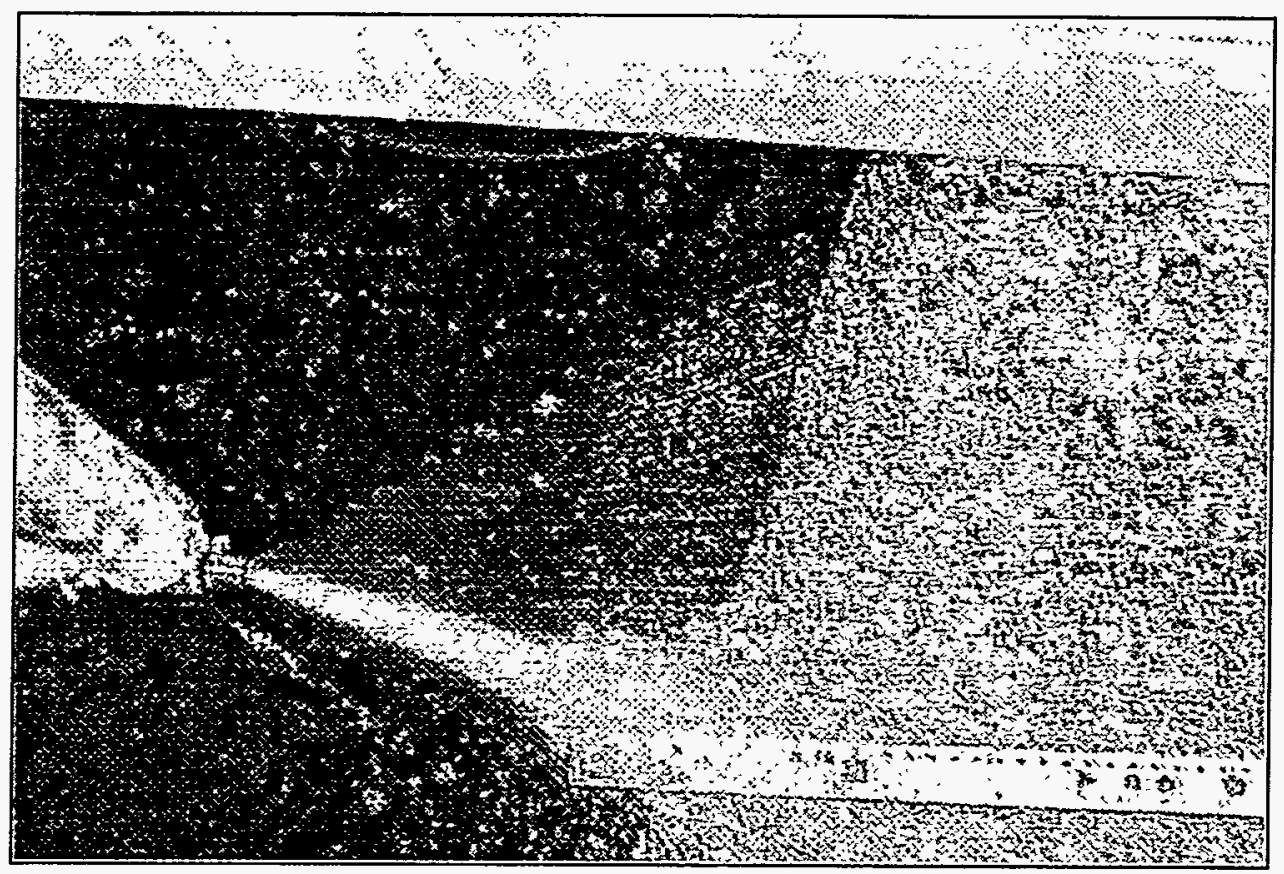

Figure 5.4. $\mathrm{D}=0.9 \mathrm{~cm}, \mathrm{~L} / \mathrm{D}=1.7, \mathrm{P}=7 \mathrm{psig}$, No Flow Straightener or Flow Divider 
Test Plan: DSTRTP-FY95-SM1 Rev.: 0 Date: October 24, 1994

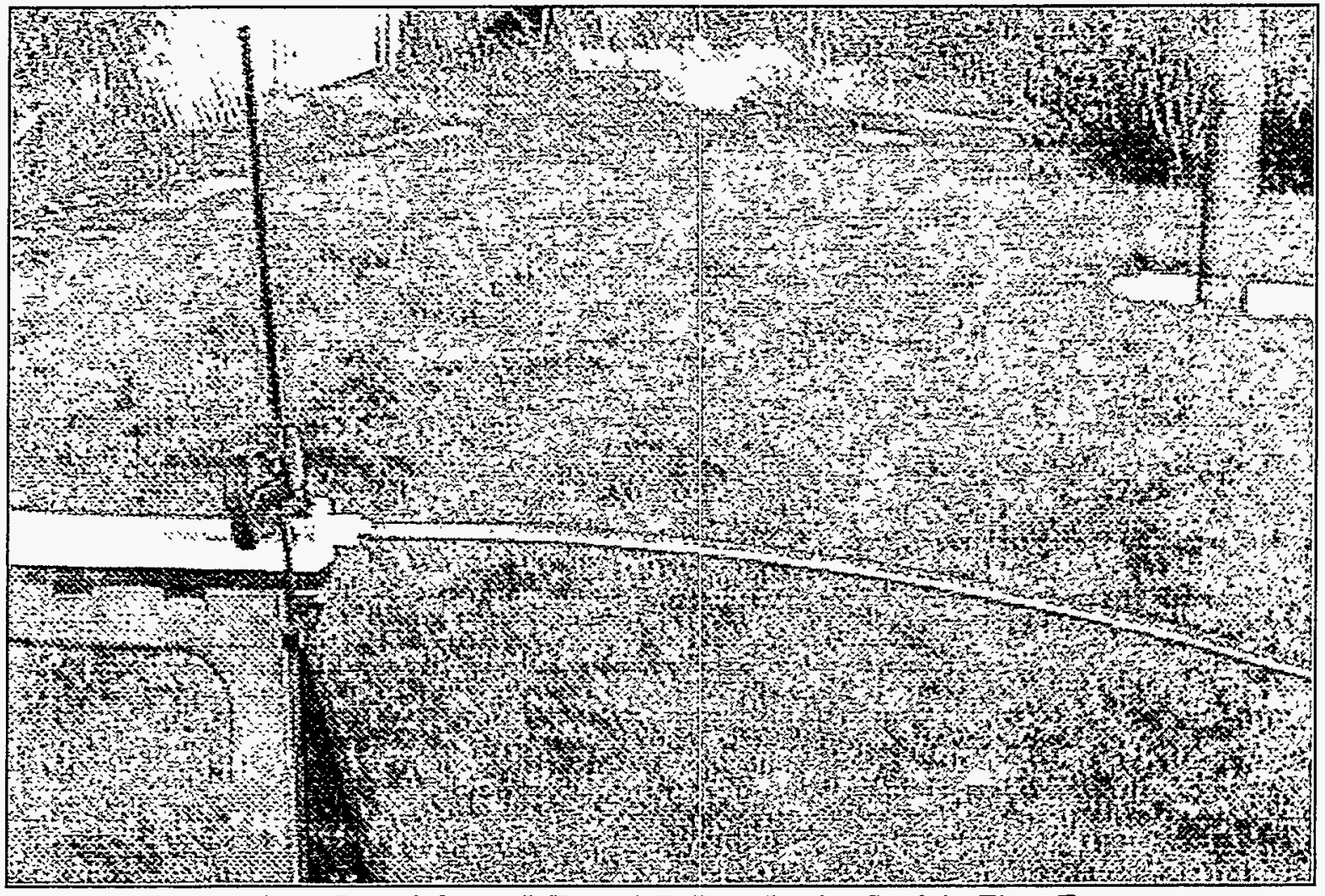

Figure 5.5. $D=0.9 \mathrm{~cm}, \mathrm{~L} / \mathrm{D}=1.7, \mathrm{P}=7 \mathrm{psig}$, Straight Flow Entrance 
It is not known at this time whether the submerged jet (water-in-water) profile produced by the $1 / 25$-scale nozzle assembly is significantly different than that expected from a well-formed jet. In the absence of angular velocities in the initial jet velocity profile (i.e., no swirl), nozzle design has been shown to result in downstream maximum velocity differences on the order of 20-30\% for downstream distances of less than about 40 nozzle diameters (see Sudo et al., 1987; Obot et al., 1979). The more uniform initial velocity profile results in greater downstream velocities. However, these differences tend to persist only in the near to intermediate downstream distances. Beyond about 40 nozzle diameters, differences in the maximum downstream jet velocities are very small. It is worth noting, however, that the position of this maximum velocity may vary with changes in nozzle design.

If the initial jet velocity profile includes angular as well as axial flow, the rate of jet spread can be greatly affected at all downstream distances. Rajaratnam (1976) gives maximum jet velocity decay data for both free jets and wall jets with swirl (angular momentum). The rate of velocity decay was found to be profoundly influenced by the degree of swirl. Increasing the ratio of angular to axial momentum was found to result in lower downstream distances.

The amount of swirl and/or axial momentum uniformity present in the submerged $1 / 25$-scale jets is not known. Included in the testing described in this test plan are efforts to determine whether the non-uniform jets produced during the previous $1 / 25$-scale testing are responsible for the reduced mobilization performance of the $0.9 \mathrm{~cm}$ nozzles. Substantial improvement in the $1 / 25$-scale jets result when a flow divider and flow straightening vanes are incorporated into the design. The mobilization performance of these improved jets will be compared to that of the previous nozzle assembly design. The flow divider is a thin strip of metal positioned between the two nozzles to prevent large-scale eddies from affecting both jets. The jet that results when the flow divider and flow straighteners are employed is shown in Figure 5.6. 


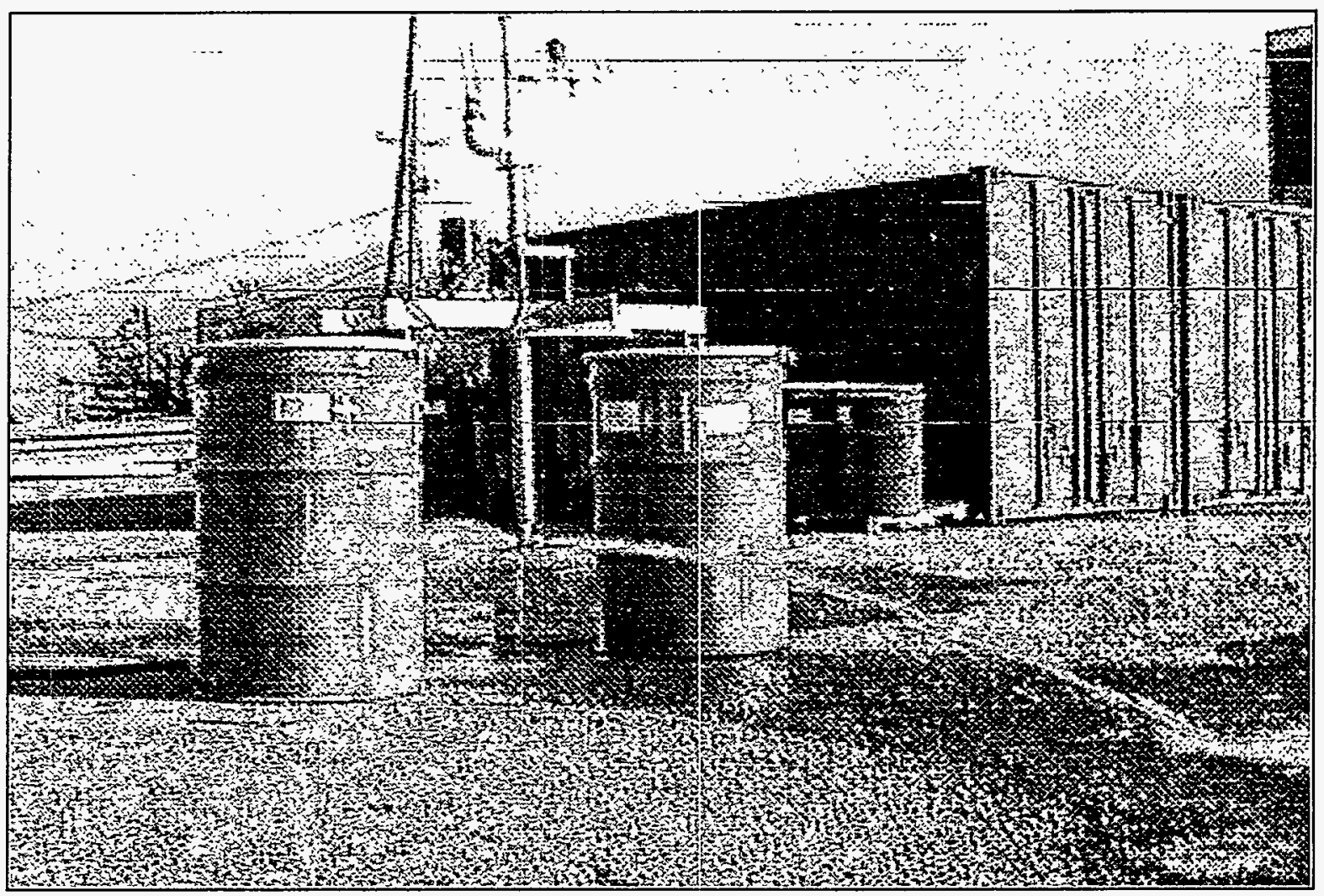

Figure 5.6. $\mathrm{D}=0.9 \mathrm{~cm}, \mathrm{~L} / \mathrm{D}=1.7, \mathrm{P}=7 \mathrm{psig}$, with Flow Divider and Flow Straighteners 
Three $1 / 25$-scale tests will be performed to resolve the question of whether ECR is proportional to $\mathrm{U}_{0} \mathrm{D}$. The first test will be conducted similarly to the FY1994 test in which the greatest difference between $0.9 \mathrm{~cm}$ nozzle and $0.6 \mathrm{~cm}$ nozzle mobilization was observed. The test will begin with the sludge packed close to the mixer pump column and the $0.9 \mathrm{~cm}$ nozzles installed. The pump will be run at $500 \mathrm{~cm}^{2} / \mathrm{s} \mathrm{U}_{0} \mathrm{D}$ until ECR growth stops. The flow straightening vanes will then be installed in one nozzle and the other nozzle hole plugged to simulate the action of the flow divider, which will not be installed until after test \#1. Operation will be continued at $500 \mathrm{~cm}^{2} / \mathrm{s}$ until ECR growth, if any, stops. Any additional ECR growth will provide an indication of the difference between the $1 / 25$-scale jets used in previous testing and the improved jet that results when the flow straighteners are used.

The next step will be to remove the flow straightener and install the other $0.9 \mathrm{~cm}$ nozzle before operating the mixer pump at a $U_{o} D$ of $1100 \mathrm{~cm}^{2} / \mathrm{s}$. This is a direct test of whether a $0.9 \mathrm{~cm}$ nozzle operated at $1100 \mathrm{~cm}^{2} / \mathrm{s}$ will result in the complete mobilization of the sludge as is predicted based on tests conducted using a $0.6 \mathrm{~cm}$ nozzle. These operating conditions represent a 9 inch $(23 \mathrm{~cm})$ full-scale nozzle operated at $29.4 \mathrm{ft}^{2} / \mathrm{s}\left(2.73 \mathrm{~m}^{2} / \mathrm{s}\right)$. It is expected that the nozzle exit velocity used in this test $(12.2 \mathrm{~m} / \mathrm{s})$ will be sufficient to mobilize the sludge in region close to the nozzle exit but below the direct jet path. Thus, this jet should overcome the effect of the the gently-sloped sludge bank noted previously when using the $0.9 \mathrm{~cm}$ nozzle at $5.6 \mathrm{~m} / \mathrm{s}$ where a $12.3 \mathrm{~cm}$ ECR was observed. If the previous result is scaled to $1100 \mathrm{~cm}^{2} / \mathrm{s}$, the predicted $E C R$ is $(1100 / 500)(12.3)=27.1 \mathrm{~cm}$. A much larger $E C R$ is expected from this test, however. If the sloped sludge bank forms during the $\mathrm{U}_{0} \mathrm{D}=500 \mathrm{~cm}^{2} / \mathrm{s}$ portion of the test but the high flow is sufficient to overcome this effect, then the ECR obtained should be equal to that expected from a $0.6 \mathrm{~cm}$ nozzle operated at the same $U_{0} \mathrm{D}$. Previous $1 / 25$-scale testing with the $0.6 \mathrm{~cm}$ nozzle would predict an ECR of 55 $\mathrm{cm}$ for kaolin/water sludge simulant at a jet $U_{0} D$ of $1100 \mathrm{~cm}^{2} / \mathrm{s}$. Since the tank radius is only 
about $45 \mathrm{~cm}$, it is expected that the simulant will be fully-mobilized during this test. Test \#1 is expected to take about 3-4 days to run.

The second test is designed to directly test whether the formation of the sloping sludge bank using the larger nozzles is due to their inability to clean the tank floor early in the mobilization process. The tank will be loaded with sludge simulant to a depth $7.5 \mathrm{~cm}$ as shown in Figure 5.7. The region near the mixer pump $(x / D<20)$ will be cleared of sludge in one half of the tank but not in the other. The $0.9 \mathrm{~cm}$ nozzles will be used to mobilize this sludge with a jet $U_{0} D$ of $500 \mathrm{~cm}^{2} / \mathrm{s}$. The flow divider and flow straighteners will be used during this test. If the hypothesized mechanism of tank floor scouring is accurate, then normal ECR growth is expected on the side of the tank where the tank floor was initially cleared of sludge and a low ECR, sloped sludge bank is expected in the remaining half of the tank. Once ECR growth has stopped, the $0.6 \mathrm{~cm}$ nozzles will be installed and the flow started and adjusted such that the same $U_{0} D$ is obtained. It is expected that this will result in further ECR growth in the side of the tank where the sloped sludge bank resulted in a smaller $E C R$. Finally, the $0.9 \mathrm{~cm}$ nozzles will be reinstalled and the flow adjusted to obtain a $U_{0} D$ of $700 \mathrm{~cm}^{2} / \mathrm{s}$. The resulting ECR growth will be monitored. It is expected that this ECR will be equal to about $7 / 5$ times that obtained using the $0.6 \mathrm{~cm}$ nozzle (due to the difference in $U_{0} D^{\prime} s$ ) because the $0.6 \mathrm{~cm}$ and $0.9 \mathrm{~cm}$ jets should be nearly identical at these axial distances (see Figure 5.2 at $x / D>20$ ). This test is expected to take 3-4 days to run.

The third $1 / 25$-scale test to be performed will involve the testing of four different nozzle diameters. The test will be initiated with the sludge packed close to the mixer pump nozzles in all directions rather than with a portion of the tank cleared as will be done in the second test. All nozzles used in this test will utilize flow straighteners immediately prior to the nozzles and a flow divider will be in place inside the mixer pump body so that good jet flow is obtained. The $0.9 \mathrm{~cm}$ nozzles will be installed first and operated at a $U_{0} D$ of 500 $\mathrm{cm}^{2} / \mathrm{s}$. The ECR growth will be monitored until the ECR growth has apparently stopped. 
Test Plan: DSTRTP-FY95-SM1 Rev.: $0 \quad$ Date: October 24, 1994

2

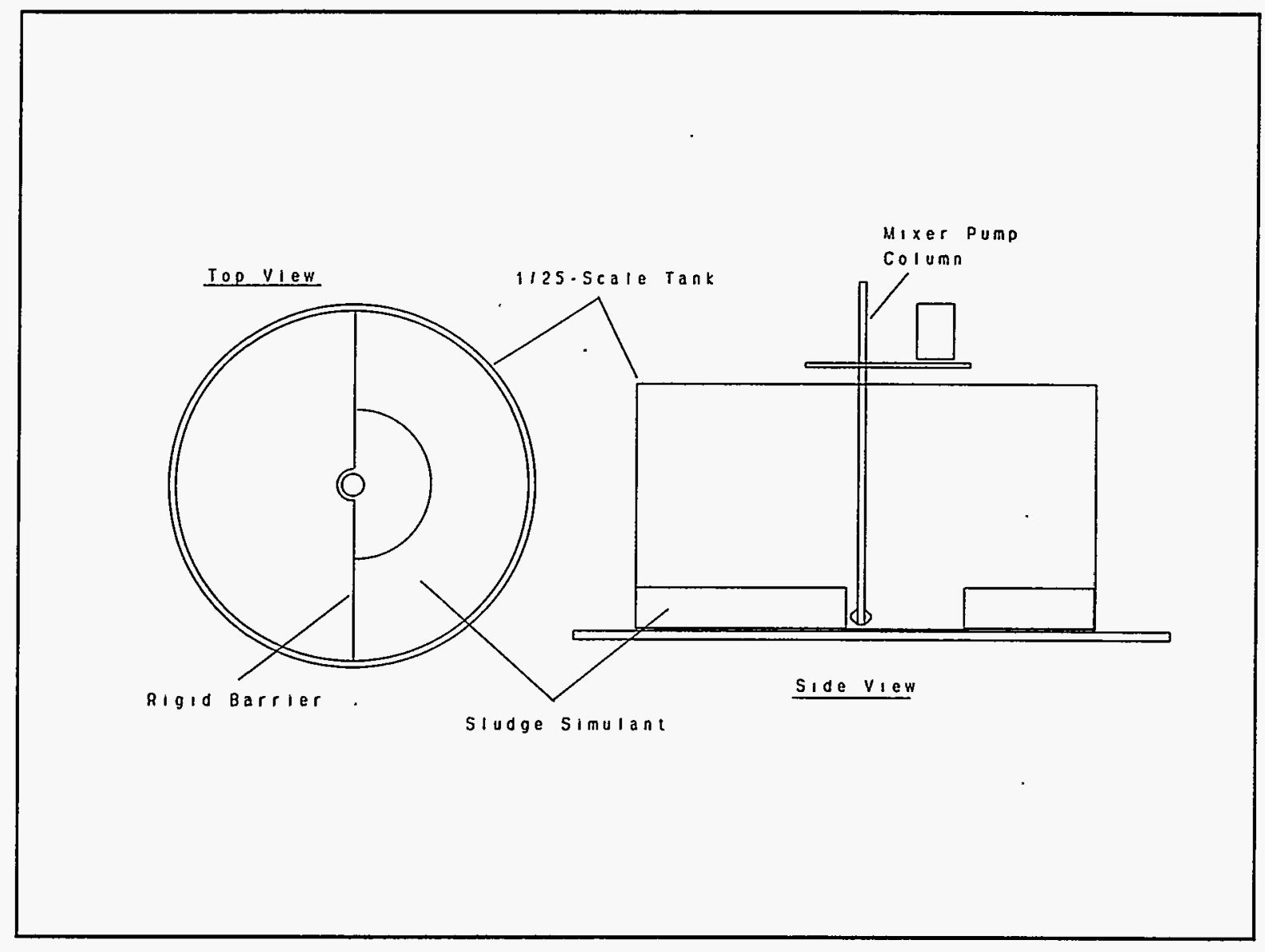

Figure 5.7. Schematic of $1 / 25$-Scale Test $\# 2$ 
The $0.75 \mathrm{~cm}$ nozzles will then be installed and operated at the same $U_{0} D$ until ECR growth (if any) stops. This process will be repeated using $0.6 \mathrm{~cm}$ and $0.4 \mathrm{~cm}$ nozzles. The $0.9 \mathrm{~cm}$ nozzles will then be re-installed and the $U_{0} D$ set to about $700 \mathrm{~cm}^{2} / \mathrm{s}$. ECR growth will be monitored until growth stops before switching through the progressively smaller nozzles. A trend towards larger ECRs as the nozzle size is decreased will be interpreted as evidence for recommending smaller nozzles for the DST mixer pumps. If the ECRs obtained using different nozzles at $700 \mathrm{~cm}^{2} / \mathrm{s}$ are within the experimental uncertainty of each other it will be concluded that larger nozzles at least equal the performance of the smaller nozzles provided that the sloped sludge bank is avoided by using a sufficiently high nozzle exit velocity. This test is expected to take about 9-10 days to run.

All three tests will be conducted using a ka.olin/water sludge simulant of about 20-30 $\mathrm{kdyn} / \mathrm{cm}^{2}$ shear strength (approximately $65 \mathrm{wt} \%$ ). This is the same simulant used during the fiscal year 1994 1/25-scale test in which a significant effect of nozzle diameter was observed.

The prepared sludge simulant will be placed into the tank to a depth of $7.6 \pm 0.8 \mathrm{~cm}$ (corresponds to tank volume of $50 \mathrm{l}$ ). The tank will then be filled to the $38 \pm 0.6 \mathrm{~cm}$ level with simulated supernate (requires $200 \pm 31$ of supernate). All three tests will use water as the simulated supernate. A rigid barrier will be employed in the second test to separate the tank as shown in Figure 5.7. This barrier will be in place in only one half of the tank. No barrier will be used in the opposite side of the tank where the cleared-away sludge meets the normal sludge bank. There is some concern that the presence or absence of the barrier may adversely affect the results of test \#2. By running with the barrier present in only one side of the tank it is possible to assess the effect of the barrier.

In the second and third tests the nozzle sizes will be changed during the test as described above. All nozzle changes will be performed by deactivating the mixer pump prior 
to replacing the nozzles. The tank will not be mixed during this period. Nozzle exchanges done during previous test programs were usually accomplished in less than about 5 minutes.

The ECR will be measured periodically as described below by observing the ECR profile through the plexiglass bottom of the tank. During the first 10 minutes of operation at each $\mathrm{U}_{o}$, the ECR will be measured at 8 points once every two minutes. Following this, ECR measurements ( 8 points) will be made once every 5 minutes for 1 hour, and then made periodically thereafter until ECR growth stops.

In addition to the ECR measurements, the density of the tank slurry will be periodically measured using a digital density meter and a pycnometer. The digital density meter measures density using a mechanical oscillation method that is accurate to about $\pm 0.002 \mathrm{~g} / \mathrm{ml}$. Slurry density will also be measured by weighing a known volume of sample roughly twice per hour (pycnometer method) as a check for any calibration drift in the digital density meter. The slurry density provides an indication of the actual fraction of the waste that has been mobilized and whether chunks of dislodged sludge are settling in the regions of the tank not well stirred by the mixer pump jets.

\subsection{Equipment Description}

Figure 6.1 shows a schematic of the $1 / 25$-scale test facility. The tank that will be used during $1 / 25$-scale testing is a $91 \mathrm{~cm}(3 \mathrm{ft})$ diameter, $61 \mathrm{~cm}(2 \mathrm{ft})$ high, plexiglass tank with clear sides and a clear bottom. The clear bottom allows the visual measurement of the ECR. The slurry will be continuously pumped using twin $1500 \mathrm{~W}(2 \mathrm{hp})$ centrifugal pumps. A direct current motor with oscillation control will be used to turn the nozzles through a $180^{\circ}$ rotation. 
Test Plan: DSTRTP-FY95-SM1 Rev.: $0 \quad$ Date: October 24, 1994

A single, centrally-located, simulated mixer pump will be mounted in the test tank such that it is capable of automatically oscillating through $180^{\circ}$ of rotation. The oscillation rate will be set to a slow rate in the range of 0.1-0.5 $\mathrm{rpm}$. The fluid will be discharged through two opposing nozzles and recovered via a suction located above the discharge nozzles. Other scaled measurements can be seen in Figure 6.1. The designs of the nozzles that will be used during the testing are shown in Figures 6.2 though 6.5.

The dry components of the kaolin/water sludge simulants will be mixed with water using a Littleford Mixer located outside the 336 building. After mixing the simulant, it will be placed into the $1 / 25$-scale tank and covered with plastic to prevent the evaporation of water prior to testing. Operation of the Littleford mixer is documented in the safe operating procedure \#39 revision 2, which is entitled "Littleford Mixer" and was prepared by M. R. Elmore.

The slurry flow rate will be controlled and monitored by means of manual valves and a Schlumberger Industries (Model FM100) pulsed DC magnetic flow meter calibrated by the user for 10 to $95 \mathrm{lpm}$ ( 3 to $25 \mathrm{gpm}$ ) slurry flow prior to and after the testing. This calibration will utilize at least 10 points between 1.0 and $95 \mathrm{lpm}$. Flow rate will be measured by weighing the quantity of water that is delivered to a container in a measured amount of time. These data will be recorded in the laboratory record book (\#55541). 


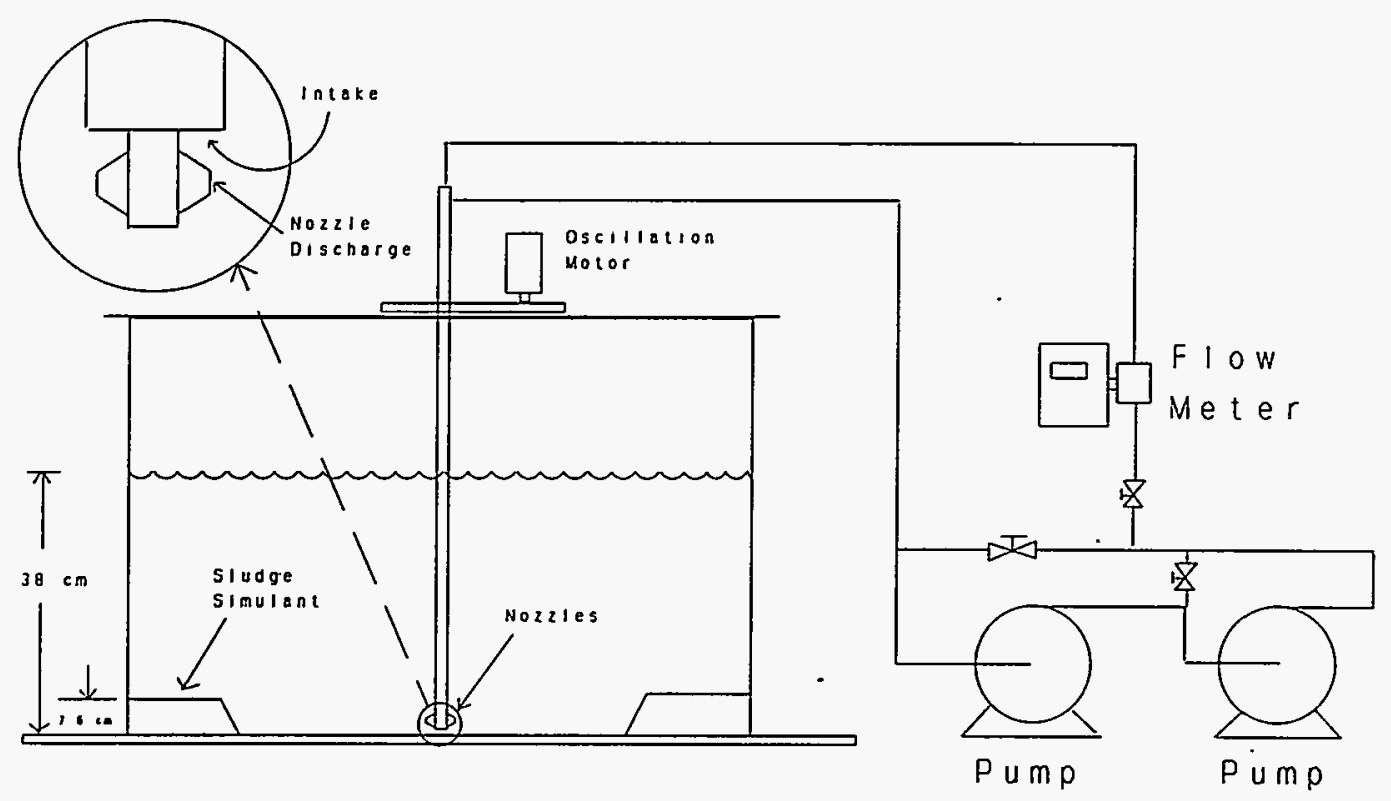

Figure 6.1: Sketch of 1/25-Scale Testing Apparatus 


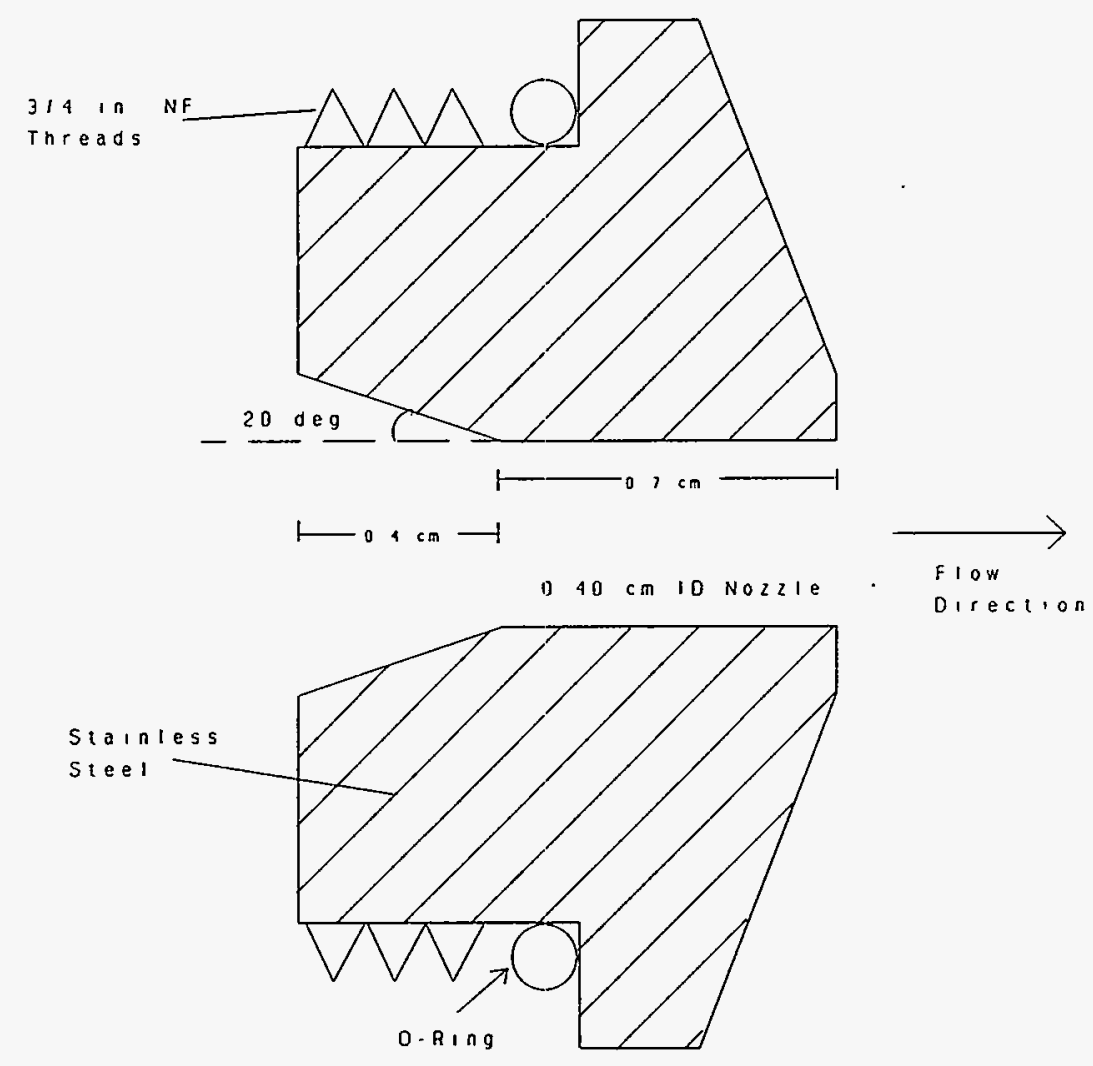

Figure 6.2. $\mathrm{D}=0.40 \mathrm{~cm}$ Nozzle Design 


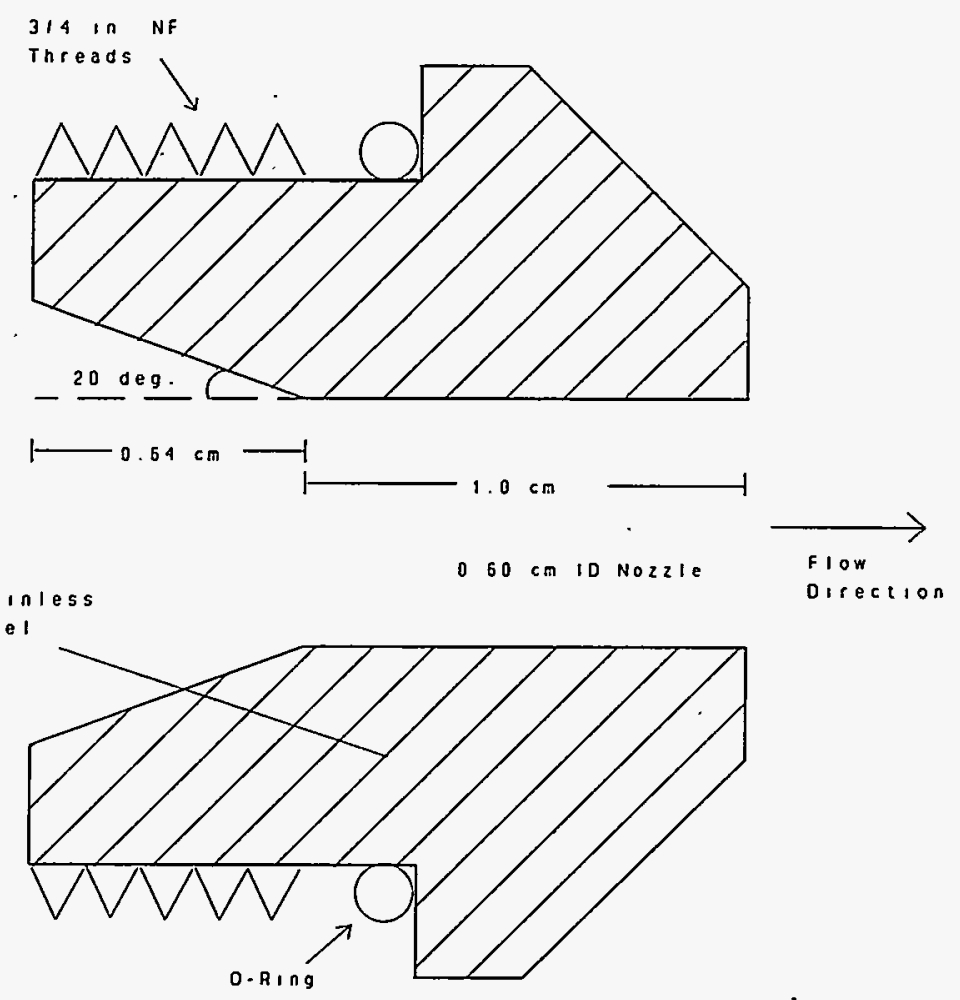

Figure 6.3. $D=0.6 \mathrm{~cm}$ Nozzle Design 
Test Plan: DSTRTP-FY95-SM1 · Rev.: $0 \quad$ Date: October 24, 1994

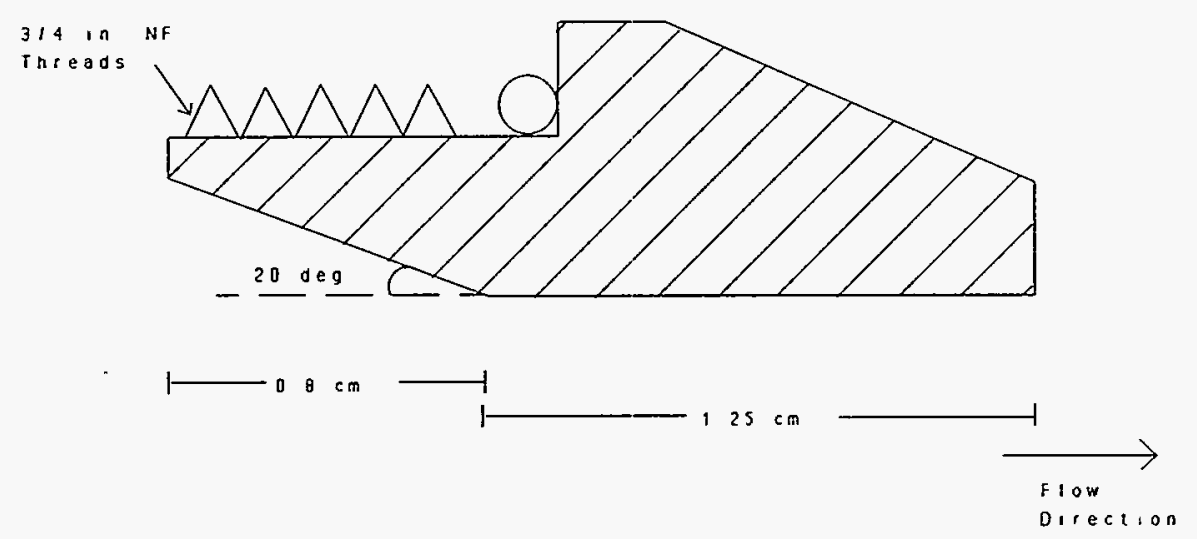

$075 \mathrm{~cm} 10$ NOZZIE

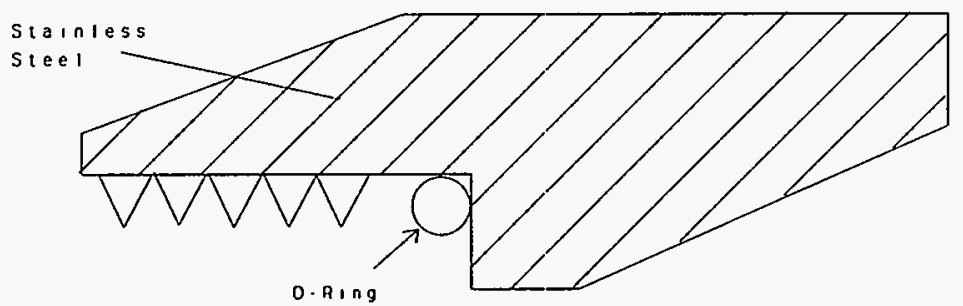

Figure 6.4. $\mathrm{D}=0.75 \mathrm{~cm}$ Nozzle Design 


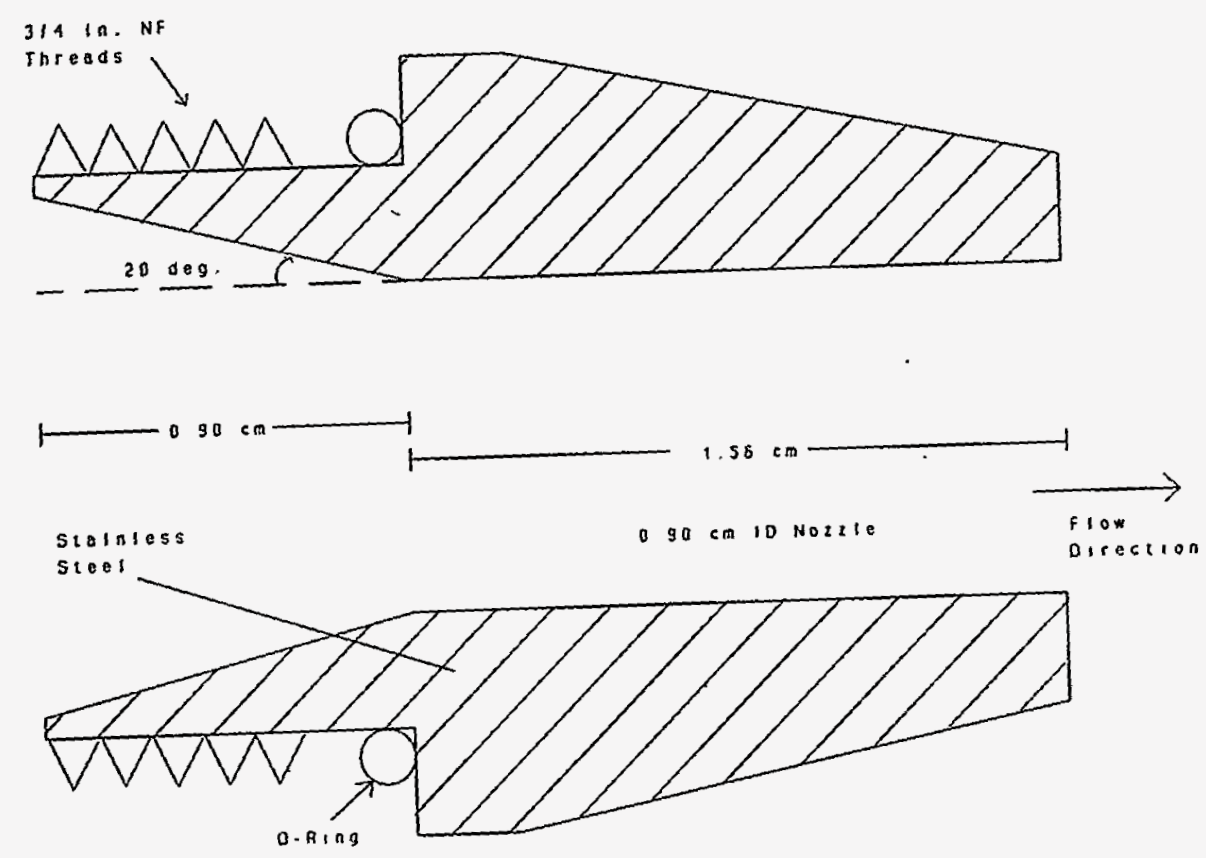

Figure 6.5. $\mathrm{D}=0.9 \mathrm{~cm}$ Nozzle Design 
Test Plan: DSTRTP-FY95-SM1 Rev.: $0 \quad$ Date: October 24, 1994

\subsection{Hazards Assessment}

The materials used in the tests will be non-hazardous. Kaolin clay is essentially inert and requires only protection from nuisance dust. Micron-sized silica particles, however, present a significant health hazard if inhaled. The clays are obtained naturally and often contain trace amounts of free silica particles. Therefore, when handling the dry kaolin clay, full-face filtration masks equipped with HEPA filters will be worn by all involved personnel to avoid exposure to silica particles. All personnel using the filtration masks shall have received a mask fit and the proper respiratory protection training. Once the simulants are mixed with water, the silica dust hazard no longer exists and the masks need not be worn.

The mixer pump column oscillation mechanism is driven by a slow-moving chain. A chain-guard has been fabricated to protect personnel from becoming entangled in the chain and sprocket. The mixer pump oscillation motor shall not be operated unless the chain guard is in place.

\subsection{Personnel Safety}

All testing and operations will conform to PNL-MA-43 (Industrial Hygiene, Occupational Safety and Fire Protection Programs), building requirements, SOPs and line management direction. Requirements associated with these tests are listed below.

1) Personnel Protective Equipment:

When the potential for the generation of airborne silica exists, full-face HEPA filtration masks will be worn by all involved personnel. Hardhats and safety glasses are required for access to the 336 building high bay. 
2) Material Safety Data Sheets (MSDS):

The kaolin clay MSDS will be reviewed by each staff member who is involved in the tests described in this test plan. Copies of the kaolin MSDS are kept in the DST Sludge Mobilization project files as well as in the MSDS files of the 336 building.

3) Respiratory Protection Requirements:

HEPA Filtration masks will be worn when airborne silica particles are potentially present, that is, during the handling of dry kaolin clay powder.

4) Medical Requirements:

All personnel handling the dry simulants shall be medically approved for the use of full-face respirators.

5) Confined Space:

These testing activities will not involve work in a confined space. However, confined space training is required for access to the levels of the 336 building below the level where the $1 / 25$-scale tank is located. Only qualified personnel are allowed to enter these lower levels. No aspect of this testing should require personnel to access these lower levels.

6) Emergency Response:

Any emergency situation will be handled by contacting the appropriate Hanford Emergency Response Unit (Dial 375-2400).

\subsection{Waste Minimization/Management}

All waste generated during the course of this test will be appropriately disposed per PNL-MA-8. All material will be collected in 55 gallon drums and appropriately tested, if necessary. If the final waste volume is determined to be non-hazardous it will be sent to a non-regulated waste disposal site. All testing described in this test plan will be conducted using non-hazardous, non-regulated materials. The only test materials involved are kaolin clay and water. 
Test Plan: DSTRTP-FY95-SM1 Rev.: $0 \quad$ Date: October 24, 1994

\subsection{Test Modifications and Quality Assurance}

Work authorized by this test plan will be conducted in accordance with Impact Level II requirements as identified in Quality Assurance Plan No. WTC-051, Rev. 3.

All laboratory data, general observations, and details of the activities performed per this test plan will be documented in a Laboratory Record Book (LRB). The current LRB assigned to this task is BNW55541. It is important that all records of data, calculations, and analyses reported from this test be documented in a sufficient manner to be traceable from the primary data and the methods and equipment used, through the assumptions and/or interpretations made, to the corresponding results reported in the summary letter that will be delivered following the completion of this testing. For sludge mobilization testing, the majority of data will be collected on data and status log sheets and test instructions, reduced copies of which will be affixed into the LRB. Any additional observations, data, and remarks will also be recorded in the LRB.

Change control shall be accomplished by the following methods:

"In process" changes (those that are editorial, or do not change the overall objectives) shall be made by mark up of the controlled workplace copy and signed and dated by the cognizant task manager. These changes are to be followed up with an official revision at a logical break point. The need to make minor changes is to facilitate changes needed for offshift hours. In the front of the controlled test plan that is used for minor change mark ups, a listing of changes will be maintained. 
Changes that are considered to be major (defined as those that would affect the overall objectives) shall be implemented per PNL Administrative Procedure PAP-70-602, "Procedure and Instruction Change Control and Change Request."

\subsection{Test Instructions}

The specific instructions that will be followed to perform the nozzle diameter effects tests are given in this section. The test instructions are separated into two sections. The first section (11.1) gives the instructions for preparing the sludge simulants to used in all three nozzle diameter effects tests. The second section (11.2) gives the general procedure for operating the $1 / 25$-scale facility and recording the necessary data.

\subsection{FIELD PREPARATION OF NON-HAZARDOUS SLUDGE SIMULANTS}

This procedure shall be followed when preparing the simulants to be utilized during 1/25-scale sludge mobilization nozzle diameter effects testing in the 336 building as outlined in the Test Plan DSTRTP-FY95-SM1.

\section{Kaolin/Water Simulant:}

This procedure shall be used when preparing "kaolin/water" sludge simulant.

Date/Time: $1 /$ at $:$ Name:

1. Review the target simulant composition given in the table below:

Weight \% Kaolin in Simulant:_ 65.0 wt \% 
Test Plan: DSTRTP-FY95-SM1 Rev.: $0 \quad$ Date: October 24, 1994

\begin{tabular}{||c|c|}
\hline Material & Quantity (lb) \\
\hline \hline Kaolin Clay & 150 \\
\hline Water & 81 \\
\hline Total: & 231 \\
\hline
\end{tabular}

2. Ensure that the Littleford simulant mixer is clean.

CAUTION: Air filtration masks shall be worn when working with dry kaolin clay to prevent the inhalation of the small amount of free silica dust particles present in the kaolin clay.

3. Place $100 \mathrm{lbs}(45 \mathrm{~kg})$ of dry kaolin clay into the Littleford mixer.

4. Add all the water specified in step $1(81 \mathrm{lbs})$ to the dry clay in the Littleford mixer.

5. Activate the Littleford Mixer (Refer to SOP \#39 rev. 2, if necessary).

6. After 10-15 minutes of mixer operation, stop the mixer and add the remaining $50 \mathrm{lbs}$ of dry clay to the Littleford mixer.

7. Restart the mixer and allow the mixer to operate for at least 20 minutes following the completion of step 6 .

8. Position a suitable container under the Littleford mixer, then open the mixer effluent hatch. The simulant will drop out of the mixer and into the container.

9. Close the mixer hatch.

10. Collect approximately $2 \mathrm{~kg}$ of simulant for physical property characterization.

11. Clean the mixer using water. Collect the rinse water in a suitable waste container. 
Test Plan: DSTRTP-FY95-SM1 Rev.: $0 \quad$ Date: Óctober 24, 1994

\subsection{1/25-SCALE SLUDGE MOBILIZATION TESTING}

The procedure given below shall be used to perform the $1 / 25$-scale sludge mobilization nozzle diameter effects tests as described in this test plan (DSTRTP-FY95-SM1). The testing will involve the measurement of the amount of simulated sludge mobilized by a single, centrally-located, simulated mixer pump. The effective cleaning radius (ECR) will be used to quantify the amount of sludge mobilized. The ECR will be measured frequently during the test so that an ECR vs. time profile can be generated. As a check on the ECR measurements, the slurry density will be monitored during the test. Based on the sludge and supernate densities, the density profile (with respect to time) can be calculated from the plot of ECR vs. time. Likewise, the ECR profile (with respect to time) can be calculated from the plot of measured density vs. time.

The specific operating conditions and nozzle exchange sequences that are planned are:

Test \#1: $\quad \mathrm{D}=0.9 \mathrm{~cm}$ at $500 \mathrm{~cm}^{2} / \mathrm{s}(42.3 \mathrm{lpm}=11.2 \mathrm{gpm})$ until ECR growth stops. Then plug one hole and install flow straighteners in other nozzle and resume same $U_{0} \mathrm{D}$ (total flow $=21.2 \mathrm{lpm}=5.6 \mathrm{gpm}$ ) until ECR growth stops. Reinstall other $\mathrm{D}=0.9 \mathrm{~cm}$ nozzle and remove straightener then operate at 1100 $\mathrm{cm}^{2} / \mathrm{s}$ until ECR growth stops (all sludge will probably be mobilized). Total flow rate to be used is $93 \pm 2 \mathrm{lpm}(24.5 \pm 0.5 \mathrm{gpm})$. If all sludge is not mobilized, the flow straighteners will be installed and the pump operated at $1100 \mathrm{~cm}^{2} / \mathrm{s}$ until ECR growth stops.

Test \#2: $\quad \mathrm{D}=0.9 \mathrm{~cm}$ at $500 \mathrm{~cm}^{2} / \mathrm{s}$ until ECR growth stops $(42 \mathrm{lpm}=11.1 \mathrm{gpm})$. Flow divider and flow straighteners will be used. Begin test with the rigid tank divider in place and sludge in one half of the tank removed out to a radial distance of $20 \mathrm{~cm}$. Following completion of ECR growth using $0.9 \mathrm{~cm}$ nozzle, $0.6 \mathrm{~cm}$ nozzle will be installed and operated at $500 \mathrm{~cm}^{2} / \mathrm{s}(28 \mathrm{lpm}=7.4 \mathrm{gpm})$ until ECR growth stops. Then install $0.9 \mathrm{~cm}$ nozzles and operate at $700 \mathrm{~cm}^{2} / \mathrm{s}$ until ECR growth stops $(58.8 \mathrm{lpm}=15.5 \mathrm{gpm})$. 
Test \#3: Using $U_{0} D=500 \mathrm{~cm}^{2} / \mathrm{s}$, run each of the 4 nozzle sizes $(0.9 \mathrm{~cm}, 0.75 \mathrm{~cm}, 0.6$ $\mathrm{cm}$, and $0.4 \mathrm{~cm}$ ) until ECR growth stops (flow rates of $11.1 \mathrm{gpm}, 9.25 \mathrm{gpm}$, $7.4 \mathrm{gpm}$, and $4.9 \mathrm{gpm}$, respectively). Flow divider and flow straighteners will be used for all nozzles. Repeat the same nozzle sequence (largest to smallest) using $U_{o} D=700 \mathrm{~cm}^{2} / \mathrm{s}$ (flow rates of $15.5 \mathrm{gpm}, 12.95 \mathrm{gpm}, 10.35 \mathrm{gpm}$, and $6.9 \mathrm{gpm}$, respectively). If time permits, repeat the nozzle sequence using $\mathrm{U}_{0} \mathrm{D}$ $=1100 \mathrm{~cm}^{2} / \mathrm{s}(24.5,20.4,16.3$, and $10.9 \mathrm{gpm})$.

The test data sheets to be used during these tests are given in the pages that follow.

Test ID \#:

Date: Time:

Names of Test Operators:

Simulant Type:

Mass of Sludge Loaded into Tank:

Mass of supernate (Water): lbs. lbs.

$\mathrm{U}_{0} \mathrm{D}$ 's to be tested:

1) $\mathrm{cm}^{2} / \mathrm{s}=$ $\mathrm{cm}^{2} / \mathrm{s}=$ gpm total flow gpm total flow

End of Test Configuration ECR Growth Rate Criterion: No growth for at least: 4 h

1. Record the initial supernate density as measured by the digital density meter (4 measurements):

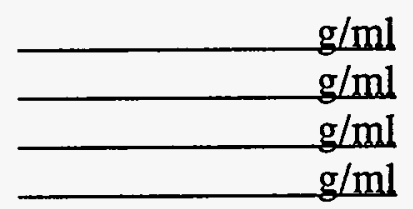

2. Record the initial supernate density as measured by the $100.0 \mathrm{ml}$ stainless steel density flask (4 measurements):

$\begin{array}{lll}\text { Mass }= & \mathrm{g}-> & \mathrm{g} / \mathrm{ml} \\ \text { Mass }= & \mathrm{g}-> & \mathrm{g} / \mathrm{ml} \\ \text { Mass }= & \mathrm{g}-> & \mathrm{g} / \mathrm{ml} \\ \text { Mass }= & \mathrm{g}-> & \mathrm{g} / \mathrm{ml}\end{array}$




\section{Test Plan: DSTRTP-FY95-SM1 Rev.: $0 \quad$ Date: October 24, 1994}

3. Lower the simulated mixer pump into the sludge simulant so that the nozzle centerline is $1.8 \pm 0.2 \mathrm{~cm}$ above the tank floor.

4. Prime the pumping system by pumping supernate through the piping system using an auxiliary pump.

5. Activate the mixer pump oscillation electronics and adjust the speed and oscillation times so that the pump oscillates through a $180^{\circ}$ rotation at a rate of $2.5 \pm 0.2 \mathrm{rpm}$

6. Close the mixer pump flow control valve (V-2).

7. Ensure that the centrifugal pump has been primed.

8. Turn on the centrifugal pump.

9. Adjust the flow control valve to obtain the desired total flow rate. Note the time at which this is done in the table below.

10. Record the ECR and density vs. time data in the tables below until the rate of change of the measured ECR is less than that specified above. "Time $=0$ " is established in step \#9 for the first $U_{o}$ setting. (use copies of page 6 of this procedure for times exceeding 240 minutes).

11. Once the average ECR growth rate is less than the specified growth rate criterion, the flow control valve shall be adjusted as necessary to obtain the second desired flow rate. When this adjustment is made, a new "Time $=0$ " is recorded on a new copy of the tables that follow.

12. If the nozzles are to be exchanged, the pump motors shall be deactivated while changing the nozzles. The pumps are then reactivated and the flow adjusted using the flow control valve.

13. Continue to record the required data until the ECR growth rate limit is met again.

14. Deactivate the centrifugal pump.

15. Collect samples of the slurry for rheological characterization.

16. Pump the slurry in the $1 / 25$-scale tank into a waste container (steel drum). 
17. Take measurements and generate a detailed sketch of the observed remaining sludge bank. Also take photographs of the sludge bank.

18. Remove any remaining sludge from the tank and flush all piping with clean water. 


\begin{tabular}{|c|c|c|c|c|c|c|c|c|c|c|c|}
\hline \multicolumn{12}{|c|}{ 1/25-Scale Testing Data Table: } \\
\hline \multicolumn{3}{|c|}{ Test No: } & \multicolumn{3}{|c|}{ Date: } & \multicolumn{6}{|c|}{ Time $=0$ at } \\
\hline $\begin{array}{r}\text { Time } \\
\text { (min) }\end{array}$ & $\begin{array}{c}E C R \\
a \\
\end{array}$ & $\begin{array}{c}E C R \\
b \\
\end{array}$ & $\begin{array}{c}\text { ECR } \\
C \\
\end{array}$ & $\begin{array}{c}E C R \\
d\end{array}$ & $\begin{array}{c}\text { ECR } \\
\mathrm{e} \\
\end{array}$ & $\begin{array}{c}E C R \\
f\end{array}$ & $\begin{array}{c}\mathrm{ECR} \\
\mathrm{g} \\
\end{array}$ & $\begin{array}{c}\mathrm{ECR} \\
\mathrm{h}\end{array}$ & $\begin{array}{l}\text { ECR } \\
\text { avg } \\
\end{array}$ & $\begin{array}{c}\text { Temp } \\
{ }^{\circ} \mathrm{C} \\
\end{array}$ & $\begin{array}{c}\rho_{\text {sluurry }} \\
(\mathrm{g} / \mathrm{m} \mathrm{T})\end{array}$ \\
\hline 0 & & & & & & & & & & & \\
\hline 2 & & & & & & & & & & & \\
\hline 4 & & & & & & & & & & & \\
\hline 6 & & . & & & & & & & & & \\
\hline 8 & & & & & & & & & & & \\
\hline 10 & & & & & & & & & & & \\
\hline 15 & & & & & & & & & & & \\
\hline 20 & & & & & & & & & & & \\
\hline 25 & & & & & & & & & & & \\
\hline 30 & & & & & & & & & & & \\
\hline 30 & & ry & nsit & from & 100.0 & $7 \mathrm{f}$ & sk: & & $\mathrm{g} / \mathrm{mT}$ & nass $=$ & g) \\
\hline 35 & & & & & & & & & & & \\
\hline 40 & & & & & & & & & & & \\
\hline 45 & & & & & & & & & & & \\
\hline 50 & & & & & & & & & & & \\
\hline 55 & & & & & & & & & & & \\
\hline 60 & & & & & & & & & & & \\
\hline 60 & $\mathrm{~S} 7$ & ry 1 & sit & from & 100.0 & 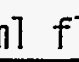 & & & $\mathrm{g} / \mathrm{mT}$ & nass $=$ & g) \\
\hline
\end{tabular}

NOTES: 


\begin{tabular}{|c|c|c|c|c|c|c|c|c|c|c|c|}
\hline \multicolumn{6}{|c|}{ 1/25-Scale Testing Data Table: } & \multicolumn{6}{|c|}{ Flow Rate $=$} \\
\hline \multicolumn{3}{|c|}{ Test No: } & \multicolumn{3}{|c|}{ Date: } & \multicolumn{6}{|c|}{ Time $=0$ at } \\
\hline $\begin{array}{c}\text { Time } \\
(\min )\end{array}$ & $\begin{array}{l}\text { ECR } \\
a\end{array}$ & $\begin{array}{l}\text { ECR } \\
b\end{array}$ & $\begin{array}{l}\text { ECR } \\
C\end{array}$ & $\begin{array}{l}\text { ECR } \\
d\end{array}$ & $\begin{array}{l}\text { ECR } \\
\mathrm{e}\end{array}$ & $\begin{array}{l}\text { ECR } \\
f\end{array}$ & $\begin{array}{l}\text { ECR } \\
\mathrm{g}\end{array}$ & $\begin{array}{l}\text { ECR } \\
h\end{array}$ & $\begin{array}{l}\text { ECR } \\
\text { avg }\end{array}$ & $\begin{array}{c}\text { Temp } \\
{ }^{\circ} \mathrm{C}\end{array}$ & $P_{\text {slurry }}(\mathrm{g} / \mathrm{m} 1)$ \\
\hline & & & & & & & & & & & \\
\hline & & & & & & & & & & & \\
\hline & & & & & & & & & & & \\
\hline & \multicolumn{8}{|c|}{ S7urry Density from $100.0 \mathrm{~m} 7$ flask: } & \multicolumn{2}{|c|}{$\mathrm{g} / \mathrm{m} 1$ (mass $=$} & g) \\
\hline & & & & & & & & & & & \\
\hline & & & & & & & & & & & \\
\hline & & & & & & & & & & & \\
\hline & \multicolumn{8}{|c|}{ Slurry Density from $100.0 \mathrm{~m} 7$ flask: } & \multicolumn{2}{|c|}{$\mathrm{g} / \mathrm{m} 1$ (mass $=$} & g) \\
\hline & & & & & & & & & & & \\
\hline & & & & & & & . & & & & \\
\hline & & & & & & & & & & & \\
\hline & \multicolumn{8}{|c|}{ Slurry Density from $100.0 \mathrm{ml}$ flask: } & \multicolumn{2}{|c|}{$\mathrm{g} / \mathrm{m} 1$ (mass $=$} & g) \\
\hline & & & & & & & & & & & \\
\hline & & & & & & & & & & & \\
\hline & & & & & & & & & & & \\
\hline & \multicolumn{8}{|c|}{ Slurry Density from $100.0 \mathrm{ml}$ flask: } & \multicolumn{2}{|c|}{$\mathrm{g} / \mathrm{m} 1(\operatorname{mass}=$} & g) \\
\hline & & & & & & & & & & & \\
\hline & & & & & & & & & & & \\
\hline & & & & & & & & & & & \\
\hline & \multicolumn{8}{|c|}{ Slurry Density from $100.0 \mathrm{ml}$ flask: } & \multicolumn{2}{|c|}{$\mathrm{g} / \mathrm{m}] \quad(\operatorname{mass}=$} & g) \\
\hline & & & & & & & & & & & \\
\hline & & & & & & & & & & & \\
\hline & & & & & & & & & & & \\
\hline & \multicolumn{8}{|c|}{ Slurry Density. from $100.0 \mathrm{~m}$ l flask: } & \multicolumn{2}{|c|}{$\mathrm{g} / \mathrm{ml}(\operatorname{mass}=$} & g) \\
\hline
\end{tabular}


Test Plan: DSTRTP-FY95-SM1 Rev.: $0 \quad$ Date: October 24, 1994

\subsection{REFERENCES}

Churnetski, Bernice V. 1982. "Prediction of Centrifugal Pump Cleaning Ability in Waste Sludge." Nuclear and Chemical Waste Management. v. 3, p. 199-203.

Obot, N. T., A. S. Majumdar, and W. J. M. Douglas. 1979. "The Effect of Nozzle Geometry on Impingement Heat Transfer under a Round Turbulent Jet." ASME Paper 79WA/HT-53.

Powell, M. R., C. M. Gates, C. R. Hymas, M. A. Sprecher, and N. J. Morter. 1994. Fiscal Year 1994 1/25-Scale Sludge Mobilization Testing. PNL-10582, Pacific Northwest Laboratory, Richland, Washington. September 1994.

Powell, M. R., G. R..Golcar, C. R. Hymas, R. L. McKay. 1993. FY 1993 1/25-Scale Sludge Mobilization Testing. PNL-10464, Pacific Northwest Laboratory, Richland, Washington. November 1993.

Rajaratnam, N. 1976. Turbulent Jets. Elsevier Scientific Publishing Company, Amsterdam, The Netherlands.

Sudo, Kozo, T. Takami, and H. Hibara. 1987. "Jet Issuing from 90 degree Curved Nozzle." Nippon Kikai Gakki Ronbunshu B. Hen. v. 53, n. 487. Mar. 1987. pp. 839-842.

Sudou, Kouzou and T. Takami. 1990. "Effects of Adjacent Wall on Turbulent Jets (1st Report, Mean Features of Offset Jet)." Nippon Kikai Gakki Ronbunshu B. Hen. v. 56, n. 524, Apr. 1990. pp. 33-39. In Japanese. 